COMISIÓN ECONÓMICA PARA AMERICA LATINA (CEPAL)

\title{
POBLACIÓN Y DESARROLLO EN AMERICA LATINA
}

\author{
Prólogo de \\ Marshall Wolfe
}

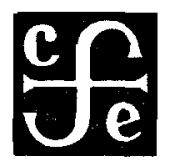

FONDO DE CULTURA ECONÓMICA 
Primera edición en español, 1975

La presente edición se publica en cooperación con las Naciones Unidas

D. R. (C) 1975 Fondo de Cuttura Económica Av. de la Universidad, 975; México 12, D. F. Impreso en México 


\section{NOTA EDITORIAL}

Los trabajos que ahora se publican reunidos en el presente volumen, precedidos de un prólogo nuevo, se recogieron originalmente en el documento E/CN.12/973 (mimeografiado), que la secretaría de la Comisión Económica para América Latina (CEPAL) puso a consideración de los participantes en la Reunión Latinoamericana Preparatoria de la Conferencia Mundial de Población. Dicha reunión, celebrada en San José de Costa Rica del 15 al 19 de abril de 1974, fue organizada por la propia CEPAL, con el auspicio conjunto de la Secretaría General de la Conferencia Mundial de Población, la División de Población de las Naciones Unidas y el Centro Latinoamericano de Demografía (CELADE). El informe sobre las deliberaciones que ha circulado ya entre los Gobiernos Miembros de la CEPAL (sT/ECLA/Conf.48/L.7/Rev. 1) se ofrece como apéñdice al final de este libro (véase pp. 279 a 305 ). 


\section{PRÓLOGO}

LA INTENCión de ofrecer una publicación más cuyo título incluya la palabra población, sugiere exceso de audacia o de ingenuidad. La explosión de documentos y exhortaciones sobre este tema está dejando atrás a la llamada "explosión demográfica". La marea creciente de pancartas, folletos, revistas pintorescamente ilustradas y monografías técnicas, que instituciones de muchos países del mundo distribuyen con profusión en América Latina, seguramente ofrece más de lo que la gente desea saber acerca de todos los aspectos del tema. Cualquier aserción formulada por alguna persona eminente de que la población es un Problema Importante tiene difusión mundial. Podríamos deducir de ello un supuesto subyacente - natural en las burocracias internacionales- de que la mejor manera de encarar un Problema Importante es ahogarlo en papeles.

Sin embargo, la rapidez sin precedente del incremento y de la redistribución espacial de la población latinoamericana es real. Plantean a quienes interpretan los procesos de desarrollo y las opciones de política desafíos concretos que no pueden desestimarse aduciendo que la campaña mundial desvía la atención de problemas verdaderamente decisivos del desarrollo, ni pueden resolverse insertando en la política de desarrollo "soluciones" universales prefabricadas. Hasta es posible que aún quede algo par decir acerca de las características peculiares del cambio demográfico en América Latina, su etiología, sus perspectivas y sus repercusiones en el desarrollo, que no pueda inferirse fácilmente de la literatura demográfica y médico-biológica de llamamientos publicitarios ni de advertencias apocalípticas. Los trabajos recopilados en el presente volumen descansan en esta suposición, y representan la contribución de la secretaría de la Comisión Económica para América Latina, en colaboración con el Centro Latinoamericano de Demografía (CELADE), para alcanzar los siguientes propósitos:

a) evaluar y mejorar la información básica sobre las principales variables demográficas para poder efectuar generalizaciones válidas, descubrir sus relaciones recíprocas con otros fenómenos y proyectar el futuro;

b) explorar las relaciones entre "población" y "desarrollo" con el fin de llegar, no a una confrontación entre dos abstracciones, sino a un conjunto coherente de proposiciones que vinculen los procesos reales de cambio económico, social, político y demográfico en los planos regional y nacional;

c) delimitar el alcance y contenido de la "política de población" - es decir, de las medidas con que el Estado pretende influir en las variables demográficas - en las condiciones existentes, y explorar su alcance y contenido potenciales si se logra el ideal de integrarla en las políticas globales de desarrollo nacional, y

d) presentar a los gobiernos y al público en general resultados objetivos, en términos fáciles de comprender. 
Este esfuerzo se ha realizado de manera concomitante, y en continua interacción, con intentos más amplios de analizar el cambio económico y social en América Latina, de explorar las características y funciones de las principales áreas de política "social" dentro de las sociedades de la región, y por último, de llegar a un "enfoque unificado del análisis y la planificación del desarrollo". ${ }^{1}$

En las diversas investigaciones han trabajado demógrafos con economistas, sociólogos, politólogos, y especialistas en políticas sociales, provenientes de diversos medios. Conciliar los distintos métodos e intereses de los representantes de estas disciplinas no ha sido fácil ni se ha logrado cabalmente pero la experiencia ha resultado fructífera.

Los demógrafos han preferido adherirse estrictamente a la evidencia estadística a través de una laboriosa evaluación de datos censales y de muestreos, la corrección de errores con técnicas estandarizadas, estimaciones para llenar vacíos, clasificadas según su confiabilidad, y la elaboración de proyecciones basadas en determinados supuestos. Comúnmente se han mostrado reacios a aceptar sin reservas las estadísticas oficiales, a decir más de lo que pueden probar con datos que consideren fidedignos, a especular acerca del futuro, a propiciar panaceas, o a contribuir a la construcción de modelos un poco a la manera de los paleontólogos, es decir, comenzando con unos pocos huesos y mucha imaginación. $Y$ han seguido insistiendo en que no disponen de datos básicos suficientes para responder a muchas de las preguntas que plantean sus colegas.

Los economistas por lo general han mostrado mayor optimismo respecto a la cantidad y calidad de la información estadística existente, y más disposición a aceptarla de buenas a primera y a llenar las lagunas como mejor puedan, que a admitir incertidumbre o imposibilidad de cuantificar. ${ }^{2}$ Han considerado las estructuras y tendencias en materia de población como limitaciones o recursos para sus estrategias de desarrollo encaminadas a maximizar la producción, es decir, como fuente de mano de obra, demanda de consumo, necesidades de gasto "improductivo" en servicios sociales y de infraestructura. Han exigido respuestas claras que puedan utilizarse en la planificación, y datos pormenorizados para insertarlos en los modelos: $¿ E s$ o no deseable una tasa elevada de crecimiento de la población en una etapa dada de desarrollo? ¿Cuáles

1 Véase El cambio social y la politica de desarrollo social en América Latina, publicación de las Naciones Unidas, núm. de venta: e.70.r.c.3; Informe sobre un criterio unificado pasa el análisis y la planificación del desarrollo. Informe preliminar del Secretario General, (E/CN.5/477) 25 de octubre de 1972; Estudio Económico de América Latina, diversos años.

2 Gunnar Myrdal, que es economista, ha expresado en relación con la "poca confianza" que merecen los datos estadísticos en que se basan las estimaciones del producto nacional bruto de los países en desarrollo: "Para con éstos [los economistas], será cosa de su profesión, que trabajan con menos cuidado y sentido de responsabilidad que los demógrafọs; éstos siguen manteniendo su vieja tradición de escrupulosidad analítica y crítica con respecto a los datos que utilizan y siempre tienen en cuenta su posible inexactitud." ("En la investigación no hay diplomacia que valga", entrevista publicada en Ceres, Fao, Roma, vol. 4, núm. 2, marzo-abril de 1971.) 
son los efectos de las tendencias demográficas en el tamaño del mercado interno $y$ de la fuerza de trabajo, en la distribución de los gastos públicos, en la división de los presupuestos familiares entre consumo y ahorro?

Los sociólogos y los politólogos han planteado preguntas diferentes, también difíciles de responder con cierta confianza sobre la base de los datos disponibles: ¿Cuáles son las formas de interacción e interdependencia de las estructuras y tendencias demográficas, de un lado, y de las estructuras de clase, la distribución del poder y de la participación en las sociedades nacionales y las formas de dependencia de estas sociedades con relación a centros mundiales? ¿Cabe esperar cambios en los patrones de fecundidad elevada de los grupos campesinos y marginales y en los patrones de concentración humana en las ciudades más grandes, sin una transformación de las relaciones de clase y de las estructuras de producción y distribución? En general, estos especialistas se han mostrado predispuestos a considerar las tendencias demográficas como determinadas por el orden social o el sistema de dominación, y reacios a ver en el crecimiento y redistribución rápidos de la población factores parcialmente autónomos que influyen en el orden social y que se pueden modificar deliberadamente con independencia de cambios más amplios en dicho orden.

Los especialistas en políticas sociales se han ocupado principalmente del efecto que pueden tener el crecimiento rápido de la población, las proporciones excepcionalmente altas de niños y jóvenes "dependientes" en las poblaciones nacionales y la acelerada redistribución espacial y concentración urbana de la población, en el logro de niveles siquiera mínimos de vida, la prestación de servicios sociales básicos, el funcionamiento de mecanismos de participación, la expresión de intereses individuales $\mathrm{y}^{\prime}$ colectivos $\mathrm{y}$ el mantenimiento de relaciones familiares $\mathrm{y}$ comunitarias satisfactorias. En las condiciones existentes, zes realmente posible una mayor difusión de la justicia social y del bienestar humano? ¿Cómo adaptar las políticas de educación, vivienda, salud pública, abastecimiento de alimentos $\mathrm{y}$ otras políticas sociales sectoriales a las presiones cambiantes y cada día mayores que acompañan al crecimiento y redistribución de la población? ¿Cómo adecuar su contenido y ponerlas al servicio de los grupos que más lo necesitan? ¿Reside realmente la dificultad esencial en los efectos concomitantes del crecimiento rápido de la población, o deben confrontarse primero las estructuras económicas, sociales y políticas que conducen a mala distribución y desperdicio de recursos que podrían mejorar la calidad de la vida humana?

Pese a estas diferencias de criterios e intereses, sintetizadas aquí de manera simplificada y esquemática que probablemente no deje satisfechos a las representantes de ninguna de las disciplinas señaladas, quienes han participado en el programa de investigaciones de la CEPAL han considerado que el problema de población es complejo, que sus características difieren de un país a otro y que no se presta para soluciones globales. No esperan que su trabajo culmine con la aseveración de que el 
crecimiento de la población es incompatible con el desarrollo y de que todos los gobiernos responsables deben colocar de inmediato en el primer plano de su estrategia de desarrollo una campaña generalizada de planificación de la familia o de limitación de la fecundidad; tampoco se sienten atraídos por aquella posición contraria que sostiene que la campaña mundial en materia de población es una conjura imperialista y que el "problema" se resolverá automáticamente con el advenimiento de un orden social diferente.

Los estudios compilados en este volumen, subproductos del programa permanente de investigación de la cEPAL, fueron concebidos con diversos propósitos concretos: proporcionar a la Comisión, en sus períodos de sesiones, una visión panorámica del "estado del problema"; incorporar los aspectos demográficos a la primera evaluación regional de la Estrategia Internacional de Desarrollo patrocinada por las Naciones Unidas y contribuir a reuniones preparatorias de la Conferencia Mundial de Población de 1974, como los simposios internacionales sobre población y desarrollo, población y medio ambiente y población y derechos humanos. Se han eliminado las duplicaciones de material y se han efectuado revisiones para armonizar el conjunto, pero aún quedan algunas repeticiones y se observan ciertas discrepancias en la forma en que los diferentes autores han tratado su parte del tema.

Los estudios que se presèntan aquí consideran que la redistribución y concentración espacial de la población son tan dignas de interés como el crecimiento de la población y que probablemente son más susceptibles de modificarse utilizando instrumentos de política pública de corto y mediano plazo. Suponen que las repercusiones del crecimiento y de la redistribución de la población en el desarrollo dependen en muchas formas de las estructuras económicas y sociales en que se desenvuelven, del estilo de desarrollo preferido por las fuerzas sociales dominantes -es decir, de la imagen del futuro orden social que inspira la pugna por el desarrollo- y de la combinación de medios que proporcionen la capacidad y los valores de la sociedad para aproximar la realidad a la imagen. Fenómenos que en determinado estilo de desarrollo constituyen una carga o una limitación, en otro pueden convertirse en estímulos, recursos o simplemente factores neutrales. Sin embargo, estos estudios se abstienen de llevar el raciocinio a una conclusión doctrinaria. Reconocen que el crecimiento de la población a las elevadas tasas observadas últimamente èn América Latina y las formas que toma actualmente la redistribución de la población, son restricciones formidables para el desarrollo, como quiera que se defina o busque el desarrollo. Los gobiernos no podrán sustraerse a intervenir cada día más, puedan o no integrar sus intervenciones en estrategias de desarrollo generales, les parezca o no que estas intervenciones hayan de ser decisivas. En gran medida, tendrán que determinar lo que pueden hacer, y luchar con espinosas, cuestiones de valores, derechos y demandas populares en el camino, mientras tratan de emprender o perfeccionar intervenciones limitadas y experimentales en los procesos de cambio demográfico. Las sociedades 
latinoamericanas, como las del resto del mundo, están iniciando una transformación revolucionaria de sus actitudes ante la fecundidad y la vida familiar, transformación que se interrelaciona con los avances tecnológicos en los medios para controlar la fecundidad, y con los cambios en las modalidades de producción y consumo, los estilos de vida y las formas de asentamiento humano. La capacidad de las políticas públicas y de las campañas publicitarias para influir en la tasa y dirección de estos cambios no debe desestimarse, pero tampoco exagerarse. Los cambios demográficos cobran impulso con cierta lentitud, pero una vez en marcha un proceso de descenso rápido de la fecundidad o de concentración urbana, la experiencia histórica sugiere que la capacidad estatal de modificar o invertir la tendencia en función de nuevas interpretaciones de prioridades nacionales es muy baja, o, en el mejor de los casos, puede tener resultados sólo después de un lapso bastante largo. Los estudios que se presentan aquí sugieren, entre otras cosas, que los partidarios de políticas de población uniformes, urgentes y aplicadas en gran escala harían bien en reflexionar acerca de ese viejo proverbio que dice: "No por mucho madrugar amanece más temprano."

Marshall Wolfe

Nota: Los autores de capítulos del estudio, en orden alfabético, son: Warwick Armstrong, Henry Kirsch, George Martine, César Peláez, Luis Ratinoff y Marshall Wolfe. Otros demógrafos, economistas y sociólogos, dentro y fuera de la cEPaL, han participado en la crítica de las ideas presentadas. Las proyecciones demográficas y parte de la información básica, en particular la información sobre fecundidad y mortalidad en el capítulo m, son del Centro Latinoamericano de Demografía (CELADE). 



\section{TENDENCIAS DEMOGRAFICAS Y OPCIONES PARA POLITICAS DE POBLACIÓN}

DURANTE los dos últimos decenios, el rápido crecimiento de la población y su redistribución geográfica en la mayoría de los países latinoamericanos han despertado creciente preocupación pública como problemas que exigen una mejor comprensión, y una política consecuente con la política general del desarrollo y con las concepciones nacionales sobre un orden social futuro que sea viable. Siguen expresándose opiniones extremadamente divergentes con respecto al significado de estos fenómenos y a lo que debería hacerse al respecto careciéndose aún de gran parte de la información necesaria para comprobar los aspectos esenciales de las diferentes hipótesis, o siendo la que existe de dudosa confiabilidad. Sin embargo, la prolongada polémica ha contribuido a apreciar mejor cuan complejos son los factores en juego y cuan inadecuados los enfoques tanto si son simplemente conformistas como simplemente críticos. Mucho se ha avanzado, gracias a las investigaciones realizadas por el Centro Latinoamericano de Demografía (CELADE) y por un número cada vez mayor de instituciones y estudiosos pese a la abismante insuficiencia de la información básica y a que los gobiernos siguen asignando escasos recursos para la compilación de estadísticas demográficas que permitieran aclarar las tendencias actuales y efectuar proyecciones confiables para el futuro.

En agosto de 1970 se presentaron a la primera Conferencia Regional Latinoamericana sobre Población ${ }^{1}$ casi doscientos documentos que discutían e informaban sobre investigaciones relativas a fecundidad, mortalidad, migración, urbanización y distribución regional de la población; relaciones entre población y desarrollo económico y social; tendencias demográficas futuras, políticas de población y el estado de la investigación y enseñanzas demográficas en América Latina. Estos documentos, que presentan una gran diversidad de teorías, opiniones e información empírica, brindan una buena oportunidad para hacer un examen general de la cuestión demográfica en América Latina y para perfeccionar análisis anteriores. ${ }^{2}$

En las páginas siguientes se resumirá muy brevemente la situación demográfica actual de América Latina, prestando especial atención a la probabilidad de que continúen o cambien en grado importante las ten-

I Celebrada en México, D. F., y patrocinada conjuntamente por la Unión Intemacional para el Estudio Científico de la Población, la Comisión Económica para América Latina, el Centro Latinoamericano de Demografía y El Colegio de México. Los títulos citados a continuación en el texto sin hacer referencia a lugar y fecha de publicación son documentos presentados a dicha Conferencia.

2 Véase Gepal, Estudio económico de América Latina, 1969, publicación de las Naciones Unidas, núm. de venta: s.71.c.1, primera parte, y El cambio social y la política de desarrollo social en América Latina, publicación de las Naciones Unidas, núm. de venta: s.70.II.c.3, capítulo xvnr. 
dencias anteriores que sirven necesariamente de base a las proyecciones estadísticas del futuro demográfico, y a lo que sobre estas cuestiones revelan las informaciones preliminares obtenidas en algunos de los últimos censos. A continuación se analizarán los principales factores sociales y económicos que ejercen una influencia importante en el cambio demográfico y sobre los cuales este, a su vez, influye o ejerce un efecto limitante. Será necesario estudiar una gran variedad de temas sobre los cuales los especialistas no han alcanzado un consenso. En varios casos no será posible sino resumir los argumentos utilizados y expresar una preferencia preliminar, basada en el diagnóstico general hecho por la CEPAL, con respecto a los problemas y requisitos del desarrollo. Se explorará después la cuestión crucial de la formulación de políticas, intentándose dar una visión objetiva de las correspondientes posiciones ideológicas. Por último, se confrontará la necesidad de asignár, a la política demográfica un lugar legítimo y claramente definido dentro de una estrategia de desarrollo a largo plazo con la necesidad de contar con criterios realistas para apreciar lo que se justificaría que hicieran o dejaran de hacer los gobiernos mientras intentan aún elaborar una estrategia de este tipo. En materia de población, como en todas las demás esferas de la acción social pública, se están contrayendo obligaciones, se impulsan programas y se generan presiones que no permiten esperar hasta que el Estado esté dispuesto a integrarlas en una estrategia global, o pueda hacerlo.

\section{La SITUACión ACtUAL Y EL FUTURo PREvisible ${ }^{3}$}

\section{a) Las tasas de crecimiento y sus determinantes}

La tasa de crecimiento demográfico de un país tiene tres determinantes inmediatos: la fecundidad, la mortalidad y la migración internacional. Para el conjunto de América Latina suele aceptarse que de la primera de esas variables dependerán los principales cambios posibles y que en ella está la clave para predecir el crecimiento demográfico y la composición por edades de la población.

Habría mucho margen para seguir reduciendo las tasas de mortalidad por edades, si se compararan con las de los países de altos ingresos. Se espera que las disminuciones futuras sean relativamente lentas en comparación con el pasado inmediato, pero sus efectos sobre las tasas globales de crecimiento deberían bastar al menos para contrarrestar los descensos iniciales de la fecundidad. Sólo unos pocos de los países más pobres y pequeños tienen aún posibilidades de lograr grandes reducciones en un lapso de pocos años como los que produjo, para la región en su conjunto, la rápida aceleración del crecimiento demográfico en los últimos decenios. No cabe esperar aumentos de la tasa de mortalidad -a

3 Para un análisis más detallado de las cuestiones tratadas en la presente sección y de las estadísticas que lo apoyan, véase el capítulo In de este libro. 
menos que ocurran catástrofes imprevisibles en este momento- salvo en los países del Cono Sur.

Es del todo improbable que la inmigración recupere alguna vez el importante papel que tuvo en el pasado en el crecimiento de la población de algunos países latinoamericanos.

La migración internacional desempeñará principalmente un papel cualitativo, y dependerá del equilibrio entre la capacidad latinoamericana para atraer inmigrantes con las calificaciones necesarias y su capacidad para limitar la emigración de sus nacionales que posean esas calificaciones. Desgraciadamente, parece que va a predominar esta última corriente. La migración puede además tener importancia para cambiar el equilibrio de la población entre algunos países dentro de la región, y en este sentido el progreso de la integración económica puede facilitar los movimientos de población entre países latinoamericanos. Pero hasta esto es dudoso, dadós el creciente grado de desempleo estructural en casi todos los países y las resistencias que se oponen a este tipo de migración una vez que alcanza una escala suficiente como para alterar significativamente las características demográficas del país receptor.

Por ello, la atención se centra en el comportamiento futuro de la fecundidad, no sólo por ser la variable más susceptible de cambiar considerablemente, sino por ser la más sensible a la influencia de una política encaminada a controlar la tasa de crecimiento demográfico. De ahí que gran proporción de las investigaciones demográficas recientes esté dedicada a esta variable. 4 La composición por edad, con extremado predominio de los jóvenes, que deriva de la combinación en los últimos años de alta fecundidad y mortalidad decreciente, da un enorme impulso al crecimiento demográfico; mantiene elevada la tasa bruta de natalidad e inalterada la tasa de crecimiento durante algunos años después del comienzo de un descenso en las tasas de fecundidad correspondientes a las mujeres en edad de procrear. Según los precedentes históricos, los cambios en el comportamiento reproductivo de la mujer han sido lentos y graduales, salvo unas pocas excepciones en epocas recientes (Japón, por ejemplo). Por lo tanto, las proyecciones de las tasas de crecimiento demográfico basadas en diferentes hipotesis sobre las tendencias de la fecundidad señalan la probabilidad de que los límites de variación sean relativamente estrechos. Según la variante baja usada en las proyecciones recientes hechas por la CEPAL y el cELADE, la tasa de crecimiento demográfico de toda América Latina podría disminuir de $2.83 \%$ en el período 1960-1965 a $2.69 \%$ en el período 1980-1985. Según la hipótesis media, aumentaría ligeramente, a $2.91 \%$, y según una variante alta la tasa podría subir a $3.19 \%$. La población aumentaría pues en 1985 a 411 millones, 425 millones y 440 . millones de habitantes, respectivamente, en comparación con los 238 millones que había en $1965 . .^{5}$

4 Más de cuarenta de los trabajos presentados a la Conferencia Regional Latinoamericana sobre Población estuvieron dedicados a la fecundidad. Véase en especial el trabajo preparado por Walter Mertens, Fertility and family planning research in Latin America.

5 Véase El cambio sacial y la política de desarrollo social en América Latina, op. 
Las proyecciones demográficas se basan necesariamente en las tendencias del pasado y en la posibilidad de modificar esas tendencias que ha demostrado la experiencia. Los demógrafos saben muy bien que esas tendencias no proporcionan una orientación segura para pronosticar el futuro. ${ }^{6}$ El progreso de las técnicas anticonceptivas, la difusión de los servicios públicos y privados de planificación de la familia, la penetración cada vez mayor de los medios de comunicación y los cambios radicales en los patrones sociales, el modo de vida, el medio físico y los estímulos del consumo a los que está expuesta la mayor parte de la población latinoamericana podrían, combinados en cierta forma aún indefinible, provocar cambios sin precedentes en cuanto a su rapidez en el comportamiento reproductivo $y$, por consiguiente, en el crecimiento de la población y en la distribución por edades. Como sucedió recientemente con la mortalidad, el cambio tecnológico y la acción pública organizada podrían hacer que los cambios en la fecundidad dependieran mucho menos de los progresos económicos y sociales a los que habían estado supeditados hasta ahora.

Dos países de la región, la Argentina y el Uruguay, no han compartido las características de alta fecundidad y aumento acelerado de la población comunes al resto de la región. En los últimos decenios sus patrones demográficos se han acercado más a los de Europa que los del resto de América Latina. Otros dos países, Chile y Cuba, están alcanzando niveles de fecundidad y crecimiento demográfico moderados. La natalidad baj6 en Chile de 37.1 por mil habitantes en 1963 a 27.8 en 1969. Más recientemente unos pocos países pequeños han iniciado la mismo evolución. La tasa de natalidad de Costa Rica, que se mantuvo

cit., cuadros 9 a 11 en el capítulo Iv. Estos totales incluyen las 20 repúblicas latino americanas y 4 países del Caribe. Si se incluyen todos los países y territorios del Caribe, los totales aumentan en casi 8 millones para 1965 y 10 millones para 1985.

6 "El cálculo de poblaciones futuras por medio de proyecciones de tendencias pasadas dentro de marcos estrictamente demográficos tiene sus riesgos en cualquier época. Esto es particulammente cierto en América Latina en el período que se analiza. El supuesto de continuidad en las tasas de crecimiento debe llegar a ser, tarde o temprano, un supuesto contrario a los hechos." (Irene S. Taeuber, Tendencias demográficas futuras en América Latina.)

"[Todas las predicciones de los dembgrafos] han dependido de una premisa: "si las tendencias actuales se mantienen...' Es una antigua falacia estadística realizar extrapolaciones en base a esta premisa cuando en realidad no es válida. Sostengo principalmente que las tendencias del pasado reciente no se han mantenido, ni es probable que Io hagan... los acontecimientos (recientes) son $\tan$ nuevos y $\tan$ novedosos que las tendencias demográficas anteriores a 1960 son en gran medida inútiles para predecir lo que sucederá en el futuro" (Donald Bogue, The End of the Population Explosion, Central Statistical Office, Research Papers, núm. 4, Trinidad y Tabago, diciembre de 1967). Nathan Keyfits, haciendo una distinción entre simples proyecciones y proyecciones que aspiran a servir de predicciones, ha hecho hincapie en las grandes discrepancias entre las predicciones del pasado y lo que ha sucedido, y en el escaso número 'de estudios de evaluacion: “...miles de páginas impresas dan cifras futuras, unos cuantos cientos de páginas establecen los supuestos sobre los que se basan dichas cifras, unas cuantas docenas cuando mucho evalúan lo métodos mediante la comparación de proyecciones pasadas con el desarrollo subsecuente". (La proyección y la predicción en demografía: Una revisión del estado de este arte.) 
casi estacionaria a un nivel muy elevado hasta 1963, bajo de 45.3 en ese año a 34.5 en 1969. En todos los países de habla inglesa del Caribe se registró una importante tendencia decreciente durante el decenio de 1960.

En el Brasil las estimaciones indicarían que la tasa declinó levemente entre 1960 y 1970, pero en la ciudad de São Paulo, después de varios años de estabilidad, bajó de 31.9 en 1963 a 25.1 en 1968.7 En algunos otros países la tasa también acusó una tendencia declinante. En estos últimos casos, sin embargo, el descenso puede deberse, al menos en parte, a los cambios habidos en los niveles de la mortalidad y en la estructura por edades, desconociéndose hasta qué punto ha habido una verdadera baja de la fecundidad derivada de cambios en el comportamiento procreativo de la población. Para verificar si la ha habido, habría que examinar la evolución de otros índices, que no pueden calcularse sobre la base de las informaciones disponibles en esos países. En Chile, Costa Rica y Panamá, en cambio, las disminuciones en la tasa de reproducción bruta (relación entre el número de nacimientos de niñas entre dos generaciones sucesivas, suponiendo nula la -mortalidad hasta el final del período de procreación) confirman las tendencias derivadas de las tasas de natalidad.

Es interesante señalar que en varios países se inició alrededor de 1963 un brusco descenso de la natalidad, después de un período de estabilidad. Esta tendencia se dio tanto en países en que la fecundidad había descendido ya a un nivel moderado, como en países con una natalidad alta y estable en que no había habido disminuciones anteriores. Los programas de divulgación de las prácticas anticoncepcionales eran demasiado incipientes a comienzos del decenio de 1960 como para que tuvieran una influencia significativa sobre la fecundidad. Tampoco corresponde la rapidez de la disminución al lento avance que han tenido las prácticas de control de la natalidad en las diferentes clases sociales según la experiencia histórica. Podría adelantarse la hipótesis de que durante ese período gran número de personas que ya intentaban controlar su fecundidad, o que querían hacerlo, tuvieron, por propia iniciativa, oportunidad de usar métodos más eficientes.

Los datos preliminares de seis censos levantados en 1970 sugieren que en unos pocos países en que la transición demográfica hacia una fecundidad más baja comenzó hace algún tiempo, el proceso ha avanzado más rápidamente de lo que se esperaba, pero que en otras partes el descenso de la fecundidad, cuando lo hay, apenas basta todavía para compensar la baja de la mortalidad. (Merece señalarse que los totales preliminares llevan frecuentemente a conclusiones erradas cuando no se toma en cuenta la omisión censal.) En tres países la población que da el censo está tan por debajo de la proyectada que la diferencia no puede explicarse solamente por la omisión censal. En la Argentina, las proyecciones demográficas dan un total superior en $4.8 \%$ a los resul-

7 Olavo Baptista Filho, Extensión del período de formación profesional y el comportamiento de la natalidad. 
tados del censo ( 24444000 frente a 23323000 ). Si se toma en cuenta un margen de omisión (probablemente menos del $3 \%$ ), la población habría estado creciendo con una rapidez algo menor que la esperada. En Chile, la discrepancia es de $10.2 \%$ (9735000 frente a 8835000 ), de modo que debe ser bastante significativo el descenso de la tasa de crecimiento demográfico. En la República Dominicana, la diferencia es de $6.6 \%$ (4 277000 y 4012000 ). En este caso la discrepancia es más difícil de explicar. La mortalidad puede haberse mantenido ta un nivel más alto que el que se esperaba o puede haber habido una omisión censal considerable. No ha habido, ni se esperaba que hubiera, un gran descenso de la fecundidad, dadas las características del país. En Panamá las proyecciones demográficas dan un total de población inferior en $2 \%$ al total censal (1 399000 frente a 1425000 ), diferencia que fácilmente podría doblarse si se tuviera en cuenta la omisión censal; pero la fecundidad ha bajado mucho más durante el decenio que lo que se supuso en la proyección, de modo que cabía esperar una cifra más elevada que en el censo. Es posible que un saldo positivo de migración internacional o un descenso más rápido de la mortalidad que el supuesto en las proyecciones puedan haber compensado la baja de la fecundidad, aunque no es posible confirmar ninguna de estas hipótesis con la información disponible. En México la discrepancia de $3.4 \%$ podría explicarse principalmente por la omisión censal, con lo cual no habría disminuido significativamente la tasa de crecimiento demográfico. El caso del Brasil es particularmente interesante. Las cifras preliminares del censo dan una población de 92300000 , que difiere sólo en $1.5 \%$ de la proyección para la fecha del censo ( 93687000$)$; el grado de omisión en el Brasil puede ser relativamente importante, y con toda probabilidad compensará con creces esa diferencia de $1.5 \%$. Si esto se debe al mantenimiento de la fecundidad a niveles más altos que los esperados, a una baja más pronunciada de la mortalidad, o a ambos fenómenos, no podrá determinarse hasta contar con los resultados completos del censo.

En otras partes, los demógrafos vigilan con ansiedad la aparición de indicios de cambio en el comportamiento reproductivo y especulan sobre las influencias en juego. Incluso las tasas más altas de fecundidad de América Latina se encuentran muy por debajo del máximo biológico. Por lo tanto, un aumento sería teóricamente posible, aunque no probable. Se ejerce algún grado de control sobre la fecundidad, mediante cierta combinación de medidas en las que influyen los patrones sociales y culturales, medidas que pueden o no estar deliberadamente dirigidas al control de la fecundidad. Aunque las tasas de fecundidad de las mujeres en edad de procrear siguen siendo altas en la mayoría de los países, las tasas de fecundidad general pueden ocultar variaciones que tendrán importancia en el futuro. En México, por ejemplo, las mujeres en edad de procrear pertenecientes al grupo de edad más joven (15 a 24 años) tienen una tasa de fecundidad bastante más baja que la que tenían las mujeres de la misma edad hace unos pocos años debido al efecto combinado de la postergación del matrimonio, el uso más di- 
fundido de anticonceptivos y el aborto. En la tasa general esta disminución se compensa con la mayor fecundidad de las mujeres de 30 a 39 años, a causa probablemente del mejor estado de salud de este grupo y de la disminución de la mortalidad masculina que contribuye a reducir la proporción de viudas entre las mujeres de edad fértil. De persistir el nuevo patrón de reproducción de las mujeres más jóvenes y mantenerse su preferencia por tener menos hijos durante todo su período de procreación, la tasa general comenzará a disminuir a la postre. ${ }^{8}$

En casi todos los países latinoamericanos se ha demostrado que existen diferencias de fecundidad según los niveles de ingreso y de educación y el grado de urbanización. Es dable suponer que si continúa acentuándose la urbanización, y si mejoran la educación y el ingreso - sobre todo si hay una distribución más equitativa de los ingresos y de las posibilidades de educación-, se reducirán las tasas generales de fecundidad.

A base de estos antecedentes, por endebles que sean, los demógrafos se inclinan a esperar que durante el decenio de 1970 comenzará un pronunciado descenso de la fecundidad en los países de la región más dinámicos desde el punto de vista económico y social. La rapidez e importancia de ese descenso siguen "siendo materia de especulación en este momento".9

Más adelante, otras secciones del presente estudio se ocuparán nuevamente de los antecedentes en que se pudieran apoyar estas especulaciones, aunque forzosamente el análisis no será concluyente. Por el momento, parecen seguras dos generalizaciones.

En primer lugar, cualesquiera que sean los cambios en la fecundidad, las tasas de crecimiento de la población seguirán siendo durante muchos años suficientemente altas como para que la población crezca enormemente. A medida que se amplíe la base de la población, incluso tasas de incremento mucho menores que las actuales se traducirán en aumentos absolutos muy grandes. Sería imposible derivar de los antecedentes de que se dispone actualmente un pronóstico fehaciente sobre las posibilidades de que América Latina alcance una población estacionaria y la fecha en que ello ocurriría, pero difícilmente podría suceder antes del año 2050 , y para entonces la población regional tendría un tamaño varias veces superior al actual. ${ }^{10}$

En segundo lugar, las reducciones de la fecundidad y del número de hijos se distribuirán muy desigualmente; es probable que lo hagan

8 Centro de Estudios Económicos y Demográficos, El Colegio de México, Dinámica de la población de México, México, D. F., 1970, pp. 60 a 61,83 y 187.

9 Walter Mertens, op. cit.

10 Se ha calculado que la población de un país sigue creciendo 65 a 70 años después de alcanzar una tasa unitaria de reproducción (dos niños por pareja sobreviviendo a sus padres). Si América Latina llegase a una tasa unitaria hacia el período 1980-85, la población se haría estacionaria con 552400000 habitantes hacia el año 2045. Si se llegase a la tasa unitaria en el período 1990-95, en el año 2050 habría una población de 654800000 habitantes, y si ello ocurriese en el período 2000-05, la población se estacionaría en 783200000 habitantes en el año 2070 (proyecciones hechas por la Oficina del Censo de los Estados Unidos, mayo de 1970). Parece altamente improbable que se alcance una tasa unitaria antes del año 2000. 
en relación inversa a la capacidad de mantener esas cargas y de aprovechar las posibilidades que se presentan con el aumento del número de hijos. El descenso de la fecundidad se producirá en los países más urbanizados y más dinámicos, y en los capaces de mantener niveles relativamente altos de educación y de servicios sociales, antes que en los países más pequeños y más pobres, que ya tienen las tasas de fecundidad más elevadas de la región. Dentro de cada país, la fecundidad descenderá en las localidades más ricas, más "modernas", más urbanizadas, antes de hacerlo en las regiones rurales internas más pobres. En lo que respecta a las clases sociales y a los grupos según sus ingresos, sabido es que los estratos medios y superiores practican ya la limitación de la familia en forma más constante y eficaz que los estratos inferiores, especialmente que la población marginal urbana y que las masas rurales. Es probable que esta diferencia subsista, cualesquiera que sean la velocidad y la eficacia de la difusión de las prácticas de limitación de la fecundidad entre estos últimos grupos. ${ }^{11}$ De ser así, el constante aumento de la población puede ser un factor importante para acentuar los múltiples desequilibrios e injusticias en la distribución que caracterizan hoy al crecimiento económico y el cambio social en América Latina.

\section{b) Distribución geográfica, urbanización y migración interna}

Como es sabido, en la mayoría de los países latinoamericanos el rápido aumento demográfico ha ido acompañado de una desigualdad cada vez mayor en la distribución geográfica de la población y de una urbanización extraordinariamente rápida y concentrada. En los últimos dos decenios ha habido algunos progresos importantes en materia de colonización de tierras, y hay polos nuevos de crecimiento urbano en regiones que antes estaban despobladas. Sin embargo, la mayoría de las regiones que antes estaban deshabitadas o escasamente pobladas siguen en esa condición; en la mayoría de las regiones predominantemente rurales de ocupación más antigua el crecimiento neto de la población ha sido moderado, y en algunas la población se ha mantenido estacionaria o ha disminuido. En efecto, entre las zonas que han perdido población se encuentran varias escasamente pobladas, de ocupación relativamente reciente, como el Chaco argentino.

Puesto que no hay razones para dudar de que la tasa de crecimiento natural sea tan alta en las zonas rurales como en las urbanas, si no superior, la urbanización rápida y concentrada evidentemente debe implicar un traslado muy importante de población de zonas rurales a zonas definidas como urbanas. Aunque hay grandes diferencias entre países, puede estimarse aproximadamente que, para la región en su conjunto, la mitad del incremento natural de la población rural (3\% anual) ha estado

11 En Chile, la tasa bruta de natalidad baj6 entre $15 \%$ y $23 \%$ en las provincias más urbanizadas entre 1961 y 1967 ; en las provincias predominantemente rurales el descenso fue muy inferior. Mientras bajó la tasa de natalidad legítima, permaneció constante la de natalidad ilegítima (a la que abultan principalmente los estratos más pobres). 
saliendo de la categoría rural y contribuyendo directamente de un tercio a la mitad del crecimiento urbano. Esta población recientemente incorporada al área urbana, formada sobre todo por adultos jóvenes, da cuenta de una importante proporción del crecimiento natural urbano.

Pese a las numerosas investigaciones locales y a los muchos análisis efectuados, no es ahora más fácil que en $1959^{12}$ hacer generalizaciones valederas acerca de las causas, características y consecuencias de este fenómeno. 'Parte de la dificultad estriba en las deficiencias de las informaciones censales anteriores. La mayor parte de la información con que se cuenta proviene de los censos de 1950 y 1960, en circunstancias que las ciudades crecieron enormemente en el decenio de 1960 y que la composición de su población puede haber cambiado considerablemente. Parte se debe también a la ambigüedad de la terminología. No pueden darse definiciones satisfactorias, para todo uso, de las expresiones "migrante", "urbano" y "rural", dificultad que deriva, a su vez, de la complejidad y diversidad de los procesos en juego. Hay muchos tipos de zonas urbanas y rurales. El carácter "urbano" de una metrópoli moderna de varios millones de habitantes es muy distinto del carácter urbano de un nuevo centro especializado de industria pesada, una capital provincial tradicional de tamaño mediano, o una pequeña ciudad que suministra servicios administrativos y comerciales a una pequeña zona rural de influencia. En cuanto a lo rural, hay también marcadas diferencias - tanto culturales y demográficas como económicas - entre las zonas de agricultura mecanizada, las grandes plantaciones, las haciendas tradicionales, los asentamientos aldeanos compactos, las comunidades indígenas y los minifundistas dispersos. Es muy probable que la composición de la migración hacia y desde los diferentes tipos de localidades urbanas y rurales sea bastante diferente. Casi cualquier afirmación relativa a la urbanización y la migración puede ser válida respecto de algunas zonas urbanas y de algunos migrantes. Hechas estas salvedades, los hechos recientes apoyan las conclusiones siguientes: ${ }^{13}$

I) Los migrantes que llegan a las ciudades más grandes constituyen un grupo sumamente heterogéneo en cuanto a su educación, ocupación y características sociales. Provienen predominantemente de otras ciudades y núcleos urbanos más pequeños. Es insostenible la opinión, que aún se da en artículos sobre problemas urbanos, de que los migrantes son principalmente campesinos desplazados y jóvenes procedentes de familias campesinas, aunque este tipo de migrantes pueda tener gran importancia en algunas ciudades. (También debería tenerse presente que, desde el

12 En 1959 en un seminario patrocinado conjuntamente por las Naciones Unidas, la cepar y la unEsco se presentaron documentos que constituían el primer estudio interdisciplinario general de la urbanización en la región (UNESCO, La urbanización en América Latina, París, 1961). Véase además "Distribución geográfica de la población de América Latina y prioridades regionales del desarrollo", Boletín Económico de América Latina, vol. VIII, núm. 1. Nueva York, 1963.

13 Estas conclusiones derivan principalmente de dos trabajos presentados a la Conferencia Regional Latinoamericana sobre Población en 1970: Juan C. Elizaga, Migraciones interiores: evolución reciente y estado actual de los estudios, y John J. Macisco Jr., Some thoughts on an analytical framework for rural to urban migrations. 
punto de vista de la metrópoli moderna, las características culturales de los migrantes procedentes de pueblos pequeños pueden parecer "rurales".)

II) Por un proceso de autoselección, la población migrante se compone predominantemente de adultos jóvenes, con mayor instrucción y mejor preparados que lo corriente en su población de origen, aunque menos que lo común en las ciudades a las que han migrado. No hay pruebas de que los migrantes hayan sido "marginalizados" en proporción superior a la población originariamente urbana. Sin embargo, hay motivos para suponer que a medida que ha seguido aumentando su escala, la migración hacia algunas de las grandes ciudades se ha tornado menos selectiva y menos predominantemente urbana. ${ }^{14}$

III) Las investigaciones efectuadas no abonan la hipótesis de que la migración por etapas haya sido considerable, es decir, que los migrantes se hayan ido primero a los centros urbanos locales más pequeños, y luego a las grandes ciudades. Sin embargo, la diferencia que existe entre las tasas de crecimiento natural y neto de la población rural muestra que, de alguna manera, grandes cantidades de habitantes de zonas rurales se están transformando en "urbanos". En parte el fenómeno se explicaría por el crecimiento de los pequeños centros hasta superar el límite de los 2000 habitantes que se usa habitualmente para distinguir entre lo rural y lo urbano, pero en parte debe también ocurrir porque en los pueblos y ciudades provinciales los inmigrantes rurales están reemplazando a los emigrantes. ${ }^{15}$

Iv) En algunos de los países más grandes hay señales de que está comenzando a invertirse la tendencia a la concentración del crecimiento urbano en los centros de mayor tamaño. Algunas ciudades de segunda magnitud están creciendo más rápidamente que las aglomeraciones principales, y se registran importantes aumentos en el número y en la importancia cuantitativa de las pequeñas ciudades. ${ }^{16}$ Sin embargo, la ciudad

14 Véase Alan B. Simmons y Ramiro Cardona G., La selectividad de la migración en una perspectiva histórica: EI caso de Bogotá (Colombia) 1929-1968; Jorge Balán y Elizabeth Jelin, Migración a la ciudad y movilidad social: Un caso mexicano, y Jorge Balán, "Migrant-native socio-economic differences in Latin American cities: A structural analysis" (con comentarios de diversos sociólogos), Latin American Research Review, IV, 1, 1969. Sobre la base de estudios hechos en Río de Janeiro y Santiago se ha propuesto también la hipótesis de que la migración a las grandes ciudades es selectiva de ambos extremos del espectro socioeconómico (Bruce H. Herrick, Urban Migration and Economic Development in Chile, NrT Press, Boston, 1965).

15 En Colombia, "según se infiere de los datos fragmentados que se poseen, las migraciones revisten sobre todo una forma de 'trasiego' (los migrantes rurales se instalan en las aldeas y las pequeñas aglomeraciones, mientras que los residentes en éstas emigran a aglomeraciones más grandes y a ciudades) y no constituyen una emigración por fases... La significación de este proceso de trasiego es muy importante y merece análisis más detallado y nuevos estudios. Parece implicar que las pequeñas aglomeraciones pasan por una crisis más grave de lo que usualmente se cree. Después de todo las grandes ciudades se benefician de los migrantes más dinámicos y jóvenes; las pequeñas aglomeraciones pierden algunos de sus mejores elementos, substituidos por campesinos sin calificaciones y desprovistos de capital" (Hacia el pleno enpleo. Un programa para Colombia, preparado por una misión internacional organizada por la Oficina Internacional del Trabajo (orr), Ginebra, 1970, Apéndice 5, párrafo 9).

16 Dinámica de la población de México, op. cit., Pp. 124 a 125, 132; además, John V. 
principal suele predominar a tal punto que los pequeños cambios observados pueden no llevar a una disminución notoria de ese predominio. (En Colombia, al contrario, el predominio creciente de Bogotá ha transformado un proceso de crecimiento urbano que era antes mucho más equilibrado que en los otros países.) Al mismo tiempo, en algunos de los países más grandes la importancia relativa de la población urbana y, dentro de ella, la importancia de los centros mayores, ha crecido a tal extremo que se reducirá en el futuro la participación de la migración en el mayor crecimiento de las ciudades y se acentuará el carácter interurbano de esta migración.

Estas conclusiones provisionales se basan principalmente en investigaciones sobre el terreno efectuadas en unas pocas ciudades y en períodos diferentes durante los decenios de 1950 y 1960. No puede pues descartarse la posibilidad de que las tendencias predominantes en otras partes sean diferentes con respecto a la importancia de los migrantes rurales y a la marginalización diferencial de los migrantes, o de que las tendencias predominantes hayan cambiado desde la fecha de la investigación. Tampoco arrojan suficiente luz sobre el futuro. Aunque la tasa de crecimiento de la población es relativamente inflexible a corto plazo, las corrientes de redistribución geográfica de esa población podrían cambiar considerablemente en pocos años. Es muy posible que las grandes aglomeraciones urbanas se vean cada vez más constreñidas por su incapacidad para ofrecer servicios infraestructurales mínimos, en tanto que los beneficios que ahora se pretende alcanzar viviendo en esas aglomeraciones seguramente se difundirán en forma más equitativa gracias a mejores comunicaciones y transportes. Presumiblemente, el factor más importante sea la capacidad de las distintas localidades para ofrecer empleo, o al menos una subsistencia marginal, en las condiciones de desajuste creciente entre oferta y demanda de mano de obra que pueden preverse. Es probable que siga creciendo la sensibilidad de la población, tanto rural como urbana, a cualquier incentivo para migrar. Pueden tener influencia decisiva en el alcance y la dirección de esas migraciones las políticas y medidas nacionales relativas a la ubicación de la industria, las carreteras y otras obras públicas, la reforma agraria y la distribución de los servicios sociales y de asistencia social. La dificultad estriba en que los estímulos contenidos en programas públicos pueden provocar corrientes migratorias mayores que las que pueden absorberse en forma productiva.

Se ha sugerido que una reducción del ritmo de la urbanización podría significar una postergación de los descensos esperados en las tasas nacionales de natalidad, ya que son más débiles las motivaciones y los medios con que cuentan las zonas rurales para el control de la fecundidad. Sin embargo, es muy posible que este factor sea contrarrestado por la penetración cada vez más acelerada de las características y aspiraciones culturales urbanas en el campo.

Grauman y Chia-Lin Pan, "Rasgos distintivos de la urbanización en América Latina". Las conclusiones sobre la importancia de esta tendencia deben esperar el análisis de los censos de 1970 y 1971 . 


\section{c) Esperanza de vida y distribución de la población por edad y sexo}

La duración media de la vida para el conjunto de América Latina ha aumentado en forma marcada en los últimos años, y se espera que este aumento continúe. Los aumentos anteriores se han distribuido en forma muy dispareja; se espera que los países más pequeños y más pobres progresen más rápidamente que el resto en los próximos años, pero aún estarán rezagados en el período 1980-1985. Lo mismo puede pronosticarse respecto de las regiones internas más pobres y más agrestes de cada país. Por ejemplo, la esperanza de vida proyectada para Guatemala, Honduras, Nicaragua y El Salvador va desde 56.8 a 63.9 años, mientras para Bolivia y Haití será de 50.0 y 53.5 , respectivamente; Brasil llegaría a 67.6, Colombia a 65.5, México a 68.6, Perú a 67.0 y Venezuela a $70.2 .^{17}$

Sin embargo, las elevadas tasas de fecundidad y de aumento de la población significan que incluso cambios de estas dimensiones en la esperanza de vida tendrán escaso efecto sobre la distribución de la población por edades y en la proporción marcadamente elevada de la población de las edades que convencionalmente se definen como dependientes con respecto a la de aquellos grupos de la población en edad "activa". El porcentaje de la población en el grupo de edad de 0 a 14 años bajaría sólo ligeramente, según las variantes medias de las proyecciones (42.5\% en 1965 a $41.4 \%$ en 1985). El grupo en edad potencialmente activa, de 15 a 64 años, aumentaría ligeramente (de $53.8 \%$ a $54.4 \%$ ). El grupo de 65 años o más, aunque aumentaría rápidamente en números absolutos por la mayor longevidad media, aumentaría su participación sólo de $3.6 \%$ a $4.0 \%$ del total. Desde luego que los promedios ocultan importantes diferencias entre países. En Argentina, Chile, Cuba y Uruguay, la proporción de población joven, ya muy por debajo del promedio regional; descenderá más todavía, y la de población en edad avanzada, que ya está por sobre el promedio regional, experimentará un aumento importante. En Chile y Cuba, los porcentajes de población en el grupo de edades "activas" aumentarán considerablemente si continúa el descenso de la fecundidad. En la Argentina y el Uruguay, donde hay poco margen para lograr nuevas disminuciones de la fecundidad, las cohortes nacidas en períodos del pasado de mayor fecundidad, están llegando a la edad de retiro y los porcentajes de población en el grupo de edades activas disminuirán en relación con los otros dos grupos dependientes en conjunto. ${ }^{\text {is }}$ En unos pocos países más pequeños seguirá aumentando el porcentaje de la población en el grupo de 0 a 14 años.

De ello se desprende que la alta relación de población dependiente (menores de 15 y mayores de 64 años) a población potencialmente activa ( 15 a 64 años) no cambiará mucho en los próximos 15 años, salvo

17 Véase El cambio social y la política de desarrollo social en América Latina, op. cit,, capítulo $\mathrm{IV}$.

18 Esta tendencia se debe también en parte a que están llegando a la edad de jubilación las cohortes que en el pasado fueron afectadas por la inmigración en gran escala de adultos en edad de trabajar. 
en los cuatro países antes mencionados. Según una proyección, la relación bajaría para toda la región de $86 \%$ en 1970 a $84 \%$ en 1985 , comparado con relaciones de 57 y $58 \%$ para las regiones "desarrolladas" del mundo y 81 y $77 \%$ para todas las regiones "en desarrollo". ${ }^{19}$ Como en los cuatro países antes señalados la relación de dependencia es sólo ligeramente superior al promedio de las regiones "desarrolladas", las relaciones de la mayoría de los demás países latinoamericanos están muy por encima del promedio para la región, siendo en unos pocos casos la población dependiente casi del mismo tamaño que la población en edad activa. Más adelante se analizarán diversas consecuencias de estas relaciones de dependencia.

Dentro de los países latinoamericanos, las corrientes de redistribución geográfica y urbanización están afectando en importante medida tanto a la distribución de la población por edades como a la distribución por sexos. Dado lo inadecuado de la información relativa a las migraciones sólo cabe mencionar estos fenómenos en términos muy generales. Queda en claro que los adultos jóvenes están sobrerrepresentados en las poblaciones de las ciudades que reciben estas migraciones y subrepresentados en las zonas rurales y en los pueblos pequeños que son fuentes de migrantes. Las mujeres están sobrerrepresentadas en las migraciones hacia las ciudades y en las migraciones a distancias cortas. Los hombres están sobrerrepresentados en las migraciones a zonas de habilitación de tierras y en migraciones a grandes distancias. Cabría esperar que estas diferencias tuviesen importantes repercusiones en el dinamismo relativo de la mano de obra y en la capacidad de innovación en las zonas de emigración y de inmigración. La migración diferencial de las mujeres debería repercutir en la formación de las familias. Se ha especulado sobre estos temas durante algunos años, pero sigue escaseando la información pertinente.

\section{d) Tipos de paises}

El resumen anterior sugiere que los países latinoamericanos se dividen en varios grupos en cuanto a la estructura de sus poblaciones. Estos coinciden en lo principal con tipos que pueden distinguirse a base de otras características sociales y económicas. Para los fines del presente estudio es innecesario entrar en un análisis sistemático de las tipologías que se han propuesto. ${ }^{20}$ Para no caer en una generalización excesiva, sin embargo, puede ser útil señalar aproximadamente la distribución de la población latinoamericana en grupos con diferentes situaciones demográficas y con diferentes combinaciones de factores que influyen en la evolución futura. Estas situaciones diferentes sugieren la conveniencia

19 La relación de dependencia así definida es, por supuesto, muy inferior a la relación real de dependencia, a causa principalmente de la limitada participación de las mujeres en la actividad económica.

20 Véase EI cambio social y la política de dessarrollo social en América Latina, op. cit., capítulos m y xvmr. Además Carmen A. Miró, Aspectos demográficos de América Latina, CELADE, Documento A/88. 
de introducir las correspondientes diferencias, al menos de acento, en la política de población de cada país:

r) Cerca del $10 \%$ de la población de la región vive en dos países (la Argentina y el Uruguay) cuya fecundidad y mortalidad han descendido a niveles análogos a los que existen en países altamente urbanizados e industrializados de otras regiones.

II) Cerca del $7 \%$ vive en dos países (Chile y Cuba) cuya transición a un patrón demográfico análogo al de la Argentina y el Uruguay parece estar muy avanzada.

III) Más del $67 \%$ vive en cinco países grandes (Brasil, Colombia, México, Perú y Venezuela) que hasta ahora tienen una elevada tasa de aumento demográfico, con una urbanización acelerada y un vigoroso crecimiento económico, pero con grandes desigualdades, que probablemente sigan agrandándose, entre distintas regiones internas, entre zonas urbanas y rurales, y entre sectores económicos.

iv) Cerca de un $1 \%$ vive en dos países pequeños (Costa Rica y Panamá) que hasta ahora han tenido tasas muy altas de crecimiento demográfico, pero en los que ha habido indicaciones recientes del comienzo de una transición. En estos países el grado de urbanización, niveles de ingreso y educación son superiores al promedio regional.

v) Cerca del $9 \%$ vive en siete países pequeños con poblaciones no superiores a 6000000 de habitantes en 1970 (Ecuador, El Salvador, Guatemala, Honduras, Nicaragua, Paraguay y República Dominicana) con tasas muy elevadas de crecimiento de la población. En estos países el grado de urbanización y los niveles de ingreso y educación son inferiores a los de cualquiera de los grupos anteriores, aunque las tasas de crecimiento de estos factores son similares a las del tercero.

vi) Cerca del $3 \%$ vive en dos países (Bolivia y Haití) en los que la mortalidad más alta de la región limita el crecimiento de la población a tasas moderadas, pese a una elevada fecundidad. En estos países los niveles de urbanización, ingreso y educación son incluso inferiores a los del quinto grupo, y las tasas de crecimiento de estos factores también tienden a ser bajas.

viI) Cerca del $3 \%$ vive en cuatro países independientes y en cerca de 20 otras unidades territoriales en la zona del Caribe; la mayoría de estos países y territorios pequeños y densamente poblados tienen tasas de fecundidad y de crecimiento de la población que han experimentado importantes reducciones desde niveles anteriormente altos; en muchos de ellos la emigración fuera de la región ha contribuido bastante a reducir las tasas de crecimiento de la población y ha afectado su distribución por edades.

Deberían variar considerablemente entre cada grupo, e incluso entre países dentro de cada grupo, las justificaciones, la viabilidad y los objetivos de los programas públicos encaminados a influir en las variables demográficas y especialmente la urgencia de prestar ese apoyo a los programas. Las razones para intentar reducir las tasas de fecundidad, por ejemplo, tendrían más peso en el caso de los países del quinto grupo, en 
tanto que en el caso de los del tercer grupo parecería más urgente tomar medidas que influyan sobre la distribución geográfica de la población.

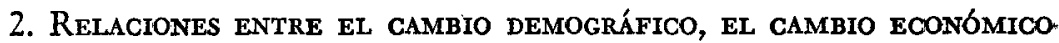 Y SOCIAL Y LA POLf́TICA PÚBLICA}

Es razonable suponer que los cambios demográficos resumidos anteriormente influyen en toda la variedad de procesos de cambio económico y social que están ocurriendo en América Latina, así como en la política pública que aspira a orientar esos cambios hacia el desarrollo económico y un mayor bienestar humano, y que a su vez reciben la influencia de esos procesos y esa política. También cabe suponer que, si bien esas influencias pueden aislarse para facilitar el análisis; en la práctica no. actúan unilateralmente ni por sí solas. El significado que tendrá cada factor dependerá de cómo se inserte en una estructura social y económica determinada y cómo afecte a determinadas clases sociales y tipos. de familia dentro de esa estructura. Según una conocida leyerida, un sencillo campesino que da alojamiento a un desconocido en una noche muy fría sospecha que hay artes de magia de por medio cuando el forastero sopla sus manos para calentarlas y luego sopla la sopa para enfriarla. Igual de ingenuo sería sorprenderse de que la prosperidad 0 la pobreza puedan promover un rápido crecimiento de la población y la concentación urbana en determinadas circunstancias y desalentar estas. tendencias en otras, 0 de que esas tendencias demográficas pueden promover el crecimiento económico en algunos casos y frustrarlo en otros.

La mayoría de las generalizaciones relativas a las relaciones recíprocas entre el cambio demográfico y otras variables culturales, sociales y económicas se han basado en investigaciones que toman como punto de mira el pasado histórico de los países industrializados de altos ingresos, o en modelos incompletos, o en supuestos de dudosa validez para las situaciones reales de América Latina. Esas generalizaciones han sido sometidas a una aguda crítica, sobre todo en algunos de los documentos presentados a la Conferencia Regional Latinoamericana sobre Población; pero es todavía insuficiente la información empírica y se carece de una interpretación conceptual completa que explique las interrelaciones entre todas las variables esenciales. Por consiguiente, la presente sección habrá de limitarse a una confrontación muy preliminar de esas generalizaciones con el diagnóstico de la realidad latinoamericana tal como ha sido planteado en anteriores estudios de la CEPAL.

\section{a) La estratificación social y la familia}

Las investigaciones y los análisis demográficos, incluso unos pocos relativos a América Latina, han revelado que existen relaciones bastante definidas entre la estratificación social y la fecundidad. Esta llega a su punto máximo en los estratos inferiores o más pobres, desciende en los 
estratos medios, y aumenta de nuevo ligeramente en los estratos superiores o más ricos. Relaciones inversas pero parecidas se han descubierto entre los niveles de fecundidad y los de ocupación (la que frecuentemente se usa como principal indicador de la estratificación social), ingreso, educación, y la residencia (gran ciudad, pueblo, zona rural).

La estratificación social influye sobre la fecundidad a través de la familia, al configurar valores y decisiones, primero sobre la formación de la familia, luego sobre el número de hijos y su espaciamiento, y más tarde al ayudar a determinar la capacidad de la familia para actuar a base de esas decisiones y los medios que usará para ello. La fuerza de las motivaciones familiares es más importante que la fácil disponibilidad de los medios. Así, como se ha señalado, en la Europa occidental del siglo xIx se alcanzó una baja fecundidad por decisión de las familias, pese a la desaprobación pública y a que los medios de control eran deficientes y de difícil acceso. En muchos países sigue siendo hoy elevada la fecundidad pese a que las técnicas anticonceptivas son relativamente fáciles de adoptar y a que su uso recibe un fuerte respaldo público.

Cabe suponer que las familias de los estratos urbanos superiores y medios de toda América Latina tienen objetivos relativamente bien definidos en cuanto al número de hijos que desean tener y que tienen acceso a medios eficaces para alcanzar sus objetivos. El hecho de que los estratos medios decidan tener relativamente pocos hijos puede atribuirse a las dificultades que tendrían, con mayor número de hijos, en conservar el estándar de vida que se asocia con su condición media, más bien precaria, y en educarlos de manera que la generación siguiente pueda conservar o mejorar esa condición. Puede atribuirse la mayor fecundidad de los estratos superiores a su mayor seguridad y capacidad para mantener a muchos hijos en condiciones que les parecen aceptables. En ambos estratos, las limitaciones de la fecundidad al parecer son muy recientes y se asocian con la rápida "modernización" que han alcanzado estos estratos por la influencia cultural de los centros mundiales de altos ingresos. De hecho, hasta hace muy poco, los miembros de los estratos superiores tenían tantos hijos que se les acusaba con frecuencia de monopolizar los papeles ocupacionales medios para dar sustento a sus hijos, con lo cual se inhibía la movilidad social ascendente. El aumento del ingreso y una mayor seguridad podrían alentar a los estratos medios a tener más hijos, y una mayor inseguridad y las desventajas de la división de la propiedad entre muchos herederos podrían instar a los estratos superiores a tener menos. En todo caso, cabe esperar que el conjunto de las decisiones de las familias de estos estratos se traduzcan en tasas moderadas de aumento de la población, con algunas fluctuaciones según la situación económica y política de los países; así también en los países en que el crecimiento económico y la urbanización avancen a una velocidad al menos moderada, cundiría la proporción de familias que adoptarían decisiones conducentes a una fecundidad moderada.

Pero los problemas realmente urgentes se refieren a las familias - la mayoría en casi todos los países de la región- que pertenecen a 
los estratos inferiores rurales y urbanos. Prácticamente en todas las sociedades estos estratos han tenido las más altas tasas de fecundidad, tasas que ahora no se compensan con una alta mortalidad. Abundan las explicaciones de la alta fecundidad de los pobres: la necesidad que hubo en el pasado de tener muchos hijos para asegurar la supervivencia de algunos; el valor económico de los niños en las actividades agrarias y artesanales tradicionales; el deseo, determinado culturalmente, de engendrar muchos niños como prueba de hombría (machismo); el papel de los descendientes como única fuente de previsión social para los ancianos; la incapacidad de los estratos inferiores marginalizados de ejercitar tipo alguno de previsión, o su falta de confianza en que cualquier limitación de la procreación pudiera mejorar su suerte.

Sin duda los estratos inferiores abarcan muchos tipos de familias que experimentan diferentes tipos de cambio, pero la sociología de la familia ha sido objeto en América Latina de tan poca atención que no es posible elaborar una tipología de las familias para evaluar la importancia relativa de estas explicaciones. Cabe suponer grandes diferencias en cuanto a motivaciones entre las familias urbanas y rurales de los estratos inferiores y es probable que las diferencias sean igualmente grandes entre familias de diferentes tipos de localidades rurales o urbanas.

En la actualidad, en las condiciones de cambio económico y social con las muchas contradicciones y soluciones de continuidad que caracterizan a América Latina, la mayoría de las familias de los estratos inferiores está expuesta a valores y motivaciones contrapuestos. Las motivaciones tradicionales que se traducen en una mayor fecundidad han seguido influyendo en la conducta después de haber perdido sentido con respecto a la situación de la familia y se combinan con reacciones de apatía y pasividad ante las dificultades y motivos de inseguridad que Jas familias son incapaces de resolver. Con la posible excepción de algunas de las regiones internas más remotas y pobres, en las que la alta mortalidad contrarresta todavía una alta fecundidad, todas estas familias están expuestas a los procesos concretos de "modernización" que están ocurriendo en América Latina; pero el efecto de esos procesos sobre ellas no tiene precedentes, de modo que toda conclusión derivada del comportamiento procreativo de las sociedades tradicionales o de las clases más pobres-de las sociedades altamente industrializadas es de dudosa aplicación como orientación para el futuro. Las consecuencias de las tendencias actuales para las familias de bajos ingresos pueden resumirse de la manera siguiente:

I) Acceso cada vez más generalizado a los medios de comunicación modernos que no requieren alfabetización: la televisión en las ciudades, las radios de transistores en casi todas partes.

II) Difusión de los servicios educacionales, médicos y otros servicios públicos que se distribuyen muy desigualmente y son en general de baja calidad, pero que están más al alcance y son más activamente solicitados que en las sociedades con ingresos equivalentes en el pasado.

III) Acceso a los medios de transporte, sobre todo el ómnibus, que 
hacen fácil y de bajo costo el desplazamiento entre las zonas rurales, los pueblos y las ciudades.

Iv) Exposición a los estímulos al consumo moderno, frustrados en gran medida por los bajos ingresos y la deformación de la industria nacional, que produce para el mercado de altos ingresos.

v) Oportunidades de empleo en empresas modernas, mecanizadas y racionalizadas, ampliamente conocidas, pero accesibles sólo para una pequeña minoría; para la mayoría, la "modernización" en esta esfera adopta la forma de la "marginalización": los medios de subsistencia anteriores de orden agrícola o artesanal se tornan más inseguros y menos atractivos desde el punto de vista de los ingresos relativos, si nó absolutos, mientras que parte de la mano de obra que anteriormente se ocupaba en estos sectores se ve desplazada y pasa a depender de medios de subsistencia precarios.

Hasta el momento, las dificultades y formas de inseguridad a que deben hacer frente los estratos inferiores en vías de urbanización no han tenido un efecto mensurable en su comportamiento procreativo; según la información fragmentaria existente, las tasas de fecundidad parecen ser tan elevadas en las poblaciones urbanas marginales como en las. zonas rurales. De ello se ha deducido que, si bien la inseguridad de la clase media da lugar a una baja fecundidad, la inseguridad de la clasebaja produce una aceptación pasiva de su alta fecundidad, limitada sblo. por aquellos medios que menos previsión requieren, sobre todo el aborto.

No es que la inseguridad de la clase baja no pueda tener efectos. distintos en el futuro, a medida que haya métodos anticonceptivos más. modernos y fáciles y que se internalicen valores y aspiraciones de consumo urbanos "modernos". Puede haber cierta propensión a subestimar la capacidad de previsión y de toma de decisiones de esos estratos, y. a sobrestimar el plazo - que a menudo se fija en una generación- necesario para introducir cambios efectivos en sus actitudes con respecto a la fecundidad. Los antecedentes, por escasos que sean, muestran que las decisiones sobre migración se toman, en general, racionalmente, y con una apreciación objetiva de las diversas posibilidades de ganarse la vida, ninguna de las cuales es muy alentadora. Que cambien los patrones de fecundidad de los estratos inferiores urbanos y rurales en medida importante mientras se mantenga la tendencia a la marginalización es uno de los muchos problemas demográficos que todavía no pueden ser resueltos con grado alguno de seguridad. ${ }^{21}$

Dada la amplitud de las diferencias probables entre las estructuras $\mathrm{y}$. las tendencias familiares en los diferentes medios, es arriesgado generalizar acerca de la influencia que puedan tener las características familiares sobre la fecundidad o la de los posibles cambios de la fecundidad sobre

21 Un estudio de comportamiento en relación con la fecundidad entre mujeres de los. estratos bajos de Río de Janeiro efectuado en 1969, mostró un aumento muy importante en los conocimientos y uso de los métodos anticonceptivos más recientes comparado con los datos de la encuesta hecha por CELADE en 1963, aunque la pobreza y la información. inadecuada obstruyeron el uso eficiente de estos métodos. (George R. Martine, Fertility; Behaviour of Lower-Class Women in Rio de Janeiro.) 
la familia. Si la mujer está motivada más fuertemente y toma la delantera en la limitación de la fecundidad - lo que es probable según las investigaciones- la baja de la fecundidad sería a la vez consecuencia de la independización de la mujer en la vida familiar y en la sociedad y un estímulo para lograr esa independencia. Las familias centradas en la mujer, en que ésta asume la principal responsabilidad de la crianza de los hijos engendrados por una serie de hombres, son, desde hace tiempo, características de los estratos inferiores en algunas partes de América Latina, aunque son raras y alejadas de lo normal en otros. La combinación del control de la fecundidad ejercido por la mujer con la incapacidad del hombre para garantizar el sustento de la familia, podría favorecer la formación de familias de este tipo.

También sería ingenuo desconocer que gran parte de la actividad sexual, que puede contribuir en forma apreciable a la tasa de natalidad cuando no están en uso generalizado los anticonceptivos o el aborto, no se relaciona con ninguna estructura familiar, ni siquiera con el tipo de familia centrado en la mujer. En muchos medios urbanos en los que los patrones y controles familiares del pasado están en crisis, este fenómeno, o al menos los males sociales que de él derivan, parecen estar cobrando mayor importancia. Las jovenes que conciben en relaciones sexuales casuales o experimentales recurren al aborto 0 abandonan a sus hijos. Sería preciso efectuar mayores investigaciones para aquilatar la verdadera importancia de este fenómeno, en contraposición con las generalizaciones alarmistas que a veces se hacen al respecto, así como para comprobar la hipótesis de que el fenómeno se autoperpetúa, a medida que cantidades cada vez mayores de niños que han carecido de toda estabilidad familiar llegan a la pubertad. ${ }^{22}$ En la medida en que exista un patrón procreativo de este tipo, carecerá de sentido la importancia que atribuyen la mayoría de las declaraciones de política demográfica al derecho de la familia a determinar el número de sus hijos y el espaciamiento entre ellos; el problema se centrará en el derecho de la juventud a tener relaciones sexuales sin consecuencias indeseadas, o el derecho de la sociedad a tomar medidas para combatir la procreación en circunstancias tan poco propicias.

\section{b.) Servicios sociales}

Con respecto a todos los servicios sociales públicos y los componentes del nivel de vida con ellos relacionados se plantean dos preguntas principales: I) cuáles son las influencias del crecimiento de la población y de su redistribución sobre la capacidad del Estado para proveer esos servicios y sobre la capacidad de la familia para utilizarlos; iI) cuáles son las influencias de los propios servicios, y del aumento de los niveles de vida que se espera obtener de ellos, sobre el crecimiento y redistribucion de la población.

22 El Consejo Venezolano del Niño ha estimado que en ese país hay 350000 niños sbandonados (Centro Venezolano de Población y Familia, La mujer venezolana y la regulación de nacimientos, Caracas, 1970). 
No se las puede responder con estudios limitados a las variables demográficas y a los servicios sociales sectoriales considerados por separado. El crecimiento, la distribución y el contenido de los servicios sociales reciben la influencia de los valores y prioridades dominantes en una sociedad determinada. Las tendencias demográficas agravan dificultades o facilitan oportunidades que existirían en todo caso. Ha sido limitada la función redistributiva de los servicios sociales en la mayoría de los países latinoamericanos; las diferencias de acceso a esos servicios corresponden en general a las diferencias en cuanto al nivel de ingreso, los niveles de ocupación y a la residencia en un lugar urbano o rural. ${ }^{23}$ En este cuadro general sería difícil demostrar si los servicios sociales tienen un papel importante en determinar las diferencias de características demográficas entre estratos sociales y localidades.

En lo que toca a la influencia futura de los cambios demográficos sobre los propios servicios sociales, cabe suponer que en todos los sectores sociales la baja de la fecundidad aumentará la capacidad del Estado para mejorar la calidad de los servicios y ampliar su cobertura, así como la capacidad de las familias para aprovecharlos. Sin embargo, debe tenerse presente que la acumulación de demandas insatisfechas y la necesidad de mejorar la nutrición y la vivienda son de tal magnitud que no sería realista esperar a corto y mediano plazo, y a través del cambio demográfico, algún alivio de las presiones a que está sometido el Estado para que asigne recursos a la acción social. Por el contrario, en la medida en que las familias sean capaces de controlar su propia fecundidad estarán en mejores condiciones de expresar sus demandas de acción gubernamental y de obligarla a ayudarles a satisfacer sus demás necesidades. A más largo plazo, los cambios en la distribución por edades provocarán modificaciones apreciables en la importancia relativa de distintos servicios sociales y en las actividades más concretas de cada sector. En el decenio de 1970, sin embargo, este factor no tendrá mucha trascendencia salvo en la minoría de países antes mencionados en que ha avanzado bastante la transición hacia nuevos patrones demográficos.

I) Enseñanza. En la mayoría de los países latinoamericanos, la proporción de población correspondiente al grupo cuya edad va de 5 a 14 años es de un 26 a un $28 \% .{ }^{24}$ Este grupo crece en un $3 \%$ anual más o menos. Si se supone que el objetivo mínimo de la enseñanza universal es de seis años de escolaridad para cada niño, la matrícula primaria debería alcanzar por lo menos a trés quintas partes de ese grupo de edad, es decir, más del $15 \%$ de la población total. El porcentaje equivalente en la mayoría de los países industrializados de altos ingresos sería de 9 a $10 \%$, y la tasa anual de aumento iría de 1 a $2 \%$. La mag-

23 Véase El cambio social y la política de desarrollo social en América Latina, op. cit., parte II.

${ }^{24}$ Las excepciones son Argentina, Cuba, Chile, Uruguay y los países de habla inglesa del Caribe, en los que el grupo de esta edad es más pequeño en diversos grados. El grupo de edad es utilizado convencionalmente por los demógrafos. El grupo de 7 a 16 años de edad, que correspondería más exactamente a las edades escolares normales, sería solo ligeramente inferior en tamafío. 
nitud de la carga de financiar y suministrar personal para servicios de enseñanza adecuados en estas condiciones no requiere mayor demostración.

Sin embargo, esto no ha sido óbice para el mejoramiento progresivo de los niveles educacionales en la mayoría de los países latinoamericanos durante los últimos decenios. La matrícula en todos los grados ha crecido más rápidamente que la población. Los datos censales de 1960 señalan un índice más alto de alfabetización y una escolaridad más prolongada para los grupos más jóvenes que para los mayores, y no hay razones para dudar de que el censo de 1970 mostrará una tendencia semejante. La enseñanza está pasando en América Latina por una crisis compleja, en la que los costos desempeñan un importante papel, pero no puede demostrarse que el gran tamaño y el rápido crecimiento de la población escolar tornen prohibitivo el costo de la atención de sus necesidades mínimas de instrucción formal. Lo que es más, muchos educadores están convencidos de que la enseñanza básica podría impartirse en menos tiempo y a menor costo por alumno si se aprovecharan en forma inteligente las innovaciones tecnológicas y se eliminaran las asignaturas inútiles y los métodos docentes anticuados.

Pese a las tendencias cuantitativas aparentemente favorables, la enseñanza sigue distribuyéndose en relación inversa al nivel social de los diferentes grupos de la población, tanto cualitativa como cuantitativamente. La diferencia deriva en parte de la capacidad de los estratos más pudientes para influir en la distribución de los recursos educacionales, pero también obedece a las desventajas de los estratos más pobres para aprovechar los servicios que se les ofrecen. No procede aquí analizar ese problema, ${ }^{25}$ pero parecería que la alta fecundidad de estos estratos explica en gran parte su muy limitada capacidad para aprovechar eficazmente los servicios de enseñanza. El gran número de hijos de una familia no impide que asistan unos pocos años a la escuela elemental, pero el hacinamiento y la desnutrición reducen su capacidad para aprender. A medida que aumentan los costos incidentales en los años superiores del sistema escolar y surge la posibilidad de que el niño trabaje, se reducen al mínimo sus posibilidades de seguir asistiendo a la escuela.

La redistribución geográfica de la población complica el problema de distribuir los servicios educacionales; las zonas urbanas de inmigración se ven especialmente afectadas. Sin embargo, la calidad de los servicios educacionales de las zonas rurales y de los pueblos pequeños suele ser tan deficiente que en ellos probablemente no habría gran capacidad ociosa ni siquiera cuando comience a disminuir la población infantil. Lo más grave es que al tener las ciudades mayor capacidad de obtener recursos públicos para la enseñanza, las escuelas rurales siguen escasas de fondos $\mathrm{y}$ atendidas por profesores sin preparación.

En cuanto a la influencia de la enseñanza sobre el cambio demográ-

25 Véase Educación, recursos humanos y desarrollo en América Latina, publicación de las Naciones Unidas, núm. de venta: s.68.II.6.7, capítulo III. 
fico, es muy conocida la relación negativa que existe entre el nivel educacional y la fecundidad, que suele alcanzar dimensiones significativas para los padres con más de cuatro años de escolaridad y que aumenta mientras más alto sea el nivel educacional; sin embargo, difícilmente puede separarse el efecto de la enseñanza del que corresponde a la ocupación, el ingreso y la residencia en un lugar urbano..26 Una vez que las familias logran una situación que les permite abrigar esperanzas fundadas de poder mantener a sus hijos en la escuela tiempo suficiente para mejorar su condición social y ocupacional futuras, es casi inevitable que se den cuenta de las ventajas de facilitar ese proceso teniendo menos hijos.

Frecuentemente se ha dicho que el cariz urbano que tiene la enseñanza rural en América Latina fomenta una corriente excesiva de migración hacia las ciudades. La afirmación parece razonable, pero no hay pruebas concluyentes de que eso suceda. En cambio, las investigaciones muestran que la posibilidad de obtener una mejor enseñanza en la ciudad es un motivo primario o secundario para muchas familias de migrantes y migrantes jóvenes. Probablemente es menos importante el papel persuasivo que desempeña la débil escuela rural en la migración de los jóvenes campesinos que la que representa la pequeńa escuela pueblerina en la migración de la juventud local en busca de una versión más "moderna" de la vida urbana.

Sólo recientemente se está comenzando a analizar y ensayar la posibilidad de que las escuelas influyan directa e intencionalmente por medio de la educación sexual, la enseñanza de la vida familiar y lo que se ha dado en llamar la "concientización demográfica" sobre el comportamiento procreativo y las actitudes frentes a cuestiones relativas a la política de población. ${ }^{27}$ Es probable que este tipo de enseñanza se extienda rápidamente en las escuelas a que asisten los niños de los estratos medios urbanos. Su utilidad en las escuelas de los estratos inferiores de alta fecundidad será mucho más dudosa mientras los niños asistan a la escuela sólo cuatro años o menos, antes de la adolescencia, y con antecedentes culturales que dificultan la comunicación con el maestro sobre estos temas. Con frecuencia se han cifrado esperanzas exageradas en la función potencial de las escuelas (incapaces de llevar a cabo sus tareas mínimas de alfabetización y de impartir los valores de la sociedad nacional) para fomentar la innovación agrícola, el desarrollo de la comunidad, etc. No parecen mejores las posibilidades inmediatas de educación demográfica y sexual, aunque a más largo plazo puedan llegar a tener gran importancia, siempre que fructifiquen reformas educacionales más generales y que se produzcan una gran expansión y transformación de la enseñanza de adultos.

26 Véase El cambio social y la política de desarrollo social en América Latina, op. cit., capítulo Iv, y "Dinámica de la población en México", pp. 76 y 77.

27 Véanse el informe final y los documentos de trabajo de la Reunión de Especialistas en Población-Educación, organizada por la unesco en Santiago de Chile del 28 de septiembre al 19 de octubre de 1970 . 
II) Salud. Se reconoce generalmente la función clave que han desempeñado la salud pública y otras actividades conexas en la reducción de las tasas de mortalidad y la consiguiente aceleración del crecimiento de la población. Su influencia se ha manifestado principalmente a través de actividades de un costo por habitante relativamente bajo y que requerían escasos cambios fundamentales en las actitudes y los modos de vida de los beneficiarios: el control de las enfermedades epidémicas y endémicas mediante vacunas, insecticidas, mejoramiento de los suministros de aguas y alcantarillado. Aún pueden mejorarse mucho las actividades de control y prevención. En especial, gran parte de la población urbana y la mayor parte de la rural carecen aún de agua potable y de sistemas higiénicos de eliminación de excretas. La contaminación del aire, el tránsito de vehículos motorizados y otros problemas derivados de la urbanización plantean nuevos peligros para la salud que requerirán medidas de control.

Al mismo tiempo, el crecimiento de la población, su concentración urbana y la difusión de actitudes "modernas" a través de los medios de comunicación masivos generan una enorme demanda de servicios curativos. Como lo enseña la experiencia de los países de altos ingresos, los costos por habitante de la atención médica moderna son muy altos y tienden a elevarse más rápidamente que el nivel general de precios. Evidentemente es exigua la capacidad de la mayoría de las familias latinoamericanas para hacer frente a esos costos con sus propios recursos, y los intentos del Estado no bastan, ni con mucho, para suplir esa demanda. En general, la distribución por edades implicará que la atención pediátrica seguirá predominando desde el punto de vista numérico, y que esta demanda aumentará mientras no mejoren marcadamente las condiciones generales de vida, por la mala alimentación, las malas condiciones sanitarias y la deficiencia habitacional. Las mismas condiciones aumentarán la demanda de servicios curativos de parte de la población en edad activa. La población de los grupos en edad avanzada seguirá siendo una parte relativamente pequeña del total, pero su número absoluto sigue creciendo muy rápidamente, y la aterición geriátrica adecuada es especialmente costosa.

Los programas de planificación familiar que se están estableciendo en los proyectos de salud pública entrarán en pugna con todos los demás servicios preventivos y curativos por la asignación de fondos. Podría argumentarse que estos programas reducirán las necesidades generales de medicina curativa en la medida en que logren reducir la fecundidad; que reducirán la carga que significa en la actualidad la atención de las secuelas de abortos ilegales llevados a cabo por personas inexpertas, y que su relación de costo-beneficio será mejor que la de los servicios curativos. Argumentos semejantes pueden esgrimirse en favor de los programas de nutrición. Esos beneficios hipoteticos, sin embargo, no aliviarán la carga real que pesa sobre los servicios de salud. Es muy grande la demanda potencial insatisfecha de servicios curativos y es seguro que seguirá creciendo cualquiera que sea la tendencia de la fe- 
cundidad. En efecto, en la medida en que las familias practiquen verdaderamente la "paternidad responsable", insistirán cada vez más enérgicamente en obtener atención médica para sus hijos. Como en el caso de la enseñanza, las tendencias demográficas intensificarán las presiones que existirían en todo caso, y será muy difícil conciliarlas con un buen sistema de prioridades de asignación de recursos para salud.

III) Suministro de alimentos y nutrición. En los últimos tiempos, la producción de alimentos en América L̇atina ha crecido con un ritmo ligeramente superior al necesario para igualar el ritmo del aumento de la población. La capacidad de producción de la mayoría de los países basta, sin duda, para mantener esta tendencia en un futuro previsible, o para mejorarla si se introducen las reformas de organización y tecnología apropiadas. Es muy poco probable que la escasez de alimentos o una hambruna lleguen a frenar el crecimiento de la población en América Latina.

Al mismo tiempo, es muy sabido que, en la mayoría de los países, los niveles actuales de consumo de alimentos por la mayoría de la población son gravemente deficientes. El problema inmediato radica en la organización ineficiente de la producción y distribución agrícolas (lo que eleva los costos de los alimentos, provoca una lenta reacción entre la demanda, y produce una pérdida de cerca del $30 \%$ de los productos alimenticios entre productor y consumidor); en los bajos ingresos, que limitan la capacidad de la mayoría para adquirir suficientes alimentos, y en el contenido de la dieta alimenticia, determinado en parte por la pobreza y en parte por malos hábitos de consumo. Ha disminuido la producción de proteínas por habitante, y es de presumir que la desnutrición proteínica, grave entre los estratos más pobres, se esté agudizando, lo que tiene repercusiones perjudiciales sobre la calidad de la población futura, ya que la deficiencia de proteínas en la infancia afecta la estatura y probablemente la capacidad mental del adulto. ${ }^{28}$

Con respecto a la distribución de los alimentos, apenas si es necesario decir que una oferta nacional adecuada desde el punto de vista estadístico no asegura que los pobres tengan suficiente para comer. Al mismo tiempo, diversas investigaciones dietéticas han señalado una mala distribución de los alimentos dentro de las familias de bajos ingresos que afecta especialmente a los numerosos niños: los padres consumen la mayoría de los pocos alimentos con contenido proteínico que puede comprar la familia, y el consumo de proteínas no aumenta con el tamaño de la familia. ${ }^{29}$

rv) Seguridad social. En la mayoría de los países latinoamericanos con altas tasas de crecimiento demográfico, la seguridad social se ha

28 Se ha señalado que la desnutrición proteínica, al reducir la estatura y el vigor de la población, reduce además las necesidades de alimentos por habitante. Si se la eliminase, la futura población adulta sería más alta y robusta, y requeriría a la vez más alimentos. (Howard A. Osbom, asesor regional en estadística de la FAo para América Latina, Relaciones entre niveles nutricionales y crecimiento de población en América Latina.)

29 Ibid. 
limitado hasta ahora a una parte relativamente pequeña de la población urbana asalariada. Los únicos países que han logrado extenderla a la mayor parte de su población activa pertenecen a la minoría que tiene un grado relativamente elevado de urbanización y tasas moderadas de aumento de la población. ${ }^{30}$ De ahí que no pueda demostrarse una clara influencia de la seguridad social sobre el cambio demográfico, pero sí existe una relación evidente entre el acelerado crecimiento de la población -con la distribución por edades y características de la población activa que ese crecimiento trae aparejadas- y la incapacidad de universalizar la seguridad social.

Hasta aquí, la legislación y los programas de seguridad social han prestado escasa atención a la información demográfica, y ésta ha sido inadecuada para la planificación de la seguridad social. La mayoría de los programas latinoamericanos se ha preocupado preferentemente de la atención médica y las pensiones de jubilación. Los servicios médicos responden a una demanda muy fuerte, como se señaló anteriormente, pero es probable que se hayan inclinado demasiado por las actividades curativas; que no se hayan basado en concepciones claras de las necesidades prioritarias en materia de salud, y que no estén coordinados con los servicios de salud suministrados por otros organismos públicos. Comúnmente las jubilaciones han dado lugar a la inequidad entre los diferentes grupos amparados por la previsión social, y la edad para optar a la jubilación ha sido demasiado temprana. A medida que aumenta la esperanza de vida y que mayor número de beneficiarios supera la edad de jubilación, los sistemas resultan cada vez más incapaces de cumplir sus obligaciones. A defecto de adoptar una base actuarial más realista para determinar la jubilación, lo cual desde el punto de vista político es muy difícil, no quedan más que la bancarrota o esperar que la inflación elimine casi toda la carga que significa el pago de jubilaciones.

Muy pocos sistemas han intentado ajustarse a la situación planteada por el predominio de los niños y los jóvenes dependientes en la estructura de la población. Aparte de los servicios médicos que se prestan a las familias de los trabajadores afiliados al sistema, el principal medio para lograr ese ajuste sería el pago de subsidios familiares para contrarrestar los desequilibrios que acarrea el tener numerosos hijos y bajos ingresos. A menudo se argumenta que los subsidios familiares constituirían un estímulo inconveniente pues propenderían a mantener la alta tasa de fecundidad. Aunque el argumento no puede demostrarse, probablemente tendrá cierto grado de validez para las familias que viven en condiciones tan precarias que los subsidios familiares constituyen la fuente principal de ingreso y quizá la única segura. Pero el sistema no parece haber tenido ningún efecto generalizado sobre la fecundidad en los países europeos en los que se ha aplicado durante muchos años, a menudo con la intención expresa de estimular familias más numerosas. Los pocos países latinoamericanos que los han incorporado a la previsión

30 Véase El cambio social y la política de desarrollo social en América Latina, op. cit., capítulo XIv. 
social son el Uruguay, con baja fecundidad, y Chile y Costa Rica, cuya tasa de fecundidad va en descenso. Parece razonable esperar que los subsidios familiares fomenten en general la paternidad responsable y el control racional de la fecundidad, sobre todo si se combinan con servicios bien concebidos de atención médica, nutrición y bienestar social para los niños. Sin embargo, parecen insuperables las dificultades para conceder esos subsidios a las familias que más los necesitan a menos que se introduzcan cambios mucho más amplios en las prioridades societales, la organización económica y la distribución del ingreso. El financiamiento de los subsidios familiares, basado en descuentos por planilla que los hace formar parte del costo de los salarios, implica, en la práctica, una redistribución del ingreso entre ciertos estratos de asalariados y el traslado de parte de los costos a los consumidores de los artículos producidos por los trabajadores adscritos al sistema -incluso las familias marginales que no reciben ningún beneficio. El sector público, en las condiciones actuales, sería incapaz de financiar el subsidio familiar para todas las familias cuyos ingresos son demasiado bajos como para satisfacer ciertas necesidades mínimas de sus hijos. ${ }^{31}$

v) Vivienda. A juzgar por los antecedentes disponibles, hasta ahora las deficiencias de la vivienda parecen no haber tenido ninguna influencia definida sobre las tendencias demográficas de América Latina. Es probable que la mala vivienda contribuya a elevar la mortalidad, pero este factor no puede aislarse de las demás influencias desfavorables del medio. También es probable que la escasez y el elevado costo de la vivienda sean un motivo que inste a las familias de la clase media a tener menos hijos, pero al parecer ni los peores hacinamientos ni las dificultades con que tropiezan las nuevas familias para encontrar habitación tienen efectos apreciables en la fecundidad de los estratos más pobres. En efecto, cuando el hacinamiento y la incapacidad para sufragar los costos de la vivienda convencional llegan a cierto punto, estos estratos resuelven su problema instalándose en viviendas no convencionales que escapan a toda reglamentación.

Se ha responsabilizado a veces a los programas públicos de vivienda y a otros servicios urbanos que proporciona el Estado, de estimular la excesiva afluencia de migrantes hacia las grandes ciudades, pero sería difícil demostrar que haya habido estímulos directos de este tipo. Las investigaciones realizadas entre los migrantes urbanos no indican que la esperanza de mejorar la vivienda tenga importancia alguna entre los mo-

31 Según el informe del equipo interorganismos sobre políticas de empleo en Colombia, "es discutible el hecho de que un país con el problema demográfico a que hace frente Colombia pueda mantener un sistema de subsidios familiares... Podría argüirse que el objetivo que se persigue es el bienestar, pero los subsidios familiares se pagan fundamentalmente a quienes trabajan en el sector moderno (y en los servicios públi$\cos$ ), y no a los desempleados o a los trabajadores rurales, cuyo derecho a ellos, desde el punto de vista moral, es incomparablemente mayor. En cualquier caso, la manera más efectiva de proteger a los niños contra los efectos de la pobreza es suministrarles leche y otros medios de alimentación en forma gratuita y directa a través de las clínicas y escuelas". (orT, Hacia el pleno empleo, Ginebra, 1970, párrafo 640.) 
tivos para migrar. Además, dada la dimensión de los programas habitacionales públicos, hasta de los más vastos, los migrantes sólo podrían optar a esas viviendas al cabo de varios años de residir en la ciudad. No obstante, quizá haya una influencia indirecta de alguna importancia: los grandes programas públicos de vivienda crean oportunidades de trabajo no calificado y semicalificado que pueden realizar los migrantes, lo que tal vez los atraiga en mayor número. Pero en eso la vivienda no difiere de los demás grandes proyectos de obras públicas.

Desde el otro punto de vista - el de la influencia del cambio demográfico en la vivienda y los programas habitacionales - la combinación de un crecimiento acelerado y una urbanización concentrada plantea al Estado exigencias inmanejables, y lo ha obligado a distraer cuantiosos recursos para programas de vivienda que muy escasamente han atendido las necesidades de los estratos más pobres y no han hecho casi nada por la población rural. ${ }^{32}$ Hoy los programas públicos se están volviendo forzosamente hacia soluciones de más bajo costo encaminadas a complementar el esfuerzo de las propias familias, como el suministro de solares_urbanizados y de materiales de construcción, y diversos planes de autoayuda dirigida. Sin embargo, la demanda de vivienda con el fuerte apoyo político generado, seguramente seguirá ejerciendo presiones muy fuertes sobre los recursos públicos y la capacidad administrativa en un futuro previsible.

Cualquier reducción de la tasa de incremento demográfico sólo se haría sentir en la demanda de nuevas unidades habitacionales al cabo de veinte años, pues esa demanda depende del ritmo de formación de nuevas familias por los adultos jóvenes. En cambio, afectaría casi de inmediato los aspectos cualitativos de las necesidades habitacionales, ya que las unidades pequeñas no resultarían tan inadecuadas para las familias con menos hijos.

vi) El bienestar social $y$ otros servicios relacionados con la familia $y$ la vida de la comunidad. El examen de las relaciones entre estas formas de acción social pública y el cambio demográfico debería expresarse casi enteramente en términos de posibilidades futuras. Hasta ahora la cobertura de los programas de bienestar social, desarrollo de la comunidad y otros programas conexos ha sido demasiado limitada como para influir en el cambio demográfico, aunque hubiera sido esa su intención, que no lo ha sido.

Ultimamente los que abogan por la planificación de la familia han comenzado a considerar los programas de bienestar social y a los trabajadores sociales como posibles agentes para difundir una actitud propicia a. la planificación de la familia, sobre todo entre las familias marginales. Se está tratando de dar un contenido demográfico en la formación de los trabajadores sociales. Todo esto puede desembocar en una promoción más eficaz del bienestar de la familia, pero parece poco proba-

32 Véase El cambio social y la política de desarrollo social en América Latina, op. cit., capítule $\mathrm{xuI}$. 
ble que afecte en forma apreciable a las tendencias demográficas cuantitativas.

\section{c) Empleo}

En países con las estructuras y tendencias demográficas típicas de Amé rica Latina la población en edad de trabajar está creciendo aproximadamente en $3 \%$ anual. Esta fuerza de trabajo potencial es predominantemente juvenil, especialmente en las zonas urbanas. Cabe suponer que en los países más grandes, con sus tasas altas de urbanización y de desplazamiento de la población fuera de la agricultura, los que ingresan cada año a la población masculina que busca trabajo en ocupaciones no agrícolas llegan a cerca de $7 \%$ del total de esta población o aún más. (A medida que la población se vuelve predominantemente urbana y disminuye la importancia relativa del proceso de abandono de la agricultura, como tiene que suceder en estos países, este porcentaje bajará a alrededor del $5 \%$, siempre y cuando la tasa global de crecimiento se mantenga en $3 \%$.) En circunstancias propicias, una fuerza de trabajo de este tipo, abundante y adaptable por su juventud, podría constituir: un factor positivo para la industrialización, y así parece haber sucedido, por lo menos en algunos países. ${ }^{33}$ Actualmente, sin embargo, la lenta creación de nuevas oportunidades de empleo productivo, la creciente diferencia entre la preparación que exigen las industrias tecnológicamente avanzadas y la preparación real de la fuerza de trabajo potencial, así como las rigideces salariales que impiden absorber con rapidez la mano de obra poco productiva, se traducen en un desempleo y una marginalización crecientes, considerados como quizá la deficiencia más peligrosa de las tendencias del crecimiento económico en el futuro inmediato. Este problema se analizará en otro lugar, de modo que aquí no se profundizará en él.

Evidentemente, la reducción de la fecundidad, por radical que sea, no podrá influir en el incremento de la población en edades activas antes de 15 años por lo menos, y durante varios años más sólo podrá tener una influencia secundaria frente a otros factores que influyen en el porcentaje de la población en edades activas que efectivamente busca trabajo. Todo descenso importante de la fecundidad seguramente iría acompañado de un incremento de la proporción de mujeres que ingre-

33 En México, "el crecimiento industrial se ha visto favorecido por una oferta abun. dante y creciente de mano de obra provocada por el intenso proceso de migración de la población rural a zonas urbanas, lo que además ha facilitado que los salarios reales se mantuviesen en niveles relativamente bajos e incluso decrecieran durante un largo plazo (hasta 1956)." La oferta abundante de mano de obra barata también contribuyó a la expansión de la agricultura comercial en zonas previamente inexplotadas, y a la construcción en gran escala de carreteras y sistemas de riego que apoyaron dicha expansión. Sin embargo, la aceleración del crecimiento demográfico también "complicb el proceso ayudando a que el descenso de los salarios reales se prolongara por un. tiempo probablemente mayor del necesario". (Dinámica de la población de México, op. cit., pp. 216 y 249.) 
san a la fuerza de trabajo, y por consiguiente, de la presión general por que se amplíe el empleo. ${ }^{34}$

El análisis de los efectos del empleo en el cambio demográfico se ha centrado en esta mayór participación de la mujer. En los países industrializados de altos ingresos, la participación de la mujer en la fuerza de trabajo ha estado asociada sostenidamente a una fecundidad declinante, lo que parece lógico, cualquiera que sea la relación de causa y efecto. Los pocos estudios sobre la materia que se han hecho en América Latina confirman esta relación con respecto a las mujeres de las zonas urbanas, pero no en forma muy marcada. La participación de la mujer latinoamericana en la fuerza de trabajo es bastante baja si se la compara con la que se observa en los países de Europa y Norteamérica. En la mayoría de los países latinoamericanos trabaja menos del $20 \%$ de las mujeres en edad activa ( 15 a 64 años), cifra que se eleva a $25 \%$ en los países con una fecundidad relativamente baja; en Europa occidental, en cambio, el porcentaje llega a $43 \%$ y en Europa oriental a $60 \%$. Las tasas bajas de participación en países como la Argentina y el Uruguay, en los cuales el cuidado de los hijos no es más obstáculo que en Europa para que la mujer trabaje, sugiere que la escasa demanda global de mano de obra (que se conjuga posiblemente con un prejuicio cultural en vías de desaparecer) limita la participación de la mujer, y en América Latina este factor seguramente continuará limitando además cualquier efecto importante en la fecundidad. Se ha señalado asimismo que el efecto inhibidor del trabajo de la mujer en la fecundidad probablemente derive sólo de su participación en las actividades asalariadas en sectores urbanos modernos. Es probable que una mayor participación en las formas tradicionales del trabajo agrícola o artesanal, del trabajo a destajo en el hogar y el comercio, no tenga este efecto. El empleo de mujeres jóvenes en el servicio doméstico probablemente retarde la formación de sus familias, pero casi en todas partes el servicio doméstico parece estar absorbiendo una proporción declinante de las mujeres que trabajan.

Durante el siglo $\mathrm{xx}$ las fluctuaciones de la fecundidad en los países industrializados han estado cada vez más ligadas a grandes cambios en los niveles de empleo y de seguridad económica. La fecundidad decayó en los años de crisis del decenio de 1930 y en lọs años de guerra que vinieron después; luego, desmintiendo predicciones de un incremento demográfico lento, se elevó a alturas inesperadas durante los años de empleo casi pleno que siguieron a la segunda guerra mundial. Cabe esperar relaciones similares en países como la Argentina y el Uruguay, pero parece probable que los efectos limitantes de la fecundidad que derivan del desempleo y la inseguridad están determinados por el contraste con un período anterior de relativa prosperidad. Las altas tasas de desempleo y subempleo en América Latina entre poblaciones que en su mayoría no tienen experiencia previa en el trabajo asalariado moderno, acompañadas por una exposición desigual a diferentes rasgos de la

34 Véase El cambio social y la política de desarrollo social en América Latina, op. cit., capítulo $\mathbf{~ v .}$ 
modernización, tienen características sin precedentes que hacen imposible predecir su efecto, si es que tienen alguno.

\section{d) Ahorro}

Es obvio que el ahorro personal está directamente relacionado con el nivel de ingreso y, ceteris paribus, existe una relación inversa -en un nivel de ingreso dado- entre la capacidad de ahorro y el tamaño de la familia. Se ha afirmado que un descenso de la fecundidad lograría aumentos significativos en el ahorro disponible para la inversión y así se contribuiría a un desarrollo más acelerado. Este razonamiento, sin embargo, no puede aplicarse sin más al caso de América Latina. Más aún, ciertos autores le han negado toda validez e importancia, por la distribución marcadamente desigual del ingreso y la asociación de bajos ingresos a una alta fecundidad. Es un hecho que el nivel de consumo de los grupos de ingresos bajos es tan inadecuado, que podrían pasar al menos dos decenios antes de que pudiera esperarse un aumento del ingreso por habitante que contribuyera significativamente a lograr un aumento del ahorro personal. En los otros grupos de niveles de ingreso, que en gran parte ya han logrado una fecundidad moderada, los cambios culturales y otras influencias sobre la propensión del ahorro probablemente tendrán más importancia que los cambios en la fecundidad. Por lo demás, la gran presión que se registra por nuevas formas de consumo haría que la diversificación de éste absorbiera de inmediato el mejoramiento relativo del ingreso que se lograra por una disminución de la natalidad.

Tales afirmaciones, aunque tengan cierta validez, no enfrentan la real importancia que tiene un nivel de fecundidad más bajo en el uso de los ingresos familiares.

La afirmación de que las familias de ingresos bajos no pueden ahorrar es exagerada, aunque su ahorro puede no tomar formas convencionales ni contribuir directamente a la inversión en equipo productivo. La capacidad de las familias urbanas de ingresos bajos para dedicar parte apreciable de sus ingresos a vivienda, cuando tienen la oportunidad y alguna garantía para esta inversión, constituye un ejemplo notorio. La importancia económica potencial de reducir la carga de la fecundidad en esas familias residiría en la oportunidad de "invertir" en mejoramiento de la calidad de sus hijos como recursos humanos. El que esta oportunidad pudiese aprovecharse dependería de las decisiones de las familias respecto al destino que han de dar a sus ingresos, lo que a su vez dependería de las características de la sociedad futura y de los tipos de consumo que ésta estimulara. Las tendencias actuales, con una creciente presión sobre los ingresos de todos los estratos sociales en respuesta a la difusión del consumo "moderno" que hacen los medios de información, sugieren que esta presión puede ejerce un efecto limitante. de la fecundidad en los estratos de población que están comenzando a incorporarse al mercado de bienes de consumo modernos, pero que esa 
menor fecundidad puede no reflejarse en ahorros invertibles o en líneas de consumo que realmente mejoren la calidad de la nueva generación.

Deben tenerse en cuenta las presiones que ejercen el incremento rápido de la población y la concentración urbana en la capacidad del sector público para ahorrar é invertir. En el pasado, algunos países lograron. mantener tasas apreciables de inversión pública en producción e infraestructura sólo porque podían hacer caso omiso de la mayoría de las. necesidades básicas de los estratos de ingresos bajos (educación, vivien$\mathrm{da}$, salud, ingresos adecuados para subsistir). Esto ya no es así. Comose indicó antes sería poco realista esperar que la menor fecundidad y una urbanización más lenta hayan de aliviar estas presiones, pero este tipo de cambio demográfico ayudaría a las autoridades a satisfacer esas. necesidades en forma más significativa.

\section{e) Uso y tenencia de la tierra}

En una sociedad rural aislada y estática, las principales consecuencias. del incremento de la población por un período indefinido podrían ser la expansión gradual de la superficie de cultivo, o bien el empobrecimiento gradual, lo que dependería de las disponibilidades de tierras. Ambos procesos se observan en las zonas rurales de América Latina, pero esas zonas han dejado de ser aisladas o estáticas. El incremento de la población se combina con varias otras fuerzas, interrelacionadas pero. que no actúan todas en la misma dirección, para hacer cada vez menos viables las modalidades existentes de tenencia de la tierra, cultivo, comercialización, lazos vecinales y relaciones urbano-rurales. En sus actuales combinaciones, esas fuerzas apuntan a crecientes disparidades entre los grupos rurales capaces de encarar el cambio, y los grupos rurales: "marginalizados", y a presiones crecientes sobre el Estado y la economía urbana para que absorban o subvencionen a la porción "superflua" de la fuerza de trabajo rural. La importancia del problema en el panorama nacional de cambio económico y social, y la viabilidad de las. políticas para, resolverlo, están condicionadas por el tamaño del país, la tasa de incremento de la población y el grado de urbanización que se haya alcanzado; pero el problema mismo se encuentra incluso en países. donde el crecimiento neto de la población rural ha descendido a cero y la población urbana constituye mayoría.

En todos los tipos de países que se mencionaron en la sección $1 \mathrm{~d}$ ), las empresas agrícolas disponen ahora de una gran variedad de técnicas. para acrecentar la producción con una fuerza de trabajo estacionaria o aun una menor, haya o no justificación económica o social para aplicarlas. La producción de subsistencia y los mercados locales están perdiendo importancia frente a la producción para el mercado nacional, lo que trae presiones para racionalizar la producción y distribución. Las. fuentes de ingreso rurales no agrícolas tienden a contraerse, aunque aparecen algunas nuevas. Incluso en las zonas rurales más remotas penetran crecientemente influencias contrarias a la inmovilidad geográfica 
y a la aceptación pasiva de la pobreza: las carreteras y el transporte público barato, los medios de información, la educación pública, los servicios de salud y los llamamientos políticos de origen urbano. Entre las variedades de patrones de asentamiento y de regímenes de tenencia de la tierra, se observa que las haciendas tradicionales y los minifundios están expeliendo el exceso de población y absorbiendo poco del incremento natural de la población rural. Los crecientes asentamientos de trabajadores rurales sin tierras junto a las carreteras o en los alrededores de los pueblos pequeños muestran que una proporción creciente de la población rural no encuentra alternativa frente a la pobreza marginalizada. La reforma agraria "planificada" y los asentamientos de colonización, que hasta ahora abarcan una parte muy pequeña de la población rural, tienen la posibilidad, si se aplican políticas de reforma agraria realmente vigorosas, de aumentar mucho la capacidad de la agricultura para absorber productivamente a la fuerza de trabajo $y$, por consiguiente, la capacidad de las zonas rurales para retener población. Sin embago, aun en el mejor de los casos, esta capacidad tiene limitaciones. Los nuevos asentamientos sólo podrán ofrecer ingresos satisfactorios a sus miembros si restringen el número de ellos al necesario para que la explotación sea eficiente, y los seleccionan. No se puede esperar de ellos que absorban todo el exceso de mano de obra rural, y menos aún la parte más marginal de ella. ${ }^{35}$

Las fuerzas que actúan, en sus variadas combinaciones, excluyen la posibilidad de aplicar la política que a veces se ha propuesto, de retener la mayor parte del incremento de la población rural en la agricultura hasta que la economía urbana pueda absorber productivamente el excedente de la fuerza de trabajo rural. Esta política sólo podría aplicarse mediante tácticas rígidamente autoritarias que no son practicables ni aceptables, o mediante una falta total de oportunidades urbanas. La población rural ni siquiera podría mantener los actuales niveles de vida, y estos niveles, apoyados en el trabajo manual primitivo, ya no son aceptados por las masas rurales, ni menos por la juventud.

\section{f) Recursos naturales y espacio}

Salvo en algunos de los países latinoamericanos más pequeños, la dotación de recursos naturales permitiría mantener a poblaciones mayores en niveles de vida más altos que los actuales, si pudieran movilizarse las inversiones para aprovecharlos, aunque esos recursos generalmente no están bien equilibrados ni son de fácil acceso. Podría hasta sostenerse que varias regiones internas necesitan una población mayor para poder aprovechar eficientemente sus recursos en aras del desarrollo. La dificultad estriba en las altas tasas globales de crecimiento de la población nacional y en el uso y abuso de los recursos naturales asociados a las tendencias actuales. de cambio económico, tecnológico y social.

35 Véase un análisis más detenido de estos problemas en EI cambio social y la política de desarrollo social en América Latina, op. cit., capítulos III y vIr. 
El uso actual de los recursos naturales renovables, y en especial de la tierra, es extremadamente dispendioso y destructivo. Aunque todavía sigue pesando el optimismo tradicional en cuanto a que los recursos latinoamericanos son inagotables, hoy es evidente que esta noción es falsa y que las riquezas se están dilapidando a un ritmo alarmante. El monopolio por las haciendas de las tierras más accesibles y más aptas para el cultivo ha obligado a los minifundistas a hacer uso excesivo de las laderas más pobres, lo que ha causado agotamiento de los suelos, erosion y destrucción de los bosques. Lo mismo ha sucedido como consecuencia de la acción de ocupantes ilegales y de la tala y quema de la vegetación para preparar tierras de cultivo en zonas muy poco pobladas. Algunos tipos de plantaciones modernas también causan el agotamiento y el abandono de grandes superficies. Las actividades madereras y los incendios están destruyendo bosques sin que se tomen medidas para reemplazarlos. Hasta los recursos del mar están siendo amenazados por una explotación descontrolada. Aunque la presión demográfica está acelerando el proceso de destrucción, no constituye su factor determinante. En muchas zonas densamente pobladas de otras regiones los pequeños agricultores han cultivado la tierra por siglos sin dañarla seriamente; pero en gran parte de América Latina, donde se observa mayor destrucción es en las zonas rurales poco pobladas. Contribuyen a esa destrucción tanto los sistemas primitivos de uso de la tierra, como los métodos tecnológicamente avanzados y muy mecanizados. En los dos extremos han sido escasas la inversión y la aplicación de tecnología a la conservación y mejoramiento de la tierra, si se comparan con las de países de pequeños agricultores como China, o con países con agricultura moderna industrializada, como los Estados Unidos. Para invertir esta tendencia se necesitarán grandes inversiones y un enfoque diferente de la innovación tecnológica. Para incorporar al cultivo las regiones casi vacías de América Latina -que todavía salen a relucir en los argumentos "poblacionistas"- en forma que no lleve a su destrucción, habrá que hacer inversiones ingentes y cuidadosamente planificadas.

Los recursos naturales no renovables (principalmente el petróleo y los minerales metálicos) están siendo explotados para la exportación con toda la intensidad que permiten los mercados y los recursos tecnológicos, pues su papel principal es el de proporcionar las divisas necesarias para mantener en marcha a las economías. Es probable que cuando llegue el momento en que una población mucho más grande e industrialmente más avanzada necesite esos recursos para uso interno, algunos de ellos se hayan agotado ya y otros sólo puedan obtenerse a un costo más alto.

La concentración urbana y la importancia creciente en la vida urbana de ciertos tipos de consumo (bienes duraderos, viajes, etc.) generan una demanda por habitante de recursos naturales mucho mayor que en civilizaciones anteriores, $y$ a la vez causan efectos perniciosos, como la contaminación del aire y del agua, el ruido y las enormes cantidades de 
desperdicios perecederos e imperecederos que deben eliminarse de alguna manera.

Si la tierra es fértil y está bien cultivada, la población campesina puede alcanzar una gran densidad sin que esto provoque presiones insuperables sobre los recursos o la organización social. Dentro de límites más estrechos, las poblaciones urbanas también pueden alcanzar tamaño considerable si la mayoría acepta niveles de vida bajos, movilidad espacial limitada y gran densidad de asentamiento. A medida que se elevan los ingresos y las aspiraciones de la población, y ésta viaja ampliamente en la zona urbana y fuera de ella, compra bienes de consumo duraderos, exige casas con jardines y va de vacaciones a la playa y a otros lugares, crecen con rapidez las presiones sobre los recursos naturales, sobre el espacio disponible y sobre la organización social.

Los países de altos ingresos están luchando ahora con problemas de esta índole y han verificado un deterioro evidente de ciertos aspectos de las condiciones de vida, que contrarrestan los beneficios representados por niveles de consumo más altos. Los países latinoamericanos, en especial los más grandes, más dinámicos y más urbanizados, están comenzando a confrontar las mismas dificultades, en niveles de ingreso mucho más bajos y con una capacidad mucho más limitada para resolver los problemas de recursos y organización. Por ejemplo, si el parque de automóviles sigue aumentando a las tasas actuales, el patrón cada vez más disperso y menos denso de urbanización hará cada vez más prohibitivos los costos de las carreteras y de otras inversiones en infraestructura; grandes extensiones de tierra agrícola serán invadidas por el avance urbano, la contaminación del aire se irá agravando, y el creciente consumo de gasolina puede llegar a limitar la función exportadora del petróleo en algunos países, y ejercer una presión creciente en el balance de pagos de otros que importan este producto.

Los cálculos sobre las cantidades de recursos no renovables que se necesitarían si el resto del mundo comenzara a usarlos a la tasa que lo hacen los Estados Unidos, demuestran que esto sería imposible. Los Estados Unidos, con $6 \%$ de la población mundial, consumen la mitad de la producción mundial de los minerales más importantes. ${ }^{36}$ Se ha estimado que, al nivel de consumo de este país, el mundo podría mantener una población de 500 millones, comparada con los 3000 millones de 1970 y los 7000 millones calculados para el año 2000. Este es sólo uno de los factores que pone en tela de juicio la viabilidad de aplicar en América Latina los actuales modelos de desarrollo que ofrecen los países de ingresos altos. Las posibilidades que ofrecen las nuevas tecnologías para sustituir materias primas y fuentes de energía y reaprovechar el agua y los minerales, y para la explotación permanente y con altos rendimientos de la tierra y el mar, auguran capacidad suficiente para mantener a poblaciones inevitablemente mayores, pero este augurio no se cumplirá si no se toman medidas realistas para resguardar los recursos

36 Véase Stuart Mudd (Compilador), The Population Crisis and the Use of World Resources, Dr. W. Gunk, Publishers, La Haya, 1964, p. 238. 


\section{TENDENCIAS DEMOGRAFICAS}

naturales y encauzar el consumo por líneas que en e problemas insolubles y que sean compatibles con el ju la población a los recursos.

\section{Políticas de población}

\section{a) Delimitación de la política de población}

Desde el siglo xIx varios líderes políticos latinoamericanos han propuesto políticas de población, y varios Gobiernos han tomado medidas con el fin concreto de influir en el crecimiento y la distribución demográficos. Sin embargo, sólo a fines del decenio de 1960, y en medio de concepciones cambiantes y contrapuestas sobre la naturaleza del problema de población, pasó a primer plano la necesidad de definir una política de población y determinar el lugar que ocupa en el campo cada vez más vasto de intervención estatal en la economía y en la sociedad. Esta tarea ha tropezado con una contradicción inicial: La "población" - la raza humana- es el sujeto y el objeto de toda política pública. Sería posible, aunque de escasa utilidad, incluir todos los programas de desarrollo económico y social en la "política de población". Al mismo tiempo, es pequeño el radio de maniobra que tiene el sector público para intervenir directamente en el cambio demográfico. Las actividades públicas que tienen mayor influencia potencial o real en las variables demográficas están regidas principalmente por consideraciones de política en las cuales esta influencia se desestima o se considera secundaria. Otras de las influencias más importantes quedan fuera del alcance de la política pública, ya sea por los valores prevalecientes o porque dificultades de orden práctico excluyen la intervención estatal.

Como lo han señalado varios observadores, la contradicción se ha traducido en formulaciones de política demasiado generales como para ser operativas, yuxtapuestas con una concentración casi exclusiva, tanto en las polémicas como en los programas operativos, en la planificación de la familia como medio de influir en la variable de la fecundidad.

El intento más ambicioso de formular una definición se hizo en una Reunión sobre Políticas de Población en relación con el Desarrollo en América Latina, realizada en Caracas en setiembre de $1967,{ }^{37}$ luego de un Seminario Preparatorio efectuado en Washington en marzo de 1967:

Debe entenderse por política de población el conjunto coherente de decisiones que conforman una estrategia racional adoptada por el sector público, de acuerdo a las necesidades y aspiraciones de la colectividad, para desarrollar, conservar y utilizar los recursos huma-

37 Esta reunión fue copatrocinada por la Organización de los Estados Americanos, las Organización Panamericana de la Salud, el Consejo de Población y el Aspen Institute for Humanistic Studies, con la colaboración del Gobierno de Venezuela. En ella participaron a título personal ministros y otros funcionarios páblicos procedentes de 15 países, junto con expertos invitados. 
nos influyendo sobre la magnitud y el crecimiento probables de la poblacion, su distribucion por edades, la constitución y composición de las familias, la localización regional o rural-urbana de los habitantes y la incorporación a la fuerza de trabajo y a la educación, con el fin de facilitar los objetivos del crecimiento económico y posibilitar la participación de la población en las responsabilidades $y$ beneficios del progreso.

Esta definición ha sido objeto de bastantes críticas, ${ }^{38}$ y actualmente hay consenso en que se necesita una definición más restrictiva, que limite el alcance de la política de población a las medidas encaminadas a influir en el crecimiento y la distribución demográficos, siempre que esté integrada en una política global de desarrolio. Una política de esta índole deberá procurar ante todo una comprensión adecuada de las repercusiones de las variables demográficas y de las limitaciones que ellas imponen a las demás áreas de la política de desarrollo, y luego hacer que todas las medidas que afecten a estas variables sean compatibles y se refuercen mutuamente.

Esta norma apunta en la dirección debida para el futuro, pero no muestra cómo resolver los principales problemas inmediatos:

I) Pese a un decenio de experiencia en la planificacion del desarrollo, casi ninguno de los países tiene por ahora políticas o estrategias auténticas, coherentes y operativas, capaces de proporcionar el marco de referencia necesario para la racionalización demográfica. Mientras la política económica y social siga siendo fragmentaria y sectorial, y esté determinada en gran parte por la fuerza relativa de las presiones de grupos profesionales y burocráticos, de clientelas electorales y de fuentes externas de ayuda financiera y cooperación técnica, y mientras existan hasta dentro de las políticas sectoriales programas y normas más concretos que suelen contraponerse, no es fácil que las actividades que abarca la política de población no adquieran características similares. Al respecto, los problemas de delimitar y formular políticas de población se parecen a los que encaran todos los grandes objetivos intersectoriales de mediano

38 "Se torna difícil en estas circunstancias trazar una clara línea divisoria entre política de población y política econbmica y social, en general. Es esta dificultad lo que debe haber llevado a los redactores de la definición de política de población que se adoptó en una reciente conferencia, a darle al término una acepción tan amplia que prácticamente quedaron englobados en ella todos los objetivos del desarrollo." (Carmen A. Miró, Política de población: ¿Qué? ¿Por qué? ¿Para qué? ¿Cómo?) La revisión de la definicion propuesta por el Seminario Preparatorio "se produjo mediante supresiones, sustituciones $\mathrm{y}$ adiciones que reflejan claramente el 'tira $\mathrm{y}$ afloja' de las distintas posiciones en juego. El resultado es la típica definición que deja contentos a todos, pero que resulta inoperante tanto para un análisis térico como para una orientación de la acción política." (Gérardo González C., Políticas de población y marginalidad social.) "Un ejemplo de esta confusión está constituido por lo que planteó como objetivos de una política de población el informe final ... Si, en efecto, quisiera incluirse en lo poblacional todo aquello que tiene consecuencias en la población o de ella se deriva, tendría que enumerarse todos los sectores o aspectos que constituyen una sociedad." (Roger Vekemans, S. J., Política de población: Esbozo de Status Quaestiomis, DESAI, Santiago de Chile, agosto de 1970.) 
plazo que se han señalado como esenciales para el desarrollo, como la redistribución del ingreso y la política de recursos humanos. ${ }^{39}$

II) Los demógrafos aún no están en condiciones de ofrecer a las autoridades públicas consejos incontrovertibles sobre las relaciones entre cambio demográfico y desarrollo, o sobre todas las consecuencias a largo plazo de las medidas que se pueden tomar. Esta deficiencia, como otras similares en diversas áreas de la política intersectorial, sólo deriva en parte de la falta de investigación básica; las interrelaciones y consecuencias dependen de la definición previa de los patrones de desarrollo a los que se aspira en tipos específicos de países. El carácter de la información necesaria sobre temas como redistribución de la población, urbanización, empleo y estructuras familiares depende también de la formulación de demandas claras por quienes forjan las políticas de desarrollo.

III) El hecho de que el cambio demográfico futuro dependa de las tendencias y políticas de empleo y educación, de los niveles de ingreso y de la distribución del mismo, así como de diversos tipos de innovaciones tecnológicas, hace que las medidas inspiradas primordialmente por consideraciones de política de población han de tener siempre un papel secundario o auxiliar - aunque éste sea de considerable importancia- dentro del conjunto de influencias que afectan a las variables demográficas. Las políticas en todas esas áreas deberían tomar en cuenta los objetivos de población, una vez que éstos se hayan formulado claramente, y deberían hacer mucho mayor uso que hasta ahora de la información que el análisis demográfico pueda dar sobre la viabilidad de sus metas y técnicas; pero en la definición de esas políticas, hay que tomar en cuenta aspectos tanto o más importantes que sus consecuencias demográficas. Un área de gran importancia potencial en la que ahora sólo existen iniciativas desarticuladas es la política de robustecimiento de la familia, que necesariamente se verá afectada por la divulgación de la "planificación de la familia" en su sentido más estrecho; pero aún aquí los objetivos demográficos deberán subordinarse a los objetivos derivados de las concepciones de los derechos humanos y del papel de la familia en el desarrollo. Las políticas que afectan a la distribución geográfica de la población, que hasta en las definiciones más estrictas se incluyen en la política de población, en la práctica suelen encararse en el marco de la política de desarrollo regional, de desarrollo urbano y de desarrollo rural.

b) Concepciones e ideologías relativas al papel de la población en el desarrollo de América Latina

En las actitudes hacia la población que predominan en América Latina pueden distinguirse varias etapas históricas, cada una de ellas asociada a determinados patrones económicos y sociales, a formas de interdependen-

39 Véase El cambio social y la política de desarrollo social en América Latina, op. cit., capítulos x y xI. Carmen A. Miró, op. cit., destaca fuertemente la necesidad y la actual carencia de políticas de desarrollo a las que puedan integrarse las políticas de poblacíon. 
cia con el resto del mundo y a concepciones de las fuentes de progreso nacional.

I) Desde la época de la independencia a comienzos del siglo xIx hasta el decenio de 1920: El progreso y el poder nacionales se identificaban con el incremento rápido y la "europeización" de la población. Esta ideología predominante (que encontró diversos grados de resistencia en corrientes nacionalistas defensoras de lo autóctono) se asociaba a economías orientadas casi enteramente hacia la exportación de materias primas y a la dominación de élites terratenientes-comerciales convencidas de la inferioridad étnica de las masas de población. En este período las poblaciones eran muy pequeñas en relación con el territorio, las tasas de incremento natural eran bajas y la urbanización limitada. Había gran disponibilidad de migrantes europeos y los países capaces de atraerlos se adelantaban al resto de la región en términos económicos y de estabilidad política; el incremento de la población por medio de la inmigración significaba que la mayor parte de dicho incremento podía incorporarse directamente a la fuerza de trabajo en los modestos niveles de preparación que requerían los sistemas de producción existentes, y que los costos de esa preparación habían sido sufragados por el país de origen.

II) Desde los años veinte a los años sesenta: Seguía aceptándose sin reservas la conveniencia de que la población aumentara con rapidez, pero se valorizaba más a la población autóctona y se hacía mayor hincapié en la necesidad de mejorar su calidad mediante la educación y otras medidas sociales. La creciente urbanización se miraba con optimismo como un estímulo para el desarrollo, pues concentraba la demanda de consumo y la oferta de trabajadores calificados. Estos puntos de vista iban unidos a un creciente nacionalismo y a la defensa de lo autóctono frente a los rasgos culturales de Europa y Norteamérica; a un crecimiento rápido de estratos medios urbanos capaces de expresarse políticamente; a una extinción parcial de las fuentes preferidas de inmigración, que en los años treinta coincidió con la crisis económica, el desempleo urbano y las restricciones legales a la inmigración; a una transformación de los patrones económicos orientados a la exportación hacia el crecimiento (especialmente en los decenios de 1940 y 1950) de industrias de sustitución de importaciones que ofrecían nuevas oportunidades de trabajo en las ciudades; una aceptación cada vez mayor de políticas de desarrollo basadas en la industrialización, la cooperación financiera y técnica internacional, la integración latinoamericana, la planificación sistemática de largo plazo y la reforma de las estructuras socioeconómicas.

III) Desde comienzos del decenio de 1960 hasta ahora: Las interpretaciones del papel del cambio demográfico han ido divergiendo cada vez más, se han hecho más conflictivas y de inspiración más ideológica. Esta etapa se asocia con la frustración parcial de las esperanzas que se habían puesto en las políticas de desarrollo globales del decenio; con el acelerado incremento del número de personas que todos los años ha llegado a la edad de trabajar a consecuencia de la aceleración del crecimiento demográfico desde mediados del decenio de 1940; con la manifestación cada 
vez más evidente y el alcance cada vez mayor de los problemas de marginalidad urbana, desempleo estructural y subutilización de los recursos humanos; con la discrepancia creciente entre las aspiraciones de obtener servicios sociales y las realizaciones; con la creciente y compleja influencia de las innovaciones tecnológicas y de organización así como los estímulos al consumo que se originan en los países industrializados de altos ingresos; con la creciente capacidad técnica para actuar directamente sobre algunos componentes del crecimiento demográfico, y con la extensión bastante súbita hasta América Latina de una campaña mundial que insiste en las consecuencias catastróficas del crecimiento sostenido de la población, y en la planificación de la familia como único remedio.

En la etapa actual, aunque siguen siendo comunes e influyentes antiguas opiniones optimistas y la identificación tradicional del poder nacional con el tamaño de la población, cabe distinguir algunas posiciones más nuevas, cada una con diversas variantes:

I) Importantes sectores de opinión continúan considerando que el "desarrollo" es principalmente el logro de tasas mayores de incremento de la producción y del consumo, para eliminar la diferencia entre los niveles actuales y los del país europeo o norteamericano típico, suponiendo que esto se puede hacer si se aplican con más vigor las políticas de desarrollo y las reformas estructurales acordadas en el decenio anterior y si la cooperación internacional en materia de comercio y financiamiento se hace más generosa y más segura. Desde este punto de vista, la absorción de la población urbana marginal -y de la población rural subempleada que la alimenta- en empleos productivos y su plena participación en el orden social dependen primordialmente de que se logre una tasa alta de crecimiento económico. Toda medida eficaz para reducir el crecimiento de los estratos de población expuestos a la marginalización, o para reducir la tasa de migración de esos estratos hacia las ciudades, alivia las presiones en favor del uso no productivo de los recursos públicos, reduce la posibilidad de violencia y otorga a las autoridades nacionales más tiempo y mayor flexibilidad para asignar recursos a tareas prioritarias de desarrollo. Los que se oponen a este punto de vista suelen caricaturizarlo diciendo que aboga por el control de la natalidad como alternativa en lugar del desarrollo económico, pero es improbable que alguien piense en esos términos.

Ir) En el otro extremo, se asevera que, en caso de ser viable una estrategia de desarrollo basada en las premisas que se resumieron antes, ésta sólo produciría un seudo desarrollo injusto e inaceptable, que perpetuaría una situación perniciosa de dependencia. Se infiere que el desarrollo auténtico sólo será posible después de una transformación revolucionaria de las estructuras de poder existentes, y de un rompimiento de los lazos de dependencia. Desde este punto de vista, el sistema de crecimiento económico dependiente, por su misma naturaleza, genera el crecimiento de la población marginal y esto constituye una de las contradicciones que finalmente ha de llevar a la ruptura del sistema. En las condiciones actuales, de ser eficaces las medidas de control de la natali- 
dad, aliviarían las tensiones y prolongarían la supervivencia de estructuras económicas y sociales que deberían desaparecer cuanto antes para dar paso a la construcción de un nuevo orden social. Esta posición puede caricaturizarse fácilmente diciendo que se inclina por aumentar las presiones sociales para fomentar una transformación inmediata. En algunas de sus manifestciones parece envolver cierta insensibilidad frente a las necesidades inmediatas de los estratos de bajos ingresos, así como un alto grado de optimismo respecto a la capacidad posterior para satisfacer dichas necesidades.

III) Un tercer punto de vista acentúa las connotaciones que tiene el crecimiento rápido de la población para el bienestar de la humanidad, y el derecho de la familia a tener acceso a los medios de limitar el número de hijos, cualesquiera que sean los efectos de esta acción en el desarrollo y la política pública sobre el incremento de la población. Este punto de vista es compatible con casi todas las interpretaciones del proceso de desarrollo y sus requisitos, pero normalmente va acompañado de cierto escepticismo respecto a la capacidad de las autoridades públicas para aplicar políticas de población basadas en las concepciones de desarrollo más ambiciosas, y una disposición a aceptar medidas fragmentarias que respondan a las necesidades inmediatas de las familias. Algunos defensores de esta posición limitan su apoyo a cierto tipo de técnicas de planificación de la familia que se consideran moralmente legítimas, mientras otros están dispuestos a apoyar los abortos gratuitos y otros medios.

Iv) Un cuarto punto de vista, más complejo y más difícil de resumir, acepta el argumento basado en los derechos humanos y también considera muy deseable que bajen las tasas de incremento de la población en todos los países latinoamericanos que aún no han experimentado una transición demográfica, cualquiera que sea su futuro patrón de desarrollo. Al mismo tiempo, quienes así opinan creen que la urgencia del desarrollo y el contenido apropiado de las políticas de racionalización demográfica difieren ampliamente según las circunstancias de los distintos países; que es posible poner en tela de juicio la importancia de estas políticas para aliviar las presiones que surgen de la marginalización, se considere o no conveniente este alivio, y que la capacidad del Estado para controlar el crecimiento de la población en el futuro previsible mediante las técnicas que ahora se propugnan probablemente influirá mucho menos que los cambios en la vida familiar y las actitudes culturales que derivarán de los cambios sociales y económicos que están en marcha. Se acepta como parcialmente válida la aseveración de que las actuales campañas para controlar el crecimiento de la población derivan de ciertas concepciones de desarrollo dependiente y que están concebidas para facilitar la supervivencia, con reformas y mejoramientos, de las actuales estructuras económicas y sociales. No se acepta la inferencia de que estas expectativas constituyan motivo suficiente para apoyar o rechazar las políticas mismas, o para dar por sentado que los resultados de las políticas han de corresponder necesariamente a las expectativas de sus patrocinadores. Se supone que los efectos a corto plazo de estas políticas en el desarrollo serán 
limitados y que tendrán más importancia para el bienestar de las familias que para resolver los problemas de distribución de recursos que confronta el Estado, pero se estima que la atención no puede limitarse sólo al plazo corto.

v) Cabe distinguir otra posición más entre algunos proponentes de políticas de desarrollo y analizadores del cambio social: hacer caso omiso del problema de población o negar su importancia, con el fin consciente de distraer lo menos posible la atención pública de problemas que se consideran más urgentes y más manejables.

En la prolongada polémica sobre políticas de población pueden distinguirse muchas posiciones intermedias; con frecuencia no aparecen explícitas las bases ideologicas de cada posición. Las declaraciones públicas sobre políticas de población tienden a envolverse en expresiones calculadas para anular ataques o para no herir susceptibilidades políticas o religiosas, y los términos vigorosos con que se muestra la gravedad del problema contrastan con la ambiguiedad de las recomendaciones. Entretanto, las polémicas extraoficiales tienden a ser un diálogo de sordos, en el cual las partes rechazan sus propias versiones caricaturizadas de la posición opuesta, o los motivos supuestamente inaceptables de sus proponentes, especialmente cuando se pone sobre el tapete el apoyo decidido de algunos poderes fuera de América Latina a determinadas políticas de población. La posición tomada por la principal fuente externa de ayuda y asesoramiento para el desarrollo ha producido, por una parte, una aceptación a veces renuente del control del crecimiento de la población como parte de un conjunto de políticas encaminadas a obtener cierta ayuda financiera, y por otra, un rechazo automático de la conveniencia de ese control en los sectores de opinión a los que preocupa la dependencia.

\section{c) Politicas y actitudes gubernamentales}

Según la definición de política de población que se adopte, puede afirmarse que ningún país de América Latina tiene una política de población o que casi todos la tienen. Dos presidentes de páses latinoamericanos (Colombia y la República Dominicana) y dos primeros ministros de países del Caribe (Barbados y Trinidad y Tabago) firmaron en 1967 la Declaración de los Jefes de Estado sobre el Problema de Población, que combinaba una vigorosa afirmación de los peligros de un incremento rápido de la población con el apoyo a la planificación de la familia como único remedio. A partir de 1967, jefes de Estado o ministros de casi la mitad de los países latinoamericanos han hecho declaraciones públicas que afirman o niegan la conveniencia de reducir el incremento de la población. En algunos países, altos funcionarios públicos han expresado opiniones muy divergentes respecto a los objetivos en materia de población. ${ }^{40}$ Sblo un gobierno, el de Colombia, ha incorporado criterios y

40 En Brasil, en 1969, "de cuatro discursos de gobierno, tres fueron favorables a una política demográfica restrictiva y uno fue en favor de la política expansionista". (Glycon de Paiva, "Política demográfica para el Brasil: Dificultades para establecerla".) Véase 
objetivos generales de política de población (basados en la definición de la Conferencia de Caracas) en su último plan de desarrollo, que se presentó al Congreso para su aprobación a fines de 1969.41 Hasta ahora ningún gobierno ha fijado metas cuantitativas para los cambios en las variables demográficas. ${ }^{12}$

Cuando se desciende de las declaraciones de política a examinar lo que se ha hecho efectivamente en nombre de la política de población o sin una política declarada, las diferencias entre las posiciones nacionales parecen menos evidentes. La política práctica ha sido de laissez faire, combinada con diversos grados de apoyo público a las actividades de planificación de la familia. La política de migración, que en una época fue el único componente activo de las políticas nacionales de población, ha recibido poca atención en los últimos años, excepto en los países del Caribe; en la práctica, la política de población se ha ido equiparando

también Rubens Vaz da Costa (Presidente del Banco do Nordeste do Brasil), "El crecimiento de la población y el desarrollo económico. El caso brasileño", Boletín de población, II, 3, mayo de 1970.

41 Las bases para la política de población de Colombia son las siguientes:

"a) Criterios:

1) El Estado debe intervenir con el establecimiento de una política, en cuanto el bien del conjunto social está comprometido, tanto a nivel macroeconómico, como a nivel de la familia y del individuo, pero respetando sus derechos e intimidad.

2) La política de población se considera como un componente indispensable de la política general de desarrollo y por lo tanto se da énfasis a la educación integral.

"b) Objetivos:

Dos son los objetivos inmediatos: lograr una mejor distribución territorial de la población y modificar el actual ritmo de crecimiento de la población por medio de una reducción de la fecundidad.

Con relación al segundo objetivo de reducción del crecimiento de la población, por medio de una disminución de la fecundidad, la política contempla los dos niveles, el macrosocial y el familiar: uno y otro dentro de un enfoque educativo hacia la responsabilidad.

A nivel de la sociedad el Estado ha lanzado una amplia campania sociocultural en favor de Ia Paternidad Responsable por medio de la Ley 75 de 1968.

Se busca reducir la ilegitimidad, aliviando así en parte el problema demográfico.

A nivel del individuo y de la familia y como tarea propia del Ministerio de Salud Pública, se preve, dentro de los programas matemo-infantiles, el suministro de la información y los servicios médicos de planificación familiar, tarea que cumplen igualmente el Instituto Colombiano de Seguros Sociales y la Caja Nacional de Previsión Social." (Gustavo Pérez Ramírez, La política de población en Colombia al término de la década del 60, citando al Departamento Nacional de Planeación, Planes y Programas de Desarrollo 1969/70, capítulo 1.)

42 Se han citado metas cuantitativas para la reducción de la natalidad en algunos pocos paises del Caribe (María L. García, Informe sobre el estado de los programas de planificación familiar en América Latina, celade, Serie A, núm. 97, 1968). Sin embargo, esas metas parecen haber sido formuladas por los programas de planificación de la familia con fines administrativos, y estar encaminadas a mostrar los resultados que se esperan de la cobertura de un número de familias fijado como metas, sin construir objetivos oficiales de política. 
cada vez más a la aceptación de la planificación de la familia. El proceso se describió y justificó recientemente en la siguiente forma:

"Los primeros pasos casi siempre fueron dados por iniciativa privada o entidades del mismo carácter que, generalmente, se crearon específicamente para el fin con apoyo económico de organismos internacionales, sin encontrar mayor oposición de los gobiernos respectivos. $Y$ esto de no oponerse y dejar para ver las reacciones, no deja de ser una política bastante prudente, dadas las circunstancias. A medida que los servicios y programas privados fueron demostrando que tenían aceptacion y que cumplían una necesidad no ofrecida por los gobiernos o autoridades gubernamentales, éstas fueron, poco a poco, y con grandes temores... entrando a participar con la bandera de que el Estado debía ejercer control en una actividad que debía ser mirada con sumo cuidado por las implicancias médicas, sociales, económicas y morales que podía tener. Todo esto parecería confirmar las apreciaciones precedentes en el sentido de que ha habido y sigue habiendo temor a la definición abierta y franca, en muchos casos no por falta de convicción en las bondades del programa, sino por el posible mal uso que sectores de oposición gubernamental podrían hacer de estas medidas para criticarlas $y$ atacarlas sin tener, generalmente, elementos de juicio suficientes ni para justificar ni para rechazar estas políticas." 43

Tanto la actitud de laissez faire como la de identificar la política de población con la planificación de la familia han sido criticadas desde ángulos muy diferentes:

I) Se ha dicho que es esencial lograr un incremento de la población igual a cero en el menor tiempo posible, que la planificación de la familia, tal como se la define y practica hoy, es un medio ineficaz para lograrlo, y que distrae de otras medidas de control más radicales. Este punto de vista casi no ha tenido representantes en América Latina, pero ha sido expuesto vigorosamente por Kingsley Davis y otros, refiriéndose al mundo entero, comprendidos los países que hoy tienen tasas de incremento relativamente bajas. ${ }^{44}$

II) Se afirma que el control del crecimiento de la población es indeseable, que la planificación de la familia es un medio demasiado eficaz para lograrlo y que la forma en que la planificación de la familia se está introduciendo en América Latina significa que las autoridades nacionales están cediendo su control de la política nacional en favor de organizaciones internacionales y gobiernos que actúan movidos por su propio interés.

III) Se sostiene que las propias tendencias demográficas y la probable influencia en ellas de la rápida expansión de las actividades de planifica-

13 Carlos A. Uriarte, Información sobre la situación de las políticas, Seminario sobre Política de Población, Caracas, 25 al 28 de agosto de 1970.

44 Kingsley Davis, "Políticas de poblacion: ¿Tendrán exito los programas actuales?", Demografía y economía, 8, 1969. (La versión original en inglés se publicó en Science, 10 de noviembre de 1967.) El autor reitera estos argumentos en un trabajo que presentó ante la Conferencia Regional Latinoamericana sobre Población de 1970, titulado Orígenes de las deficiencias de los programas de población modernos. 
ción de la familia, tienen repercusiones en el desarrollo futuro, y que los dirigentes y planificadores no pueden seguir desestimándolas. Este punto de vista da por sentado que la política no debería limitarse al control del crecimiento de la población o a la planificación de la familia, pero que esta última es una forma deseable de acción sectorial dentro de una política más amplia. ${ }^{45}$

45 "Para aproximamos a lo que proponemos definir como política de población, podemos comenzar por descartar lo que nosotros, numerosos latinoamericanos $y$, sorprendentemente, algunos norteamericanos, creemos que no es. Nos referimos, claro está, a las acciones de planificación familiar que en la actualidad se desarrollan en todos los países latinoamericanos. Estas acciones las descalificamos como política de población, aun en el caso que se dieran - cosa que aún no ocurre en ningún país de la regióndentro de un plan coherente, como parte de una política de salud... la planificación familiar se convierte en uno de los elementos a ser considerados dentro de una política de población... Es por esto que consideramos altamente negativa la posición que, en general, han adoptado en América Latina los encargados de la planificación económica y social de ignorar - no evaluando los efectos tanto demográficos como económicoslas acciones de planificación familiar que se llevan adelante en todos los países de la region. Esta actitud de avestruz puede reservarles grandes sorpresas en plazos relativamente cortos. Compilaciones hechas por el Centro Latinoamericano de Demografía (CELADE), que indudablemente reflejan de manera incompleta lo que ocurre en la realidad, revelan que a fines de 1969 existían en la región más de mil clínicas anticonceptivas, de las cuales el $72 \%$ operaba en servicios gubernamentales. El número de clínicas existentes a fines de ese año representó un aumento de $43 \%$ sobre las que se encontraban en funcionamiento a fines de 1968." (Carmen A. Miro, Política de población: ¿Qué? ¿Por qué? ¿Para qué? ¿Cómo?, op. cit.)

Esta fuente cita la notable declinación de la natalidad en Chile durante el decenio de 1960 como prueba de los efectos de un programa de planificación de la familia que emprendió el servicio nacional de salud sin objetivos manifiestos de control del crecimiento de la población. La misma prueba ha sido citada por una autoridad en planificación de la familia, tanto para refutar a Kingsley Davis, como para argumentar en favor de la política de laisssez faire: "Con sigilo o sin estridencias, por lo menos, debería iniciar el programa, limitándose a poner los métodos anticonceptivos al alcance fácil ... de las personas que quieran emplearlos. Son tantas que, en las fases iniciales, cabe prescindir de toda motivación y, particularmente, de la educación de masa que está erizada de peligros. Es ella la que despierta antagonismo. Por sí sola esa acción pone en evidencia e incita la demanda social de regulación. Llega a hacerse tan incontenible como para que no se atrevan a contrariarla la Iglesia ni los políticos. A esta altura procede quizá pedir un pronunciamiento del Gobierno y, en todo caso, impulsar la educación y la motivación ... Dada la prodigalidad relativa de la ayuda internacional -que suele ser forzoso disimular en cierto grado- no son de témer, por el momento, las estrecheces de recursos monetarios." (Hernán Romero, América Latina, Chile y las políticas de población.)

José Vera, en Población y desarrollo: Notas para una política de población en América Latina, enfoca de manera algo diferente el papel de la planificación de la familia en la política de desarrollo, así como su justificación: "En resumen, una política de población para América Latina debería incluir dos típos básicos de acción: a) programas educativos y, en casos extremos, de subsidios, destinados a proveer de acceso real a la oportunidad de decidir conscientemente sobre el tamańo de sus familias a aquellas pare. jas que puedan verse afectadas por situaciones de desequilibrio demográfico, y b) reorientación de los programas nacionales de desarrollo en función del empleo pleno de la fuerza de trabajo. Es probable que una combinación adecuada de estos dos tipos de acción en América Latina contribuya al cumplimiento simultáneo de varios fines utiles: a) aliviar el sufrimiento de millones de familias a las cuales el progreso de las técnicas de la salud ha otorgado el obsequio de una menor mortalidad, rápidamente negada en la práctica por el retraso de los restantes componentes del nivel de vida; b) incrementar ta racionalidad y en más de un sentido "humanizar" la planificación del desarrollo, 


\section{d) Objetivos e instrumentos de una política de población}

$\mathrm{El}$ análisis anterior señala que las actividades públicas destinadas a influir en las variables demográficas no pueden aplazarse hasta la formulación de políticas de desarrollo capaces de servir de marco para ellas, y que no tiene objeto definir una política de población en términos tan generales que la hagan coincidir con la política de desarrollo. En las condiciones actuales, la política de población debe conciliar tres objetivos generales: contribuir a elevar el bienestar y los derechos humanos en el plano de la familia y del individuo, influir en el crecimiento de la población, su distribución por edades y su distribución geográfica para que concuerden lo más posible con el desarrollo acelerado y con una distribución más equitativa de los frutos del desarrollo; dar a conocer mejor las tendencias demográficas a los dirigentes políticos, los planificadores y el público en general y lograr que se tengan debidamente en cuenta en todas las esferas de la política y de la planificación. Ya se ha señalado que hay poca variedad de instrumentos para estos fines, y que los valores predominantes o la sujeción de los instrumentos teóricamente aplicables a otros fines impiden que muchos de ellos se incluyan dentro de la política de población.

I) Instrumentos encaminados a elevar el bienestar humano y a actuar sobre el aumento de la población mediante la variable de la fecundidad. $\mathrm{La}$ "planificación de la familia" ha llegado a significar la enseñanza de las ventajas de espaciar y limitar la cantidad de hijos, junto con dar a conocer las técnicas anticonceptivas y suministrar anticonceptivos, por regla general dentro de programas de salud pública dirigidos casi exclusivamente a mujeres de familias constituidas en forma regular. Lo ideal sería que la política del sector público reflejara una interpretación más amplia de la expresión, y que la mayor posibilidad de planificar la cantidad de hijos fuese acompañada de una mayor capacidad familiar para planificar el medio de ganarse la vida, el consumo, la enseñanza y la participación en la vida comunitaria local y nacional de sus miembros. $\mathrm{El}$ alivio de la carga que significa la fecundidad sin control puede reforzar la capacidad familiar para ser previsora en otros aspectos, pero no siempre tiene este resultado. Esta consideración pone de relieve problemas de capacidad pública para aplicar una política familiar más amplia y de compatibilidad de las estructuras sociales y económicas con una mayor participación de las familias de bajos ingresos, que son demasiado complejos para analizarlos aquí.

Aun entendida tan estrechamente como en la actualidad, la planificación familiar sirve más como contribución al ejercicio de los derechos humanos y al bienestar humano que como instrumento de racionalización demográfica. Sus efectos en esta última son difícileš de predecir, como lo señalan las opiniones divergentes de los especialistas que se

mediante el simple expediente de organizarla en función del desarrollo de los seres humanos antes que de las cosas que los rodean y sirven, y c) consolidar la obsolescencia de la idea de que la abundancia de recursos humanos en una sociedad puede ser la causa de su subdesarrollo." 
than citado, pero cualesquiera que sean, resultarán irreversibles y difíciles de manipular para alcanzar los objetivos a corto o mediano plazo que pueda establecer la política pública. Los efectos derivarán del conjunto de decisiones de millones de familias, o sólo de las decisiones de las mujeres. La decisión del Estado de reducir los servicios de planifica-ción de la familia porque el aumento de la población está decreciendo con demasiada rapidez sería inaceptable, dadas las consideraciones de derechos humanos que justifican los programas, y en todo caso sería ineficaz, salvo en familias demasiado pobres o demasiado carentes de iniciativa como para buscar fuentes privadas de anticonceptivos.

Los programas de planificación de la familia que existen hoy en América Latina utilizan casi exclusivamente dos técnicas anticonceptivas: la "píldora" y los dispositivos intrauterinos. Ambas tienen ventajas sobre las técnicas anteriores, especialmente para su aplicación masiva, pero ninguna es completamente satisfactoria; cabe esperar que en el próximo decenio se produzcan grandes cambios en la tecnología anticonceptiva.

Debería tenerse presente que los programas de planificación de la familia abarcan sólo una parte, y generalmente una parte pequeña, del uso de las técnicas anticonceptivas que se aplican en las ciudades. Las investigaciones realizadas por CELADE a fines de 1963 y comienzos de 1964 entre mujeres urbanas de 20 a 50 años de edad, casadas o "convivientes", revelaron que los siguientes porcentajes usaban algún tipo de técnica anticonceptiva: Buenos Aires, 84.5; Río de Janeiro, 38.2; Bogotá, 36.6; San José, 56.8; Panamá, 30.7; Caracas, 62.4, y México, 30.8. En esa época no se usaban aún los dispositivos intrauterinos, comenzaban a usarse los anticonceptivos de ingestión oral, y no existían servicios de planificación de la familia en las ciudades, o éstos tenían un alcance muy limitado. No cabe duda de que la práctica privada de la anticoncepción está mucho más extendida en la actualidad, y que se ha orientado hacia técnicas más seguras.

En la polémica suscitada en torno a la política de población las conocidas aseveraciones de que los gastos hechos en planificación de la familia, considerados como inversión para el desarrollo, tienen un rendimiento muchas veces superior a otras inversiones, han sido refutadas de plano por quienes afirman que los recursos destinados a la planificación de la familia estarían mejor usados si se dedicaran directamente a inversiones productivas. Sin -embargo, no se dispone de información alguna sobre las sumas totales destinadas a la planificación de la familia en los países de América Latina, sobre la medida en que los recursos utilizados para la planificación de la familia pueden desviarse hacia otros fines, sobre los costos por cliente, ni sobre los costos de "evitar" un nacimiento. ${ }^{46}$ En la actualidad, una gran proporción de los costos di-

46 Una fuente estima en 10 dólares el costo de evitar un nacimiento (incluidos costos médicos, educativos y de organización de un programa de planificación de la familia), y en 20000000 de dolares el costo anual para toda América Latina de evitar 2000000 de nacimientos, lo que bastaría para reducir la tasa de aumento de la población de $2.9 \%$ en 1970 a $2.3 \%$ en 1980 . No se da a conocer la base de esta estimación. (W. Brand, Política de población para América Latina.) El costo 
rectos se financia desde fuentes externas, que estarían dispuestas a suministrar los mismos fondos para otros fines, ${ }^{47}$ y una gran proporción. de los costos de infraestructura y de personal no se puede separar de los costos generales de los servicios de salud que patrocinan los programas de planificación de la familia. Mientras los programas sólo se limiten a responder a la demanda, los costos por habitante no debieran, ser muy altos; pero subirán inevitablemente si se proyectan campañas. educativas y de extensión a la población rural. Aunque desaparezca la. posibilidad de usar fondos externos con destino fijo, o se la rechace por considerarla incompatible con el control nacional de los programas, no. parece probable que los costos de programas de planificación de la familia que se amplíen prudentemente en respuesta a la demanda requieran: una distracción verdaderamente grave de recursos públicos que podrían destinarse a otros fines de desarrollo. Al mismo tiempo, no cabe esperar que estos programas tengan gran prioridad en la asignación de fondos públicos, y es probable que como todos los programas sociales y económicos más nuevos, estén expuestos a reducciones presupuestarias. cuando los recursos públicos no llegen al nivel esperado.

Es muy sabido que en América Latina, como en muchas otras partes del mundo, el aborto ha sido hasta ahora el medio más usado por la población urbana para limitar su fecundidad. Naturalmente, no hay.

anual mínimo medio de "protección" en Chile es probable que esté entre $4.15 \mathrm{y}$ 4.65 dólares (Country Profiles, Chile, Population Council, octubre de 1970); cálculos. hechos para algunos países asiáticos arrojan cifras más bajas, con diferencias aproximadamente proporcionales a las diferencias de ingreso por habitante. (Véase Warren Robinson, A Cost-Effectiveness Analysis of Selected National Family Programmes, citado por Bernard Berelson en "The Present State of Family Planning Programs", Studies in Family Planning, 57, septiembre de 1970.) También se ha calculado el mercado privado efectivo y potencial para los anticonceptivos orales en México. Se estima que 3 millones de familias (que representan 4500000 mujeres en edad de procrear) gastan más de mil pesos (80 dólares) al mes, y que el $2 \%$ de este gasto. bastaría para suministrar anticonceptivos orales a los precios que actualmente tienen en el mercado ( 10 a 20 pesos por ciclo mensual). La venta de estos momentos abarca. a cerca de $11 \%$ de este mercado potencial (en 1968 se distribuyeron 5.4 ciclos por cada 100 mujeres entre 15 y 44 años). (Alfred D. Sollins, "Commercial production and distribution of contraceptives", Reports on Population Family Planning, 4, junio de 1970.)

47 Los fondos comprometidos por la AID para actividades en materia de población y planificación de la familia en América Latina a través de diversas organizaciones. públicas y privadas aumentaron de 2324000 dólares en 1967 a 7924656 dólares en 1968. Hasta comienzos de octubre de 1968, la Fundación Ford había otorgado unos 4000000 de dólares a instituciones latinoamericanas para investigaciones y capacitación relacionadas con la población. Otros gobiernos de fuera de la región, así como otras. fundaciones, han entregado sumas más pequeñas: Agencia para el Desarrollo Internacional, The Office of the War on Hunger, Population Service. (Population Program Assistance, Washington, D. C., septiembre de 1968.) Los fondos de asistencia exterior que el Congreso de los Estados Unidos asigno exclusivamente a las actividades. relacionadas con población y planificación de la familia en todo el mundo, salvo los. Estados Unidos, alcanzaron a 50000000 de dólares en 1969, 75000000 de dólares. en 1970 y llegarán a 100000000 de dólares en 1971, es decir, aproxidamente un $2.3 \%$ de la ayuda oficial de los Estados Unidos a los países menos desarrollados durante el año fiscal de 1970 (Philander P. Claxton Jr., La política de los Estados Unidos respecto de los asuntos de población y planificación familiar). 
estadísticas fidedignas ya que los únicos abortos que se conocen son los que fracasan y requieren la intervención de los servicios públicos de salud, pero esta práctica parece estar muy extendida en todos los estratos sociales. Según las investigaciones hechas por el CELADE en 1963 y 1964, el porcentaje de mujeres que reconocía haberse provocado uno o más abortos alcanzaba a 10.3 en Río de Janeiro, 8.0 en Buenos Aires y 7.1 en México. En los estratos superiores y medios el aborto sirve principalmente como último recurso cuando fallan los anticonceptivos, pero entre los estratos más bajos es el principal de los medios empleados. Hasta ahora ningún sector importante de la opinión pública ha propuesto en América Latina la legalización del aborto como medio legítimo de planificar la familia o de controlar el crecimiento de la población. Por el contrario, muchos de los primeros programas de planificación de la familia se han justificado inicialmente como una manera de evitar que las mujeres tengan que recurrir al aborto.

Es dudoso que este rechazo se mantenga en forma permanente, pese a los fuertes sentimientos religiosos que hay tras el, dada la amplia aceptación del aborto por las propias mujeres y la tendencia a la legalización del aborto en el resto del mundo. El peligro para la salud de la mujer prácticamente desaparece cuando la operación se realiza en una clínica, y nuevas técnicas auguran que la operación habrá de ser cada vez más sencilla y barata. Se ha criticado justificadamente la prohibición legal del aborto como una forma de discriminación contra los pobres, ya que no se puede velar eficazmente por su cumplimiento. Las mujeres que pueden pagar honorarios elevados pueden abortar sin riesgos. El resto también aborta cuando quiere hacerlo, pero en condiciones que producen enorme sufrimiento, enfermedades y muchas muertes que podrían evitarse. Las principales objeciones que siguen en pie son que el aborto, por no necesitar previsión, no contribuye en nada a la paternidad responsable y a las actitudes favorables desde el punto de vista del desarrollo que se suponen relacionadas con la planificación de la familia, y que la mujer que confía sólo en el aborto tendrá que recurrir a él con mucha frecuencia. ${ }^{48}$ Como sigue difundiéndose el uso de los anticonceptivos, la principal función del aborto, legal o ilegal, será probablemente la de reparar las fallas de los anticonceptivos y evitar las consecuencias de uniones sexuales casuales.

La esterilización se ha convertido en una técnica importante de los. programas de planificación de la familia en la India y el Pakistán (principalmente la masculina) y en Puerto Rico (principalmente la femenina); en algunos de los primeros lugares se paga a las personas que se someten a la esterilización. En general se ha prestado poca atención a este medio en los programas latinoamericanos de planificación de la

48 "Tengo reservas respecto a su legalización, Entre ellas destacan el fatalismo de nuestra gente que prefiere afrontar el hecho consumado a tomar medidas preventivas y que, a poco de interrumpido el embarazo, la mujer recupera, de ordinario, su fecundidad. Podría producirse así una cadena sin fin, inconveniente por sí misma y muy gravosa para nuestros servicios de atención médica" (Hernán Romero, op. cit.). 
familia. Como normalmente se ofrece sólo a personas que ya han tenido todos los hijos que querían, su contribución a la reducción de la fecundidad sólo puede ser complementaria de los anticonceptivos. ${ }^{49}$

El reconocimiento casi universal del derecho de la familia a determinar el número de sus hijos y su espaciamiento, y el reconocimiento más condicionado del deber del Estado de ofrecer medios eficaces para que la familia actúe conforme a su decisión, deja en pie la delicada cuestión de determinar si son legítimas las actividades del Estado encaminadas a influir en la decisión de la familia, cuando éste ha adoptado objetivos respecto al crecimiento de la población. Puede descartarse la compulsión por razones prácticas así como por consideraciones morales; es difícil imaginar a alguna autoridad latinoamericana pidiendo sanciones penales contra los padres, y menos aún estableciendo el aborto obligatorio. $^{50}$ En principio, serían legítimas las medidas persuasivas y disuasivas. El Estado ya interviene de diversas formas en los asuntos familiares, mediante las leyes educativas, las disposiciones de seguridad social, y los impuestos, subsidios, etc., encaminados a fomentar, regular o desalentar diferentes formas de consumo y ahorro. Sería ilógico esperar que se dejasen los patrones de procreación al criterio de la familia sin intentar influir en su decisión, si se les concibe como asuntos de importancia para toda la sociedad. En la práctica, muchos programas de planificación de la familia que existen en la actualidad dentro de servicios de salud pública confían en la fuerte influencia de la persuasión ejercida sobre la mujer en el momento en que es más susceptible a ella, es decir, inmediatamente después de haber dado a luz.

Diversas fuentes han propuesto una gran variedad de medidas para influir en el comportamiento procreativo sin llegar a la compulsión. ${ }^{51}$ Sin embargo, en las condiciones concretas de América Latina, casi todas parecen ser de poca utilidad, inaceptables en términos de valores; in-

49 Según las investigaciones hechas por el CELADE en 1963 y 1964, el porcentaje de mujeres de las grandes ciudades que se han sometido a la esterilización es pequeno, pero no insignificante: cerca de $6 \%$ en Caracas, Río de Janeiro y San José; $2 \%$ en ciudad de México, $1 \%$ en Bogotá. El caso de Panamá es una excepción. Según un estudio reciente, $20 \%$ de las mujeres casadas o convivientes encuestadas habían sido esterilizadas. El efecto de la esterilización ha sido estimado en una reducción media de $25 \%$ en la fecundidad total de todas las mujeres casadas. (Véase Robert $\mathbf{B}$. Hartford y George C. Myers, "Esterilización femenina en la ciudad de Panamá, su difusión, efectos y correlativos".)

50 Las sanciones penales y el aborto obligatorio han sido propuestos seriamente para luchar contra los nacimientos ilegítimos, por considerarse éstos las contribuciones menos deseables a la natalidad, pero tampoco en este caso podrian aplicarse dichas sanciones ni serían toleradas por la sociedad.

51. Una autoridad en materia de planificación de la familia, después de resumir las propuestas planteadas o adoptadas en diversos países fuera de América Latina, observa: “...no sólo hay cuestiones de ética ... y problemas políticos, sino que además los problemas prácticos son enormes. Como se ha dicho, si un país pudiese administrar sistemas tan complejos para fines demográficos, probablemente no necesitaría hacerlo ... Creo justo decir que se ha estado buscando con diligencia algo "más allá de la planificación de la familia', algo practicable y ético, económico y con alguna posibilidad de eficacia, incluso sobre bases experimentales o de demostración. No se ha encontrado nada, y seguimos buscando" (Bernard Berelson, op. cit.). 
aplicables, o excesivamente costosas. Las propuestas de eliminar los vestigios jurídicos de políticas anteriores que favorecían las familias numerosas, como los premios a las mujeres que tuviesen cierto número de hijos y las leyes que prohibían la venta y divulgación de los anticonceptivos son sensatas, pero no tienen trascendencia. Las propuestas de eliminar las exenciones del impuesto sobre los ingresos derivados de hijos. a cargo sólo afectarían a las minorías de altos ingresos que pagan esos impuestos, que ya controlan su fecundidad. Si se pudieran hacer cumplir, los impuestos punitivos para las familias que tuviesen más de cierto número de hijos tendrían efectos desastrosos sobre las condiciones de vida de los niños ya nacidos en familias de bajos ingresos, y no garantizarían una reducción importante de la fecundidad futura; en todo caso, este tipo de impuestos no podría aplicarse a la población marginal urbana, a la población rural, ni a las madres solteras. Es muy probable que las propuestas de aumentar la edad legal mínima para el matrimonio, o de fomentar el matrimonio más tardío otorgando franquicias tributa. rias a los solteros no tuviesen efecto alguno en el comportamiento procreativo de los estratos que se caracterizan actualmente por una muy alta fecundidad, sin cambios culturales que hicieran corresponder la edad de iniciación en las relaciones sexuales con la edad mínima para el matrimonio. En los demás estratos el efecto sobre la fecundidad sería escaso, ya que con la práctica anticoncepcional generalizada y con objetivos relativamente claros en cuanto al tamaño de la familia, los nacimientos se postergarían más que se evitarían. Los pagos públicos como incentivos para casarse a mayor edad o para espaciar los hijos dentro del matrimonio serían difíciles de administrar, costosos e impopulares. Con los actuales niveles de ingreso de los estratos que más necesitan seguridad social, sería imposible financiar mediante un sistema de contribuciones la universalización de las pensiones de jubilación $y$ de otros beneficios para eliminar como incentivo el deseo de tener muchos hijos para que sean un sostén de la ancianidad, es decir, de buscar en la familia numerosa una suerte de "seguridad social"; y tampoco el Estado estaría en condiciones de otorgar ese financiamiento. En todo caso, el influjo de una medida tal en el comportamiento procreativo es dudoso, por conveniente que ella parezca por otras razones. Las grandes campañas de propaganda de la planificación de la familia realizadas con fondos públicos podrían justificarse si las precede un amplio debate público que provoque consenso suficiente respecto al carácter del problema de población y sus connotaciones en materia de política, y si se basan en una mayor comprensión de las motivaciones del comportamiento procreativo en los diferentes estratos sociales. De otra manera, este tipo de campañas quizá sería contraproducente por las resistencias que podría provocar.

En resumen, la capacidad del Estado para influir en el comportamiento procreativo parece ser muy limitada, tanto con medidas encaminadas a estimular la fecundidad como con las que se enderezan a reducirla, sobre todo cuando se trata de cambiar la dirección de las tendencias 
del comportamiento familiar. Durante muchos años, diversos gobiernos de Europa occidental han intentado fomentar la natalidad mediante exhortaciones, incentivos como los subsidios familiares, limitaciones a la venta y divulgación de los anticonceptivos, etc. El efecto sobre el comportamiento procreativo parece haber sido insignificante.

II) Instrumentos encaminados a influir en el incremento y la calidad de la población mediante la migración internacional. Las corrientes cambiantes de migración internacional demuestran que las consecuencias para el desarrollo de las tendencias demográficas dependen de cambios en los patrones de crecimiento económico e interdependencia internacional. Hasta el decenio de 1920 Europa, con una población mucho más pequeña que la actual, parecía una fuente inagotable de emigrantes hacia América Latina y otras partes poco pobladas del mundo. Esta corriente casi ha desaparecido, tanto debido al pleno empleo en los países que fueron fuente de emigración, como a la menor atracción que ejercen las oportunidades ofrecidas por los países de inmigración. La menor demanda de mano de obra sin calificación o con semicalificación, tanto en América Latina como en los países de altos ingresos, significa que América Latina no tiene interés en admitir los tipos de inmigrantes que aún estarían disponibles, y no tiene casi ninguna posibilidad de aliviar el exceso de mano de obra nacional estimulando la emigración. La migración internacional ha perdido casi toda su importancia en América Latina respecto a la magnitud de la población nacional, y es muy improbable que la recupere. Al mismo tiempo, mantiene su influencia en la calidad de la población, pero ésta está cambiando en forma que, en definitiva, es muy desfavorable para el desarrollo latinoamericano. Son pocas las posibilidades de atraer hacia América Latina a inmigrantes con las calificaciones técnicas y profesionales necesarias para las etapas siguientes de desarrollo. En cambio, hasta ahora ha sido grande la capacidad de los países de altos ingresos para atraer emigrantes de América Latina con esas calificaciones, en especial ingenieros, médicos y enfermeras. Este problema al que se ha dado en llamar "fuga de cerebros", ha atraído la atención internacional; y ha hecho que se propongan algunos instrumentos de política para lograr que la tendencia se invierta. Como en el caso de las medidas analizadas antes con respecto al comportamiento procreativo, la mayoría de estos instrumentos parecían ser ineficaces, inaceptables desde el punto de vista de los derechos humanos, excesivamente costosos o inaplicables sin cambios más amplios en las estructuras económicas y sociales. Dichas medidas incluyen: hacer que los salarios y las oportunidades para adquirir bienes de consumo (sobre todo, automóviles) equiparen los que ofrecen los países de altos ingresos; prohibir la emigración de las personas que poseen las calificaciones necesarias, o imponer impuestos elevados a esa migración; exigir que los egresados de las instituciones nacionales de capacitación profesional y técnica trabajen durante un período fijo en programas nacionales para compensar los costos de su capacitación; reformar las instituciones de capacitación para hacer que sus egresados 
correspondan más estrechamente a las necesidades nacionales y que superen su dependencia de los modelos, las demandas y los incentivos de los países de altos ingresos. Cabe señalar que es posible que las actuales dificultades económicas y sociales y la reducción de la demanda de profesionales en los países que han ejercido mayor atracción reduzcan la importancia del problema en lo que toca a América Latina.

IIr) Distribución geográfica y ocupacional de la población: objetivos e instrumentos. En las páginas anteriores se ha hablado repetidamente de las relaciones entre el crecimiento de la población y su redistribución por zonas geográficas y por sectores de actividad económica dentro de cada país. A corto y mediano plazo, las posibilidades de planificar la acción pública para controlar la redistribución de la población en consonancia con una determinada estrategia del desarrollo parecen mejores que las de planificar el crecimiento de la población. La variedad de instrumentos a disposición del Estado es mayor, y resulta más fácil, y és socialmente más aceptable, tomar como objetivo la redistribución de la población al escoger y manipular los instrumentos.

Se ha señalado también que las medidas relativas a la redistribución de la población son más fáciles de planificar en el marco de una política de desarrollo regional, urbano o rural, como parte de una política general de población, aunque esto último no puede descartarse del todo. En este examen de los instrumentos de una política de población bastará con hacer hincapié en la importancia potencial de la selección de los objetivos e instrumentos apropiados para las condiciones de cada país, y con tomar nota de que existe amplio consenso en estimar que, en la mayoría de los países de América Latina, las próximas etapas del desarrollo requieren esquemas más descentralizados de crecimiento urbano y de distribución de las actividades económicas.

rv) Información necesaria para una politica de población. La información demográfica tiene tres fuentes principales: los censos, los registros de estadísticas vitales y los estudios por muestreo. Todas estas fuentes adolecen de graves deficiencias frente a las necesidades de la política de población. Algunas de esas deficiencias son inherentes a los métodos de recolección de datos, cualquiera que sea su destino, y a la dificultad de definir algunos de los fenómenos en forma sencilla y uniforme, para poder registrarlos sin problemas. Otras derivan de la poca prioridad que, desgraciadamente, la mayoría de los gobiernos latinoamericanos asigna a la recolección cuidadosa y a la pronta difusión de la información demográfica. $Y$ otras son inherentes al subdesarrollo: el analfabetismo, la marginalidad, el aislamiento rural, la inestabilidad política y los mecanismos deficientes de administración pública, limitan la capacidad nacional para elaborar estadísticas confiables, tanto demográficas como de otro tipo. Las deficiencias del segundo grupo tienen más fácil remedio que las demás; basta que se efectúe un cambio moderado en el orden de prioridad que rige la utilización de los recursos públicos, que se preste cierta atención a la capacitación de personal, y, 
sobre todo, que haya una clara demanda de mejor información por parte de los dirigentes políticos y los planificadores.

Tanto en los países como en las organizaciones regionales, se ha dedicado gran cantidad de esfuerzo e ingenio a las técnicas para cuantificar los factores demográficos y de otro orden relacionados con el desarrollo, sobre la base de la información disponible. Dadas las circunstancias esto es inevitable y útil, pero es probable que haya estimulado la ilusión de que se sabe más de lo que efectivamente se sabe, y puede haber ayudado a perpetuar la poca prioridad asignada a la recolección de información básica, que es laboriosa y cara. Cuando estimaciones de este tipo adquieren autoridad al repetirlas en diversas fuentes sin las reservas y explicaciones metodológicas formuladas por sus autores, cabría a veces sospechar que se está diagnosticando y planificando para un país imaginario respecto del cual existe información completa, en lugar de hacerlo para un país sobre el que existe poca información confiable. ${ }^{2}$

Censos de población: Durante largo tiempo las organizaciones interamericanas han estado intentando reforzar e institucionalizar la práctica de realizar censos al comienzo de cada decenio. El mayor éxito se logró en 1950 , cuando 18 de 20 repúblicas latinoamericanas (las excepciones fueron Perú y Uruguay) completaron sus censos entre 1947 y 1953. En 1960, no realizaron censos Bolivia, Cuba y Haití, y al parecer las omisiones y los retrasos en las tabulaciones estuvieron más extendidos que en 1950. Es probable que el número de omisiones sea semejante en 1970. Como es natural, en los países con menores ingresos y mayor porcentaje de población rural es más difícil realizar el gran esfuerzo concentrado que se necesita para establecer un mecanismo censal eficiente cada diez años, pero la mayoría de ellos ha logrado hacerlo. Los censos se han visto afectados por diversos grados de omisión ${ }^{53}$ y por la dudosa confiabilidad de las respuestas a algunas preguntas en la forma en que las registran enumeradores sin capacitación. Una deficiencia aún más grave ha sido lo lento e incompleto de la tabulación y publicación de los datos. ${ }^{54}$

Los censos constituyen las principales fuentes para la información y las proyecciones demográficas básicas. Para obtener las cifras anuales, los demógrafos dependen de las tendencias que revelan los censos

52 E1 informe del equipo interinstitucional sobre política de empleo en Colombia hace hicapié repetidas veces en las dificultades planteadas a su trabajo por estadísticas inadecuadas, $y$ observa que "en algunos aspectos se ha invertido excesivamente en análisis $y$, en cambio, no se ha invertido lo suficiente en la recolección de estadísticas fidedignas". (Véase orr, Hacia el pleno empleo, op. cit., párrafo 929.)

53 Algunas evaluaciones de censos hechas por el cetade contienen cálculos de por. centajes de omisión; por ejemplo, 3.46 para Colombia en 1964, 2.3 para Ecuador en 1962, y 2.9 para México en 1960. La omisión real, sin embargo, puede ser mucho mayor, si se toma en cuenta que probablemente han quedado excluidas las poblaciones tribales y algunos de los núcleos de población rural más aislados y dispersos. Véase G. Mortara, "Evaluación de la información censal para América Latina", en Demogratía y salud pública en América Latina, Milbank Memorial Fund, 1964.

54 En un caso aún no se dispone de los resultados definitivos del censo de 1960. 
sucesivos. Cuando los datos de un censo son más inexactos que los de otro en grado desconocido, y cuando el censo más reciente data de varios años, el margen de error se amplía. Si bien en los últimos años se han perfeccionado sostenidamente los métodos para hacer proyecciones, y la comprobación cruzada con otras fuentes de información ofrece cierto grado de protección, debe tenerse presente que la mayor parte de las cifras de población para 1970, así como las proyecciones para el futuro, derivan todavía de censos realizados hacia 1950 y 1960 . Los resultados pueden ser tolerablemente fidedignos en cuanto a tamaño de la población, tasa de crecimiento y distribución por edades en el ámbito nacional, pero pueden distar mucho de la realidad en lo que respecta a la redistribución de la población dentro de cada país. Esta limitación suele olvidarse cuando quienes no se especializan en demografía intenten relacionar las tendencias de población con tendencias económicas y sociales que pueden medirse con indicadores recogidos año a año.

Estadísticas vitales $y$ otras series permanentes recolectadas por la administración pública: Hasta ahora, la posibilidad de presentar tasas confiables de natalidad, de mortalidad y de nupcialidad, así como de comprobar en forma cruzada la información censal sobre aumento de la población ha dependido del mantenimiento de un completo registro de estadísticas vitales. Es dudoso que pueda lograrse este objetivo mientras los países alcancen cierto grado de urbanización, alfabetismo, difusión de la propiedad y disponibilidad de servicios sociales que requieran prueba documental sobre la constitución de la familia y el origen del individuo. La información estadística precisa es entonces un subproducto de los usos sociales del sistema de registro. Según las Naciones Unidas - cuyos criterios en este caso se han considerado excesivamente generosos - los registros de estadísticas vitales son incompletos en 15 de 26 países de América Latina y el Caribe.

Estudios por muestreo: El medio más practicable y flexible para obtener información actualizada sobre migración interna, patrones de urbanización, niveles de vida de las familias, ingresos, ocupaciones, actitudes y prácticas con respecto a la fecundidad, así como sobre muchas otras cuestiones importantes para determinar la política, es el estudio por muestreo. Las deficiencias del registro de estadísticas vitales mencionadas antes han hecho además que se lleven a cabo valiosos experimentos en el uso de esta técnica (mediante el registro continuo de una muestra de la población, sin propósito legal o administrativo alguno) para obtener estadísticas vitales más precisas. ${ }^{55}$ En los dos últimos decenios se ha reiterado la necesidad de hacer estudios por muestreo sistemáticos y de establecer instituciones nacionales facultadas para llevarlos a cabo, pero hasta ahora ningún gobierno latinoamericano ha suministrado los recursos mínimos necesarios para que el estudio por muestreo

55 Forest E. Linder, New Approaches to the Measurement of Mortality. Se han realizado dos estudios experimentales por muestreo sobre estadísticas vitales: uno de zona urbana (Guanabara, Brasil) y otro en una zona rural (Cauquenes, Chile). Véanse Naciones Unidas, Guanabara Demographic Pilot Survey, Population Studies núm. 35, y CELADE, Encuesta demográfica experimental, Cauquenes, Santiago de Chile, 1968. 
se convierta en un instrumento confiable de la política, aunque es posible que varios países lo hagan pronto si se llevan a cabo sus planes y se mantiene la continuidad en los estudios. Se han hecho muchos estudios por muestreo de cuestiones demográficas, entre ellos, estudios de migración interna hacia las capitales (Lima y Santiago); de mortalidad urbana, y de actitudes ante la fecundidad entre mujeres de origen urbano y rural de diferentes países; pero estos estudios han sido organizados principalmente por instituciones regionales como el cELADE, o por universidades, y se han iniciado en su mayoría con donaciones de fundaciones y de otros organismos de fuera de la región. ${ }^{56}$

56 Se informa sobre los estudios de migración en Encuesta sobre inmigración en el Gran Santiago (CEIADE, Serie A, núm, 15) y en Encuesta de inmigración de Lima Metropolitana (DINEC, Lima). Sobre los estudios relativos a la mortalidad informan Ruth Rice Puffer y G. Wynne Griffith, Patterns of Urban Mortality, Report of the Inter-American Investigation on Mortality, Organizacion Panamericana de la Salud, Publicación Científica núm. 151, septiembre de 1967. Los estudios sobre fecundidad urbana abarcaron Bogotá, Buenos Aires, Caracas, ciudad de México, Panamá, Río de Janeiro y San Jose, se han terminado estudios sobre fecundidad rural en Chile y Co lombia, y se efectuarán otros en la mayoría de los países incluidos en los estudios urbanos. 


\section{LAS TENDENCIAS DE LA POBLACIÓN EN EL DECENIO DE 1960}

No cabe duda de que en el transcurso de los últimos decenios la población de América Latina ha experimentado cambios importantes en su patrón y tasa de crecimiento y su distribución geográfica. En vista de la magnitud de estos cambios y su probable significación para las diferentes opciones de desarrollo de la región, el presente estudio intenta evaluar la estructura y la dinámica de la población en el período 19601970. Con este propósito se analizarán las siguientes tendencias y temas en el orden que se indica: el crecimiento demográfico durante el decenio de 1960; los componentes del crecimiento demográfico (fecundidad, mortalidad y migración internacional); las perspectivas futuras de crecimiento; la urbanización y la distribución espacial; población y desarrollo.

Los análisis y el material que se presentan se basan en gran parte en la información que proporcionan los censos de 1960 y 1970 , y en su ausencia, en otras fuentes oficiales, o proyecciones y estimaciones.

\section{El CRECIMIENTO DEMOGRÁfico EN EL DECENio DE 1960}

El crecimiento sin precedentes que ha experimentado la población de muchos países latinoamericanos y la región en su conjunto en los últimos decenios es un hecho bien fundamentado. Además, está muy difundida la idea de que estas tasas de crecimiento ejercen en cierto modo gran influencia sobre las diversas opciones de desarrollo que se le presentan a América Latina, aunque no se conoce todavía con exactitud la forma en que las afectan ni sus consecuencias. En todo caso, el reconocimiento de que existe una relación íntima aunque indeterminada entre ambos fenómenos hace que el crecimiento demográfico sea considerado un problema apremiante en la actual coyuntura latinoamericana.

Lo primero que cabe preguntarse es si durante los años sesenta se mantuvieron las tendencias registradas anteriormente hacia tasas y niveles cada vez más altos de crecimiento demográfico, o si es posible detectar indicios de disminución o inversión de esas tendencias. En cifras absolutas, la población de América Latina aumentó de 210 millones en 1960 a 279 millones en 1970. (Véase el cuadro 1.) Este incremento de 69 millones de personas (comparado con el de 50.5 millones del decenio anterior) representa un aumento de casi un tercio de la población total al comienzo del decenio y constituye por sí solo una masa de población algo mayor que la que habitaba la región a comienzos de siglo. No es de extrañar que el incremento absoluto por países se correlacione con el tamaño de sus poblaciones a comienzos del decenio, pero cabe señalar que el $56 \%$ del aumento total correspondió a sólo dos países: Brasil y México. 
Cuadro 1. América Latina: población por países, 1920-1970 (en miles)

\begin{tabular}{|c|c|c|c|c|c|c|c|c|c|c|c|}
\hline Pais & 1920 & 1925 & 1930 & 1935 & 1940 & 1945 & 1950 & 1955 & 1960 & 1965 & 1970 \\
\hline $\begin{array}{l}\text { Argentina } \\
\text { Bolivia } \\
\text { Brasil } \\
\text { Colombia } \\
\text { Costa Rica } \\
\text { Cuba } \\
\text { Chile } \\
\text { Ecuador } \\
\text { El Salvador } \\
\text { Guatemala } \\
\text { Haitú } \\
\text { Honduras } \\
\text { México } \\
\text { Nicaragua } \\
\text { Panamá } \\
\text { Paraguay } \\
\text { Perú } \\
\text { República Dominicana } \\
\text { Uruguay } \\
\text { Venezuela }\end{array}$ & $\begin{array}{r}8861 \\
1918 \\
27404 \\
6057 \\
421 \\
2950 \\
3783 \\
1898 \\
1168 \\
1450 \\
2124 \\
783 \\
14500 \\
639 \\
429 \\
699 \\
4862 \\
1140 \\
1391 \\
2408\end{array}$ & $\begin{array}{r}2022 \\
30332 \\
6669 \\
456 \\
3364 \\
4084 \\
2009 \\
1301 \\
1532 \\
2260 \\
862 \\
15204 \\
687 \\
464 \\
785 \\
5229 \\
1258 \\
1540 \\
2650\end{array}$ & $\begin{array}{r}11896 \\
2153 \\
33568 \\
7350 \\
499 \\
3837 \\
4424 \\
2160 \\
1443 \\
1771 \\
2422 \\
948 \\
16589 \\
742 \\
502 \\
880 \\
5651 \\
1400 \\
1704 \\
2950\end{array}$ & $\begin{array}{r}2.314 \\
37150 \\
8147 \\
551 \\
4221 \\
4778 \\
2352 \\
1531 \\
1996 \\
2610 \\
1027 \\
18089 \\
809 \\
524 \\
988 \\
6134 \\
1567 \\
1836 \\
3300\end{array}$ & $\begin{array}{r}14169 \\
2508 \\
41233 \\
9077 \\
619 \\
4566 \\
5147 \\
2586 \\
1633 \\
2201 \\
2825 \\
1119 \\
19815 \\
893 \\
595 \\
1111 \\
6681 \\
1759 \\
1947 \\
3710\end{array}$ & $\begin{array}{r}15390 \\
2740 \\
46126 \\
10202 \\
717 \\
4932 \\
5556 \\
2863 \\
1753 \\
2596 \\
3085 \\
1236 \\
22841 \\
999 \\
675 \\
1213 \\
7285 \\
2002 \\
2060 \\
4335\end{array}$ & $\begin{array}{r}3013 \\
52326 \\
11629 \\
849 \\
5520 \\
6058 \\
3225 \\
1922 \\
3024 \\
3380 \\
1389 \\
26640 \\
1133 \\
765 \\
1337 \\
7968 \\
2303 \\
2198 \\
5330\end{array}$ & $\begin{array}{r}18908 \\
3322 \\
60586 \\
13516 \\
1020 \\
6133 \\
6823 \\
3709 \\
2210 \\
3450 \\
3727 \\
1581 \\
30798 \\
1292 \\
882 \\
1526 \\
8790 \\
2673 \\
2366 \\
6405\end{array}$ & $\begin{array}{r}20850 \\
3696 \\
70327 \\
15877 \\
1249 \\
6819 \\
7683 \\
4323 \\
2512 \\
3965 \\
4138 \\
1849 \\
36046 \\
1501 \\
1.021 \\
1740 \\
10024 \\
3129 \\
2542 \\
7741\end{array}$ & $\begin{array}{r}22545 \\
4136 \\
80954 \\
18692 \\
1494 \\
7553 \\
8691 \\
5098 \\
2917 \\
4581 \\
4633 \\
2182 \\
42696 \\
1745 \\
1197 \\
2041 \\
11649 \\
3671 \\
2718 \\
9112\end{array}$ & $\begin{array}{r}24352 \\
4658 \\
93245 \\
22160 \\
1736 \\
8341 \\
9717 \\
6028 \\
3441 \\
5282 \\
5229 \\
2583 \\
50718 \\
2021 \\
1406 \\
2419 \\
13586 \\
4348 \\
2889 \\
10755\end{array}$ \\
\hline Subtotal (20 países) & 84885 & 93066 & 102889 & 112968 & 24194 & 138606 & 157094 & 179717 & 207032 & 238305 & 274914 \\
\hline $\begin{array}{l}\text { Otros paises de la región } \\
\text { Barbados } \\
\text { Guyana } \\
\text { Jamaica } \\
\text { Trinidad y Tabago }\end{array}$ & $\begin{array}{l}155 \\
295 \\
855 \\
389\end{array}$ & $\begin{array}{l}156 \\
302 \\
922 \\
390\end{array}$ & $\begin{array}{r}159 \\
309 \\
1009 \\
405\end{array}$ & $\begin{array}{r}168 \\
325 \\
1108 \\
451\end{array}$ & $\begin{array}{r}179 \\
344 \\
1212 \\
510\end{array}$ & $\begin{array}{r}194 \\
376 \\
1298 \\
566\end{array}$ & $\begin{array}{r}211 \\
423 \\
1385 \\
632\end{array}$ & $\begin{array}{r}227 \\
486 \\
1489 \\
721\end{array}$ & $\begin{array}{r}233 \\
564 \\
1629 \\
831\end{array}$ & $\begin{array}{r}245 \\
648 \\
1790 \\
973\end{array}$ & $\begin{array}{r}254 \\
745 \\
1996 \\
1067\end{array}$ \\
\hline Total otros paises & 109T & 1770 & 1882 & 2052 & 2245 & 2434 & 2651 & 2923 & 3257 & 3656 & 4062 \\
\hline Total & 86579 & 94836 & 104771 & 115020 & 126439 & 141040 & 159745 & 182640 & 210289 & 241961 & 278976 \\
\hline
\end{tabular}

Fuzarte: CELADE, Boletín Demográfico, núm. 10, julio de 1972. 
El ritmo de crecimiento medio anual de la población latinoamericana en su conjunto experimentó un aumento insignificante durante el decenio, pues pasó de poco menos de $2.9 \%$ en 1960, a una cifra apenas superior en 1970. Un análisis de la tendencia a largo plazo (véase el cuadro 2) confirma que en el decenio de 1960 se mantuvo la tendencia a una elevación constante de la tasa de crecimiento registrada desde 1930.1 Sin embargo, tiene cierta significación el hecho de que el decenio de 1960 se haya caracterizado por una desaceleración de las tasas de crecimiento demográfico, lo que adquiere considerable importancia en un análisis de tendencias de largo plazo. El examen más detenido de estas tendencias y su proyección hacia el futuro parecería indicar que América Latina ha alcanzado, en efecto, su tasa más elevada de crecimiento demográfico, y que luego de mantener aproximadamente este mismo nivel por algunos años más, dicha tasa empezará a declinar hacia comienzos del próximo decenio.

Sin embargo, debe tenerse presente que estas cifras globales para la región encubren gran diversidad de modalidades nacionales. (V́éase el cuadro 3.) La Argentina y el Uruguay se encuentran en la última etapa de la transición demográfica, y sus tasas de crecimiento -que ya en 1960 se asemejaban a las de muchos países desarrollados- continuaron declinando durante el período hasta llegar en 1970 a niveles de 1.5 y de $1.2 \%$, respectivamente. Cuba y Chile se encuentran asimismo en una etapa de transición bien avanzada y sus tasas de crecimiento han bajado aproximadamente a $2.0 \%$ anual en la actualidad. ${ }^{2}$

Otros tres países - Brasil, Venezuela y Costa Rica - alcanzaron su nivel más alto de crecimiento demográfico alrededor de 1960, pero las tasas respectivas comenzaron a declinar durante el período estudiado. En el Brasil, el cambio fue insignificante, pues su tasa anual de crecimiento bajó de algo más de $3.0 \%$ en 1960 a poco menos de $2.9 \%$ en 1970. En Venezuela la reducción fue mayor, pero como ella comenzó desde un nivel mucho más alto, el país sigue perteneciendo a la categoría de alto crecimiento, con una tasa de $3.3 \%$ en 1970. En cambio, el ritmo de crecimiento de Costa Rica bajó en forma más marcada en ese período: desde uno de los niveles más altos registrados en América Latina descendió a uno bastante inferior a $3.0 \%$.

En los demás países (excepto Guatemala, cuyo crecimiento se mantuvo básicamente estacionario) las tasas de crecimiento se aceleraron

I La aparente estabilización momentánea de las tasas de crecimiento en los períodos 1955-1960 y 1960-1965 sugerida en el cuadro 2, probablemente obedece a cambios en la estructura de la población por edades y a la disminución de la inmigración extranjera en países como Argentina, Brasil y Venezuela, más que a la interrupción de la tendencia a largo plazo.

2 Las tasas de crecimiento natural que figuran en el cuadro 3 se equiparan con las tasas de crecimiento demográfico. Se adopt 6 este procedimiento por dos motivos: primero, es difícil obtener datos cuantitativos sobre la dimension de las migraciones internacionales a comienzos y a fines del decenio; segundo, en la gran mayoría de los países y en América Latina en su conjunto las migraciones internacionales no han tenido en realidad efectos apreciables sobre las tasas de crecimiento durante el período. 
CuAdro 2. América Latina: tasas de crecimiento demográfico por países, 1920-1970

\begin{tabular}{|c|c|c|c|c|c|c|c|c|c|c|}
\hline País & $1920-1925$ & $1925-1930$ & $1930-1935$ & $1935-1940$ & $1940-1945$ & $1945-1950$ & $1950-1955$ & $1955-1960$ & $1960-1965$ & $1965-1970$ \\
\hline Argentina & 3.17 & 2.81 & 1.86 & 1.67 & 1.67 & 2.11 & 2.05 & 1.98 & 1.58 & 1.56 \\
\hline Bolivia & 1.06 & 1.26 & 1.45 & 1.62 & 1.78 & 1.92 & 1.97 & 2.16 & 2.29 & 2.41 \\
\hline Brasil & 2.05 & 2.05 & 2.05 & 2.11 & 2.27 & 2.55 & 2.97 & 3.03 & 2.86 & 2.87 \\
\hline Colombia & 1.94 & 1.96 & 2.03 & 2.19 & 2.36 & 2.65 & 3.05 & 3.27 & 3.32 & 3.46 \\
\hline Costa Rica & 1.61 & 1.82 & 2.00 & 2.35 & 2.98 & 3.44 & 3.74 & 4.13 & 3.65 & 3.05 \\
\hline Cuba & 2.66 & 2.67 & 1.93 & 1.58 & 1.55 & 2.28 & 2.13 & 2.14 & 2.07 & 2.00 \\
\hline Chile & 1.54 & 1.61 & 1.55 & 1.50 & 1.54 & 1.74 & 2.41 & 2.40 & 2.50 & 2.26 \\
\hline Ecuador & 1.14 & 1.46 & 1.71 & 1.91 & 2.06 & 2.41 & 2.83 & 3.11 & 3.35 & 3.41 \\
\hline E1 Salvador & 2.18 & 2.09 & 1.19 & 1.30 & 1.23 & 2.05 & 2.51 & 2.90 & 3.04 & 3.36 \\
\hline Guatemala & 1.11 & 2.94 & 2.42 & 1.97 & 3.36 & 3.10 & 2.67 & 2.82 & 2.93 & 2.89 \\
\hline Haití & 1.25 & 1.39 & 1.51 & 1.60 & 1.78 & 1.84 & 1.95 & 2.15 & 2.28 & 2.45 \\
\hline Honduras & 1.94 & 1.92 & 1.61 & 1.73 & 2.01 & 236 & 2.62 & 3.18 & 3.37 & 3.43 \\
\hline México & 0.95 & 1.76 & 1.75 & 1.84 & 2.88 & 3.12 & 2.94 & 3.20 & 3.45 & 3.50 \\
\hline Nicaragua & 1.46 & 1.55 & 1.74 & 2.00 & 2.27 & 2.55 & 2.66 & 3.04 & 3.06 & 2.98 \\
\hline Panamá & 1.58 & 1.59 & 0.86 & 2.57 & 2.55 & 2.53 & 2.89 & 2.97 & 3.23 & 3.27 \\
\hline Paraguay & 2.35 & 2.31 & 2.34 & 2.37 & 1.82 & 2.01 & 2.60 & 2.78 & 3.24 & 3.46 \\
\hline Perú & 1.47 & 1.56 & 1.65 & 1.72 & 1.75 & 1.81 & 1.98 & 2.66 & 3.05 & 3.12 \\
\hline República Dominicana & 1.99 & 2.16 & 2.28 & 2.34 & 2.62 & 2.84 & 3.02 & 3.20 & 3.25 & 3.44 \\
\hline Uruguay & 2.06 & 2.04 & 1.50 & 1.18 & 1.13 & 1.30 & 1.48 & 1.44 & 1.35 & 1.23 \\
\hline Venezuela & 1.93 & 2.17 & 2.27 & 2.37 & 2.84 & 3.11 & 3.99 & 3.92 & 3.31 & 3.37 \\
\hline Subtotal (20 países) & 1.86 & 2.03 & 1.89 & 1.91 & 2.22 & 2.54 & 2.73 & 2.85 & 2.85 & 2.91 \\
\hline \multicolumn{11}{|l|}{ Otros países de la región } \\
\hline Barbados & 0.13 & & & & - & & & & & \\
\hline Guyana & 0.47 & & & & & . & & & & \\
\hline Jamaica & 1.52 & & & & & & & & & \\
\hline Trinidad y Tabago & 0.05 & & & & & & & & & \\
\hline Total otros países & 0.88 & 1.22 & 1.74 & 1.82 & 1.63 & 1.72 & 1.97 & 2.19 & 2.34 & 2.13 \\
\hline Total & 1.84 & 2.01 & 1.88 & 1.91 & 2.21 & 2.52 & 2.71 & 2.84 & 2.84 & 2.90 \\
\hline
\end{tabular}

Fuente: Celade, Boletín Demográfico, núm. 10, julio de 1972. 
Cuadro 3. América Latina: crecimiento natural, natalidad y mortalidad, por países, 1960-1970

\begin{tabular}{|c|c|c|c|c|c|c|c|}
\hline \multirow[t]{2}{*}{ País } & \multirow{2}{*}{$\begin{array}{c}\text { Población } \\
1970 \\
\text { (en miles) }\end{array}$} & \multicolumn{2}{|c|}{$\begin{array}{l}\text { Tasa media anual } \\
\text { de crecimiento } \\
\text { natural (por } \\
\text { ciento) }\end{array}$} & \multicolumn{2}{|c|}{$\begin{array}{c}\text { Tasa bruta } \\
\text { de natalidad } \\
\text { (poi mil) }\end{array}$} & \multicolumn{2}{|c|}{$\begin{array}{l}\text { Tasa bruta } \\
\text { de mortalidad } \\
\text { (por mil) }\end{array}$} \\
\hline & & 1960 & 1970 & 1960 & 1970 & 1960 & 1970 \\
\hline $\begin{array}{l}\text { Argentina } \\
\text { Bolivia } \\
\text { Brasil } \\
\text { Colombia } \\
\text { Chile } \\
\text { Ecuador } \\
\text { Paraguay } \\
\text { Perú } \\
\text { Uruguay } \\
\text { Venezuela } \\
\text { Costa Rica } \\
\text { El Salvador } \\
\text { Guatemala } \\
\text { Honduras } \\
\text { Nicaragua } \\
\text { Panamá } \\
\text { México } \\
\text { Cuba } \\
\text { Haití } \\
\text { República Dominicana }\end{array}$ & $\begin{array}{r}24352 \\
4658 \\
93245 \\
22160 \\
9717 \\
6028 \\
2419 \\
13586 \\
2889 \\
10755 \\
1736 \\
3441 \\
5282 \\
2583 \\
2021 \\
1406 \\
50718 \\
8341 \\
5229 \\
4348\end{array}$ & $\begin{array}{l}1.66 \\
2.30 \\
3.03 \\
3.29 \\
2.45 \\
3.23 \\
2.95 \\
2.85 \\
1.39 \\
3.59 \\
3.89 \\
2.81 \\
2.88 \\
3.12 \\
3.05 \\
3.10 \\
3.32 \\
2.42 \\
2.20 \\
3.22\end{array}$ & $\begin{array}{l}1.52 \\
2.46 \\
2.88 \\
3.51 \\
1.96 \\
3.41 \\
3.53 \\
3.14 \\
1.21 \\
3.26 \\
2.92 \\
3.44 \\
2.88 \\
3.30 \\
3.12 \\
3.26 \\
3.50 \\
2.00 \\
2.54 \\
3.51\end{array}$ & $\begin{array}{l}23.3 \\
44.0 \\
39.8 \\
45.0 \\
38.3 \\
46.0 \\
45.0 \\
43.0 \\
22.0 \\
43.4 \\
48.0 \\
47.6 \\
47.6 \\
46.7 \\
47.0 \\
42.1 \\
45.0 \\
31.5 \\
44.0 \\
49.1\end{array}$ & $\begin{array}{l}22.9 \\
43.8 \\
37.3 \\
44.0 \\
27.4 \\
45.0 \\
45.0 \\
41.0 \\
21.1 \\
40.6 \\
34.5 \\
46.7 \\
42.5 \\
48.3 \\
46.4 \\
39.8 \\
44.0 \\
28.0 \\
44.0 \\
48.3\end{array}$ & $\begin{array}{r}6.7 \\
21.0 \\
9.5 \\
12.1 \\
13.8 \\
13.7 \\
15.5 \\
14.5 \\
8.1 \\
7.5 \\
9.1 \\
19.5 \\
18.8 \\
15.5 \\
16.5 \\
11.1 \\
11.8 \\
7.3 \\
22.0 \\
16.9\end{array}$ & $\begin{array}{r}7.7 \\
19.2 \\
8.5 \\
8.9 \\
7.8 \\
10.9 \\
9.7 \\
9.6 \\
9.0 \\
8.0 \\
5.3 \\
12.3 \\
13.7 \\
15.3 \\
15.2 \\
7.2 \\
9.0 \\
8.0 \\
18.6 \\
13.2\end{array}$ \\
\hline Subtotal (20 países) & 274914 & 2.90 & 2.91 & 40.1 & 38.2 & 11.1 & 9.2 \\
\hline Otros países de la región a & 4062 & & & & & & \\
\hline Total & 278976 & & & & & & \\
\hline
\end{tabular}

Fuente: Estimaciones basadas en datos censales y estadisticas vitales, y en proyecciones tomadas de cruAde, Boletín Demográfico, año V, núm. 10, julio de 1972.

- Bathadne Cuvana Tamaim v Trinidad "Taham 
en el período considerado. Bolivia y Haití se encuentran en un extrema del continuum, dado que sus tasas de crecimiento en 1960 eran inferiores a las de los demás países, con la excepción de Argentina, Uruguay y Cuba. Durante la última década sus niveles de mortalidad experimen. taron un leve mejoramiento con el resultado de que en 1970 sus tasas de crecimiento demográfico alcanzaron un nivel moderado $(2.5 \%$ aproximadamente) que aún estaba bastante por debajo del promedio de la región. En Panamá, Nicaragua, Perú y Honduras el ritmo de crecimiento también se aceleró moderadamente, y si bien esos países comenzaron el período con tasas de crecimiento mucho más altas (entre 2.9 y $3.1 \%$ ) que Haití y Bolivia, en 1970 esas tasas fluctuaron entre 3.1 y $3.3 \%$. En Colombia, Ecuador, México y la República Dominicana se produjeron aumentos símilares; en efecto, estos países comenzaron el período con tasas de crecimiento anual más elevadas, que fluctuaban entre $3.2 \%$ y $3.3 \%$, para terminarlo con niveles que iban de $3.4 \%$ a $3.5 \%$. No obstante, la aceleración más rápida se registró en Paraguay y El Salvador, pues de un nivel bastante inferior a $3.0 \%$ en 1960 las tasas se elevaron por encima del $3.4 \%$ en 1970.

En suma, el examen de las tendencias de las tasas de crecimiento en el decenio considerado permite establecer seis categorías generales. En dos de esas categorías las tasas de crecimiento declinaron, en tanto que en las cuatro restantes se aceleraron. Las tendencias van desde una considerable disminucion en países que ya tenían bajas tasas de crecimiento al iniciarse el decenio, hasta aumentos apreciables en países que comenzaron el período con altas tasas y lo terminaron con un ritma de crecimiento aún más acelerado. La resultante de estas tendencias compensatorias en el conjunto de la región es prácticamente el estancamiento de las tasas de crecimiento en los niveles elevados que antes tenían. El examen de los componentes del crecimiento que se hace a continuación proporcionará una base mejor para evaluar las tendencias futuras probables.

\section{COMPONENTES DEL CRECIMIENTO DEMOgRÁfico}

Si bien las informaciones sobre la evolución general del crecimiento demográfico inspiran suficiente confianza, las relativas a los componentes del crecimiento - fecundidad, mortalidad y migraciones internacionales-, por su misma naturaleza están más sujetas a especulaciones. Los datos disponibles permiten formular estimaciones generales que pueden complementarse con estudios de casos más concretos en aquellos países sobre los que se tiene información más detallada. Sin embargo, téngase presente el carácter muy provisional de las cifras.

\section{a) Tendencias de la fecundidad}

La tasa de natalidad correspondiente a la región en su conjunto dismi. nuyo ligeramente, de cerca de 40 por mil en 1960 a poco más de 38 
por mil en 1970. (Véase de nuevo el cuadro 3.) La reducción de estas tasas en el decenio, sin ser igual en la totalidad de los países, se observa prácticamente en todos ellos. Chile y Costa Rica, cuyas tasas brutas anuales de natalidad bajaron entre 1960 y 1970 de 38 y 48 por mil a 27 y 35 por mil, respectivamente, son los países que muestran mayor declinación. Disminuciones menos marcadas pero apreciables se registraron también en Cuba, Brasil, Venezuela, Guatemala y Panamá. Es probable que la disminución de las tasas de natalidad de América Latina sea atribuible en gran parte a las reducciones experimentadas en este grupos de países.

En Argentina y Uruguay las tasas de natalidad declinaron levemente con respecto a sus bajos niveles de comienzos del decenio. En la mayoría de los demás países las estimaciones hechas indicarían una disminución muy leve, realmente tan leve que cabe suponer que se trata más bien de fluctuaciones en tomo a un nivel que de un indicio de que las tasas de natalidad vayan a bajar apreciablemente.

Para resumir, en América Latina la fecundidad ha mostrado en el decenio de 1960 una gran heterogeneidad, tanto en el nivel como en la magnitud de los cambios. En general, los niveles de fecundidad continúan siendo muy elevados $\mathrm{y}$, como se espera que declinen tarde o temprano, convendría detenerse a examinar brevemente en qué forma se está efectuando esta reducción en determinados países. A este respecto merecen atencion especial los casos de Brasil y Costa Rica; el primero por su gran gravitación sobre la configuración global, y el segundo porque ha experimentado recientemente una transformación demográfica que otros países podrían imitar en los decenios venideros.

Por lo que toca a Brasil, las informaciones de los últimos cuatro censos relativos al número de niños nacidos vivos por cada mujer permiten analizar el comportamiento de la fecundidad en los tres últimos decenios. La tasa de natalidad baj6 de 45.7 por mil en 1940 a 39.8 por mil en 1960 y a 37.3 por mil en 1970. Entre tanto, la tasa bruta de reproducción bajó de 2.80 en 1940-1950 a 2.61 en 1960-1970. ${ }^{3}$ Esa dismi- . nución, a pesar de ser significativa desde el punto de vista de las tendencias de largo plazo, continúa siendo relativamente pequeña. Además, el número de niños nacidos en 1970 fue superior en $25 \%$ al de 1960 y duplic6 al de 1940. Por otra parte, si la tasa de natalidad de 1940 se hubiera mantenido hasta el presente, en 1970 el número anual de nacimientos habría superado en más de 700000 a las cifras efectivas estimadas para ese año.

Estas tendencias globales registradas en el Brasil son, evidentemente, el resultado neto de las variadas evoluciones que se observan en las diferentes regiones, grupos sociales e individuos. Las cifras correspondientes a la tasa de fecundidad por cohorte (véase el cuadro 4) muestran que la declinación de la tasa de natalidad en la población total del país puede atribuirse principalmente a la reducción de la fecundidad

3 Cifras tomadas de Carmen Arretx, Revisión de las estimaciones de la fecundidad del Brasil a base de los censos de 1940, 1950, 1960 y 1970, CELADE, S/66/25. 
CuADRo 4. Brasil: promedio de niños nacidos vivos de mujeres brasileñas por edad y región, 1960 y 1970

\begin{tabular}{|c|c|c|c|c|c|c|c|c|c|c|c|c|}
\hline \multirow{2}{*}{ Categorías de edad } & \multicolumn{2}{|c|}{ Brasil } & \multicolumn{2}{|c|}{ Norte } & \multicolumn{2}{|c|}{ Nordeste } & \multicolumn{2}{|c|}{ Sudeste } & \multicolumn{2}{|c|}{ Sur } & \multicolumn{2}{|c|}{ Centro Sur } \\
\hline & 1960 & 1970 & 1960 & 1970 & 1960 & 1970 & 1960 & 1970 & 1960 & 1970 & 1960 & 1970 \\
\hline $\begin{array}{l}15-19 \\
20-24 \\
25-29 \\
30-39 \\
40-49 \\
50 \text { y más }\end{array}$ & $\begin{array}{r}12.9 \\
128.2 \\
220.8 \\
433.6 \\
563.3 \\
575.4\end{array}$ & $\begin{array}{r}12.4 \\
100.6 \\
240.7 \\
415.0 \\
525.8 \\
548.9\end{array}$ & $\begin{array}{r}15.3 \\
147.7 \\
259.6 \\
483.3 \\
598.7 \\
558.0\end{array}$ & $\begin{array}{r}21.6 \\
142.7 \\
284.4 \\
515.3 \\
634.1 \\
659.5\end{array}$ & $\begin{array}{r}14.4 \\
135.7 \\
237.5 \\
512.3 \\
653.0 \\
612.8\end{array}$ & $\begin{array}{r}14.6 \\
113.3 \\
277.8 \\
492.6 \\
634.9 \\
628.1\end{array}$ & $\begin{array}{r}11.5 \\
119.5 \\
201.9 \\
376.4 \\
496.4 \\
544.4\end{array}$ & $\begin{array}{r}8.9 \\
82.8 \\
206.5 \\
356.5 \\
446.3 \\
488.6\end{array}$ & $\begin{array}{r}11.3 \\
127.4 \\
221.4 \\
420.1 \\
553.0 \\
574.4\end{array}$ & $\begin{array}{r}13.3 \\
103.0 \\
241.9 \\
411.4 \\
532.7 \\
553.2\end{array}$ & $\begin{array}{r}17.6 \\
149.6 \\
263.6 \\
487.5 \\
632.7 \\
649.0\end{array}$ & $\begin{array}{r}17.4 \\
134.4 \\
283.8 \\
459.9 \\
570.1 \\
593.8\end{array}$ \\
\hline $\begin{array}{l}\text { Promedio de niños } \\
\text { nacidos vivos }\end{array}$ & 323.3 & 307.7 & 334.1 & 346.4 & 358.8 & 354.7 & 298.1 & 274.8 & 314.4 & 303.2 & 342.2 & 317.1 \\
\hline $\begin{array}{l}\text { Promedio de niños } \\
\text { nacidos vivos es- } \\
\text { tandarizado se- } \\
\text { gún la edad }\end{array}$ & 347.6 & 330.6 & 365.1 & 404.2 & 387.5 & 386.5 & 316.2 & 286.5 & 343.1 & 332.6 & 394.3 & 366.5 \\
\hline
\end{tabular}

Fuentes: Para 1960, Operación Muestra de Censos (omvece), crlade, Programa de Tabulaciones Básicas, Brasil, cuadro 31 ; para 1970, xвge, VII Recensamento Geral, 1970, Tabulaçóes Avançadas do Censo Demographico, Resultados Preliminares, Cuadro 13. 
en todos los grupos de edades excepto en el de 25 a 29 años, que experiment6 un leve aumento. Estas tendencias coinciden con la modalidad clásica de reducción de la fecundidad por grupo de edad y tentativamente podrían interpretarse como resultantes del leve aumento en la edad media al casarse y del uso más extendido de prácticas de control de la natalidad, especialmente en la segunda mitad del ciclo reproductivo.

Durante 1960-1970 la fecundidad disminuyó, aunque no en la misma proporción, en cuatro de las cinco grandes regiones fisiográficas. La región Norte, escasamente poblada, fue la única que experimentó un incremento, y hacia 1970 tenía la más alta tasa de fecundidad, estandarizada por edades, de todas las regiones. La disminución fue mayor en el Sudeste, es decir, precisamente en la región que ha tenido desde hace mucho tiempo el más alto nivel de desarrollo socioeconómico del país y que ya en 1960 tenía un nivel de fecundidad inferior al del resto del país. Por el contrario, la región fronteriza del Centro-Oeste tenía los niveles más altos de fecundidad en 1960, pero éstos experimentaron un descenso significativo durante el decenio, en tanto que en la región Sur la reducción fue menor, partiendo de niveles iniciales más bajos. La región Nordeste prácticamente mantuvo sus altos niveles durante el período, pues en ella la disminución fue insignificante. En suma, dejando de lado la región Norte, cuyos patrones de fecundidad difieren radicalmente de los del resto del país, la disminución de la fecundidad en el Brasil en el decenio de 1960 estuvo en relación directa con el grado de modemización y el dinamismo de las economías regionales respectivas.

Si se tiene presente que en el Brasil siempre han imperado las políticas poblacionistas y que, como se verá en las secciones posteriores de este trabajo, el respaldo público y privado a los programas de planificación de la familia tiene poca influencia relativa, la reducción de la fecundidad por grupos de edad y por regiones refleja simplemente el resultado del conjunto de iniciativas individuales simultáneas de control de la fecundidad. Grosso modo, la reducción de la fecundidad puede atribuirse a la influencia combinada de la rápida urbanización, la difusión de la educación y el efecto de la sociedad de consumo que actúa de un modo u otro sobre un sector cada vez más amplio de la población, por lo menos de la urbana.

Estas influencias, en conjunto, hacen que una proporción aún pequeña - pero cada vez mayor- de matrimonios se den cuenta de que, ante una gran disminución de la mortalidad, la procreación irrestricta les impediría cumplir sus nuevas aspiraciones. Además, aunque las informaciones sobre las diferencias de fecundidad por lugares de residencia urbana o rural o por estratos socioeconómicos son todavía incompletas, puede afirmarse que la tasa de fecundidad de las personas nacidas en zonas urbanas suele ser inferior a la del resto de la población, y que existe una relación inversa entre clase social y fecundidad. Dada la elevada proporción de la población total que corresponde a los estratos socioeconómicos inferiores, las futuras reducciones de los niveles de fe- 
cundidad dependerán en gran medida del comportamiento reproductivo de la población de esos estratos.

En contraste con la reducción lenta y gradual de la tasa de natalidad en el Brasil, la de Costa Rica experimentó una de las disminuciones más abruptas observadas en el mundo occidental. El caso de Costa Rica reviste particular interés porque sugiere que, así como el descenso de la mortalidad fue mucho más acelerado en los países subdesarrollados que en los desarrollados, otro tanto podría ocurrir con el descenso de la fecundidad, en determinadas circunstancias. La tasa de natalidad de Costa Rica en el decenio de 1950 llegó casi a los niveles más altos conocidos y en 1960 todavía alcanzaba al 48 por mil. (Véase la gráfica I.)

Gráfica I. Costa Rica: Tasas de natalidad, de mortalidad $y$ de crecimiento natural en el presente siglo

(Escala natural)

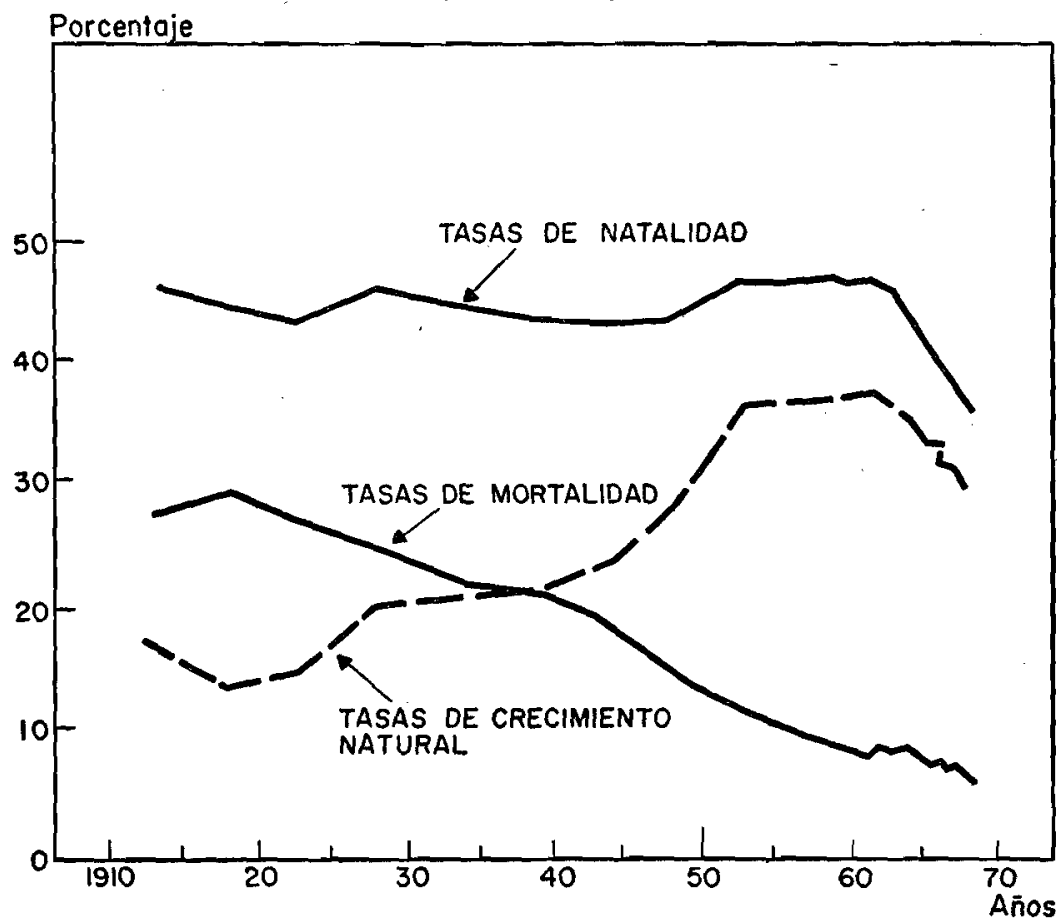

En los primeros años del decenio de 1960 declinó gradualmente, pero en el segundo quinquenio lo hizo a un ritmo tan acelerado que en 1970 había bajado aproximadamente a 35.0 por mil, lo que equivale a una reducción de $30 \%$ en ese infervalo.

Dada la calidad que suelen tener las estadísticas latinoamericanas, cabe suponer de inmediato que la causa de esa disminución tan marca- 
da podría ser la deficiencia en la información. 4 Sin embargo, en este caso pueden descartarse los erróres de medición, porque se reconoce que las estadísticas vitales de Costa Rica son en general completas, y los cálculos realizados con los datos no muestran ningún error importante.

¿Cuál fue entonces la causa de esta repentina disminución de la tasa de fecundidad? En primer lugar, el análisis de esas tasas estandarizadas según la edad indica que la disminución no puede atribuirse a cambios en la composición por edades de la población femenina en edad de procrear. Además, muestra que en Costa Rica la fecundidad declinó en todos los grupos de edades y que el descenso fue mayor precisamente en el grupo de 30 a 34 años lo que contrasta con el patrón clásico observado en las primeras etapas del descenso de la fecundidad según el cual la disminución que experimenta la actividad procreadora de la mujer en la segunda mitad del ciclo reproductivo se compensa con un pequeño incremento de la del grupo de 20 a 29 años de edad. Esto quiere decir que la disminución de la fecundidad en Costa Rica ha sido más concentrada que en el patrón clásico, y, por lo tanto, sean cuales fueren los factores sociosicológicos que están contribuyendo a modificar los valores y actitudes con respecto al tamaño de la familia, ellos están ejerciendo gran influencia en todos los grupos de edades, acelerando de ese modo la reducción general.

En segundo lugar, en el período considerado bajó levemente la edad media en que las parejas contraen matrimonio, y también la tasa bruta de nupcialidad. Sin embargo, los cálculos realizados sobre tasas estandarizadas por edades muestran que menos de la cuarta parte de la reducción total podría atribuirse a cambios en el patrón de nupcialidad. En todo caso, los cambios súbitos en ese patrón serían también el reflejo de modificaciones en los valores y actitudes con respecto al tamaño de la familia. Por consiguiente, cabe concluir que la rápida disminución de la tasa de natalidad en Costa Rica es atribuible en gran medida a un cambio real en los valores relativos al tamaño de la familia, a la mayor difusión de las prácticas de control de la natalidad en importantes sectores de la población que están en edad de procrear y, posiblemente, a la aplicación de métodos modernos más eficaces.

En años recientes se ha intensificado notablemente el respaldo del Gobierno de Costa Rica a las actividades de planificación de la familia, y esto induce a pensar en una relación causal entre ese apoyo y la disminución de la fecundidad. Sin embargo, los hechos probarían lo contrario, ya que la asistencia oficial sólo comenzó en gran escala después de iniciado ese brusco descenso. En vista de que hay una disposición favorable hacia lá planificación de la familia, cabe suponer que la acción del gobiemo contribuirá significativamente a que continúen las tendencias actuales, e influirá particularmente en las mujeres de 30 y más años que ya tienen todos los hijos que desean, pero que por problemas mate-

4 El análisis que se hace a continuación se basa en gran medida en los trabajos prosentados al Quinto Seminario Nacional de Demografía (Costa Rica, septiembre de 1970), y, especialmente, en el trabajo de Miguel Gómez B., EI rápido descenso de la fecundidad en Costa Rica, pp. 271 a 308. 
riales o de educación no habrían podido controlar de otro modo el número o el espaciamiento de su prole. Sin embargo, es importante destacar el hecho de que la natalidad inició su descenso en Costa Rica después de que el país había alcanzado un nivel moderadamente elevado de desarrollo económico y social en relación con otros países de la región, y paralelamente a otras manifestaciones del proceso de desarrollo, como la reducción de la mortalidad general e infantil, el mejoramiento del nivel de educación, la expansión de los medios de comunicación de masas, etc. (Véase el cuadro 5.)

Cuadro 5. Costa Rica: casos nuevos y control en clínicas públicas $y$ privadas de planificación familiar, 1966-1970

\begin{tabular}{|c|c|c|c|c|c|c|c|}
\hline \multirow{2}{*}{ Año } & \multicolumn{3}{|c|}{ Total } & \multicolumn{2}{|c|}{ Privadas } & \multicolumn{2}{|c|}{ Públicas } \\
\hline & Total & Nuevos & Control & Nuevos & Control & Nuevos & Control \\
\hline $\begin{array}{l}1966 \\
1967 \\
1968 \\
1969 \\
1970\end{array}$ & $\begin{array}{r}6645 \\
10793 \\
27254 \\
46662 \\
33960\end{array}$ & $\begin{array}{r}6645 \\
4810 \\
10238 \\
12753 \\
7391\end{array}$ & $\begin{array}{r}5983 \\
17016 \\
33909 \\
26569\end{array}$ & $\begin{array}{l}6645 \\
4810 \\
4215 \\
2002 \\
1148\end{array}$ & $\begin{array}{l}5983 \\
9106 \\
6574 \\
4467\end{array}$ & $\begin{array}{r}6023 \\
10751 \\
6243\end{array}$ & $\begin{array}{r}7 \ddot{910} \\
27335 \\
22102\end{array}$ \\
\hline
\end{tabular}

FueNTe: cepar, sobre datos oficiales.

Este análisis de la situación de Costa Rica podría sugerir que la misma declinación rápida podría ocurrir en otros países o subregiones, siempre que se combinasen adecuadamente actitudes favorables y mejores niveles de vida. Pero sería arriesgado hacer predicciones basándose en esta sola experiencia, dado el tamaño tan pequefio y las peculiaridades de esta nación.

\section{b) Tendencias de la mortalidad}

Entre 1960 y 1970 la tasa bruta de mortalidad de América Latina bajó gradualmente de 11 a 9 por mil. (Vease de nuevo el cuadro 3.) Esta reducción fue inferior a la de los decenios precedentes, como era de esperar dado los bajos niveles que tenían muchos países a comienzos del período. En efecto, las tasas brutas de mortalidad de América Latina son en la actualidad prácticamente iguales a las de los Estados Unidos o el Canadá, e inferiores a las de Europa septentrional u occidental, cuya población es evidentemente más vieja que la de América Latina.

Las diferencias en los niveles de mortalidad que existen entre los países: latinoamericanos son tan notables como las anotadas antes con respecto. a la fecundidad. Además, si se dispusiera de la información pertinente seguramente se vería que también existe gran heterogeneidad entre las: diferentes regiones de cualquier país. No obstante, puede apreciarse nítidamente que con el tiempo tienden a converger, a medida que el mejoramiento de los métodos de control de las enfermedades epidiemicas. $y$ 
parasitarias hace bajar significativamente las tasas de mortalidad de los países menos desarrollados, y el envejecimiento de la población en los países más avanzados tiende a invertir la tendencia a la disminución que los ha caracterizado en períodos anteriores. Ello explica que las tasas brutas de mortalidad de Argentina, Uruguay y Cuba subieran levemente en el período estudiado. 5 En los períodos restantes esas tasas declinaron a un ritmo que vario fundamentalmente según el nivel de comienzos del período. Con todo, en varios países -especialmente Bolivia, El Salvador, Guatemala, Honduras, Nicaragua, Haití y la República Dominicana- la mortalidad continúa siendo elevada, lo que evidentemente refleja su menor desarrollo relativo. Sin embargo, cabe esperar que este nivel continúe bajando en los decenios venideros, mejore o no significativamente el nivel general de bienestar socioeconómico.

Las comparaciones de tasas brutas de mortalidad entre países o regiones están sujetas a distorsiones por las diferencias que existen en la composición por edades, razón por la cual es preferible utilizar la esperanza de vida al nacer. Sin embargo, la mayoría de las estimaciones sobre la esperanza de vida se refieren a períodos quinquenales, to que hace difícil presentar información para el comienzo y el fin del decenio. En todo caso, la esperanza de vida de los varones aumentó de 54.9 a 58.9 años y la de las mujeres de 60.2 a 63.6 años entre 1960-1965 y 1965-1970. (Véase el cuadro 6.) En el período de 1965 a 1970 la esperanza de vida de los varones era en siete países de más de 60 años, y en cuatro, inferior a 50 años. Para las mujères era superior a 70 años en la Argentina y el Uruguay, entre 60 y 70 en ocho países e inferior a 50 en Haití y Bolivia. El índice correspondiente a los varones variaba en 23 años entre los países que tenían la más alta y la más baja mortalidad (Uruguay y Haití) y el correspondiente a las mujeres mostraba una diferencia de 27 años entre el Uruguay y Bolivia.

Para la región en su conjunto, se estima que la esperanza de vida al nacer en el período 1965-1970 era de alrededor de 61 afios, bastante más alta que la de 43 años estimada para el África o la de 49 años estimada para los países menos desarrollados del sur de Asia, pero todavía bastante inferior a la de 70 años que se observa en las regiones más desarrolladas del mundo. ${ }^{\circ}$ Se ha calculado que si América Latina hubiera alcanzado el nivel de mortalidad que prevalece en los países desarrollados, el número de defunciones en 1965-1970 habría sido de 1.3 millones en lugar de 2.5 millones.?

La esperanza de vida al nacer se correlaciona íntimamente con la incidencia de la mortalidad en los primeros cinco años de vida; cuanto más elevada sea la mortalidad en un país, mayor será la proporción de muertes entre los niños pequeños. Se ha estimado así que de los 2.5 millo-

5 Las cifras mostrarian también un ligero aumento en Venezuela, pero es probable que se deba a la exclusión de las migraciones internacionales de los cálculos.

- Naciones Unidas, La situación demográfica en el mundo en 1970, Estudios demográficos núm. 49, Nueva York, 1942, st/soA/Serie A/49.

7 Jorge Somoza, "La mortalidad en América Latina", Conferencia Latinoamericana Regional de Población, México, 1970, vol. I, p. 5. 
Cuadro 6. América Latina: esperanza de vida por país y sexo, 1960-1965 y $1965-1970$

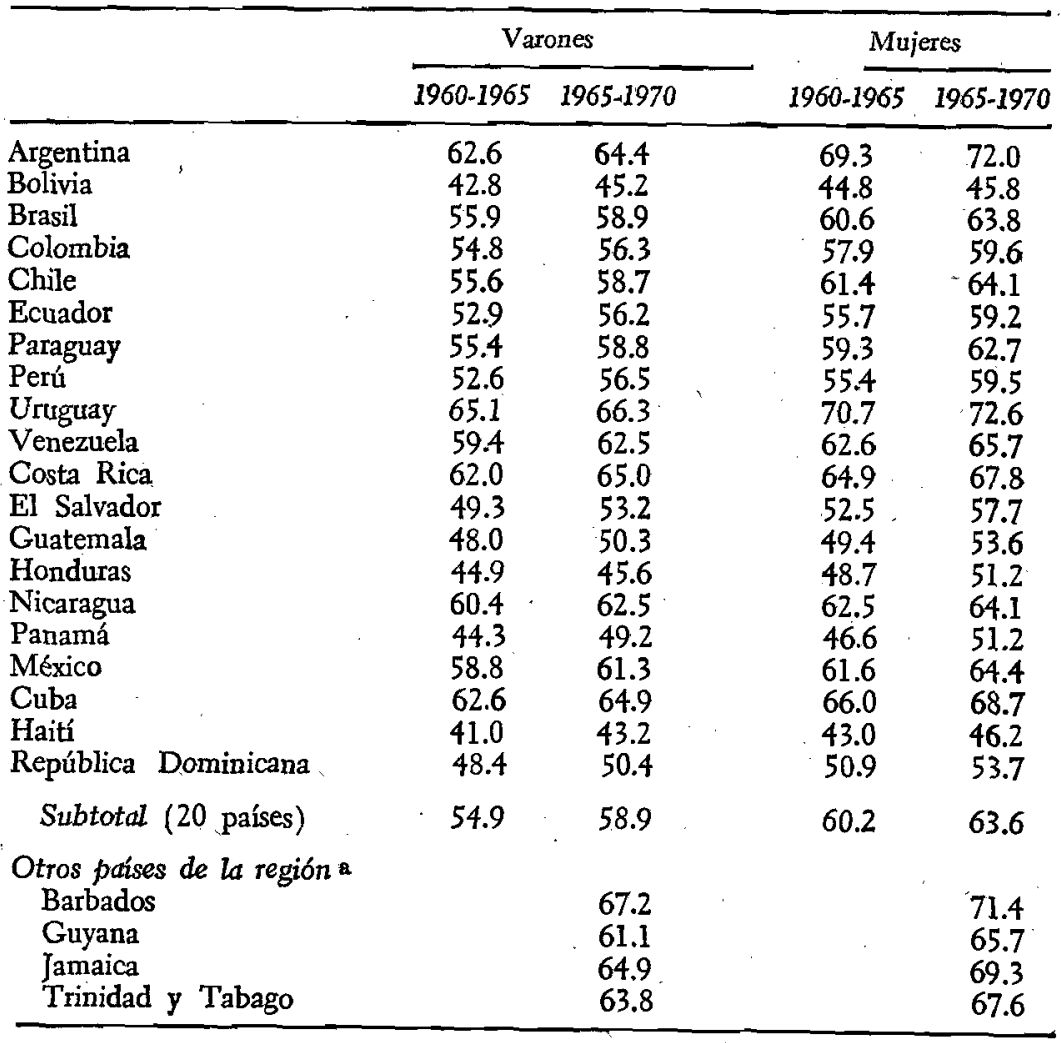

Fuentes: Carmen Arretx y José Pujol, La mortalidad en América Latina en el período 1965-1970, y Jack Harewood, "El nivel de mortalidad por sexo y edad en el Caribe Británico en 1965", en Conferencia Regional Latinoamericana de Po blación, México 1970, vol. I, pp. 30-35 y 36-41. Jorge Somoza, "Mortality in Latin America, present level and projections", International Population a 1964-1966. Conference, Londres 1969, vol. II, pp. 889-902.

nes de defunciones ocurridas en América Latina entre 1965 y 1970 , un millón correspondió a menores de cinco años. Si la mortalidad hubiera sido igual a la de los países desarrollados, sólo habrían fallecido 300000 niños menores de cinco años en lugar de un millón.8 $O$ sea, la supermortalidad de las regiones en desarrollo afecta principalmente al grupo de edad más joven.

Los niveles de mortalidad, sea que se midan por la esperanza de vida, 8 Ibid., p. 5. 
por las tasas brutas de mortalidad o por las de mortalidad infantil, varían con la educación, el grado de urbanización, la ocupacion, etc. Sin embargo, en América Latina todavía se carece en gran medida del tipo de información necesario para hacer una investigación más rigurosa de estos temas.

En suma, las investigaciones sobre el patrón de mortalidad en el último decenio muestran que persisten grandes diferencias entre los distintos países, y entre la región en su conjunto por una parte y los países desarrollados por otra. Los niveles de mortalidad bajaron en general en el decenio, especialmente en los países menos avanzados que tenían una mortalidad más alta, pero este avance no fue tan importante como en decenios anteriores ni bastó para que varios países y regiones de países abandonaran su condición de "zonas de alta mortalidad".

\section{c) La migración internacional}

Aunque la información que se posee sobre las corrientes migratorias internacionales hacia América Latina o entre los países latinoamericanos en el decenio de 1960 es incompleta, todo parece indicar que se acentuaron en ese período las tendencias hacia la disminución de la inmigración europea observadas anteriormente. Además, es muy probable que las migraciones internacionales, especialmente las de origen extracontinental, contribuyeran muy poco durante el decenio al crecimiento demográfico de la región. Las corrientes migratorias registradas se produjeron principalmente entre países contiguos y sus dimensiones fueron por lo general insignificantes en comparación con el tamaño de la población de los países hacia los cuales se dirigieron o de donde procedieron.

\section{Perspectivas de crectmiento}

Una vez analizados los niveles actuales de los componentes del crecimiento demográfico y sus tendencias recientes es posible formular algunas consideraciones generales sobre las tendencias probables del crecimiento futuro.

Es probable que el ritmo de crecimiento demográfico observado en América Latina en el decenio de 1960 se mantenga invariable hasta fines del decenio de 1970, porque la declinación de las tasas de mortalidad -que hasta ahora ha sido la causa de la aceleración del ritmo de crecimiento- será probablemente pequeña y se compensará cada vez más al continuar la declinación gradual de las tasas de fecundidad observada en el decenio de 1960.

La tendencia prevista en el conjunto de América Latina es el resultado neto de las diferentes tendencias registradas en distintos grupos de países, que se neutralizan entre sí y hacen prever que no habrá cambios en las tasas de crecimiento demográfico en el próximo decenio.

En primer lugar, el ritmo de crecimiento demográfico de la Argen- 
tina y el Uruguay, que ya era bastante lento en el decenio de 1960, continuará disminuyendo levemente por el efecto combinado de la continuación del reciente descenso de las tasas de natalidad y del leve aumento de las de mortalidad, que ya se advertía en ese decenio como consecuencia del proceso de envejecimiento de la población.

Un descenso similar, pero de mayor magnitud, cabe esperar en Costa Rica, Cuba y Chile, donde las tasas de mortalidad son ya tan bajas que es poco probable que desciendan mucho más en el futuro, pero el margen de disminución de las tasas de natalidad es mucho mayor que en la Argentina y el Uruguay.

En un tercer grupo de países, que incluye a Brasil, Colombia, Ecuador, México, Panamá, Perú y Venezuela, las tasas de crecimiento fluc-

Cuadro 7. América Latina: proyecciones de la población por paises, 1970-2000 (en miles)

\begin{tabular}{|c|c|c|c|c|}
\hline País & 1970. & 1980 & 1990 & 2000 \\
\hline $\begin{array}{l}\text { Argentina } \\
\text { Bolivia } \\
\text { Brasil } \\
\text { Colombia } \\
\text { Chile } \\
\text { Ecuador } \\
\text { Paraguay } \\
\text { Perú } \\
\text { Uruguay } \\
\text { Venezuela } \\
\text { Costa Rica } \\
\text { El Salvador } \\
\text { Guatemala } \\
\text { Honduras } \\
\text { Nicaragua } \\
\text { Panamá } \\
\text { México } \\
\text { Cuba } \\
\text { Haití } \\
\text { República Dominicana }\end{array}$ & $\begin{array}{r}24352 \\
4658 \\
93245 \\
22160 \\
9717 \\
6028 \\
2419 \\
13586 \\
2889 \\
10755 \\
1736 \\
3441 \\
5282 \\
2583 \\
2021 \\
1406 \\
50718 \\
8341 \\
5229 \\
4348\end{array}$ & $\begin{array}{r}28218 \\
6006 \\
124000 \\
31366 \\
11461 \\
8440 \\
3456 \\
18527 \\
3251 \\
14979 \\
2281 \\
4904 \\
7018 \\
3661 \\
2818 \\
1938 \\
71387 \\
10075 \\
6838 \\
6197\end{array}$ & $\begin{array}{r}31909 \\
7782 \\
164374 \\
43130 \\
13734 \\
11774 \\
4860 \\
25143 \\
3642 \\
19952 \\
2945 \\
7122 \\
9357 \\
5182 \\
3951 \\
2669 \\
99669 \\
12053 \\
9144 \\
8866\end{array}$ & $\begin{array}{rl}35 & 274 \\
10 & 081 \\
215 & 510 \\
56 & 731 \\
16272 \\
16149 \\
6619 \\
33491 \\
3999 \\
26100 \\
3682 \\
10372 \\
12355 \\
7205 \\
5460 \\
3633 \\
135089 \\
14337 \\
12347 \\
12539\end{array}$ \\
\hline Subtotal (20 paises) & 274914 & 366821 & 487258 & 637245 \\
\hline $\begin{array}{l}\text { Barbados } \\
\text { Guyana } \\
\text { Jamaica } \\
\text { Trinidad y Tabago }\end{array}$ & $\begin{array}{r}254 \\
745 \\
1996 \\
1067\end{array}$ & $\begin{array}{r}263 \\
995 \\
2382 \\
1255\end{array}$ & $\begin{array}{l}236 \\
1309 \\
2754 \\
1411\end{array}$ & $\begin{array}{l}212 \\
1646 \\
3102 \\
1555\end{array}$ \\
\hline Subtotal (4 países) & 4062 & 4895 & 5710 & 6515 \\
\hline Total & 278976 & 371716 & 492968 & 643760 \\
\hline
\end{tabular}

FuENTE: CELAdE, Boletín Demográfico, Afio V, núm. 10, julio de 1972. 
tuarán probablemente en el decenio actual en torno a los mismos niveles observados en la década anterior. Como en esos siete países vive alrededor del $72 \%$ de la población de América Latina, la explicación sobre la probable estabilización del crecimiento demográfico en el decenio venidero que se dio anteriormente para la región tiene especial validez para este grupo de países.

El grupo que incluye Bolivia, El Salvador, Guatemala, Haití, Honduras, Nicaragua, Paraguay y la República Dominicana se encuentra en una etapa anterior de la transición demográfica $y$, por consiguiente, hay muchas posibilidades de que en estos países el crecimiento sea más rápido en el próximo decenio.

Según las previsiones, es difícil que las elevadas tasas de natalidad que tienen hoy esos países se modifiquen considerablemente antes de 1980. Por otra parte, como sus niveles de mortalidad son todavía altos y como pueden reducirse con un gasto o un desarrollo socioeconómico mínimos, cabe prever que las tasas de mortalidad disminuirán apreciablemente en el futuro cercano. Por lo tanto, el crecimiento demográfico tenderá a acelerarse en proporción directa con la declinación de los actuales niveles de mortalidad.

Si se verificaran esas tendencias, especialmente en los países más populosos, América Latina tendría en 1980 alrededor de 90 millones más de habitantes que en 1970. (Véase el cuadro 7.) La mayor parte de ese aumento se produciría en Brasil, México, Colombia y Perú, países a los cuales correspondería en conjunto más del $70 \%$ del incremento total de América Latina durante el decenio. Las proyecciones de población para períodos más largos son mucho más conjeturales, pero, suponiendo que no se produzcan cambios radicales imprevistos en la dinámica de la población, las estimaciones más plausibles indican que la población total de América Latina pasaría de 640 millones a fines del siglo, y el Brasil solo tendría una población superior a la de toda América Latina en 1960.

\section{La URBANIZACIÓN Y LA DISTRIBUCIÓN ESPACIAL}

El hecho más significativo que destaca el análisis de la distribución espacial de la población en América Latina es la intensidad de su proceso de urbanización. Cualquier examen de ese proceso, por breve que sea, revela una continua y apreciable concentración de la población latinoamericana en los últimos decenios. Sin embargo, antes de entrar más a fondo en este análisis, conviene formular dos comentarios breves sobre la metodología utilizada.

Primero, la definición de "urbano" utilizada en este análisis se basa exclusivamente en el tamaño de la población; es decir, se considera "urbana" la población que reside en centros de 20000 habitantes o más. Evidentemente también podrían calificarse de urbanas concentraciones menores si dispusiéramos de información que permitiera hacer una clasificación más discriminatoria de los núcleos de población, según su 
función económica, su composición ocupacional o sus características socioeconómicas. No disponiendo de ella, nos vemos obligados a adoptar este criterio operacional algo arbitrario, conscientes de las inevitables discrepancias a que da lugar su aplicación. Según este criterio, el resto de la población (es decir, la que no vive en centros de 20000 habitantes o más) se calificaría como "rural", más por conveniencia de expresión que por exactitud en su descripción.

Al utilizar el tamaño como criterio para definir la población "urbana", la medición de la dinámica urbana en un período cualquiera implica la inclusión progresiva de localidades que no se habían considerado a comienzos del período; es decir, el número de localidades de 20000 habitantes o más, es por lo general mayor al final que al comienzo del decenio, y la población urbana aumenta no sólo por el crecimiento de las ciudades que ya existían, sino por la reclasificación de zonas que antes no eran urbanas. Por lo tanto, en el análisis que sigue deberá tenerse en cuenta que, aproximadamente, la quinta parte de la totalidad del crecimiento urbano latinoamericano durante los dos decenios últimos se origina en la inclusión de nuevas ciudades en la categoría urbana. (Véase el cuadro 8.)

CUAdro 8. América Latina: resumen del crecimiento urbano y de la urbanización, 1950-1970

\begin{tabular}{ccccccc}
\hline Periodo & \multicolumn{2}{c}{ Tasas anuales medias de crecimiento } & & $\begin{array}{c}\text { Porcentaje de } \\
\text { crecimiento }\end{array}$ \\
\cline { 2 - 5 } & $\begin{array}{c}\text { Población } \\
\text { total }\end{array}$ & $\begin{array}{c}\text { Población } \\
\text { rural }\end{array}$ & $\begin{array}{c}\text { Población } \\
\text { urbana }\end{array}$ & $\begin{array}{c}\text { Tasas } \\
\text { de urba- } \\
\text { nización }\end{array}$ & $\begin{array}{c}\text { urbano por in- } \\
\text { clusión de nue- } \\
\text { vas ciudades }\end{array}$ \\
\hline $1950-1960$ & 2.8 & 5.4 & 1.8 & 2.5 & 19.0 \\
$1960-1970$ & 2.9 & 5.2 & 1.5 & 2.2 & 17.9 \\
\hline
\end{tabular}

Fueartes: Para la población total, celade, Boletín Demográfico, núm. 10, 1972. Para la población rural y urbana, estimaciones de la cePAr.

Segundo, para mayor claridad tanto en la investigación de las tendencias como en el examen de sus repercusiones, es indispensable tener presente la distinción entre dos manifestaciones secundarias básicas del proceso de urbanización: el crecimiento urbano y la urbanización misma. En efecto, si se considerara exclusivamente la "urbanización", definida como un incremento de la proporción de la población total que vive en zonas urbanas, bien podría llegarse a la conclusión de que las tendencias recientes en América Latina no difieren mucho de las anteriores. Por ejemplo, se estima que en los dos decenios considerados la tasa de urbanización - es decir, el ritmo de aumento de la proporción de la población total que vive en centros de 20000 o más habitante- de toda la región fue de 2.5 entre 1950 y 1960 y de 2.2 entre 1960 y 1970. (Véase de nuevo el cuadro 8.) Estas tasas son en realidad muy inferiores 
a las registradas en las regiones desarrolladas durante los períodos de máxima urbanización.

Un examen más detenido de los patrones actuales y anteriores de crecimiento y redistribución de la población indica que las tasas de urbanización de América Latina no son en realidad más elevadas simplemente porque la alta tasa de crecimiento de la población urbana está siendo compensada por la elevada tasa de crecimiento de la población rural. Como la población rural sigue abarcando mucho más de la mitad de la población total de la región, las tasas de urbanización de América Latina no son indicación clara de un auge inmediato y sin precedentes del crecimiento urbano. Además, teniendo presente que la urbanización es un proceso inherentemente finito, no es de extrañar que la tasa de urbanización de 2.2 anual observada entre 1960-1970 sea algo inferior a la del decenio anterior, ni tampoco que la tasa de crecimiento de la población total en el decenio 1950-1960 haya sido más alta que la del precedente, pese a la leve declinación de las tasas de crecimiento de la población urbana y rural.

Por consiguiente, sólo cuando se examina el "crecimiento urbano" -es decir, el aumento del número de personas que residen en localidades urbanas- puede apreciarse si América Latina ha experimentado una transformación urbana excepcional. Las tasas anuales de crecimiento urbano, que actualmente fluctúan en tomo al $5 \%$, implicarían que la población urbana de la región se está duplicando en menos de 15 años; en algunos países, tasas más altas significan que se dobla cada 10 años. Estas mismas tasas también se dieron en los países desarrollados, pero eso ocurrió cuando habían alcanzado una etapa más avanzada de desarrollo socioeconómico. Es más, tasas de ese orden de magnitud se dieron en los países desarrollados como consecuencia de la rápida disminución de la población rural, en tanto que la población rural de América Latina continúa creciendo en términos absolutos en casi todos los países.

Según nuestras estimaciones, la población urbana creció en 28 millones en el decenio de 1950 y en unos 45 millones en el de 1960. (Véase el cuadro 9.) Mientras tanto, la población rural sólo creció en alrededor de 22 millones en cada uno de esos decenios. Esto quiere decir que los centros urbanos habrían absorbido una cifra equivalente al $55 \%$ del crecimiento demográfico total de América Latina en el primer decenio y al $67 \%$ en el segundo. El aumento de la población urbana es apreciable en todos los países, pero especialmente importante en los países más grandes. En general, la proporción de la población total de la región que vive en zonas urbanas subió de alrededor de $26 \%$ en 1950 a $33 \%$ en 1960 y a $41 \%$ en 1970 .

Es indudable que estos patrones de crecimiento urbano están modificando la estructura de la red urbana latinoamericana. Se explica así el significativo aumento en el número de ciudades: de 320 en 1950 a 516 en 1960 y a 828 en 1970 . Como era de esperar, aumentó más el número de los núcleos urbanos más pequeños, que pasaron de 201 
Cusdro 9. América Latina: población total, urbana y rural, 1950, 1960 y 1970

\begin{tabular}{|c|c|c|c|c|c|c|c|c|c|c|c|c|c|c|c|}
\hline \multirow{3}{*}{ País } & \multicolumn{5}{|c|}{1950} & \multicolumn{5}{|c|}{1960} & \multicolumn{5}{|c|}{1970} \\
\hline & \multirow[b]{2}{*}{$\begin{array}{c}\text { Total } \\
\text { (en } \\
\text { miles) }\end{array}$} & \multicolumn{2}{|c|}{ Urbana } & \multicolumn{2}{|c|}{ Rural } & \multirow[b]{2}{*}{$\begin{array}{l}\text { Total } \\
\text { (en } \\
\text { miles) }\end{array}$} & \multicolumn{2}{|c|}{ Urbana } & \multicolumn{2}{|c|}{ Rural } & \multirow[b]{2}{*}{$\begin{array}{c}\text { Total } \\
\text { (en } \\
\text { miles) }\end{array}$} & \multicolumn{2}{|c|}{ Urbana } & \multicolumn{2}{|c|}{ Rural } \\
\hline & & Miles & $\begin{array}{l}\text { Por- } \\
\text { cen- } \\
\text { taje }\end{array}$ & Miles & $\begin{array}{l}\text { Por- } \\
\text { cen- } \\
\text { taje }\end{array}$ & & Miles & $\begin{array}{l}\text { Por- } \\
\text { cen- } \\
\text { taje }\end{array}$ & Miles & $\begin{array}{l}\text { Por- } \\
\text { cen- } \\
\text { taje }\end{array}$ & & Miles & $\begin{array}{l}\text { Por- } \\
\text { cen- } \\
\text { taje }\end{array}$ & Miles & $\begin{array}{l}\text { Por } \\
\text { cen- } \\
\text { taje }\end{array}$ \\
\hline $\begin{array}{l}\text { Argentina } \\
\text { Bolivia } \\
\text { Brasil } \\
\text { Colombia } \\
\text { Costa Rica } \\
\text { Cuba } \\
\text { Chile } \\
\text { Ecuador } \\
\text { El Salvador } \\
\text { Guatemala } \\
\text { Haití } \\
\text { Honduras } \\
\text { Mexico } \\
\text { Nicaragua } \\
\text { Panamá } \\
\text { Paraguay } \\
\text { Perú } \\
\text { República Dominicana } \\
\text { Uruguay } \\
\text { Venezuela }\end{array}$ & $\begin{array}{r}17085 \\
3013 \\
52326 \\
11629 \\
849 \\
5520 \\
6058 \\
3225 \\
1922 \\
3024 \\
3380 \\
1389 \\
26640 \\
1133 \\
765 \\
1337 \\
7968 \\
2303 \\
2198 \\
5330\end{array}$ & $\begin{array}{r}8834 \\
593 \\
10954 \\
2438 \\
180 \\
1954 \\
2342 \\
570 \\
240 \\
312 \\
159 \\
94 \\
6638 \\
161 \\
180 \\
207 \\
1448 \\
238 \\
1000 \\
1645\end{array}$ & $\begin{array}{r}51.7 \\
19.7 \\
20.9 \\
21.0 \\
21.2 \\
35.4 \\
38.7 \\
17.7 \\
12.5 \\
10.3 \\
4.7 \\
6.8 \\
24.9 \\
14.2 \\
23.5 \\
15.5 \\
18.2 \\
10.3 \\
45.5 \\
30.9\end{array}$ & $\begin{array}{r}8251 \\
2420 \\
41372 \\
9191 \\
669 \\
3566 \\
3716 \\
2655 \\
1682 \\
2712 \\
3221 \\
1295 \\
20002 \\
972 \\
585 \\
1130 \\
6520 \\
2065 \\
1198 \\
3685\end{array}$ & $\begin{array}{l}48.3 \\
80.3 \\
79.1 \\
79.0 \\
78.8 \\
64.6 \\
61.3 \\
82.3 \\
87.5 \\
89.7 \\
95.3 \\
93.2 \\
75.1 \\
85.8 \\
76.5 \\
84.5 \\
81.8 \\
89.7 \\
54.5 \\
69.1\end{array}$ & $\begin{array}{r}20850 \\
3696 \\
70327 \\
15877 \\
1249 \\
6819 \\
7683 \\
4323 \\
2512 \\
3965 \\
4138 \\
1849 \\
36046 \\
1501 \\
1021 \\
1740 \\
10024 \\
3129 \\
2542 \\
7741\end{array}$ & $\begin{array}{r}11987 \\
759 \\
20413 \\
4760 \\
278 \\
2828 \\
3842 \\
1103 \\
426 \\
524 \\
250 \\
203 \\
11646 \\
283 \\
356 \\
289 \\
2609 \\
569 \\
1436 \\
3282\end{array}$ & $\begin{array}{r}57.5 \\
20.5 \\
29.0 \\
30.0 \\
22.3 \\
41.5 \\
50.0 \\
25.5 \\
17.0 \\
13.2 \\
6.0 \\
11.0 \\
32.3 \\
18.8 \\
34.9 \\
16.6 \\
26.0 \\
18.2 \\
56.5 \\
42.4\end{array}$ & $\begin{array}{r}8863 \\
2937 \\
49914 \\
11117 \\
971 \\
3991 \\
3841 \\
3220 \\
2086 \\
3441 \\
3888 \\
1646 \\
24400 \\
1218 \\
665 \\
1451 \\
7415 \\
2560 \\
1106 \\
4459\end{array}$ & $\begin{array}{l}42.5 \\
79.5 \\
71.0 \\
70.0 \\
77.7 \\
58.5 \\
50.0 \\
74.5 \\
83.0 \\
86.8 \\
94.0 \\
89.0 \\
67.7 \\
81.2 \\
65.1 \\
83.4 \\
74.0 \\
81.8 \\
43.5 \\
57.6\end{array}$ & $\begin{array}{r}24352 \\
4658 \\
93245 \\
22160 \\
1736 \\
8341 \\
9717 \\
6028 \\
3441 \\
5282 \\
5229 \\
2583 \\
50718 \\
2021 \\
1406 \\
2419 \\
13586 \\
4348 \\
2889 \\
10755\end{array}$ & $\begin{array}{r}15776 \\
1086 \\
36687 \\
9520 \\
560 \\
3962 \\
5303 \\
1986 \\
635 \\
937 \\
362 \\
397 \\
20565 \\
498 \\
546 \\
506 \\
4418 \\
1202 \\
2026 \\
5989\end{array}$ & $\begin{array}{r}64.8 \\
23.3 \\
39.3 \\
43.0 \\
32.3 \\
47.5 \\
54.6 \\
32.9 \\
18.4 \\
17.7 \\
6.9 \\
15.4 \\
40.5 \\
24.6 \\
38.8 \\
20.9 \\
32.5 \\
27.6 \\
70.1 \\
55.7\end{array}$ & $\begin{array}{r}8576 \\
3572 \\
56558 \\
12640 \\
1176 \\
4379 \\
4414 \\
4042 \\
2806 \\
4345 \\
4867 \\
2186 \\
30153 \\
1523 \\
860 \\
1913 \\
9168 \\
3146 \\
863 \\
4766\end{array}$ & $\begin{array}{l}35.2 \\
76.7 \\
60.7 \\
57.0 \\
67.7 \\
52.5 \\
45.4 \\
67.1 \\
81.6 \\
82.3 \\
93.1 \\
84.6 \\
59.5 \\
75.4 \\
61.2 \\
79.1 \\
67.5 \\
72.4 \\
29.9 \\
44.3\end{array}$ \\
\hline Total América Latina & 157094 & 40187 & 25.6 & 116907 & 74.4 & 207032 & 67843 & 32.8 & 139189 & 67.2 & 274914 & 112961 & 41.1 & 161953 & 58.9 \\
\hline
\end{tabular}

Furart: Véase el cuadro 8. 
Cuadro 10. América Latina: (veinte países) número de ciudades y distribución de la población urbana según el tamaño de la ciudad, 1950-1970

\begin{tabular}{|c|c|c|c|c|c|c|c|c|c|c|c|c|c|}
\hline \multirow[t]{2}{*}{$\begin{array}{c}\text { Tamafío de la } \\
\text { ciudad }\end{array}$} & \multicolumn{3}{|c|}{ Número de ciudades } & \multicolumn{3}{|c|}{$\begin{array}{c}\text { Población urbana } \\
\text { (en miles) }\end{array}$} & \multicolumn{3}{|c|}{$\begin{array}{c}\text { Población urbana en } \\
\text { cada categoría } \\
\text { (porcentaje) }\end{array}$} & \multirow[t]{2}{*}{ - } & \multicolumn{3}{|c|}{$\begin{array}{c}\text { Población total en } \\
\text { cada categoría } \\
\text { (porcentaje) }\end{array}$} \\
\hline & 1950 & 1960 & 1970 & 1950 & 1960 & 1970 & 1950 & 1960 & 1970 & & 1950 & 1960 & 1970 \\
\hline $\begin{array}{l}1 \text { millón y más } \\
500000-1 \text { millón } \\
100000-500000 \\
50000-100000 \\
20000-50000\end{array}$ & $\begin{array}{r}7 \\
5 \\
49 \\
58 \\
201\end{array}$ & $\begin{array}{r}11 \\
8 \\
73 \\
105 \\
319\end{array}$ & $\begin{array}{r}16 \\
17 \\
115 \\
169 \\
511\end{array}$ & $\begin{array}{r}16353 \\
3336 \\
10432 \\
3922 \\
6143\end{array}$ & $\begin{array}{r}29789 \\
5385 \\
15650 \\
7133 \\
9888\end{array}$ & $\begin{array}{l}51759 \\
11598 \\
22416 \\
11756 \\
15432\end{array}$ & $\begin{array}{r}40.7 \\
8.3 \\
26.0 \\
9.8 \\
15.3\end{array}$ & $\begin{array}{r}43.9 \\
7.9 \\
23.1 \\
10.5 \\
14.6\end{array}$ & $\begin{array}{l}45.8 \\
10.3 \\
19.8 \\
10.4 \\
13.7\end{array}$ & & $\begin{array}{r}10.4 \\
2.1 \\
6.6 \\
2.5 \\
3.9\end{array}$ & $\begin{array}{r}14.4 \\
2.6 \\
7.6 \\
3.4 \\
4.8\end{array}$ & $\begin{array}{r}18.8 \\
4.2 \\
8.2 \\
4.3 \\
5.6\end{array}$ \\
\hline Total & 320 & 516 & 828 & 40186 & 67845 & 112961 & 100.0 & 100.0 & 100.0 & & 25.6 & 32.8 & 41.1 \\
\hline
\end{tabular}

Fuente: Véase el cuadro 8. 
Cunaro 11. Resumen de la urbanización y el crecimiento urbano en tres grupos de países latinodmericanos, 1960-1970

\begin{tabular}{|c|c|c|c|c|c|}
\hline \multirow[t]{2}{*}{ País } & \multicolumn{3}{|c|}{ Tasa anual media de crecimiento } & \multirow[b]{2}{*}{$\begin{array}{l}\text { Tasa de ur- } \\
\text { banización }\end{array}$} & \multirow{2}{*}{$\begin{array}{l}\text { Porcentaje } \\
\text { del creci- } \\
\text { miento de- } \\
\text { mográfico } \\
\text { decenal ab- } \\
\text { sarbido por } \\
\text { las ciudades }\end{array}$} \\
\hline & $\begin{array}{c}\text { Población } \\
\text { total }\end{array}$ & $\begin{array}{l}\text { Población } \\
\text { rural }\end{array}$ & $\begin{array}{c}\text { Población } \\
\text { urbana }\end{array}$ & & \\
\hline Grupo I a & 1.8 & 0.2 & 3.0 & 1.2 & 94.2 \\
\hline Grupo II b & 3.1 & 1.5 & 6.1 & 2.9 & 69.4 \\
\hline Grupo III c & 3.0 & 2.3 & 5.5 & 2.4 & 39.4 \\
\hline Total & 2.9 & 1.5 & 5.2 & $\cdot 2.2$ & 66.5 \\
\hline
\end{tabular}

Fuente: Véase el cuadro 8.

a Argentina, Cuba, Chile, Uruguay.

b Brasil, Colombia, Costa Rica, México, Panamá y Venezuela.

c Bolivia, Ecuador, El Salvador, Guatemala, Haití, Honduras, Nicaragua, Paraguay, Pera y República Dominicana.

en 1950, a 319 en 1960 y a 511 en 1970. Pero la expansión urbana se manifesto asimismo en la proliferación de ciudades grandes, ya que el número de localidades de 500000 o más habitantes aumentó de 12 a 33 entre 1950 y 1970 , en tanto que el número de metrópolis de más de un millón de habitantes aumentó de 7 a 16 durante el mismo período.

A este respecto, una de las características más destacadas del proceso de urbanización latinoamericano es que a pesar de haberse multiplicado el número de ciudades, la población urbana se concentra cada vez más en los centros más grandes. Al examinar (cuadro 10) la distribución de la población en categorías establecidas según el tamaño de las ciudades, se comprueba que una proporción creciente de la población urbana y total de América Latina se está concentrando en las grandes ciudades. En 1950, alrededor del $49 \%$ de la población urbana y del $13 \%$ de la población total de América Latina vivía en ciudades de 500000 o más habitantes. En 1960 estas cifras habían llegado al 52 y al $17 \%$ respectivamente, y en 1970 , el $56 \%$ de los residentes urbanos y el $23 \%$ de todos los latinoamericanos vivían en ciudades grandes. Además, en esas mismas fechas la mayoría de los residentes de ciudades grandes vivían en ciudades de más de un millón de habitantes. Sin embargo, aunque esta información no aparece aquí, vale la pena señalar que el grado de primacía, medido por la proporción de la población urbana de un país que vive en su centro principal, ha bajado sostenidamente en la region en los últimos decenios, en gran medida por efecto de la proliferación y el crecimiento dinámico de grandes centros en algunos de los países más populosos. 
Cuadro 12. Número de ciudades y distribución de la población urbana según el tamaño de las ciudades en tres grupos de países latinoamericanos, 1960-1970

\begin{tabular}{|c|c|c|c|c|c|c|c|c|}
\hline \multirow[t]{2}{*}{$\begin{array}{c}\text { Paises y categorías } \\
\text { de ciudades }\end{array}$} & \multicolumn{2}{|c|}{$\begin{array}{l}\text { Número de } \\
\text { ciudades }\end{array}$} & \multicolumn{2}{|c|}{$\begin{array}{c}\text { Total de la } \\
\text { población } \\
\text { urbana } \\
\text { (en miles) }\end{array}$} & \multicolumn{2}{|c|}{$\begin{array}{l}\text { Población } \\
\text { urbana en } \\
\text { cada catego- } \\
\text { ría (porcen- } \\
\text { taje) }\end{array}$} & \multicolumn{2}{|c|}{$\begin{array}{l}\text { Población } \\
\text { total en } \\
\text { cada catego- } \\
\text { ría (porcen- } \\
\text { taje) }\end{array}$} \\
\hline & 1960 & 1970 & 1960 & 1970 & 1960 & 1970 & 1960 & 1970 \\
\hline $\begin{array}{l}\text { Srupo I a } \\
1 \text { millón y más } \\
500000-1 \text { millón } \\
100000-500000 \\
50000-100000 \\
20000-50000\end{array}$ & $\begin{array}{r}4 \\
2 \\
15 \\
22 \\
84\end{array}$ & $\begin{array}{r}4 \\
3 \\
19 \\
36 \\
126\end{array}$ & $\begin{array}{r}11423 \\
1 \\
3261 \\
3422 \\
1340 \\
2647\end{array}$ & $\begin{array}{r}14619 \\
2116 \\
4188 \\
2510 \\
3634\end{array}$ & $\begin{array}{r}30.1 \\
3.3 \\
9.0 \\
3.5 \\
7.0\end{array}$ & $\begin{array}{r}32.3 \\
4.7 \\
9.2 \\
5.5 \\
8.0\end{array}$ & $\begin{array}{r}56.8 \\
6.3 \\
17.0 \\
6.7 \\
13.2\end{array}$ & $\begin{array}{r}54.0 \\
7.8 \\
15.5 \\
9.3 \\
13.4\end{array}$ \\
\hline Total urbano & 127 & 188 & 20093 & 27067 & 53.0 & 59.7 & 100.0 & 100.0 \\
\hline $\begin{array}{l}\text { Grupo II b } \\
1 \text { millon y más } \\
500000-1 \text { millón } \\
100000-500000 \\
50000-100000 \\
20000-50000\end{array}$ & $\begin{array}{r}6 \\
6 \\
47 \\
68 \\
194\end{array}$ & $\begin{array}{r}11 \\
9 \\
83 \\
113 \\
327\end{array}$ & $\begin{array}{r}16675 \\
4124 \\
9064 \\
4727 \\
6145\end{array}$ & $\begin{array}{r}34326 \\
6177 \\
15508 \\
7863 \\
9993\end{array}$ & $\begin{array}{r}12.6 \\
3.1 \\
6.8 \\
3.6 \\
4.7\end{array}$ & $\begin{array}{r}19.1 \\
3.4 \\
8.6 \\
4.4 \\
5.5\end{array}$ & $\begin{array}{l}40.9 \\
10.1 \\
22.2 \\
11.6 \\
15.1\end{array}$ & $\begin{array}{r}46.5 \\
8.4 \\
21.0 \\
10.6 \\
13.5\end{array}$ \\
\hline Total urbano & 321 & 543 & 40735 & 73867 & 30.8 & 41.0 & 100.0 & 100.0 \\
\hline $\begin{array}{l}\text { Grupo III c } \\
1 \text { millón y más } \\
500000-1 \text { millón } \\
100000-500000 \\
50000-100000 \\
20000-50000\end{array}$ & $\begin{array}{l}\frac{1}{11} \\
15 \\
41\end{array}$ & $\begin{array}{r}1 \\
5 \\
13 \\
20 \\
58\end{array}$ & $\begin{array}{l}1691 \\
31 \overline{164} \\
1064 \\
1096\end{array}$ & $\begin{array}{l}2815 \\
3305 \\
2719 \\
1383 \\
1805\end{array}$ & $\begin{array}{l}4.6 \\
8.6 \\
2.9 \\
3.0\end{array}$ & $\begin{array}{l}5.7 \\
6.7 \\
5.5 \\
2.8 \\
3.6\end{array}$ & $\begin{array}{l}24.1 \\
45.1 \\
15.2 \\
15.6\end{array}$ & $\begin{array}{l}23.4 \\
27.5 \\
22.6 \\
11.5 \\
15.0\end{array}$ \\
\hline Total urbano & 68 & 97 & 7015 & 12027 & 19.0 & 24.3 & 100.0 & 100.0 \\
\hline $\begin{array}{l}\text { Total de América Lat } \\
1 \text { millón y más } \\
500000-1 \text { millón } \\
100000-500000 \\
50000-100000 \\
20000-50000\end{array}$ & $\begin{array}{r}11 \\
8 \\
73 \\
105 \\
319\end{array}$ & $\begin{array}{r}16 \\
17 \\
115 \\
169 \\
511\end{array}$ & $\begin{array}{r}29789 \\
5385 \\
15650 \\
7131 \\
9888\end{array}$ & $\begin{array}{l}51760 \\
11598 \\
22415 \\
11756 \\
15432\end{array}$ & $\begin{array}{r}14.4 \\
2.6 \\
7.6 \\
3.4 \\
4.8\end{array}$ & $\begin{array}{r}18.8 \\
4.2 \\
8.2 \\
4.3 \\
5.6\end{array}$ & $\begin{array}{r}43.9 \\
7.9 \\
23.1 \\
10.5 \\
14.6\end{array}$ & $\begin{array}{l}45.8 \\
10.3 \\
19.8 \\
10.4 \\
13.7\end{array}$ \\
\hline Total urbano & 516 & 828 & 67843 & 112961 & 32.8 & 41.1 & 100.0 & 100.0 \\
\hline
\end{tabular}

Funerte: Véase el cuadro 8.

Argentina, Cuba, Chile, Uruguay.

b Brasil, Colombia, Costa Rica, México, Panamá, Venezuela.

c. Bolivia, Ecuador, El Salvador, Guatemala, Haitú, Honduras, Nicaragua, Paraguay, Perá, República Dominicana. 
Nuevamente, se observa que las tendencias generales descritas en el párrafo anterior no revelan de inmediato la gran heterogeneidad del proceso de urbanización de los países que forman la región. Con el objeto de resumir las diversas situaciones, los países cuyos procesos de urbanización tienen características similares pueden clasificarse en tres categorías generales. Las cifras y las características de cada grupo, que se resumen en los cuadros 11 y 12 y que se describen a continuación, dan un resumen valedero para el grupo, aunque cada país individualmente puede variar con respecto al promedio del grupo.

La primera categoría incluye los países que se urbanizaron primero, es decir, aquellos en que, ya en 1950, más de la tercera parte de la población residía en localidades de 20000 o más habitantes. Estos eran Argentina, Cuba, Chile y Uruguay. En 1960, $55 \%$ de la población de esos países residía en zonas urbanas correspondiendo a la Argentina el más elevado porcentaje, seguida por Uruguay, Chile y Cuba, en ese mismo orden. Si se considera que el grado de urbanización inicial era muy elevado en este grupo y que el proceso de urbanización es finito no es sorprendente que el aumento de la urbanización registrado entre 1960 y 1970 fuera relativamente pequeño, llegando a un nivel de $60 \%$ en 1970. Entretanto, la población urbana creció alrededor de $3 \%$ anualmente, es decir, a una tasa equivalente a casi la mitad de la que registraron los otros dos grupos. Sin embargo, la población rural también creció a una tasa muy inferior a la de los demás grupos. Es en realidad muy significativo que la población rural disminuyera en números absolutos en el decenio pasado en Argentina y Uruguay. De este modo, para el grupo en su conjunto, las zonas urbanas absorbieron un número de personas igual a $94 \%$ del crecimiento demográfico total durante el período.

Una de las características destacadas de este grupo de países es el elevado grado de concentración urbana que ya había alcanzado en 1960 . En el conjunto del grupo la proporción de la población urbana residente en ciudades de medio millón de habitantes o más era cercana. al $57 \%$ en 1960, y si bien esta proporción disminuyó algo en 1970 con el aumento del número total de localidades urbanas de 127 a una cifra estimada en 188, seguía siendo muy superior a la registrada en los otros dos grupos en 1970.

Además, la proporción de la población total concentrada en ciudades de medio millón de habitantes o más experimentó un aumento importante en el Uruguay y menor en los otros tres países.

No obstante, es digno de mencionar que, con excepción de la Argentina, los demás países del grupo no tenían ciudades de 500000 a un millón de habitantes en 1960 ó 1970, es decir, no había en ellos ciudades intermedias entre la capital y el grueso de las ciudades que forman la red urbana. Por lo tanto, pese a que esos países habían alcanzado una etapa relativamente avanzada de desarrollo socioeconómico, y a que la proporción de la población urbana concentrada en la ciudad principal tendió a decrecer en el período, el fenómeno de la primacía sigue 
siendo muy pronunciado en la mayoría de ellos, puesto que continúa en estado embrionario la red de grandes núcleos secundarios que algunos consideran esencial para un desarrollo económico equilibrado.

El segundo grupo está formado por los países que se encuentran en una etapa intermedia de urbanización. Para fines prácticos se definen como aquellos cuya población urbana representaba entre la quinta y la tercera parte de su población total en 1950. Pertenecen a este grupo Brasil, Colombia, Costa Rica, México, Panamá y Venezuela, países en los cuales se ha acelerado recientemente el proceso de urbanización. En 1960, alrededor del $31 \%$ de la población total de los países incluidos en esta categoría residía en centros de 20000 habitantes o más, pero diez años más tarde esta proporción ha subido a más de las dos quintas partes del total. La población urbana creció a una tasa medía anual superior al $6 \%$ durante el decenio, en tanto que la población rural crecía a una tasa de $1.5 \%$, lo que da una tasa media anual de urbanización de $2.9 \%$, superior a la de cualquiera de los tres grupos examinados en este trabajo. A consecuencia de ello, las zonas urbanas absorbieron alrededor de 33 millones de personas durante el intervalo, cifra equivalente a casi el $70 \%$ del crecimiento demográfico total del grupo en el decenio.

El número de ciudades en esos seis países aumentó de 321 a 543 en el decenio. Sin embargo, es interesante señalar que si bien la gran mayoría de las nuevas localidades continuaban perteneciendo a la categoría de ciudades pequeñas en 1970, la concentración de la población urbana en las grandes ciudades de esos países es, en conjunto, mucho mayor que a comienzos del período. Se observa así que la proporción de la población urbana que vive en ciudades de un millón de habitantes o más creció de 41 a $46.5 \%$. Mientras tanto, la proporción de la población total que vive en ciudades de ese tamaño subió de $13 \%$ en 1960 a $19 \%$ en 1970, lo que comprueba el elevado ritmo a que están creciendo los centros metropolitanos. Con todo, cabe señalar que en Brasil, Colombia y Venezuela el número de ciudades de más de 500000 habitantes aumentó en el decenio, y en consecuencia puede afirmarse que por lo menos en esos países -y sobre todo en el Brasil- la concentración urbana obedece más bien a que importantes subnúcleos cambian de categoría según tamaño, que a un crecimiento sin paralelo de la ciudad principal.

El tercer grupo, formado por Bolivia, Ecuador, El Salvador, Guatemala, Haití, Honduras, Nicaragua, Paraguay, Perú y la República Dominicana, incluye los países que se caracterizan por estar en una etapa incipiente del proceso de urbanización ya que en 1950 en todos ellos menos de la quinta parte de su población total residía en zonas urbanas, y algunos sblo llegaron a esa cifra en 1970. Entre 1960 y 1970 la tasa media de crecimiento urbano del grupo llegó a $5.5 \%$ anual, pero como la población rural también creció a más de $2 \%$ anualmente, la tasa de urbanización fue sólo de $2.4 \%$ al año. Como resultado de esas tendencias el nivel de urbanización, es decir, la proporción de la 
población total que vive en zonas urbanas, aún no había llegado al $25 \%$ en 1970, y sólo dos países, Ecuador y Perú, habían superado esa cifra por amplio margen. Es más, el grado de urbanización de algunos países -en particular Bolivia, El Salvador y Haití- casi no sufrió modificaciones en el decenio.

La lenta urbanización se manifiesta asimismo en la proporción del aumento decenal de la población absorbido por las ciudades. A este respecto, es interesante señalar que mientras las ciudades del primer grupo de países absorbieron aproximadamente $95 \%$ del crecimiento demográfico total en el decenio y las del segundo grupo el equivalente a casi el $70 \%$ del crecimiento total, las del tercero sólo absorbieron una cifra equivalente a más o menos $39 \%$ de ese incremento.

No obstante, el número de localidades urbanas en el tercer grupo aumentó de 68 a 97 y el número de ciudades con más de 500000 habitantes, de 1 a 6 . La concentración de la población urbana en la ciudad principal siempre ha sido muy elevada en este grupo de países, y en 1960, solamente Ecuador, que tiene dos polos de concentración, tenía menos del $50 \%$ de la población urbana concentrada en una ciudad. Sin embargo, y como consecuencia del importante aumento en el número de ciudades, la marcada primacía de una ciudad sobre las demás que se observa en la mayoría de esos países tendib a disminuir durante el decenio, si bien se mantuvo a un nivel excepcionalmente elevado.

En suma, aunque el ritmo de urbanización de América Latina no es excepcional, el crecimiento urbano es mucho más rápido que el registrado en los paises desarrollados en la etapa más intensa de su urbanización. Además, las características y el ritmo de la urbanización son diferentes en los tres grupos principales de países. Basta un análisis somero para mostrar que esos tres grupos difieren fundamentalmente en cuanto a su grado de desarrollo socioeconómico, lo que hace aún más digna de crédito la correlación entre éste y la urbanización.

En general, las tendencias antes examinadas no causan gran extrañeza al investigador familiarizado con la historia de la urbanización latinoamericana. Quizá se hayan atenuado o acentuado algunas modalidades particulares en un grupo dado de países y no se hayan explicado los pormenores del proceso, pero en general se confirman los diagnósticos y las tendencias bosquejados durante el decenio de 1950. En esa época se levantó un gran clamor público, haciendo ver los estragos que el aumento anual de cientos de miles de nuevos residentes urbanos causaría en la estructura de las ciudades y en la sociedad latinoamericana, hasta el extremo de poner en peligro la viabilidad de los sistemas políticoeconómicos nacionales.

En la práctica, la explosión urbana ha proseguido en general el ritmo previsto, pero de algún modo no ha tenido los efectos catastróficos o catalíticos que se esperaban. Los asentamientos marginales hạn surgido y se han multiplicado en todas las grandes ciudades latinoamericanas, en tanto que ha disminuido progresivamente la capacidad de las autoridades públicas para resolver los múltiples problemas ocasionados por 
la rápida expansión urbana. Sin embargo, el sistema de alguna manera sigue funcionando, y aunque las masas no estén exactamente integradas en la sociedad urbana, hasta ahora no se han transformado en una fuerza opositora capaz de desquiciar la organización societal vigente.

La explicación de por qué la situación real ante la explosión urbana no coincide con la prevista rebasa en parte los alcances del presente análisis, al menos en lo que atañe a las discrepancias que surgen cuando se confunde la existencia de las masas con su capacidad para actuar en forma concertada. Sin embargo, desde un ángulo demográfico vale la pena mencionar dos aspectos.

Primero, salta a la vista que el crecimiento de la población urbana supera en todos los países las oportunidades de empleo en actividades productivas en las ciudades. Esta situación favorece la mantención de industrias de baja productividad, y contribuye a mantener los salarios urbanos en un bajo nivel, a intensificar la escasez de viviendas y los problemas de transporte, y a incapacitar a las autoridades para suministrar servicios básicos de educación y salud. Sin embargo, salta igualmente a la vista que el problema del empleo quizá sea aún peor en las zonas rurales y que, a pesar de sus vicisitudes, la vida urbana permite obtener ingresos monetarios muy superiores a los de las zonas rurales, tener acceso a otros beneficios como la educación gratuita, y los servicios de salud, agua potable, alcantarillado y otros, que si bien no llegan a toda la población urbana, alcanzan a una proporción aún menor de la población rural; adentás, el hecho de residir en la ciudad permite participar al menos parcialmente en la sociedad de consumo y en los agrados de la vida urbana. En resumen, ya sea que se considere el asunto desde un punto de vista objetivo o subjetivo, el habitat urbano puede significar un considerable mejoramiento en muchos aspectos con respecto al rural, y, por lo tanto, a corto plazo, la vida urbana no lleva necesariamente al rechazo del sistema.

Segundo, los efectos desintegradores del rápido crecimiento urbano pueden estar muy lejanos todavía si se considera que ese crecimiento es acumulativo y sigue una progresión geométrica. Por ejemplo, a pesar del rápido ritmo de urbanización en períodos anteriores, el volumen de crecimiento urbano en el decenio de 1960 superaba en $65 \%$ al correspondiente al de 1950; es decir, el crecimiento de la poblacion urbana durante este decenio superó en 18 millones al del decenio anterior. Se espera que en el decenio de 1970 la población urbana de América Latina crezca en alrededor de 75 millones de personas, cifra superior a la población total del Brasil de 1960, y que el incremento sea mucho mayor aún en el decenio de 1980. Dados estos antecedentes, y si persisten las tendencias actuales, las metrópolis existentes tendrán que soportar gran parte del peso del crecimiento urbano; se prevé que del incremento de 75 millones de habitantes que se producirá en el decenio de 1970, alrededor de 40 millones serán absorbidos por ciudades que tendrán más de un millón de habitantes en 1980.

Dado que el crecimiento urbano sigue una progresión geométrica, su creciente concentración en centros grandes y el hecho de que el sector 
público sea cada vez más incapaz de resolver los múltiples problemas de la rápida expansión de las áreas urbanas, parecería razonable pensar que pasado cierto límite las ciudades no pueden continuar creciendo si han de seguir siendo viables. En todo caso, como prácticamente todos los países incluidos en los grupos dos y tres tienen ya una población rural mucho más grande que la que necesitarían si aplicaran un mínimo de la tecnología agrícola existente, y dadas las altas tasas de crecimiento natural vigentes, resulta obvio que la red urbana tendrá que absorber de una u otra manera un número cada vez mayor de personas. Dado que el crecimiento urbano va a continuar inevitablemente parece que sería urgente encauzarlo a fin de prevenir la concentración excesiva de la población en las ciudades más grandes, mediante la aplicación de medidas estructurales e institucionales que lo frenen, reforzadas con mecanismos de mercado.

No habiendo razones empíricas para dudar que las tasas de crecimiento natural de las zonas rurales de América Latina son iguales o superiores a las de las zonas urbanas, es evidente que las tendencias de urbanización descritas en la sección anterior suponen una enorme corriente migratoria de las zonas rurales a las urbanas. Si bien hay importantes variaciones entre un país y otro en torno al promedio de la región, puede estimarse que aproximadamente la mitad del incremento natural de las zonas rurales se transfiere sistemáticamente a las zonas urbanas, dando origen directamente de este modo a entre la mitad y un tercio del crecimiento urbano total. Además, como las corrientes migratorias se componen predominantemente de adultos jóvenes que viven en la ciudad durante la mayor parte de su vida fértil, la contribución indirecta de los migrantes al crecimiento urbano (es decir, el incremento natural de los migrantes después de su llegada) explica asimismo una proporción importante del crecimiento urbano total.

Además de las corrientes migratorias que se originan en las zonas rurales y tienen como destino las ciudades, se han observado en América Latina otros varios tipos de corrientes migratorias, especialmente entre las zonas rurales, entre las zonas urbanas, y entre zonas político-administrativas distintas. En conjunto, estos diversos tipos de movimientos de población representan un considerable volumen de migración que tiene importantes repercusiones tanto para las estructuras demográficas y socioeconómicas de las zonas de origen y de destino como para los migrantes mismos. En el capítulo $\mathrm{v}$ se hace referencia más detenida a las modalidades de migración, las características de las corrientes migratorias y las consecuencias de la migración tanto para las zonas receptoras como para los propios migrantes.

\section{REPERCUSTONES ECONÓMTCAS DE LA ESTRUCTURA DE LA POBLACTÓN}

La relación entre las tendencias demográficas y el proceso de desarrollo es, sin lugar a duda, la cuestión más importante que aquí se examina, pero lamentablemente es también materia en que resulta muy 
difícil formular observaciones válidas y significativas por la insuficiencia de información y por la inexistencia de un marco tebrico aceptable que incluya la mayor parte de los aspectos pertinentes. Casi todas las generalizaciones sobre las relaciones recíprocas entre los cambios demográficos y otras variables sociales y económicas se han basado en modelos econométricos, en investigaciones realizadas en los países industrializados de altos ingrésos, o en posiciones ideológicas cuyos supuestos básicos tienen dudosa relación con la situación real de América Latina. Estas generalizaciones han sido objeto de severas críticas, pero no por ello se ha logrado formular un marco teórico equilibrado ni proporcionar la información adecuada para probar satisfactoriamente la vigencia de las hipótesis existentes.

Cuando -como en la presente evaluación- el problema se plantea en el sentido de analizar los efectos probables de las tendencias demográficas sobre el desarrollo en un plazo corto, los problemas de investigación se agrandan. Por consiguiente, esta sección sólo puede tener por objeto examinar en forma superficial algunas de las cuestiones más importantes.

Del análisis de la función económica de la población ha surgido una amplia variedad de opiniones $y$ argumentos, pero para fines heurísticos, ellos pueden sintetizarse en dos categorías generales. Por una parte, se ha expuesto el argumento de que, cualquiera que sea el progreso económico que se logre en América Latina, se ve en gran parte minado y absorbido por el crecimiento demográfico. Por el contrario, otros sostienen que las tasas de crecimiento demográfico influyen muy poco sobre la situación de América Latina dado que su densidad de población es baja y su potencial de crecimiento económico superior a sus tasas de crecimiento demográfico.

La confrontación de las tasas regionales de crecimiento demográfico con las del crecimiento del ingreso en el período no ayuda mucho a aclarar el problema. Por una parte, el producto interno bruto creció a una tasa media anual de $5.5 \%$ en el decenio $y$, como el crecimiento medio anual de la población fue de $2.9 \%$, podría aducirse que más de la mitad del incremento medio anual del producto interno bruto fue absorbido por el crecimiento demográfico. De otro lado, la razón entre el producto interno bruto y la población mejorb claramente con respecto al decenio de 1950 en el que el crecimiento demográfico fue aproximadamenrte igual al del decenio de 1960, pero el producto interno bruto creció en un $4.5 \%$ anualmente.

Por lo tanto, utilizando las mismas cifras y según el punto de vista del observador, puede afirmarse que el ritmo de crecimiento demográfico neutraliza una proporción elevada del crecimiento económico, $o$, que éste está aumentando a pesar de que la población crece a un ritmo rápido y sostenido, o, incluso, que el rápido crecimiento demográfico ha contribuido a que se eleven las tasas de crecimiento del producto interno bruto. Tampoco arroja luces sobre el particular la comparación de las tasas de crecimiento demográfico y las de crecimiento económico 
o crecimiento del ingreso por habitante en determinados países. El problema es aún más confuso en este caso puesto que entre los países cuyo crecimiento demográfico ha sido reducido figuran los de más alto y más bajo nivel de ingresos por habitante y algunas de las tasas más bajas e intermedias de crecimiento del producto interno bruto y del ingreso por habitante. Entre tanto, otros países que han experimentado un rápido aumento de la población en el decenio han tenido tasas elevadas, medianas y bajas de crecimiento económico y de crecimiento del ingreso por habitante.

En resumen, parece poco provechoso establecer una correlación mecánica entre las tasas de crecimiento económico y las de crecimiento demográfico de los países latinoamericanos en el decenio de 1960. En cambio, parecería más útil reexaminar algunas consideraciones generales expresas en relación con el ritmo de crecimiento demográfico y comprobar su relevancia en la situación latinoamericana en el presente decenio.

La influencia de los factores demográficos en el proceso de desarrollo socioeconómico se manifiesta a través de la población considerada en su doble función como consumidora y como productora. Por una parte, la población demanda una serie de bienes y servicios para satisfacer sus necesidades. Por la otra, los factores demográficos ejercen influencia sobre el tamaño y la composición de la fuerza de trabajo que deben producir esos bienes y servicios.

Pero el hecho de que los factores demográficos influyan en la oferta y la demanda no tiende a establecer el equilibrio entre ambos. Los segmentos productores de la población no coinciden con los consumidores y así como determinados individuos son capaces de realizar ciertas tareas productivas, hay otros que consumen ciertos tipos de bienes y servicios.

La edad y el sexo son características demográficas que determinan en gran medida la posición de la persona respecto al consumo y a la producción. Por lo tanto, además de considerar el tamaño y la tasa de crecimiento de la población, es necesario analizar las consecuencias que tiene sobre el desarrollo económico y social su composición según sexo y edad.

Así, por ejemplo, se ha sostenido que el efecto más inmediato y demostrable de la reducción de las tasas de crecimiento demográfico es el aumento del ingreso por habitante. Como la disminución del ritmo de crecimiento demográfico obedece por lo general a la disminución de la fecundidad - continúa el argumento- ella se traduce en la disminución del tamaño de la familia, que en el plano societal, se refleja en una disminución de la relación de dependencia. Como a corto plazo ese fenómeno no influye sobre la fuerza de trabajo y otros recursos, el efecto neto de la disminución de la fecundidad es que disminuye el número de personas entre las cuales se distribuye el mismo ingreso nacional, lo que permite aumentar el ahorro, perfeccionar la tecnología y mejorar la productividad. 
Este tipo de argumento ha sido objeto de severas críticas en América Latina y no se trata aquí de profundizar en esa polémica. Se hará más bien un breve análisis de la probable influencia de los cambios demográficos sobre la producción y el consumo en los últimos dos decenios.

Primero, en lo que se refiere a la población como factor productivo, como sólo la de algunos grupos de edades está capacitada para participar en actividades productivas, el porcentaje de la población total que representa las personas en edad de trabajar (en este caso la población de 15 a 64 años) puede dar una primera aproximación de la potencialidad y el aprovechamiento de los recursos humanos. En 1970, la proporción de la población latinoamericana en edad de trabajar era muy similar a la de las demás regiones menos desarrolladas del mundo pero muy inferior a la observada en las naciones más desarrolladas. (Véase el cuadro 13.) Esta proporción declinó levemente en todas las regiones, pero es importante señalar que las diferencias relativas entre las regiones persistieron durante el período.

Sin embargo, cuando se examina el aprovechamiento real de esos recursos potenciales, el cuadro se modifica radicalmente y muestra que la situación latinoamericana es mucho menos favorable -incluso en comparación con otras regiones menos desarrolladas - de lo que sugerirían las conclusiones anteriores. Así, en 1970, sólo el $31 \%$ de la población total de América Latina era económicamente activa. Esta proporción no solamente es muy inferior al $45 \%$ observado en las regiones desarrolladas sino que también está bien por debajo del $40 \%$ que corresponde al conjunto de las regiones menos desarrolladas.

También en este caso las cifras indicarian una disminución del porcentaje de población económicamente activa en todas las regiones durante el período de 1950 a 1970 . A primera vista, podría inferirse que estas declinaciones tienen su origen, en gran medida, en las reducciones aludidas de la proporción de personas de edad activa en la población total. En realidad, esta explicación podría ser válida si las tasas de participación por sexo y edad no hubieran variado apreciablemente durante el período. Pero esto no fue así ya que, por ejemplo, las tasas de participación general de la mujer aumentaron realmente durante el período en todas las regiones. (Véase de nuevo el cuadro 13.) Sin embargo, los cambios en la participación femenina fueron compensados con creces por la disminución de la participación masculina. Asf́, por ejemplo, puede calcularse sobre la base de la información del cuadro 13 que si se hubieran mantenido las tasas generales de participación, la disminución habría sido mucho más lenta, especialmente en América Latina.

En suma, los cambios en las tasas de participación han tenido por lo menos tanto efecto como los cambios en la estructura por edades sobre la reducción de la proporción de población activa durante el período de 1950 a 1970. En todo caso, lo que estas cifras ponen de relieve es que si bien la población potencialmente activa de América Latina es comparable a la de otras regiones en desarrollo, el grado de aprovechamiento de sus recursos humanos parecería ser mucho menor. 
Cuadro 13. América Latina y otras regiones del mundo: índices globales de participación en la actividad económica, 1950-1970

\begin{tabular}{l} 
Indice y región \\
\hline
\end{tabular}

Porcentaje de la población en edad de trabajar en la población total

América Latina

Regiones más desarrolladas

Regiones menos desarrolladas

55.7

64.6

56.0

59.0

Total mundial

Porcentaje de la población económicamente activa

América Latina

Regiones más desarrolladas

Regiones menos desarrolladas

Total mundial

Porcentaje de la poblacion femenina económicamente activa

América Latina

Regiones más desarrolladas

Regiones menos desarrolladas

Total mundial

Población económicamente activa como porcentaje de la población en edad de trabajar

América Latina

Regiones más desarrolladas

Regiones menos desarrolladas

Total mundial

$\begin{array}{lll}34.7 & 31.1 \mathrm{a} & 33.5 \mathrm{~b} \\ 45.7 & 44.8 \mathrm{a} & 45.0 \mathrm{~b} \\ 41.4 & 39.8 \mathrm{a} & 40.9 \mathrm{~b} \\ & & \\ 42.9 & 41.3 \mathrm{a} & 42.0 \mathrm{~b}\end{array}$

18.2

19.5

$36.5 \quad 38.3$

$29.4 \quad 32.8$

$32.0 \quad 34.6$

62.3

70.7

73.9

57.8

70.4

72.0

72.7

71.5

Fuentes: Población: Estimaciones de las Naciones Unidas.

Población econbmicamente activa: Estimaciones de la orr.

a Estimaciones correspondientes a 1970 .

b Para calcular las estimaciones estandarizadas se supuso que en el período 1950-1970 no varió la relación entre la población económicamente activa y la población en edad de trabajar estimada para 1950. 
Sin embargo, es difícil extraer conclusiones sobre la significación de estas diferencias, ya que podrían atribuirse más bien a diferencias culturales y operacionales sobre el significado de los conceptos de poblacion "activa" e "inactiva", que a diferencias reales en cuanto a la participación o a la diferente capacidad de las estructuras de empleo respectivas para absorber los recursos humanos.

Las desventajas que presenta América Latina en cuanto a su estructura demográfica se reflejan también en su relación de dependencia. Este indicador reviste especial interés porque resume la forma en que la composición de la población influye en la producción y el consumo en América Latina. Para los efectos de las consideraciones preliminares hechas, la relación de dependencia puede definirse operacionalmente como el cociente entre la población menor de 15 y mayor de 65 años, por una parte, y la del grupo de 15 a 64 años.

Se estima que la relación de dependencia en el conjunto de la región aumentó apreciablemente en el decenio de 1950 (de 795 a 844 por mil), pero a un ritmo menor en el decenio siguiente, llegando a 859 por mil en 1970. Así, en ese decenio como resultado del proceso de rejuvenecimiento de la población, continuó la tendencia hacia relaciones de dependencia cada vez más altas en América Latina. Sin embargo, el crecimiento de las relaciones es cada vez menor, lo que sugeriría que la relación de dependencia sigue un curso paralelo al del crecimiento demográfico. El examen de las perspectivas demográficas indicaría que esa relación comenzará a decrecer durante el presente decenio en la mayoría de los países y en la región en su conjunto.

En lo que toca a los niveles y tendencias de la relación de dependencia, los países latinoamericanos pueden clasificarse en varias categorías. (Véase el cuadro 14.) En la primera, que incluye sólo la Argentina y el Uruguay, esas relaciones son las más bajas de la región y fluctuaron en torno a 550 por mil entre 1950 y 1970 , pero con tendencia a subir por efecto del proceso de envejecimiento de la población. Cuba, que se encuentra en una etapa un poco menos avanzada de la transición demográfica, registraba una relación más bien baja, cercana a 670 por mil en 1950 que descendió ligeramente a 650 por mil en 1970 y es probable que continúe decreciendo en el futuro inmediato. En Chile esa relación experimentó un rápido aumento de 700 a 790 por mil entre 1950 y 1960, pero empez6 a declinar en el decenio de 1960 y cabe esperar que continúe haciéndolo.

El caso del Brasil es atípico, en el sentido de que su relación de dependencia se ha mostrado muy estable a largo plazo. Sin embargo, entre 1950 y 1960 aumentó de 800 a 840 por mil, pero comenzó a experimentar desde entonces una tendencia decreciente que probablemente se prolongará hacia el futuro.

Haití y Bolivia han tenido relaciones de dependencia relativamente bajas. Sólo recientemente muestran algunas indicaciones de una tendencia creciente. Los países restantes tienen las relaciones de dependencia más altas, que fluctuaban entre 790 y 899 por mil en 1950 y en todos ellos esas relaciones han experimentado un apreciable aumento 


\section{Cuadro 14. América Latina: estimaciones y proyecciones de la relación de dependencia a}

(Por cada 1000 habitantes entre 15 y 64 años)

\begin{tabular}{lcccc}
\hline \multicolumn{1}{c}{ Pá́s } & 1950 & 1960 & 1970 & 1980 \\
\hline Argentina & 543 & 572 & 577 & 604 \\
Bolivia & 783 & 815 & 839 & 866 \\
Chile & 704 & 793 & 782 & 698 \\
Ecuador & 857 & 937 & 993 & 980 \\
Brasil & 799 & 842 & 835 & 828 \\
Colombia & 841 & 968 & 985 & 954 \\
Paraguay & 902 & 1028 & 988 & 997 \\
Perí & 891 & 931 & 928 & 875 \\
Uruguay & 590 & 550 & 581 & 591 \\
Venezuela & 805 & 916 & 928 & 901 \\
Costa Rica & 842 & 1021 & 1046 & 1031 \\
Cuba & 667 & 680 & 652 & 638 \\
El Salvador & 790 & 947 & 1005 & 1054 \\
Guatemala & 811 & 957 & 950 & 864 \\
Haití & 724 & 811 & 833 & 870 \\
Honduras & 802 & 990 & 964 & 978 \\
México & 822 & 955 & 989 & 963 \\
Nicaragua & 854 & 993 & 1007 & 962 \\
Panamá & 813 & 891 & 934 & 932 \\
República Dominicana & 902 & 1006 & 1002 & 1007 \\
América Latina & 795 & 844 & 859 & 848 \\
\hline
\end{tabular}

a Población menor de 15 y mayor de 65 ańos dividida por la población de 15 a 64 anoos.

en los decenios siguientes, llegando a un nivel de por lo menos 900 , y en cuatro casos a más de 1000 por mil en 1970. Es probable que en la mayoría de los países comiencen a bajar durante la década de 1970 , en tanto que en unos pocos se observará probablemente un leve aumento en ese período.

La relación de dependencia se vincula íntimamente con la tasa de crecimiento demográfico y, por lo tanto, con las tasas de natalidad. En un país que registra continuamente altas tasas de natalidad, la estructura por edades de la población hace que un elevado número de jóvenes trate de incorporarse a la fuerza de trabajo todos los años y las oportunidades de empleo tienen que multiplicarse para absorber este incremento anual. Cuando esas oportunidades no aumentan a la par con el crecimiento de la fuerza de trabajo, hay una gran competencia para obtener los empleos disponibles $\mathrm{y}$, por consiguiente, los salarios tienden a bajar o a mantenerse congelados a bajos niveles.

Por otra parte, el ritmo de crecimiento de la población de edades activas, que según las informaciones disponibles fluctúa en alrededor de $3 \%$ anual en la región, puede transformarse teóricamente en una fuerza positiva para el desarrollo. En efecto, si el ritmo de absorción 
de la población en empleos productivos es igualmente elevado, la mayor fuerza de trabajo redundará en el aumento de la producción, del ingreso nacional y en un mercado más amplio con las consiguientes economías de escala.

Sin embargo, en la mayoría de los países sobre los cuales se dispone de datos parecería que en el decenio de 1960 el ritmo de crecimiento de la población en edad de trabajar fue mucho mayor que el de la población empleada. Además, nadie ignora las altas tasas de desempleo y subempleo que prevalecen en América Latina.

Dados estos antecedentes, la lentitud con que aumentan las nuevas oportunidades de empleo productivo, la creciente diferencia entre los conocimientos técnicos que se exigen en las industrias tecnológicamente más avanzadas y los que posee la fuerza de trabajo potencial, las dificultades para absorber la mano de obra de baja productividad, todo parece indicar que la mayoría de los países latinoamericanos estaría en mejor situación si la fuerza de trabajo creciera más lentamente. (Para completar este análisis habría que examinar la evolución de variables como la productividad y el nivel de capacitación técnica, pero ello alargaría mucho la consideración del tema.)

Volviendo ahora a la población como factor de consumo, la conclusión a que se llega al estudiar los efectos del crecimiento demográfico sobre cualquier servicio esencial que la sociedad debe prestar para mantener o mejorar el nivel de vida de su población, no parece variar apreciablemente según el sector que se estudie. Es decir, sea que el examen se concentre en los costos de los servicios que han de prestarse en la esfera de la salud, la educación, la seguridad social, la vivienda, el suministro de alimentos y la nutrición, el bienestar social y otros, se impone inevitablemente la conclusión de que los costos aumentarán en proporción más o menos directa con el aumento de la población.

Entre los diferentes sectores afectados por el ritmo de crecimiento de la población, el de la educación merece atención especial, pues no sblo puede utilizarse para ilustrar la presión del crecimiento demográfico sobre el consumo, sino porque tiene una gran influencia sobre la calidad de la fuerza trabajadora, que a su vez se refleja en la productividad.

La población de 5 a 14 años representa alrededor del $26 \%$ de la población total de América Latina. Esta proporción, que corresponde aproximadamente a la población en edad escolar, varía algo entre los distintos países, pero sólo en Argentina, Cuba, Chile y Uruguay alcanza valores mucho menores que el promedio regional.

$\mathrm{Si}$ se supone que todos los niños de 5 a 14 años debieran asistir a la escuela, en 1970 habrían de matricularse 18 millones de niños más que en 1960, cualesquiera que hayan sido los déficit que ya existían a comienzos del período $\mathrm{e}$ independientemente de las vacantes necesarias para personas de otros grupos de edades.

Si se parte de una hipótesis más realista -que el objetivo mínimo serían seis años de escolaridad para cada nifio-, la matrícula en la ense- 
ñanza primaria debería comprender por lo menos el $15 \%$ de la población latinoamericana. Según este razonamiento, los sistemas de enseñanza primaria de América Latina tendrían que absorber en 197010 millones más de niños que en 1960, además de todos los déficit anteriores del sistema. En estas condiciones, la magnitud de la carga que significa financiar servicios de educación adecuados y dotarlos de personal es demasiado evidente y no necesita mayor explicación. En muchos países, y pese a los serios esfuerzos desplegados por aumentar la matrícula, los sistemas de enseñanza no han sido capaces de absorber el creciente número de personas en edad escolar y el número absoluto de personas sin escolaridad ha continuado aumentando.

No cabe duda que la magnitud de la tarea no ha impedido el mejoramiento sostenido del nivel educativo de la población en la mayoría de los países latinoamericanos durante el decenio. En todos los niveles de la enseñanza la matrícula ha aumentado con mayor rapidez que la población y no puede demostrarse que la gran magnitud y el rápido crecimiento de los grupos en edad escolar tornen prohibitivo el costo de atender a su educación formal. Sin embargo, no se trata en este caso de que la educación sea ahora más completa o de mejor calidad. Lo que interesa es que si se considera la población como consumidora, sea de educación o de otros servicios, la mayor población y las mayores tasas de crecimiento demográfico significarán inevitablemente el aumento de los costos para el sector público.

Sin embargo, el modelo económico básico subyacente en este análisis ha sido simplificado en extremo por cuanto puede igualmente sostenerse que es mejor concebir el consumo no como rival directo del ahorro, sino como el estímulo indispensable para el crecimiento de la producción. Desde este punto de vista, una población joven y en crecimiento proporcionaría mereados internos cada vez más grandes para la expansión industrial. Esta afirmación se rebate a su vez en su aplicación concreta a América Latina, señalando que dadas las presentes estructuras de distribución del ingreso y de producción, la mayor parte de la población queda excluida del mercado interno.

Estas consideraciones sugieren una actitud de pesimismo, no tanto con respecto a la influencia de las actuales tasas de crecimiento demográfico sobre el desarrollo, como en lo que toca a la posibilidad de formular generalizaciones significativas acerca de los efectos de los factores demográficos en el decenio pasado a base de los datos y los marcos teóricos existentes. Si uno se viera forzado a opinar acerca del efecto del crecimiento demográfico sobre el desarrollo de América Latina en este período, probablemente sostendría que una tasa de crecimiento más baja habría sido beneficiosa para aliviar ciertos presiones. Pero las afirmaciones de esta índole no son originales ni de gran utilidad práctica.

Es posible mejorar en forma apreciable la validez de ese tipo de generalizaciones, si se analizan simultáneamente y con mayor profundidad las funciones de la población como productora y como consumidora, si se formula el análisis teniendo presentes objetivos concretos de creci- 
miento, determinados niveles de adelanto tecnológico, estructuras económicas diferentes y distintos estilos de desarrollo. Sería necesario asimismo estudiar, estableciendo las diferencias, los efectos de las tendencias demográficas en países con diversos niveles de densidad demográfica y de dotación de recursos y con diferentes patrones de composición y distribución de la población. Semejante tarea supone revisar y hacer más dinámicos la teoría y los datos, lo que rebasa con creces el alcance del presente trabajo. 


\section{FACTORES SOCIALES Y ECONÓMICOS QUE AFECTAN A LAS TENDENCIAS DE LA POBLACIÓN}

LAS MODALIDADES de crecimiento y redistribución de la población observadas últimamente en América Latina han atraído la atención mundial por la intensidad sin precedentes de las transformaciones demográficas que están ocurriendo, y por su importancia para las perspectivas del desarrollo. Al comienzo declinó marcadamente la mortalidad; en tanto que los niveles de fecundidad permanecieron casi inalterables, generándose así algunas de las tasas de crecimiento de la población más elevadas que jamás se hayan registrado. Simultáneamente, ha habido movimientos de población en gran escala, y las ciudades latinoamericanas han experimentado una impetuosa expansión tanto en tamaño como en número. En los últimos años la migración y el crecimiento urbano han continuado acelerándose, pero hay ciertos indicios de debilitamiento en las tasas de incremento demográfico. Aunque hasta ahora este fenómeno sólo afecta a algunos pocos países o regiones internas, parecería plausible pronosticar una futura declinación global de la fecundidad.

En este capítulo se examinan las rápidas transformaciones por las que atraviesa actualmente la población latinoamericana, tarea en que se encaran dos problemas metodológicos fundamentales. De un lado, la información básica sobre las tendencias en los componentes elementales del fenómeno demográfico es anticuada o simplemente inexistente en muchos países, lo que obliga a los investigadores a recurrir a proyecciones, estimaciones y medios similares, que aunque dan una noción global más o menos aceptable de las tendencias, no definen situaciones particulares recientes con la claridad indispensable para analizar los factores que los sustentan.

De otro lado, el análisis de los factores socioeconómicos que afectan a las tendencias demográficas tropieza con dificultades derivadas de la propia heterogeneidad de situaciones e influencias en la región. Que existen veinte Américas Latinas, y no una, es hoy un lugar común. Pero según el nivel y la profundidad del análisis que se efectúe, esta cifra puede multiplicarse aún más, dada la cantidad de subregiones con particularidades claramente definidas.

Para estos fines, es posible distinguir por lo menos tres grandes grupos de países, según su situación socioeconómica y demográfica. Los países de modernización temprana del Cono Sur, así como Cuba, se hallan bastante avanzados en la última etapa de su transición demográfica. En cambio, Ecuador, Bolivia, Paraguay y los países centroamericanos - salvo Panamá y Costa Rica - han registrado sólo recientemente (y por lo menos en Haití no se ha comenzado aún) las declinaciones iniciales de la mortalidad asociadas típicamente al paso de la primera a la segunda etapa de la transición demográfica. Los países restantes, que contienen la mayoría de la población latinoamericana, se encuentran 
actualmente en la segunda de estas etapas; sin embargo, su fecundidad y mortalidad, aunque variadas, los ubican en una posición intermedia entre los otros dos grupos. Dada esta gran diversidad de situaciones, casi toda generalización que pueda hacerse respecto a los factores subyacentes sólo tiene limitada validez.

Prevenidos por esta diversidad, así como por la deficiencia de los datos y de los fundamentos teóricos, se examinarán aquí sucesivamente algunos de los principales factores que influyen en la migración y urbanización, la fecundidad y la mortalidad. Cada sección del capítulo responde a enfoques e interrogantes distintos, de manera que todas ellas son bastante autónomas. Se hace hincapié en la fecundidad y en la migración y urbanización, porque en ellas influyen particularmente las transformaciones socioeconómicas, y a la vez, son ellas las que tienen mayor repercusión en las tendencias demográficas futuras. La mortalidad, por el contrario, depende mucho menos del cambio social, y además sus inclinaciones futuras tendrán menor significación en las tendencias demográficas de la mayoría de los países.

\section{PROCESOS QUE AFECTAN IA REDISTRIBUCIÓN DE LA POBLACIÓN}

La gradual concentración de gente en localidades urbanas, y especialmente en grandes metrópolis, constituye un rasgo sobresaliente de la transformación de la sociedad latinoamericana. Este fenómeno está evidentemente asociado a los traslados en gran escala de poblaciones desde las zonas rurales a las urbanas y, en gran medida, es producto de ellos.

\section{1) Factores y tendencias de la urbanización}

Desde un punto de vista lógico, el examen de los factores que determinan el crecimiento urbano y la urbanización ha de efectuarse en un plano diferente al del análisis, digamos, de los factores de la migración o las causas determinantes de la fecundidad. En efecto, estos últimos fenómenos fluctúan como producto final colectivo de motivaciones y acciones individuales, en tanto que la urbanización y el crecimiento urbano son procesos físicos de concentración de la población en respuesta a tendencias complementarias o compensatorias de la migración y el incremento natural. Así, de un lado, habrá que ocuparse de los componentes demográficos del crecimiento urbano y establecer patrones de interacción entre migración y crecimiento natural. De otro lado, sin embargo, la urbanización puede considerarse en un sentido más amplio como parte integral del proceso global de cambio estructural que arrostra una sociedad al pasar de una forma más simple de organización social y económica a otra más compleja. Por esto será provechoso examinar brevemente algunos de los antecedentes históricos que dieron 
origen a las diferentes configuraciones urbanas de hoy, antes de considerar los factores más inmediatos del crecimiento urbano.

Abordando el problema desde el punto de vista histórico, cabe distinguir tres grandes grupos de países latinoamericanos, según el nivel, la época y la dinámica de sus respectivos procesos de urbanización. Las interpretaciones de las transformaciones históricas varían, de manera que las tendencias burdas que aquí se reseñan brevemente deben considerarse con cautela. De partida, parecería que cuatro países - Argentina, Cuba, Chile y Uruguay- llegaron a un umbral urbano hacia fines del siglo xIx y en el primer cuarto del siglo $\mathrm{xx}$.

En estos países las concentraciones urbanas comenzaron a aglomerarse principalmente en función de la naturaleza y magnitud de la prosperidad generada por el sector externo. Las exportaciones, sobre todo en Argentina y Uruguay, se inclinaban fuertemente hacia productos que exigían por lo menos alguna transformación industrial rudimentaria en el país de origen. De ahí que la concentración urbana se basara no sólo en la proliferación de tareas auxiliares anexas al sector de exportación, sino también en el avance de las actividades industriales y en la creación de un mercado interno dinámico. En Chile, la desruralización de la región central, unida a la prosperidad de las exportaciones minerales, a mejores comunicaciones entre regiones y a la transición desde la agricultura de exportación al cultivo para consumo interno, fueron todos factores que favorecieron una urbanización temprana. Por su parte, Cuba había alcanzado un alto grado de urbanización a comienzos del siglo $\mathrm{xIX}$, pero luego de un largo período de relativo estàncamiento urbano, la guerra de la independencia, la afluencia de capital extranjero y el desarrollo del sistema de transporte dieron nuevo auge al crecimiento urbano a comienzos del siglo $\mathrm{xx}$.

En mayor o menor grado, en todos estos países, la inmigración extranjera contribuyó también mucho a que la urbanización fuese temprana. Por ejemplo, en 1914 los inmigrantes constituían una elevada proporción - tres décimos- de la población residente en la Argentina. En estas circunstancias la inmigración adquirió particular importancia, porque los recién llegados tendieron a concentrarse en un número restringido de localidades, y porque al parecer trajeron con ellos aptitudes y aspiraciones que les hicieron especialmente aptos para asumir papeles innovadores en la transformación de la economía.

La actual configuración urbana de estos países, caracterizados por elevados niveles y tasas de urbanización (producidas estas últimas más por la desruralización que por tasas elevadas de crecimiento urbano), y por la concentración de la población urbana y total en la ciudad más grande del país, refleja el proceso de urbanización temprana causado por una particular evolución económica, política y demográfica. ${ }^{1}$

En un segundo grupo, que se podría denominar "país de urbaniza-

1 Véase en el capítulo in el punto 4 relativo a la urbanización. Allí se proporciona información más detallada sobre los procesos recientes en cada uno de los tres grupos de países. 
ción reciente", este proceso comenzó a adquirir proporciones más o menos significativas entre 1930 y 1950 . Esta categoría incluye la mayor parte de los países latinoamericanos más grandes o populosos - Brasil, Colombia, México, Perú ${ }^{2}$ y Venezuela-, junto con Costa Rica y Panamá. En la mayoría de ellos había pueblos y grandes ciudades desde comienzos de la época colonial, y muchos experimentaron un crecimiento urbano acelerado en diferentes períodos de su historia. Sin embargo, la población de las zonas urbanas en su conjunto generalmente aumentó a parejas con la tasa de crecimiento de la población total, de manera que la urbanización mantuvo niveles relativamente bajos hasta los años treinta.

En la mayoría de los casos, el impulso inicial que aceleró el crecimiento urbano en los países de este grupo partió de la severa crisis en el mercado mundial de productos agrícolas que se hizo sentir en aquel decenio. Esta crisis, a la que pronto siguió una aceleración del crecimiento de la población, originada por declinaciones en la mortalidad, causó un excedente demográfico en las zonas rurales, a la vez que se acrecentaba la migración de importantes contingentes de mano de obra agrícola hacia los núcleos existentes. La decadencia del sector agrícola de exportación contribuyó a intensificar la busca de otros productos primarios de fácil explotación y a impulsar políticas de sustitución de importaciones.

En todo caso, disminuyó la capacidad de absorción de las estructuras de empleo no urbanas, e indujo así migraciones en gran escala hacia las localidades urbanas. Merece destacarse que el despegue de la urbanización en los países en que este proceso ha sido reciente, coincidió con el comienzo de la etapa más explosiva de transición demográfica, lo que ha influido considerablemente en la magnitud de los movimientos migratorios y en la tasa de crecimiento urbano.

Alimentado por el crecimiento rápido de la población, el proceso de urbanización en algunos de estos países continúa siendo extremadamente difuso y de gran alcance. En 1950 poco más de un quinto de la población total de estos países vivía en ciudades de 20000 habitantes o más. Hacia 1960, esta proporción había aumentado a tres décimos, y hacia 1970 a dos quintos. En estos dos decenios las tasas de crecimiento urbano y de urbanización en el grupo considerado fueron las más altas de América Latina.

El tercer grupo, formado por Bolivia, Ecuador, El Salvador, Guatemala, Haití, Honduras, Nicaragua, Paraguay y República Dominicana, incluye países que se hallan en una etapa incipiente del proceso de urbanización. En 1950, ninguno de ellos tenía una población urbana superior al quinto de su población total, y muchos de ellos sólo llegaron a esta cifra a fines de los años sesenta, en tanto que otros aún no la alcanzan. En síntesis, la aceleración del crecimiento urbano sólo ha comenzado allí en años recientes.

2Los patrones históricos de la urbanización del Perú se asemejan más a los del pre sente grupo; sin embargo, para facilitar el estudio de las tendencias recientes, se colocó al Perú en el tercer grupo en el análisis hecho en el punto 4 del capítulo II. 
Más que a cambios estructurales de la economía esto ha obedecido habitualmente a la modificación de los patrones de crecimiento de la poblacion. Es verdad que estos países también sufrieron la profunda crisis de sus sectores tradicionales de exportación que dieron el primer impulso al crecimiento urbano en otros lugares. Pero dada la naturaleza tan especializada del sector externo, la falta de recursos optativos fáciles de explotar, la persistencia de un complejo improductivo de latifundios y minifundios y la falta de un sistema básico de pueblos y ciudades, la crisis mundial no generó cambios profundos en la política económica ni en el alcance de la urbanización.

Así pues, las presiones demográficas se destacan como el factor más decisivo del despegue urbano en países de urbanización tardía. Aunque los datos son imprecisos, lo probable es que las zonas urbanas de este grupo de países hayan experimentado una declinación de la mortalidad antes que las rurales. De este modo, la tasa de crecimiento urbano fue más de dos veces y media mayor que la de crecimiento rural, tanto en el decenio de 1950 como en el de 1960 . Sin duda, la diferencia refleja en parte los movimientos intensivos de la población hacia centros urbanos, pero como se verá más adelante la mortalidad urbana es considerablemente menor que la rural, y esto, unido a una diferente composición por edades, probablemente significa que las tasas de incremento natural son más altas en las ciudades.

En síntesis, la urbanización está avanzando a ritmos variados y con rasgos peculiares en diferentes grupos de países. Todo esbozo de la historia del proceso de urbanización, por breve que sea, indica que sus características distintivas tienen sus raíces estructurales en el desarrollo histórico de las configuraciones económicas y demográficas de cada bloque de países.

\section{2) Factores inmediatos de la urbanización}

El ritmo impresionante del crecimiento urbano de América Latina en los últimos decenios ha suscitado diversas interpretaciones de los componentes del proceso. Los incrementos observados en la población de localidades urbanas se deben a variadas combinaciones de incremento natural positivo, inmigración neta y reclasificación de lugares "rurales" como "urbanos" (ya sea por anexión o por el crecimiento de comunidades rurales a tamaños urbanos). La información existente no permite dar cuenta rigurosa de la contribución relativa de cada factor, pero estimaciones ilustrativas hechas en la CEPAL parecen indicar que la reclasificación explicaría cerca del $20 \%$ de todo el crecimiento urbano observado en América Latina en los años cincuenta y sesenta. De otra parte, estimaciones provisionales mostrarían también que los incrementos naturales en las zonas urbanas - que incluyen los incrementos naturales tanto entre nativos como entre migrantes- causarían una mayor proporción del crecimiento restante que la inmigración neta. Además, la contribución de la migración interna parecería estar disminuyendo, 
lo que guarda coherencia con el concepto de la urbanización como un proceso finito.

Sin embargo, más allá de estos patrones generales, la dinámica del crecimiento de las ciudades no parece reflejar tendencia sistemática alguna que responda a los niveles de desarrollo o al tamaño de las ciudades en los distintos países. En términos absolutos, es indudable que las ciudades más grandes de cada país reciben una proporción desmedida de los migrantes nacionales hacia las zonas urbanas. No obstante, si se considera la proporción del aporte al crecimiento urbano, parecería que en muchos países las ciudades más pequeñas en realidad deben más de su incremento a la migración que las ciudades grandes. De todas maneras, para poder analizar con más detenimiento los componentes del crecimiento urbano habrá que esperar que mejoren los datos. ${ }^{3}$

En todo caso, aunque la información en que se basan las estimaciones es tentativa y varían mucho los patrones, está muy claro que en América Latina los movimientos de población hacia zonas urbanas son intensos. ${ }^{4}$ Sin embargo, los factores socioeconómicos que determinan tales movimientos son menos evidentes; es decir, parece haber consenso sobre los factores generales que impulsan los movimientos de población, pero muy poco análisis empírico de su influencia concreta.

En la sesión dedicada a la migración interna en la Conferencia Mundial de Población de 1965 se concluía que en esa esfera "se plantean varios problemas a los cuales deben prestar atención inmediata los investigadores, pero los que al parecer son los más urgentes son los relacionados con los factores que influyen en la migración interna en Asia, África y la América Latina". 5 Pese a esta exhortación, pocos intentos se han hecho para dar una visión integral de los factores que determinan la migración, ni siquiera en lo que se refiere exclusivamente a los movimientos desde las zonas rurales a las urbanas. ${ }^{6}$

Salvo en casos aislados, cuando los factores de migración se han estudiado en una determinada localidad de origen o de destino, se observa la tendencia a generalizar audazmente, con escaso respaldo de infor-

3 Véase un análisis de los procesos de crecimiento de las ciudades de tres países en: Eduardo Arriaga, "Components of city growth in selected Latin American countries", Milkbank Memorial Fund Quarterly, núm. 46, pp. 237 a 252 (1968). Análisis más: detallados de ciertas ciudades aparecen en George Martine, "Migration natural increase: and city growth: the case of Rio de Janeiro", International Migration Review, 6 (2), pp. 200 a 215 (1972), y "Migrant fertility adjustment and urban growth in Latin America", russ? General Conference, Meeting 2.4, Lieja (agosto de 1973).

4 Merece destacarse que aunque sólo se consideran aquí los movimientos desde el: campo a las zonas urbanas, no son los únicos, ni siempre los más importantes. Las migraciones de una zona rural a otra, o de una localidad urbana a otra, pueden tenerprecedencia en determinadas regiones, y estas altimas inevitablemente adquirirán una: importancia cada vez mayor a medida que se urbanice América Latina.

5 K. C. Zachariah, "Exposición del Relator", Conferencia Mundial de Población,. 1965, vol. 1, p. 198.

6 Tal vez el esfuerzo más importante en este sentido es el que está efectuando un! grupo especial de estudio en el Consejo Latínoamericano de Ciencias Sociales (cLAcso). Varios de los trabajos resultantes aparecen en Migración y desarrollo, consideraciones: teóricas, Buenos Aires, 1972, ccacso, Serie Población, Informe de Investigación. 
maciones empíricas. Además - dado el hincapié que se hace en los movimientos hacia las ciudades-, los investigadores han descrito de preferencia los factores que empujan a la población fuera de las zonas rurales y los que la atraen hacia las zonas urbanas de destino. Se han sugerido otros enfoques de gran perspicacia, ${ }^{7}$ pero hasta ahora no han dado frutos en análisis nacionales representativos. Por lo tanto, el examen siguiente se centrará en los factores generales de atracción y repulsión, complementados con datos sobre las motivaciones personales que influyen en la decisión de migrar.

Los factores que causan la migración son complejos, difíciles de definir $y$, probablemente, difieren de manera radical de una a otra región. Sin embargo, aquellos que parecen contribuir a expulsar a la gente de las zonas agrícolas y rurales en general, se repiten bastante en los distintos países, y así lo reflejan las obras de quienes se ocupan de este fenómeno. 8 Entre esos factores predomina la estructura agraria incapaz de generar nuevos empleos o de absorber una fuerza de trabajo

7 Touraine, por ejemplo, distingue tres tipos de movimientos migratorios: a) desplazamiento, que deriva de circunstancias fortuitas o presiones más que de decisiones personales; b) partida, que entrafia una intención consciente del migrante, y c) movilidad, motivada por aspiraciones de un status más alto (citado en Gino Germani, Sociología de la modernización, Paidós, Buenos Aires, 1969, cap. Iv, p. 140). Germani sugiere que se analice la migración en tres niveles: a) el objetivo, que incluye los factores de expulsión y de atracción, así como la naturaleza de las comunicaciones y el contacto entre las zonas rurales y urbanas; b) el nivel normativo, marco dentro del cual se examinan las condiciones objetivas, y c) el nivel subjetivo, que considera actitudes y comportamientos individuales concretos. (Germani, op. cit., Pp. 126 a 128.) Esta pauta se utilizó con interesantes resultados en un estudio antropológico del proceso de migración en Argentina, a través de una comunidad de emigración y un lugar de destino urbano (Mario Margulis, Migración y marginalidad en la sociedad argentina, Paidos, Buenos Aires, 1968). Forni y Marmora han formulado un interesante conjunto de hipótesis respecto a la propensión a atraer o expulsar migrantes de diversos tipos de comunidades. Así, el comportamiento en materia de migración dependerá de las características de la estructura socioeconómica de la comunidad (valor de la tierra, régimen de tenencia de la tierra, desarrollo tecnológico) y de la intervención de otra variable, que es el "clima social" (abierto o cerrado a los cambios, integrado o desintegrado con respecto a normas y expectativas de comportamiento social). (Véase F. Forni y L. Marmora, "Migración diferencial en comunidades rurales", Cuadernos del Centro de Estudios Urbanos y Regionales, núm. 10, Buenos Aires, 1967.)

8 Véanse análisis generales de los factores de la migración en los siguientes trabajos: Giorgio Mortara, "Factores de la migración del campo a la ciudad en América Latina: influencia de las condiciones económicas y sociales de esos dos medios", Conferencia Mundial de Poblacion, 1965, vol. N, Pp. 546 a 550; Donglas Butterworth, "Migración rural-urbana en América Latina: el estado de nuestro conocimiento", América Indígena, 1971, 31 (1), pp. 85 a 105; Sergio Bagú y E. Palermo, "Condiciones de vida y salud de los trabajadores migrantes y sus familias en América Latina", Cuademos Americanos, 1966, año xxv, núm. 2, Pp. 15 a 34; CEPAL, "Los patrones de asentamiento rural y el cambio social en América Latina", Boletín económico de América Latina, 1965, vol. x, núm. 1, pp. 1 a 22; José Pastore, "Migraçẫo, mobilidade social e desenvolvimento", en Manuel Costa (compilador), Migraçסes internas no Brasil, IPEA-nNPE, Brasil, 1971, pp. 59 a 93; Moisés Poblete Troncoso, "El éxodo rural, sus orígenes, sus repercusiones", América Latina, ańo v, núms. 1-2, 1962, pp. 41 a 49. Son numerosos los ejemplos de estudios más especificos sobre factores de migración en el plano nacional o subnacional, pero un análisis país por país alargaría indebidamente. esta presentación. 
cada vez mayor. Esto es válido tanto para los sistemas de latifundio y minifundio como para diferentes combinaciones de ambos. De un lado, el latifundio tiende a caracterizarse por una rígida estructura de clases, salarios bajos, aprovechamiento insuficiente de los recursos naturales y poca productividad. Pero incluso los latifundios con una productividad razonable generalmente son incapaces de absorber mano de obra adicional, y la introducción de nueva tecnología quizás reduzca aún más las necesidades de mano de obra. De otro lado, la mayoría de los minifundios se caracteriza por su inclinación a la agricultura de subsistencia, y hasta los más productivos suelen poseer una capacidad de absorción muy limitada. Las reformas agrarias más radicales -las de México y Cuba - han logrado aparentemente que la gente arraigue en la tierra, pero la experiencia general ha sido de fracasos. ${ }^{9}$ Los defectos de la estructura socioeconómica en las zonas agrícolas se traducen en desempleo y subempleo, en bajos niveles de vida, falta de servicios de salud, educación y recreación, todo lo cual puede transformarse en motivo para migrar.

La influencia de la estructura agraria en la migración se halla estrechamente vinculada a las condiciones del mercado externo, al rápido crecimiento de la población, al abandono social del sector rural y en ocasiones a calamidades meteorológicas o sociales. Las demandas del mercado externo imponen abruptos cambios en el tipo de producción y de este modo favorecen la sustitución de ciertos cultivos por otros. La migración se intensifica cuando los precios internacionales obligan a sustituir por la producción mecanizada la agricultura que hace uso intensivo de mano de obra. El desequilibrio entre los precios de los productos primarios y manufacturados en el mercado internacional y los tipos de demandas que surgen en los países importadores influyen considerablemente también en los movimientos de la población latinoamericana.

Sequías, tormentas y otras calamidades naturales han ejercido asimismo considerable influjo en la migración. Ejemplos clásicos son las emigraciones desde el Nordeste brasileño cuando sequías periódicas obligan a los residentes a huir del "polígono árido" como si fuera la peste. En esas circunstancias los desastres meteorológicos acentúan las deficiencias y la precariedad de la producción agrícola de la zona. Similares características presentan los movimientos de población provocados por la violencia y la lucha civil en varios países.

La mayor parte de las condiciones señaladas suele agravarse por el incremento rápido de la población en las zonas rurales. Las regiones de mucha emigración se caracterizan siempre por severas presiones demográficas que favorecen el desempleo y el subempleo dentro de las estructuras económicas existentes. Que las presiones demográficas dependen

- El resultado preliminar de un estudio efectuado en zonas rurales de Chile indica que las unidades de producción denominadas Centros de Reforma Agraria (CERA) tenían una proporción considerablemente menor que los fundos tradicionales de trabajadores que deseaban migrar o que estaban planeando hacerlo. (Véase Omar Argüello, "Modemización de la estructura agraria y migraciones internas", Seminario de Evaluación del Programa de Intercambio cepal/Celade, Santiago, julio de 1973.) 
más del carácter de las econónías que del tamaño de la población se hace evidente en la falta de correlación entre la densidad y la propensión a emigrar. Sin embargo, a igualdad de condiciones, las tasas más altas de incremento de la población provocan excedentes de mano de obra y estimulan la emigración.

Por último, cabe señalar que todas las condiciones señaladas - salvo tal vez la sobrepoblación relativa - se observaban mucho antes de que se produjera el éxodo rural más bien reciente. Los servicios rurales de salud, educación y bienestar por mucho tiempo han sido deficientes medidos por los estándares urbanos, y la pobreza rural ciertamente no es atributo exclusivo de los últimos decenios. Sin embargo, sólo en este último período ha conducido a movimientos masivos de población. Parte de las diferencias entre patrones anteriores y actuales podría probablemente atribuirse a las nuevas tasas de crecimiento demográfico, pero el factor principal reside quizá en el cambio de las expectativas de las poblaciones rurales, unidas a mejores transportes y comunicaciones. Los medios de información han divulgado nociones de otros estilos de vida a núcleos hasta ahora aislados, en momentos en que las opciones no tradicionales se tornan cada día más accesibles.

Las diversas condiciones que constituyen factores de repulsión en la dinámica de las migraciones del campo a la ciudad se hallan aliadas en principio a la fuerza de atracción ejercida por las grandes ciudades. En los decenios últimos las estrategias de desarrollo han asignado una mayor proporción de los gastos generales y del capital de inversión a las zonas urbanas, y se han dedicado a elevar la producción económica a través de la expansión del sector industrial. Teóricamente, el acento en el sector industrial urbano que han puesto las autoridades públicas y privadas debe contribuir a acrecentar las oportunidades de empleo y los salarios. En realidad, ha habido avances considerables en el sector secundario de la mayoría de los países, y como esto ha ido a parejas con el crecimiento (productivo o improductivo) del empleo en el sector terciario, se ha acrecentado enormemente la capacidad del sector urbano industrial para absorber fuerza de trabajo. Mantengan o no el mismo ritmo de incremento las oportunidades de empleo productivo y la fuerza de trabajo urbana, es una atracción formidable para los migrantes potenciales el hecho de que se estén creando empleos.

La asignación de una proporción importante del gasto social a las zonas urbanas ha acentuado también los desequilibrios entre el campo y la ciudad en lo que se refiere a bienestar social, educación, servicios de salud, saneamiento, recreación, subsidios de vivienda y otros. Además, los avances en la legislación del trabajo, así como la protección y asistencia sociales, se han concentrado decididamente en las localidades urbanas. El deseo de aprovechar estos servicios (aspiración que tal vez nunca se cumple) sin duda forma parte importante de la idiosincrasia del migrante. Además, lazos familiares y de vecindad con personas que han emigrado pueden ir generando cadenas de migración parcial o totalmente ajenas a propósitos económicos concretos. 
En resumen, la atracción que tienen las zonas urbanas para los migrantes potenciales puede ser ilusoria en gran medida. Tal vez les sea difícil encontrar trabajo; es posible que los niveles de ingreso real sean considerablemente más bajos que lo esperado y que, además, los corroa la inflación, que la seguridad social sea precaria y que no haya viviendas disponibles. La propia inmigración presiona y contribuye a incapacitar a las instituciones existentes para atender a la población. Pese a todo, es posible que los migrantes -particularmente si vienen de zonas rurales - disfruten en promedio de condiciones de vida superiores, o por lo menos de alguna participación marginal en los beneficios sociales urbanos, lo que basta para impedir movimientos de regreso en gran escala.

Por convincentes que puedan ser las anteriores generalizaciones sobre los factores de atracción y repulsión, es preciso recordar que la influencia concreta de las condiciones estructurales de las zonas de origen y destino depende mucho de los valores, las actitudes y las motivaciones de los migrantes potenciales. Como señala correctamente Germani:

"Bajo condiciones desesperadamente malas, la gente no emigra. Por otra parte, frente a situaciones más aceptables, la gente emigra. Lo que pasa es que los factores llamados objetivos se filtran a través de actitudes y decisiones de los individuos. Las decisiones impersonales no deciden la migración. Ellas son personales y condicionadas por las actitudes de los individuos." 10

La investigación de motivaciones personales tiene así gran importancia para ayudar a comprender los factores que determinan la migración. Lamentablemente, las investigaciones empíricas que se han realizado sobre las motivaciones de los migrantes han tropezado con graves dificultades; las preguntas de las encuestas generalmente obligan a comprimir en categorias prestablecidas y rígidas, racionalizaciones falaces o motivaciones imprecisas y complejas que los propios migrantes pueden no ser capaces de expresar.

En todo caso, la investigación de las motivaciones subjetivas que llevan a la decisión de migrar tienden a corroborar en líneas generales lo sugerido por el análisis anterior acerca de los factores de atracción y repulsión. La mayor parte de estos estudios se ha efectuado en zonas urbanas de destino, pero las poblaciones incluidas en las muestras incluyen siempre migrantes que provienen de todo tipo de localidades. La motivación que mencionan con más frecuencia estos estudios es la "económica" o "de trabajo". ${ }^{11}$ En Monterrey, más de dos tercios de Ios encuestados señalaron las aspiraciones de trabajo como el principal motivo para trasladarse. ${ }^{12}$ En Santiago, el $62 \%$ de los varones y el $56 \%$

10 Véase Butterworth, op. cit., p. 87.

11 Juan C. Elizaga, Migraciones a las áreas metropolitanas de América Latina, CELAde, 1970 , pp. 88 a 95; Mario Margulis, "Análisis de un proceso migratorio rural-urbano en Argentina", Aportes, núm. 3, 1967, pp. 73 a 128. CELADE, tabulaciones inéditas de la encuesta en Lima Metropolitana (1965-1966); Harley Browning y W. Feindt, "The socioeconomic context of migration to Monterrey", en F. Rabinowitz y M. Trueblood (compiladores), Latin American Urban Annual, Sage Publications, 1970,-vol. I.

12 Browning y Feindt, op. cit. 
de las mujeres dieron razones similares. En esta encuesta se destac6 un punto interesante: que los migrantes desde las zonas rurales y los núcleos más pequeños, así como los trabajadores manuales, migran más por razones de trabajo que los trabajadores no manuales o que los migrantes originarios de centros urbanos más grandes. ${ }^{13}$ La mitad de los migrantes varones y tres décimos de las mujeres manifestaron en Lima que habían migrado a la capital por razones económicas; las razones de trabajo también fueron apreciablemente más frecuentes entre los trabajadores manuales y los migrantes con un nivel educativo bajo, aunque el tamaño del lugar de origen no aparecía relacionado de manera significativa con las motivaciones. ${ }^{14}$

En una investigación realizada en Argentina, en una comunidad rural de emigración, y en Buenos Aires, se preguntó a los encuestados algo diferente: ¿por qué migra la gente (en general)? Más de nueve décimos de quienes respondieron, tanto en la comunidad de origen como en la de destino, dijeron que la gente migraba en busca de trabajo. ${ }^{15}$

Resumiendo, hay acuerdo generalmente en que los migrantes consideran que la busca de trabajo o de un mejor empleo constituye el principal aliciente para migrar. Entre los motivos secundarios se hallan las necesidades de educación, los problemas familiares, la salud y otras razones diversas. Pese a que los resultados de estos distintos estudios son coincidentes, no parecen del todo satisfactorios. Aparte las dificultades metodológicas para medir las motivaciones, es probable que la falta de comparaciones de control entre migrantes y no migrantes, el tiempo transcurrido entre la decisión de migrar y la fecha de la encuesta, y la disyunción entre los motivos expresados y el verdadero perfil de los factores determinantes del desplazamiento, sean elementos todos que conspiren para restar significación a los resultados. Además, el descubrimiento de que los migrantes andan en busca de trabajo no ayuda particularmente a discernir, ya que no se distingue entre el campesino sin calificación que no ha podido ganarse la vida en otra parte, el universitario titulado que acude a trabajar en una firma de ingenieros, el oficinista cuyo ascenso lo lleva a otra ciudad y la adolescente que busca trabajo remunerado en los servicios domésticos por primera vez.

La investigación de las causas que determinan la migración podría hacerse también analizando los factores que influyen en el carácter selectivo de la propia emigración. Se sabe que los migrantes no constituyen una muestra fortuita de la población de las zonas de origen ni de las receptoras. Así, de la composición concreta de las corrientes migratorias se podrían inferir las circunstancias más propicias para la migración. En realidad, fuera de los trabajos mencionados, que clasifican las motivaciones de la migración por niveles educativos o grupos socioeconómicos, son pocos los estudios que han tratado de relacionar expresamente las características de selectividad de la migración con su etiología. Por lo demás, la única generalización respecto a la selectividad válida para

13 Elizaga, op. cit, pp. 88 y 95.

I4 CELADE, véase nota 11 en que se mencionan tabulaciones inéditas.

15 Margulis, op. cit. 
la mayoría de las corrientes migratorias hacia zonas urbanas en América Latina, es la que se refiere a la composición por sexo y edad; los adultos jóvenes tienden a una mayor movilidad que la población en general, y las mujeres -en particular las más jóvenes- tienden a migrar más que los hombres a distancias menores. Aparte estas características, quienes migran a las ciudades latinoamericanas configuran un grupo extremadamente heterogéneo por su educación, ocupación y características sociales. Es difícil por tanto evaluar la importancia de estos factores como determinantes de la migración. ${ }^{16}$

En general, vemos entonces que existe bastante coherencia y complementación entre lo que se ha escrito sobre los factores objetivos de repulsión y atracción, por un lado, y los estudios que investigan las motivaciones subjetivas de la decisión de migrar, por otro. Sin embargo, muchas de las generalizaciones existentes son demasiado absolutas y axiomáticas. Hay ciertamente algunos ejemplos de análisis más perspicaces de los factores de la migración en determinadas circunstancias y lugares; y este tipo de análisis, que vincula condiciones objetivas de las zonas de origen y de recepción a motivaciones individuales, dentro de los procesos más amplios de desarrollo nacional y regional, es el que parece más promisorio para futuras investigaciones. Sin embargo, parece difícil ir más allá de las burdas generalizaciones actuales, ya que las corrientes migratorias hacia zonas urbanas incluyen una gran gama de tipos sociales que varían no sólo en lo que toca a sus experiencias migratorias, sino también a su grado de socialización y a su status anterior a la migración.

B

PROCESOS SOCIALES Y ECONÓMICOS QUE INFLUYEN EN LOS CAMBIOS dE LA FECUNDIDAd EN AMÉrica LATINA

La evolución de la fecundidad en América Latina durante los últimos años muestra considerable heterogeneidad tanto en lo que se refiere a niveles como a tendencias. En general, las tasas de fecundidad siguen siendo muy altas, pero estudios recientes han atribuido mucha importancia a su leve declinación, luegu de prolongados períodos de natalidad elevada y hasta ascendente en casi la mitad de los países latinoamericanos. La importancia de la declinación no reside tanto en su magnitud, sino en la probabilidad de que sea precursora de un descenso mayor y continuo. La información disponible parecería indicar que las declinaciones no se deben simplemente a cambios en la distribución por sexo y edad, sino más bien a modificaciones de la información, las actitudes y las prácticas relacionadas con la fecundidad en ciertos gru-

16 Para un examen de las generalizaciones actuales sobre las características de los migrantes, véase Harley Brown, "Migrant selectivity and the growth of large cities in developing societies", Rapid Population Growth, The Johns Hopkins Press, Baltimore, 1971 , pp. 273 a 314. 
pos socioeconómicos. Se resume aquí la información existente sobre la influencia de factores socioeconómicos en los niveles, las tendencias y las diferencias de fecundidad en América Latina.

\section{1) Marco orgánico}

Pese a la gran cantidad de estudios que últimamente han procurado explicar los factores que influyen en la fecundidad, no parece aventurado afirmar que no se ha formulado todavía un marco teórico claramente definido para delinear los importantes procesos socioeconómicos que influyen en la fecundidad en América Latina. A falta de él, se usará un marco orgánico simple para examinar los factores más destacados, marco que se apoya en el supuesto de que las fuerzas sociales y económicas no influyen directamente en los procesos biológicos de reproducción, sino que más bien actúan sobre un conjunto de variables determinantes del riesgo de exposición en cada una de las etapas de la reproducción biológica: relaciones sexuales, concepción, gestación y parto. ${ }^{17}$ Para examinar cómo influyen los factores socioeconómicos en los niveles, las tendencias y las variaciones de la fecundidad es preciso analizar el efecto de estos procesos sobre las variables intermedias, dentro de las experiencias históricas de los países.

Siguiendo prácticas establecidas, las variables intermedias pueden dividirse inicialmente en $a$ ) las que entrañan nupcialidad, y $b$ ) las que afectan a la fecundidad dentro de las uniones. Aunque las fuerzas que actúan en ambos conjuntos de variables pueden ser similares, su distinción sigue siendo justificada, pues actúan de manera diferente en uno u otro. Por lo demás, la decisión de realizar una unión, ya sea que la tomen la pareja o los padres, generalmente no se adopta sólo sobre la base de las perspectivas de tener hijos, aunque el matrimonio y la procreación se hallan entrelazados.

Además, conviene distinguir dos categorías adicionales entre las variables intermedias dentro de las uniones: $b l$ ) las involuntarias y relacionadas primordialmente con la salud, como el aborto espontáneo o la esterilidad involuntaria, y $b 2$ ) las que entrañan alguna acción consciente para controlar la procreación, como el uso de anticonceptivos o el aborto inducido. Esta separación analítica de las variables intermedias en tres conjuntos permite analizar sistemáticamente el efecto neto de los procesos históricos de la sociedad en la fecundidad de los grupos, considerando los efectos de estos proceso en cada uno de los conjuntos de variables intermedias.

Puesto que los procesos societales que afectan al nivel de control consciente de la fecundidad se manifiestan a través de las acciones de individuos o parejas, tórnase lógico examinar los procesos en función de su efecto en las condiciones necesarias para que los individuos puedan

17 Judith Blake y Kingsley Davis formularon por primera vez once variables intermedias en un trabajo clásico: "Social structure and fertility: an analytical framework", Economic Development and Cultural Change, vol. rv, núm. 3, abril de 1956. 
ejercer ese control. Estas condiciones incluirían la motivación, la capacidad de instrumentación, el concepto de la legitimidad de controlar el tamaño de la familia. El grado en que los grupos de una sociedad intentan controlar su fecundidad depende de la medida en que se cumplan estas tres condiciones.

Haciendo uso de este marco orgánico, conviene pasar revista a investigaciones e hipótesis sobre los procesos sociales y económicos que afec$\tan$ a los tres conjuntos de variables intermedias. Cabe señalar que ni el marco mismo ni el análisis que sigue intentan explicar los procesos socioeconómicos en un contexto histórico y estructural. Hacerlo, requeriría una teoría que no se ha formulado todavía. Sin embargo, se espera -cuando los avances teóricos permitan hacer aclaraciones sobre varios países latinoamericanos- que el marco orgánico hará posible relacionar los conceptos teóricos más abstractos con los fenómenos concretos de la fecundidad.

Puesto que las diferencias y los cambios observados en los niveles de fecundidad derivan de los efectos netos y a veces contrapuestos de los procesos económicos y sociales sobre los factores que los determinan, no se examina aquí directamente la importancia relativa de las alteraciones de los factores que determinan dichos niveles.

\section{2) Influencias de la nupcialidad en la fecundidad}

a) Nupcialidad $y$ fecundidad. La fecundidad de una sociedad o grupo social en un momento dado es una función del número de nacimientos por mujer que vive en unión marital y de la proporción de todas las mujeres en edad de procrear que cohabitan. Aunque los datos sobre la formación de uniones en América Latina son más bien fragmentarios, no cabe duda que, para investigar las tendencias de la fecundidad, el término "unión marital" debe incluir no sólo las uniones institucionalizadas, sino también las consensuales. Además, también alcanzan cierta magnitud las uniones relativamente permanentes $\mathbf{u}$ otras que no significan cohabitación, pero como su número y efecto se desconocen en gran medida, aquí se examinarán primordialmente las uniones que significan cohabitación.

La importancia de distinguir en la fecundidad global entre dos componentes - la nupcialidad y la fecundidad marital- se ilustra en el cálculo de Collver de que alrededor de 1960 la fecundidad en América Latina era aproximadamente la mitad del máximo biolbgico, debido a las mujeres solteras, separadas, viudas o divorciadas. ${ }^{18}$ Por lo demás, los cambios en las variables intermedias relativas a la nupcialidad pueden actuar sobre la fecundidad en las mismas direcciones que los factores determinantes de la fecundidad marital o también en sentidos opuestos. Por ejemplo, en los años sesenta la reducción de la tasa de nupcia-

18 A.O. Collver, Birth rates in Latin America: New estimates of historical trends and tuctuations, Institute of International Studies, Res. Series, núm. 7, Universidad de California (Berkeley), 1965, p. 47. 
lidad y una baja de la fecundidad marital contribuyeron a que descendiera la fecundidad global en Costa Rica, ${ }^{19}$ en tanto que en Chile la tasa bruta de nupcialidad puede haber estado ascendiendo entre 1962 y 1965, precisamente cuando diversas medidas vinculadas a la fecundidad estaban augurando el comienzo de una larga declinación. ${ }^{20}$

Es una pena que se haya dedicado poca atención al estudio de la nupcialidad en América Latina. Ello se debe, en parte, a que una gran proporción de mujeres no vive en uniones legales. Por definición, quedan al margen de los registros de matrimonios, y en los censos suelen aparecer como célibes, particularmente si son separadas. (Por estas razones, autores como Dixon ${ }^{21}$ excluyen los países latinoamericanos de los estudios comparativos sobre la nupcialidad.) En consecuencia, estudiar las tendencias de la nupcialidad y su efecto sobre la fecundidad es difícil en muchos países. Sin embargo, Zulma Camisa ${ }^{22}$ y C. Arretx ${ }^{23}$ han realizado algunos trabajos sobre esas tendencias, analizando datos de los censos de 1950 y 1960 . Campanario usa estos datos para calcular índices que separan las tendencias globales de la fecundidad, incluidas todas las mujeres, en los componentes de nupcialidad y fecundidad marital. Sus datos muestran, por ejemplo, que mientras la fecundidad en las uniones decreció levemente en Brasil entre 1940 y 1950, la nupcialidad tomó la dirección opuesta. ${ }^{24}$

Se han realizado algunas investigaciones sobre los tipos de uniones y su efecto sobre la fecundidad, particularmente en los países caribeños de habla inglesa. ${ }^{25}$ En general, se ha comprobado que mientras más estable es la unión mayor es la fecundidad; es decir, en las uniones legales la fecundidad es más alta, seguidas por las consensuales y por las transitorias; el último lugar lo ocupan las uniones sin cohabitación. ${ }^{26} \mathrm{En}$ América Latina, Yaukey, Thorsen y Osaka, ${ }^{27}$ utilizando datos de siete zonas metropolitanas, ${ }^{28}$ encontraron que las mujeres que vivían en unio-

19 M. Gómez, "El rápido descenso de la fecunididad en Costa Rica", Informe del $5^{\circ}$ Seminario Nacional de Demografía, Asociación Demográfica Costarricense, San José (Costa Rica).

20 F. Flores, Estudio de la nupcialidad en Chile: Análisis en el tiempo y en el espacio, Santiago, CELADr, 1972 (documento mimeografiado).

21 R. Dixon, "Explaining cross-cultural variations in age at marriage and proportions never marrying", Population Studies (1971), vol. 25, Pp. 215 a 233.

22 Z. Camisa, La nupcialidad femenina en América Latina durante el período intercensal 1950-1960, CELADE, AS/10, San José de Costa Rica, 1971.

23 C. Arretx, "Nuptiality in Latin America", Proceedings of the General Conference of the IUSSP, Londres, 1969, vol. 3.

24 P. Campanario, Factores que influyen en la fecundidad y los factores maltusiano y neomaltusiano, CELADE, Serie c/142, Santiago, 1972.

25 W. Mertens, "Investigación sobre la fecundidad y la planificación familiar en América Latina", Documentos de la Conferencia Regional Latinoamericana, El Colegio de México, 1970, vol. 1, pp. 193 a 235.

26 G.W. Roberts, "Fertility in some Caribbean countries", Proceedings of the General Conference of the IUSSP, Londres, 1969.

27 D. Yaukey, T. Thorsen y A.T. Osaka, "Marriage at an earlier than ideal age in six Latin American cities", Population Studies, 1972, vol, 26-2, pp. 263 a 272.

28 A. Conning los proporciona en Encuestas comparativas de fecundidad en América 
nes consensuales perdían mucho más tiempo por separaciones que aquellas cuyas uniones eran legales; sin embargo, las diferencias entre ambos tipos de uniones variaban de dirección entre una ciudad y otra. ${ }^{29}$ Por lo general, las mujeres que vivían en uniones consensuales tendían a una fecundidad mayor que las casadas legalmente en ciudades en que ese tipo de uniones abarcaba un porcentaje elevado de las uniones totales. Sin embargo, Miró y Mertens ${ }^{30}$ previenen contra el riesgo de extraer conclusiones sin encuestas más precisas y complejas. Se precisará asimismo mucha cautela al analizar la fecundidad por tipos de unión actuales, ya que las uniones consensuales tienden a legalizarse a medida que las mujeres envejecen, y esto puede causar cambios en los niveles de fecundidad aparentemente asociados a las uniones legales. ${ }^{31}$ Tabulaciones inéditas del CELADE, basadas en encuestas en zonas rurales y pequeñas localidades urbanas, ${ }^{32}$ muestran que un gran porcentaje de las mujeres que aparecen en una segunda unión son mujeres que siguen viviendo con el mismo hombre, pero ahora en unión legalizada.

\section{b) Procesos socioeconómicos que afectan a la nupcialidad}

Hay una falta general de investigaciones que exploren la nupcialidad. ${ }^{33}$ En América Latina, a la carencia de datos y de análisis descriptivos de este tema se agrega la ausencia general de investigaciones sobre los factores y procesos socioeconómicos que generan las modalidades de unión y los cambios en ellas registrados.

Se ha investigado algo sobre las diferencias en la edad de la primera unión. Por ejemplo, Yaukey, Thorsen y Osaka observaron que en siete ciudades - de conformidad con las encuestas PECFAL-U (CELADE, Programa de Encuestas Comparativas de Fecundidad-Zona Urbana)las mujeres con más educación tendían a realizar su primera unión a edades más tardías, y luego intentaron explicar, sin mucho éxito, las edades reales de matrimonio en términos de las edades ideales de las mujeres para casarse..$^{34}$ En el plano global, Collver afirmó que las condiciones económicas durante la primera mitad del siglo $\mathrm{xx}$ llevaron a diferencias en las tasas de nupcialidad de muchos países latinoamericanos, las que a su vez causaron fluctuaciones en la natalidad. Además, encontró pruebas circunstanciales para sostener que los países más dependientes de las exportaciones y del capital extranjero fueron los que sufrieron las mayores declinaciones en sus tasas brutas de natalidad durante la Gran

Latina: Algunos aspectos metodológicos, documento preparado para la 24a. reunión anual de la Sociedade Brasileira para o Progresso da Ciencia, São Paulo, 1972.

20 C. Miró y W. Mertens, "Influences affecting fertility in urban and rural Latin

American", Milbank Memorial Fund Quarterly, 1968, vol. XLVI-3, pp. 89 a 117.
30 Ibid., p. 102.

81 W. Mertens, op. cit., p. 201.

32 Estos datos aparecen en Conning, op. cit.

33 J. Heeren, "Marriage as a Demographic Variable", Proceedings of the General Conference of the russp, Lieja, 1973, Pp. 9 a 17; Geoffrey Hawthome, The Sociology of Fertility, Londres, Collier Macmillan, 1970.

34. Yaukey y otros, op. cit. 
Depresión de los años treinta. ${ }^{35}$ Por su parte, Flores ha observado que las tasas de nupcialidad e inflación en Chile parecen variar juntas, y que muestran una correlación clara con acontecimientos políticos importantes (elecciones presidenciales, por ejemplo), aunque no lo ha intentado explicar en detalle. ${ }^{36}$ Parece haber algunos indicios de que la tasa de matrimonios aumentó en Cuba luego de la Revolución de 1959. Ello podría haber explicado el gran incremento de las tasas brutas de natalidad, que habían estado declinando: de 27 por mil en 1958 a cerca de 37 por mil en 1962. Tanto los cambios en la natalidad como en la nupcialidad probablemente guardaron relación con el mayor bienestar que disfrutó la población durante el mismo período, ya que el empleo total se elevó en un gran porcentaje, los alquileres urbanos bajaron a la mitad y se pusieron en práctica otras medidas similares. Cuando las condiciones económicas empezaron a hacerse más difíciles en 1962, la tasa de natalidad comenzó a bajar otra vez. ${ }^{37}$

Habrá que profundizar más en el estudio de la nupcialidad, a través de mediciones más adecuadas de sus niveles y tendencias, y el examen de los factores que influyen en estas últimas. Ya que es posible aplazar el matrimonio (es decir, cambiar la edad de matrimonio) ante condiciones económicas o sociales reales o previstas, sin que cambien los factores subyacentes, es importante tratar de distinguir entre las tendencias a corto y a largo plazo. Cabría esperar que la elevación de los niveles de escolaridad y de la educación de adultos, el grado cada vez mayor de conciencia y de participación políticas, los cambios en los niveles y la distribución del ingreso, los métodos más eficientes de control de la natalidad (que disminuyen las uniones forzadas por embarazos premaritales), la mayor participación de mujeres solteras en la fuerza de trabajo y en empleos de más categoría, y en general los cambios en los papeles y el status de la mujer, son factores que a largo plazo llevarán a uniones en edades más tardías en los grupos que actualmente llegan bastante jóvenes a la primera unión.

\section{3) Factores determinantes de la fecundidad marital}

a) La salud biológica y las variables vinculadas al control deliberado de la fecundidad. De acuerdo con el marco orgánico antes propuesto, cabe centrarse ahora en la fecundidad marital - esto es, la fecundidad dentro de las uniones legales o consensuales-- excluyendo las consideraciones relativas a la nupcialidad. Con este fin, se tratará de verificar el efecto de los factores socioeconómicos sobre la propia fecundidad marital, pero - ya se dijo- un enfoque de esta índole resta precisión al

35 Collver, op. cit., pp. 33 a 36, y A.O. Collver, "Current trends and differentials in fertility as revealed by official data", Milbank Memorial Fund Quarterly, XLVI, 1968, 2 ? parte, p. 42 .

36 F. FJores, Estudio de la nupcialidad en Chile: Análisis en el tiempo y en el pacio, op. cit.

${ }^{37}$ Barent Lanstreet, Jr., "Marxists" en J.M. Stycos, Ideology, Faith and Family. Planning in Latin America, Nueva York, 1971. 
análisis. En efecto, los procesos sociales y económicos no afectan la fecundidad de manera directa, sino más bien a través de su influencia en las variables intermedias.

Concentrarse en el estudio de las variables intermedias más que en la propia fecundidad marital tiene importancia por dos razones. Primero, un gran porcentaje de la variación de la fecundidad entre las personas puede atribuirse a factores biológicos y accidentales que hacen difícil analizar los efectos directos de cambios sociales complejos sobre la fecundidad, particularmente en el plano individual. ${ }^{38}$ Segundo, otro enfoque sería que ciertos cambios sociales o económicos no están afectando a la fecundidad, cuando en realidad están influyendo de diferentes maneras en las distintas variables intermedias, o anulándose recíprocamente en otras formas. Por ejemplo, la modificación del nivel económico de un grupo social podría llevar a una disminución de la tasa de aborto espontáneo, lo que ejercería una influencia positiva en la tasa de fecundidad, ${ }^{39}$ pero al mismo tiempo podría conducir también a un uso más generalizado de los anticonceptivos $\mathrm{y}$, por ende, a una menor fecundidad. Es concebible entonces que el resultado neto de estas influencias contradictorias sobre la fecundidad pueda ser nulo, por lo menos en las etapas iniciales de la transformación.

Como se indicó al esbozar el marco orgánico, es conveniente subdividir las variables intermedias que actúan dentro de las uniones en dos categorías generales: las variables relativas a la salud biologica, que incluyen la abstinencia por enfermedad, esterilidad involuntaria y aborto espontáneo; y las variables que obedecen a un control deliberado,40 como la abstinencia (así en el método del ritmo, por ejemplo), los anticonceptivos, la esterilización para evitar la procreación y el aborto inducido. ${ }^{11}$ Que una acción dada se ubique en una u otra categoría puede depender de las circunstancias. En una sociedad puede practicarse la lactancia prolongada por razones ajenas al control de la natalidad, en cuyo caso se hablaría de esterilidad temporal "involuntaria"; pero si se utiliza para evitar el embarazo, se considerará como una medida consciente para reducir la fecundidad. La distinción entre la salud biológica y la acción consciente en ciertas situaciones concretas podría ser problemática, pero sigue siendo útil desde el punto de vista analítico. Las modificaciones en las variables relativas a la salud biológica explican diferencias de fecundidad "natural" y también disparidades entre poblaciones que sólo últimamente han comenzado a practicar alguna forma de control de la natalidad. Las variables correspondientes a acciones delibe-

38 P.C. Sagi y C.F. Westoff, "An exercise in partitioning some components of the variance of family size. Emerging trends in population research", Milbank Memorial Fund Quarterly, 1963, pp. 130 a 140.

39 F. Flores, Efectos de los cambios de la mortalidad sobre la fecundidad: aplicación de un modelo de simulación, cELAde, Santiago, 1971.

40 Pese a que éste no es un término muy feliz se prefiere al de "control voluntario", porque evita las ambigüedades de este áltimo.

41 La frecuencia del coito no se ha incluido en ninguna de las dos categorias, porque la información es inadecuada. 
radas son más sensibles al cambio socioeconómico y explican satisfactoriamente anteriores bajas de la fecundidad.

\section{b) Fecundidad marital no controlada ("natural")}

Por razones ya señaladas, la información sobre la fecundidad marital en América Latina es deficiente, en particular respecto de cada subgrupo interno. Sin embargo, es lógico suponer que estos niveles son altos en la mayoría de los países, ya que las tasas nacionales (incluidas todas las mujeres en edad de procrear) son generalmente elevadas. ${ }^{42}$ Además, es.muy probable que la mayoría de los países - incluso aquellos con niveles intermedios de fecundidad- tenga en su seno subgrupos considerables de elevada fecundidad. De aquí que el análisis de los factores socioeconómicos que influyen en la fecundidad conyugal deba precederse de un examen de la fecundidad no controlada o "natural", definida por Henry como la que existe en uniones cuyo comportamiento reproductivo no se altera con el número de hijos ya nacidos..3 ${ }^{43}$ Por definición, las acciones de control deliberado no se practican en las poblaciones con fecundidad natural. Puesto que la fecundidad natural es el resultado no sólo de los niveles biológicos inherentes, sino también de los efectos biológicos de variables determinadas por factores sociales (salud y nutrición, por ejemplo) ${ }^{44}$ y de prácticas de la población que reducen la fecundidad de manera no deliberada, es comprensible que los niveles de fecundidad natural varíen de una sociedad a otra. Sin embargo, pese a las variaciones, la estructura de las tasas de fecundidad por edades tiende a ser independiente del nivel. ${ }^{45}$

El reconocimiento de la importancia teórica y empírica de la fecundidad natural es muy reciente $y$, por lo tanto, se han hecho pocos intentos de revelar niveles y diferencias de fecundidad natural en América Latina. Sin duda esta es una esfera importante para investigaciones futuras y puede llevar al descubrimiento de prácticas de control no observadas anteriormente. El punto tiene cierta trascendencia, porque los investigadores suelen suponer que las grandes mayorías de la población nunca han conocido ni practicado forma alguna de control de la natalidad antes de que apareciesen los métodos anticonceptivos modernos. Sin embargo, los antropólogos dan a entender que casi todos los grupos primitivos comprenden la vinculación existente entre la relación sexual y la procreación, ${ }^{46}$ y es difícil aceptar a priori que métodos como el aborto o el coitus interruptus fuesen desconocidos para la mayoría de las poblaciones latinoamericanas, aunque sólo se practicaran ocasionalmente

42 A.M. Conning, "Latin American fertility trends and influencing factors", Proceedings of the General Conference of the russp, Lieja, 1973, pp. 125 a 147.

43 L. Henry, "Some data on natural fertility", Eugenics Quarterly, vol. 8, núm. 2, 1961.

44 J. Sheps, M. Ridley y otros, "The effects of changing mortality on natality", Milbank Memorial Fund Quarterly, XIV-1, pp. 77 a 97.

45 Thomas Espenshade, "A new method for estimating the level of national fertility in population practicing birth control", Demography, 1971, vol. 8-4, pp. 525 a 536.

46 G. Hawthome, The Sociology of Fertility, op. cit., p. 38. 
o de manera ineficiente. La comprobación de diferencias en los niveles de fecundidad de poblaciones que en lo demás son similares, podría reflejar prácticas de control y una motivación básica para regular la fecundidad.

\section{c) El control de la fecundidad marital}

r) Diferencias y declinación de la fecundidad. Las diferencias de fecundidad existentes entre muchas ciudades latinoamericanas - y en menor medida en algunas zonas rurales- sugieren que en la mayoría de los países ciertos sectores de la población pueden estar ejerciendo algún control sobre su fecundidad. ${ }^{7}$ Sin embargo, comprobar las diferencias es sólo un punto de partida para comprender las modalidades y cambios de la fecundidad. Para pasar más adelante, será preciso dilucidar los cambios macroeconómicos y macrosociales que originan esas disparidades, así como los mecanismos sociales y sicológicos a través de los cuales actúan ciertos factores en determinadas condiciones historicas. Se explorarán a continuación los procesos socioeconómicos y los mecanismos que modifican aquellas variables intermedias que entrañan accion deliberada, es decir, los anticonceptivos, el aborto inducido, la esterilización y la abstinencia voluntaria.

No se espera encontrar leyes universales que expliquen los variados niveles del control deliberado de la fecundidad en todas las circunstancias. Es efectivo que hasta ahora ninguna generalización absoluta ha logrado explicar las diversas transiciones europeas desde tasas altas a bajas de fecundidad marital. ${ }^{48}$ Las variables pertinentes y los procesos que las modifican parecen cambiar con las condiciones históricas. Además, la acción concreta de los factores puede depender de las formas de organización social. Es probable que la educación en una sociedad socialista como Cuba tenga distintas repercusiones que la educación en una sociedad como la de la República Dominicana. Aun cuando la educación afecte a la fecundidad en ambos países, la naturaleza de la educación y la interpretación de cómo actúa probablemente diferirán mucho entre las dos sociedades.

Esas dificultades limitan la capacidad para generalizar sin un marco teórico básico, pero no impiden definir un paradigma simple que establece los requisitos básicos para el control de la fecundidad. Tales requisitos permiten organizar la información conocida y proponen o sugieren investigaciones que pueden tener utilidad, cualquiera que sea el marco teórico que se elabore en el futuro. $\mathrm{El}$ examen de esos requisitos propicia asimismo una revisión sistemática de los procesos socioeconómicos que influyen en los factores determinantes del control deliberado de la fecundidad marital.

47 Véanse Mertens, op. cit. (cuadros sobre el uso de anticonceptivos), y E. Carrasco, "Incidence of abortion, fertility and contraception in Latin America", Proceedings of the General Conference of the russP, Lieja, 1973 (datos más restringidos sobre el aborto).

48 Véase, por ejemplo, E. Van de Walle y J. Knodel, "Demographic transition and fertility decline: the European case", Proceeding of the IUssp Conference, 1967, p. 47. 
II) Precondiciones para el control de la fecundidad marital. Comiéncese por suponer que el descenso significativo y permanente de la fecundidad marital de un grupo por debajo de la fecundidad natural requiere normalmente algún consciente esfuerzo por parte de los individuos o las parejas, por ambiguo, confuso o incierto que sea. Esto es así, estén o no relacionados directamente con el coito los métodos que se empleen, aunque estos últimos parecerían requerir una motivación menos constante. Cualquiera que sea el método elegido, el individuo o la pareja debe adoptar alguna forma de acción deliberada. El hecho de adoptarla indica que existen ciertas condiciones o requisitos previos en el plano individual; $y$, para que cambie la fecundidad del grupo, deben hallarse bastante difundidos. Por ello, interesa definir qué condiciones deben darse en la sociedad para que un número significativo de personas regule deliberadamente su fecundidad.

Los requisitos lógicos para controlar la fecundidad -antes implícitos en muchas obras especializadas - últimamente han sido descritos de manera explícita, en todo o en parte, por diversos autores. ${ }^{49}$ Parece esencial definir tres condiciones fundamentales: motivación: el control de la fecundidad debe considerarse ventajoso por las parejas, aunque éstas no tengan clara su motivación exacta, que puede variar en su dirección o su intensidad o en ambas cosas; capacidad: es preciso disponer de técnicas de control, y la gente debe conocerlas y ser capaz de utilizarlas; esto va más allá de la simple capacidad técnica; por ejemplo, tal vez sea indispensable la comunicación entre los cónyuges para identificar motivaciones comunes y controlar adecuadamente su fecundidad, y legitimidad: el control de la fecundidad debe hallarse "dentro del cálculo de la decisión consciente". Este concepto difiere del de la motivación para controlar la fecundidad, pues una pareja puede tener razones válidas para no tener más hijos, pero a la vez creer que no es legítimo desvirtuar los procesos naturales, o que deben aceptar con fatalismo todo lo que ocurra.

III) Grado en que se dan estas condiciones en América Latina. Las tres condiciones señaladas son necesarias para que se lleve a cabo el control de la fecundidad. Sin embargo, una o más de ellas pueden darse en sociedades que no ejercen este control. Determinar si existen en poblaciones que no practican en su mayoría el control de la fecundidad, es un paso necesario para conocer el avance de los grupos hacia ese control conforme las fuerzas socioeconómicas crean o retardan las demás condiciones.

En alguna medida estas condiciones tal vez están presentes en todas

49 Véanse R.O. Carleton, Aspectos metodológicos y sociológicos de la fecundidad humana, CELADE, Serie E/7, Santiago, 1970; C.B. Rosen y A.B. Simmons, "Industrialization, family and fertility: A structural psychological analysis of the Brazilian case", Demography, 8, 1971, pp. 49 a 69; A.B. Simmons, "Social economic factors influencing fertility in Latin America", 1973, CELADE (documento de trabajo mecanografiado), y "Ambivalencia en la preferencia por familias chicas en América Latina rural", sTEF, Documento Al/Pl (S/101/32/73), 1973; A. Coale, "The demographic transition reconsidered", Proceedings of the General Conference of the noss, Lieja, 1973, pp. 53 a 72. 
las sociedades latinoamericanas, entre ciertos grupos de las grandes ciudades y -en forma mucho más limitada - en algunas zonas rurales. Un examen de los indicadores pertinentes parece indicar que en muchos de los países están poco difundidas las condiciones de motivación y capacidad. Sin embargo, como los datos sobre la capacidad de instrumentación -y en particular sobre èl conocimiento de métodos anticonceptivos- normalmente se han obtenido en encuestas realizadas entre mujeres, tal vez se haya subestimado el conocimiento real de la pareja, porque los varones pueden saber más al respecto o estar más dispuestos a revelar su conocimiento. Por otro lado, la medición de las preferencias respecto al tamaño de la familia, por ejemplo, pueden sobrestimar la motivación, ya que la mayor parte de las encuestas que han proporcionado dicha información tienden a suponer que el encuestado posee una idea clara sobre el tamaño de la familia, y, por lo tanto, obligan a dar una sola respuesta numérica. En realidad, hay indicios de que los encuestados - por lo menos en las zonas rurales- suelen tener sentimientos ambivalentes lo mismo ante familias grandes que pequeñas, aun cuando sientan cierta predilección por una u otra. ${ }^{50}$

\section{4) Procesos sociales que influyen en las condiciones necesarias para el control de la fecundidad marital}

a) Consideraciones metodológicas. Dadas las diferencias básicas entre sistemas sociales y antecedentes históricos, es muy poco probable que un conjunto de factores socioeconómicos influya de igual manera en cada uno de los países latinoamericanos sobre las condiciones necesarias para que exista control de la fecundidad. Por lo tanto, no se enumerarán aquí variables aparentemente relacionadas con la motivación, la capacidad, la legitimidad o la fecundidad. En cambio, se esbozarán brevemente algunos procesos socioeconómicos de importancia ${ }^{51}$ que se observan en muchas sociedades latinoamericanas y que parecen influir en una o más de las condiciones previas. ${ }^{52}$ Se tratará aquí por separado cada una de estas condiciones, pero en un enfoque más "sofisticado" habría que reseñar sus efectos conjuntos.

Los procesos en marcha en cada sociedad adquirirán rasgos peculiares por la acción de sus características y condiciones particulares. Así, el mismo proceso general puede influir en las condiciones señaladas mediante diferentes mecanismos y en distintos grados. Cabe además des-

50 A.B. Simmons, "Ambivalencia en la preferencia por familias chicas en América La. tina rural", op. cit.

51 La palabra "proceso" se emplea en un sentido dinámico y no estático. En su sentido estático, "proceso" indica una cadena de acontecimientos relacionados cntre sí que se repite indefinidamente sin cambiar sus características (por ejemplo, el procesa. biológico normal de la reproducción, desde la concepción hasta el parto). Aquí, la pa. labra proceso se usa en el sentido dinámico de cambios interrelacionados que provocan una alteración permanente de la sociedad.

52 Algunas de las ideas presentadas aquí se elaboraron en el Primer Seminario de. Capacitación en Investigación (CELADE, Santiago de Chile, septiembre de 1972 a fe. brero de 1973). 
tacar que, aunque la noción dinámica de proceso aquí adoptada requiere datos empíricos de estudios longitudinales, el material disponible proviene de investigaciones realizadas en cortes transversales. En tanto que algunos estudios tal vez se aproximen a eslabones causales, cabe recordar que la mayor parte de la información procede de estudios de diferencias, que no distinguen normalmente entre la posibilidad de que una variable dada "cause" la diferencia, y la posibilidad de que la diferencia obedezca a otro factor o exista previamente.

b) Procesos que influyen en la motivación. Determinar cuáles son los proceso sociales importantes que parecen influir en la motivacion para controlar la fecundidad es más difícil que definir los procesos que afectan a la capacidad de controlarla. Estos últimos - aunque abarcan algo más que simples conocimientos técnicos - tienen contenidos relativamente concretos. No sucede lo mismo con los que se refieren a la motivación. Además, los procesos que influyen en ésta se hallan relacionados más estrechamente con la organización económica y social de cada sociedad y con las complejas fuerzas que pueden estar dando nueva forma a sus estructuras.

Otra dificultad para definir los procesos que influyen en la motivación reside en que - dada la índole de las relaciones sociales dentro de las comunidades y sociedades - los procesos que comenzaron a alterarla pueden perder importancia a medida que afectan a segmentos más amplios de la población, y ciertos aspectos del comportamiento comienzan a regirse por nuevas normas que afectan a todos. Por ejemplo, las diferencias de motivación debidas a factores educativos son bastante sistemáticas: quienes han recibido más educación tienen aspiraciones más ambiciosas para sus hijos.58 Pero, a medida que crece la proporción de la sociedad que hace suyas tales aspiraciones, éstas se transforman en normativas y las diferencias derivadas de la educación decrecen, porque casi todos tienen aspiraciones elevadas. Así, paradojicamente, los procesos que modifican las motivaciones pueden llegar a influir en grupos a los que no afectan en forma directa.

Esta enumeración de procesos no incluye directamente dos factores ampliamente discutidos: la educación y la urbanización. Los avances en la educación pueden mirarse en un sentido limitado como un incremento del número medio de años de escolaridad, y, en un sentido más amplio, incluir todas las nuevas situaciones de aprendizaje que acrecientan la educación, ya sea a través de la educación sistemática, de los medios de información o del contacto con otras comunidades (particularmente en lo que toca a los grupos rurales). Considerando la educación en el sentido más amplio, se ha subsumido en varios procesos generales, en los cuales la educacion desempeña un papel de importancia. Esto no sólo parece colocar en una adecuada perspectiva su importancia, sino que ayuda a precaverse de la simplificación excesiva de

53 J. de Jong, "Aceptación de cambios en la posición de la mujer: su valor explicativo en relación a las actitudes hacia la fecundidad", documento presentado en el Primer Seminario SIEF (Al/P4), CELADE, Santiago de Chile, 1973. 
que el cambio en la educación de por sí elevará la motivación, y, por lo tanto, reducirá los niveles de fecundidad.54 En tanto que los incrementos en el nivel de educación sistemática no se consideran procesos por ser demasiado específicos, no se ha hecho hincapié en la urbanización cemo proceso, por ser demasiado general y ambiguo. Sin embargo, algunos aspectos de la urbanización -por ejemplo, la migración del campo a la ciudad-guardan relación con varios de los procesos reseñados.

Entre los procesos más importantes parecerían hallarse los siguientes:

I) Cambios en la economía. Incremento en el ingreso y los servicios por habitante. Entre los cambios de las economías que afectan a la motivación para regular la fecundidad son corrientes los que se derivan de la industrialización. Esta merma normalmente el porcentaje de la población que se dedica a las actividades agrícolas, y va acompañada de migraciones hacia las zonas urbanas desde zonas rurales de mayor fecundidad. Cabe suponer que los hombres o mujeres que ingresan a fábricas o establecimientos comerciales estarán más propensos a adoptar normas urbanas. $Y$ puesto que la educación es un requisito necesario para ascender en su situación, pueden modificar sus aspiraciones para sus hijos. Rosen y Simmons ${ }^{55}$ afirman que la educación y las oportunidades de trabajo que ofrece la industrialización a las mujeres puede conducir a que prefieran tener familias más pequeñas. Sin embargo, como la industria latinoamericana no ha logrado absorber todos los emigrantes de las zonas rurales, son muchos los hombres y las mujeres que se incorporan al sector de actividades varias o al servicio doméstico: estos grupos son menos propensos a adoptar las normas urbanas, entre ellas las relacionadas con la fecundidad.

Los cambios en la economía pueden acrecentar el ingreso por habitante y elevar así el bienestar general si los incrementos llegan a toda la población. A su vez, esto podría aumentar el número de hijos sobrevivientes, $\mathrm{y}$, por lo tanto, reducir la motivación para procrear ilimitadamente. La mayoría de los países cuya fecundidad parece haber declinado de 1960 en adelante, tuvo incrementos relativamente grandes del ingreso por habitante entre 1960 y 1970. Sin embargo, hay que destacar que muchos países con fecundidad aparentemente estable tendieron también a registrar importantes incrementos del ingreso nacional por habitante, lo que sugiere que esos cambios globales no son razón suficiente. $^{56} \mathrm{Si}$ el examen de la distribución del mayor ingreso puede o no explicar lo observado es algo que habría que averiguar.

La extensión de servicios básicos a sectores más vastos de la población puede influir en la motivación, ya que cambia la gravitación de los hijos en la economía familiar y tiende a acrecentar algunos gastos de la familia. Así sucede en especial con la extensión de la enseñanza, que

$54 \mathrm{El}$ error metodologico de este raciocinio reside en que las diferencias educativas que aparecen en cortes transversales no significan necesariamente que un incremento de los niveles educativos a través del tiempo lleven a un descenso de la fecundidad.

55 Rosen y Simmons, op. cit.

56 Conning, op. cit. 
mantiene más tiempo a los niños fuera de la fuerza de trabajo. Además, la elevación de los niveles educativos puede generar aspiraciones socioeconómicas más ambiciosas y, por ende, una mayor motivación para controlar la fecundidad.

II) Propagación de nuevos estilos de vida orientados al consumo. Este fenómeno puede ser concomitante del desarrollo económico, aunque las condiciones objetivas de la población en general tal vez cambien muy poco en situaciones de escasa redistribución del ingreso o reducida participación en los frutos del desarrollo. No obstante, se observan cambios en el nivel de aspiraciones para los hijos aun cuando las probabilidades de realizarlas sean muy limitadas. Por ejemplo, en las zonas rurales de Costa Rica casi todas las mujeres cuyos cónyuges trabajan en ocupaciones no agrícolas y cuyas viviendas son adecuadas, desean que sus hijos reciban enseñanza secundaria o superior; lo mismo desea un porcentaje menor, pero todavía alto $(79 \%)$, de mujeres que viven en viviendas muy inadecuadas y cuyos maridos trabajan en labores agrícolas. No es de extrañar que en México y Perú todas las mujeres que disfrutan de las mejores condiciones de vida tengan elevadas aspiraciones para sus hijos, pero entre aquellas que viven en situación desmedrada en zonas agrícolas los porcentajes eran sólo de 56 y $67 \%$, respectivamente. ${ }^{57}$

III) Cambios en la estructura familiar y en la relación de la familia con la sociedad nacional. La familia como institución se especializa cada vez más en actividades de producción separadas del consumo a medida que cambia la economía. Como resultado, dispone menos de los hijos para ejecutar trabajos remunerativos, en parte porque aumentan las exigencias de educación junto con las aspiraciones. De este modo, cambia el concepto de valor que se tiene de los hijos. Crece la necesidad de realizaciones fuera del círculo familiar, mientras disminuye el valor económico de los hijos para sus padres. Este efecto se hace sentir con más rapidez en las familias urbanas y en aquellas pertenecientes a los estratos sociales medios. El cambio del valor de los hijos para la economía familiar es probable que sea la causa de que aproximadamente el $50 \%$ de los encuestados en la muestra PECFAL-Rural 1969-1970 creyera que era más ventajoso, desde el punto de vista económico, tener una familia pequeña, en tanto que igual porcentaje creía que esto también era cierto en una familia numerosa (aunque sólo el $18 \%$ creía desventajoso tener una familia pequeña).$^{58}$ Estos resultados no son necesariamente contradictorios, ya que es posible ver ventajas y desventajas similares en familias grandes y pequeñas, sobre todo cuando están cambiando las condiciones en que se desenvuelven.

IV) Cambios en los papeles y el status de la mujer. Se ha adelantado la hipótesis de que la modificación de los papeles y el status de la mujer tanto dentro como fuera del hogar influyen en la motivación para regu-

57 J. de Jong, "Hallazgos provenientes de PECFAL-Rural", CELAdE, Santiago de Chile, 1973 (trabajo inédito).

58 Simmons, "Ambivalencia en la preferencia por familias chicas en América Latina rural', op. cit. 
lar la dimensión de la familia. Este proceso puede significar alguna incompatibilidad de funciones, primordialmente por el conflicto entre las responsabilidades hogareñas y el empleo, pero también porque la participación política u otras actividades hacen pasar más tiempo fuera del hogar. El trabajo externo puede originar no sólo incompatibilidad de funciones, sino también un mayor interés en actividades no familiares, reduciendo así la motivación para tener hijos. Por último, la incorporación activa de parte de las mujeres de un país o comunidad a actividades no domésticas puede influir sobre otras que no trabajan a través de la comunicación con las primeras, o de cambios en las normas básicas.

Aunque los cambios en el papel y en el status de la mujer no se traducen sólo en mayores oportunidades de trabajo y niveles de educación más altos para las mujeres, estas tendencias son fundamentales, como en parte han mostrado Rosen y Simmons. ${ }^{59}$ Utilizando datos de siete zonas metropolitanas, se ha observado también que las características de la ciudad eran útiles para determinar el efecto de la incompatibilidad de funciones en la fecundidad y los métodos anticonceptivos. ${ }^{60} \mathrm{El}$ efecto era mayor cuando la fecundidad declinaba y se miraban con aprobación las actividades no domésticas. La incompatibilidad no guardaba relación con la fecundidad en ciudades donde ésta era muy alta o muy baja.

v) Movilización de masas. La movilización y organización políticas pueden influir en el comportamiento reproductivo. Esta hipótesis no cuenta aún con mucho respaldo empírico, pero varios autores la han propuesto desde un punto de vista teórico. ${ }^{81}$ Puede decirse en parte que la movilización política orientada hacia un país socialista hace menos hincapié en la familia y más en la sociedad, con lo cual disminuye la motivación personal para tener muchos hijos. González y Errázuriz han sugerido también que la particular forma de movilización de los diferentes partidos políticos en Chile debería tener efectos diferentes sobre la motivación de las mujeres para controlar el tamaño de la familia en los tugurios. ${ }^{62}$

Nuevos estudios sobre Chile mostrarán tal vez que la declinación de la fecundidad iniciada a comienzos de los años sesenta obedeció a los mismos factores que primero llevaron al poder a un gobierno demócratacristiano de centro-izquierda (1964-1970) y luego a un gobierno marxista (1970-1973). Ambas cosas pueden estar relacionadas con cambios que agudizaron la conciencia política y las nuevas aspiraciones populares. El estudio de los efectos de las políticas del gobierno marxista en las condiciones necesarias para el control de la fecundidad y en la fecundidad marital (así como en la nupcialidad) tendrá que tomar en cuenta

59 Rosen y Simmons, op. cit.

60 Véase Paula Hass, Maternal Employment and Fertility in Metropolitan Latin America (tesis inédita para el doctorado), Duke University, 1971, pp. 315 a 317.

61 J. Duque y E. Pastrana, Las estrategias de supervivencia económica del sector po. pulat urbano, elas-rLacso, 1973. Véase más información sobre este punto en el capítulo Iv.

62 G. González y M.M. Errázuriz, The Marginal Family: Social Change and Women's Contraceptive Behavior, documento preparado para el Congress of Anthropological and Ethnological Sciences, CELADE, 1973 (manuscrito). 
no sólo los cambios en la movilización política, sino también los efectos a corto plazo de la redistribución del ingreso lograda en 1970-1971, y de las díficultades económicas de 1972-1973.

\section{c) Procesos que influyen en la capacidad para controlar la fecundidad marital}

La capacidad para controlar con eficacia la fecundidad, ya sea a través de los anticonceptivos, el método del rítmo, la esterilización o el aborto, tiene tres dimensiones principales: 1 ) conocimiento de las técnicas de control e información sobre cómo y dónde se obtienen los medios necesarios; . II) acceso a esos medios, y III) conocimiento social, esto es, capacidad de utilizar tanto la información como los medios para lograr el fin deseado. Este último aspecto puede incluir la capacidad para actuar teniendo en cuenta las consecuencias probables de los actos, de comunicarse y de cooperar con el cónyuge, o simplemente de ejecutar instrucciones. ${ }^{63}$

Como se verá cuando se esbocen los procesos que tienden a modificar estas dimensiones, la capacidad de una persona o grupo depende en gran medida de su ubicación en la estructura social. El acceso a métodos mecánicos o químicos abarca posibilidades geográficas o financieras. $\mathbf{Y}$ es posible que aun disponiendo de medios en estos dos sentidos (por ejemplo, en una clínica gratuita), tal vez algunos grupos carezcan de la información indispensable para utilizarlos.

I) Divulgación de la información. Lo que aquí se denomina "proceso de divulgación" podría tratarse de manera más pormenorizada distinguiendo, por ejemplo, entre medios de información, educación, contacto a través de la migración, etc. Cada uno de éstos puede divulgar no sólo conocimiento técnico, sino también algunos aspectos del conocimiento social necesario para hacer uso efectivo de las técnicas de control. Cabe reconocer que el contenido específico que transmiten los medios de información puede no ser su única contribución al conocimiento técnico en este campo, puesto que - al igual que otros tipos de "educación"esa información puede acrecentar la receptividad ante conocimientos que se adquieran después, o que se persigan activamente. Además, y así lo ilustran las campañas publicitarias comerciales, es posible que la gente no capte bien la información al escucharla por primera vez y que necesite estar constantemente expuesta a ella. Dado que muchos datos se transmiten en forma oral, el nivel de información de las personas suele depender del nivel general de información de la comunidad. La migración, en particular de las zonas rurales a las urbanas, explica también la divulgación de informaciones, pues personas no expuestas a ellas en las zonas rurales, tienen más probabilidades de adquirirlas en las zonas

63 Lee Rainwater, And the Poor Get Children: Sex, Contraception and Family Planning in the Working Class, Quandrangle Paperbooks, Chicago, 1960, reedición de 1967; R. Hill, J.M. Stycos y K.W. Back, The Family and Population Control: A Puerto Rican Experiment in Sccial Change, Union of North Carolina Press, Chapel Hill, 1959; Rosen y Simmons, op. cit. 
urbanas, donde prevalecen. De todas maneras, merece la pena examinar la hipótesis de que las zonas rurales pueden estar perdiendo por emigración las personas más jóvenes y con mayor nivel educativo, que son las que probablemente poseen más información sobre el control de la natalidad.

II) Cambios en los papeles y el status de la mujer. Diversos autores han mostrado que en muchas situaciones las parejas con mayor grado de comunicación son las más proclives a utilizar anticonceptivos. ${ }^{84} \mathrm{La}$ mayor comunicación y cooperación en el hogar parecen lograrse por un proceso que comienza con cambios en la estructura social que influyen en la educación y en el empleo de las mujeres. Esto, a su vez, cambia las funciones de las mujeres y las actitudes ante sus funciones en el hogar. Hay entonces una familia más igualitaria. Por su parte, esto acrecienta la comunicación sobre diversas materias, entre ellas el tamaño familiar. ${ }^{65}$ Además, las mujeres que trabajan $\longrightarrow$ que viven rodeadas de mujeres que trabajan - se hallan más expuestas que otras a las nuevas informaciones.

III) Introducción de programas de planificación de la familia. En América Latina ha surgido un elemento relativamente nuevo que está influyendo en la capacidad de los grupos para controlar su fecundidad, y que es la institucionalización de los programas de planificación de la familia, generalmente con participación del gobierno. Algunos partidarios de estos programas creen que bastan por sí solos para reducir la fecundidad. Ello significa suponer que existen las condiciones necesarias de motivación y legitimidad, o que pueden crearse a través de los programas. Cualquiera que sea el futuro efecto de estos últimos, parecería que los países cuya fecundidad ha declinado claramente experimentaron esa declinación antes de que tales programas se extendieran. ${ }^{66}$ Es posible que los acalorados debates que precedieron a la institucionalización de los programas ${ }^{67}$ hayan reafirmado la legitimidad de la planificación de la familia, dando en general a conocer la existencia de los métodos.

Puesto que en la mayoría de los países la cobertura de los programas de planificación de la familia es mucho menor que el número aparente de usuarios, ${ }^{68}$ es evidente que la mayoría de quienes utilizan métodos anticonceptivos modernos obtienen lo que necesitan fuera de esos programas. En Costa Rica - pese a que la cobertura del programa es una de las más altas en América Latina- parece ser "muy numeroso" el grupo que obtiene píldoras anticonceptivas de otras fuentes. ${ }^{69}$

64 M. Stycos, Human Fertility in Latin American Sociological Perspectives, Cornell University Press, Ithaca, 1968; Mauricio Culagorski, "Etapas en la adopción de la planificación familiar: un estudio escalogramétrico", CELADE-SIEF (A-I/P2, S/102/19/73). 65 Rosen y Simmons, op. cit.

$\$ 6$ Conning, op. cit.

67 J.M. Stycos, "Case studied in public opinion formation: Colombia and Brazil", Ideology, Faith and Family Planning in Latin America, Mc Graw Hill, Nueva York, 1971, pp. 145 a 173.

68 M.L. García, "Programas de planificación familiar en América Latina", Documentos de la Conferencia Regional Latinoamericana. 1970, vol. I, pp. 393 a 400.

69 Gómez, op. cit. 


\section{d) Procesos que influyen en el concepto de legitimidad del control de la fecundidad.}

El grado de legitimidad que en América Latina se reconoce a la regulación de la fecundidad parece en parte depender de la medida en que se acepten: r) los postulados de la Iglesia católica, que en el pasado hizo un ideal de la familia numerosa y que se ha opuesto a los medios "artificiales" de controlar la fecundidad, y $\mathbf{n}$ ) el "machismo" y su complemento femenino, el "marianismo". Aunque muchos han aceptado de buenas a primeras que estos dos factores contribuyen a restar legitimidad al control de la fecundidad, cabe preguntarse si son fuerzas sociales que actúen efectivamente en este sentido. Si no lo son, es posible que hoy exista esa condición necesaria que es la legitimidad.

En cuanto a los postulados de la Iglesia católica, hay que distinguir entre sus efectos en la población general -que puede o no considerar aceptable el hacer uso de controles - y el efecto en las élites que tienen poder para imponer su propia concepción de lo que es legítimo a aquella otra población. Stycos examinó los efectos del catolicismo en personas de las siete zonas metropolitanas incluidas en el estudio PECFALUrbano, y observó que, controlando el nivel de educación, el tamaño ideal de la familia estaba relacionado positivamente con la religiosidad (medida por la asistencia a la iglesia), pero que solo había pequeñas diferencias entre los católicos observantes y los nominales. ${ }^{70}$ Además, aunque la religiosidad mostraba algunas relaciones cokerentes, en el sentido que cabía esperar, con la actitud ante el control de la fecundidad y el uso de anticonceptivos, no se observaban variaciones en la dirección esperada en ninguna de las ciudades, cuando la variable dependiente era la fecundidad y se controlaba el nivel de educación. Stycos concluía que “...si el catolicismo está teniendo poca repercusión en la fecundidad, puede ser en parte porque la mujer media no es muy 'católica' según los cánones de la Iglesia, y en parte porque las actitudes y prácticas de las mujeres menos religiosas no son especialmente eficaces para el control de la fecundidad". ${ }^{11}$ Otro análisis del efecto de la religión en las zonas rurales de cuatro países también comprobó que era débil en este campo.72

Aunque el catolicismo no haya logrado mucha influencia sobre los: individuos, cabe decir que ha establecido las normas sociales para la población en general, sin que ésta advierta su origen. Sin embargo, según las encuestas PECFAL-Urbanas, entre el 50 y $75 \%$ de las mujeres se declararon en todas las cindades partidarias de que se divulgara información sobre el control de la natalidad. ${ }^{33}$ Así pues, la influencia de la ideología católica en esta materia no parece haberse extendido mucho. Sin embargo, el influjo ejercido en el pasado por la Iglesia sobre algunas élites gobernantes parece haberlas hecho reacias a aceptar públicamente

70 Stycos, op. cit.

71 Ibid., p. 183.

72 Edgar Baldión, Anticoncepción, fecundidad y catolicismo en las áreas rurales y semiurbanas de Colombia, 1969, cELADE, Santiago de Chile, 1973 (documento inédito).

73 Stycos, op. cit., p. 176. 
el uso generalizado del control de la fecundidad en la población. Esta negativa a legitimar a través de leyes u otros medios el suministro de información y de material puede haber limitado la capacidad de algunos sectores para regular el tamaño de la familia. Otras élites, inspiradas por el nacionalismo, temerosas del dominio de potencias extranjeras o deseosas de no debilitar las probabilidades de una revolución, se han opuesto también al control de la natalidad. Sin embargo, entre 1966 y 1973 los gobiernos de casi todos los países latinoamericanos comenzaron a ofrecer servicios de planificación de la familia de alguna índole, ya sea como parte de su propio programa, o para proporcionar facilidades a organizaciones privadas. ${ }^{74}$ Las opiniones de las élites respecto a la legitimidad de la planificación de la familia, así como la evolución de sus puntos de vista, fueron analizados por Stycos y otros. ${ }^{75}$

Como ya se señaló, los debates que precedieron a la aceptación general de los programas de planificación de la familia por parte de las élites tal vez acrecentaron el conocimiento y posiblemente la motivación en esta materia, e introdujeron gradualmente el concepto de su legitimidad en la mente de quienes consideraban que el control de la fecundidad era censurable. A ello puede haber contribuido la constante discusión abierta de temas que antes la población en general no se atrevía a mencionar en público.

El otro importante factor cultural que probablemente ha influido en el grado de legitimidad atribuido al control de la fecundidad es el complejo de machismo-marianismo (o hembrismo) que exagera tanto la "masculinidad" como la "femineidad". El machismo tiende a poner el acento en la conquista de la hembra por el macho, en la potencia sexual, en los muchos hijos como una prueba de virilidad y en el papel autoritario del hombre en la familia. ${ }^{76}$ El marianismo, que para Stycos es un "complejo de virginidad", ${ }^{77}$ refleja creencias que prohíben las relaciones premaritales a la mujer, pero que, en un sentido más amplio, la definen como un ser inocente, puro y perfecto, que no disfruta de las relaciones sexuales, ni siquiera dentro del matrimonio religioso santificado por la Iglesia, y que no se interesa por las cosas del sexo ni por el control de la natalidad. ${ }^{78}$

Aunque se sigue prestando mucha atención a este síndrome cultural por su supuesto influjo en ese control, las investigaciones mismas no

74 CEPAL, op. cit., p. 44; García, op. cit.

75 Stycos y otros, Ideology, Faith and Family Planning in Private and Public Opinion on Fertility Control, op. cit.

${ }_{76}$ J. Mayone y Stycos, Family and Fertility in Puerto Rico: A Study of the Lower Income Group, Columbia University Press, Nueva York, 1955, p. 35; Hill, Stycos y Back, op. cit., PP. 100 a 102.

77 Stycos, op. cit., p. 35.

78 Véase el análisis y la reseña histórica que hace Stevens, "Marianismo: The other face of machismo in Latin America", en Female and Male in Latin America: Essays, A. Pescatello (Ed.), University of Pittsburgh Press, 1973, pp. 90 a 101. Véase también el examen de una extensa bibliografía sobre machismo y marianismo en Kinzer, "Priests, machos and babies: Or, Latin American Women and the Manichaen heresy", Of Marriage and the Family, vol. 35-2, mayo de 1973, pp. 300 a 312. 
han revelado claras relaciones entre ambas cosas. La conclusión general -basada primordialmente en datos obtenidos en Puerto Rico-79 es que el complejo machismo-marianismo no parece guiar las acciones y actitudes del varón frente al control de la natalidad, pero que la falta de comunicación entre los esposos puede hacer que la mujer base su opinión de lo que es legítimo en el estereotipo machista, y no en lo que verdaderamente piensa su marido.

\section{$\mathrm{C}$ \\ FACTORES SOCIOECONÓMICOS QUE INFLUYEN EN LOS PATRONES DE MORTALIDAD}

Es un hecho comprobado que la notable disminución de las tasas de mortalidad registrada en los tiempos modernos puede atribuirse al dominio cada vez mayor del hombre sobre su medio, más que a cambios en la constitución genética de la humanidad. Sin embargo, tanto el origen como la evolución de este descenso difieren esencialmente en los países desarrollados y en los países en desarrollo. El control de la mortalidad en las naciones hoy desarrolladas se logró a través de prolongados períodos durante los cuales los mejoramientos pausados y laboriosos en las condiciones de vida y en la prevención y el tratamiento de las enfermedades acompañaban una gradual modernización de las sociedades. En cambio, las rápidas declinaciones iniciales de la mortalidad en los países en desarrollo han sido en gran medida independientes de transformaciones estructurales de la sociedad. ${ }^{80}$ En realidad, la merma se ha debido en gran parte a la importación en escala muy considerable de nuevas técnicas para prevenir y controlar las enfermedades.

Dado el origen predominantemente exógeno de la tecnología con que se combate la mortalidad, los cambios en la tasa latinoamericana no exigen cambios fundamentales en los conceptos de legitimidad, ni en las motivaciones y los actos de los individuos, como sucede con las modificaciones de los patrones de fecundidad antes examinados. Sin embargo, se observan importantes diferencias entre los patrones de mortalidad de diversos grupos sociales, lo que atestigua la influencia persistente de los factores socioeconómicos en la mortalidad, aunque éstos tal vez tengan una importancia hasta cierto punto residual frente a la tecnología. La forma y preponderancia de estos factores socioeconómicos serán el principal objeto del siguiente análisis.

\section{1) Diferencias de mortalidad por paises}

La evaluación más general de la influencia de los factores socioeconómi-

79 Hill, Stycos y Back, op. cit.

so Véase un breve análisis de este fenómeno en Eduardo Arriaga y Kingsley Davis, "The pattern of mortality change in Latin America", Demography, 1969, 6 (3), pp. 223 a 242, y Kingsley Davis, "Amazing decline of mortality in underdeveloped areas", The American Economic Review, 1956, 46, pp. 305 a 318. 
cos en los niveles de mortalidad en América Latina proviene de una investigación de los variados patrones que se observan en los países de la región. Según estimaciones recientes, en América Latina las tasas brutas de mortalidad declinaron gradualmente de 11 a 9 por mil en el decenio de 1960.81 Como cabía esperar, esta declinación fue menor que las registradas en decenios anteriores. En realidad, si estas cifras son correctas, los niveles actuales de las tasas brutas de mortalidad en América Latina son prácticamente equivalentes a las que prevalecen en los Estados Unidos o el Canadá, e inferiores a las de Europa septentrional y occidental, regiones todas cuyas poblaciones son evidentemente más viejas que las de esta región.

Como es obvio, el nivel de mortalidad varía mucho de un país a otro, y si se dispusiera de los datos, también se comprobarían diferencias dentro de los países. No obstante, se tiende a una gradual convergencia, a medida que innovaciones fundamentales en la prevención de las enfermedades parasitarias e infecciosas reducen significativamente la mortalidad de los países menos desarrollados y el envejecimiento de la población en países más avanzados - Argentina, Cuba y Uruguayinvierte su anterior tendencia descendente.

Todos los demás países latinoamericanos experimentaron un descenso mayor o menor de sus tasas brutas de mortalidad. No obstante, todavía se observan tasas elevadas en varios países de la región, en particular Bolivia, El Salvador, Guatemala, Haití, Honduras, Nicaragua y República Dominicana. Ia mortalidad en estos países refleja sin duda su menor subdesarrollo relativo, pero cabe esperar que baje algo en los próximos años, haya o no avances generales significativos en su bienestar económico y social.

Las comparaciones de las tasas brutas de mortalidad pueden deformarse con las diferencias en la composición por edades, pero el mismo. tipo de conclusiones se desprende de un examen de la esperanza de vida al nacer en diversos países. Una mirada rápida a la primera colum= na del cuadro 15 muestra que la esperanza de vida en Ámérica Latina varía de 44.5 años en Haití a 69.2 años en Uruguay, hecho que acentúa la persistencia de agudas disparidades en los niveles de desarrollo de la región.

Para explicar las diferencias de mortalidad entre países o grupos se puede formular un sencillo paradigma en el cual se subsumen todos los factores socioeconómicos que influyen en la mortalidad. Así, la influencia de los factores socioeconómicos se hace sentir a través de las condiciones generales de vida (particularmente trabajo y vivienda), la nutrición y el medio ambiente, las nociones de higiene y las instalaciones de saneamiento, y por el nivel, el alcance y la accesibilidad del conocimiento médico. Cabe suponer que estos factores - vinculados todos entre sí- pueden explicar la abrumadora proporción de las diferencias de mortalidad una vez descontadas características físicas como la edad y el

81 Para mayores detalles sobre tendencias recientes en materia de morbilidad, véasq. el capítulo $\pi$. 
Cundro 15. América Latina: esperanza de vida al nacer y algunos indicadores de bienestar socioeconómico por paises, 1965 \& 1970

\begin{tabular}{|c|c|c|c|c|c|}
\hline País & $\begin{array}{l}\text { Esperanza } \\
\text { de vida } \\
\text { al nacer }\end{array}$ & $\begin{array}{l}\text { Número de } \\
\text { habitantes } \\
\text { por cama } \\
\text { de hospital }\end{array}$ & $\begin{array}{l}\text { Consumo } \\
\text { diario de } \\
\text { proteínas } \\
\text { por habi- } \\
\text { tante }\end{array}$ & $\begin{array}{c}\text { Porcentaje } \\
\text { de alfabe- } \\
\text { tismo en la } \\
\text { población } \\
\text { de } 15 \text { años } \\
\text { y más }\end{array}$ & $\begin{array}{l}\text { Porcentaje } \\
\text { de vivien- } \\
\text { das dota- } \\
\text { das de agua } \\
\text { corriente }\end{array}$ \\
\hline Argentina & 67.4 & 160 & 88.0 & 91.4 & 62.3 \\
\hline Bolivia & 45.3 & 435 & 48.0 & 39.8 & 10.2 \\
\hline Brasil & 60.6 & 350 & 66.3 & 60.6 & 23.0 \\
\hline Colombia & 58.5 & 400 & 52.3 & 72.9 & 45.1 \\
\hline Costa Rica & 66.8 & 268 & 70.0 & 85.8 & 63.6 \\
\hline Cuba & 66.8 & 180 & 85.8 & 96.1 & 42.0 \\
\hline Chile & 60.9 & 253 & 76.0 & 88.8 & 43.4 \\
\hline Ecuador & 57.2 & 440 & 56.0 & 72.0 & 26.8 \\
\hline El Salvador & 54.9 & 457 & 47.0 & 50.8 & 23.6 \\
\hline Guatemala & 51.1 & 420 & 56.8 & 37.9 & 12.1 \\
\hline Haití & 44.5 & 400 & 37.4 & 18.8 & 3.1 \\
\hline Honduras & 48.9 & 480 & 58.0 & 47.0 & 21.1 \\
\hline México & 62.4 & 500 & 65.7 & 65.4 & 40.5 \\
\hline Nicaragua & 49.9 & 430 & 59.0 & 49.8 & 16.8 \\
\hline Panamá & 63.4 & 318 & 64.7 & 78.3 & 44.4 \\
\hline Paraguay & 59.3 & 440 & 65.5 & 69.0 & 6.0 \\
\hline Perú & 58.0 & 418 & 54.0 & 67.0 & 21.5 \\
\hline República Dominicana & 52.1 & 391 & 54.0 & 53.1 & 22.7 \\
\hline Urüguay & 69.2 & 158 & 116.0 & 89.4 & 58.0 \\
\hline Venezuela & 63.7 & 315 & 67.5 & 85.0 & 68.0 \\
\hline Barbados & 65.1 & 96 & 64.6 & 97.4 & 43.9 \\
\hline Guyana & 61.0 & 200 & 53.0 & 83.0 & 51.8 \\
\hline Jamaica & 64.6 & 268 & 63.7 & 81.9 & 32.7 \\
\hline Trinidad y Tabago & 64.2 & 192 & 62.0 & 89.0 & 51.1 \\
\hline
\end{tabular}

Fuenres: Esperanza de vida al nacer: cerade, Boletín demográfico, año IV, núm. 8, julio de 1971; Indicadores de bienestar socioeconómico: Rolando Franco, Tipologia de América Latina. Ensayo de medición de las discontinuidades sociales, Cuadernos del Instituto Latinoamericano de Planificación Económica y Social, Serie II, núm. 17, 1973.

sexo. La correlación conjunta y separada entre algunos de estos factores y la mortalidad por países puede comprobarse con ayuda de varios indicadores. (Véase de nuevo el cuadro 15.)

En comparaciones internacionales es difícil establecer y evaluar el efecto de las condiciones de trabajo sobre la mortalidad, pero para fines. de demostración preliminar, las condiciones de vivienda pueden representarse por el porcentaje de residencias que tienen agua corriente, en tanto que el número de gramos de proteinas consumidas por habitante puede tomarse como indicador de nutrición. El número de habitantes. por cama de hospital indica la accesibilidad de los servicios médicos, y 
la proporción de individuos de más de 15 años que sabe leer y escribir puede considerarse un indicador burdo pero adecuado de las nociones de higiene.

La correlación lineal que vincula la esperanza de vida al nacer con los cuatro indicadores seleccionados es aproximadamente de 95 a 100 , y el coeficiente de determinación es también extremadamente alto $\left(\mathrm{R}^{2}=0.89\right)$. Tomado separadamente, cada uno de los indicadores tiene también una correlación alta con la esperanza de vida: 0.72 para el número de habitantes por cama de hospital, 0.73 para el consumo de proteínas, 0.93 para los niveles de alfabetismo y 0.82 para el porcentaje de viviendas dotadas de agua corriente. Pese a que los datos provienen de cortes transversales, la magnitud de los coeficientes pone de relieve que las alteraciones de los niveles de bienestar y del suministro de bienes y servicios básicos pueden tener influencia decisiva en declinaciones futuras de la mortalidad.

Así, una de las pocas conclusiones empíricas en los distintos países es la estrecha relación entre la mortalidad y los niveles generales de desarrollo económico y social. Sin embargo, si se abandona esta generalización en favor de informaciones más particularizadas, los datos de ciertas localidades permiten un examen más profundo de las diferencias en la mortalidad y de los factores subyacentes.

\section{2) Urbanización y mortalidad}

Puede afirmarse que es ambiguo el efecto de la residencia urbana o rural sobre la mortalidad. En países de desarrollo temprano, la residencia urbana estuvo asociada a tasas sostenidamente más altas de mortalidad en la época de la máxima expansión industrial y urbana, ya que el carácter incipiente de la medicina, los riesgos del trabajo, las precarias condiciones de vida, la falta de alcantarillado y, en general, el ambiente insalubre, provocaban en poblaciones de gran concentración demográfica una mortalidad elevada que se acentuaba periódicamente por epidemias y pestes.

Las zonas urbanas en la América Latina contemporánea parecen ser mucho más ricas y "modernas", y además, aprovechan la concentración en ellas de la mayor parte del personal y los servicios médicos existentes. De otro lado, las condiciones de vida que prevalecen en proporciones apreciables de la población urbana - hacinamiento en viviendas insalubres, nutrición deficiente, riesgos ambientales, etc.- son factores que tenderían a elevar la mortalidad urbana. De aquí que cabría esperar a priori cierto equilibrio entre la mortalidad urbana y la rural.

Contradicciones de esta índole hicieron que un estudio efectuado en 1946 llegara a la conclusión de que los resultados de la serie censal de 1940 no habían logrado señalar diferencias sistemáticas entre la mortalidad urbana y la rural, ${ }^{82}$ Sin embargo, estos datos se refieren a un

82 Véase Kingsley Davis y Ana Casis, "Urbanization in Latin America", The Milbank Memorial Fund Quarterly, vol. 24, núm. 2, 1946. 


$$
\begin{aligned}
& 301.32065 \\
& 5471 \\
& 31.32 \\
& 042
\end{aligned}
$$



período anterior a la importación en gran escala de técnicas para reducir la mortalidad en América Latina. Como tales técnicas se aplicarían primero en las ciudades, cabría suponer que podrían reducir la mortalidad urbana hasta el momento en que los frutos del desarrollo se tendiesen a todo el país. Por otra parte, la mayor proporción de migrantes jóvenes y vigorosos en los movimientos hacia las zonas urbanas bien podría tener un efecto adverso en la mortalidad rural.

Un estudio realizado últimamente por la Organización Panamericana de la Salud (ops) en diez ciudades latinoamericanas reveló que en realidad la mortalidad era mucho más baja en las ciudades estudiadas que en los países respectivos y que las diferencias eran particularmente pronunciadas en la primera mitad de la existencia. ${ }^{83} \mathrm{E} 1$ informe comenta en seguida que "... esto no es extraño ya que en América Latina la protección de la salud y los servicios médicos se concentran fuertemente en las ciudades. Además, las personas que migran a la ciudad pueden diferir de aquellas que permanecen en las zonas rurales en formas que influyan en la mortalidad ... En los últimos 30 años la mortalidad en las zonas rurales entre los 15 y los 44 años de edad es probablemente entre dos y cuatro veces mayor que en las ciudades capitales". ${ }^{84}$

El censo de 1971 en Nicaragua formuló preguntas especiales que permiten examinar las diferencias entre las zonas urbanas y rurales con mayor detenimiento. En el cuadro 16 se compara la mortalidad por cada mil niños nacidos vivos entre los hijos de mujeres residentes en zonas

CuAdro 16. Nicaragua: muertes de hijos por cada mil nacidos vivos, por residencia urbana o rural $y$ edad actual de la madre, 1971

\begin{tabular}{lccc}
\hline $\begin{array}{l}\text { Edad actual } \\
\text { de la madre }\end{array}$ & $\begin{array}{c}\text { Residencia } \\
\text { urbana }\end{array}$ & $\begin{array}{c}\text { Residencia } \\
\text { rural }\end{array}$ & Total \\
\hline $20-24$ & 152 & 159 & 156 \\
$25-29$ & 146 & 177 & 164 \\
$30-34$ & 166 & 189 & 178 \\
$35-39$ & 207 & 219 & 214 \\
$40-44$ & 213 & 236 & 225 \\
$45-49$ & 277 & 254 & 265 \\
$50-54$ & 276 & 278 & 277 \\
$55-59$ & 321 & 289 & 305 \\
$60-64$ & 338 & 311 & 325 \\
65 y más & 386 & 345 & 368 \\
\hline
\end{tabular}

Fuente: Ministerio de Economía, Industria y Comercio, Banco Central de Nicaragua, Censos nacionales, 20 de abril de 1971, "Población". Tabulaciones preliminares de una muestra del $10 \%$, Oficina Ejecutiva de los Censos, Boletín núm. 3, abril de 1972, cuadro 16.

83 Ruth Rice Puffer y G. Wynne Griffith, Patterns of Urban Mortality, Organización Panamericana de la Salud/Organización Mundial de la Salud, 1967, pp. 36 a 38.

84 Ibid., pp. 36 a 38. 
rurales y de aquellas que habitan zonas urbanas, según las edades de las madres en la fecha del censo. Como el grupo más joven estaba formado por madres de 20 a 24 afios, puede suponerse que la mortalidad corresponde en él a los años inmediatamente anteriores al censo. Puesto que la mortalidad infantil se concentra fuertemente en los primeros meses y primeros años de vida, el indicador en general se referirá a períodos gradualmente más lejanos, al ir aumentando la edad de las madres.

Evidentemente, los datos del cuadro 16 no están libres de errores de memoria y omisiones, pero por lo menos la información referente a las madres más jóvenes ciertamente es exacta en grado razonable. A medida que se eleva la edad del grupo, la probabilidad de error aumenta, en parte porque son más probables los errores de memoria y en parte porque la migración puede contribuir a deformar el efecto de la residencia rural o urbana. En todo caso, el cuadro 16 muestra que la mortalidad rural es más alta, en mayor o menor grado, en todos los grupos de edades hasta llegar a los 45 af́os. De allí en adelante la tendencia se invierte y muestra, con una excepción, que la mortalidad urbana es mayor. Si el supuesto con respecto a la distribución de las muertes es correcto, estos datos revelarían que en períodos recientes la mortalidad urbana ha sido más baja que la rural, pero que este fenómeno constituye una inversion de los patrones prevalecientes hasta hace 15 o 20 años.

La Encuesta Demográfica Nacional (EDENH) también brinda información excepcional y reciente sobre la mortalidad en Honduras. E1 cuadro 17 muestra datos derivados de esta encuesta sobre las tasas brutas de mortalidad registradas en las zonas rurales y urbanas de ese país. ${ }^{85}$ Se desprende claramente que la mortalidad en las zonas rurales es $80 \%$ más alta que la observada en las urbanas. Parte de esta diferencia podría explicarse evidentemente por disparidades en la composición por edades y por los efectos de migraciones selectivas, pero la magnitud de la variación indica que aun tomando en cuenta estos factores la diferencia residual es considerable.

Cuadro 17. Honduras: mortalidad por residencia rural o urbana, 1971

\begin{tabular}{llcr}
\hline $\begin{array}{c}\text { Lugar } \\
\text { de resi- } \\
\text { dencia }\end{array}$ & $\begin{array}{c}\text { Tiempo de } \\
\text { exposición } \\
\text { (años) }\end{array}$ & Muertes & $\begin{array}{c}\text { Morta- } \\
\text { lidad } \\
\text { (por mil) }\end{array}$ \\
\hline Urbano & 16014 & 144 & 8.99 \\
Rural & 35143 & 581 & 16.53 \\
Total & 51157 & 725 & 14.17 \\
\hline
\end{tabular}

Fuente: Encuesta Demográfica Nacional de Honduras (EDENH), 1971-1972; tabulacio nes provisionales de la encuesta.

85 . Por haberse considerado un número relativamente pequeño de casos, conviene no exagerar la significación de estos resultados. 
En resumen, los datos disponibles sugerirían que antes de los ańos cuarenta influencias diversas contribuyeron probablemente a mantener una suerte de equilibrio entre la mortalidad rural y urbana de la mayoría de los países latinoamericanos. Sin embargo, datos más recientes parecen indicar ventajas urbanas apreciables, nacidas de la concentración de conocimientos y servicios médicos, y de migrantes jóvenes, en las zonas urbanas.

\section{3) La mortalidad y la estratificación social}

Al contrario de lo que sucede con la fecundidad, la motivación para vivir generalmente no varía con las épocas, las circunstancias o los grupos sociales. Puesto que el deseo de vivir es universal y constante, las personas y los grupos cuya mortalidad es más baja en cualquier localidad estarán entre quienes disfruten de condiciones de vida más favorables y tengan mayor acceso a los medios para prolongar su existencia. De este modo, y casi por definición, las diferencias de mortalidad en países en desarrollo emanan de disparidades en los niveles de bienestar socioeconómico. Puesto que las desigualdades socioeconómicas se reflejan con mayor exactitud en los niveles de ingreso, educación, ocupación, etc., debería ser tarea fácil formular en los diversos estratos sociales correlaciones entre estos factores y la mortalidad tan sólidas como para conferirles categoría de leyes científicas. Pero, aunque todos saben que tales relaciones existen, los datos actuales no permiten establecer empíricamente la existencia ni la magnitud de las diferencias, salvo en algunos casos.

Un estudio realizado con datos de 1957 en Chile compara la mortalidad de empleados y obreros. Se omitió a los empleadores, que representaban alrededor del $10 \%$ de la población, por su heterogeneidad. Como cabía esperar, las diferencias entre ambos grupos eran significativas, según todos los indicadores. ${ }^{86}$ Otros cálculos basados en estos datos revelaron además que, en tanto la mortalidad infantil endógena era casi igual en ambos grupos, la mortalidad debida a causas exógenas era casi el doble entre los obreros que en los estratos socioeconómicos más privilegiados (111 y 53 por mil, respectivamente). Estas diferencias ahorran todo comentario, pero merece destacarse que en la época en que se realizó el estudio los estratos de menores ingresos representaban el $66 \%$ de la población total de Chile.

Respecto a Honduras, datos extraídos de la Encuesta Demográfica Nacional (véase el cuadro 18) destacan también que la probabilidad de una muerte temprana aumenta marcadamente al descender el status socioeconómico. En este caso, el status social se ha medido tanto por la ocupación como por la educación. La mortalidad anual en el estrato más elevado es menos de la mitad de la que se registra en los dos grupos inferiores. Estos resultados no pueden atribuirse a diferencias en 1962.

86 Hugo Behm Rosas, Mortalidad infantil y nivel de vida, Universidad de Chile, 
CUAdRo 18. Honduras: mortalidad por niveles socioeconómicos, 1971

\begin{tabular}{lccr}
\hline $\begin{array}{c}\text { Nivel socio- } \\
\text { económico }\end{array}$ & $\begin{array}{c}\text { Tiempo de } \\
\text { exposición } \\
\text { (años) }\end{array}$ & Muertes & $\begin{array}{c}\text { Morta- } \\
\text { lidad } \\
\text { (por mil) }\end{array}$ \\
\hline Alto & 3319 & 22 & 6.63 \\
Mediano & 7869 & 77 & 3.79 \\
Mediano bajo & 14153 & 210 & 14.84 \\
Bajo & 22771 & 415 & 16.10 \\
\hline
\end{tabular}

Fuenre: Encuesta Demográfica Nacional de Honduras (EDENA), 1971-1972, tabulaciones provisionales.

la composición por edades, porque los patrones de fecundidad observados deberían en realidad acrecentar la edad media en los estratos más altos y contribuir así a una mortalidad mayor y no menor. La importancia de estas disparidades en la mortalidad se acentúa aún más si se toma en cuenta que los dos grupos con mortalidad elevada constituyen aproximadamente el $78 \%$ de la población incluida en la muestra.

La información censal de 1971 en Nicaragua permite evaluar los efectos de la educación en la mortalidad infantil durante 1970, según la residencia urbana o rural de la madre. (Véase el cuadro 19.) En ambas esferas se encuentra de nuevo una relación inversa monotónica entre educación y mortalidad infantil. Interesa subrayar que la variación de las tasas es mayor en las zonas urbanas que en las rurales. Así, pese a que la mortalidad infantil urbana general es bastante más baja que la rural, quienes se hallan en peor situación son los residentes urbanos que no han recibido educación sistemática alguna. Esto quiere decir que las peores condiciones de vida en todo el país son las que soportan los grupos marginales urbanos.

Por último, la información sobre la mortalidad según el color y la raza brinda datos indirectos sobre otra dimensión del mismo problema. Puesto que los investigadores no han descubierto razon alguna para

CUADRo 19. Nicaragua: muertes de hijos por cada mil nacidos vivos, por nivel educativo y residencia urbana o rural de la madre, 1971

\begin{tabular}{lccc}
\hline $\begin{array}{c}\text { Nivel educativo } \\
\text { de la madre }\end{array}$ & $\begin{array}{c}\text { Residencia } \\
\text { urbana }\end{array}$ & $\begin{array}{c}\text { Residencia } \\
\text { rural }\end{array}$ & Total \\
\hline 0 & 152 & 138 & 142 \\
$1-3$ años & 113 & 124 & 118 \\
$4-9$ años & 102 & 105 & 103 \\
10 y más años & 62 & 71 & 62 \\
Total & 118 & 133 & 127 \\
\hline
\end{tabular}

FueNTE: Ministerio de Economía, Industria y Comercio, op. cit., cuadro 17. 
creer que la raza o el color tiene efectos genéticos o biológicos en la mortalidad, las diferencias de mortalidad por razas, sin aventurarse demasiado, pueden atribuirse a las condiciones de vida más favorables de que disfrutan ciertos grupos $y$, en definitiva, a las raíces históricas de esas situaciones.

Por ejemplo, los datos obtenidos en el censo de 1950 de Guatemala mostraron que la esperanza de vida de los ladinos varones era de 10 años mayor que la de la población indígena. Entre las mujeres la diferencia se aproximaba más a los 12 años. A la vez, se observaron diferencias coincidentes en la mortalidad infantil de ambas poblaciones. ${ }^{87}$ Informaciones relativas a cuatro estados del sur del Brasil indican asimismo que la esperanza de vida en todos ellos es mayor para la población blanca, más baja para la población negra e intermedia para la población mestiza. Además, la dispersión de valores alrededor de la mediana es mucho mayor en los dos últimos grupos que en la población blanca, 88

En síntesis, se comprueba que el status socioeconómico se halla claramente ligado a la mortalidad y la longevidad no constituye una sorpresa, pero vale la pena investigar el grado y la significación de las diferencias resultantes. Pese a que la información disponible es pobre y poco representativa, es interesante que todos los indicadores, cualquiera que sea el país o la localidad, muestran diferencias acusadas y persistentes entre los distintos estratos sociales. También tiene cierto peso el hecho de que los grupos de mortalidad elevada constituyen en todos los casos la proporción mayor de la población del país respectivo.

\section{RESUMEN Y CONCLUSIONES}

De conformidad con la estrategia aquí delineada, los factores sociales y económicos que influyen en las tendencias de la población latinoamericana se han tratado en tres capítulos de extensión moderada. En un análisis más refinado podría intentarse el examen de las múltiples relaciones entre los factores intermedios que afectan a la urbanización -la migración, la fecundidad y la mortalidad - o, en un nivel mayor de abstracción, la investigación de la influencia de procesos sociales en gran escala, con el encabezamiento de "modernización", en el conjunto de las variables demográficas. Sin embargo, la estrategia que aquí se aplica se adoptó en vista de la situación en materia de información y análisis, suponiendo que las preguntas elementales que necesitan respuesta varían en cada uno de los sectores primarios.

En la primera sección sustantiva, interesaba descubrir las influencias

87 Jorge Arias, "Tablas abreviadas de mortalidad para la República, 1950", Boletín núm. 54, Dirección General de Estadística, Guatemala, 1955.

88 Ana Torres de Ribeiro, Regiao sul do Brasil - mortalidade e fecundidade, CEIADE, 1971 (documento mimeografiado); rBGE, "Pesquisas sobre a mortalidade no Brasil". Estadística Demográfica núm. 14. 
básicas tras las tendencias observadas últimamente en la urbanización y la migración interna, procesos ambos que evidentemente pertenecen a esferas teóricas distintas pero compenetradas. Así, en una perspectiva global, la urbanización es parte fundamental de un proceso más amplio de cambio social por el cual las sociedades evolucionan a otra forma diferente desde alguna forma característica de organización social y modalidad de producción. En esta perspectiva, se distinguieron tres grandes grupos de países, según la época de despegue de su proceso de urbanización y según la naturaleza de la interacción de los factores socioeconómicos y demográficos en que arraiga ese proceso.

Pero la urbanización es también un proceso físico de concentración humana que entraña el traslado de gente desde las zonas rurales a las urbanas. En este sentido, es preciso considerar el aporte de la migración interna al crecimiento urbano y, por ende, las causas estructurales y las motivaciones personales que impulsan a emigrar hacia la ciudad. Un examen de los estudios sobre el tema mostro una coherencia razonable entre los factores estructurales de repulsión y atracción, y las motivaciones personales para emigrar; ambos tipos de causas giran sobre todo en torno a consideraciones económicas. Sin embargo, los estudios acerca de la migración no han logrado mejorar significativamente el marco teórico - que sigue siendo rudimentario- ni documentar las generalizaciones actuales.

Pasando a los factores que influyen en las teridencias de la fecundidad en América Latina, cabe hacerse aquí una pregunta fundamental: ¿En qué forma han influido los procesos sociales sobre la voluntad y la capacidad de la gente para regular el tamaño de su familia? Si se consideran ante todo los factores relativos a la nupcialidad, cabría suponer que su influencia es considerable, pero la falta de estudios explicativos impide especificar los mecanismos concretos de influencia. Los factores determinantes de la fecundidad marital han sido los más examinados por los autores; para estudiarlos es necesario ante todo eliminar las diferencias producidas por variables relacionadas con la salud biológica; sólo entonces las diferencias restantes pueden atribuirse a un control deliberado.

Para que una persona o una población adopte medidas deliberadas en el control de la fecundidad deben darse ciertas condiciones previas en cuanto a motivación, capacidad y legitimidad. Algunos de los procesos sociales que influyen en los niveles de motivación en América Latina son a) los cambios en la economía y los incrementos en el ingreso y los servicios por habitante; $b$ ) la propagación de nuevos estilos de vida, en especial los orientados al consumo; $c$ ) los cambios en la estructura de la familia y en la relación de la familia con la sociedad nacional; d) los cambios en el papel y el status de la mujer, y e) la movilización de masas.

La capacidad para regular eficazmente el tamaño de la propia familia depende de la divulgación de información, de los cambios en los papeles de la mujer y de la introducción de programas de planificación de la 
familia. Por último, entre los factores que influyen en la legitimidad de controlar la fecundidad se hallan la gravitación directa o indirecta de la Iglesia católica y los síndromes culturales relacionados con los complejos de machismo-marianismo.

Contrariamente a los que sucede con las tendencias de la migración y la fecundidad, en los patrones de mortalidad no influyen la motivación personal ni la legitimación social. Los cambios en las tasas de mortalidad de los países en desarrollo dependen principalmente del acceso oportuno a técnicas adecuadas para prolongar la vida, y sólo de manera residual de decisiones individuales. En consecuencia, el principal propósito de este capítulo sobre la mortalidad ha sido el de investigar la capacidad relativa de los diferentes grupos para precaverse de la muerte. En este sentido, es evidente que la salud y la mortalidad varían fundamentalmente de acuerdo con la capacidad de evitar enfermedades, y que ésta se relaciona a su vez directamente con los niveles de bienestar social y económico.

Con todos estos antecedentes, no es de extrañar que las naciones más privilegiadas entre los países latinoamericanos tengan una mortalidad menor y una mayor esperanza de vida. Por lo demás, esta última se halla altamente correlacionada con varios indicadores de bienestar socioeconómico, tomados separadamente o en conjunto. Lo mismo sucede con respecto a los grupos sociales dentro de cada país. El examen de la información existente que aquí se ha hecho mostró las claras ventajas que en materia de mortalidad y esperanza de vida tienen los estratos socioeconómicos más altos.

Al examinar el efecto teóricamente ambiguo de la residencia rural o urbana en los patrones de mortalidad, los datos muestran claramente que las localidades urbanas, favorecidas por la concentración de personal y servicios médicos, así como por su composición demográfica, tienen una ventaja decidida sobre las zonas rurales. Ello refleja posiblemente un cambio radical de las tendencias dominantes hasta hace unos pocos decenios. 


\section{POBLACIÓN Y MODERNIZACIÓN}

EI TEMa de las políticas de población debe examinarse en el marco del proceso de desarrollo y en función de estrategias de cambio y de proyectos optativos de sociedad. Por sus repercusiones se vincula en lo inmediato a la política de corto y mediano plazo, pero a la vez es imposible formular el modelo de una estructura social futura sin . discutir cuestiones relativas a la calidad, cantidad y localización de la población. Las políticas que tocan estos problemas afectan vitalmente por su naturaleza las creencias y los compromisos valorativos de los grupos y de las clases sociales, influyen en el marco ideológico en virtud del cual se juzga la estabilidad y el cambio, y se asocian a una redefinición del sistema de relaciones humanas y, en especial, de la función de la familia y del papel social de la mujer.

Esta multiplicidad de perspectivas contribuye a que el tema sea a la vez concreto y difuso: concreto cuando se intenta simplificarlo en un esquema mínimo de variables; difuso cuando se explora su rica complejidad. Los aspectos que toca son susceptibles de un alto grado de formalización, y es sin embargo difícil entender el significado de esas abstracciones si no se recuerda que cada una de ellas está vinculada de manera directa no sólo con las orientaciones racionales de los seres humanos, sino también con sus imágenes vitales, identificaciones y metas personales. El exito de las políticas que en este campo pueden adoptar los gobiernos depende hasta ahora, más que del consenso político que se alcance en un determinado momento, de la posibilidad de persuadir a los individuos y a las familias para que, de acuerdo con las metas de la sociedad, circulen y se establezcan físicamente en áreas determinadas del territorio, regulando la natalidad. A su vez, la capacidad de hacer realidad el consenso político en las bases está condicionada por muchos factores que suelen escapar a la acción gubernamental en el corto plazo, y responden en todo caso al ritmo y dirección del progreso general.

Los problemas de población de América Latina se insertan en un clima de semidesarrollo económico y social. La diversidad de situaciones nacionales puede describirse en función dẹ una modalidad típica de evolución. En efecto -aunque se han superado o están en vías de superarse la estructura social y las instituciones de un pasado rural, y se han hecho significativos avances en la industrialización - es difícil afirmar que los países hayan logrado transformarse en modernas sociedades industriales.

Algunos indicadores definen la naturaleza de esta coyuntura peculiar. Se observan disparidades significativas entre el crecimiento económico y el grado de progreso social; coexisten sectores interrelacionados que responden a diversas etapas del proceso de modernización; hay signos de una marcada heterogeneidad cultural, y se manifiestan agudos contrastes en el acceso de grupos sociales y regiones a los beneficios del progreso técnico. (Véase el cuadro 20.) 


\section{CuADro 20. Indicadores de desarrollo por regiones del mundo alrededor de 1970}

\begin{tabular}{|c|c|c|c|c|c|}
\hline Regiones del mundo & $\begin{array}{c}\text { Producto } \\
\text { interno } \\
\text { bruto por } \\
\text { habitante } \\
\text { (d6lares } \\
\text { de 1969) }\end{array}$ & $\begin{array}{c}\text { Consumo } \\
\text { de energía } \\
\text { comercial } \\
\text { por habi- } \\
\text { tante (kilo- } \\
\text { gramos) a } \\
1969\end{array}$ & $\begin{array}{l}\text { Esperanza } \\
\text { de vida } \\
\text { al nacer } \\
1965-1970\end{array}$ & $\begin{array}{c}\text { Porcentaje } \\
\text { de analfa- } \\
\text { betismo } \\
\text { entre adul- } \\
\text { tos } \\
1970\end{array}$ & $\begin{array}{c}\text { Porcentaje } \\
\text { de la po } \\
\text { blación en } \\
\text { aglomera- } \\
\text { ciones } \\
\text { urbanas } \\
1970\end{array}$ \\
\hline $\begin{array}{l}\text { América del Norte } \\
\text { Estados Unidos } \\
\text { Canadá }\end{array}$ & $\begin{array}{l}4574 \\
3473\end{array}$ & 7192 & 70.5 & 1.5 & 62 \\
\hline $\begin{array}{l}\text { Europa } \\
\text { Unión Soviética }\end{array}$ & 2020 & $\begin{array}{l}2472 \\
2753 b\end{array}$ & $\begin{array}{l}70.9 \\
70.3\end{array}$ & 3.6 & $\begin{array}{l}47 \\
43\end{array}$ \\
\hline Oceanía & 2708 & - & 64.8 & 10.3 & 58 \\
\hline América Latina & 510 & 571 & 60.2 & 23.6 & 38 \\
\hline $\begin{array}{l}\text { Asia } \\
\text { Sur de Asia }\end{array}$ & 130 & - & $50.5 c$ & $\begin{array}{r}46.8 \\
-\end{array}$ & $22 d$ \\
\hline Africa & 190 & - & $4 \overline{3.3}$ & 46.8 & 16 \\
\hline $\begin{array}{l}\text { Otros países desarro- } \\
\text { llados } \\
\text { Resto del mundo }\end{array}$ & & $\begin{array}{r}2736 \\
216\end{array}$ & & & \\
\hline
\end{tabular}

FUENTR: Estimaciones de las Naciones Unidas a base de cifras oficiales.

a Expresado en unidades de energía contenidas en un kilogramo de petróleo.

b Se refiere a Europa oriental, incluida Rusia.

e Se refiere a Asia oriental y sudoriental, excluido Japón.

d Se refiere al Asia oriental.

Es difícil interpretar el sentido de estos indicadores, sobre todo porque se ha hecho punto menos que imposible proyectar la dirección futura de los países a partir de su evolución reciente. Los acontecimientos del decenio de 1960 han dejado atrás los modelos económicos y sociales que durante más de 30 años inspiraron la acción de los gobiernos y de sus opositores. El dilema de fondo es decidir si la coyuntura presente constituye sólo una transición en el complejo itinerario de la industrialización, o si los signos apuntan a que se agotaron paulatinamente las posibilidades de avances significativos y el progreso depende ahora de una modificación de las reglas del juego en el plano nacional e internacional.

En un ambiente en que los análisis de la realidad se ocupan cada vez menos de proyectar modelos sociales, y cada vez más de identificar los supuestos e incongruencias de esos modelos - dando lugar a un estilo casi introspectivo de reflexionar acerca del sentido y de los límites del desarrollo reciente--, el tema de la población surge como resultado de la búsqueda de nuevas estrategias y caminos para superar la ambiguiedad de este estado intermedio de semidesarrollo.

Es evidente que la preocupación contemporánea por el tema constituye un reconocimiento indirecto de que el desarrollo de América Lati- 
na ha sido desequilibrado e insuficiente, planteamiento que refleja a su vez los nuevos y más elevados niveles de progreso alcanzados por la región.

Este interes cada vez mayor se alimenta en tres fuentes complementarias: a) las interpretaciones científicas y doctrinales de la evolución económica y social que, al reconocer la importancia de aspectos no eçonómicos, deben precisar cuáles son las principales relaciones que parecen existir entre las tendencias demográficas y el progreso general, para definir así el papel de la población como factor de desarrollo; $b$ ) la evo lución de la conducta demográfica de los diversos grupos sociales en su intento de ajustarse a sus posibilidades y circunstancias dentro de una coyuntura global de semiindustrialismo, y c) la acción de los gobiernos expresada a través de planes, políticas y programas que responden de algún modo a la necesidad de armonizar sus macroestrategias de desarrollo con las demandas de servicios provenientes de los núcleos familiares.

A

I.A POBLACIÓN EN LAS INTERPRETACIONES DEL DESARROLLO ${ }^{1}$

\section{1) La situación reciente}

Durante el decenio de 1960 la preocupación de los círculos académicos de América Latina por los problemas de población se mantuvo a la zaga de las consideraciones ideológicas. Los análisis del desarrollo más en boga se interesaron indirectamente en el problema, e incorporaron el volumen, la localización y la tasa de crecimiento de la población como datos 0 antecedentes para elaborar algunas interpretaciones del desarrollo. Diversos institutos y centros de investigación social tendieron durante los años sesenta a circunscribir estas cuestiones al campo estricto de la demografía, dejando por regla general el estudio de las relaciones entre población y desarrollo, y la formulación de políticas, a doctrinas sociales que tenían su principal fuente de inspiración en la controversia ideológica sobre la naturaleza del orden social; y sobre el papel de los países de la región en el sistema mundial.

Los principales argumentos de carácter doctrinal se referían a la mayor o menor importancia del problema de población en las políticas de desarrollo, y, en el mediano y largo plazo, en los objetivos de transformación económica y social. Si se examinan los supuestos en que se basan los argumentos es posible distinguir dos corrientes de pensamiento en torno a los cuales se han definido las posiciones. Reconociendo que tanto el volumen como la tasa de crecimiento de la población influyen de alguna manera en la transformación de la organización económica y de la estructura social de los países, se ha querido evaluar el efecto de los factores demográficos $\mathrm{y}$, sobre todo, determinar cuándo los exceden-

1 Véase L. Ratinoff, "Población y desarrollo en América Latina: evolución de las doctrinas", Temas del BID, ním. 12, abril de 1971. 
tes de población constituyen un elemento adverso para la aceleración del proceso de desarrollo, y bajo qué condiciones se convierten en un factor dinámico de transformaciones.

Se ha examinado también la relación inversa entre estos dos procesos y el efecto que la evolución económica y social de los países latinoamericanos podría tener en un futuro próximo sobre las actuales tendencias demográficas.

En el primer caso, los argumentos parten de algunos diagnbsticos e interpretaciones de la naturaleza del desarrollo de los países; en el segundo se han elaborado imágenes que intentan esclarecer el significado de la actual transicion demográfica.

\section{2) Diagnóstico de la crisis y papel del crecimiento demográfico}

El semidesarrollo logrado por América Latina mostró que el progreso no había sido suficiente para resolver algunos problemas que se arrastraban desde el pasado, y que además había generado problemas nuevos. que respondían a una más elevada diferenciación social.

En estas circunstancias se reconocio, de un lado, un desfase entre la dinámica política interna de los países que se orientaban hacia un desarrollo más autónomo, $y$, de otro, la creciente necesidad de recursos, téc. nicas y conocimientos científicos provenientes de los países centrales, y la dependencia de los mercados mundiales de materias primas. El rápido pero limitado crecimiento parecía haber conducido a una situación en que las potencialidades de desarrollo se encontraban circunscritas por obstáculos internos de naturaleza estructural e institucional. Había que enfrentar demandas cada vez más contradictorias entre las necesidades y aspiraciones sociales y los requerimientos de eficiencia económica general, y se apreciaba a la vez una crítica falta de continuidad entre la capacidad de las instituciones para movilizar, generar consensos, encauzar de manera funcional las aspiraciones de grupos y sectores, y administrar el logro de metas sociales.

a) Los pronósticos. Como era de esperar, el diagnóstico de la crisis se expresó en pronósticos acerca de las posibilidades del establecimiento para explorar nuevas aperturas y sentar las bases de un orden más eficiente.

Durante las últimas décadas las ideologías orientadoras del cambio social en América Latina han acentuado cada vez más la necesidad de organizar a cada nación con el máximo de autonomía, y acrecentar la participación de la gran mayoría de la población mediante la ampliación del mercado interno y la reforma de las instituciones administrativas y políticas. Las màyores diferencias se han referido naturalmente à la intensidad de las reformas, a la estrategia o trayectoria crítica elegida, y a los modelos optativos de organización social.

La visión del desarrollismo conservador se afirma en las potencialidades que ofrece el modelo actual para un rápido desarrollo basado en la consolidación del orden interno, en la concentración de los recursos y en su aplicación a las metas de industrialización, en atraer la inversión 
extranjera, y en una explotación más eficiente de los mercados de los países industriales.

Otros han acentuado la necesidad de eliminar gradualmente, a mediano y largo plazo, aquellos obstáculos de naturaleza estructural que limitan el desarrollo; es decir, de pagar un "costo" económico y social razonable para crear las condiciones, los incentivos y las instituciones que permitan ajustar el orden social a un sistema de desarrollo que haga compatibles la elevación de la productividad industrial y la ampliación del mercado interno.

Los revolucionarios predican que las posibilidades del establecimiento están agotadas, y que el futuro de la industrialización dependerá de la creación de un nuevo sistema de relaciones políticas y sociales que redefina radicalmente las instituciones de propiedad y la estructura del poder político.

Los tres pronósticos varían entre sí en la interpretación de la importancia de las variables políticas y sociales, y en la selección de modelos - proyectos de sociedad. Para los conservadores, la consolidación del orden político descansa en las oportunidades relativamente amplias de crecimiento económico, que en el largo plazo permitirán compensar los desequilibrios y sacrificios que en lo inmediato entraña el desarrollo. Aceptan además el modelo de la sociedad capitalista de consumo que tiende a una doble expansión del mercado interno, intensificando el consumo de los grupos de más altos ingresos, e incorporando de manera lenta pero sostenida a aquellos sectores sociales que, por la dinámica del proceso mismo, se van colocando en el umbral del mercado. Las imágenes que se utilizan para explicar el sentido de la transición y de las fases críticas se extraen fundamentalmente del estudio de los procesos de modernización que llevaron al nacimiento de un orden industrial en los países más avanzados.

Los revolucionarios consideran que el progreso económico potencial está aprisionado por el sistema existente de dominación, y que su liberación exige dar prioridad a las grandes tareas de transformación y creación política que supone el paso hacia un sistema socialista. El modelo del futuro orden social se inspira en la experiencia revolucionaria de los países socialistas, y para su aplicación a las condiciones locales se recurre a los instrumentos de análisis y a las orientaciones que proporcionan las ideologías revolucionarias.

Para quienes consideran que el modelo es permeable a la introducción de sucesivas reformas destinadas a hacer más funcional y justo el orden social, es esencial equilibrar el crecimiento económico con medidas redistributivas y de transformación del marco institucional. La 16gica interna de esta estrategia descansa en las ventajas que ofrece la gradualidad, y supone que los sucesivos cambios económicos y sociales en una misma dirección termina al cabo por modificar el sistema político. El modelo de sociedad implícito en esta tesis es difícil de precisar, por cuanto implica la definición de formas de vida y de controles no revolucionarios, pero al mismo tiempo acepta los valores de un orden 
político liberal. Está implícita la idea de alguna forma de estructura social mixta, que ha de surgir pragmáticamente de la experiencia del desarrollo.

b) La población y las perspectivas de cambio. Estos pronósticos acerca de las posibilidades del establecimiento en la presente coyuntura de semiindustrialización, constituyen el marco de referencia del debate latinoamericano sobre los problemas de población. Tradicionalmente, la doctrina aceptada descansaba en la idea de que el crecimiento demográfico era un factor positivo de desarrollo. Se pensaba que el aumento de la población contribuía a elevar y a diversificar la demanda, generaba presiones para utilizar mejor los recursos y estimulaba la formación de las capacidades indispensables para elevar la productividad general. Se afirmaba que el ambiente que originaban las grandes densidades humanas facilitaba el surgimiento de una moderna cultura industrial, a través de avances en la división del trabajo y la diversificación social, creando una escala que daba sentido al desarrollo científico y tecnológico. Se aceptaba incluso que el más rápido reemplazo de las generaciones contribuía a acelerar los cambios, ya que los individuos jóvenes y mejor preparados eran de hecho portadores de nuevas concepciones, más acordes con el progreso productivo y la modernización social.

Además, se creía que sólo los países que habían alcanzado un apreciable volumen de población podían desempeñar un papel en el balance de poder mundial y que, para los efectos prácticos, las oportunidades de desarrollo no debían abstraerse de la posición relativa que ocupaban las naciones en el sistema internacional.

Los dilemas planteados por la situación de subdesarrollo llevaron a los distintos grupos a revisar esta concepción tradicional, en función de sus objetivos económicos y sociales de cambio.

c) La población y el desarrollismo conservador. Para los sectores más representativos de la opinión conservadora, las altas tasas de crecimiento de la población plantean un dilema difícil de resolver, que obliga a poner en la balanza, por un lado, consideraciones tradicionales de carácter moral y, por otro, el propósito de alcanzar un rápido progreso dentro del orden establecido. Se reconoce que una expansión demográfica acelerada puede crear contradicciones insuperables entre las metas de desarrollo económico y las de mejoramiento social. En su versión más extrema, este planteamiento contrapone el crecimiento de la población al desarrollo económico, pues la capacidad de los servicios y las instituciones sociales, y los recursos que pueden destinarse a fines productivos, correrían el peligro de quedar a la zaga de las demandas de una población en rápido crecimiento. Sin embargo, esta posición no agota las alternativas que ofrece el desarrollismo conservador. Hay otros que aceptan la importancia del problema, pero destacan que la idea del carácter "agobiante" de las tasas demográficas supone, a plazo mediano, un estado de movilización de masas; y señalan que, allí donde existen condiciones que garantizan un período de aminoración de la participación y la continuidad del orden social, los excedentes de pobla- 
ción contribuyen a mantener bajos los salarios. De este modo, en países donde el mercado interno ha alcanzado un volumen compatible con la escala de la tecnología moderna, controlar la rápida elevación de los salarios industriales sería una ventaja comparativa para la exportación de manufacturas. Además, dentro de una estrategia de aceleración del crecimiento económico, la población tendría funciones adicionales. Con recursos naturales abundantes habría una mayor capacidad social de colonización y en general de expansión de la frontera interior. Con ello se incorporarían a la economía nuevos factores y posibilidades. De otra parte, asegurado el crecimiento de la economía durante una etapa de transición en un mundo sujeto cada vez más a la escala de producción que impone la tecnología moderna, una fase ulterior de redistribución ofrecería una reserva dinámica de amplias posibilidades para consolidar el desarrollo logrado.

d) La población en la ética y en la práctica revolucionaria. El desarrollismo revolucionario enfoca el problema del crecimiento de la población desde una doble perspectiva. Al nivel de la conducta privada favorece una procreación responsable y voluntaria, y, en último término, una ética de liberación e igualdad de la mujer. Se acepta que en la sociedad prerrevolucionaria deben apoyarse los esfuerzos destinados a proporcionar a quienes lo requieran los servicios y las informaciones indispensables, pero de ningún modo aceptar presiones o incentivos de la élite de poder para controlar la natalidad de las grandes masas con propósitos políticos. La idea central es que las decisiones de las parejas en cuanto a la natalidad deberían reflejar un cambio cultural inducido por la mayor participación en los beneficios del progreso, de modo que la realización plena de estas metas sólo se alcanzaría en una sociedad revolucionaria.

Al nivel de las tendencias generales, se considera que los excedentes de población constituyen un genuino instrumento de cambios. Al igual que en los sectores conservadores, las ideologías revolucionarias destacan que allí donde hay un mínimo de movilización política el rápido crecimiento demográfico acentúa las presiones sobre instituciones y recursos. Dentro de una dinámica de enfrentamiento entre masas y minorías ello puede contribuir a crear aquellas condiciones generales que conducen a una revolución. Además, la mayor presión de la población es en sí misma un incentivo para la adopción de nuevos y más avanzados criterios de racionalidad y justicia social. La síntesis de estas dos perspectivas es la afirmación de que sólo en el seno de una sociedad revolucionaria, que evoluciona conforme a estos criterios, las metas generales de población deberán y podrán coincidir con las decisiones de las parejas en cuanto al número de hijos.

e) El crecimiento demográfico y los cambios de estructuras. Para lo que se podría llamar el desarrollismo estructuralista, la cuestión central estaría definida por la singularidad histórica de la situación latinoamericana. El rápido aunque "insuficiente" crecimiento económico durante las últimas tres décadas llevó a la ruptura del equilibrio tradicional entre 
mortalidad y natalidad, en un contexto de modernización tecnológica y de elevacion de las aspiraciones de consumo inducido por el nuevo nivel de progreso. Hay que colocar los problemas de población dentro de este marco de desarrollo y determinar cómo las tendencias demográficas y la dinámica y los estrangulamientos del progreso influyen unos sobre otros para definir así políticas realistas que consideren el papel del incremento demográfico en el desarrollo.

Estas grandes orientaciones conducen a algunas conclusiones generales que ayudan a definir la posición de los estructuralistas. Lo esencial de la argumentación descansa en la idea de que en América Latina la importancia de estos problemas y de una política de población surge de la necesidad de acelerar los cambios, y de que esta política no es en modo alguno una alternativa a los esfuerzos de transformación económica y social. Además, en sentido estricto, las políticas de población parecen ser inseparables de la política social. Por ahora es ilusorio imaginar opciones que en forma aislada pudieran alterar de manera significativa las tendencias demográficas. Por el contrario, el rápido incremento de los excedentes de población tiene en el corto y mediano plazo consecuencias que deben tomar en consideración las políticas de desarrollo.

Ahora bien, los estructuralistas afirman que - aceptada una estrategia de desarrollo en que se intenta armonizar la necesidad de maximizar la eficiencia económica general con la gradual y sostenida elevación del nivel de vida de las grandes mayorías- se requieren en el mediano y largo plazo tasas de crecimiento de la población que sean compatibles con el logro de esos objetivos. La mezcla de crecimiento económico con justicia social, sobre la base de una transformación tecnológica de gran envergadura, supondría el rápido logro de tasas declinantes de crecimiento demográfico.

\section{3) Imágenes de la transición demográfica}

Estas concepciones del papel de la población en la presente coyuntura de desarrollo se apoyan en ciertas imágenes de la transición demográfica. La decisión de intervenir o de abstenerse en estas materias supone que en los planes de desarrollo hay áreas prioritarias en las que influyen las tendencias de población, y además que esas tendencias reflejan el nivel y la naturaleza del desarrollo alcanzado. Si se acepta que, a partir de un cierto punto en la historia reciente de América Latina, la alteración del equilibrio tradicional ha generado una evolución demográfica distinta, cabe preguntarse por el curso "natural" de esta transición, es decir, la dirección que el proceso ha de seguir de no mediar políticas y programas que influyan directamente en la natalidad.

a) La autorregulación. Una interpretación muy difundida hace hincapié en que la aceleración del desarrollo lleva necesariamente a la autorregulación del proceso demográfico, ya que la natalidad dependería directamente de variables tales como la escolaridad, la incorporación de la mujer a la fuerza de trabajo, y la elevación de las aspiraciones que van asociadas a un mejor nivel de ingresos. Al destacar que el juego de los. 
factores en el proceso de modernización termina al cabo por inducir un nuevo equilibrio entre la natalidad y la mortalidad, se afirma de una parte que la transición demográfica ha de seguir necesariamente el curso que tomó ese proceso en los países industriales, y, de otra parte, se sugiere que hay serias limitaciones en cuanto a intentar alterar la trayectoria que definen las fuerzas y factores que intervienen en la transición.

b) La fase crítica de indeterminación. Quienes acentúan la importancia de los desequilibrios internos como características de una coyuntura de semidesarrollo, argumentan que el "ciclo natural de autorregulación" no es necesario ni irreversible, ya que hay una fase de "indeterminación" que es consecuencia del retraso con que descienden las tasas de natalidad. Dando por aceptado que las modernas técnicas médicas causan una situación demográfica históricamente distinta, se concluye que la duración y las posibilidades de modificar las tendencias durante la fase de "indeterminación" dependen de la naturaleza e intensidad de los desequilibrios. Sólo un ambiente en que la política económica se apoya en medidas de modernización social permite crear las fuerzas sociales y los mecanismos institucionales que contribuyen al éxito de programas destinados a hacer descender la natalidad.

c) La trampa demográfica. Está finalmente la posición de quienes creen que la transición tiende al deterioro acumulativo de algunas relaciones, de modo que permitir el libre juego de las tendencias conduce necesariamente a una "trampa demográfica", que en último término puede llegar a constituir un obstáculo irreversible para el proceso de desarrollo.

La "trampa" es consecuencia del estado de semimodernización de la sociedad, y de la falta de sincronía en el ritmo de las transformaciones económicas y sociales. Al descender la mortalidad y mantenerse los niveles tradicionales de natalidad se crea una estructura de edades que tiende a intensificar el ritmo de crecimiento demográfico, sobre la base de un sostenido aumento de la población dependiente. En estas condiciones el efecto de las políticas destinadas a mejorar la "calidad" de la población, y a integrar los sectores sociales "marginales" a las tareas productivas, es aminorado por las tendencias demográficas, que acentúan paulatinamente las condiciones que llevan al estrangulamiento.

La trampa demográfica obliga así al Estado a asumir la responsabilidad de controlar el crecimiento demográfico, como parte de la política general de desarrollo.

B

ESTRUCTURA SOCIAL Y EVOLUCIÓN DEMOGRÁFICA

\section{1) Hipótesis sobre la transición demográfica}

Una breve reseña de la evolución demográfica reciente de los países de América Latina muestra mucha variedad en las etapas actuales del pro- 
ceso de transición demográfica. Sin embargo, en la gran mayoría de los países ha tendido a acelerarse el crecimiento de la población como consecuencia del desequilibrio cada vez mayor entre las tasas de natalidad y mortalidad. ¿Cuál será el curso probable del crecimiento de la población en esos países? Para contestar cabalmente a esta pregunta debería hacerse en cada país un análisis minucioso y profundo de la situación y las tendencias de los componentes del cambio demográfico y de los factores económicos y sociales relacionados con ellas, análisis que queda fuera del marco del presente capítulo. Sin embargo, cabe hacer aquí algunas consideraciones de carácter general sobre las perspectivas del crecimiento demográfico de esos países.2

Primero, dado que el margen de variación probable de la mortalidad en el futuro será relativamente estrecho y de que la migración internacional, además de imprevisible, tendrá seguramente muy poca importancia en la mayoría de los países, cabe concluir que la fecundidad es la variable crítica, cuya evolución determinará en gran medida el ritmo de crecimiento de la población.

Segundo, investigaciones recientes respecto a la existencia de diferencias en los niveles de fecundidad y sobre la información, las actitudes y las prácticas anticonceptivas en las poblaciones de muchos países, así como el alcance cada vez mayor de los programas de planificación familiar y el interés de los gobiernos en ellos, permiten inferir que el proceso de cambio en el comportamiento reproductivo de la población es mucho más dinámico de lo que sugieren los análisis de las tendencias recientes de indicadores globales como la tasa bruta de natalidad.

Tercero, parece cada vez más evidente que los adelantos en las técnicas anticonceptivas, junto con la creciente extensión y eficacia de los medios de información, han debilitado las relaciones entre cambio económico y sociál y descenso de la fecundidad. Esto vendría a reforzar una predicción hecha por las Naciones Unidas ${ }^{3}$ sobre la base de un análisis de la relación entre patrones de fecundidad e indicadores socioeconómicos: en varios países de América Latina que actualmente tienen un elevado crecimiento de la población, la fecundidad estaría en el umbral del descenso. Las reducciones que se han observado en diversos países durante el último decenio corroboran esta tendencia.

Por último; es importante destacar que, habida cuenta de las consideraciones precedentes, la disminución de la fecundidad puede acelerarse en la misma forma en que se ha acelerado la reducción de la natalidad en las regiones en desarrollo. Es decir, que la transición demográfica, que tomó más de un siglo en las naciones tecnológicamente avanzadas, pudiera desarrollarse en unos pocos decenios en muchos países latinoamericanos.

2 El cambio social y la política de desarrollo social en América Latina, Publicación de las Naciones Unidas, núm. de venta: s.70.II.c.3, p. $45 \mathrm{ss.}$

3 Population Bulletin of the United Nations, núm. 7, Publicacion de las Naciones Unidas, núm. de venta: 64.XIII.2. 


\section{2) Urbanización y fecundidad}

En el ambiente urbano, sobre todo en las grandes ciudades, es donde se producen los principales cambios en la conducta reproductiva. Las situaciones que define esta estructura social, las motivaciones que induce y las expectativas que crea, son el factor dinámico por excelencia en el proceso de modernización de la conducta demográfica.

Si bien la ciudad latinoamericana es el escenario a la vez que el foco que impulsa esta transformación, en muchos países la naturaleza misma de la urbanización, a la vez que crea las condiciones indispensables para el cambio, mantiene otras que constituyen verdaderas barreras para su difusión.

Un breve examen de las ciudades de la región vistas como sistemas de vida, sugiere la existencia de estructuras sociales que tal vez representen momentos de una evolución típica a los cuales corresponden también patrones definidos de natalidad.

Para ilustrar el sentido de estos cambios pueden señalarse cuatro tipos de establecimiento urbanos. Cabe clasificar las estructuras sociales históricas, según la naturaleza de la élite predominante, en aristocráticas y oligárquicas; y las estructuras contemporáneas, definidas por la incidencia de la industrialización, pueden dividirse en dos tipos de establecimientos, uno en que se acentúa la dominación de las clases medias, y otro, en que los avances de la industrialización crean una situación de semidesarrollo donde las expectativas exceden las posibilidades concretas.

Los antecedentes muestran que ha habido una evolución sostenida en el sentido de reemplazar actitudes natalistas basadas en una ideología y en una ética religiosa, por criterios seculares inducidos por la movilidad social y el consumo, y que estos nuevos valores han surgido en parte de las transformaciones, de la élite, y de la consolidación de una cultura de clase media.

a) Las estructuras históricas. Vale la pena referirse a los tipos de ciudades del pasado, por regla general aglomeraciones relativamente pequeñas, organizadas para prestar servicios a una élite más o menos reducida, durante las fases preindustriales del desarrollo latinoamericano.

I) La ciudad aristocrática. El establecimiento urbano aristocrático se estructuró en torno a un grupo de familias que fundaba sus posibilidades de existencia en la propiedad y explotación de tierras. La escasa diferenciación económica reflejó una estructura social, en la cual la élite no sólo ocupó el lugar central y predominante, sino que en gran medida fue para los demás sectores de la ciudad la fuente directa de la mayor parte de las oportunidades de empleo y de ingreso. Predominaban los criterios de estratificacion: las escasas capas medias ocupaban una posición subordinada de servicio $\mathrm{y}$, aunque un poco más abundantes, los sectores populares estaban jerarquizados de acuerdo con la cercanía de sus tareas en relación con la aristocracia.

En este ambiente de oportunidades restringidas, y por ende de escasa movilidad, donde los valores de competencia significaban poco frente 
a los criterios de estratificación, la reproducción de la élite y de las capas medias estuvo ideologicamente regulada por normas trascendentes que favorecían una fecundidad abundante, y que permeaban la conducta de los estratos populares.

Ir) La ciudad oligárquica. El establecimiento urbano oligárquico refleja una etapa de mayor diferenciación. Las exportaciones de materias primas a los mercados internacionales favorecen la consolidación de una estructura social basada en la alianza de intereses de terratenientes y exportadores. Aumenta el volumen de la ciudad y se multiplica la magnitud del excedente económico.

Como la exportación exige servicios más especializados, se crean nuevas oportunidades que favorecen la formación de una clase media más extensa y compleja, y de estratos bajos que siendo más amplios son a la vez menos jerarquizados. Sin embargo, en el seno de las capas populares el artesanado mantiene su importancia tradicional y deriva en una subélite popular que lentamente se organiza, en muchos casos tras el ideario de formar una cultura obrera.

Las capas medias monopolizan las oportunidades de movilidad social, y la élite deja de ser un núcleo de familias relacionadas entre sí para incorporar intereses vinculados al comercio de exportación. Tras esta apertura hay un cambio en las ideologías que justifican el orden social. Se secularizan muchas de las nociones trascendentes que regulaban la conducta, y se acentúa la importancia de los valores adquisitivos.

Sin embargo, los nuevos niveles de competencia no afectan de manera seria las posiciones detentadas por la élite, que tiende a mantener su conducta reproductiva tradicional. Las clases medias, a medida que aumentan en volumen, intensifican su compromiso con los valores seculares. Se observan aquí las primeras manifestaciones de una conducta reproductiva que se orienta hacia la movilidad y la adquisición de status, y se inicia lentamente la tendencia hacia una disminución del tamaño medio de esas familias.

Las capas populares conservan su fecundidad tradicional.

b) Las estructuras contemporáneas. La industrialización trae consigo un gran vuelco de las pautas de vida urbana. Hay una significativa transformación de la estructura del empleo y una ampliación sin precedentes de oportunidades. Las ciudades crecen con rapidez hasta transformarse en algunos casos en metrópolis y aun megalópolis. El ritmo de aumento del excedente económico no sólo supera las tendencias históricas, sino que además escala rápidamente niveles muy elevados. Junto a las escuelas, la expansión del mercado urbano ocupa un lugar preponderante en la socialización de la población, y ambas instituciones crean nuevas expectativas y hábitos de consumo.

La élite cambia de naturaleza. Un nuevo pacto social conduce a la admisión gradual de empresarios industriales, administradores y tecnócratas. Las normas que regulan las situaciones de poder deben ajustarse a las necesidades de una élite más amplia, fluida y compleja. No sólo se intensifica la secularización de las ideologías, sino que comienzan a 
penetrar concepciones que acentúan metas de funcionalidad a expensas de los valores de jerarquización.

Esta expansión abre nuevas avenidas de movilidad social y adquieren preeminencia las ideologías que justifican el desplazamiento social de familias e individuos. Algunos sectores de las clases medias son absorbidos en la élite, a la vez que se aflojan parcialmente las normas que regulan el ingreso a esas posiciones.

El artesanado pierde significación en la vida de la ciudad, los obreros industriales organizados se convierten en el sector que articula las presiones sociales de las capas populares. Se modifica el sistema de calificaciones, y con ello la idea de una jerarquía obrera natural basada en los oficios. El acceso al mercado urbano mediante el empleo industrial, y las posibilidades de influir en la estructura de poder a través de organizaciones, son los criterios que determinan el grado de integración en la cultura de la ciudad. Es así como comienzan a abrirse tímidamente nuevas vías para la movilidad social de individuos provenientes de las clases bajas.

El balance entre las expectativas y las posibilidades de movilidad es en general crítico. El desarrollo insuficiente contribuye a que las expectativas tiendan a exceder las oportunidades.

Dentro de este cuadro general pueden distinguirse dos etapas. La primera se inicia con la crisis del sistema de dominación oligárquica, y por las grietas del orden que se derrumba surge un establecimiento en el que las clases medias pasan gradualmente a desempeñar un papel central. En la segunda fase el fenómeno dominante es la industrialización, cuyos efectos se manifiestan en todos los niveles de la estructura social, pero que tiene una capacidad limitada para crear un sistema de vida fundado en la tecnología y en el modo de producción industrial.

I) El establecimiento urbano mesocrático. En sus primeras etapas la industrialización favoreció la formación de un establecimiento urbana caracterizado por tres rasgos fundamentales:

un aumento cuantitativo de los sectores populares que pasan a representar una proporción elevada de la población de la ciudad, pero de los cuales sólo un núcleo muy pequeño se encuentra políticamente organizado;

una expansión de las clases medias, que acrecientan significativamente su influencia política y social y que incluyen diversos segmentos empresariales, $y$

una intensificación del proceso de secularización apoyado en el desarrollo del mercado urbano, y en una clase media comprometida con valores adquisitivos y de movilidad social.

En este marco el ascenso de las clases medias está asociado a ideologías que cuestionan la legitimidad del orden existente y ofrecen alternativas que acentúan el premio al mérito individual. La idea central es. 
la de crear una jerarquía estable, que permita el libre acceso a posiciones dentro de la sociedad según la capacidad individual.

En la medida que la clase media pasa a constituir el principal soporte del orden social, y se eleva su nivel de vida, se intensifica la competencia por los medios y los símbolos indispensables para alcanzar y conservar el status.

El destino de las capas populares queda definido por el acceso al empleo estable y productivo y a la cultura, y por su capacidad de organización. De cualquier modo, la lucha de las capas populares tiene como objetivo colocarse en los umbrales del mercado a través de organizaciones que acentúan la solidaridad. Por lo tanto, las orientaciones adquisitivas y de movilidad penetran en forma lenta y selectiva.

La fecundidad se ajusta muy de cerca a este cuadro general. Los grupos más fuertemente comprometidos con la adquisición de status tienden a regular su natalidad, y esta orientación se convierte muy pronto en un rasgo distintivo de la naciente cultura de clase media. Se observa también que en esas capas aumenta la incidencia del aborto inducido.

Los grupos tradicionales de la élite consideran la reproducción de acuerdo con normas trascendentes, y en las clases populares los hijos siguen constituyendo un hecho inevitable.

II) La ciudad semiindustrial. La ciudad semiindustrial se caracteriza por el inicio de una profunda transformación de la cultura urbana, y por el desequilibrio entre las expectativas y la capacidad del sistema para satisfacerlas, y entre las necesidades y las posibilidades de resolver los problemas que plantea la aglomeración humana.

Las clases medias son ahora una proporción elevada de la población, hay una étite más compleja en que las relaciones primarias pierden importancia relativa, y las capas populares se estratifican como consecuencia de la aparición de situaciones de marginalidad.

Aumenta la capilaridad social, pero la secularización y universalización de las costumbres encuentra límites que están implícitos en los sistemas de prestigio y en la difusión de las oportunidades de movilidad. Los frutos del progreso urbano se distribuyen de manera selectiva y sblo las capas más altas de los sectores populares logran acceso al mercado y movilidad social. Esta diversificación insuficiente y selectiva da mayor estabilidad a los sistemas de prestigio, y a los principios asociados tradicionalmente al rango de las familias.

Por debajo de los obreros industriales especializados, los diversos núcleos que están en situaciones de marginalidad se organizan en torno a sus problemas más elementales de incorporación y presionan para tener acceso a los mercados.

La conducta reproductiva responde a esta diversidad de situaciones:

La nueva complejidad de la élite, y el reemplazo del sistema de relaciones primarias por otro de representación y administración de intereses, induce una natalidad menor, en concordancia con una coyuntura de mayor competencia entre los individuos. 
En las clases medias continúa el descenso de la natalidad a medida que se elevan los niveles de consumo y se intensifica la competencia por las oportunidades de movilidad social.

Algo similar ocurre entre los obreros industriales sindicalizados, en cuanto desarrollan aspiraciones de movilidad y se orientan hacia el consumo.

En los sectores marginales, la movilización política y las organizaciones de base constituyen factores de racionalización de la conducta reproductiva, en comparación con aquellos estratos que constituyen todavía una masa amorfa.

Tomando en cuenta, de una parte, las limitaciones del proceso de urbanización y secularización cultural, $y$, de otra, la intensificación de las aspiraciones de consumo y movilidad, se observa un incremento del aborto inducido, sobre todo en los estratos populares.

\section{3) Estructura social de la ciudad e incidencia de algunas variables}

En investigaciones recientes se muestra que el comportamiento de algunas variables estratégicas que influyen en la conducta reproductiva de la población, parece modificar sus efectos en función de los tipos de estructuras sociales urbanas. Por desgracia, los resultados son apenas indicativos de la existencia de relaciones, y los antecedentes permiten a lo más conjeturar acerca de lo que ellas significan.

a) Escolaridad de la madre. Los antecedentes muestran que en América Latina la escolaridad influye en la conducta reproductiva. Los estudios apuntan a que habría una relación inversa entre el número de hijos y la educación de la mujer. Sin embargo, si bien la relación es unívoca en todos los casos investigados, hay variaciones importantes en cuanto a los niveles de natalidad y de educación. En algunos centros urbanos las diferencias en la natalidad atribuibles a la educacion parecen ser menores; en otras ciudades el umbral crítico en el cual la escolaridad influye en el descenso de la natalidad es más elevado, e incluso se observa la existencia de distintos umbrales críticos. Es evidente que si bien la educación tiene una influencia unívoca sobre la natalidad, su papel varía de conformidad con marcos sociales específicos. ${ }^{4}$

Algunas hipótesis son ilustrativas del sentido de estas variaciones. $\mathrm{Pa}$ -

4 Ana María Rothman, La fecundidad en Buenos Aires según algunas características demográficas y socioeconómicas, cexane, Serie C, núm. 99, 1967; Carmen Mir6 y Walter Mertens, Influencia de algunas variables intermedias en el nivel y en los diferenciales de fecundidad urbana y rural en América Latina, cELAde, Serie A, núm. 92, 1969; Virginia Rodríguez, Fecundidad difetencial según nivel de instrucción, crLade, Serie C, núm. 97, 1971; Alfredo Enrique Lattes, La fecundidad efectiva en República Argentina según algunas características de la madre, CELADE, Serie C, núm. 96, 1967; M. Elsa Cerisola, Fecundidad diferencial en la Republica del Paraguay según condición de ruralidad y nivel de instrucción de la mujer, CELADE, Serie C, núm. 101, 1967. 
reciera en efecto que, en ambientes sociales donde hay una experiencia más generalizada de movilidad y participación en el mercado, y un elevado grado de secularización cultural, grandes incrementos en la escolaridad causan pequeñas diferencias en la natalidad; el umbral crítico se produce sólo respecto de quienes en la práctica carecen de instrucción, es decir, cuando de hecho se es marginal al mercado y a la movilidad. ${ }^{5}$

La educación tiene un papel distinto en los ambientes sociales urbanos en que la participación en el mercado y las experiencias de movilidad ocurren de manera más selectiva dentro de una cultura menos secularizada. Como se observan en promedio natalidades más altas, tasas equivalentes a las del primer tipo de ambiente descrito exigen una educación sistemática más prolongada. De otra parte, hay significativas diferencias en el número de hijos como consecuencia de la educación recibida. Un rápido examen de los umbrales de escolaridad indicaría una relación directa entre las situaciones de mayor movilidad y participación en el mercado y el nivel crítico de educación necesario para hacer descender la natalidad. ${ }^{6}$

Cabría agregar, por último, que en los ambientes en que predominan las normas de una cultura trascendente, una educación prolongada de la madre parecería contribuir a la adopción de nociones seculares para la conducta reproductiva.

b) Participación económica de la mujer. Los estudios muestran que la natalidad es menor entre las mujeres que trabajan. ${ }^{7}$ Aun cuando este resultado se reitera en la mayor parte de las investigaciones, los datos no permiten aclarar el sentido de la relación. La hipótesis básica es que hay una incompatibilidad fundamental entre el trabajo fuera del hogar y la crianza de los hijos, lo que parecería estar confirmado por estudios que muestran que en las mujeres que trabajan la diferencia entre el número ideal de hijos a que se aspira y el número conveniente que se acepta es significativamente mayor, por una propensión más alta al celibato, y por un relativo retardo en la edad de matrimonio. ${ }^{8}$

Hay indicios que muestran que el trabajar fuera del hogar no es en sí mismo un factor determinante de una menor natalidad, comparado con la influencia que tienen las motivaciones que acompañan esa actividad. Se observa que en los empleos de "cuello blanco" que sugieren una orientación más definida hacia la movilidad y el consumo, se intensifica la incompatibilidad entre el trabajo y el hogar.

Además, la cultura del medio urbano parece condicionar el grado de compatibilidad de los papeles sociales de la mujer. En ciudades en que

5 Virginia Rodríguez, op. cit.

6 Alfredo Enrique Lattes, op. cit.

7 Ana María Rothman, La participación femenina en actividades economicas en su relación con el nivel de fecundidad en Buenos Aires y México, CELADE, Serie C, núm. 108, 1969; Paula Hollerbach Hass, Maternal Employment and Fertility in Metropolitan Latin America, Duke University, 1971; Henry Kirsch, Development Strategy, Implications of Population Growth and Labour Force Absorption in Latin America, CEPAI, 1971.

8 Ana María Rothman, op. cit. 
las experiencias adquisitivas del mercado y la movilidad afectan a grupos pequeños de la población, y el proceso de secularización de la cultura es aún incipiente, se observa una fecundidad alta, poco acceso a la información sobre los métodos anticonceptivos, y en general a la educación, carencia de estímulos para desempeñar papeles no domésticos $\mathrm{y}$, por lo tanto, una marcada incompatibilidad entre el empleo y el hogar.

Los antecedentes muestran que en las ciudades en que predominan las orientaciones adquisitivas hay niveles elevados de participación femenina en la fuerza de trabajo y una mayor proporción de mujeres se desempeña en ocupaciones productivas que exigen algún grado de calificación; así han alcanzado niveles de escolaridad comparables a los de los varones.

Además, parece haber una vinculación ostensible entre el tipo de estructura social urbana y los niveles de calificación y de participación por edades de la fuerza de trabajo femenina. Hay indicios de que en los sistemas sociales urbanos menos evolucionados la mayoría de las mujeres que trabajan posee bajos índices de escolaridad, de modo que al aumentar su educación disminuiría la participación femenina en el empleo, con la sola excepción del grupo que alcanza niveles universitarios. Ahora bien, en las ciudades en que se intensifica la capilaridad social y predominan los criterios adquisitivos se daría la relación inversa y habría una proporción cada vez menor de mujeres sin calificación.

Otro tanto puede suponerse respecto de la participación por edades. Los datos indican que en los sistemas urbanos más tradicionales no habría grandes diferencias en la participación femenina por edades, y que se observaría tal vez una ligera propensión a aumentar entre los 40 y 50 años; en cambio, las tendencias serían diferentes allí donde la población está sometida con más intensidad a las experiencias del mercado y a la movilidad. El aumento de la participación femenina ocurriría de tal manera que gradualmente se transformaría en una función decreciente, expresión de un nuevo ajuste entre las aspiraciones de consumo y movilidad y la vida familiar.

Resumiendo lo anterior, es evidente que la evolución de las tendencias anotadas refleja el surgimiento de un nuevo estilo de vida dominado por los valores adquisitivos de una cultura secular, donde el mercado y la movilidad terminan al cabo por redefinir el papel social de la mujer. El incremento de la actividad económica femenina está asociado a la escolarización, a un paulatino pero sostenido alejamiento de los empleos tradicionales de baja productividad, a una postergación de la edad de matrimonio, primero, y de la edad de procreación, después. El resultado neto es el descenso de la natalidad. ${ }^{9}$

c) Estratificación social, movilidad y conducta reproductiva. Hasta ahora las escasas investigaciones que relacionan la natalidad con la estratificación social recurren por desgracia a indicadores parciales y a categorías globales.

Por regla general se ha utilizado la ocupación para comprobar la hi-

- Paula Hollerbach Hass, op. cit. 
pótesis de que mientras más elevada es la posición ocupacional del marido, las familias tienden a tener un número menor de hijos. ${ }^{10}$ Ahora bien, al igual que en las variables anteriores, esta relación parece ser función del tipo de estructura social urbana.

En efecto, bajo ciertas condiciones la regulación del número de hijos de acuerdo con criterios racionales se asocia más intensamente con los valores y con la cultura de clase media, mientras que en otras circunstancias esas orientaciones penetran en los niveles de la élite y se filtran hacia las clases bajas. El efecto neto en la natalidad de la ciudad depende por cierto de la proporción de la población que se encuentra en cada estrato. Allí donde este comportamiento es apenas un rasgo exclusivo de los sectores medios, el efecto en la natalidad de la ciudad no será apreciable dado que este es un segmento reducido de la población total. El mayor volumen de las clases medias se vincularía a una reducción más intensa de su tasa de reproducción y a la gradual difusión de esos criterios en la élite y en las capas populares, y habría así un ostensible descenso de la fecundidad urbana media.

Los escasos estudios sobre movilidad social y fecundidad complementan estas hipótesis. Según uno de ellos, el éxito educacional de los estudiantes de clase baja estaría relacionado con el menor tamaño de la familia de origen, y los grupos que ascienden se caracterizan por núcleos familiares más reducidos que los que descienden; a su vez, los que no cambian de status tienen familias más extensas que el resto. ${ }^{11}$

d) Movilización de masas y natalidad. Resultados parciales de investigaciones sugieren que la movilización y organización política serían factores de racionalización de la conducta reproductiva. Si bien no existen hasta ahora pruebas que lo demuestren, los antecedentes guardan coherencia con esta hipótesis. ${ }^{12}$

Se ha observado en repetidas ocasiones que en las clases populares los integrantes de núcleos protestantes que se caracterizan por un nivel elevado de organización y cohesión tienen familias más reducidas. Se ha notado también que en las capas populares los obreros organizados son el primer sector que tiende a reducir la natalidad. En ambos casos, si bien las variables que intervienen explican por sí solas la menor tasa de reproducción, sería erróneo despreciar el papel que en esos sectores ha desempeñado la concientización.

Una investigación reciente muestra que en los estratos marginales el número de hijos parece disminuir bajo condiciones de organización comunitaria y movilización política. Estudiadas las mismas cohortes de edad, se observa que la escolaridad y la participación femeninas en la fuer-

$10 \mathrm{M}$. Helena Henriques, La movilidad social y la fecundidad en Río de Janeiro, CELAde, Serie C, núm. 112, 1968.

11 Véase la investigación realizada por Ruth Sautú sobre la base del censo universitario de Buenos Aires en 1958, y de la encuesta de estratificación y movilidad social en el Gran Buenos Aires realizada en 1960-1961 y publicada en el Boletín de Investigaciones del Instituto de Sociología de la Universidad de Buenos Aires, 1963.

12 Duque y Pastrana, Las estrategias de supervivencia económica del sector popular urbano, Escuela Latinoamericana de Sociología, ruacso, 1973; Ramiro Pavón González, Fecundidad diferencial en poblaciones periféricas del Gran Santiago, cELade, 1972. 
za de trabajo tienen un efecto diferente en la conducta reproductiva cuando se dan las condiciones mencionadas. En un grupo social amorfo, el trabajo y la educación de las mujeres son variables que explican muchas de las diferencias en fecundidad. En cambio, allí donde predominan niveles precarios de escolaridad y de participación en el empleo, y el grupo social está organizado para alcanzar metas, se observa que la natalidad también tiende a disminuir.

Al parecer, la movilización de un grupo marginal tras propósitos concretos crea en los individuos un umbral de conciencia que ayuda a entender mejor su situación con relación a la estructura de la sociedad, e induce conductas que tienden a vincular el destino personal a determinados proyectos de acción. La movilización crea expectativas de una vida mejor, y define aspiraciones de movilidad en sectores carentes de los atributos que habilitan para participar en el mercado; es una fuente de socializaciones que por la vía de una comprensión de las oportunidades políticas que se ofrecen para lograr algunos beneficios concretos de las autoridades, favorece la gradual asimilación de principios racionales de acción. Además, cabe suponer que la organización que surge de la movilización inicial redefine completamente las situaciones de los individuos y de sus familias; al reemplazar la solidaridad tradicional basada en la explotación de relaciones primarias para la supervivencia en un medio adverso, por la solidaridad que crea la obtención de metas comunes mediante el poder que da la mayor cohesión, se refuerza la idea de que mediante conductas racionales es posible redefinir el destino personal.

\section{C \\ LA ACCIÓN PÚBLICA EN EL CAMPO DE POBLACIÓN}

\section{1) Consideraciones sobre políticas de población}

Una peculiaridad de la coyuntura latinoamericana es la intervención del Estado en los problemas de población, amplia en algunos países, incipiente en otros. Es probable que ello se deba a la función desempeñada por el Estado en el proceso de desarrollo, y a la larga tradición de salud pública y de medicina social que caracteriza a la mayoría de los países de América Latina.

La intervención del sector público ha respondido aquí a dos tipos de consideraciones. Unas de naturaleza abstracta, que se fundan en la proyección de un modelo futuro de sociedad y en el esbozo de estrategias globales de desarrollo, y suponen que tanto el volumen de la población como las tasas de crecimiento demográfico tienen un papel significativo. Las otras se refieren a la salud y el bienestar de las familias.

Por regla general, los gobiernos han evitado formular políticas explicitas de población. Cuando han formulado propósitos expresos con 
miras a modificar las tasas de natalidad, han esbozado lo que podría llamarse políticas demográficas. Estas metas han variado hasta ahora desde simples declaraciones generales hasta la formulación de planes que establecen objetivos en el tiempo y definen los medios para alcanzarlos. Sin embargo, la dimensión puramente demográfica de esas políticas no agota los alcances reales que ha tenido la acción del sector público. Algunos países han reconocido la conveniencia de que el Estado se abstenga de formular metas demográficas explícitas, sin que ello signifique renunciar a proporcionar aquellos servicios especializados que demanda la comunidad, y que eventualmente influyen en la natalidad. Esta neutralidad del sector público no ha sido norma general, pues en algunos casos los compromisos adquiridos para la prestación de servicios han sido de tal magnitud, que de hecho expresan propósitos demográficos tácitos, mientras en otras oportunidades han estado circunscritos a responder a las demandas sociales directas, o son simplemente marginales.

\section{2) El consenso social y la justificación de la intervención del Estado}

Un somero examen de los antecedentes indica que en la formulación de políticas cuyo proposito central es alterar la tasa de natalidad han tenido un papel fundamental las interpretaciones acerca de la naturaleza del proceso de desarrollo y del destino del país como proyecto social, así como las orientaciones de los grupos religiosos e instituciones que ejercen influencia en la definición de los valores morales de la comunidad.

Tales interpretaciones han servido de base a la formulación de estas políticas cuando han facilitado un consenso efectivo. Sin embargo, esto ha sido la excepción más que la regla general. A falta de consenso, las interpretaciones disidentes han impedido lograr ese propósito. Y también han esgrimido su poder de veto los grupos religiosos.

Los compromisos del Estado para proporcionar simplemente servicios requieren en la práctica un grado de consenso mucho menor. Se han organizado programas para satisfacer necesidades concretas de salud, que han crecido apoyándose en el patrocinio de los sectores sociales y grupos profesionales más directamente interesados. La relativa neutralidad del Estado en cuanto a establecer metas demográficas ha reflejado en parte la capacidad de disuasión de las opiniones disidentes; a su vez, la existencia de programas que comprometen al sector público suele expresar la aceptación generalizada de un conjunto de acciones indispensables que aun sus oponentes estiman necesario tolerar.

La justificación de estas políticas es distinta si el Estado observa una posición de neutralidad frente a las decisiones de las familias, o si no lo hace. El proposito de alterar las tasas de reproducción se fundamenta en consideraciones económicas relativas al ritmo y la naturaleza del desarrollo, a concepciones de colonización e integración territorial, y a visiones geopolíticas de poder e influencia internacional.

En cambio, cuando se adopta una política de neutralidad pero se interviene a través de programas concretos, el factor principal es el 
bienestar del núcleo familiar y, por ende, la concepción tácita de que las posibilidades de intervenir están limitadas en la práctica por los desequilibrios del semidesarrollo y la existencia de sectores sociales rezagados; estas actividades se conciben entonces en función de la política social, y no como parte de una estrategia económica de desarrollo.

El concepto de bienestar familiar se ha asociado con frecuencia a la idea de que toda mujer tiene derecho a decidir libremente acerca del número de hijos, y que la prestación de los servicios indispensables y el acceso a la información deben formar parte de la política redistributiva en el área de la educación y la cultura; de este modo se modificarían situaciones en las cuales algunos sectores están en condiciones de decidir acerca del tamaño de sus familias, en tanto que para las grandes masas el destino es el factor decisivo.

\section{3) Situación en materia de politicas de población}

Las intenciones demográficas del sector público no siempre se han traducido en la definición de propósitos concretos. (Véase el cuadro 21.) En países como Argentina y Uruguay las manifestaciones esporádicas de personeros públicos en favor de tasas más altas de crecimiento de la población, si bien no constituyen políticas en sentido estricto, reflejan el deseo de algunos grupos significativos de opinión de que el Estado intervenga. Esta parece haber sido también la situación del Ecuador en el pasado reciente.

En Venezuela y, hasta hace poco más de un año, en México, los gobiernos habían hecho presentes sus reservas ante intervenciones directas para alterar las tasas demográficas. En El Salvador, Honduras y la República Dominicana se han formulado políticas demográficas destinadas a hacer descender la natalidad, llegando incluso a definir tasas y plazos.

En general, pueden distinguirse las siguientes situaciones en cuanto a la definición de propósitos públicos en materia de población:

a) gobiernos favorables a un más rápido crecimiento demográfico, pero que no han traducido esas intenciones en políticas (Argentina y Uruguay);

b) gobiernos que consideran que las tasas actuales y su evolución son aceptables, y que el sector público debe evitar la definición de metas demográficas (Brasil y, tal vez, Perú);

c) gobiernos que manifiestan sus intenciones de intervenir mediante programas de alcance nacional con posibles efectos ulteriores en la natalidad, pero que se abstienen de fijar metas demográficas (Colombia, Costa Rica, Cuba, Chile, Guatemala, México, Nicaragua y Panamá);

d) gobiernos que intervienen apoyando programas especiales de alcance local o limitado (Paraguay y Venezuela), y

e) gobiernos que han definido metas de reducción de la natalidad (El Salvador, Honduras y la República Dominicana). 
Cuadro 21. Políticas demográficas y servicios de planificación familiar en 20 países de la región

\begin{tabular}{|c|c|c|}
\hline \multicolumn{2}{|c|}{$\begin{array}{l}\text { El gobierno proporciona } \\
\text { servicios de planificación } \\
\text { familiar }\end{array}$} & \multirow{2}{*}{$\begin{array}{l}\text { El gobierno } \\
\text { no propor- } \\
\text { ciona servi- } \\
\text { cios de pla- } \\
\text { nificación } \\
\text { familiar }\end{array}$} \\
\hline $\begin{array}{l}\text { Programas } \\
\text { nacionales } \\
\text { o amplios }\end{array}$ & $\begin{array}{l}\text { Programas } \\
\text { especiales, } \\
\text { locales o } \\
\text { limitados }\end{array}$ & \\
\hline
\end{tabular}

Tienen política demográfica:

a) Favorable al rápido crecimiento de la población

b) Desfavorable al rápido crecimiento de la población

El Salvador

Honduras

Rep. Domi-

nicana

c) Que acepta las tasas y tendencias existentes

Brasil

Perú

Argentina

Uruguay

No tienen política demográfica:

a) Manifestaciones públicas en favor de un más rápido crecimiento de la población

b) Manifestaciones públicas en fa- Colombia vor de un más lento crecimien- Costa Rica

Hait' to de la población

c) Neutralidad del gobiemo

\begin{tabular}{lll} 
Cuba & Ecuador & Bolivia \\
Chile & $\begin{array}{l}\text { Paraguay } \\
\text { Guatemala }\end{array}$ & \\
Venezuela & \\
Mexico & \\
Nicaragua & \\
Panamá & & \\
\hline
\end{tabular}

4) Los programas del sector público

Paralelamente a las intenciones y políticas demográficas de los gobiernos, a veces para apoyarlas y a veces casi en abierta contradicción con ellas, se han expandido los programas de planificación familiar del sector público. Durante los años sesenta los planificadores y los expertos en salud pública han reconocido que hay necesidades insatisfechas en el campo de la salud materno-infantil, y que en las zonas urbanas habría 
claras indicaciones de una creciente demanda de informaciones y servicios de planificación familiar.

Este reconocimiento se ha traducido en una rápida expansión de programas públicos y semipúblicos de diversa naturaleza y alcance, que tienden generalmente a mejorar la salud materno-infantil, y que proporcionan en ese marco informaciones y servicios médicos que influyen en la planificación de la familia. Se han creado así en algunas dependencias del gobierno unidades administrativas especializadas, se han iniciado programas de acción y de capacitación de personal, se han multiplicado las investigaciones médicas y sociales sobre este problema, $e$ incluso se ha invertido en instalaciones destinadas a alcanzar este objetivo.

Dada su preocupación. por el costo unitario de la atención médica en condiciones de escasez de recursos, y dada la desproporcionada porción del presupuesto total que se dedica a la salud materno-infantil, no es de extrañar que los médicos y los administradores del sector de la salud hayan sido quienes han ejercido mayores presiones para establecer este tipo de programas. Estas iniciativas han logrado establecerse con frecuencia pese a un ambiente de opinión adversa, y su supervivencia ha dependido de su capacidad para circunscribir su acción a cuestiones de salud pública. En el plano global se ha mantenido la controversia acerca del papel que desempeña el crecimiento de la población en el desarrollo, en tanto que la mayor conciencia de los problemas de salud que afectan a las capas populares y la necesidad de mejorar la asignación de los escasos recursos destinados al sector de la salud, han hecho que la administración pública patrocine estas iniciativas y se comprometa a expandirlas de acuerdo con las demandas y las necesidades.

\section{5) Origen de las actividades}

Por regla general, las actividades de planificación de la familia se inicias ron en asociaciones privadas. Estos programas - muchas veces no reco. nocidos por las autoridades competentes- alcanzaron un nivel significativo luego de su fase inicial. La duración de esta fase parece haberse determinado por la relación entre el interés por los problemas sociales y médicos que había en la comunidad, y las resistencias culturales y religiosas.

Un rápido examen de la evolución de tales programas indica que mientras más tardío fue su comienzo más corto es su período de gestación. (Véase el cuadro 22.) Todo parece indicar que la situación general ha cambiado y que, en forma paulatina, la opinión va siendo menos marcada. Esto bien puede haber coincidido con incrementos en la escolaridad, una mayor urbanización, la creciente secularización de los, valores, el aumento del número de hijos vivos por mujer en edad fértil observado a partir de 1950, y la expansión de los servicios médicos. $\mathbf{Y}$ todo ello ha permitido conocer mejor los problemas de salud que afligen: a las capas populares.

Esa fase privada fue seguida en la mayoría de los casos por una etapa 
Cuadro 22. Fechas de iniciación y consolidación de las actividades de planificación familiar de las asociaciones privadas, $y$ acuerdos de colaboración con las universidades y el sector público

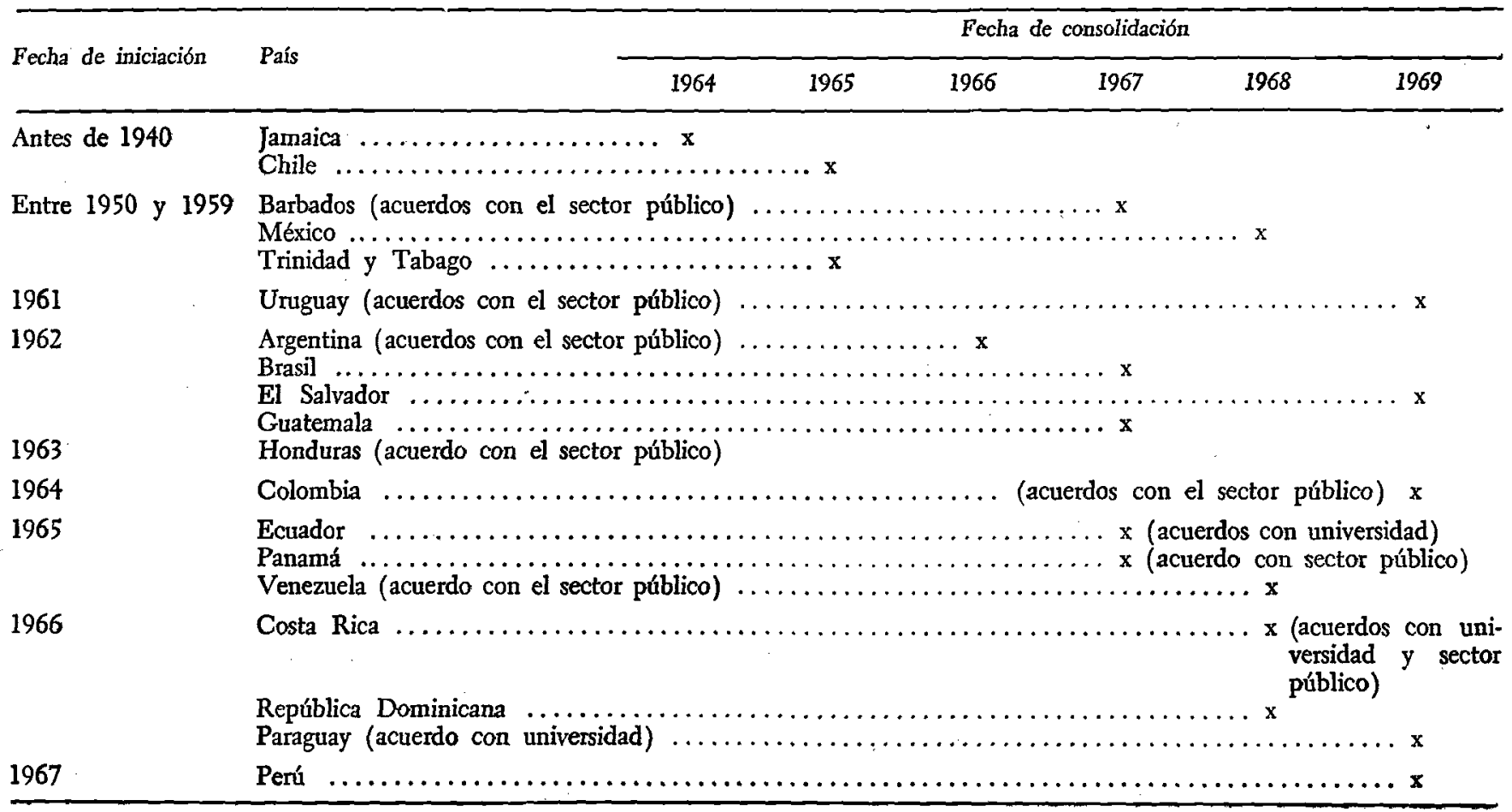


de estatización de las actividades. La labor de esas asociaciones particulares se vinculó luego a la acción del sector público de tres maneras:

a) en muchos países las asociaciones privadas comenzaron sus actividades en colaboración con clínicas y hospitales públicos, y, posteriormente, las instituciones estatales se interesaron en ampliar y racionalizar el servicio;

$b$ ) en otros casos, el trabajo de las asociaciones privadas allanó el camino para la intervención del Estado, y

c) finalmente, en algunos países el Estado ha evitado intervenir, pero ha permitido el gradual fortalecimiento de esas actividades y el uso cada vez mayor de instalaciones públicas.

Se observa también que las actividades del sector público alcanzaron un nivel significativo tras un período de gestación o consolidación de los programas, durante el cual se definieron los objetivos, su ubicación administrativa y su financiamiento y modalidades de operación. Es evidente que la evolución de los programas ha dependido de factores muy diversos, entre otros, la importancia que alcanzaron esas iniciativas en su fase privada, las resistencias sociales y culturales encontradas, y la capacidad de gestación de la administración de salud. Se aprecia también que mientras más se tardó en iniciar estas actividades, menor fue el período de consolidación de los programas. (Véase el cuadro 23.)

Cunadro 23. Fechas de iniciación y de consolidación de las actividades de planificación familiar del sector público

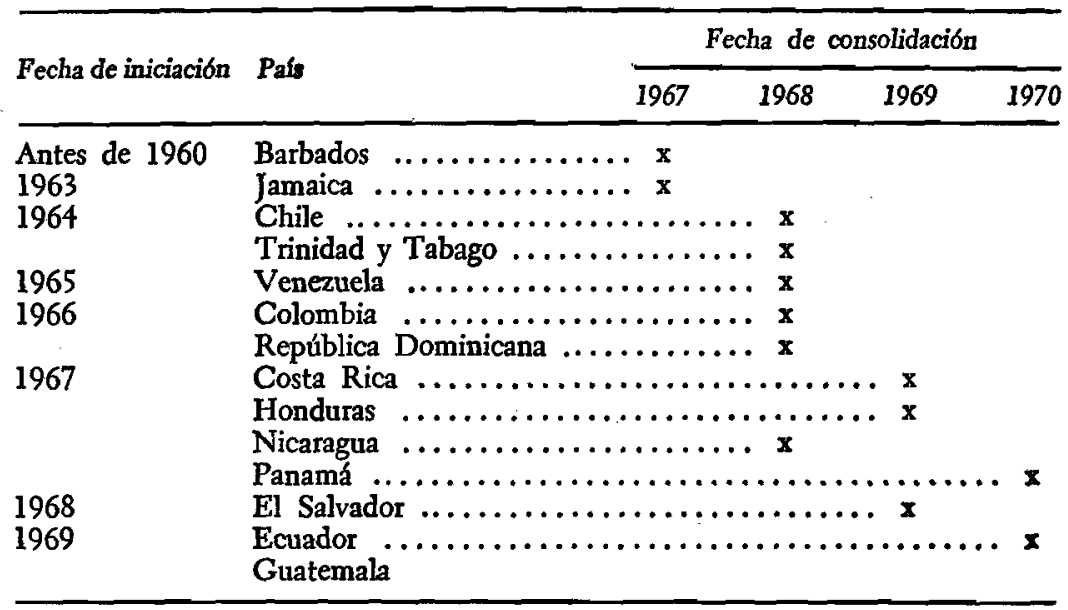

6) Situación actual de los programas

Es difícil evaluar el alcance que tienen las actividades del sector público en este campo. Son recientes en su mayoría, y los datos sobre ellas son 
fragmentarios o incompletos y están atrasados en casi tres años. Sin embargo, las diferencias en las situaciones nacionales son evidentes, y es muy probable que las variaciones recientes no hayan modificado demasiado el panorama general existente hasta 1969. (Véase el cuadro 24.) La eficacia de los programas no parece haber sido satisfactoria, pues 12 países tenían protegidas menos de $3 \%$ de las mujeres, y sólo dos estaban por encima del $10 \%$.

Cuadro 24. Países clasificados según el número de mujeres en edad fecunda por cada clinica de planificación familiar, $y$ porcentaje de mujeres en edad fecunda protegidas, a comienzos de 1969

\begin{tabular}{|c|c|c|c|c|}
\hline \multirow{2}{*}{$\begin{array}{l}\text { Porcentaje de } \\
\text { mujeres en edad } \\
\text { fecunda pro- } \\
\text { tegidas }\end{array}$} & \multicolumn{4}{|c|}{ Mujeres en edad fecunda por cada clínica de planificación familiar } \\
\hline & $\begin{array}{c}\text { Menos de } \\
10000\end{array}$ & $\begin{array}{c}10000 \mathrm{a} \\
20000\end{array}$ & $\begin{array}{c}20000 \mathrm{a} \\
50000\end{array}$ & $\begin{array}{c}\text { Más de } \\
50000\end{array}$ \\
\hline Menos de 3 & & $\begin{array}{l}\text { Colombia } \\
\text { Paraguay } \\
\text { Guatemala }\end{array}$ & $\begin{array}{l}\text { Haití } \\
\text { Uruguay } \\
\text { República Do- } \\
\text { minicana } \\
\text { Ecuador }\end{array}$ & $\begin{array}{l}\text { Argentina } \\
\text { Brasil } \\
\text { México }\end{array}$ \\
\hline De 3 a 5 & & $\begin{array}{l}\text { Panamá } \\
\text { Honduras }\end{array}$ & & \\
\hline Más de 10 & $\begin{array}{l}\text { Costa Rica } \\
\text { Chile }\end{array}$ & & & \\
\hline
\end{tabular}

Un examen muy preliminar de la información permite distinguir tres situaciones: primero, los países que no tienen una infraestructura de servicios; segundo, los que están ampliando esa infraestructura, $y$, tercero, los que ya tienen una dotación satisfactoria.

En los países con una natalidad elevada, la carencia de infraestructura puede originarse en políticas (o más bien en orientaciones demográficas) adversas a la intervención del Estado en estas materias, o en la falta de un sistema adecuado de servicios médicos.

Allí donde la infraestructura es insuficiente y éstá en vías de ampliarse, los factores críticos parecen ser la consolidación demasiado reciente de los programas y un sistema de salud muy inadecuado todavía. A su vez, los países dotados de servicios satisfactorios, comenzaron mucho antes, poseen un sistema de salud pública más evolucionado, o bien son países pequeños de baja urbanización, pero con población rural que se concentra en algunas áreas densamente pobladas. De otra parte, la eficacia de los programas en los países que tienen servicios adecuados. parece depender de los niveles generales de desarrollo y modernización. 


\section{CONCLUSTONES}

De lo anterior se desprende que en América Latina el interés por los problemas de población responde a factores y circunstancias generados por el crecimiento económico y por el proceso de modernización social. Estos factores y esas circunstancias se han expresado gradualmente en la revisión del sistema de desarrollo y de sus objetivos, en modificaciones profundas de la conducta y de los valores de la población, y en nuevas soluciones y respuestas institucionales. Dentro de los desequilibrios y ambivalencias que caracterizan a una situación de semidesarrollo, el tema ha perdido su aparente especificidad para vincularse a las concepciones e ideologías del cambio social, y para constituir por derecho propio una de las variables fundamentales en los esbozos o proyectos de sociedad que se debaten hoy día.

Por eso, al considerar el tema de la población como parte de los diagnósticos y pronósticos del desarrollo, se aprecia la importancia que se da en América Latina a la idea de acelerar este proceso y de afinar y precisar sus objetivos. Muchos de los dilemas que aparecen en la discusión del papel de la población en el desarrollo, oscurecido a veces por cuestiones de política contingente, se refieren más bien a la definición de los objetivos sociales y políticos que orientan el crecimiento econbmico. Todo esto surge de la conciencia de la crisis de los modelos convencionales de convivencia y de transformación, y explora las fronteras sociales y políticas con que tropiezan los procesos económicos en esta coyuntura de semidesarrollo, así como los nuevos derroteros de integración social y racionalización institucional.

El semidesarrollo de América Latina ha producido a su vez importantes modificaciones de la conducta de la población, sobre todo en los centros urbanos. Este es un fruto evidente del progreso. Lo que comenzó siendo apenas un impérceptible desplazamiento, termina por convertirse en la afirmación de nuevos valores y modelos de vida. En poco más de medio siglo se han perfilado los rasgos de una cultura secular, basada cada vez más en orientaciones adquisitivas.

Los desequilibrios y falta de continuidad del semidesarrollo dan lugar a una situación demográfica peculiar que acelera las tasas de crecimiento de la población. Aunque evidente, el progreso es limitado y afecta selectivamente a estratos, sectores y grupos de la sociedad.

La secularización de la conducta se refleja en tres procesos paralelos $\rightarrow \mathrm{y}$ con frecuencia asincrónicos-, que definen la naturaleza del sistema de modernización:

a) la intensificación de las relaciones de mercado y, concomitantemente, la incorporación de nuevos sectores de la población;

b) la difusión e intensificación de las experiencias de movilidad social, $y$ 
c) la expansión de la ciudadanía mediante la movilización política y el surgimiento de organizaciones de base.

Las informaciones disponibles señalan el papel que estos procesos desempeñan en la secularización de la conducta reproductiva, y la forma selectiva en que ésta evoluciona. En una fase de semidesarrollo, su efecto global es necesariamente lento y gradual, aunque es probable que la aparente estabilización de la tasa de reproducción oculte situaciones dinámicas de fondo. Los síntomas más claros de esta evolución se relacionan sin duda con la redefinición del papel social de la mujer, y con el ajuste de las relaciones de familia a un horizonte urbano más competitivo e inestable.

Otro indicio de evolución reside en que - a diferencia de lo ocurrido en el pasado en los países industriales- en América Latina los problemas de población han comprometido la acción del sector público. Esto plantea el problema de la definición de estilos optativos de desarrollo, y de la existencia de necesidades y demandas sociales. Con frecuencia la intervención del Estado se ha producido en ausencia de consenso efectivo, simplemente por la necesidad de encarar las penosas realidades de la reproducción humana en los estratos urbanos bajos.

Todos estos antecedentes indican que la incorporación de la variable población a las políticas de desarrollo deberá reflejar la variedad de situaciones nacionales y tener en cuenta que recurrir al control de la natalidad como una alternativa al desarrollo es desconocer la dinámica social en que se apoyan los cambios de la conducta reproductiva.

Además, es evidente que las interpretaciones de los problemas de población se han dado hasta ahora en dos planos relativamente aislados: a) las macrointerpretaciones, que en general no consideran las necesidades y demandas sociales, y $b$ ) la visión de las prácticas que intentan responder de manera directa a problemas concretos de salud y bienestar. Las políticas de población tienen que integrar ambas perspectivas. 


\section{LA ACTIVIDAD ECONÓMICA DE LA MUJER Y LA FECUNDIDAD}

CoNocer las características y la evolución de la fuerza de trabajo es fundamental cuando se pretende elevar el nivel de desarrollo de una nación. Sin duda, uno de los problemas cruciales que confrontan quienes forjan las políticas latinoamericanas es el rápido incremento de la población económicamente activa, unido a la incapacidad de las economías para utilizar recursos humanos en forma productiva.

En esta esfera, la actividad econ6́mica de la mujer tiene particular influencia en la magnitud y en las características de la fuerza de trabajo. Ante todo, su participación en las actividades productivas acrecienta directamente la población económicamente activa y a la vez modifica su calidad y composición; de aquí la importancia de ponderar las consecuencia del ingreso proyectado de más de diez millones de mujeres a la fuerza de trabajo latinoamericana antes de fines del siglo. Pero esta participación femenina ejerce a la vez un influjo poderoso en los patrones de fecundidad $y$, por ende, en la estructura de la fuerza de trabajo futura. Y, si se mira el problema desde el otro extremo, la participación de la mujer en la fuerza de trabajo ocupa un lugar preponderante en cualquier examen de los efectos económicos de la declinación de la fecundidad. Este capítulo se endereza a estudiar ciertos aspectos de esta doble influencia de la actividad económica femenina.

\section{1) Niveles y aspectos conexos de la actividad económica femenina}

La evaluación de la actividad económica femenina es empresa ardua, pues la participación de la mujer en la fuerza de trabajo responde no sólo a las variables que determinan la participación de los varones -estructura de edades, demanda de mano de obra, nivel educativo, servicios de seguridad social-, sino también a otras como estado civil, número y edad de los hijos, ingresos del marido y diversos factores culturales. Por otra parte - dada la carencia de datos-, es casi imposible efectuar un análisis completo de la dirección en que actúa cada variable o determinar su gravitación. No sólo faltan datos censales que permitan medir sus efectos en las tasas de actividad según la edad y número de los hijos, sino que en algunos casos se carece hasta de la información más elemental. En Ecuador, por ejemplo, los censos de 1950 registraron tasas de actividad femenina de $30.3 \%$, en tanto que en 1962 éstas fueron de $16.7 \%$. En un análisis reciente de los recursos humanos en ese país, luego de llegarse a la conclusión de que la diferéncia se debía a graves errores en el empadronamiento efectuado en 1962, se resolvió sumariamente el problema elevando la participación femenina rural en poco más de $50 \% .^{1}$

I Junta Nacional de Planificación y Coordinación (JunaplaN), Plan Ecuatoriano para el desarrollo de los recursos humanos, Quito, 1970, vol. I, p. 89. Este mismo es 
En tanto no se disponga de datós empíricos más fidedignos y detallados, obtenidos de muestras oficiales de los censos nacionales o de encuestas, será imposible extraer conclusiones definitivas que muestren con precisión el juego recíproco de todas las variables pertinentes. Sin embargo, la información existente permite formular algunos comentarios que revelan las principales corrientes observadas en este campo. En su mayor parte, el presente análisis se sustenta en un estudio comparativo de la fecundidad en siete grandes zonas metropolitanas de América Latina, realizado por el CELADE dentro de su Programa de Encuestas Comparativas de Fecundidad-Zona Urbana. ${ }^{2}$ Las encuestas en estas unidades, con muestras de 2100 a 2500 mujeres entre 20 y 50 años de edad, se realizaron a fines de 1963 y durante 1964. Lamentablemente, las tabulaciones existentes cuando se escribió este trabajo constaban de dos variables y las demás escapaban a todo control. Por lo tanto, los resultados que aquí se ofrecen son sólo provisionales.

Las tasas de actividad de las mujeres en las siete ciudades estudiadas varían entre 26.8 y $39.5 \%$. (Véase el cuadro 25.) La evolución de las tasas por edades en cada una de estas capitales corresponde en general a la observada en la nación respectiva, salvo en Costa Rica y Venezuela. (Véase el cuadro 26.) Numerosos estudios han señalado la correlación directa que existe entre el curso de la urbanización y la industrialización, y la participación femenina en la fuerza de trabajo. El cuadro 25 respalda decididamente esta afirmación. Las tasas de actividad de las mujeres en las siete ciudades son considerablemente mayores que en los países respectivos. Como es natural, la limitación de las edades en la muestra tiende a deformar las diferencias y en los totales nacionales

Cuadro 25. Tasas de actividad femenina por ciudades $y$ países

(Porcentajes)

\begin{tabular}{lclc}
\hline \multicolumn{1}{c}{ Ciudad } & $\begin{array}{c}\text { Tasa de } \\
\text { actividad }\end{array}$ & País a & $\begin{array}{c}\text { Tasa de } \\
\text { actividad }\end{array}$ \\
\hline Bogotá & 39.1 & Colombia & 20.3 \\
Buenos Aires & 38.2 & Argentina & 23.2 \\
Caracas & 26.8 & Venezuela & 20.2 \\
México & 26.8 & México & 19.7 \\
Panamá & 38.1 & Panamá & 24.7 \\
San José & 39.5 & Costa Rica & 17.5 \\
Río de Janeiro & 30.7 & Brasil & 18.4 \\
\hline
\end{tabular}

FuENTE: CELADE, PECFaI- 0 , grupo de tabulaciones II, variables $25 \times 12$; Oficina Intemacional del Trabajo, Anuario de Estadísticas del Trabajo, 1969, cuadro 2A. a 15 años y más, según la serie de censos de 1960 .

tudio revela que de una muestra de 377931 varones y 156107 mujeres, el $12.8 \%$ de los primeros y el $15.3 \%$ de las segunda trabajan más de 70 horas semanales, y que el $2.4 \%$ del total desea trabajar otras 30 horas semanales 0 más.

2 Programa que de aquí en adelante se denominará PECFAL-v. 
Cusdro 26. Tasas de actividad femenina por edades, por zonas urbanas y por paises

(Porcentajes)

\begin{tabular}{|c|c|c|c|c|c|c|c|c|c|c|c|c|c|c|}
\hline \multirow{2}{*}{ Edad } & \multicolumn{7}{|c|}{$\begin{array}{l}\text { A. Tasas de actividad femenina por edades } \\
\text { y por zonas urbanas }\end{array}$} & \multicolumn{7}{|c|}{$\begin{array}{l}\text { B. Tasas de actividad femenina por edades y por } \\
\text { palses, alrededor de } 1960\end{array}$} \\
\hline & Bogotá & $\begin{array}{l}\text { Buenos } \\
\text { Aires }\end{array}$ & $\begin{array}{c}\text { Cara- } \\
\text { cas }\end{array}$ & México & $\begin{array}{c}\text { Pana- } \\
\text { má }\end{array}$ & $\begin{array}{c}\text { San } \\
\text { José }\end{array}$ & $\begin{array}{l}\text { Río de } \\
\text { Janeiro }\end{array}$ & $\begin{array}{c}\text { Colom- } \\
\text { bia }\end{array}$ & $\begin{array}{c}\text { Argen- } \\
\text { tina }\end{array}$ & $\begin{array}{l}\text { Vene- } \\
\text { zuela }\end{array}$ & México & $\begin{array}{c}\text { Pana- } \\
\text { má }\end{array}$ & $\begin{array}{l}\text { Costa } \\
\text { Rica }\end{array}$ & Brasil \\
\hline 20 a 24 & 45.6 & 59.1 & 32.0 & 32.8 & 37.4 & 34.6 & 28.0 & 26.3 & 39.7 & 25.8 & 23.0 & 31.2 & 24.4 & 22.5 \\
\hline 25 a 29 & 37.2 & 36.9 & 30.6 & 25.8 & 38.2 & 35.7 & 26.6 & 21.6 & 29.4 & 23.8 & 16.9 & 28.3 & 20.3 & 18.8 \\
\hline 30 a 34 & 36.4 & 34.4 & 31.2 & 29.2 & 33.9 & 30.6 & 24,4 & 19.8 & 24.4 & 22.9 & 16.1 & 27.7 & 18.8 & 17.4 \\
\hline 35 a 39 & 39.7 & 37.0 & 30.7 & 29.6 & 39.3 & 33.2 & 19.9 & 19.7 & 22.6 & 22.0 & । 17.1 & 27.1 & 17.9 & 17.2 \\
\hline 40 a 44 & 37.0 & 30.1 & 38.2 & 33.0 & 41.9 & 33.3 & 18.4 & 19.8 & 21.5 & 21.0 & 18.3 & 27.0 & 16.6 & 16.8 \\
\hline 45 a 49 & 37.3 & 23.5 & 31.1 & 34.6 & 40.3 & 30.0 & 22.2 & 19.3 & 19.4 & 19.3 & 18.3 & 26.1 & 14.9 & 16.3 \\
\hline 50 y más & 25.9 & 22.1 & 29.8 & 32.0 & 32.6 & 34.2 & 9.2 & & & & & & & \\
\hline
\end{tabular}

Fuentes: Para A: Celade, Pecral-v, grupo de tabulaciones II, variables $14 \times 26$.

Para B: cELade, Boletín demográfico, año 2, vol. IIl, enero de 1969, cuadro 5, y El Colegio de México, Dinámica de la población de México, México, 1970, cuadro VI-7. 
hay omisiones de segmentos del sector rural, no sólo por error, sino también intencionalmente (por ejemplo, las mujeres campesinas que colaboran en las labores agropecuarias). Sin embargo, es interesante comprobar (cuadro 26) que las tasas de actividad entre los 20 y los 50 años muestran la misma ventaja para las zonas urbanas. El tamaño de la ciudad también parece ejercer influencia en las tasas de actividad. En 1961, para las mujeres que habitaban zonas urbanas de Venezuela (excluida Caracas), dicha tasa era de $16.6 \%$, en tanto que para las caraqueñas era de $29.1 \%$. La misma situación se observó en Guatemala en 1964: las tasas en Ciudad de Guatemala eran de $28.2 \%$ y en las demás zonas urbanas de $13.7 \%$. De manera similar en Chile las tasas en 1960 eran, para Santiago, de $31.6 \%$, y para las demás zonas urbanas, de $23.9 \%$. En el mismo año, en México, también eran considerables las diferencias entre las tasas del Distrito Federal y de otras localidades urbanas. $^{3}$

Como cabía esperar, las proporciones mayores de mujeres incluidas en las encuestas de las siete ciudades tenían empleos de baja categoría, pero se observaban diferencias considerables entre países, debidas probablemente a etapas de transición en las estructuras economicas nacionales, a una fuerte migración hacia las ciudades o a un mayor grado de industrialización sobre bases económicas amplias. En Buenos Aires el $16.2 \%$ de las mujeres activas se dedicaba a ocupaciones manuales no calificadas, lo que contrasta en diversos grados con las cifras de México $(27.2 \%)$, Bogotá $(36.2 \%)$, Caracas $(41.3 \%)$, y Río de Janeiro $(51.9 \%)$, dejando de lado por el momento Panamá y San José, pues la estructura y la evolución económica nacional de estos dos países son algo desusadas. (Véase el cuadro 27.)

Cuadro 27. Distribución de las mujeres económicamente activas
según su ocupación

(Porcentajes)

\begin{tabular}{lrrrrrrr}
\hline \multicolumn{1}{c}{ Ocupacion } & $\begin{array}{c}\text { Bogo- } \\
\text { tán }\end{array}$ & $\begin{array}{c}\text { Buenos } \\
\text { Aires }\end{array}$ & $\begin{array}{c}\text { Cara- } \\
\text { cas }\end{array}$ & $\begin{array}{c}\text { Méxi- } \\
\text { co }\end{array}$ & $\begin{array}{c}\text { Pana- } \\
\text { má }\end{array}$ & $\begin{array}{r}\text { San } \\
\text { José }\end{array}$ & $\begin{array}{r}\text { Río de } \\
\text { Janeiro }\end{array}$ \\
\hline Profesional & 0.9 & 0.7 & 2.3 & 3.0 & 1.3 & 1.1 & 1.7 \\
Administrativa & 4.0 & 1.5 & 2.1 & 5.5 & 7.3 & 3.8 & 14.2 \\
Supervisora superior & 5.0 & 19.4 & 15.5 & 11.7 & 26.5 & 22.6 & 11.2 \\
Supervisora inferior & 17.9 & 28.4 & 14.0 & 25.6 & 6.3 & 13.5 & -8.1 \\
Manual calificada & 36.0 & 33.8 & 24.8 & 27.0 & 27.1 & 44.0 & 12.9 \\
Manual no calificada & 36.2 & 16.2 & 41.3 & 27.2 & 31.5 & 15.0 & 51.9 \\
$\quad$ Total & 100.0 & 100.0 & 100.0 & 100.0 & 100.0 & 100.0 & 100.0 \\
\hline
\end{tabular}

Fuente: cRlade, pecfal-d, grupo de tabulaciones II, variables $14 \times 26$.

3 Murray Gendell, "The trends and patterns of the economic activity of women in Latin America during the 1950's", Estadistica, vol. XXVI, núm. 100, Washington, septiembre de 1968, p. 567; El Colegio de México, Dinámica de la población de México, México, D. F., 1970, cuadro VI-8; celade, "Operación Muestra de Censos" (Proyecto omurce), tabulaciones de una muestra del censo de 1960 en Chile, cuadro 33. 
Cuadro 28. Actividad femenina por niveles de educación

\begin{tabular}{|c|c|c|c|c|c|c|c|c|c|}
\hline \multirow[b]{2}{*}{ Ciudad } & \multicolumn{4}{|c|}{$\begin{array}{l}\text { A. Tasas de actividad por niveles } \\
\text { de educación }\end{array}$} & \multicolumn{5}{|c|}{$\begin{array}{l}\text { B. Distribueión de mujeres económicamente activas } \\
\text { por niveles de educación }\end{array}$} \\
\hline & $\begin{array}{c}\text { Hasta } 3 \text { años } \\
\text { de educación } \\
\text { primaria }\end{array}$ & $\begin{array}{c}4 \text { años y } \\
\text { más de edu- } \\
\text { cación pri- } \\
\text { maria }\end{array}$ & $\begin{array}{l}\text { Educación } \\
\text { secunda- } \\
\text { ria }\end{array}$ & $\begin{array}{c}\text { Educación } \\
\text { universi- } \\
\text { taria }\end{array}$ & $\begin{array}{c}\text { Hasta } 3 \text { años } \\
\text { de educación } \\
\text { primaria }\end{array}$ & $\begin{array}{c}4 \text { años y } \\
\text { más de edu- } \\
\text { cación pri- } \\
\text { maria }\end{array}$ & $\begin{array}{l}\text { Educaeión } \\
\text { secunda- } \\
\text { ria }\end{array}$ & $\begin{array}{c}\text { Educación } \\
\text { universi- } \\
\text { taria }\end{array}$ & Total \\
\hline Bogotá & 40.6 & 37.2 & 38.2 & 69.0 & 38.8 & 30.3 & 28.3 & 2.6 & 100.0 \\
\hline Buenos Aires & 39.6 & 31.6 & 46.4 & 65.9 & 6.9 & 52.4 & 29.3 & 11.4 & 100.0 \\
\hline Caracas & 29.4 & 29.7 & 35.3 & 57.5 & 32.3 & 38.5 & 22.8 & 6.4 & 100.0 \\
\hline México & 37.9 & 27.5 & 37.1 & 50.0 & 36.3 & 29.3 & 26.1 & 8.3 & 100.0 \\
\hline Panamá & 32.0 & 32.0 & 39.0 & 63.3 & 7.5 & 31.7 & 45.0 & 15.8 & 100.0 \\
\hline San José & 34.1 & 36.2 & 42.5 & 70.5 & 22.6 & 37.9 & 27.8 & 11.7 & 100.0 \\
\hline Río de Janeiro & 35.3 & 24.5 & 31.8 & 49.3 & 34.8 & 28.6 & 32.0 & 4.6 & 100.0 \\
\hline
\end{tabular}

FUENTE: CELADE, PECFAL-U, grupo de tabulaciones II, variables $20 \times 25$. 
En alguna medida este perfil se halla condicionado también por la preparación de la mujer que participa en la fuerza de trabajo. Los niveles educativos bajos limitan las posibilidades de empleo de las mujeres a cargos que no requieren preparación especial y cuya productividad e ingreso son insignificantes (el sector de los servicios generales, por ejemplo). El cuadro 28 revela una decidida relación entre las mujeres que han tenido entre cero y 3 años de educación primaria, lo que en la mayoría de los casos las transforma en analfabetas funcionales, y las categorías ocupacionales más bajas. Esto corresponde en general a las diferencias entre ciudades respecto a las mujeres que se dedican a labores manuales no calificadas. Así, en Buenos Aires el $6.9 \%$ de las mujeres activas tiene tres años o menos de escolaridad, en tanto que en la ciudad de México las cifras correspondientes son $36.3 \%$, en Bogotá $38.8 \%$, en Caracas $32.2 \%$ y en Río de Janeiro $34.8 \%$.

Se observa también (véase de nuevo el cuadro 28) una diferencia apreciable en las tasas de actividad según el nivel de educación, pues existe una correlación positiva respecto de las mujeres con estudios universitarios, aunque sean incompletos. Tal vez se observaría una correlación más alta en relación con la actividad de las mujeres con educación secundaria, si en esta categoría se distinguiese entre las que recibieron 1 a 3 años de esta enseñanza y las que terminaron el ciclo. La relación de este fenómeno con condiciones de menor fecundidad puede hallarse vinculada a la posibilidad de que los gobiernos extiendan a más educandos la oportunidad de continuar su educación, con lo cual ingresarán a la fuerza de trabajo en edad más tardía. Sin embargo, a largo plazo, se incorporarán a la fuerza de trabajo contingentes mayores de mujeres con más educación y con aspiraciones ocupacionales más altas; esto obligará a efectuar las vastas reformas indispensables para que el proceso global de desarrollo pueda proporcionar un número mucho mayor de empleos con ingresos adecuados a una fuerza laboral calificada.

Vale la pena examinar la proporción de mujeres económicamente activas que trabajan dentro o fuera del hogar, ya que esta variable seguramente tiene alguna relación directa con la fecundidad. Los mayores porcentajes de mujeres empleadas fuera del hogar se registraron en Panamá, Buenos Aires y San José, con marcadas diferencias entre ellos y los observados en Bogotá, Caracas, México y Río de Janeiro. (Véase el cuadro 29.) En cambio, las mayores proporciones de mujeres que trabajan dentro del hogar se observaron en Bogotá, San José y Río de Janeiro. Esto indica la gran incidencia de las industrias caseras artesanales y de los servicios en estas ciudades. Los datos también sugieren que los cambios en los sistemas de producción y distribución - por ejemplo, el crecimiento de industrias modernas - están mermando en las demás ciudades actividades como la costura, el pequeño comercio, etc., y ello redunda en una menor participación económica femenina basada en trabajos caseros.

Para comprender mejor la forma en que opera este mecanismo de transición conviene examinar los cambios en las tasas de participación 
Cusdro 29. Distribución porcentual de mujeres económicamente activas $e$ inactivas dentro $y$ fuerd del hogar

\begin{tabular}{lccccccc}
\hline & $\begin{array}{c}\text { Bogo- } \\
\text { tán }\end{array}$ & $\begin{array}{c}\text { Buenos } \\
\text { Aires }\end{array}$ & $\begin{array}{c}\text { Cara- } \\
\text { cas }\end{array}$ & $\begin{array}{c}\text { Méxi- } \\
\text { co }\end{array}$ & $\begin{array}{c}\text { Pana- } \\
\text { má }\end{array}$ & $\begin{array}{c}\text { San } \\
\text { José }\end{array}$ & $\begin{array}{c}\text { Río de } \\
\text { janeirc }\end{array}$ \\
\hline $\begin{array}{l}\text { Inactivas } \\
\begin{array}{l}\text { Activas dentro del } \\
\text { hogar }\end{array}\end{array}$ & 60.9 & 61.8 & 73.2 & 73.2 & 61.9 & 60.5 & 69.3 \\
$\begin{array}{l}\text { Activas fuera del } \\
\text { hogar }\end{array}$ & 19.7 & 8.5 & 7.6 & 9.3 & 7.6 & 14.2 & 13.1 \\
$\quad 19.4$ & 29.7 & 19.2 & 17.5 & 30.5 & 25.3 & 17.6 \\
$\quad$ Total & 100.0 & 100.0 & 100.0 & 100.0 & 100.0 & 100.0 & 100.0 \\
\hline
\end{tabular}

Fueatre: GRLade, PEcFaL-v, grupo de tabulaciones II, variables $25 \times 12$.

femenina observados en México entre 1950 y 1960 . En la gráfica II puede verse que en el conjunto del país, así como en la región que abarca el estado de México y el Distrito Federal -es decir, la zona más urbanizada-, la actividad económica femenina se elevó en todos los grupos de edad entre 15 y 59 años, y disminuyó en los grupos que se encuentran en los extremos del espectro de edades.

Mientras en 1950 las tasas de participación eran prácticamente constantes desde los 25 años de edad en adelante, en 1960 descendieron sostenidamente a partir de los 50 años. Puesto que la participación masculina mostraba la misma tendencia — sólo que más marcada-, cabe suponer que los cambios en los grupos de los extremos corresponden a factores de extensión de los servicios educativos y de seguridad social. Un examen más detenido del confrontamiento de los diferentes grupos de 15 a 59 años de edad entre 1950 y 1960 revela cambios que en alguna medida pueden estar vinculados a la evolución de la estructura económica que se mencionó antes. En 1950 las tasas más altas de participación en los grupos más jóvenes correspondían al grupo de 15 a 19 años; en cambio, en 1960 correspondían al de 20 a 24 años. $Y$, sin embargo, en este último año se observó una actividad económica significativamente más alta entre las mujeres de 40 a 50 años. La curva en forma de U que se formó así en 1960 parecería indicar una etapa de transición económica con tasas elevadas para la población femenina de más edad (características de los países menos desarrollados), y tasas ascendentes para la generación joven (típicas de las economías industriales más concentradas). Aunque esto sugiere la coexistencia de dos sistemas económicos, México tiende entre 1950 y 1960 al predominio cada vez mayor de técnicas modernas de producción y distribución.

Dada la estrecha vinculación entre las obligaciones domésticas y la actividad económica de la mujer, merece especial estudio la relación entre su participación en la fuerza de trabajo y su estado civil. Hay diferencias apreciables en las tasas de actividad de las mujeres casadas 
Grírica II. México: Tasa de actividad femenina por edades, 1950-1960 (Escala natural)

\section{ESTADO DE MEXICO Y DISTTRITO FEDERAL}
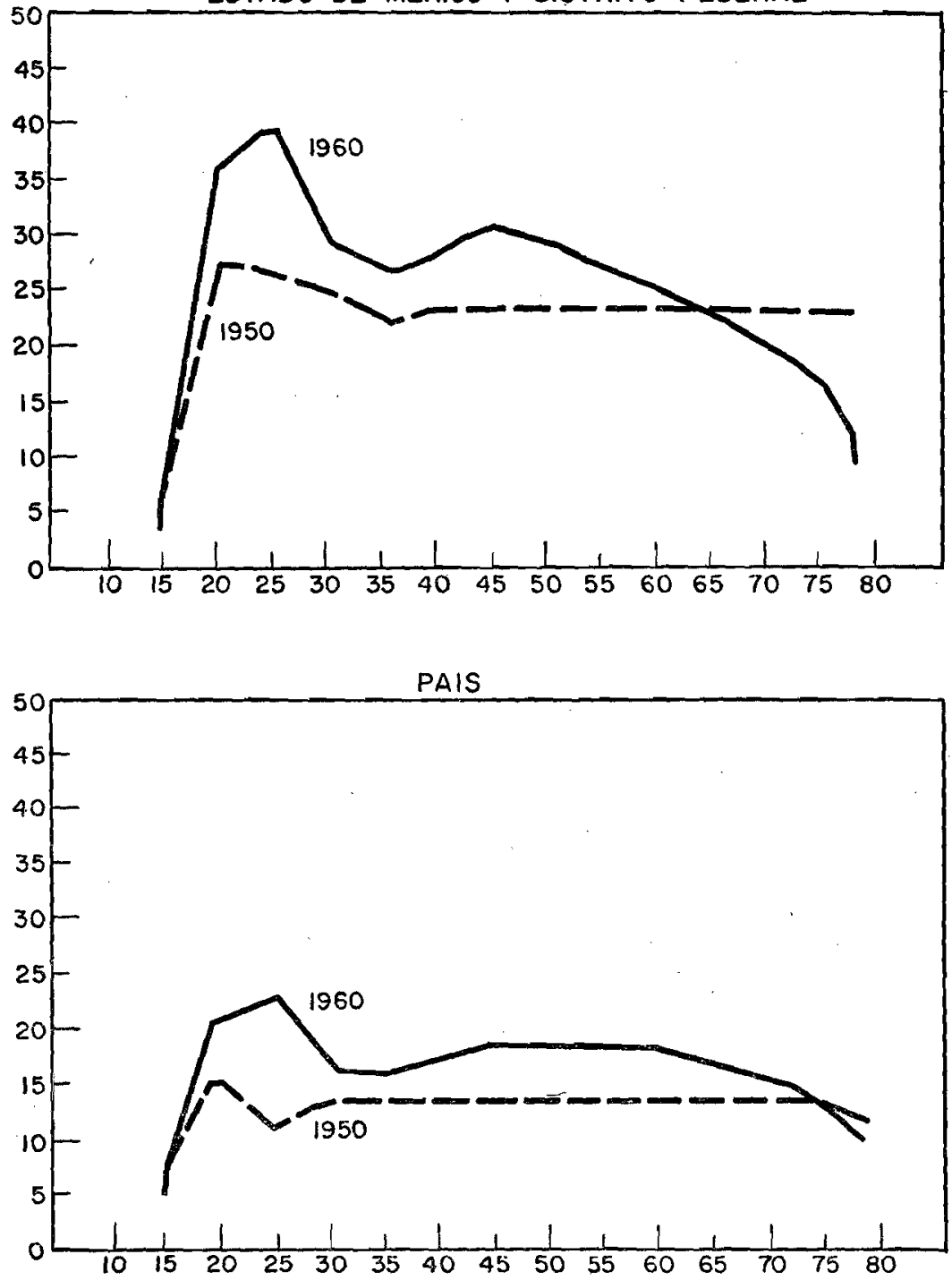

o en unión consensual, por un lado, y las mujeres solteras, viudas, separadas o divorciadas, por otro. (Véase el cuadro 30.) Con ligeras variaciones, las tasas en esta última categoría tienden a ser mucho más altas 
Cundro 30. Actividad económica de la mujer según su estado civil (Porcentajes)

\begin{tabular}{|c|c|c|c|c|c|}
\hline Ciudad & Solteras & Casadas & $\begin{array}{l}\text { En union } \\
\text { consensual }\end{array}$ & $\begin{array}{l}\text { Viudas, se- } \\
\text { paradas, etc. }\end{array}$ & Total \\
\hline
\end{tabular}

A. Tasas de actividad según el estado civil

$\begin{array}{llllll}\text { Bogotá } & 72.0 & 25.4 & 34.3 & 62.1 & 39.3 \mathrm{a} \\ \text { Buenos Aires } & 70.2 & 25.7 & 21.1 & 67.6 & 35.5 \mathrm{a} \\ \text { Caracas } & 57.9 & 10.6 & 13.5 & 54.2 & 31.8 \mathrm{a} \\ \text { México } & 62.0 & 17.6 & 27.6 & 61.6 & 30.4 \mathrm{a} \\ \text { Panamá } & 55.6 & 31.5 & 24.4 & 59.6 & 37.9 \mathrm{a} \\ \text { San José } & 60.4 & 21.5 & 26.6 & 50.5 & 33.2 \mathrm{a} \\ \text { Río de Janeiro } & 49.3 & 12.2 & 29.3 & 43.9 & 23.3 \mathrm{a}\end{array}$

B. Distribucion de las mujeres activas según su estado civil

$\begin{array}{lrrrrr}\text { Bogotá } & 34.9 & 41.4 & 4.0 & 19.7 & 100.0 \\ \text { Buenos Aires } & 34.0 & 55.7 & 0.5 & 9.8 & 100.0 \\ \text { Caracas } & 29.2 & 34.4 & 6.3 & 30.1 & 100.0 \\ \text { México } & 33.7 & 37.7 & 7.2 & 21.4 & 100.0 \\ \text { Panamá } & 25.1 & 34.3 & 17.1 & 23.5 & 100.0 \\ \text { San José } & 38.6 & 39.1 & 5.9 & 16.4 & 100.0 \\ \text { Ŕo de Janeiro } & 40.5 & 34.3 & 7.1 & 18.1 & 100.0\end{array}$

C. Distribución de mujeres inactivas según su estado civil

$\begin{array}{lrrrrr}\text { Bogotá } & 8.8 & 78.6 & 4.9 & 7.7 & 100.0 \\ \text { Buenos Aires } & 8.0 & 88.3 & 1.1 & 2.6 & 100.0 \\ \text { Caracas } & 9.9 & 59.1 & 19.1 & 11.9 & 100.0 \\ \text { México } & 9.0 & 77.0 & 8.2 & 5.8 & 100.0 \\ \text { Panamá } & 12.3 & 45.5 & 32.5 & 9.7 & 100.0 \\ \text { San José } & 12.6 & 71.1 & 8.2 & 8.1 & 100.0 \\ \text { Río de Janeiro } & 12.7 & 75.1 & 5.2 & 7.0 & 100.0\end{array}$

D. Distribución de todas las mujeres según su estado civil

\begin{tabular}{lrrrrr} 
Bogotá & 19.1 & 64.0 & 4.5 & 12.4 & 100.0 \\
Buenos Aires & 17.2 & 76.8 & 0.9 & 5.1 & 100.0 \\
Caracas & 16.0 & 51.3 & 15.0 & 17.7 & 100.0 \\
México & 16.5 & 65.0 & 7.9 & 10.6 & 100.0 \\
Panamá & 17.2 & 41.2 & 26.7 & 14.9 & 100.0 \\
San José & 21.3 & 60.5 & 7.4 & 10.8 & 100.0 \\
Río de Janeiro & 19.2 & 65.5 & 5.7 & 9.6 & 100.0 \\
\hline
\end{tabular}

Furemtr: celade (prcfaul-0), grupo de tabulaciones II, variables $19 \times 26$. - Las tasas de actividad total son distintas a las del cuadro 3 debido a que varia el nt́mero de censados. 
que entre las mujeres casadas o en unión consensual. Las tasas más bajas de todas se hallaron entre las mujeres casadas, salvo en Panamá y Buenos Aires, pero en esta última ciudad tal vez haya influido el número insignificante de uniones consensuales.

Más de la mitad de las mujeres económicamente inactivas de las ciudades estudiadas eran casadas, salvo en Panamá, donde la proporción era sólo de $45.5 \%$. En esta ciudad, donde la proporción de encuestadas en uniones consensuales era muy superior, la tercera parte de las mujeres inactivas y casi $27 \%$ de todas las mujeres entrevistadas vivían en unión consensual. Un examen atento del cuadro 30 (secciones B y C) revela que en todas las ciudades hay un porcentaje mayor de mujeres solteras entre las incorporadas a la fuerza de trabajo, hecho que podría indicar el influjo de otras variables - por ejemplo, la edad al contraer matrimonio - en las tasas de fecundidad más bajas entre las mujeres económicamente activas. (Véase ahora el cuadro 31.) 4

Cuadro 31. Distribución porcentual y promedio de hijos nacidos vivos por mujer, según su actividad

\begin{tabular}{|c|c|c|c|c|c|c|c|c|}
\hline \multirow{2}{*}{ Ciudad } & \multicolumn{2}{|c|}{$\begin{array}{c}\text { Mujeres inac } \\
\text { tivas }\end{array}$} & \multicolumn{2}{|c|}{$\begin{array}{c}\text { Mujeres ac- } \\
\text { tivas }\end{array}$} & \multicolumn{2}{|c|}{ Total } & \multicolumn{2}{|c|}{$\begin{array}{l}\text { Mujeres activas } \\
\text { fuera del hogar }\end{array}$} \\
\hline & $\begin{array}{l}\text { Por- } \\
\text { cen- } \\
\text { taje }\end{array}$ & $\begin{array}{c}\text { Prome- } \\
\text { dio de } \\
\text { hijos }\end{array}$ & $\begin{array}{l}\text { Por- } \\
\text { cen- } \\
\text { taje }\end{array}$ & $\begin{array}{c}\text { Prome- } \\
\text { dio de } \\
\text { hijos }\end{array}$ & $\begin{array}{l}\text { Por- } \\
\text { cen- } \\
\text { taje }\end{array}$ & $\begin{array}{c}\text { Prome- } \\
\text { dio de } \\
\text { hijos }\end{array}$ & $\begin{array}{l}\text { Por- } \\
\text { cen- } \\
\text { taje }\end{array}$ & $\begin{array}{l}\text { Prome- } \\
\text { dio de } \\
\text { hijos }\end{array}$ \\
\hline $\begin{array}{l}\text { Bogotá } \\
\text { Buenos Ai- }\end{array}$ & 60.9 & 3.68 & 39.1 & 2.36 & 100.0 & 3.16 & 19.4 & 2.12 \\
\hline $\begin{array}{l}\text { res } \\
\text { Caracas } \\
\text { México } \\
\text { Panamá } \\
\text { San José } \\
\text { Río de Ja- } \\
\text { neiro }\end{array}$ & $\begin{array}{l}61.8 \\
73.2 \\
73.2 \\
61.9 \\
60.5\end{array}$ & $\begin{array}{l}1.78 \\
3.69 \\
4.08 \\
3.07 \\
3.58\end{array}$ & $\begin{array}{l}38.2 \\
26.8 \\
26.8 \\
38.1 \\
39.5\end{array}$ & $\begin{array}{l}1.01 \\
3.11 \\
3.77 \\
2.26 \\
1.92\end{array}$ & $\begin{array}{l}100.0 \\
100.0 \\
100.0 \\
100.0 \\
100.0\end{array}$ & $\begin{array}{l}1.49 \\
3.53 \\
4.00 \\
2.76 \\
2.92\end{array}$ & $\begin{array}{l}29.7 \\
19.2 \\
17.5 \\
30.5 \\
25.3\end{array}$ & $\begin{array}{l}0.84 \\
3.12 \\
3.42 \\
1.38 \\
1.77\end{array}$ \\
\hline
\end{tabular}

Fuentrs: CELAdE, PECraL-U, gTupo de tabulaciones II, variables $25 \times 12$.

Aparte las muchas obligaciones hogareñas de las casadas y la mayor probabilidad de embarazos (en cuyo caso el número y edad de los hijos serán factores de mucha importancia para explicar su participación en la fuerza de trabajo), en la actividad femenina influyen también otras variables de importancia: a) el papel de la mujer casada (determinado por la actitud prevaleciente hacia las mujeres que trabajan y la aversión

4 Para un estudio detallado de los efectos de la fecundidad, la estructura de edades y la edad al contraer matrimonio en las tasas de actividad, véase Ana Marfa Rothman, La participación femenina en actividades económicas en su relación con el nivel de fecundidad en Buenos Aires y México, celade, Santiago de Chile, 1969, y Murray Gendell y otros, "Fertility and economic activity of women in Guatemala City, 1964", Demography, 7, 3, agosto de 1970. 
de los empleadores a correr el riesgo de otorgar y pagar licencias maternales); $b$ ) su dependencia del ingreso del marido. Cuando la demanda de mano de obra es limitada, las mujeres casadas que en otras circunstancias se incorporarían a la fuerza de trabajo, no lo hacen; permanecen inactivas o bien - si han estado ocupadas y han perdido el empleo- es probable que se resignen a mantener la familia con el ingreso del marido.

\section{2) La actividad económica de la mujer y la fecundidad}

Mucha de la bibliografía especializada parece sugerir que existe una relación inversa entre la actividad económica de la mujer y las tasas de fecundidad. Los resultados de la encuesta en siete ciudades que se examina aquí reafirmaton este fenómeno, observado con frecuencia. (Véase de nuevo el cuadro 31 .) ${ }^{5}$ El promedio de hijos nacidos de mujeres económicamente activas era menor que el correspondiente a mujeres inactivas. Como cabía esperar, el promedio más bajo de hijos vivos por trabajadora se registró en Buenos Aires, con niveles excepcionalmente altos en México y Caracas. En cuanto a Chile, un estudio reciente ha proporcionado datos empíricos que muestran que las tasas de participación femenina varían no sólo si la mujer tiene o no hijos, sino aún más según el número de hijos, factor que influye naturalmente en las obligaciones domésticas de la mujer. En un análisis de los datos de 1960 se observó que en el conjunto del país el efecto de un hijo en las tasas de actividad femenina era mínimo, pero que entre las mujeres casadas, o en unión consensual, la existencia de dos o más hijos reducía considerablemente su actividad económica. ${ }^{\circ}$

La encuesta indica que el efecto de los hijos es muy poderoso en la actividad de las mujeres que trabajan fuera del hogar. La diferencia en el número medio de nacidos vivos es mayor si se establece una comparación entre las mujeres que trabajan fuera del hogar y las económicamente inactivas. (Véase el cuadro 32.) Como corolario de esta relación, los patrones de fecundidad de las mujeres económicamente activas dentro del hogar se asemejan más a los de las mujeres inactivas, salvo en Caracas, único lugar donde al parecer los niveles de fecundidad de las mujeres que trabajan fuera del hogar son levemente más altos que los de las mujeres económicamente activas dentro del hogar. Aunque pequeña desde el punto de vista cuantitativo, esta única desviación con respecto a otras ciudades sugiere que allí intervienen otros factores sociales con más fuerza que en las demás ciudades consideradas. En realidad, se ha informado que la mayoría de las madres que trabajan fuera

5 A comienzos de los afios sesenta se descubrí esta correlación negativa en 13 zonas metropolitanas de América Latina: por cada $1 \%$ de incremento en la tasa de participación femenina, descendía en $7 \%$ el número de hijos por cada mil mujeres. Véase Andrew Collver y Eleanor Langlois, "The female labour force in metropolitan areas: An international comparison", Economic Development and Cultural Change, 10, 4, julio de 1962, p. 384.

- Victoria Ostrovich, Características y, evolución de la población económicamente activa de Chile, 1940-1960, Centro de Estudios Socioeconómicos de la Universidad de Chile, Santiago, 1970 , pp. 30 y 31 . 
Cundro 32. Promedio de hijos nacidos vivos por mujer y diferencia observada según su actividad

\begin{tabular}{lccccc}
\hline Ciudad & $\begin{array}{c}\text { Mujeres } \\
\text { inactivas } \\
(1)\end{array}$ & $\begin{array}{c}\text { Mujeres } \\
\text { activas } \\
(2)\end{array}$ & $\begin{array}{c}\text { Mujeres ac- } \\
\text { tivas fuera } \\
\text { del hogar } \\
(3)\end{array}$ & $\begin{array}{c}\text { Diferencia } \\
\mathbf{A} \\
(2-1)\end{array}$ & $\begin{array}{c}\text { Diferencia } \\
\mathbf{B}\end{array}$ \\
\hline Bogotá & 3.68 & 2.36 & 2.12 & -1.32 & -1.56 \\
Buenos Aires & 1.78 & 1.01 & 0.84 & -0.77 & -0.94 \\
Caracas & 3.69 & 3.11 & 3.12 & -0.58 & -0.57 \\
México & 4.08 & 3.77 & 3.42 & -0.31 & -0.66 \\
Panamá & 3.07 & 2.26 & 1.38 & -0.81 & -1.69 \\
San José & 3.58 & 1.92 & 1.77 & -1.66 & -1.81 \\
Río de Janeiro & 2.46 & 1.81 & 1.44 & -0.65 & -1.02 \\
\hline
\end{tabular}

Fuswre: Cuadro 31.

del hogar lo hacen obligadas por la ausencia o falta de responsabilidad de los padres. ${ }^{7}$

Un análisis de las diferencias de fecundidad entre ciudades revela que en Buenos Aires la fecundidad es más baja en todas las categorías - mujeres inactivas, activas y activas fuera del hogar- mientras que en México y Caracas se observan los niveles más altos. La comparación de los datos de las diversas ciudades confirma que en los países en desarrollo de América Latina la tendencia a la urbanización rápida no conduce a una menor fecundidad, a menos que vaya unida a un proceso de modernización y desarrollo global. ${ }^{8}$

Lamentablemente, los datos de la encuesta no permiten realizar análisis basados en las edades de los hijos, variable fundamental, según otros investigadores, para delinear la magnitud de la actividad económica de la mujer. Un estudio muestra que en Chile la participación de la mujer en la fuerza de trabajo declina aproximadamente en $3 \%$ por cada hijo adicional menor de 14 años. ${ }^{9}$ Este fenómeno parece acentuarse cuando hay dos o más hijos, puesto que las madres - en especial las más jóvenes, que carecen obviamente de hijos mayores - tienen pocas, posibilidades de encomendar a otros el cuidado de sus hijos mientras trabajan.

\section{3) Declinación de la fecundidad y evolución de la fuerza de trabajo}

La relación entre la fecundidad y la participación urbana en la fuerza de trabajo sugiere entonces que cualquier descenso apreciable en la fecun-

7 La tasa de ilegitimidad en Venezuela es de $62.5 \%$; al respecto, el Ministerio de Salud ha expresado su preocupación por el bienestar de tantos niños que están creciendo sin una imagen paterna. Véase Population Reference Bureau, Inc., Población, vol. 2, núm. 1, 1971.

8 Como es natural, esto se refiere sólo a las diferencias entre ciudades, y no a las que se encuentran entre las zonas rurales y urbanas, donde ciertamente existen distintos: niveles de fecundidad.

- Population Council, "Chile", Country Profiles, octubre de 1970, p. 3. 
didad impulsará a más mujeres a buscar trabajo, lo que a su vez recargará aún más la capacidad de absorción de trabajadores por las economías latinoamericanas. Sea el empleo causa o efecto de la fecundidad - sin duda ambos casos se dan-, las perspectivas en este sentido no son alentadoras a plazo mediano. No obstante, es preciso tener presentes otros factores. Se ha mostrado que en México los factores demográficos sólo explican un porcentaje pequeño del incremento de la actividad femenina. ${ }^{10}$ Para muchas de las mujeres casadas y de las que viven en unión consensual, las condiciones de empleo del marido, la actitud de la sociedad frente a las esposas y madres que trabajan, y la de los empleadores frente a la posibilidad de contratar mujeres casadas -con el riesgo consiguiente de encarecer la mano de obra en virtud de las prestaciones maternales-, constituyen obstáculos potencialmente graves. Asimismo, uno de los factores que más contribuye a disminuir las tasas de actividad femenina son las limitadas oportunidades de trabajo.

Cuando los niveles del desempleo y subempleo son elevados, tal vez se pueda recurrir a las hipótesis del "trabajador desalentado" y del "trabajador adicional", para encarar el poblema de la incorporación de trabajadores potenciales a la fuerza laboral. La primera hipótesis postula que, al aumentar el desempleo, abandona la fuerza de trabajo cierto número de trabajadores potenciales, que ni siquiera busca empleo porque lo desalienta la falta de oportunidades. El contrapunto a esta hipótesis es la del "trabajador adicional": en respuesta a un desempleo cada vez mayor, ingresan a la fuerza de trabajo los denominados trabajadores secundarios. Encuestas trimestrales realizadaś en Bogotá entre 1963 y 1966, y utilizadas en un análisis regresivo para poner a prueba esta hipótesis, indicaron que las tasas totales de participación de ambos sexos entre los 15 y los 54 años descendieron al aumentar el desempleo. ${ }^{11}$ Tan vinculadas estaban ambas cosas, que un $1 \%$ de incremento en la tasa de desempleo iba acompañado de un descenso de $2.6 \%$ en la tasa de participación. Sin embargo, como entre las mujeres de 15 a 19 años y de 45 a 49 años la relación era positiva, un incremento de aproximadamente $1 \%$ en la tasa de desempleo causaba un alza de 2 a $2.6 \%$ en la tasa de participación; entre los varones de 45 a 49 años la tasa de incremento de la participación era de $0.5 \%$. La presencia del "trabajador adicional" en estos grupos de edad -en particular entre las mujeres - se explica porque en períodos de acentuación del desempleo general las mujeres de estas edades tienen más necesidad de complementar el ingreso familiar, y salen a trabajar. Esta necesidad es aún más imperiosa porque los ingresos son bajos, están mal distribuidos y no existe el seguro de cesantía. Al mismo tiempo, el estudio de Bogotá señala la exis-

10 El Colegio de México, Dinámica de la población de México, pp. 155 y 164 a 168.

11 Véase la formulación de esta hipótesis en Thomas Demberg y Kenneth Strand, "Hidden employment, 1953-1963: A quantitative analysis by age and sex", American Economic Review, 56, 1, marzo de 1966, pp. 71 a 96. Su aplicación al caso de Colombia se encuentra en Miguel Urrutia, "El desempleo disfrazado en Colombia", Empleo y desempleo en Colombia, Centro de Estudios sobre Desarrollo Económico, Bogotá, 1968, pp. 39 a 52 . 
tencia de un prejuicio social contra la contratación de mujeres, y, por lo demás, la debilidad del mercado laboral influye de manera negativa en las tasas de participación de la mayoría de las mujeres entre 15 y 54 años.

Una ponderación del efecto neto del "trabajador desalentado" y del "trabajador adicional" en la fuerza de trabajo sugiere que las tasas de actividad femenina no aumentarán apreciablemente al disminuir la fecundidad, mientras la demanda de mano de obra no experimente modificaciones de importancia. En cierta medida, la presión se compensará además con la expansión relativa del sistema de educación y capacitación, facilitada por una menor fecundidad. Es indudable que esto último no es más que un paliativo de corto plazo, y que en el futuro habrá que proporcionar empleo a las mujeres más preparadas que han completado su educación.

En términos cuantitativos, y a largo plazo, el proceso señalado puede sintetizarse aproximadamente en la proyección de la fuerza de trabajo para el año 2000. Suponiendo tasas de participación constantes, y la prolongación de las tendencias anteriores en materia de fecundidad y crecimiento económico global, se calculo que hacia fines del siglo la población económicamente activa de América Latina se acercaría a los 217.5 millones de personas. (Véase el cuadro 33, hipótesis 1.) Pero la cifra se elevaría a 221.2 millones de personas si el descenso de la fecundidad es más rápido, si hay redistribución del ingreso y de los patrones de consumo, si se amplían los servicios de educación y de bienestar social, si aumenta el ingreso por habitante y si se modifica la participación masculina y femenina en el mercado urbano del trabajo. (Véase de nuevo el cuadro 33, la hip6tesis 2.) Aunque a primera vista la diferencia dentro del marco temporal no parece muy grande, su composición por sexo y edad confrontará a la estructura económica latinoamericana con grandes exigencias de empleo para las mujeres, educación para los jóvenes y seguridad social para los ancianos.

Sin embargo, es posible que el cálculo anterior sobreestime en grado considerable el incremento de la participación femenina, pues determina la actividad económica de las mujeres urbanas basándose en los resul-

\section{CuAdro 33. América Latina: población econbmicamente activa, año 2000}

(Miles de personas)

\begin{tabular}{lrcr} 
& \multicolumn{1}{c}{ Total } & Varones & Mujeres \\
\cline { 2 - 4 } Hipótesis 2 & 221183.9 & 163888.7 & 57295.2 \\
Hipótesis 1 & 217538.3 & 170482.6 & 47055.7 \\
Diferencia & 3645.6 & -6593.9 & 10239.5 \\
\hline
\end{tabular}

Fuenre: Fucaraccio y Arretx, Relaciones entre variables económicas y demográficas, cuadro 20. 
tados de un análisis de regresión lineal que sólo depende de la variable representada por la tasa bruta de natalidad, cuando en la práctica el problema abarca otras variables de importancia. Conviene recordar al respecto que en Argentina y Uruguay la atención de los hijos no es un impedimento mayor que en los paises más industrializados para la actividad económica femenina, $y$, sin embargo, la participación de la mujer en la fuerza de trabajo es apreciablemente menor. En vista de los datos ofrecidos, no parece aventurado concluir que un mercado laboral débil - unido a prejuicios sociales- impide que las tasas de participación femenina alcancen niveles más altos. El sesgo cultural que confrontan las mujeres más capacitadas al buscar trabajo compatible con su preparación se puso de manifiesto en un estudio reciente realizado en Chile. En entrevistas con supervisores de industrias santiaguinas, quedo en claro la enorme resistencia de estos hombres a aceptar mujeres tituladas en escuelas técnicas secundarias para ocupar cargos técnicos o de supervisión. ${ }^{12}$

Puesto que son insuficientes aún los datos empíricos necesarios para medir y pronosticar con precisión el efecto neto de estas fuerzas opuestas, los resultados necesariamente tienen carácter provisional. No obstante, cabe destacar que, aunque los factores que determinan la incorporación femenina a la fuerza de trabajo son extremadamente complejos, no influyen en las tasas de participación masculina, que están regidas por la estructura de edades (salvo entre los muy jóvenes o muy viejos). A largo plazo, esto depende directamente de la natalidad. Como antes se dijo, el control de la fecundidad es el complemento esencial de una estrategia unificada de desarrollo, en la misma forma en que lo es la preocupación por incrementar el ingreso por habitante. Con una perspectiva más amplia, las opciones no son menor fecundidad y más altas tasas de crecimiento, producción o empleo; es decir, el tan pregonado problema de la proporción de los factores. Estas son meras dicotomías artificiales que pueden plantear contradicciones de corto plazo, pero que desestiman la cuestión básica del bienestar de gran parte de la población de América Latina y soslayan el problema de la planificación del bienestar humano como un proceso total. La integración -y no la separación de las políticas de población, empleo y crecimiento económico- es requisito realmente esencial para alcanzar esta meta.

12 Alicja Iwanska, "Final report from the mission: Pilot project on the acces of women to technological careers", unesco, Reg/crassoc/1 (documento inédito). 


\section{LA MIGRACIÓN INTERNA EN AMERICA LATINA: VOLUMEN, CARACTERISTICAS Y CONSECUENCIAS}

Pocos temas de fondo han despertado más interés en América Latina en los últimos diez años que la migración interna. En general se reconoce que la población latinoamericana es sumamente móvil y que los movimientos migratorios influyen hondamente en las estructuras económicas, políticas y demográficas de las regiones receptoras y de origen. Pero, pese a ese consenso, a menudo raya en lo especulativo el análisis de las dimensiones reales que alcanzan estos movimientos a escala regional, y de su influjo en el marco institucional de la sociedad.

La finalidad de este capítulo es dilucidar la importancia que revisten los movimientos internos de población en América Latina. En su primera sección se esbozarán brevemente las tendencias globales de las migraciones internas en el plano nacional, como antecedente para examinar con más detenimiento en las secciones posteriores las diferencias en las características de migración y las modalidades de adaptación de los migrantes. Al efectuar esta exposición se recurrirá con frecuencia a las experiencias recogidas en los movimientos de población en Colombia, a fin de ilustrar la magnitud y consecuencias de los procesos migratorios latinoamericanos.

\section{A. VOLUMEN DE LA MIGRACIÓN INTERNA}

El investigador que procura ofrecer una visión significativa de la magnitud de los movimientos de población ocurridos últimamente en América Latina confronta varios problemas. Ante todo, las únicas fuentes de información sobre el volumen de los movimientos internos a escala nacional son los censos periódicos de población, ${ }^{1}$ pero en algunos países, o bien no se dispone de los resultados de los censos realizados en $1960 \mathrm{y}$ 1970 , o tienen poca utilidad. Por otra parte, los intentos de realizar comparaciones internacionales de las estadísticas de migración se ven seriamente perjudicados por problemas de definición y medición. Así, por ejemplo, causa graves dificultades -especialmente en las comparaciones internacionales - la variedad de acepciones que puede tener el término "migrante" en un país determinado.

En la práctica el migrante se define inevitablemente como la persona que ha cruzado una frontera político-administrativa. Sin embargo, estas demarcaciones rara vez son las más adecuadas para comprender el proceso migratorio.

1 Es posible que, con el tiempo, las encuestas perídicas de hogares que se realizan en un número cada vez mayor de países latinoamericanos constituyan nuevas fuentes de información. 
De otro lado, las estadísticas de migración disponibles - salvo aquellas sobre características demográficas básicas - tienden a considerar al migrante como una masa amorfa. La heterogeneidad de las experiencias en materia de migración suele diluirse incluso cuando sólo se examina una localidad de determinado país, y con mayor razón cuando se trata de comparaciones internacionales. Así, por ejemplo, el campesino del Nordeste del Brasil, que huye de la sequía y que tras varias escalas más o menos prolongadas llega a Río de Janeiro empujado por una conjunción de circunstancias, tiene muy poco en común con el hombre de negocios de São Paulo que abre una sucursal en Río de Janeiro, o con el estudiante de ingeniería que viene de Goiás o el obrero especializado procedente de Paraná. Sin embargo, todos ellos quedan clasificados en una misma categoría censal: migrantes al estado de Guanabara. En este caso todos tienen, al menos, un común denominador: su lugar de destino. Pero las discrepancias evidentemente se acrecientan cuando esta variedad se multiplica para reflejar la experiencia nacional y luego para abarcar unos veinte países.

En todo caso, estos movimientos tan diversificados representan sin duda un apreciable volumen de migración. Lo primero que interesa aquí determinar es en qué proporción la población latinoamericana está constituida por migrantes. La respuesta más fácil está en función del número de personas que residen en una provincia (estado, departamen. to) distinta de aquella en que nacieron (migrantes absolutos). Como las unidades que definen la migración son de muy variada naturaleza es probable que la comparación de ciertas cifras sólo sea válida estrictamente para el mismo país en distintos momentos, y no para varios paía ses. (Véase el cuadro 34.)

Es significativo que el número absoluto de personas que reside en una unidad político-administrativa distinta de la natal aumente aprecia= blemente con cada censo en todos los países sobre los cuales se dispone de datos. Por ejemplo, el censo de 1940 de Brasil indicó que $3.4 \mathrm{mi}$ llones de personas residían en un estado diferente de aquel en que habían nacido, mientras que los resultados preliminares del censo de 1970 señalan que 10.7 millones de personas se empadronaron en una macrorregión distinta de la de su nacimiento. Es decir, el número de migrantes se triplicó, aunque se redujo a menos de la mitad el número de unidades que definían las migraciones ( 27 estados y territorios en las tabulaciones de 1940 contra sólo 10 macrorregiones de las de 1970). Por lo tanto, para ser considerada migrante, la persona tenía que recorrer en. promedio una distancia mayor. El número de migrantes interestatales. absolutos experimentó en México un incremento similar (de 2.1 millox nes en 1940 a 7.2 millones en 1970). Los demás países incluidos en el cuadro 34 acusaron incrementos similares en el número absoluto de mi. grantes, y la población migrante aumentó con más rapidez que la población total en casi todos los casos.

Es evidente que la proporción de la población total calificada de mi. grante varía mucho en términos relativos de un país a otro: así, por: 
Cuadro 34. Número de personas empadronadas en provincias distintas de aquellas en que nacieron, en algunos países latinoamericanos, 1940 a 1970

\begin{tabular}{|c|c|c|c|}
\hline País & $\begin{array}{l}\text { Año del } \\
\text { censo }\end{array}$ & $\begin{array}{c}\text { Númeto de } \\
\text { migrantes } \\
\text { (miles) }\end{array}$ & $\begin{array}{l}\text { Porcentaje de la } \\
\text { población total do- } \\
\text { finida como mi- } \\
\text { grante }\end{array}$ \\
\hline Argentina & $\begin{array}{l}1947 \\
1960\end{array}$ & $\begin{array}{l}2567 \\
4579\end{array}$ & $\begin{array}{l}20.3 \\
26.4\end{array}$ \\
\hline Brasil & $\begin{array}{l}1940 \\
1950 \\
1970 a\end{array}$ & $\begin{array}{r}3420 \\
5207 \\
10711\end{array}$ & $\begin{array}{r}8.5 \\
10.3 \\
11.6\end{array}$ \\
\hline Ecuador & 1962 & 512 & 11.5 \\
\hline Chile & $\begin{array}{l}1952 \\
1960 \\
1970\end{array}$ & $\begin{array}{l}1416 \\
1723 \\
2030\end{array}$ & $\begin{array}{l}25.1 \\
23.7 \\
23.8\end{array}$ \\
\hline Colombia & $\begin{array}{l}1951 \\
1964\end{array}$ & $\begin{array}{l}1617 \\
3164\end{array}$ & $\begin{array}{l}14.0 \\
18.1\end{array}$ \\
\hline Costa Rica & $\begin{array}{l}1950 \\
1963\end{array}$ & $\begin{array}{l}158 \\
220\end{array}$ & $\begin{array}{l}18.3 \\
16.0\end{array}$ \\
\hline Guatemala & $\begin{array}{l}1950 \\
1964\end{array}$ & $\begin{array}{l}357 \\
630\end{array}$ & $\begin{array}{l}12.8 \\
14.9\end{array}$ \\
\hline México & $\begin{array}{l}1940 \\
1950 \\
1960 \\
1970\end{array}$ & $\begin{array}{ll}2 & 120 \\
2 & 437 \\
5 & 200 \\
7 & 181\end{array}$ & $\begin{array}{l}10.7 \\
12.9 \\
15.0 \\
14.9\end{array}$ \\
\hline Nicaragua & $\begin{array}{l}1950 \\
1960\end{array}$ & $\begin{array}{l}124 \\
341\end{array}$ & $\begin{array}{l}11.7 \\
18.1\end{array}$ \\
\hline Panamá & $\begin{array}{l}1950 \\
1960\end{array}$ & $\begin{array}{r}92 \\
150\end{array}$ & $\begin{array}{l}13.0 \\
15.4\end{array}$ \\
\hline Paraguay & $1950^{a}$ & 210 & 16.4 \\
\hline Perú & $\begin{array}{l}1940 \\
1961\end{array}$ & $\begin{array}{r}675 \\
2280\end{array}$ & $\begin{array}{l}10.9 \\
23.0\end{array}$ \\
\hline República Dominicana & $\begin{array}{l}1950 \\
1960\end{array}$ & $\begin{array}{l}415 \\
679\end{array}$ & $\begin{array}{l}19.5 \\
22.3\end{array}$ \\
\hline Venezuela & $\begin{array}{l}1941 \\
1950 \\
1961\end{array}$ & $\begin{array}{r}602 \\
908 \\
1532\end{array}$ & $\begin{array}{l}15.8 \\
18.8 \\
20.4\end{array}$ \\
\hline
\end{tabular}

Fuente: Censos de población.

a Las unidades que definen la calidad de migrante son las "macrorregiones" (es decir, agrupaciones de estados). 
ejemplo, en 1940 era aproximadamente de $10 \%$ en dos de los países más grandes de la región (Brasil y México) y en 1970 más de $25 \%$ en Argentina y Chile. Además, del cuadro 34 parece desprenderse que la proporción de la población total formada por migrantes aumentó en casi todos los países en forma relativamente constante hasta los años sesenta. Los migrantes constituían $10.7 \%$ de la población total de México en $1940,12.9 \%$ en 1950 y $15.0 \%$ en 1960 . Entre tanto, en todos los demás países considerados - salvo Costa Rica y Chile- los migrantes también representaban una proporción cada vez mayor de la población total en los intervalos correspondientes. Sin embargo, en Chile y México, únicos dos países en que la comparación entre migrantes en distintas fechas puede extenderse hasta 1970, no ha habido cambios de importancia entre 1960 y 1970 . Si se comprueba posteriormente que lo mismo ha sucedido en otros países, ello indicaría que, a pesar de que sigue aumentando la cifra absoluta de migrantes, tiende a estabilizarse su proporción dentro de la población total.

Las cifras correspondientes a migración antes citadas subestiman mucho el volumen real de las migraciones internas en América Latina. En realidad, se relacionan con migraciones absolutas $y$, por lo tanto, omiten las migraciones de retorno, la mortalidad de los migrantes y los movimientos en etapas múltiples. Y lo que es aún más importante, como estas estadisticas se refieren a las unidades político-administrativas mayores - "estados", "provincias" o "departamentos"-, soblo ofrecen un panorama parcial de la movilidad total, pues gran parte de los movimientos se lleva a cabo dentro de esas unidades. Por ejemplo, si en Colombia se consideran tanto los movimientos intercomunales como los interdepartamentales, se verá que los migrantes abarcan el $36 \%$ de los colombianos, y no el $18 \% .2$ Del mismo modo, aproximadamente el $12 \%$ de la población del Brasil residía en 1970 en una macrorregión (de las que hay diez) distinta de aquella en que había nacido; pero si se tienen en cuenta los movimientos entre municipios, queda de manifiesto que uno de cada tres brasileños es migrante. ${ }^{3}$ Las cifras correspondientes a Costa Rica son notablemente similares a las de Brasil y Colombia, pues en 1964 los migrantes interprovinciales fueron s6lo $16 \%$ de la población total del país, pero una de cada tres personas había migrado por lo menos una vez de un municipio a otro."

Todas las cifras mencionadas se refieren al indicador más sencillo (y burdo) de los movimientos de población: la migración absoluta. Como indicadores de las tendencias en la movilidad de la población son más útiles los que se refieren a un determinado período, verbigracia las estimaciones de los movimientos entre censos que se obtienen por métodos residuales indirectos, o la información directa basada en preguntas

2 Véase G. Martine, "Volume and characteristics of internal migration in Colombia" (documento mimeografiado), cErax, División' de Desarrollo Social, pp. 4 a 5.

3 Datos de la Fundaçá rBge, Resultados Preliminares do Censo Demographico, VII Recenseamento Geral 1970, Río de Janeiro, 1972.

1 E. Pantelides, Costa Rica: estudio de Ia migración interna a partir de una muestra del censo de 1963, ckLADE, 1972, Serie C, núm. 141, p. 4. 
censales como "¿dónde vivía usted hace $\mathrm{x}$ años?”, o “¿cuánto tiempo hace que se traslado a esta comunidad?" En varios países se han aplicado con éxito, en el ámbito nacional o en localidades, técnicas indirectas de estimación de las migraciones, que son la principal fuente de información de que se dispone sobre el tamaño y duración de las corrientes migratorias. ${ }^{5}$ Asimismo, en las series de censos de 1960 y 1970 varios países incluyeron en el formulario preguntas directas sobre migración.

Analizar por países cualquiera de estas fuentes sobrepasaría el alcance de estas páginas. No obstante, hay un punto de particular interés para el análisis de la magnitud general de las migraciones: experiencias anteriores con datos directos mostrarían que estas fuentes acusan sistemáticamente cifras de migración más altas que las que se obtienen por métodos indirectos. Por ejemplo, si en Venezuela se aplicaran las respuestas sobre migración durante un año obtenidas en el censo de 1961 a todo el período 1950-1961, se vería que en ese lapso aproximadamente 2 millones de personas trasladaron su residencia de un estado a otro. En cambio, las estimaciones indirectas indicarian que el movimiento neto alcanzó a menos de un millón de personas. ${ }^{6}$ Podrían citarse experiencias similares en las estimaciones de la migración en Brasil, Chile o México. ¿Cómo se explican estas discrepancias entre las estadísticas directas y las estimaciones indirectas? Probablemente en parte por problemas metodologicos, pero además es indudable que la verdadera magnitud de los movimientos de la población es muy superior a la que acusan las estimaciones indirectas o las estadísticas sobre migraciones absolutas, incluso cuando para definir la migración se utilizan unidades político-administrativas adecuadamente pequeñas. Esto sugeriría, además, la extremada movilidad de un núcleo relativamente importante de latinoamericanos que migra varias veces en un lapso más bien pequeño, mientras que la mayor parte de la población no se ha trasladado nunca.

Si se recapitula y generaliza sobre la base del material reconocidamente fragmentario de que se dispone, cabría hacer una conjetura: uno de cada tres latinoamericanos ha cambiado de lugar de residencia al menos una vez en la vida. Podría afirmarse asimismo que entre un tercio y la mitad de todos estos movimientos significan traslado a otro Estado, probablemente luego de recorrer considerables distancias. La pregunta próxima sería por lo tanto: ¿De dónde vienen los migrantes y cuáles son los lugares de destino que prefieren?

En lo que se ha escrito al respecto parece reconocerse que la abrumadora mayoría de los movimientos de población en América Latina son del campo a la ciudad (y de preferencia a las grandes ciudades). Sin

5 Véase por ejemplo Chi-Yi-Chen, Movimientos migratorios en Venezuela, Instituto de Investigaciones Económicas, Universidad Católica Andrés Bello, Caracas, 1968; Zulma Recchini de Lattes y Alfredo Lattes, Migraciones en la Argentina, Instituto Torcuato di Tella, Buenos Aires, 1969; Arthur M. Conning, Estimacion de la migracion interna neta en Ias provincias de Chile, 1930-40, 1940-52, 1952-60, CELADE, Serie D, núm. 36; Jorge Arias B., "Migraciones internas en Guatemala", Conferencia Regional Latinoamericana de Población, México, 1970, pp. 509-514.

B Chi-Yi-Chen, op. cit., pp. 17 a 18. 
embargo, estas conclusiones se basan, más que en informaciones directas, en las considerables diferencias entre las tasas de crecimiento de la población urbana y rural. Por ejemplo, en un trabajo muy difundido, Ducoff afirma que entre 1950 y 1960 los movimientos de población desde las zonas rurales a las urbanas abarcaron en América Latina alrededor de 14.6 millones de personas. ${ }^{7} \mathrm{Si}$ sus cálculos se extienden a 1960-1970, en este decenio se produciría una transferencia similar de unos 24 millones de personas.

Dado que los supuestos en que se basan estos cálculos parecen razonables, y dada la magnitud del movimiento supuesto, es comprensible que en América Latina se tienda a identificar las migraciones internas con los movimientos de las zonas rurales a las urbanas y particularmente con los movimientos directos del campo a la gran ciudad, con su secuela de "ruralización" de importantes sectores de las metrópolis latinoamericanas. Por lo demás, estas conclusiones se confirman a través de las encuestas de migración realizadas en grandes ciudades, que indican que una proporción importante de los migrantes viene del medio rural.

No obstante, estas generalizaciones encubren varias hipótesis relacionadas entre sí que merecen examinarse por separado. Ante todo, y en lo que toca al lugar preferido de destino en los movimientos migratorios, conviene destacar que las afirmaciones sobre el predominio en el ámbito nacional de movimientos desde las zonas rurales a las urbanas, o en otras direcciones, suelen deducirse de las diferencias entre tasas de crecimiento. Los datos censales no proporcionan generalmente información directa sobre el origen de la población urbana y rural que ha migrado, y menos aún sobre la población que reside en localidades de diversos tamaños. En cambio, las encuestas locales informan efectivamente sobre el origen rural o urbano, pero pasan por alto otras corrientes migratorias.

Por lo que se sabe, la única fuente de información a escala nacional de que se dispone son tabulaciones iniciales efectuadas por el CELADE sobre migraciones por "ciudades capitales", "otras zonas urbanas" y "zonas rurales". ${ }^{8}$ Los resultados que arrojan los dos estudios basados en este material ponen en tela de juicio la validez de la afirmación de que en América Latina los únicos movimientos importantes son del campo a la ciudad y particularmente a la ciudad principal. Según el censo de 1964, 6.5 millones de los 17.5 millones de habitantes de Colombia residía en un municipio o departamento distinto del natal. De éstos, la proporción

7 Louis J. Ducoff, "The role of migration in the demographic development of Latin America", The Milbank Memorial Fund Quarterly, 43 (4), segunda parte, pp. 197 a 210. Similares son los enfoques que aplican Lowdon Wingo, Jr., "Recent patterns of urbanization among Latin America countries", Urban Affairs Quarterly, 1967, 2 (3), pp. 81 a 109, y U. N. Bureau of Social Affairs, "Aspectos demográficos de la urbanización en América Latina", en P. M. Hauser (Ed.), La urbanización en América Latina, UNESCO, Lieja, 1962.

8 En CELAde, Boletín del Banco de Datos, núm. 5, 1972, pueden encontrarse pormenores sobre los objetivos y características del proyecto de este organismo encaminado a proporcionar tabulaciones especiales basadas en muestras censales. 
de migrantes que había atraído Bogotá (12.6\%) sólo era levemente superior a su proporción en la población total $(9.6 \%)$. Entre tanto, las demás zonas urbanas del país, que contenían $43 \%$ de la población nacional, acogieron $53 \%$ del total de migrantes, y más revelador aún es quizá el hecho de que $36 \%$ de los migrantes residían en zonas rurales.9 Por desgracia, no hay datos sobre el origen rural o urbano de ninguno de estos movimientos, pero no es aventurado suponer que en Colombia aproximadamente la tercera parte de las migraciones son desde zonas rurales a otras también rurales.

Del estudio basado en las tabulaciones de la omuece sobre Costa Rica, puede concluirse asimismo que en 1963 la tercera parte de sus habitantes ( 1.3 millones en total) residían en un municipio o provincia distinto del natal. Aproximadamente $30 \%$ de estos migrantes residía en la capital de San José, y $14 \%$ en otras ciudades. $\mathrm{Y}$ hay algo más que viene del todo al caso: no menos de $57 \%$ del total de migrantes fue enumerado en zonas rurales. ${ }^{10}$ Por lo tanto, no hay duda de que en Costa Rica, no obstante el muy comentado atractivo que ejerce la capital, las principales corrientes migratorias se producen entre zonas rurales.

Por desgracia, no se dispone todavía de datos comparables sobre otros países. Las tabulaciones especiales basadas en la serie de censos de 1970 proporcionarán más detalles, pero por el momento los dos ejemplos señalados previenen contra el riesgo de generalizar sobre la preponderancia absoluta de los movimientos hacia zonas urbanas. Con esto no se pretende descartar la migración del campo a la ciudad, porque indudablemente este movimiento es el de mayor importancia en América Latina; sólo se busca evaluar otros tipos de migración, dado que hasta ahora se ha hecho hincapié, a veces exclusivamente, en el movimiento del campo a la ciudad. En lo que respecta al futuro, la gradual urbanización de la población latinoamericana hará que los movimientos entre zonas urbanas representen inevitablemente una proporción cada vez mayor de las migraciones.

\section{B. ADAPTACION DE LOS MIGRANTES Y CONSECUENCIAS DE LAS MTGRACIONES}

Los efectos de las migraciones, sea para las zonas de origen, para las de destino o para los propios migrantes, dependen en gran parte de la composición de la población que migra. El análisis de las funciones o disfunciones que desempeñan las migraciones en una zona de destino determinada gira en torno a la capacidad del migrante para establecerse provechosamente en su nuevo ambiente. En realidad, estas características son las que determinan si la migración ha de traducirse en una redistribución racional de la mano de obra productiva en una matriz de oportunidades desiguales a nivel nacional, o en la aglomeración de ele-

9 Martine, op. cit., pp. 5 y 6.

10 Pantelides, op. cit., pp. 4 y 5. 
mentos parasitarios en una estructura socioeconómica o de empleo de por sí confusa.

No obstante su importancia, suele faltar información satisfactoria que relacione en forma directa las características de los migrantes con las de la población no migrante en el lugar de destino, mal frecuente que ha dado margen a afirmaciones contradictorias sobre el papel que desempeñan los migrantes. ${ }^{11}$ Un conjunto de tabulaciones especiales preparadas por CELADE sobre una muestra del censo colombiano como parte del proyecto OMUECE ${ }^{12}$ permite analizar las características y la adaptación de los migrantes en forma mucho más detallada de lo que normalmente hacen posible los estudios nacionales. Estas tabulaciones distinguen entre los migrantes según tres amplias categorías de lugares de destino: la capital (Bogotá), otras zonas urbanas, y zonas rurales. El siguiente análisis de la adaptación de los migrantes y de las consecuencias de las migraciones girará en torno a dos ejes fundamentales:

a) las características demográficas de los migrantes: su composición por edad y sexo, y su estado civil, y

b) las características que determinan la adaptación económica de los migrantes: alfabetismo y nivel de instrucción, participación en la fuerza laboral, rama de actividad económica, situación ocupacional y participación en actividades económicamente marginales. La determinación de las diferencias en cada una de estas esferas debería proporcionar gradualmente elementos para lograr una visión general de las repercusiones positivas o negativas de las migraciones en las distintas zonas de recepción.

\section{1) Características sociales $y$ demográficas}

a) Composición por edades de la población migrante. Aunque la búsqueda de características universales en las migraciones ha resultado relativamente infructuosa, hay una variable - la edad de los migrantes- que muestra bastante uniformidad en todo el mundo. En América Latina, como en otros lugares, los adultos jóvenes parecen predominar entre los migrantes, particularmente en las corrientes migratorias hacia zonas de atracción urbanas. (La composición de las corrientes migratorias hacia zonas rurales se ha estudiado poco.)

11 Se cree por lo común que los migrantes predominan en los tramos más bajos de la escala socioeconómica y se supone que en este sentido las diferencias entre migrantes y nativos son pronunciadas. Varios estudios recientes sobre características de las migraciones indican que aún puede generalizarse poco sobre la materia. Véase, por ejemplo, Juan Elizaga O., "Migraciones interiores: evolución reciente y estado actual de los estudios", Conferencia Regional Latinoamericana de Población, México, 1970, tercera sesion, pp. 12 y 13, y John Macisco, "Some thoughts on an analytic framework for rural to urban migration", Ibid., pp. 7 y 8 . Véanse además Jorge Balan, "Migrant-native socioeconomic differences in Latin American cities: a structural analysis", Latin American Research Review, 1969, 4 (1), pp. 3 a 29; Harley Browning, "Migrant selectivity and the growth of large cities in developing societies", en Rapid Population Growth, The Johns Hopkins Press, Baltimore, 1971, Pp. 273 a 314.

12 Véase celade, "Banco de Datos", Boletín Informativo, núms. 3 y 4. 
En una encuesta por muestreo realizada en seis ciudades de Brasil se encontró que $66.5 \%$ de los migrantes a estas ciudades había llegado a ellas entre los 15 y los 39 años de edad. ${ }^{18}$ Del mismo modo, en San Salvador, un muestreo realizado en 1960 indicó que, en el momento de efectuarse la encuesta, $64 \%$ del total de migrantes a esa ciudad tenía entre 15 y 44 años. ${ }^{14}$ Un estudio realizado en Lima metropolitana en 1966 reveló que $56.5 \%$ del total de migrantes a la zona tenía entre 15 y 39 años de edad al llevarse a cabo dicho trabajo. ${ }^{15}$ En el Gran Santiago, entre los migrantes recientes (es decir, con menos de diez años. de residencia), $83.1 \%$ tenía entre 15 y 44 años; y más de seis de cada diez de estos migrantes recientes habían llegado antes de cumplir los 26 años. ${ }^{16}$

Frente a pruebas tan reiteradas, lo inesperado sería que en Colombia no predominaran los migrantes jóvenes. En el cuadro 35 se compara la estructura de edades, por sexo, de los migrantes recientes (es decir, los que tienen menos de cinco años de residencia en el lugar de destino) a Bogotá y a otras zonas urbanas y rurales, con la de una población en la que no influyen las migraciones, en este caso, la población total de Colombia. Debido a que en la presente muestra surgieron dificultades en la compilación de datos respecto a los menores de 10 años, la comparación debió limitarse a la población de 10 años y más.

El cuadro 35 muestra también que en Colombia los migrantes efectivamente tienden a pertenecer a los grupos jovenes, pero se observan variaciones considerables según el sexo y el lugar de destino. En los varones, la principal diferencia entre los migrantes y la población del país se encuentra en el grupo de 20 a 29 años. En síntesis, entre los migrantes varones recientes a los tres lugares de destino mencionados, pero particularmente a Bogotá, la proporción del total que tiene de 20 a 29 años es apreciablemente mayor que en el país en su conjunto; la diferencia es $\tan$ grande en la capital que entre los migrantes casi todos los demás grupos de edades son proporcionalmente más reducidos que los co. rrespondientes al total del país. Este mismo grupo de edades asimismo predomina claramente en las migraciones masculinas a otras zonas tribanas y a zonas rurales, aunque no de manera tan acentuada como en el caso de Bogotá. Así, en general, la distribución por edades de los. varones que migtan a zonas rurales es la que más se asemeja a la del país, mientras que la de los migrantes a Bogotá es la menos parecida.

El predominio de migrantes jóvenes es mayor aún en las mujeres. Las. migrantes son considerablemente más jóvenes que la población femeni-

13 Bertram Hutchinson, "The migrant population of urban Brazil", América Latina, 6 (2), abril-junio 1963, pp. 41 a 71 .

14 Naciones Unidas, Aspectos demográficos y socioeconómicos del área metropolitanaz de San Salvador, $\mathrm{x} / \mathrm{cs} .12 / \mathrm{ccE} / 333$, pp. 57 y 58.

15 Direccion Nacional de Estadística del Pert, Encuesta en Lima Metropolitana, Lima, 1966, p. 25.

16 Bruce Herrick, Urban Migration and Economic Development in Chile, MTr Press, Cambridge, Mass., 1964, pp. 73 a 76; Juan Elizaga, Migraciones a las áreas metropolitanas de América Latina, CELADE, 1970, pp. 31 a 40. 
Cuadro 35. Colombia: composición por edades de los migrantes recientes comparada con la de la población total, según sexo y lugar de destino

(Porcentajes)

\begin{tabular}{lrrrr}
\hline Edad y sexo & $\begin{array}{c}\text { Migrantes } \\
\text { recientes } \\
\text { a Bogotá }\end{array}$ & $\begin{array}{c}\text { Migrantes } \\
\text { recientes a otras } \\
\text { zonas urbanas }\end{array}$ & $\begin{array}{c}\text { Migrantes } \\
\text { recientes a } \\
\text { zonas rurales }\end{array}$ & $\begin{array}{c}\text { Población } \\
\text { de } \\
\text { Colombia }\end{array}$ \\
\hline & & & & \\
$10-19$ & 30.9 & 33.8 & 32.2 & 35.3 \\
$20-29$ & 38.4 & 29.2 & 28.9 & 21.7 \\
$30-39$ & 16.7 & 17.8 & 18.9 & 16.7 \\
$40-49$ & 6.8 & 9.1 & 10.5 & 11.6 \\
$50-59$ & 4.3 & 5.3 & 5.2 & 7.6 \\
60 y más & 2.9 & 4.7 & 4.3 & 7.1 \\
Total & 100.0 & 100.0 & 100.0 & 100.0 \\
& & & & \\
Mujeres & & & 34.9 & 34.4 \\
$10-19$ & 39.6 & 39.9 & 29.0 & 22.8 \\
$20-29$ & 31.9 & 28.1 & 17.9 & 16.9 \\
$30-39$ & 13.0 & 14.0 & 9.0 & 11.0 \\
$40-49$ & 6.0 & 7.9 & 4.9 & 7.1 \\
$50-59$ & 4.6 & 4.8 & 4.3 & 7.8 \\
60 y más & 4.9 & 5.2 & 100.0 & 100.0 \\
Total & 100.0 & 100.0 & & \\
\hline
\end{tabular}

Fuente: oduece, Colombia, cuadros 1 y 20.

na del país, pero también lo son bastante más que los migrantes varones. Esto se observa de manera especial en las migraciones a Bogotá y otras, zonas urbanas, donde aproximadamente $40 \%$ de las migrantes recientes tienen entre 10 y 19 años. En total, $72 \%$ de las mujeres de 10 años o más que migran a Bogotá y $68 \%$ de las migrantes a otras zonas urbanas tienen de 10 a 29 años. En cambio, en el plano nacional, la proporción del total es de $57 \%$. En las zonas rurales, las mujeres migrantes tienden a ser algo mayores, y aunque la proporción de ellas entre 20 y 29 años es más alta que la que se observa en la población total, en general su estructura de edades se aparta menos que en los demás grupos migrantes de la correspondiente a la población nacional.

En resumen, y como era de esperar dados los resultados de investigaciones anteriores sobre las características de las migraciones, los migrantes a todas las zonas de Colombia pertenecen principalmente a los grupos más jóvenes. Por lo general, entre los migrantes las mujeres son más jóvenes que los varones, mientras que en los movimientos migratorios a Bogotá y, en menor grado, aquellos a otras zonas urbanas, el predominio de migrantes jóvenes de ambos sexos es particularmente acentuado. Si se supone - como parece razonable- que los migrantes 
CuAdro 36. Colombia: porcentaje de nativos, migrantes e inmigrantes, por edad y sexo, en cada cohorte de la población de Bogotá, de otras zonas urbanas y de las zonas rurales

\begin{tabular}{|c|c|c|c|c|c|c|c|c|c|c|c|c|}
\hline \multirow[b]{2}{*}{ Edad y sexo } & \multicolumn{4}{|c|}{ Bogotá } & \multicolumn{4}{|c|}{ Otras zonas urbanas } & \multicolumn{4}{|c|}{ Zonas rurales } \\
\hline & $\begin{array}{c}\text { Nati- } \\
\text { vos }\end{array}$ & $\begin{array}{c}\text { Migran- } \\
\text { tes }\end{array}$ & $\begin{array}{c}\text { Inmi- } \\
\text { grantes }\end{array}$ & Total & $\begin{array}{l}\text { Nati- } \\
\text { vos }\end{array}$ & $\begin{array}{c}\text { Migran- } \\
\text { tes }\end{array}$ & $\underset{\text { grantes }}{\text { Inmi- }}$ & Total & $\begin{array}{l}\text { Nati- } \\
\text { vos }\end{array}$ & $\begin{array}{c}\text { Migran- } \\
\text { tes }\end{array}$ & $\begin{array}{l}\text { Inmi- } \\
\text { grantes }\end{array}$ & Total \\
\hline Varones & & & & & & & & & & & & \\
\hline $0-9$ & 83.9 & 15.6 & 0.6 & 100.0 & 79.5 & 20.2 & 0.3 & 100.0 & $84.8^{\circ}$ & 15.1 & 0.1 & 100.0 \\
\hline $10-19$ & 56.7 & 42.8 & 0.5 & 100.0 & 61.1 & 38.4 & 0.4 & 100.0 & 74.1 & 25.8 & 0.1 & 100.0 \\
\hline $20-29$ & 28.3 & 70.7 & 1.0 & 100.0 & 41.8 & 57.6 & 0.5 & 100.0 & 60.9 & 38.9 & 0.2 & 100.0 \\
\hline $30-39$ & 23.3 & 73.8 & 2.9 & 100.0 & 35.6 & 63.2 & 1.2 & 100.0 & 58.0 & 41.8 & 0.2 & 100.0 \\
\hline $40-49$ & 20.4 & 77.5 & 2.1 & 100.0 & 34.9 & 64.0 & 1.0 & 100.0 & 56.8 & 43.0 & 0.2 & 100.0 \\
\hline $50-59$ & 15.8 & 79.9 & 4.3 & 100.0 & 33.2 & 65.5 & 1.3 & 100.0 & 56.4 & 43.3 & 0.3 & 100.0 \\
\hline 60 y más & 18.2 & 77.1 & 4.7 & 100.0 & 35.6 & 62.8 & 1.7 & 100.0 & 57.7 & 41.9 & 0.4 & 100.0 \\
\hline $\begin{array}{c}\text { Total } \\
\text { Mujeres }\end{array}$ & 50.5 & 48.2 & 1.3 & 100.0 & 57.5 & 41.9 & 0.6 & 100.0 & 71.3 & 28.6 & 0.1 & 100.0 \\
\hline $0-9$ & 83.4 & 16.1 & 0.5 & 100.0 & 78.8 & 21.0 & 0.2 & 100.0 & 84.9 & 15.1 & 0.1 & 100.0 \\
\hline $10-19$ & 48.4 & 50.9 & 0.7 & 100.0 & 57.0 & 42.7 & 0.3 & 100.0 & 76.6 & 23.3 & 0.1 & 100.0 \\
\hline $20-29$ & 25.5 & 73.5 & 1.1 & 100.0 & 40.2 & 59.2 & 0.6 & 100.0 & 66.6 & 33.2 & 0.2 & 100.0 \\
\hline $30-39$ & 21.5 & 77.0 & 1.6 & 100.0 & 37.4 & 61.8 & 0.7 & 100.0 & 63.1 & 36.8 & 0.2 & 100.0 \\
\hline $40-49$ & 19.4 & 78.5 & 2.1 & 100.0 & 35.6 & 63.5 & 1.0 & 100.0 & 63.8 & 36.0 & 0.2 & 100.0 \\
\hline $50-59$ & 16.3 & 81.3 & 2.3 & 100.0 & 36.6 & 62.7 & 0.7 & 100.0 & 63.8 & 36.1 & 0.1 & 100.0 \\
\hline 60 y más & 15.2 & 83.0 & 1.7 & 100.0 & 39.2 & 60.0 & 0.9 & 100.0 & 65.3 & 34.4 & 0.2 & 100.0 \\
\hline Total & 45.3 & 53.6 & 1.1 & 100.0 & 55.0 & 44.5 & 0.5 & 100.0 & 74.6 & 25.2 & 0.1 & 100.0 \\
\hline
\end{tabular}

Fuente: omuece, Colombia, cuadro 18. 
anteriores surgieron en gran parte de los mismos grupos de edades que los migrantes recientes en 1964, cabría preguntarse cuál ha sido el efecto a largo plazo de esta modalidad en las estructuras demográficas de las zonas receptoras.

Es interesante observar que el análisis por corte transversal de la composición según edad y sexo de nativos, migrantes e inmigrantes (véase el cuadro 36) no revela de inmediato este predominio de migrantes jóvenes. De hecho, la superioridad numérica de los migrantes sólo se manifiesta en las cohortes mayores de 20 años y tiende a acentuarse a medida que aumenta la edad.

Como es natural, esto se explica porque la distribución por edad y sexo de la población nativa se ve afectada por nacimientos, defunciones y migraciones, mientras que en la de los migrantes sólo influyen las muertes y la migración. De ahí que la población nativa de Bogotá y de otras zonas urbanas y rurales aumente con el nacimiento de hijos tanto de los nativos como de los migrantes. Por lo tanto, la composión de la población tiene una amplia base que disminuye en cada cohorte sucesiva debido al curso normal de la mortalidad y a la emigración. En cambio, la migración neta acrecienta continuamente cada nivel de la población migrante. Así, por ejemplo, los migrantes que en 1964 tenían entre 30 y 39 años incluían todos los sobrevivientes de los migrantes de 30 a 39 años en el período 1954-1964, más los sobrevivientes de los migrantes de 20 a 29 años en el período 1944-1954, y así sucesivamente. Por lo tanto, aunque la pirámide por edad y sexo de los nativos era más o menos normal, la de los migrantes absolutos sobrevivientes se ensanchaba en los grupos de edades centrales como consecuencia de una constante infiltración en ellos.

Estas consideraciones elementales explican que el corte transversal de la composición de la población no revela de inmediato la juventud de los inmigrantes.

Aparte este comentario metodol6gico, el cuadro 36 permite observar una gran proporción de migrantes en la población tanto masculina como femenina de Bogotá, de otras zonas urbanas y de zonas rurales. Aunque esta afirmación se aplica a todas las cohortes, en Bogotá la proporción es particularmente grande entre mayores de 30 años, grupos constituidos en un 70 a $80 \%$ por migrantes. En otras zonas urbanas, los migrantes constituyen más de $60 \%$ de todos los grupos de varones y mujeres mayores de 30 años, y en las zonas rurales, la proporción correspondiente fluctúa entre 40 y $45 \%$ en los varones y entre 35 y $40 \%$ en las mujeres.

b) Composición por sexo de las corrientes migratorias. Las modalidades de migración por sexo llaman quizá menos la atención que aquellas por edad; sin embargo, las fuentes de que se dispone parecerían indicar que en la mayoría de las corrientes migratorias latinoamericanas, particularmente entre los migrantes a corta distancia y en dirección a las ciudades, predominan las mujeres. Luego de examinar la tasa anual de migración, por sexo, a las principales ciudades latinoamerica. 
nas entre 1938 y 1963, se llega a la conclusión de que la migración femenina es más intensa que la masculina. ${ }^{17}$ Los estudios antes mencionados sobre la migración a seis ciudades de Brasil y a Lima, San Salvador y Santiago, acusaron resultados similares, ${ }^{18}$ corroborados por el hecho de que la relación de masculinidad urbana es inferior a la nacional en todos los páses latinoamericanos, salvo Perú, al parecer como consecuencia del predominio de las mujeres en las migraciones del campo a la ciudad, característico de la región. ${ }^{19}$

Sin embargo, en un estudio de las migraciones interdepartamentales en Guatemala, se comprobó que la migración era en general mayor entre los varones; sólo en 6 de 22 departamentos las cifras correspondientes a las mujeres fueron más altas y, de éstos, sólo el de Guatemala acusó un aumento neto. ${ }^{20}$ Por otra parte, se estima que en Venezuela los datos revelan un notable equilibrio entre ambos sexos, tanto en la migración interestatal como en la intraestatal, 21 y se afirma que en México, en los decenios de 1930 y 1940 el número de varones en las migraciones interestatales es bastante superior al de mujeres. Aunque las tasas correspondientes a ambos sexos aumentaron entre los años treinta y los años cuarenta, se observó aproximadamente la misma diferencia en las tasas femeninas y masculinas. ${ }^{22}$

No obstante, las discrepancias entre ambos conjuntos de observaciones no son necesariamente inconciliables. En efecto, cuando se controla la distancia y la dirección - como se sugiri6 originalmente ${ }^{23}$-, se comprueba que en los movimientos del campo a la ciudad y aquellos a corta distancia predominan las mujeres. Esto puede relacionarse principalmente con las metas ocupacionales de las jóvenes de zonas rurales que se inclinan más a buscar empleo en las ciudades, sobre todo en el servicio doméstico o en la industria. Como en los movimientos a larga distancia y entre zonas rurales predominan los varones jóvenes, al analizar las modalidades generales de la migración, las tendencias contrarias tienden a compensarse.

Según lo expuesto, Bogotá atraería un número desproporcionadamente alto de migrantes mujeres; otras zonas urbanas (que incluyen grandes zonas metropolitanas, pueblos pequeños y todas las ciudades de tamaño intermedio) tendrían una mayoría no tan marcada, pero

17 Juan Elizaga, "Internal migrations in Latin America", Mitbank Memorial Fund Quarterly, 43 (3-4), pp. I49 a 150.

18 Véanse supra las notas 13 a 16 .

19 Naciones Unidas, División de Población, "Demographic aspects of urbanization in Latin America", en P. M. Hauser (Ed.) Urbanization in Latin America, UNEsco, 1961, pp. 101 y 102.

20 Jorge Arias, "Internal migration in Guatemala", Proceedings of the International Population Conference, Nueva York, 1961, p. 400.

21 Juan Elizaga, "Differential migration in Latin America", Proceedings of the International Population Conference, p. 418.

22 Robert G. Burnight, "International migrations in Mexico", Proceedings of the Intèrnational Population Conference, p. 468.

23 Véase E.G. Ravenstein, "The laws of migration", Journal of the Royal Statistical Society, vol. 48, junio de 1885, segunda parte, Pp. 167 a 235 , y vol. 52, junio de 1889, pp. 241 a 345. 
siempre importante, de mujeres entre los migrantes, $y$, por último, las zonas rurales incluirían una proporción mayor de migrantes varones.

El cuadro 37 indica que efectivamente éstas son las modalidades predominantes. Del total de migrantes a Bogotá $56 \%$ está constituido por mujeres; además, en todas las cohortes de edad (salvo el grupo de 30 a 39 años que mostraba una ligera mayoría de varones), predominaban las mujeres. Del total de migrantes a otras zonas urbanas las mujeres constituían el $54 \%$ y predominaban en todas las cohortes, salvo entre los 30 y 39 años. En cambio, una fuerte mayoría (59\%) del total de migrantes a zonas rurales estaba formada por varones, que predominaban sin excepción en todos los grupos de edades.

\section{Cuadro 37. Colombia: relación de masculinidad de los migrantes recientes, por edad y lugar de destino}

\begin{tabular}{lccc}
\hline & \multicolumn{3}{c}{ Lugar de destino } \\
\cline { 2 - 4 } Edad & Bogotá & $\begin{array}{c}\text { Otras zonas } \\
\text { urbanas }\end{array}$ & $\begin{array}{c}\text { Zonas ru- } \\
\text { rales }\end{array}$ \\
\hline $10-19$ & 62 & 71 & 130 \\
$20-29$ & 95 & 88 & 141 \\
$30-39$ & 101 & 108 & 148 \\
$40-49$ & 90 & 98 & 165 \\
$50-59$ & 57 & 94 & 150 \\
60 y más & 47 & 77 & 140 \\
Total & 79 & 85 & 141 \\
\hline
\end{tabular}

Fuente: omuece, cuadro 23.

Sin embargo, dentro de cada uno de estos grupos se observan importantes diferencias en la relación de masculinidad por edades. Por ejemplo, en las migraciones a Bogotá el número de mujeres supera al de varones en proporción de diez a seis entre los 10 y los 19 años. Esto concuerda con el anterior análisis de las modalidades de la migración por edades (véase nuevamente el cuadro 35 ), en que se demostró que es mucho más probable encontrar mujeres que varones entre los migrantes recientes de 10 a 19 ańos. Este mismo fenómeno se observa en la mayoría de las migraciones hacia zonas urbanas en América Latina y lo más probable es que en este caso también pueda atribuirse a la afluencia de mujeres jóvenes que van a la capital en busca de empleo en el servicio doméstico. Entre los migrantes a Bogotá el número de mujeres también es superior al de varones en todos los demás grupos de edades, salvo la cohorte de 30 a 39 años, pero la diferencia es particularmente marcada en el grupo de 50 años y más. Parece razonable atribuir esto último a diferencias de mortalidad por sexo en las zonas de origen, que impulsarían a las mujeres sobrevivientes a trasladarse a vivir con familiares que hubiesen migrado antes. 
Los datos sobre diferencias de sexo en las migraciones a otras zonas urbanas se asemejan mucho a los de Bogotá, pero son menos marcadas. Más concretamente, las mujeres vuelven a predominar en todos los grupos de edades, salvo entre los 30 y los 39 años, y las diferencias son mayores en ambos extremos de la escala de edades. Es probable que aquí influyan también las razones que se dieron con respecto a Bogotá, y que la atenuación de las diferencias se deba a la inclusión de pueblos y ciudades más pequeños entre las "otras zonas urbanas". Así, Bogotá sería prototipo de las diferencias que pueden preverse en los movimientos migratorios hacia las grandes ciudades, diferencias que se atenuarían al tenerse en cuenta centros menores. En lo que respecta al sexo, las características de los movimientos migratorios hacia zonas rurales contrastan marcadamente con las esbozadas para Bogotá y otras zonas urbanas. En ellos los migrantes varones son considerablemente más numerosos que las mujeres en todos los grupos de edades, sin excepción alguna. Este perfil, tan contrario al de las migraciones hacia las ciudades, refleja posibles movimientos estacionales y, lo que es más importante, el tipo de oportunidades de empleo existentes en las zonas rurales. Las mujeres, jóvenes o adultas, simplemente no migran en gran escala a zonas rurales en busca de nuevas oportunidades.

Así pues, la composición de los migrantes por edad y sexo en Colombia adopta una modalidad general concordante con la que cabría esperar sobre la base de los principios de selectividad que se confirman de manera constante en los estudios sobre la migración realizados en América Latina. La abrumadora mayoría de los migrantes recientes son jóvenes cuando llegan a su lugar de destino; además, en las corrientes migratorias a las ciudades y pueblos predominan las mujeres, mientras que las migraciones a zonas rurales incluyen una importante mayoría de varones. Al parecer, estas diferencias emanan en forma natural de las oportunidades de empleo que ofrece cada zona de destino.

c) Estado civil. El estado civil de quienes integran las corrientes migratorias latinoamericanas se ha analizado insuficientemente, no por falta de interés, ya que las diferencias de estado civil sin duda influyen en forma considerable en los sistemas sociales de las zonas de origen y destino, sino más bien por falta de información.

Los escasos estudios existentes en América Latina sugieren que entre los que migran a las grandes ciudades hay una proporción de solteros muy superior a la que se observa en los lugares de que proceden o a los que se dirigen. ${ }^{24}$ Basándose en las encuestas por zonas realizadas en Colombia, sólo cabe suponer que el estado civil de los migrantes varía considerablemente según su origen y destino. ${ }^{25}$ Sin embargo, a pesar de estas variaciones locales, cuando se examina el estado civil de nuestros tres grandes grupos de migrantes se observa bastante uniformidad.

24 Browning, op. cit., p. 288.

25 William L. Flinn, Rural to urban migration: a Colombian case, Land Tenure Center, University of Wisconsin, RP núm. 19, julio de 1966; W. Flinn y J. Converse, "Eight assumptions concerning rural-urban migration in Colombia: a three shantytown test", Land Economics, 44 (4), pp. 456 a 466 (noviembre de 1970). 
La visión global y comparada del estado civil de los migrantes recientes y los residentes que ofrece el cuadro 38 permite distinguir modalidades reveladoras. ${ }^{26}$ En primer término, en los migrantes recientes hay una proporción bastante más alta de hombres y mujeres no casados (es decir, solteros, separados o viudos) que en la población residente, sea de la capital o de otras zonas urbanas, y la diferencia es mucho más marcada en la primera. En cambio, aunque entre los migrantes varones recientes a las zonas rurales la proporción de no casados es ligeramente más alta que entre los residentes, la diferencia se compensa con creces porque el fenómeno contrario predomina en la población femenina. Ninguna de estas relaciones parece guardar una relación significativa o coherente con las migraciones a corta distancia (intermunicipales) o a larga distancia (interdepartamentales).

Los datos analizados se refieren a la totalidad de los migrantes y residentes, sin considerar más variables que el sexo. Como gran parte de

Cuadro 38. Colombia: comparación del estado civil de migrantes $y$ residentes, por sexo, 1964

\begin{tabular}{|c|c|c|c|c|c|c|}
\hline \multirow{3}{*}{ Estado civil } & \multicolumn{6}{|c|}{ Lugar de destino } \\
\hline & \multicolumn{2}{|c|}{ Bogotá } & \multicolumn{2}{|c|}{ Otras zonas urbanas } & \multicolumn{2}{|c|}{ Zonas rurales } \\
\hline & $\begin{array}{c}\text { Varo } \\
\text { nes }\end{array}$ & $\begin{array}{c}\text { Muje- } \\
\text { res }\end{array}$ & $\begin{array}{c}\text { Varo- } \\
\text { nes }\end{array}$ & $\underset{\text { res }}{\text { Muje- }}$ & $\begin{array}{c}\text { Varo- } \\
\text { nes }\end{array}$ & $\overline{\text { res }}$ \\
\hline \multicolumn{7}{|l|}{ No casados } \\
\hline Residentes & 52.0 & 56.8 & 57.9 & 59.7 & 57.7 & 53.6 \\
\hline Inter-DAI a & - & - & 62.2 & 64.5 & 60.3 & 48.0 \\
\hline Inter-DAM $\mathbf{b}$ & 67.1 & 68.1 & 63.7 & 63.2 & 63.9 & 46.7 \\
\hline \multicolumn{7}{|c|}{ En union marital } \\
\hline Residentes & 48.0 & 43.2 & 42.2 & 40.3 & 42.3 & 46.3 \\
\hline Inter-DAI & - & - & 37.9 & 35.5 & 39.7 & 52.0 \\
\hline Inter-DAM & 33.0 & 31.9 & 36.2 & 36.8 & 36.2 & 53.3 \\
\hline
\end{tabular}

Fuente: omuece, Colombia, cuadro 20.

a Division administrativa intermedia.

b División administrativa mayor.

26 En la presente exposición se utilizan con frecuencia comparaciones porcentuales entre migrantes reciente y residentes, por lo que quizá convenga explicar los métodos de computación empleados. La omuEce proporciona dos series de cuadros: una se refiere a la población total de la capital, de las zonas urbanas y de las zonas rurales, y la otra ofrece la misma información respecto de los migrantes recientes a cada una de estas zonas. Para hacer una comparación significativa entre los migrantes recientes y todos los demás residentes, hay que restar cada subgrupo de migrantes recientes del sub. grupo pertinente en el cuadro total de población. Para simplificar la redacción, de ahora en adelante los nacidos en el lugar más todos los migrantes anteriores a cada una de las zonas de destino se denominarán simplemente "residentes". Cabe observar que la inclusion de migrantes no recientes en la categoría de residentes puede servir para alterar o minimizar diferencias importantes en las comparaciones entre migrantes y no migrantes. 
la variación observada podría atribuirse simplemente a la variada composición por edades de los distintos grupos, en todo análisis más detenido será preciso considerar también la edad. El cuadro 39 presenta una comparación del estado civil de los migrantes recientes a las tres zonas principales y de los residentes en ellas, expresada en tasas normalizadas sobre la base de la composición de la población de Colombia en 1964. Aunque se elimine el efecto de la edad en el estado civil, las modalidades analizadas siguen siendo válidas, si bien en algunos casos son menos marcadas.

Cuadro 39. Colombia: comparación de la proporción de personas no casadas en la población de migrantes y residentes, por sexo, lugar de destino y tipo de migración: tasas normalizadas sobre la base de la distribución por edades de la población, 1964

\begin{tabular}{lcccccccc}
\hline & \multicolumn{2}{c}{ Bogotá } & & \multicolumn{2}{c}{ Otras zonas urbanas } & & \multicolumn{2}{c}{ Zonas rurales } \\
\cline { 2 - 3 } & $\begin{array}{c}\text { Varo- } \\
\text { nes }\end{array}$ & $\begin{array}{c}\text { Muje- } \\
\text { res }\end{array}$ & & $\begin{array}{c}\text { Varo- } \\
\text { nes }\end{array}$ & $\begin{array}{c}\text { Muje- } \\
\text { res }\end{array}$ & & $\begin{array}{c}\text { Varo- } \\
\text { nes }\end{array}$ & $\begin{array}{c}\text { Muje- } \\
\text { res }\end{array}$ \\
\hline Residentes & 54.5 & 60.0 & & 57.6 & 59.9 & & 58.1 & 53.8 \\
Inter-DAI & - & - & & 59.0 & 61.1 & & 59.4 & 49.2 \\
Inter-DAM & 64.3 & 65.0 & & 61.6 & 61.2 & & 63.4 & 48.5 \\
\hline
\end{tabular}

Fuente: omuece, Colombia, cuadros 1 y 20.

En Bogotá, el predominio observado anteriormente de migrantes no casados se confirma tanto en las mujeres como en los hombres. En otras zonas urbanas de Colombia las diferencias apuntan en la misma dirección, pero la mayor proporción de migrantes, especialmente mujeres, en la categoría de los no casados se reduce a un nivel insignificante. Como en las zonas rurales la estandarización no ha alterado mucho la distribución, los migrantes recientes del sexo masculino todavía se hallan en mayor proporción que los residentes en la categoría de los no casados, en tanto que las migrantes tienden a aparecer en menor proporción que las residentes en este grupo. La confirmación de la tendencia divergente que se observa en las mujeres que migran a zonas rurales concuerda con los datos sobre la elevada relación de masculinidad en los movimientos migratorios hacia esas zonas, y sugiere que las mujeres que participan en ellos lo hacen principalmente acompañando al marido. Por último, cabe destacar que la distancia recorrida en la migración no parece influir gran cosa en las diferencias por estado civil.

En síntesis, los datos de que se dispone actualmente parecen indicar que en los movimientos migratorios hacia la ciudad los migrantes de ambos sexos son sobre todo jóvenes sin ataduras familiares que se lanzan en busca de una vida nueva, y permiten deducir que mientras más grande es la ciudad de destino, más pronunciada es la tendencia. En 
los movimientos hacia zonas rurales, los migrantes varones se ciñen al mismo esquema, pero las mujeres probablemente migran con sus cónyuges. Es indudable que estas características dependen en gran medida de la relación de masculinidad y de la distribución por edades de cada corriente migratoria. Por lo tanto, la normalización tiende a atenuar algunas diferencias. No obstante, lo esencial sigue siendo que los migrantes están representados desproporcionadamente en la categoría de los no casados.

2) Características que determinan la adaptación económica de los migrantes

Desde el punto de vista económico, quizá el efecto más importante de la composición demográfica de las corrientes migratorias se hace sentir en la capacidad física de los migrantes para incorporarse en forma productiva a la fuerza laboral de las zonas receptoras. Dado que entre los migrantes predominan los jóvenes no casados, las zonas receptoras se ven en teoría favorecidas por la afluencia constante de personas que, al menos físicamente, son capaces de ingresar a la fuerza de trabajo en , proporción superior que la población nativa. A su vez, las zonas de origen se ven privadas de una parte considerable de su fuerza laboral joven.

Sin embargo, es cosa muy diferente que los migrantes también sean cualitativamente capaces de incorporarse a la fuerza de trabajo de las zonas receptoras en mayor proporción que la población nativa. Es muy posible que a las zonas receptoras lleguen migrantes en cantidad superior a las necesidades de mano de obra, o que no estén bien preparados para participar en forma provechosa en la economía de esas zonas.

a) Alfabetismo y educación. En lo que respecta a la capacidad de] migrante de incorporarse a la fuerza laboral de las zonas receptoras pueden sostenerse dos hipótesis aparentemente antagónicas. La primera de ellas es que los migrantes proceden fundamentalmente de los sectores más instruidos, más inteligentes o más capaces de la población; por lo tanto, los migrantes están mejor preparados o más capacitados para aprender, más atentos a nuevas oportunidades, y tienen movilidad para aprovecharlas.

La segunda hipótesis postula que las posibilidades de educación en las regiones donde la migración es severa son tan limitadas, que por lo general los migrantes tienen menos educación sistemática que los residentes en el lugar de destino $\mathrm{y}$, por lo tanto, están destinados a ingresar en los estratos más bajos de empleo e ingreso.

Como quiera que estas hipótesis caracterizan situaciones diferentes pero cronológicamente simultáneas, es probable que ambas tengan cierta validez. Pero en realidad, la situación es bastante más compleja que lo que ambas sugieren, $y$, en definitiva, son varias las influencias antagónicas, de estructuras y motivaciones, que determinan tanto la selectividad educacional de las corrientes migratorias como las diferencias en el nivel de instrucción entre migrantes y nativos en la zona de destino. 
Fundamental es en esto la estructura del sistema educativo de las zonas receptora y de origen. En general, dicho sistema es menos adecuado en las zonas rurales y ciudades más pequeñas, que en los centros urbanos más importantes, lo que induce a los jóvenes a migrar en busca de una mejor educación. Por otra parte, la educación en sí puede estimular la migración al acrecentar las aspiraciones y las necesidades insatisfechas de quienes habitan en comunidades rurales y poblados menores. Es posible, además, que las personas con un nivel más alto de instrucción encuentren difícil hallar empleo adecuado en los centros más pequeños y que, por lo tanto, estén más dispuestas a migrar.

En otro plano, se puede conjeturar que si los migrantes responden básicamente a factores de atracción del lugar de destino, lo lógico sería esperar una selección positiva. Las personas más instruidas tendrían más información sobre las oportunidades existentes y estarían en mejores condiciones de aprovecharlas. Sin embargo, cuando las decisiones de migrar se deben esencialmente a factores negativos existentes en la zona de origen, es posible que surjan dos tendencias antagónicas. Por una parte, los sectores más instruidos de la población percibirían mejor las precarias perspectivas que les esperan en su propia comunidad y serian los primeros en irse; por otra, podría sostenerse que en migraciones de repulsión, los sectores menos preparados de la población serían los menos capaces de mantenerse en la zona de origen y, por lo tanto, se verían obligados a abandonarla.

Es particularmente difícil aislar y verificar empíricamente esta variedad de factores contrapuestos y sin embargo "traslapados", y cuya influencia seguramente ha de variar mucho en el espacio y en el tiempo. No obstante, cualquiera que sea la naturaleza de los factores concretos que influyen en el perfil educativo de las corrientes migratorias, lo escrito sobre la materia parece indicar que en los países latinoamericanos se repiten en forma constante dos generalizaciones fundamentales. Primero, las migraciones del campo a la ciudad incluyen los elementos más capacitados de la población del lugar de origen. Segundo, los migrantes a los grandes centros urbanos generalmente poseen un nivel de instrucción inferior al de la población nativa de la ciudad de destino. ${ }^{27}$ En otras palabras, aunque la migración moviliza a los elementos más capacitados del lugar de origen, las diferencias de estructura entre el sistema educativo de la zona receptora y de la de origen hacen que el nivel de instrucción de los migrantes en el lugar de destino sea inferior, sobre todo en las ciudades grandes.

Los estudios realizados en Colombia tenderían a confirmar estas conclusiones. Por ejemplo, la condición social de los migrantes y de sus padres (medida por el nivel de instrucción y por el empleo) es significativamente superior a la de la población nativa de su zona de origen, pero bastante inferior a la de los naturales de Bogotá. ${ }^{28}$ En cambio, otros

27 Véase Browning, op. cit., y además, supra, las notas 9 a 12, 16 y 17.

28 Véase Alan Simmons y Ramiro Cardona, "La selectividad de la migración en una perspectiva histórica: el caso de Bogotá, 1929-1968", Conferencia Regional Latinoamericana de Población, México, 1970, pp. 7 a 11. 
estudios indican que la tasa de alfabetismo de los migrantes a algunas de las ciudades secundarias y a comunidades rurales es superior a la de la población nacida en esas zonas de destino. ${ }^{20}$

Como se hace aquí referencia a estadísticas relacionadas con tres amplias zonas de destino, no se pretende establecer la compleja etiología ni las características de las distintas corrientes migratorias. Se intentará más bien evaluar el esquema general que resulta de combinar esas diversas corrientes.

Los datos sobre alfabetismo del cuadro 40 ofrecen una visión general de la capacitación relativa de los diversos grupos de migrantes y residentes. Lo primero que llama la atención cuando se examina el porcentaje de alfabetos en cada grupo migrante y residente es que el nivel de los migrantes parece bastante aceptable en este sentido. Los migrantes a Bogotá, tanto varones como mujeres, incluyen una proporción más alta de analfabetos que los migrantes a otras zonas urbanas $\mathrm{y}$, a su vez, éstos predominan todavía más entre los migrantes a zonas rurales. Sin embargo, cuando se compara la tasa de alfabetismo de la población migrante y residente en cada una de estas zonas de destino, a menudo se comprueba que las diferencias son insignificantes, aunque todas apuntan en la dirección sugerida por las conclusiones anteriores, a saber: que las tasas de alfabetismo de los migrantes a Bogotá son ligeramente inferiores a las de los residentes, mientras sucede lo contrario en otras zonas urbanas, en especial en las zonas rurales. También vale la pena observar en el cuadro 40 que ninguna de estas diferencias

Cuadro 40. Colombia: alfabetismo de migrantes recientes y residentes, por sexo y lugar de destino: comparaciones expresadas en porcentajes y tasas normalizadas, 1964 a

\begin{tabular}{lcccccc}
\hline \multirow{2}{*}{$\begin{array}{c}\text { Clase de comparación } \\
\text { y sexo }\end{array}$} & \multicolumn{2}{c}{ Bogotá } & \multicolumn{2}{c}{ Otras zonas urbanas } & \multicolumn{2}{c}{ Zonas rurales } \\
\cline { 2 - 7 } & $\begin{array}{c}\text { Migran- } \\
\text { tes }\end{array}$ & $\begin{array}{c}\text { Residen- } \\
\text { tes }\end{array}$ & $\begin{array}{c}\text { Migran- } \\
\text { tes }\end{array}$ & $\begin{array}{c}\text { Residen- } \\
\text { tes }\end{array}$ & $\begin{array}{c}\text { Migran- } \\
\text { tes }\end{array}$ & $\begin{array}{c}\text { Residen- } \\
\text { tes }\end{array}$ \\
\hline $\begin{array}{l}\text { Porcentaje de alfabetos } \\
\text { Varones }\end{array}$ & 93.9 & 94.9 & 87.6 & 86.3 & 65.6 & 60.8 \\
$\quad \begin{array}{l}\text { Mujeres } \\
\text { Alfabetismo: }\end{array}$ & 85.0 & 88.0 & 82.9 & 82.7 & 60.0 & 56.5 \\
$\begin{array}{l}\text { tasa normalizada a } \\
\quad \text { Varones }\end{array}$ & & & & & & \\
$\quad$ Mujeres & 92.7 & 94.8 & 86.8 & 86.5 & 64.8 & 61.1 \\
\hline
\end{tabular}

Fuente: omuece, Colombia, cuadros 15 y 23.

a Tasas normalizadas basándose en la composición por edades de la población colombiana.

29 Miguel Urrutia M., Estudio económico social de los centros de la CAR, Corporación Autónoma Regional, Bogotá, 1963; véase también Marco C. Reyes, Rafael D. Prieto y William Hanneson, Estudio agro-económico de la hoya del Río Suárez, Universidad de Los Andes, Bogotá, 1965. 
entre grupos migrantes, o entre migrantes y residentes, puede atribuirse a diferencias en la composición por edades, puesto que al normalizar las tasas de alfabetismo por edad simplemente se confirma lo anterior.

Si se examina el nivel de instrucción, la composición educacional relativa de los grupos migrantes a Bogotá, a otras zonas urbanas y a zonas rurales que se ofrece en el cuadro 41 confirma la tendencia sugerida. Más concretamente, los migrantes a Bogotá son indudablemente más instruidos que los que se dirigen a otras zonas urbanas. Del mismo modo, estos últimos aventajan en forma clara y considerable a los migrantes a zonas rurales. Estas diferencias son similares en todas las cohortes por edad y sexo.

Cabría argumentar que parte de la variación puede deberse a las distintas posibilidades de acceso a los servicios educativos en cada una de las tres zonas examinadas. Así, por ejemplo, el grado de instrucción de los migrantes a Bogotá sería superior al de los que migran a otras zonas urbanas tan sólo porque en la capital es mucho mayor la matrícula escolar. Este hecho tal vez ejerza cierta influencia, pero de seguro será mínima, porque aquí se hace referencia a migrantes recientes, es decir, a personas que llevan menos de cinco años en su lugar de residencia actual. Por lo tanto, la educación que hayan recibido se les imparti6 principalmente antes de llegar al punto de destino. Naturalmente, esto es particularmente efectivo en todos los grupos mayores de 20 años, en que la instrucción es fundamentalmente una característica estática.

En síntesis, la primera conclusión sobre la selectividad por grado de instrucción de quienes participan en las diversas corrientes migratorias es clara: mientras más instrucción tenga el migrante más atraído se sentirá por los grandes centros urbanos industriales.

Cabe comparar ahora el grado de instrucción de los grupos de migrantes recientes y el de la población residente en cada zona de destino. Las tasas normalizadas según la edad que se presentan en el cuadro 42 indican que la respuesta varía de acuerdo con el destino y el sexo de los migrantes. En Bogotá, la proporción de migrantes con 10 años y más de escolaridad es igual que la de residentes, aparece menor en la categoría siguiente y mayor entre los que tienen menos de 4 años de escolaridad. Entre los migrantes a Bogotá, las mujeres se hallan en mayor desventaja que los varones, pues tienen proporciones menores que las mujeres residentes en las dos categorías más altas, y proporciones mayores en las dos más bajas.

En realidad, en las zonas urbanas el total de migrantes recientes es proporcionalmente mayor que el de residentes en la categoría más alta, y menor en la categoría más baja. Sin embargo, estas diferencias no son grandes y en cierta medida se compensan con la proporción mayor de residentes con 4 a 9 años de escolaridad. Las migrantes mujeres muestran asimismo leve ventaja sobre las residentes en el nivel educacional más alto, pero su posición general es considerablemente inferior, dada la mayor proporción de ellas que se halla en las dos categorías 
CuAdro 41. Colombia: comparación del nivel de instrucción de migrantes recientes y residentes, por edad sexo y lugar de destino, 1964

(Porcentajes)

\begin{tabular}{|c|c|c|c|c|c|c|c|c|c|c|}
\hline & \multicolumn{2}{|c|}{ Sin escolaridad } & \multicolumn{2}{|c|}{1 a 3 años } & \multicolumn{2}{|c|}{4 a 9 años } & \multicolumn{2}{|c|}{10 y más afios } & \multicolumn{2}{|c|}{ Total } \\
\hline & Migrantes & Residentes & Migrantes & Residentes & Migrantes & Residentes & Migrantes & Residentes & Migrantes & Residentes \\
\hline &. & & \multicolumn{4}{|c|}{ Capital } & & & & \\
\hline $\begin{array}{l}\text { Varones } \\
\begin{array}{l}10-19 \\
20-29 \\
30-39 \\
40 \text { y más }\end{array}\end{array}$ & $\begin{array}{l}4.6 \\
4.0 \\
6.7 \\
9.6\end{array}$ & $\begin{array}{l}4.8 \\
3.3 \\
5.2 \\
7.5\end{array}$ & $\begin{array}{l}42.7 \\
30.6 \\
27.9 \\
30.4\end{array}$ & $\begin{array}{l}36.7 \\
20.5 \\
27.6 \\
25.6\end{array}$ & $\begin{array}{l}51.8 \\
52.4 \\
44.8 \\
39.2\end{array}$ & $\begin{array}{l}56.9 \\
59.0 \\
50.2 \\
48.1\end{array}$ & $\begin{array}{r}1.0 \\
13.0 \\
20.6 \\
20.8\end{array}$ & $\begin{array}{r}1.6 \\
17.2 \\
16.9 \\
18.8\end{array}$ & $\begin{array}{l}100.0 \\
100.0 \\
100.0 \\
100.0\end{array}$ & $\begin{array}{l}100.0 \\
100.0 \\
100.0 \\
100.0\end{array}$ \\
\hline Total & 5.5 & 5.4 & 32.3 & 25.8 & 48.6 & 52.8 & 13.6 & 16.1 & 100.0 & 100.0 \\
\hline $\begin{array}{r}\text { Mujeres } \\
10-19 \\
20-29 \\
30-39 \\
40-49\end{array}$ & $\begin{array}{l}12.5 \\
14.4 \\
23.8 \\
30.1\end{array}$ & $\begin{array}{r}9.5 \\
9.8 \\
12.3 \\
24.2\end{array}$ & $\begin{array}{l}54.5 \\
37.0 \\
29.2 \\
30.1\end{array}$ & $\begin{array}{l}34.8 \\
30.6 \\
31.0 \\
29.0\end{array}$ & $\begin{array}{l}32.6 \\
41.3 \\
40.0 \\
30.1\end{array}$ & $\begin{array}{l}52.9 \\
50.5 \\
48.6 \\
38.9\end{array}$ & $\begin{array}{l}0.4 \\
7.3 \\
6.9 \\
9.6\end{array}$ & $\begin{array}{l}2.9 \\
9.1 \\
8.1 \\
7.8\end{array}$ & $\begin{array}{l}100.0 \\
100.0 \\
100.0 \\
100.0\end{array}$ & $\begin{array}{l}100.0 \\
100.0 \\
100.0 \\
100.0\end{array}$ \\
\hline Total & 15.6 & 13.8 & 43.7 & $\begin{array}{c}31.0 \\
\text { Otras zo }\end{array}$ & $\begin{array}{c}36.5 \\
\text { uas urbana }\end{array}$ & 47.6 & 4.2 & 7.6 & 100.0 & 100.0 \\
\hline $\begin{array}{r}\text { Varones } \\
10-19 \\
20-29 \\
30-39\end{array}$ & $\begin{array}{r}12.6 \\
9.1 \\
10.4\end{array}$ & $\begin{array}{r}14.8 \\
9.7 \\
12.6\end{array}$ & $\begin{array}{l}45.9 \\
35.9 \\
32.2\end{array}$ & $\begin{array}{l}41.7 \\
33.6 \\
34.5\end{array}$ & $\begin{array}{l}40.7 \\
46.9 \\
46.1\end{array}$ & $\begin{array}{l}42.8 \\
50.5 \\
46.2\end{array}$ & $\begin{array}{r}0.8 \\
8.1 \\
11.3\end{array}$ & $\begin{array}{l}0.6 \\
6.2 \\
6.6\end{array}$ & $\begin{array}{l}100.0 \\
100.0 \\
100.0\end{array}$ & $\begin{array}{l}100.0 \\
100.0 \\
100.0\end{array}$ \\
\hline
\end{tabular}


40 y más

16.6

18.6

33.4

Total

11.7

14.3

35.9

Mujeres

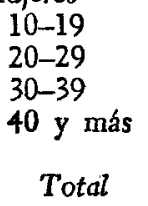

20.4

16.7

24.4

36.1

15.5

12.9

18.8

30.5

50.0

42.0

35.8

27.9

21.8

19.6

42.5

Varones

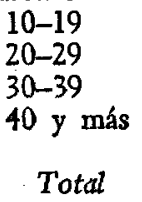

36.1

37.1

51.1

29.1

33.1

47.3

33.4

38.1

39.7

46.2

43.7

40.7

34.0

39.4

45.9

Mujeres

$\begin{array}{cccc}10-19 & 33.9 & 36.3 & 46.3 \\ 20-29 & 32.2 & 40.7 & 37.7 \\ 30-39 & 40.1 & 51.8 & 33.1 \\ 40 \text { y más } & 55.5 & 66.5 & 25.8 \\ \text { Total } & 38.9 & 51.3 & 37.1\end{array}$

FUENTE: OMUECE, cuadros 13 y 25. 


$\begin{array}{lllllll}35.0 & 41.6 & 40.8 & 8.4 & 5.6 & 100.0 & 100.0 \\ 35.3 & 44.5 & 44.9 & 7.8 & 5.5 & 100.0 & 100.0 \\ & & & & & & \\ 44.9 & 29.4 & 38.8 & 0.1 & 0.8 & 100.0 & 100.0 \\ 32.6 & 37.4 & 49.3 & 3.9 & 5.1 & 100.0 & 100.0 \\ 35.6 & 35.8 & 42.2 & 3.9 & 3.4 & 100.0 & 100.0 \\ 30.5 & 31.2 & 36.6 & 4.9 & 2.4 & 100.0 & 100.0 \\ 35.1 & 33.2 & 42.2 & 2.5 & 3.1 & 100.0 & 100.0\end{array}$

Zonas rurales

\begin{tabular}{lllllll}
49.7 & 12.7 & 13.2 & 0.1 & 0.0 & 100.0 & 100.0 \\
49.9 & 22.6 & 16.6 & 1.0 & 0.4 & 100.0 & 100.0 \\
46.4 & 21.2 & 15.0 & 1.6 & 0.4 & 100.0 & 100.0 \\
40.2 & 17.9 & 13.1 & 1.6 & 0.5 & 100.0 & 100.0 \\
45.9 & 19.1 & 14.3 & 1.1 & 0.4 & 100.0 & 100.0 \\
& & & & & & \\
44.6 & 19.7 & 19.0 & -5 & -1.0 & 100.0 & 100.0 \\
36.1 & 28.0 & 22.3 & 2.1 & 1.0 & 100.0 & 100.0 \\
31.3 & 23.2 & 16.4 & 3.5 & 0.4 & 100.0 & 100.0 \\
22.0 & 17.4 & 11.3 & 1.3 & 0.3 & 100.0 & 100.0 \\
31.8 & 22.4 & 16.5 & 1.6 & 0.4 & 100.0 & 100.0 \\
\hline
\end{tabular}


CuAdro 42. Colombia: comparación del nivel de instrucción de los migrantes recientes y residentes, por sexo y lugar de destino: tasas normalizadas de acuerdo con la composición por edades de la población, 1964

\begin{tabular}{|c|c|c|c|c|c|c|c|c|}
\hline \multirow{3}{*}{ Sexo y destino } & \multicolumn{8}{|c|}{ Nivel de instruccion } \\
\hline & \multicolumn{2}{|c|}{ Sin escolaridad } & \multicolumn{2}{|c|}{1 a 3 años } & \multicolumn{2}{|c|}{4 a9 años } & \multicolumn{2}{|c|}{100 más años } \\
\hline & Migrantes & Residentes & Migrantes & Residentes & Migrantes & Residentes & Migrantes & Residentes \\
\hline Varones & 6.1 & 5.3 & 34.4 & 28.7 & 47.4 & 53.9 & 12.1 & 12.1 \\
\hline Mujeres & 19.4 & 13.8 & 39.9 & 31.7 & 35.2 & 48.0 & 5.5 & 6.5 \\
\hline \multicolumn{9}{|c|}{ Otras zonas urbanas } \\
\hline Varones & 12.5 & 14.3 & 38.2 & 37.0 & 43.2 & 44.5 & 6.1 & 4.1 \\
\hline Mujeres & 24.3 & 19.3 & 40.1 & 36.8 & 32.8 & 41.2 & 2.9 & 2.6 \\
\hline \multicolumn{9}{|l|}{ Zonas rurales } \\
\hline Varones & 35.1 & 38.8 & 46.3 & 46.7 & 17.6 & 14.2 & 1.0 & 0.3 \\
\hline Mujeres & 40.1 & 47.7 & 36.8 & 34.6 & 21.6 & 17.3 & 1.4 & 0.4 \\
\hline
\end{tabular}

FuENTE: OMUECE, Colombia, cuadros 12 y 25. 
más bajas. Es interesante observar que la escolaridad de los migrantes recientes a las zonas rurales, que según se dijo antes son los que poseen menos instruccion, es bastante mayor que la de los residentes en las zonas de destino; la diferencia es significativa y se observa en ambos sexos.

En síntesis, la información disponible tendería a confirmar las ideas preliminares respecto a educación derivadas del examen de los datos sobre alfabetismo. Aunque los migrantes recientes a Bogotá son los que tienen más escolaridad, su nivel de instrucción es levemente inferior al de los residentes, entre los varones, y bastante más bajo entre las mujeres. En otras zonas urbanas los migrantes varones aventajan ligeramente a los residentes pero la situación se invierte en el caso de las mujeres. Sin embargo, el nivel de instrucción de los migrantes a zonas rurales es claramente superior al de la población residente, en ambos sexos.

Considerados en su conjunto, los datos relativos al alfabetismo y la educación parecen indicar que - cualquiera que sea la naturaleza de los factores que generan las diferencias educativas- los migrantes parecen buscar su propio nivel de formación. Las diferencias entre grupos de migrantes que se dirigen a las distintas zonas son mucho más significativas que aquellas entre migrantes y residentes en el lugar de destino. En realidad, mientras más grande es la ciudad, más alto es el nivel de instrucción de los migrantes que atrae. ${ }^{30} \mathrm{De}$ todos los grupos de migrantes, los que se dirigen a comunidades rurales tienen el promedio más bajo de escolaridad, y sin embargo son los únicos que pueden preciarse de aventajar apreciablemente a la población residente en materia de educación.

b) Participación de la fuerza laboral. El análisis de la composición demográfica del movimiento migratorio en Colombia llev6 a concluir que en los migrantes a las tres zonas de destino estudiadas predominan los jóvenes libres de ataduras familiares. En igualdad de condiciones, una estructura demográfica de esta naturaleza debería traducirse en una tasa de actividad económica más alta de los migrantes a esas tres zonas.

Conviene señalar al respecto que en un estudio muy completo del empleo realizado en Colombia se llegó a la conclusión de que:

"En todas las ciudades, con excepción de Bogotá, por lo menos la mitad de los desempleados son nacidos en ellas o en el departamento anejo y su proporción es por lo general ligeramente mayor entre los que buscan trabajo por primera vez. Acaso sea más sorprendente el hecho de que en todas las ciudades en que se realizb la encuesta, los inmigrantes tienen tasas de participación mucho más altas y tasas de desempleo considerablemente más bajas que las personas nacidas en esas ciudades.

so Según se recordará, la indole de las tabulaciones aquí empleadas obliga a comparar los migrantes recientes con todos los demás residentes. Como la última categoría inciuye no soblo a la población nacida en el lugar, sino a todos los migrantes anteriores, podría objetarse que la inclusion de los migrantes anteriores en la categoría "otros" dificulta la comparación entre los migrantes recientes y todos los demás en función de una característica estática como el nivel de instrucción. Sin embargo, esto no resta validez a las conclusiones aquí obtenidas, ya que tal raciocinio simplemente indicaría que las migraciones anteriores fueron igualmente selectivas. 
En Bogotá, por ejemplo, $23 \%$ de los desempleados son nacidos en la ciudad, $12 \%$ corresponde a personas nacidas en otra localidad del mismo departamento y $15 \%$ en otros departamentos. Aunque esta situación puede explicarse en gran parte por las diferencias de edad entre los dos grupos, es posible que las tasas inferiores de desempleo observadas entre los inmigrantes tengan relación importante con las características de la migración interna, por lo cual convendría estudiar el asunto con mayor detenimiento." 31

Considerado desde este punto de vista, es interesante comprobar en el cuadro 43 que la proporción de migrantes a las tres zonas consideradas que pertenecen a la categoría de personas económicamente activas tiende a ser mayor que la proporción de nacidos en las zonas de destino que se halla en esa misma categoría. ${ }^{32}$ Esta conclusión es válida para

Cuadro 43. Colombia: migrantes recientes y residentes económicamente activos, por edad, sexo y lugar de destino, 1964

(Porcentajes)

\begin{tabular}{|c|c|c|c|c|c|c|}
\hline \multirow[b]{2}{*}{ Edad y sexo } & \multicolumn{2}{|c|}{ Bogotá } & \multicolumn{2}{|c|}{ Otras zonas urbanas } & \multicolumn{2}{|c|}{ Zonas rurales } \\
\hline & $\begin{array}{c}\text { Migran } \\
\text { tes }\end{array}$ & $\begin{array}{c}\text { Residen- } \\
\text { tes }\end{array}$ & $\begin{array}{c}\text { Migran- } \\
\text { tes }\end{array}$ & $\begin{array}{c}\text { Residen- } \\
\text { tes }\end{array}$ & $\begin{array}{c}\text { Migran- } \\
\text { tes }\end{array}$ & $\begin{array}{c}\text { Residen- } \\
\text { tes }\end{array}$ \\
\hline \multicolumn{7}{|l|}{ Varones } \\
\hline $\begin{array}{l}10-19 \\
20-29 \\
30-39 \\
40 \text { y más }\end{array}$ & $\begin{array}{l}44.0 \\
85.8 \\
93.0 \\
81.7\end{array}$ & $\begin{array}{l}21.3 \\
88.1 \\
97.5 \\
86.7\end{array}$ & $\begin{array}{l}30.5 \\
88.1 \\
94.4 \\
85.1\end{array}$ & $\begin{array}{l}21.4 \\
88.9 \\
97.0 \\
85.2\end{array}$ & $\begin{array}{l}57.8 \\
97.3 \\
98.4 \\
93.2\end{array}$ & $\begin{array}{l}48.7 \\
97.3 \\
98.8 \\
92.1\end{array}$ \\
\hline Totd & 73.5 & 68.3 & 69.2 & 64.4 & 84.0 & 78.7 \\
\hline \multicolumn{7}{|l|}{ Mujeres } \\
\hline $\begin{array}{l}10-19 \\
20-29 \\
30-39 \\
40 \text { y más }\end{array}$ & $\begin{array}{l}46.9 \\
51.2 \\
37.6 \\
16.9\end{array}$ & $\begin{array}{l}14.8 \\
42.3 \\
33.8 \\
25.2\end{array}$ & $\begin{array}{l}26.2 \\
35.0 \\
29.0 \\
19.6\end{array}$ & $\begin{array}{l}11.3 \\
29.8 \\
22.6 \\
17.3\end{array}$ & $\begin{array}{l}11.4 \\
15.3 \\
13.5 \\
14.4\end{array}$ & $\begin{array}{r}5.9 \\
11.2 \\
11.9 \\
13.0\end{array}$ \\
\hline Total & 42.4 & 28.0 & 27.9 & 18.8 & 13.5 & 10.0 \\
\hline \multicolumn{7}{|c|}{$\begin{array}{c}\text { Tasas de actividad } \\
\text { normalizadas a }\end{array}$} \\
\hline $\begin{array}{l}\text { Varones } \\
\text { Mujeres }\end{array}$ & $\begin{array}{l}71.2 \\
38.5\end{array}$ & $\begin{array}{l}65.7 \\
27.0\end{array}$ & $\begin{array}{l}68.0 \\
27.0\end{array}$ & $\begin{array}{l}65.5 \\
19.0\end{array}$ & $\begin{array}{l}82.5 \\
13.4\end{array}$ & $\begin{array}{l}79.0 \\
10.0\end{array}$ \\
\hline
\end{tabular}

Fuevre: omuzce, Colombia, cuadros 5, 23 y 25.

- Tasas normalizadas de acuerdo con la composición por edades de la población de Colombia.

31 Naciones Unidas, Hacia el pleno empleo. Un programa para Colombia, Oficina Internacional del Trabajo, Ginebra, 1970, apéndice 1, p. 387.

32 En la forma en que se utiliza en el censo colombiano, la población económicamente activa se define como "aquella de 12 anfos y más [en las muestras de la omvece se cambia a 10 años y más] que dutrante el año censal ejerció una ocupación remune- 
hombres y mujeres; en ella no influye en absoluto la normalización sobre la base de la composición por edades. (Véase ahora el final del cuadro 43.) Sin embargo, cuando se examinan más detenidamente las variaciones por grupos de edades, queda de manifiesto que, en el caso de los varones, la ventaja de los migrantes recientes puede atribuirse sólo al número desproporcionadamente alto de jóvenes de 10 a 19 años que tienen actividad económica. Así, los migrantes recientes tendrían un porcentaje más alto de hombres económicamente activos simplemente porque una proporción muy inferior de sus jóvenes asiste a la escuela, lo que a la larga los colocaría en desventaja.

En las mujeres, la proporción más alta de migrantes recientes economicamente activas puede comprobarse en todos los grupos de edades de cada corriente migratoria, salvo las de 40 años y más en Bogotá. Desde luego, la tasa más alta de participación en ocupaciones remunerativas concuerda con la proporción más alta de no casados, que se señaló antes. Sin embargo, esa tasa más alta de participación también puede ser una espada de doble filo, porque quizá indica que las mujeres migrantes recientes suelen verse obligadas a buscar trabajo remunerado para complementar un magro ingreso familiar. A la inversa, en el resto de la población habría una proporción más alta de dueñas de casa que podrían darse el lujo de no emplearse.

De esta manera, aunque a primera vista los migrantes recientes a Bogotá, a otras zonas urbanas y a zonas rurales parecerían disfrutar de una tasa más alta de participación en la fuerza laboral económicamente activa, la descomposición de esta tasa más alta por grupos de edades y sexo podría sugerir una situación global desfavorable a los migrantes recientes. En realidad, los migrantes recientes tienen una tasa de actividad más alta precisamente en los sectores menos productivos de la población. Por otra parte, podría aducirse que, cualquiera que sea la estructura de sus poblaciones económicamente activas, los residentes tienen más personas a cargo que los migrantes recientes. En otras palabras: los residentes activos tienen que mantener a una proporcion mayor de personas inactivas que los migrantes.

Como es natural, para analizar más a fondo este problema habría que complementar los datos sobre tasas de participación con estadísticas sobre desempleo, subempleo y sobre la proporción de amas de casa y estudiantes que hay en cada uno de los grupos migrantes y no migrantes. En todo caso, es un dato significativo la mayor tasa de actividad de los migrantes. El examen de la adaptación ocupacional de los migrantes contribuirá a esclarecer el tema.

c) Adaptación ocupacional. Se demostró antes que los migrantes pre-

rada en la producción de bienes y servicios, y la que en condición de ayudantes familiares' trabajo sin remuneración en la empresa de su respectivo jefe de familia 0 pariente por lo menos durante un tercio del tiempo normal de trabajo. Dentro del año censal o período de referencia, el censo establece un límite de duración de actividad continua o discontinua, de nueve meses, para la denominación de 'ocupados' y "no ocupados"". (República de Colombia, Departamento Administrativo Nacional de Estadística, XII Censo Nacional de Población, 15 de julio de 1964, Resumen general.) 
dominan entre los jóvenes no casados en edad de trabajar y que éstos registran tasas más altas de participación en la fuerza de trabajo que los residentes. Estas circunstancias, consideradas aisladamente, parecerían indicar que los migrantes se adaptan en forma satisfactoria y que en general tienden a ser elementos positivos para las zonas receptoras porque, al menos físicamente, están en condiciones de incorporarse a la fuerza laboral en número superior a la población nacida en el lugar.

La anterior afirmación pierde fuerza al observar que, al menos en Bogotá, la tasa de alfabetismo y el nivel de instrucción de los migrantes son inferiores a los de los residentes. Además, la mayor participación relativa de los migrantes en la fuerza de trabajo se debe únicamente al número desproporcionado de ellos que se halla en las cohortes de edad y sexo menos productivas. Por lo tanto, sigue siendo discutible si la relación favorable entre los migrantes y el número de personas a su cargo significa ventajas reales.

En las páginas que siguen se presentará información sobre la adaptación efectiva de los migrantes. La penetración cualitativa de los migrantes en la estructura ocupacional de las zonas receptoras se analizará en varios niveles complementarios. En cierto sentido, los datos relativos a la categoría de la ocupación son los más decisivos para medir el ajuste y la contribución relativa de los migrantes a las zonas receptoras. Por desgracia, este indicador, en sus diversas dimensiones, también se basa en conceptos discutibles y ambiguos. Las definiciones de empleo, desempleo y subempleo son necesarias, pero varían enormemente y, por lo general, dejan mucho que desear, particularmente si se procura aplicarlas. Las clasificaciones de la ocupación, la categoría de la ocupación y la rama de actividad económica están constituidas por categorías heterogéneas de status; de manera que para poder utilizarlas hay que formular algunas hipótesis. ${ }^{33}$ Además, en la estructura económica de cada una de las zonas receptoras hay diferencias fundamentales que dificultan las comparaciones de la adaptación ocupacional en estas zonas.

No obstante estas dificultades, el problema de la adaptación ocupacional no se puede pasar por alto, puesto que es fundamental para la dinámica de las migraciones y para el proceso de asimilación de los migrantes. En el presente caso, hubo que formular algunos supuestos básicos sobre el ordenamiento por status en los diversos criterios utilizados para clasificar la ocupación. Sin embargo, hay que destacar que la formulación de estos juicios no significa en modo alguno desconocer la heterogeneidad y las duplicaciones parciales de las categorías; sólo indica que en el plano global, un determinado grupo aventaja a otro no obstante las discrepancias individuales dentro de las clases y entre éstas.

33 Para un examen y una crítica de este problema y de los esquemas de clasificación existentes, véase Joseph Hodara, En torno al mercado del empleo en América Latina, CEPAI (primer borrador). Respecto a referencias más concretas a la medición del desempleo y subempleo en Colombia: R.L. Slighton, Urban employment in Colombia. Measurement, Definitions and Policy Problems, Rand, 1968; orr, op. cit., capitulo I ("The employment problem"); Centro de Estudios sobre Desarrollo Económico (CEDE), Empleo y desempleo en Colombia (particularmente el capítulo 2), Ediciones Universidad de Los Andes, Bogotá, 1968. 
Cuadro 44. Colombia: rama de actividad económica de los migrantes recientes y residentes, por sexo y lugar de destino, 1964

\begin{tabular}{|c|c|c|c|c|c|c|c|c|c|c|c|c|}
\hline \multirow{3}{*}{ Ramas de actividad económica } & \multicolumn{6}{|c|}{ Varones } & \multicolumn{6}{|c|}{ Mujeres } \\
\hline & \multicolumn{2}{|c|}{ Bogotá } & \multicolumn{2}{|c|}{ Otras zonas urbanas } & \multicolumn{2}{|c|}{ Zonas rurales } & \multicolumn{2}{|c|}{ Bogotá } & \multicolumn{2}{|c|}{ Otras zonas urbanas } & \multicolumn{2}{|c|}{ Zonas rurales } \\
\hline & $\begin{array}{l}\text { Migran- } \\
\text { tes }\end{array}$ & $\begin{array}{l}\text { Residen- } \\
\text { tes }\end{array}$ & $\begin{array}{l}\text { Migran- } \\
\text { tes }\end{array}$ & $\begin{array}{l}\text { Residen- } \\
\text { tes }\end{array}$ & $\begin{array}{l}\text { Migran- } \\
\text { tes }\end{array}$ & $\begin{array}{c}\text { Residen- } \\
\text { tes }\end{array}$ & $\begin{array}{l}\text { Migran- } \\
\text { tes }\end{array}$ & $\begin{array}{l}\text { Residen- } \\
\text { tes }\end{array}$ & $\begin{array}{c}\text { Migran- } \\
\text { tes }\end{array}$ & $\begin{array}{l}\text { Residen- } \\
\text { tes }\end{array}$ & $\begin{array}{l}\text { Migran- } \\
\text { tes }\end{array}$ & $\begin{array}{c}\text { Residen } \\
\text { tes }\end{array}$ \\
\hline Agricultura, ganadería, caza y pesca & 4.1 & 2.2 & 16.2 & 20.8 & 79.7 & 91.0 & 0.3 & 0.3 & 1.3 & 2.0 & 21.8 & 42.9 \\
\hline Minería & 0.5 & 0.6 & 0.9 & 1.0 & 1.2 & 1.0 & 0.2 & 0.2 & 0.1 & 0.3 & 0.5 & 4.6 \\
\hline Manufactura & 24.3 & 29.3 & 19.0 & 23.6 & 4.3 & 2.6 & 9.6 & 19.6 & 10.8 & 23.3 & 6.2 & 18.5 \\
\hline Construccion & 11.1 & 12.6 & 7.8 & 9.6 & 2.8 & 1.2 & 0.2 & 0.4 & 0.2 & 0.4 & 0.4 & 0.2 \\
\hline $\begin{array}{l}\text { Electricidad, gas, agua, y servicios } \\
\text { sanitarios }\end{array}$ & 0.4 & 0.8 & 0.5 & 0.6 & 0.1 & 0.1 & 0.1 & 0.2 & 0.1 & 0.1 & 0.1 & 0.0 \\
\hline Comercio & 16.9 & 16.6 & 15.2 & 16.2 & 2.3 & 1.3 & 7.3 & 15.0 & 7.2 & 14.8 & 4.0 & 4.1 \\
\hline $\begin{array}{l}\text { Transporte, almacenaje y comunica- } \\
\text { ciones }\end{array}$ & 6.9 & 9.1 & 7.4 & 8.6 & 1.6 & 0.7 & 0.9 & 2.1 & 0.8 & 1.7 & 1.0 & 0.2 \\
\hline Senvicios personales & 4.4 & 3.9 & 4.9 & 3.9 & 0.9 & 0.5 & 64.2 & 35.3 & 59.0 & 36.4 & 45.9 & 21.8 \\
\hline Otros servicios & 22.2 & 16.4 & 21.3 & 9.5 & 6.0 & 1.2 & 13.1 & 19.6 & 17.6 & 15.9 & 19.4 & 6.0 \\
\hline Otros & 9.1 & 8.6 & 6.6 & 6.1 & 0.9 & 0.6 & 4.1 & 7.2 & 2.9 & 5.0 & 0.8 & 1.6 \\
\hline Total & 100.0 & 100.0 & 100.0 & 100.0 & 100.0 & 100.0 & 100.0 & 100.0 & 100.0 & 100.0 & 100.0 & 100.0 \\
\hline
\end{tabular}

Fuente: omuece, cuadros 6 y 25 . 
1) Rama de actividad económica. Después de establecer que el nivel de participación de los migrantes es generalmente superior al de los residentes, pero que esta ventaja puede atribuirse en gran medida a la diferencia en la composición por edad y sexo de los dos grupos, la siguiente pregunta se referirá a la incorporación de los migrantes en las diferentes ramas de actividad económica. ${ }^{34}$ De acuerdo con las conclusiones anteriores sobre la preparación de migrantes y residentes por sexo, los datos relativos a la rama de actividad económica que aparecen en el cuadro 44 deberán examinarse por separado para varones y mujeres, a fin de que sean comprensibles.

En lo que respecta a los varones, las principales diferencias consisten en que la proporción de los migrantes varones a Bogotá y otras zonas urbanas que trabajan en los servicios (personales y de otra índole) y en actividades del sector primario es mayor que la proporción de los residentes varones de esas ciudades y pueblos que se dedican a labores similares. A la inversa, los migrantes varones tienen una proporción correspondiente menor de sus integrantes en las actividades fabriles, de la construcción y del transporte. El porcentaje que se dedica al comercio es de igual magnitud entre migrantes y residentes. En síntesis, parecería que la observación más importante que sugiere el cuadro 44 es que los recién llegados a Bogotá y otras ciudades y pueblos de Colombia encuentran empleo más fácilmente en los servicios que en los sectores más modernos de la economía.

Las migrantes recientes a Bogotá y otras ciudades ingresan en proporción aún mayor que los hombres a las actividades de servicios. Más de 3 cuartos de las migrantes económicamente activas en Bogotá y otras zonas urbanas trabajan en ese sector, especialmente en los servicios personales, lo que confirma de manera categórica la enorme atracción de la ciudad para las jóvenes campesinas no calificadas, que buscan empleo en el servicio doméstico. En cambio, de la población femenina residente en esas mismas zonas sólo $35 \%$ trabaja en servicios personales, y es mucho mayor su participación en la manufactura y el comercio.

Naturalmente, las actividades agrícolas ocupan la mayor parte de la población migrante y no migrante de Colombia, pero es interesante observar que, en proporción, entre los varones los migrantes recientes están menos representados en el sector agrícola que los residentes. La diferencia es absorbida en forma gradual por los demás sectores (minería, construcción, comercio y transportes), pero muy especialmente por los servicios. Entre las mujeres activas, las migrantes recientes son menos propensas que el resto de la población a dedicarse a las actividades agrícolas, pero su participación también es inferior en la minería y en la manufactura. Por lo tanto, predomina casi sin contrapeso el sector de los servicios (particularmente personales).

Ir) Ocupación. Para evaluar la adaptación económica de los migrantes reviste mayor importancia el tipo y nivel de la ocupación lograda

34 'La 'rama de actividad económica' se refiere a la clase de actividad del establecimiento o Ingar donde trabaj6 la persona durante el año censal." (República de Colombia, XII Censo, op. cit.) 
que la rama de actividad económica a que se dedican. Por desgracia, los datos relativos a este aspecto fundamental no son- fáciles de sintetizar en un indicador satisfactorio. Por ello se intentará determinar los niveles ocupacionales relativos de migrantes y residentes analizándolos desde tres puntos de vista.

Dicotomía entre actividad manual y no manual. Un primer examen de la preparación de migrantes y residentes puede realizarse según la proporción que se dedica a las actividades manuales y a las no manuales. Aquí la categoría no manual incluye profesionales, técnicos, gerentes, administradores y vendedores, aparte otras actividades conexas. Por lo tanto, el status que se atribuye a estas actividades es sin duda más alto generalmente que el de la categoría manual, en la que quedan todos los demás miembros de la fuerza laboral - salvo las fuerzas armadas y las que se dedican a "ocupaciones no especificadas" - que no se incluyeron en el análisis. (Véase el cuadro 45.)

Cuadro 45. Colombia: porcentaje a de migrantes recientes y de residentes económicamente activos que trabajan en actividades manuales y no manuales, por sexo y lugar de destino, 1964

\begin{tabular}{|c|c|c|c|c|c|c|}
\hline \multirow{2}{*}{ Sexo y ocupación } & \multicolumn{2}{|c|}{ Bogotá } & \multicolumn{2}{|c|}{ Otras zonas urbanas } & \multicolumn{2}{|c|}{ Zonas rurales } \\
\hline & Migrantes & Residentes & Migrantes & Residentes & Migrantes & Residentes \\
\hline \multicolumn{7}{|l|}{ Varones } \\
\hline Manual & 50.1 & 49.0 & 54.9 & 63.4 & 90.4 & 96.6 \\
\hline No manual & 37.5 & 44.6 & 33.1 & 31.9 & 6.1 & 2.9 \\
\hline \multicolumn{7}{|l|}{ Mujeres } \\
\hline Manual & 76.7 & 55.0 & 75.1 & 63.1 & 77.2 & 88.8 \\
\hline No manual & 20.5 & 40.4 & 22.2 & 33.3 & 22.1 & 9.9 \\
\hline
\end{tabular}

Fuente: omuece, Colombia, cuadros 13 y 27.

a Los porcentajes citados en este cuadro no suman 100 porque se han omitido algunas categorías (a saber, fuerzas armadas y ocupaciones no especificadas).

De partida, y en lo que respecta a los varones de Bogotá, se observa que, comparados con los residentes, los migrantes recientes tienen una proporción ligeramente más alta de su población económicamente activa dedicada a actividades manuales, y una proporción menor en las ocupaciones de más prestigio. La diferencia se multiplica en las mujeres, puesto que el porcentaje de residentes que se dedica a las actividades no manuales dobla el porcentaje correspondiente de migrantes, $y$, por consiguiente, es mucho menor en las actividades manuales.

Por el contrario, en otras zonas urbanas de Colombia la proporción de migrantes varones que se dedica a actividades no manuales es ligeramente superior a la de los residentes, y bastante menor la que realiza trabajos manuales. (Cabe hacer notar que los migrantes tienen una proporción más alta de la población económicamente activa en las fuer- 
zas armadas y en ocupaciones no especificadas.) Sin embargo, la situación de las migrantes es decididamente inferior a la de las residentes, ya que - como sucede con las mujeres que han migrado a Bogotá - una proporción bastante reducida se dedica a actividades no manuales. Por último, en lo que respecta a las zonas rurales, una proporción abrumadora tanto de migrantes como de residentes se concentra en las actividades primarias (aquí clasificadas como manuales), por ello se precisan mayores pormenores antes de extraer conclusiones respecto al status relativo de ambos grupos dentro del sector primario. Sin embargo, es interesante observar que los migrantes - particularmente las mujerespredominan en términos relativos en las actividades no manuales.

En síntesis, cuando se compara la situación ocupacional de los migrantes varones a zonas rurales y otras zonas urbanas con la de la población residente en los respectivos lugares de destino, la de los primeros parecería ser algo más favorable que la de los migrantes a Bogotá. Sin embargo, si se compara la estructura ocupacional de los migrantes a cada uno de estos lugares de destino, queda de manifiesto que los migrantes varones a Bogotá disfrutan de una situación más favorable, a juzgar por la mayor proporción de ellos que se dedican a actividades no manuales. En lo que toca a las mujeres migrantes, la característica más notable es la regularidad de su estructura ocupacional, cualquiera que sea el lugar de destino; aproximadamente un quinto de cada grupo ingresa a las ocupaciones no manuales, mientras que la mayoría se dedica a ocupaciones manuales, principalmente en actividades de servicios.

Categoría de la ocupación. La evaluación de la categoría de la ocupación relativa basada en la clasificación del trabajo en manual y no manual deja mucho que desear en lo que toca a elaboración y detalle. En tal dicotomía es fácil señalar casos muy heterogéneos dentro de cada clase, e incluso demostrar que algunas "actividades manuales" tienen indudablemente más categoría que las "no manuales".

Uno de los métodos que por lo común se utiliza para concretar y profundizar el análisis de las ocupaciones consiste en clasificar la población económicamente activa en empleadores, trabajadores por cuenta propia, asalariados y trabajadores familiares no remunerados. Sin embargo, esta clasificación se presta a confusiones, sobre todo por las incongruencias que surgen entre los "trabajadores por cuenta propia" y los "asalariados". 35

Al intentar obtener por lo menos algunos pormenores, se reagruparon ciertas categorías de las tabulaciones de la OMUECE sobre la ocupación por categorías de ocupación. (Véase el cuadro 46.) Las dos primeras categorías allí indicadas (profesionales y técnicos y empleadores) no ne-

35 Para concretar: se considera generalmente que los "trabajadores por cuenta propia" tienen menos categoría que los asalariados, porque se piensa que la modemización de la economía trae consigo el reemplazo de las pequeñas empresas individuales por el empleo remunerado. No obstante, se incluye en ese grupo a los profesionales que trabajan por cuenta propia junto con los vendedores ambulantes, los agricultores de subsistencia y otros. Además, la categoría "asalariados" puede incluir a sirvientes domésticos cuyo empleador - contador o médico- pertenece a la misma categoría. 
cesitan más explicación. El término "empleados" (white collar employees) incluye tanto a gerentes y administradores como a oficinistas y vendedores (salvo los ambulantes). La expresión obreros (blue collar workers (incluye a todos los asalariados fabriles, industriales, artesanales, del transporte y de la minería. La categoría "trabajadores por cuenta propia no profesionales" incluye sobre todo empresas individuales de poca monta (comercio ambulante, compraventas varias, agricultura de subsistencia y artesanado). Los "servicios" abarcan tanto los domésticos como otros, pero el número de los primeros es inmensamente superior. Por último, "otros trabajadores manuales y trabajadores familiares no remunerados" comprende los trabajadores de la construcción, estibadores, porteros, empleados de lavanderías, etc., además de los trabajadores agrícolas y de todos los trabajadores familiares no remunerados, cualquiera que sea su ocupación.

Cuadro 46. Colombia: categoría de la ocupación de los migrantes y de los residentes económicamente activos, por sexo y lugar de destino, 1964

(Porcentajes)

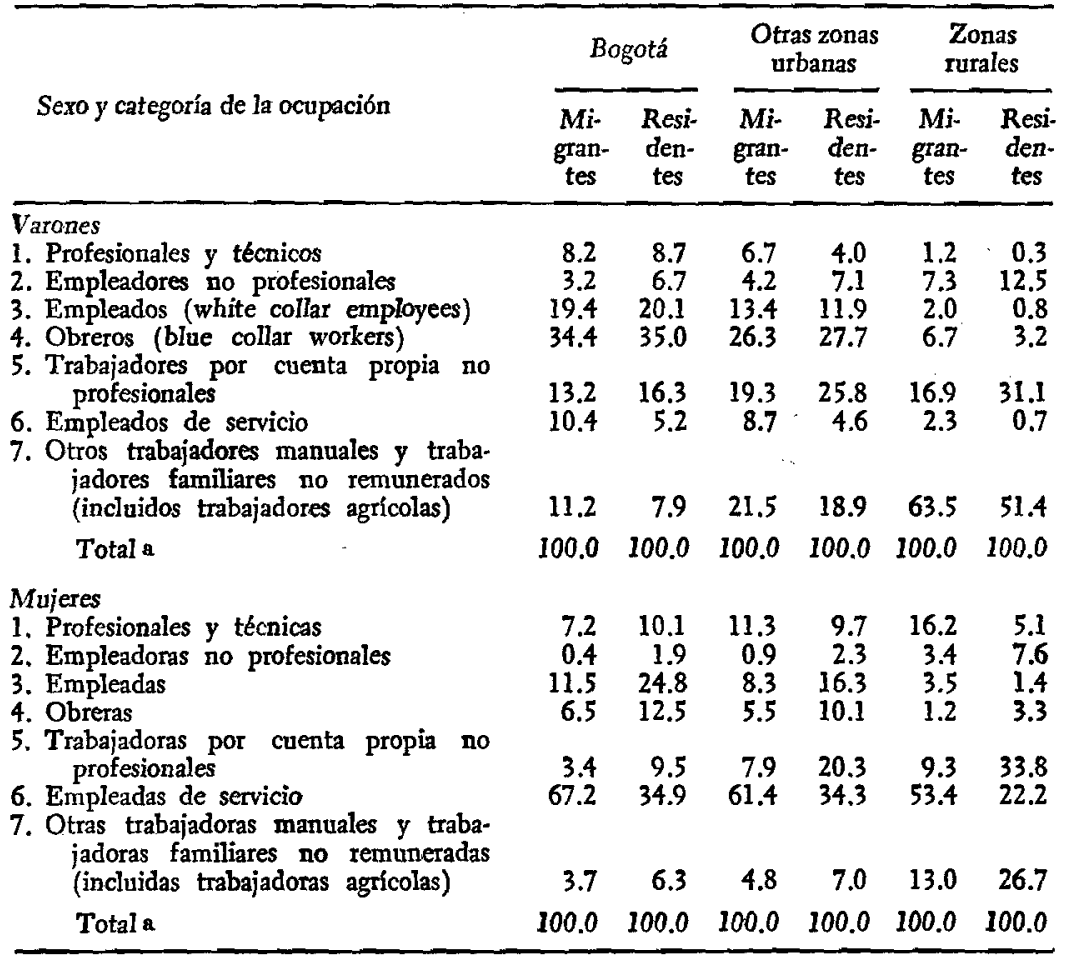

Furente: omuece, Colombia, cuadros 8 y 27.

a El cuadro no incluye el personal de las fuerzas armadas. 
Tampoco en este caso se pretende afirmar que cada una de estas categorías sea homogénea, ni que alguna categoría o grupo de categorías pueda definirse satisfactoriamente como un estrato o clase. Lo único que aquí se supone es que las personas incluidas en cierta categoría tienen en general un status superior o inferior a los comprendidos en otra. En términos más concretos: lo que se sugiere es que las categorías de profesionales y técnicos y de empleadores contienen en promedio las posiciones de status más elevado (sin que se postule relación ordinal alguna entre ellas), seguidas de los empleados y luego de los obreros. El status relativo de las tres últimas categorías es quizá menos definido, pero su nivel global es ciertamente inferior al de las cuatro primeras. El interés principal al describir estos tres subgrupos radica en su utilidad para el estudio de las modalidades de adaptación de los migrantes a posiciones de menos categoría, y no en la formulación de posiciones diferenciadas desde un punto de vista jerárquico.

Puestos en guardia por estas observaciones, se puede comparar ahora la categoría de la ocupación de residentes y migrantes. En la población masculina de Bogotá, los residentes llevan ligera ventaja relativa a los migrantes en cada una de las cuatro categorías superiores. Sin embargo, en términos estadísticos, la diferencia sólo puede apreciarse en una de ellas: la de los empleadores no profesionales. En los tres grupos de menos status es también mayor la proporción de residentes que trabaja por cuenta propia, particularmente en tareas menudas y como buhoneros; por su parte, los migrantes están representados en mayor proporción en los servicios y "otras ocupaciones manuales". Los migrantes varones a Bogotá tienden en general a ubicarse en niveles más bien inferiores y tienen menos propensión que los residentes a vivir de empresas propias, sea como empleadores o como pequeños empresarios. La renuencia o incapacidad del migrante reciente para instalar su propia empresa se comprende fácilmente si se considera su relativo desconocimiento de oportunidades y mercados, incluso en los niveles comerciales más bajos.

La categoría de la ocupación de los migrantes varones en otras zonas urbanas, en relación con la de los residentes, tiende a ser ligeramente más alta que en Bogotá. En los dẹmás pueblos y ciudades de Colombia los migrantes tienen también menos inclinación que los residentes a ser empleadores, pero llevan una ventaja relativa apreciable entre los profesionales y técnicos y algo menor entre los empleados. En el grupo de los obreros; los residentes acusan una ligera diferencia en su favor, y también tienden más a establecerse por cuenta propia en empresas de poca categoría. El número de migrantes que se desempeña en otros trabajos manuales y en los servicios es desproporcionadamente elevado, como en Bogotá.

Los migrantes varones a zonas rurales de Colombia tienen menos probabilidades de ser duefios de la tierra, sea como empleadores o como agricultores de subsistencia. Tanto la mayor parte de los migrantes como de los residentes trabaja para empresas agrícolas, ganaderas, pesqueras y de caza, pero, debido a su inferioridad numérica en la categoría 
de propietarios de tierras, casi 2 tercios de la fueza laboral fomada por los migrantes se hallan en el sector primario; en cambio, sólo la mitad de los residentes activos forman parte de ese sector. En términos relativos, los migrantes aventajan asimismo a los residentes entre los profesionales y técnicos, empleados y obreros y en el sector de los servicios.

En síntesis - si se examinan las tres corrientes de migrantes varones- puede afirmarse que aunque la proporción de migrantes a Bogotá que se dedica a actividades de mayor status es superior a la que se observa en otros migrantes, en lo que toca a categoría de ocupación su situación es ligeramente inferior a la de los varones residentes en Bogotá. Por su parte, los varones que han migrado a otras zonas urbanas aventajan en medida similar a la población residente. Entre los varones que migran a zonas rurales la proporción de propietarios de tierras - sobre todo de minifundistas- es mucho más reducida, y la de asalariados agrícolas mucho mayor; además, muestran leve ventaja en todas las categorías de status más alto, salvo la de los empleadores. En general, la distribución relativa de migrantes y residentes por sectores es bastante uniforme en los diversos lugares de destino: los migrantes se encuentran más representados en los servicios y "otras ocupaciones manuales", en tanto que los residentes tienen mayor propensión a trabajar por cuenta propia. Las demás diferencias son menos importantes que esta distribución de las actividades de menos categoría.

La proporción siempre más alta de migrantes asalariados, unida al predominio de los residentes entre los empresarios (diferencia que se hace más notoria en los niveles más bajos), parecería indicar que los migrantes son capaces de incorporarse a la fuerza laboral productiva. En un intento de explicar la mayor tasa de actividad de los migrantes basándose en ideas preconcebidas sobre status ocupacional supuestamente inferior, se ha afirmado que "los naturales de Bogotá prefieren ocuparse como asalariados mientras que los inmigrantes se inclinan más a trabajar por cuenta propia. Obviamente, esta diferencia influye en las tasas de actividad porque, en sentido estricto, los primeros estarán más expuestos al desempleo y, además, en el primer caso, el período de desempleo será mayor".3e

Sin embargo, en la práctica, las tasas de actividad de los migrantes son más altas no obstante estar más representados en puestos asalariados supuestamente más difíciles de obtener. Por lo tanto, no parece haber confirmación empírica de que los migrantes estén imposibilitados de lograr empleos productivos. El que tiendan a no a acrecentar desmedidamente la oferta laboral, y a reducir los salarios, es otro problema que no puede resolverse fácilmente con los datos de que se dispone en la actualidad.

En la población femenina, la categoría de la ocupación de las migrantes recientes tanto a Bogotá como a otras zonas urbanas es claramente inferior a la de las residentes. Las migrantes a las zonas urbanas

36 Véase Carlos García Navia, "Educación y desempleo en Bogotá, 1969", trabajo presentado al Seminario sobre Marginalidad en América Latina, CEPAL, Santiago, noviembre de 1970 . 
de Colombia incluyen una proporción inferior de profesionales y técnicas (salvo en "otras zonas urbanas" donde acusan una leve ventaja), de empleadoras, de empleadas y de obreras que las residentes. Con la sola excepción anotada, las migrantes tienen menor participación en todas las categorías salvo en los servicios, donde duplican casi la proporción de las residentes. En las zonas rurales, las migrantes tienen de nuevo proporciones marcadamente superiores a las de las residentes en los servicios; más de la mitad de las migrantes económicamente activas y sólo un quinto de las residentes se desempeñan en tareas de esta índole. Por otra parte, $16 \%$ de las mujeres que migran a las zonas rurales trabajan en labores profesionales y técnicas (principalmente como maestras y enfermeras), frente a sólo $5 \%$ de las residentes, y también se hallan en desventaja entre las empleadas. Una vez más se nota la ausencia de migrantes en las categorías empleadoras y trabajadoras por cuenta propia y su muy inferior proporción en las labores agrícolas y en otros trabajos manuales.

De esta manera, en cada uno de los grupos de mujeres migrantes la mayoría de las económicamente activas trabaja en servicios. Además, como entre los varones, la proporción de mujeres migrantes que trabaja en empresas propias importantes o pequeñas es considerablemente inferior a la de residentes. Sin embargo, contrariamente a lo que sucede con los migrantes varones -quienes en algunos casos disfrutan de una distribución ocupacional más ventajosa que la de los residentes-, las mujeres migrantes se encuentran regularmente con mayor frecuencia que las residentes en las ocupaciones de menor categoría, con la sola excepción de aquellas que se trasladan a zonas rurales para realizar tareas no manuales.

III) Proporción de migrantes que se dedica a actividades económicamente marginales. Ante los movimientos de población en gran escala, la urbanización acelerada y la disociación de los procesos de industrialización y urbanización que suelen denunciarse en América Latina, cabe tal vez preguntarse en qué medida los migrantes contribuyen a engrosar los sectores económicamente marginales de la población. En realidad, dada la particular composición y función del sector terciario que caracteriza la estructura económica latinoamericana, la elevada proporción de migrantes que trabaja en los servicios -especialmente los personalesvendría a confirmar la idea de que los migrantes se hallan en categorías inferiores de ocupación. Además, suele sostenerse que la migración excede las oportunidades de empleos y, por ende, que los migrantes - carentes en su mayoría de preparación adecuada- se ven empujados hacia actividades económicamente marginales. Sin embargo, esta hipótesis sólo se ha podido poner a prueba directamente en ciertas localidades, y uno de los méritos de las tabulaciones de la omuece es que permiten explorarla en forma aproximada en un plano más general.

A los fines de este trabajo, la mano de obra marginal puede definirse como aquella que vive en el nivel de ingreso más bajo -cercano al de subsistencia - sea por la naturaleza improductiva y prescindible de sus 
ocupaciones, o porque el trabajo es irregular o imposible de obtener. La mano de obra marginal más las personas a su cargo constituyen la población marginal.

Con todo, la aplicación práctica de esta definición es variable, y en cierto modo arbitraria. En las tabulaciones de la omuEce aquí utilizadas las actividades marginales se agruparon en tres categorías principales: trabajadores por cuenta propia que incluyen minifundistas, jornaleros y vendedores ambulantes, personas dedicadas a los servicios y artesanos no calificados; trabajadores familiares no remunerados en la agricultura, el comercio ambulante y el trabajo manual, y, por último, servidores domésticos. Dentro de las limitaciones impuestas por los datos censales esta clasificación da una visión bastante aproximada del subempleo y de la marginalidad. ${ }^{37}$

Utilizando estas delimitaciones, puede compararse el porcentaje de migrantes recientes activos de 10 años y más, que trabajan en actividades marginales, con el que corresponde a la población residente. (Véase el cuadro 47.) Resulta evidente que la proporción de migrantes varones

Cuadro 47. Colombia: comparación del porcentaje de migrantes recientes $y$ de residentes de 10 años y más que se dedican a actividades marginales, por sexo y lugar de destino, 1964

\begin{tabular}{|c|c|c|c|c|c|c|}
\hline \multirow{3}{*}{ Sexo } & \multicolumn{6}{|c|}{ Lugar de destino } \\
\hline & \multicolumn{2}{|c|}{ Capital } & \multicolumn{2}{|c|}{ Otras zonas urbanas } & \multicolumn{2}{|c|}{ Zonas rurales } \\
\hline & $\begin{array}{c}\text { Migran- } \\
\text { tes }\end{array}$ & $\begin{array}{c}\text { Residen } \\
\text { tes }\end{array}$ & $\begin{array}{l}\text { - Migran- } \\
\text { tes }\end{array}$ & $\begin{array}{l}\text { Residen- } \\
\text { tes }\end{array}$ & $\begin{array}{l}\text { Migran- } \\
\text { tes }\end{array}$ & $\begin{array}{l}\text { Residen } \\
\text { tes }\end{array}$ \\
\hline \multirow{4}{*}{$\begin{array}{l}\text { Varones } \\
\text { Trabajadores por cuenta propia } \\
\text { Trabajadores familiares no re- } \\
\text { munerados } \\
\text { Servicio doméstico }\end{array}$} & & & & & & \\
\hline & 6.1 & 7.7 & 9.3 & 12.9 & 13.0 & 23.8 \\
\hline & 0.2 & 0.0 & 0.7 & 1.3 & 6.4 & 12.6 \\
\hline & 1.0 & 0.3 & 0.9 & 0.5 & 0.5 & 0.3 \\
\hline Total & 7.3 & 8.0 & 10.9 & 14.7 & 19.9 & 36.7 \\
\hline \multirow{4}{*}{$\begin{array}{l}\text { Mujeres } \\
\text { Trabajadoras por cuenta propia } \\
\text { Trabajadoras familiares no re- } \\
\text { muneradas } \\
\text { Servicio doméstico }\end{array}$} & & & & & & \\
\hline & 1.3 & 2.3 & 1.9 & 3.1 & 0.1 & 2.9 \\
\hline & 0.1 & 0.1 & 0.1 & 0.2 & 0.0 & 1.1 \\
\hline & 26.0 & 8.0 & 14.9 & 5.5 & 0.7 & 2.1 \\
\hline Total & 27.4 & 10.4 & 16.9 & 8.8 & 0.8 & 6.1 \\
\hline
\end{tabular}

FueNte: omUece, cuadros 8 y 26.

37 Carmen Arretx propone un esquema distinto en La información y los estudios demográficos en América Latina (ST/ECLA/Conf.41/L.9), documento presentado al Seminario sobre utilización de estudios y datos demográficos en la planificación (agosto de 1971). Si se verifican simultáneamente la edad, la educación, la acupación y la categoría de la ocupación, se puede llegar a una definición operativa más adecuada del subempleo. Lamentablemente, en el presente caso no se dispuso de tabulaciones de esa naturaleza. 
a Bogotá, a otras zonas urbanas y a zonas rurales que se dedica a actividades marginales es inferior a la de residentes. La diferencia es mínima en el caso de Bogotá, mayor en otras zonas urbanas y se acentúa aún más en las zonas rurales. La diferencia se debe en cada caso a la proporción mayor de naturales del lugar que trabajan por cuenta propia en actividades marginales, conclusión que concuerda con observaciones que se formularon al analizar la categoría de la ocupación. Sin embargo, los residentes en zonas rurales tienen una proporción mayor de sus integrantes en la categoría de trabajadores familiares no remunerados.

Cabe observar de paso que la proporción de varones migrantes o residentes que se dedican a actividades marginales es considerablemente menor en Bogotá que en otras zonas urbanas, y en las zonas rurales alcanza su nivel más alto. Como es natural, esto se debe a que en esta clasificación se ha incluido la agricultura de subsistencia entre las actividades marginales.

La clasificación relativa de migrantes y residentes según la respectiva proporción de mujeres que se dedica a actividades marginales es diametralmente opuesta, salvo en las zonas rurales, donde la mayor proporción de mujeres residentes que trabaja en la agricultura de subsistencia compensa una situación que, de lo contrario, sería desfavorable para las migrantes. Como entre los migrantes varones, las mujeres que han migrado a Bogotá y otras zonas urbanas tienen así una proporción menor que las residentes dedicadas a actividades marginales por cuenta propia, pero esta diferencia se compensa con creces por su predominio en los servicios domésticos. Sin embargo, lo más importante tal vez es que 3 quintos del total de las migrantes económicamente activas -cual. quiera que sea su lugar de destino - trabajan en actividades marginales, mientras que entre los varones la proporción fluctúa entre la quinta y la décima parte. (Véase de nuevo el cuadro 47.)

Así pues, este esquema de clasificación de las actividades marginales sugeriría que hay que enfocar desde ángulos muy diferentes la migración masculina y femenina. En realidad, los migrantes varones derivan en menor proporción que los residentes hacia actividades marginales. Es cierto que en esta conclusión pueden haber influido los criterios que aquí se han aplicado, pero a falta de información más adecuada hay que tenerla en cuenta. En lo que se refiere a las mujeres, es indudable que las migrantes acrecientan los contingentes de población que realizan actividades improductivas desde el punto de vista económico.

\section{RESUMEN Y CONCLUSIONES}

Considerados en su conjunto ¿qué sugieren estos datos sobre el volumen y las características de las corrientes migratorias acerca de la redistribución de la población y de la adaptabilidad y productividad de los migrantes? Ante todo $-\mathrm{y}$ aunque la información sobre el volumen de 
las migraciones no sirve para evaluar los movimientos generales registrados en los países latinoamericanos-, hay indicadores burdos de que los movimientos migratorios son en efecto amplios y diversificados: probablemente uno de cada tres latinoamericanos reside en una zona administrativa distinta de aquella en que nació. Estos movimientos son principalmente hacia zonas urbanas, pero no se puede pasar por alto el hecho de que en Colombia y Costa Rica - dos países sobre los cuales se poseen datos a escala nacional- las migraciones hacia zonas rurales representaron respectivamente más de un tercio y más de la mitad de todos los movimientos de población.

Como consecuencia del movimiento de migrantes cada vez mayor a lo largo de los años, la composición demográfica de las zonas receptoras se ha visto seriamente afectada por la población inmigrante. En Colombia, por ejemplo, los migrantes constituyen aproximadamente el $75 \%$ de la población de 30 años y más en la capital, y el $60 \%$ en otras zonas urbanas. Sin embargo, incluso en las zonas rurales son apreciables los efectos de las migraciones, pues 2 quintos de la población rural de Colombia están formados por migrantes. Así pues, en mayor o menor medida, casi todas las ciudades, los pueblos y villorrios y las zonas agrícolas se ven afectadas por la llegada de inmigrantes o por la salida de emigrantes.

Las consecuencias que acarrean estos movimientos dependen mucho de la composición de las corrientes migratorias, lo que otorga considerable importancia al estudio de las características demográficas, económicas y sociales de los migrantes. En Colombia, la composición por edad y sexo de los migrantes concuerda con las de otros movimientos latinoamericanos: las corrientes migratorias a Bogotá y otras zonas urbanas incluyen una proporción elevada de mujeres y jóvenes, y los movimientos migratorios hacia zonas rurales también abarcan un segmento apreciable de jóvenes. Sin embargo, ahí termina la semejanza, puesto que los varories constituyen la mayoría de los migrantes a zonas rurales.

El estudio comparativo del estado civil de migrantes y residentes mostró que quienes más migran son los solteros. Con excepción de las mujeres migrantes a zonas rurales (cabe suponer que generalmente acompañan a sus cónyuges), los migrantes de todas las cohortes de edades y de ambos sexos, cualquiera que sea su lugar de destino o la distancia que recorran, tienden a incluir una proporción mucho más alta de solteros que las categorías correspondientes de residentes.

Así pues, a juzgar exclusivamente por estas características demográficas, bien podría decirse que una elevada proporción de migrantes son físicamente vigorosos y no tienen ataduras familiares. Por tanto, cabría postular que los migrantes estarían particularmente capacitados - por lo menos en términos físicos y cuantitativos - para participar en forma plena en los procesos económicos de sus respectivas zonas de destino. Que sean o no cualitativamente capaces de hacerló es otro problema, que ha sido abordado desde varios puntos de vista. 
En lo que toca al alfabetismo y la educación, los migrantes que se dirigen a Bogotá superan considerablemente a los que se trasladan a otras zonias urbanas y aún más a los que se dirigen a zonas rurales. Sin embargo, debido a los diferentes niveles educativos de las respectivas zonas receptoras, los migrantes con más educación (es decir, los que se dirigen a Bogotá) poseen un nivel de instrucción inferior al de los residentes en la capital; los migrantes y residentes de las demás zonas urbanas poseen aproximadamente el mismo nivel de educación general, mientras que los migrantes con menos instrucción (los que se dirigen a zonas rurales) aventajan notablemente a los naturales de esos lugares. Sin embargo, las diferencias entre migrantes y residentes tienen en cada caso menos importancia que las diferencias entre los diversos grupos de migrantes.

¿De qué manera se reflejan estas diferencias de educación en la estructura del empleo de las zonas receptoras? Ante todo, es hasta cierto punto significativo que los migrantes recientes a Bogotá, a otras zonas urbanas y a zonas rurales aventajen considerablemente a los residentes en lo que toca a su participación en las actividades económicas. No obstante, al examinar con más detenimiento esta diferencia, queda de manifiesto que la superioridad de los migrantes se concentra sistemáticamente en dos categorías: los varones de 10 a 19 años y las mujeres de todos los grupos de edades. Esto indicaría que las tasas más altas de actividad de los migrantes son disfuncionales, porque pueden interpretarse como indicio de que es mucho menor la proporción de varones jovenes que asiste a la escuela y la proporción de dueñas de casa desempleadas.

En vista de las diferencias mencionadas en lo que respecta a calificación y participación por sexo en la fuerza laboral, se hace imprescindible estudiar por separado los varones y las mujeres en cada una de las zonas de destino, a fin de ofrecer un resumen coherente de la forma en que se distribuyen los migrantes y residentes en las diversas categorías de ocupación.

Los varones migrantes a Bogotá constituyen indudablemente el grupo de migrantes mejor preparado y su adaptación al trabajo es la más satisfactoria. Sin embargo, su situación ocupacional suele ser inferior a la de la población residente. Por ejemplo, es menor la proporción de sus miembros económicamente activos que trabaja en actividades no manuales y pertenece a cada una de las cuatro categorías de ocupación de mayor status, aunque la diferencia sólo es de significación en la categaría de los empleadores, donde los migrantes están marcadamente menos representados. Uno de los rasgos sobresalientes de la estructura ocupacional de los migrantes es que son mucho menos propensos que los residentes a establecerse por su propia cuenta, sea como empleadores o como empresarios de bajo nivel. Por otra parte, es desproporcionadamente alta la participación de los migrantes en actividades de servicios y otros trabajos manuales. Así, aunque en los varones de Bogotá las diferencias entre migrantes y residentes son pequeñas, indican 
en forma persistente que los migrantes se hallan en un nivel algo inferior al de los residentes dentro de la jerarquía ocupacional. Sin embargo, gracias a la aversion de los migrantes a trabajar por cuenta propia, esta inferioridad no los conduce hasta el denominado sector marginal, porque en la práctica los residentes tienen una proporción levemente superior de sus miembros en esta categoría, cuyo status es el más bajo.

La comparación entre migrantes y residentes en otras zonas ụrbanas de Colombia en lo que respecta a ocupación parecería favorecer a los primeros. Por una parte, los migrantes tienen una mayor proporción de su contingente en las actividades de servicio y en "otras ocupaciones manuales", pero también la tienen entre los profesionales, técnicos y empleados. Por otra parte, es menor su participacion relativa en actividades genéricamente "manuales". Al igual que en Bogotá, los migrantes a otras zonas urbanas tienen menos propensión a ser empleadores o a trabajar por cuenta propia. Por último, la proporción de personas que realizan actividades económicamente marginales entre los migrantes es sustancialmente menor que entre los residentes.

En lo que toca a las zonas rurales, la fuerza laboral formada por los migrantes varones se caracteriza esencialmente por la ausencia de propietarios de tierras, sea como empleadores o como agricultores de subsistencia. Con ese motivo, los migrantes se hallan por lo común en la categoría de los asalariados. Si se considera la rama de actividad económica, las ocupaciones de los migrantes tienden a ser más diversificadas que las de los residentes, aunque naturalmente la mayor proporción de ambos grupos trabaja en la agricultura. Además, el porcentaje de los migrantes que se dedica a actividades no manuales y trabajos de obrero es inferior al que se registra entre los residentes. En cambio, la proporción de los migrantes que desempeña actividades marginales es apreciablemente menor que entre los residentes.

Por lo tanto, parecería que al compararlos con los residentes varones en sus respectivos lugares de destino, los migrantes a zonas rurales y a zonas urbanas de Colombia - excluido Bogotá- disfrutan de una posición ocupacional favorable con relación a los residentes, mientras que los migrantes a Bogotá son los que se encuentran en la situación más desventajosa. Sin embargo, es preciso subrayar que se trata de términos relativos y que la variada estructura ocupacional que se encuentra en esas tres zonas de destino impide generalizar. Con todo, al comparar los distintos grupos migrantes se comprueba la existencia de un claro ordenamiento jerárquico. En efecto, los migrantes varones a Bogotá, que incluyen una mayor proporción de profesionales, técnicos, empleados y obreros, disfrutan de una situación privilegiada que deriva de su mayor preparación; del mismo modo, los migrantes a zonas urbanas aventajan considerablemente a las cohortes correspondientes de migrantes a zonas rurales que se hallan en las mismas categorías.

Volviendo ahora a la distribución de las migrantes mujeres por categoría de ocupación, es evidente que, aunque sólo se considere la población económicamente activa, las mujeres que migran a Bogotá o a otras 
zonas urbanas tienen una situación inferior a la de los migrantes varones y de las mujeres residentes.

La principal característica del empleo de las migrantes en Bogotá y otras zonas urbanas es su predominio en el sector de los servicios, fenómeno que puede interpretarse literalmente como una tasa más alta de empleo en los servicios domesticos. Es muy probable que las mujeres solteras, acudan o no a los pueblos y ciudades con la intención de dedicarse al servicio doméstico, se encuentren en esa situación poco después de su llegada. Como consecuencia de este proceso, el porcentaje de mujeres migrantes a las zonas urbanas que pertenecen a las categorías de técnicas y empleadoras, y de empleadas y obreras, es menor que el que se observa entre las residentes. Además, como en el presente modelo los servicios domésticos se clasificaron como actividad económicamente marginal, es natural que las migrantes se destaquen más en las actividades maginales.

La distribución por categorías de ocupación de las migrantes a las zonas rurales es un poco más ambigua. De una parte, su tasa de actividad es muy inferior a la de cualquier otro grupo migrante, y también aquí se destacan en el servicio doméstico; de otra, tienden a trabajar en minifundios familiares en grado mucho menor que las mujeres residentes, y su participación en las categorías profesionales es significativamente alta. En síntesis, podría deducirse que las mujeres migrantes a zonas rurales ingresan a la estructura ocupacional en los niveles más altos como maestras y enfermeras, o en los niveles más bajos como sirvientas domesticas, posibilidad que es tres veces más frecuente.

Así pues, considerados en su conjunto, los datos que se ofrecen en esta oportunidad indican que en Colombia los migrantes varones más capacitados se encauzan espontáneamente hacia los lugares de destino que ofrecen mejores posibilidades económicas. Los migrantes con más educación se dirigen a la capital y logran mejores empleos que los demás grupos. Las ciudades y pueblos menores atraen a un grupo algo menos preparado, pero que es sin embargo capaz de obtener empleo en cierto sentido superior al de los residentes. Si se pudiera llevar a cabo una verificación por tamaño de las ciudades, tal vez quedaría de manifiesto una gradación de las características de capacitación y empleo en las diversas ciudades, determinada por su tamaño y categoría. Los migrantes con menos preparación se dirigen a las zonas rurales, pero tienden en general a poseer más instrucción y a tener una situación ocupacional ligeramente superior a la de los residentes de esas zonas.

Al reflexionar sobre el nivel de instrucción relativo de migrantes y residentes, sus respectivas tasas de participación en la fuerza laboral y las categorías de ocupaciones que obtienen, no parece razonable seguir afirmando que los migrantes varones están imposibilitados para competir por empleos productivos con la población natural de las localidades hacia las cuales migran. Antes de adelantar conclusiones, lo ideal sería contar con información más completa y detallada; sin embargo, no es aventurado deducir que, pese a las grandes diferencias que se observan 
en la composición de los tres grupos de migrantes varones, la comparación global del aporte potencial y real de migrantes y residentes a la fuerza de trabajo de las respectivas zonas de destino ha de arrojar resultados que no serán desfavorables para los migrantes.

Sin embago, lo que a la larga realmente interesa saber en virtud de los estudios de las migraciones no es tanto la composición relativa de migrantes y naturales, sino si la afluencia en gran escala de migrantes puede perjudicar a ambos grupos al acrecentar excesivamente la oferta de mano de obra. Ahora bien, este último punto no se puede examinar sin analizar a la vez la capacidad real de las estructuras existentes en la zona de origen para asimilar en forma productiva a los eventuales migrantes. Pese a que no se pueden abordar con la información de que se dispone actualmente, estas cuestiones más generales sirven para reordenar las conclusiones alcanzadas dentro de una perspectiva más amplia, y señalan temas que deben investigarse.

Por último, la presente investigación deja en claro que las mujeres que migran a cualquiera de los tres lugares de destino constituyen el grupo migrante menos capacitado y menos productivo. Sin embargo, el problema no puede considerarse desde el punto de vista más bien estrecho de la productividad económica, pues si estas mujeres se desarraigan y migran en busca de empleo en el servicio doméstico, es porque subjetivamente consideran que esa vida es mejor que la que llevan en su tierra natal. Es probable además que la situación no varíe mientras no se introduzcan profundas modificaciones en la estructura socioeconómica circundante que permitan ofrecer a esas mujeres mejor educación y empleo más productivo. 


\section{POBLACIÓN, MEDIO AMBIENTE Y DESARROLLO: LA EXPERIENCIA LATINOAMERICANA}

\section{1) El desdrrollo y sus componentes}

Tradicionalmente se ha estimado que tierra, mano de obra y capital son los factores básicos de la producción en que descansa la riqueza de un país, y que lo que hace que un país se "desarrolle" o no es la forma en que se manejan tales factores. En términos generales, éstos se conciben respectivamente como recursos naturales (disponibilidad de tierras fértiles, bosques, minerales, productos del mar); recursos humanos (conocimientos, inventiva, espíritu creador e iniciativa comercial, así como la propensión a consumir, que da lugar a un mercado adecuado y cada vez mayor), y riqueza (niveles globales de ingreso, ahorro, inversión y acervo de bienes de capital en la economía). El exito del desarrollo nacional se ha medido en función de la magnitud global del ingreso nacional, el ingreso por habitante (desestimando en la práctica la distribución social y regional), las tasas de crecimiento y el comportamiento del comercio internacional.

En los últimos treinta años la atención se ha centrado sucesivamente en ciertas variables e interrelaciones que se consideran cruciales para el proceso de desarrollo. La función que desempeñan la población, la tecnología, los recursos y el producto no sólo es importante en sí, sino también como consecuencia de su acción recíproca; el uso que hace la población de los recursos es lo que influye en los niveles y el tipo de producción, que determinan a su vez la calidad y gama del consumo popular. Además, el uso de los recursos depende de la percepción que tenga la sociedad de lo que constituye un recurso utilizable, y de su capacidad para traducirla en la aplicación de tecnología a las materias primas de que dispone. En los últimos doscientos años este proceso de influencias recíprocas ha tenido una expansión acumulativa que se ha traducido - sobre todo en las naciones ricas- en mayor demanda de nuevas técnicas para aprovechar los recursos naturales, así como en mejorar los sistemas de transporte, a medida que las sociedades industrializadas amplían su búsqueda de tierras cultivables y de materias primas para sustituir recursos caros o agotados en las regiones ya explotadas. Además, el constante progreso técnico ha llevado a descubrir nuevas fuentes de riqueza y ha modificado a su vez los métodos y tipos de producción, creando nuevas formas de bienes de consumo y nuevas demandas.

El esquema "población-tecnología-recursos-producto" (con el consiguiente consumo), es útil para describir la estructura básica y el curso del proceso de desarrollo, y su expansión constante en los doscientos años transcurridos desde la revolución industrial. Sin embargo, aunque allí están los ingredientes técnicos y económicos esenciales, para explicar por qué el crecimiento adopta determinada modalidad se necesita 
algo más: ¿en qué medida su particular estructura ha mejorado la calidad de la vida humana? Y lo que quizá viene más al caso: ¿ha variado la calidad de la vida de manera diferente en distintos sectores de la humanidad, y qué desventajas ha traído consigo?

El desarrollo ha sido en general un proceso de crecimiento acumulativo tanto en términos de conocimiento tecnológico como de complejidad de la producción y del consumo. Sin embargo, la desigual distribución social y espacial de los frutos del crecimiento -unida a la degradación del medio ambiente por la destrucción y el uso dispendioso de los recursos naturales, así como a la perpetuación a escala mayor todavía de condiciones inadecuadas de asentamiento humano- han planteado una serie de interrogantes que no pueden resolverse única ni siquiera básicamente en los términos técnicos o económicos tradicionales. Pese a la enorme capacidad técnica de que dispone la humanidad, las principales características del proceso de desarrollo en los años setenta siguen siendo la desigualdad y el desequilibrio, la división del mundo en desarrollados y subdesarrollados en el plano nacional, regional y social. Para tratar de explicarlo hay que introducir variables que no son ni económicas ni técnicas.

Los factores sociales y políticos y los problemas espaciales y del medio ambiente se consideran hoy cada vez más en la apreciación del proceso de desarrollo, conjuntamente con las variables más tradicionales. Mientras tanto, los sociólogos y planificadores buscan un enfoque que les permita a la vez analizar el proceso de desarrollo sobre una gama más amplia de criterios, y encontrar la respuesta a los problemas planteados en un conocimiento a fondo de las repercusiones de las distintas decisiones políticas.

El análisis de las variables sociopolíticas podría ayudar al planificador a comprender por qué la actividad económica y la población se concentran cada vez más en un número reducido de grandes centros; por qué se emplean determinadas técnicas que exigen gran densidad de capital cuando hay excedente de mano de obra; por qué se producen - importan artículos suntuarios cuando otros criterios indiquen tal vez que, desde el punto de vista social, producir artículos básicos para la mayoría mal nutrida, mal cobijada y mal vestida de la población sería una inversión nacional más justa. La combinación de las variables sociopolíticas, técnicas y económicas ayudaría a analizar con mayor profundidad y penetración el funcionamiento de una sociedad, a través del examen de sus motivaciones, sus objetivos y sus principios.

En esta búsqueda de un enfoque integral de la política de desarrollo -que, por lo general, se encuentra aún en las primeras etapas de su evolución- los factores espaciales y ambientales contribuyen mucho a esclarecer algunas consecuencias de los distintos tipos de desarrollo, en función de la forma y estructura de los asentamientos humanos, las relaciones entre ciudad y campo, la distribución espacial de la actividad económica y la distribución espacial del consumo de bienes y servicios.

Los componentes de carácter ambiental y espacial se encuentran estre- 
chamente relacionados. En efecto, ambos proporcionan indicadores físicos sobre el funcionamiento (bueno o malo) de la sociedad. El uso del medio ambiente natural puede conducir a desarrollar o a destruir los recursos; a crear o no un medio ambiente urbano o rural aceptable para la vida humana, o un medio ambiente social habitable. Todo esto demuestra en forma práctica que la sociedad es capaz de actuar en bien de la ciudadanía a través de la proyección de los resultados concretos - por así decirlo- del funcionamiento y del juego recíproco de otros aspectos menos tangibles del sistema.

El "desarrollo" equivale entonces a la forma en que interactúan todas las variables del sistema - población, tecnología, recursos, producción ( $\mathrm{y}$ consumo) - y los factores sociales, políticos, espaciales y ambientales. A su vez, para cumplir con ciertos propósitos o principios, las estrategias de desarrollo deben seleccionar y conciliar estas variables y sus relaciones recíprocas.

\section{2) El factor población}

a) Crecimiento y tamaño. La "población" es el factor que inicia y realiza el proceso de desarrollo, el fín último del desarrollo mismo y el elemento que soporta los desajustes y contradicciones en el funcionamiento del sistema. Las demás variables guardan una relación de dependencia con la "población" constituida en comunidades organizadas; así, los recursos son función del concepto que se tenga de la sociedad, y de la capacidad del hombre para utilizarlos mediante la aplicación del conocimiento técnico; la clase y variedad de bienes producidos, conjuntamente con la ubicación de la actividad económica y del asentamiento humano, dependen en gran parte del tipo de sociedad que se construya para satisfacer las exigencias de los grupos sociales dominantes.

Por lo demás, son inmediatos y evidentes los estrechos vínculos que existen entre los problemas demográficos y ambientales. El hombre ha influido mucho en la evolución del medio ambiente a través de la historia, y particularmente en los últimos doscientos años, en que ha aumentado en forma acelerada la especie humana y su capacidad técnica para producir y destruir. En los dos últimos decenios ha pasado a convertirse en obsesión mundial el fenómeno de una población que aumenta a ritmo acelerado y que exige cada vez más del medio ambiente y del acervo de recursos disponibles para mantener a la humanidad.

América Latina, con una tasa de crecimiento de la población más alta que la de las demás grandes regiones del mundo, es particularmente sensible a la afirmación de que la presión de ese crecimiento es una de las principales razones que ha agudizado los problemas ambientales. Distintos gobiernos han adoptado posiciones que fluctúan entre dos extremos: reconocer que es necesario reducir tan rápido crecimiento mediante políticas de población concretas, y rechazar de plano cualquier sugerencia de que convendría moderar el incremento de la población. (Cabe observar que en materia de política hay una gran diferencia entre las declaraciones y la acción en ambos extremos de la gama de opciones.) 
No es este el lugar para realizar una evaluación detallada de las distintas posiciones, ni tendría mucha utilidad analizar en términos generales la población del continente, dadas las enormes diferencias entre los países no sólo en cuanto a tamaño, sino también en lo que respecta a la densidad de la población y las tasas, la distribución y los componentes del crecimiento demográfico.

En la mayor parte de los países latinoamericanos sigue siendo baja la densidad de la población, lo que ha llevado a sostener que la región - $O$ al menos algunos países de ella - necesita gente para poblar sus grandes extensiones deshabitadas y para explotar y utilizar la gran abundancia y diversidad de sus recursos. Además, una población de 650 millones de personas en el año 2000 “....coloca a América Latina en otro nivel con relación a la situación mundial. Hay muchos en la región que equiparan la población con el poder político o, en todo caso, con una mayor influencia en los problemas mundiales". ". Aún más: no puede pasarse por alto el problema de las fronteras cuando hay gobiernos que estiman que el incremento acelerado de la población de su vecino constituye una amenaza potencial contra su propia integridad.

Aunque estos argumentos pueden ser válidos -0 al menos comprensibles-, hay otros dos factores que también deben tenerse en cuenta cuando se analizan los problemas del desarrollo nacional. El primero de ellos es la relación entre la densidad de la población y el nivel de desarrollo económico. Suele afirmarse que la densidad de la población por kilómetro cuadrado hace de América Latina una región comparativamente subpoblada. Esto no tiene mucho sentido en un continente cuyas condiciones geográficas y meteorológicas son tan variables, y que cuenta con grandes extensiones no aptas para la ocupación -al menos con las actuales técnicas y capacidad de inversión-y con otras propicias para formas de explotación que requieren muy baja densidad de población, como la silvicultura o la ganadería ovejuna. Si se analiza la relación entre población y desarrollo socioeconómico -o más simplemente, entre el número de personas a las que hay que alimentar, albergar, vestir, emplear y proporcionar servicios sociales básicos, y la capacidad para hacerlo de la mayor parte de las sociedades dada su actual estructura económica y social- América Latina tiene hoy más población que la que puede atender.

Cabe considerar en segundo lugar que ła distribución de la población es sumamente desigual y que gran número de personas se concentra en unas pocas zonas metropolitanas - generalmente las capitales-, mientras la población de las zonas rurales sigue aumentando con rapidez debido a la elevada tasa de incremento natural. (Más adelante se analizará la influencia que ejercen en el medio ambiente los millones de personas que se concentran en una o dos zonas geográficas delimitadas, así como la falta de desarrollo de las zonas periféricas.) ${ }^{2}$

1 Véase Víctor L. Urquidi, "Latin American demographic growth: political, social and economic forces", trabajo leído ante la Population Association of America, Nueva Orleans, 26 a 28 abril 1973 , p. 4.

2 Según la Oficina de Ciencia y Tecnología de la ATD, su estudio realizado en 35 
b) La distribución de la población. Los niveles de urbanización registran un aumento general, pese a que várían mucho de un país a otro, pues fluctúan entre los de las comunidades altamente urbanizadas de Argentina, Chile y Uruguay y los de las comunidades predominantemente rurales de Bolivia, Ecuador y Paraguay en América del Sur, y Guatemala, Haití y Honduras en América Central y el Caribe.

La combinación de altas tasas de crecimiento general de la población con la tendencia a migrar -en particular, aunque no exclusivamente, desde el campo y los pueblos pequeños a los grandes centros metropolitanos - se ha traducido, en algunos casos, en tasas de crecimiento de $607 \%$ anual, lo que equivale a duplicar la población de las grandes ciudades aproximadamente cada 10 años. ${ }^{3}$

Merecen mención especial dos características de este proceso de hiperurbanización. Ante todo, el proceso es muchísimo más pronunciado que en las naciones ricas donde, a pesar de haberse producido una tendencia centralizadora similar, no ha alcanzado nunca el mismo ritmo que en América Latina. En esta región, las capitales o centros urbanos principales contienen en varios casos entre un tercio y la mitad de la población del país y siguen captando todos los años, a través de las migraciones, una parte importante de la población con una continua extensión de sus límites.

El proceso no va acompañado de tasas de desarrollo industrial y comercial suficientes para que el centro absorba la corriente de migrantes desde la periferia. Tanto a éstos como a gran parte de la población nacida en las ciudades les resulta muy difícil encontrar un trabajo productivo que permita satisfacer en la gran ciudad sus necesidades sociales y físicas básicas: alimentación, vivienda y servicios de salud y educación."

Las actividades secundarias, que en las naciones ricas caracterizaron las primeras etapas de su expansión industrial, han sido menos dinámicas en el conjunto de América Latina en lo que toca al aumento del ingreso y del empleo. Lo que ha predominado en el sector terciario. Por

países del mundo en desarrollo “... revela que hay una estrecha relación inversamente proporcional... entre la presión de la población humana y la urbanización, por una parte, y la calidad del medio ambiente, por otra". (Véase el documento mimeografiado "Environmental problems in selected developing countries: Preliminary survey", Washington, julio de 1971 , p. 8.)

3 En Brasil, por ejemplo, el promedio anual de crecimiento de las ciudades con más de 500000 habitantes alcanz6 a $6.2 \%$ en $1940-50$, a $7.2 \%$ en $1950-60$ y a $6.8 \%$ en 1960-70; las tasas correspondientes al total de zonas urbanas fueron de 5.3, 6.4 y 6.1 , respectivamente. Véase George Martine y César Peláez (CEPAL), "Tendencias de la urbanización del Brasil, 1940-1970", documento mimeografiado que se presentó al Seminario Técnico sobre Urbanización y Crecimiento Demográfico en Ámérica Latina (Río de Janeiro, 3-7 de abríl de 1972). Es posible que se esté produciendo una declinación gradual a largo plazo del predominio de la metrópoli, peto si ello es efectivo la tendencia tardará mucho en manifestarse, dados los grandes incrementos en cifras absolutas.

1 No obstante que, como en el caso de Bolivia, tal vez el $60 \%$ de la industria nacional y el $55 \%$ de la fuerza laboral industrial se concentran en la capital. Véase Comisión Interministerial Permanente, Ministerio de Relaciones Exteriores y Culto, Informe Nacional de Bolivia sobre "EI Medio Humano", La Paz, marzo de 1971, p. 4. 
lo tanto, no es posible aceptar sin reservas la simplificadora afirmación de que la urbanización inevitablemente trae consigo progreso social y económico para la población, ni la aseveración contraria de que una expansión rápida de grandes ciudades crea necesariamente graves problemas sociales sin aparejar la compensación de ventajas económicas. ${ }^{5}$

En realidad, la situación es compleja: hay grupos importantes - sobre todo la clase media y los trabajadores sindicalizados- que están en condiciones de aprovechar las mayores oportunidades de empleo y movilidad social que ofrece la ciudad. Al mismo tiempo, los grupos más marginales todavía se encuentran social y económicamente restringidos en un marco que al parecer es más ventajoso y dinámico. En estas circunstancias, es posible que las contradicciones se hagan más evidentes y que las paradojas sociales queden enteramente de manifiesto, por la mayor percepción de las desigualdades y la ampliación de las expectativas. A su vez, quizá esto lleve a exigir un alivio ante los problemas inmediatos y las soluciones requeridas - aunque sean transitorias y parciales- para. los males más apremiantes.

Así pues, es posible que el rasgo más destacado de esas ciudades sea la contradicción entre las condiciones objetivas de movilidad socioeconómica limitada y una mayor conciencia de las desigualdades del sistema. Tal contradicción, en la que influyen el grado de flexibilidad de las autoridades y los recursos de que estas disponen, probablemente se agudice a medida que la población continúe concentrándose y que los migrantes inunden las aglomeraciones urbanas no planificadas del continente y contribuyan al crecimiento acelerado de los "barrios marginales", los "tugurios", las "callampas" y las "favelas" que circundan las ciudades latinoamericanas y que contienen tal vez un tercio de su población urbana.

c) La población y otras variables del desarrollo. El papel de la "población" en el proceso de desarrollo sólo puede analizarse de manera eficaz en función de sus relaciones con las demás variables: tecnología, recursos, producción y dimensión espacial. (La relación población-medio ambiente se analizará por separado más adelante.) La forma en que la población se relacione con otras variables dependerá en gran medida de la estructura y del funcionamiento de la sociedad, de sus instituciones, de su sistema político y de la influencia relativa de los distintos grupos sociales. Por ejemplo, las actitudes, los valores y las normas del comportamiento político, económico, social y cultural ayudarán a determinar de qué manera se utilizan los recursos; qué clases de técnicas se emplean; qué gama de productos se ofrece a los consumidores y cómo se distribuyen espacialmente la actividad económica y el asentamiento humano en la sociedad.

En América Latina se puede observar cómo interactúan las distintas variables en modalidades cambiantes y complicadas dentro del marco

5 Véase un breve resumen de ambas posiciones en Pierre de Briey, "L'urbanisation, le développement et le processus révolutionnaire dans le Tiers Monde", Civilisations, vol. XVIII, núm. 3, 1968, pp. 342 a 352 . 
de sus economías de mercado, de carácter dependiente. La elección de tecnología para explotar los abundantes recursos naturales, así como la distribución de los frutos de esa explotación entre los distintos grupos sociales - medida en función del consumo, de la distribución del ingreso y de las oportunidades de empleo-, reflejan en gran medida el juego recíproco de los dos factores sociopolíticos, la dependencia de los centros mundiales y el sistema de mercado. La variable espacial revela también la forma en que estos factores influyen en la variable población, y viceversa, para crear ciertas modalidades de asentamiento humano y de ubicación de la actividad económica.

El funcionamiento de las economías de mercado no ha conducido claramente a la igualdad de los grupos sociales en ninguna etapa de su evolución histórica. En las naciones ricas - pese a haberse elevado toda la pirámide de ingresos- el incremento gradual del producto nacional global no ha logrado reducir apreciablemente en la mayoría de los casos las diferencias econb́micas, sociales y políticas entre los grupos de mayores y menores ingresos. Incluso en el Estado providente hay minorías que disfrutan de los mejores empleos y servicios sociales y culturales, y que ejercen influencia dominante en los asuntos políticos.

Estos rasgos toman formas más extremas en América Latina. La distribución del ingreso es sumamente desigual a través de todo el continente. Los empleos al alcance de la mayoría de la población se limitan a trabajos manuales, o bien a actividades marginales improductivas - $-\mathrm{y}$ a menudo degradantes- en el sector de los servicios. Los servicios sociaIes en general, y particularmente la vivienda, la alimentación, el vestuario, la salud y la educación, no se comparten en forma equitativa. El acceso a la justicia y la efectiva participación en las decisiones de índole política y administrativa dependen de la posición que se ocupe en la sociedad.

Las decisiones relacionadas con la clase de bienes que se producen y con los niveles de producción reflejan del mismo modo las necesidades de consumo de los grupos sociales más adinerados. Por ello, mientras la mayor parte de la población no puede obtener muchos de los productos básicos a precios aceptables, las industrias producen bienes para los grupos de mayores ingresos a precios que ponen de relieve la estructura oligopólica del sector industrial protegido.

A los propietarios y administradores de las empresas de cualquier sector les interesa más en sus métodos de producción llevar al máximo sus utilidades - "internalizar" esas utilidades y "externalizar" los costos- que elevar totalmente el bienestar de la sociedad en general.

Las modalidades de asentamiento humano que responden al esquema centro-periferia, así como al de desarrollo y subdesarrollo, son características de la evolución desequilibrada de América Latina. Son varias las razones. Ante todo (como señalan muchos autores que se han referido al desarrollo regional -desde Myrdal, Hirschman y Perroux hasta Corraggio y Rofman - y han concretamente analizado la situación latinoamericana) en las economías de mercado, pero no sólo en ellas, existe 
la tendencia natural a centrar gradualmente la actividad económica en un número limitado de zonas urbanas bien ubicadas. Para aprovechar las economías externas, de urbanización y otras economías de escala y, por ende, para hacer óptimas las utilidades, las empresas deben localizarse cerca de los mercados principales. Tienen así acceso a toda clase de servicios y son más bajos los costos del transporte. Como la ubicación crecientemente concentrada de esta actividad económica atrae más población - por lo general, el elemento pasivo del proceso-, sigue rigiendo el patrón acumulativo que describe Myrdal.

Sin embargo, los efectos no se dejan sentir sólo en el campo económico. El centro favorecido atrae hacia sí la actividad social, política y cultural del país, privando cada vez más a las ciudades más pequeñas y a la periferia rural de este patrimonio y proclamándolas cada vez más dependientes de la capital. Tanto los grupos relativamente acomodados, que van en pos de la gama mayor de oportunidades sociales, políticas y culturales brindadas por la ciudad, como la clase media baja, la fuerza laboral organizada y los grupos marginales, aspiran a participar más efectivamente en la toma de decisiones y en la distribución de los frutos del desarrollo, y esto sucede más en la capital que en los centros urbanos menores o en las zonas rurales. La sola presencia de barrios de tugurios en las afueras de la ciudad recuerda en forma constante a los gobiernos, cualesquiera que sean, las necesidades de una poblacion que crece en forma acelerada. Y esa presencia se hace aún más evidente cuando los grupos marginales - unidos o no a la mano de obra organizada- son movilizados social y políticamente para que su voz se haga sentir de manera eficaz en demanda de vivienda, empleo, educación, servicios de salud, etc.

A menos que se introduzcan importantes cambios de política, parece poco probable que estas tendencias acumulativas hacia un esquema centro-periferia cada vez más polarizado, puedan modificarse radicalmente a corto plazo e incluso a mediano plazo. La creación de ministerios de planificación regional, la formación de centros de investigación y las continuas exhortaciones de los organismos internacionales sobre la necesidad de distribuir mejor la población, la actividad económica, los. servicios sociales y la influencia política sólo tienen efectos superficiales. Las tendencias a centralizar y concentrar el asentamiento humano. en unos pocos lugares preferidos se modifican algo por el crecimiento, y la evolución del propio sistema de mercado, pero los problemas internos de la desigualdad social, económica y política, por una parte, y sus, equivalentes espaciales por la otra, han planteado dificultades a la mayoría de los gobiernos latinoamericanos. Estos deben confrontar además los problemas derivados de su dependencia de centros mundiales cuyo poder económico y político realmente puede frenar su capacidad para abordar los factores determinantes de la concentración espacial, entre otras deficiencias de sus procesos de desarrollo.

Se ha sostenido que "la soberanía de la nación-estado misma se compromete seriamente cuando se trata de importantes decisiones que afec- 
tan la estructura social y económica nacional. Las naciones-estado latinoamericanas son parte integral de una estructura política y económica internacional... La concentración internacional del poder político y económico ha proseguido hasta tal punto que cuando llega el momento de tomar decisiones que realmente cuentan para el desarrollo nacional, las naciones 'independientes' pero subdesarrolladas frecuentemente encuentran circunscritas sus áreas de decisión. Su 'poder soberano' es, en ciertos respectos, un formulismo." 6

En otras oportunidades se han hecho notar ya las consecuencias de las inversiones extranjeras directas en la región latinoamericana. En un trabajo anterior a éste y publicado por la CEPAL se señalaban las complejas y amplias ramificaciones de tales inversiones. Estas incluyen el conflicto entre el ingreso en moneda extranjera y el requisito de servir y amortizar tal inversión; la necesidad cada vez mayor de elementos importados; el aumento de la presión sobre el balance de pagos; la disminución del ahorro interno y de los recursos crediticios disponibles para inversiones en el país; los efectos causados por nuevos tipos de inversión extranjera en las modalidades internas de consumo; la posible incompatibilidad de este sistema de asignación de recursos con esquemas destinados a satisfacer las necesidades esenciales de las mayorías, y, por último, el hecho de que las inversiones extranjeras han disminuido la eficacia de las medidas arancelarias y cambiarias encaminadas a limitar el consumo de artículos duraderos de precio elevado.?

La mayoría de los gobiernos ha aceptado pagar cierto precio que se traduce en menor capacidad de decidir el tipo de producción, las modalidades de consumo, la localización de la actividad económica (por razones económicas obvias, la mayoría de las empresas extranjeras prefiere establecerse en los centros urbanos más grandes), la contribución de la industria a la creación de empleos, y los efectos en el medio ambiente natural y creado por el hombre, a la vez que buscan medios para reducir el precio y controlar algunos de estos factores. Por ejemplo, cuando ciertos países industrializados manifiestan interés en trasladar algunos tipos de industria pesada a otros países, a fin de reducir la contaminación en su propio territorio, los gobiernos de los países más pobres están en general dispuestos a aceptar tal traslado con tal de atraer actividades que producen ingresos, aun a riesgo de aumentar su propia contaminación.

Por otra parte, es un hecho bien conocido que la aparición de las empresas transnacionales ha limitado todavía más el ámbito geográfico y el poder negociador incluso de los países más grandes del continente. Se está haciendo más hincapié en el empleo de técnicas "sofisticadas" en

- Véase Solon Barraclough, "La estrategia de desarrollo nural y la reforma agraria", documento presentado al Seminario Latinoamericano de Reforma Agraria y Colonización, organizado por la rao con la cooperación del Gobierno del Perú, en la ciudad de Chiclayo, 29 de noviembre al 5 de diciembre de 1971 , P. 3.

7 Véase Estudio económico de América Latina, 1971, Publicación de las Naciones Unidas, núm. de venta: s.73.r.c.r. (Primera parte: “América Latina y la economía mundial: Perspectivas y tendencias"). 
los sectores "modernos" de la economía, por incompatibles o socialmente destructoras que sean estas prácticas en el marco más amplio de la comunidad nacional. Además, refuerza estas presiones financieras y técnicas la dependencia cultural de los grupos dotados de gran poder adquisitivo, que asegura un mercado permanente aunque limitado a la mayo ría de los bienes de consumo extranjerizantes.

La complejidad del proceso global desarrollo/subdesarrollo puede comprobarse si se examina la acción recíproca de dos variables: de un lado, la población en su marco societal y su expresión espacial, y, de otro, el uso de los recursos.

En general, el uso de los recursos naturales de las zonas periféricas de los países latinoamericanos tiende a ser inadecuado, ya sea porque se subutilizan o porque se explotan en forma antieconómica. Salvo algunas excepciones importantes, los terrenos agrícolas se concentran en latifundios que sólo se explotan en forma parcial, o se subdividen en pequeñas parcelas que prácticamente no pueden ofrecer condiciones de vida aceptables. En ambos casos, la administración de las unidades agropecuarias ha sido muy deficiente. Los bosques - gran fuente potencial de riqueza interna y de ingresos de exportación- suelen desestimarse y considerarse un obstáculo al "desarrollo" económico. Se queman y, cuando se aprovechan, se explotan en forma descuidada para obtener utilidades a corto plazo.

La riqueza mineral también se ha explotado en forma dispendiosa para lograr utilidades rápidas. La enorme riqueza del continente -petróleo, cobre, bauxita, estaño, hierro, plata- ha hecho a lo largo de su historia una contribución al desarrollo de América Latina muy inferior a su potencialidad. Los recursos del mar, que hasta hace poco la mayoría de los países despreciaba, son objeto de explotación por grandes flotas pesqueras comerciales (a menudo extranjeras), y casi todos los puntos de pesca han quedado al alcance de sus exhaustivas actividades de extracción.

Sea que los recursos naturales de América Latina se hayan desestimado o subutilizado, sea que se hayan sometido a explotación antieconómica o excesiva - como ha sucedido cada vez con mayor frecuencia en los últimos decenios-, la combinación de los elementos societales y espaciales ha sido el factor decisivo. Las utilidades a corto plazo, la distancia de los mercados, la escasez de servicios de transporte y comunicaciones, y la indiferencia o poca capacidad de fiscalización de las autoridades centrales, son todos elementos que han influido en el uso de los recursos del continente.

Como consecuencia lógica, cuando en las zonas periféricas efectivamente se explotan los recursos agropecuarios, forestales, mineros y del mar, los frutos rara vez benefician a la zona de donde se extraen. Por el contrario, de acuerdo con el sistema de mercado dependiente, la elaboración posterior, que produce muchos más ingresos, tiene lugar en la región central del país, o en el país industrializado a que pertenece la empresa extranjera que realiza la explotación. 
Los efectos en la población de esta modalidad de crecimiento sin desarrollo son claros. El estancamiento y abandono del sector agropecuario, unido el régimen de tenencia de la tierra en que se dan el latifundio y el minifundio, ha contenido la expansion de las oportunidades de empleo, frente a la presión que significa la persistencia de tasas elevadas de crecimiento de la población en las zonas rurales. La situación se ha agravado aún más con la transferencia de utilidades a las zonas urbanas en busca de mejores inversiones en la especulación con bienes raíces, en la construcción y en las industrias de bienes de consumo. Esto ha contribuido a reducir la capacidad de la economía rural para absorber la población que permanece junto a la tierra o de proporcionarle condiciones de vida aceptables. En estos casos, el no haberse desarrollado una economía diversificada ha hecho disminuir las oportunidades de empleo y ha conducido a altos niveles de desempleo y subempleo, no sólo en la agricultura, sino también en la actividad económica de pequeños mercados urbanos.

Sin embargo, incluso en los casos en que el sector agropecuario ha crecido en forma acelerada, el empleo de métodos altamente mecanizados y con gran densidad de capital ha hecho que - como sucede en las naciones industrializadas - los empresarios prescindan de gran parte de la mano de obra campesina que hasta entonces había trabajado la tierra en condiciones técnicas. y sociales diferentes. En este sentido, los factores de repulsión que hacen abandonar las zonas rurales, sea en condiciones de estancamiento o de expansión, han sido tan importantes como los factores de atracción que ejercen los supuestos encantos de la ciudad. Del mismo modo, en el sector de las manufacturas, incluso cuando se intenta descentralizar la actividad económica, y algunas empresas grandes son lo suficientemente independientes y libres de trabas como para trasladarse a ubicaciones periféricas, ${ }^{8}$ las actividades de estas firmas, con su gran densidad de capital, no tienen grandes efectos en la zona de reubicación, salvo quizá en que contaminan el campo circundante. Cuando se amplía y moderniza la explotación de yacimientos minerales o bosques, el uso de sistemas altamente mecanizados o que requieren mucho capital puede dar lugar asimismo a la reducción neta del empleo.

El subdesarrollo relativo de las zonas periféricas está íntimamente relacionado con la hipertrofia de los centros metropolitanos. Debido a la falta de oportunidades de inversión en actividades de desarrollo diversificadas que se observa en las regiones rurales y en los pueblos pequeños, donde los proyectos en gran escala que ocasionalmente se llevan a cabo sólo utilizan cantidades considerables de mano de obra y capital en la etapa de construcción, el capital se transfiere a las zonas urbanas, en que es más amplia la gama de oportunidades y la rentabilidad de la inversión mucho mayor.

8 Véase A.B. Rofman, "El fenómeno de la concentración y centralización espacial en América Latina: elementos para una discusión", documento presentado en el Seminario Internacional sobre Planificación Regional y Urbana en América Latina (Viña del Mar, Chile, 17 al 22 de abril de 1972) organizado por el ILPES y el rnDS. 
Aunque no hay pruebas categóricas, es probable que durante largo tiempo la periferia de la mayoría de las naciones latinoamericanas haya subvencionado el crecimiento de los centros urbanos y particularmente de las metrópolis. Los recursos de inversión del sector privado y de las instituciones públicas han fomentado el desarrollo industrial de las ciudades, pero sobre todo han proporcionado fondos para el crecimiento de la infraestructura urbana y para proyectos altamente remunerativos de construcción y hermoseamiento de ciertas zonas de las capitales. Sólo en los últimos años algunos gobiernos han comenzado a modificar esta tendencia mediante políticas de desarrollo regional destinadas a promover el desarrollo agropecuario y la descentralización de la actividad industrial, con programas de obras públicas rurales. Sin embargo, una vez más resulta difícil estimar la magnitud de estos movimientos financieros, y por lo tanto, en qué medida las utilidades provenientes de estas inversiones revierten con mayor o menor rapidez a la fuente.

\section{3) Población y medio ambiente}

a) Relaciones recíprocas entre las variables. Conviene analizar ahora la acción recíproca entre la población y el medio ambiente en las condiciones sociopolíticas antes esbozadas. Ello no deja de lado el hecho de que en América Latina el sistema de mercado dependiente presenta muchas variaciones, una de cuyas principales características es la mayor o menor intervención estatal. Para la mayor parte de la población de América Latina, obligada a migrar a ciudades atestadas y cada vez más grandes, aglomerada en las laderas de los cerros o dispersa en tierras marginales, "el efecto en el medio ambiente" es en gran medida involuntario y actúa directamente sobre ella. Las elevadas tasas de crecimiento de la población -denunciadas como una de las principales causas del deterioro del medio ambiente-, unidas a la distribución desequilibrada de esa población, son sólo las causas últimas y visibles de los problemas ambientales.

b) Problemas ambientales. En todo el continente hay numerosas pruebas del despojo y degradación del medio natural y de aquel creado por el hombre, y, en muchos casos, los efectos de esta actividad humana están claramente documentados.

Por ejemplo, las prácticas agrícolas inadecuadas, unidas a los regíme-

9 Véase especialmente República de Chile: Informe para la Conferencia de las Naciones Unidas sobre el Medio Ambiente Humano, Santiago de Chile, mayo de 1971, p. 877. Gran parte de lo expuesto en el "Informe Nacional: República Argentina" (documento mimeografiado, sin fecha, preparado para la misma conferencia) se refiere también al despojo de que ha sido objeto el campo argentino a través de prácticas inadecuadas y destructivas que continúan aplicándose hasta hoy. Sin embargo, cabe agregar que aún no se ha hecho un balance sistemático basado en investigaciones adecuadas y en definiciones claras de los problemas, que abarque el conjunto de América Latina. Por lo tanto, los análisis generales (incluido el presente trabajó) se basan en "ejemplos" tomados de distintas fuentes cuya importancia y posibilidades de verificación son muy diversas. 
nes de tenencia de la tierra y a la reacción de los terratenientes a los incentivos sociales y económicos vigentes, han hecho descuidar millones de hectáreas de buenas tierras agrícolas y dejar en el abandono a zonas marginales.10 E1 excesivo apacentamiento ha arruinado las tierras de pastos naturales, con la consiguiente erosión eólica o por el agua; las prácticas de tala y quema para habilitar tierras han deforestado grandes zonas, y allí donde existe la silvicultura comercial, son poco frecuentes los intentos de replantar zonas taladas. Una vez más las consecuencias son la erosión en gran escala, la permanente denudación de las regiones montañosas, el atarquinamiento de los ríos y la creación de condiciones que favorecen la inundación periódica de grandes áreas.

En Chile son visibles los resultados de esta mala explotación, pues 20 millones de hectáreas - $80 \%$ de las tierras aptas para la agricultura- están erosionadas en algunas medida y la erosión continúa a razón de 40000 hectáreas al año. El entarquinamiento de ríos y puertos ha puesto en peligro diversos tipos de actividad industrial, ha disminuido la utilidad de las presas, ha ocasionado pérdidas de vidas humanas y ha arruinado grandes extensiones de buena tierra agrícola. ${ }^{11}$

En 'Argentina, el apacentamiento excesivo en la pampa tambien ha destruido miles de hectáreas de praderas y lo mismo ha sucedido en la región del Chaco y de la Patagonia. La erosión resultante ha afectado 20 millones de hectáreas, y $20 \%$ de ellas muy severamente. La presión demográfica en las zonas rurales ha ocasionado problemas aún mayores en México: hay 150 millones de hectáreas erosionadas y todos los años 150 a 200 mil más se ven seriamente afectadas.

En otros países la presión de la población rural ha destruido también las laderas de los cerros y otras tierras marginales, ya que los minifundistas utilizan sistemas primitivos de explotación intensiva en terrenos desbrozados no aptos para esta clase de explotación. La situación es aún más grave en terrenos lateríticos y en países tropicales como El Salvador, donde la agricultura de subsistencia se ha extendido a expensas de los bosques de especies de hojas caducas. El aumento de la densidad de la población ha obligado a los minifundistas a cambiar del cultivo trashumante al permanente de la tierra, y a acortar el período de barbecho a entre tres y cinco años, con el agotamiento y erosión consiguientes de los suelos. Efectos más generales de este fenómeno se observan, por ejemplo, en la presa Cinco de Noviembre sobre el río Lempa. Según se calcula, perderá $40 \%$ de su capacidad de almacenamiento en los próximos 20 años como consecuencia del atarquinamiento ocasionado por la erosión. Además, al eliminarse la vegetación, ha aumentado la temperatura del suelo $\mathrm{y}$ se ha modificado o destruido parcialmente

10 Véase ejemplos de una amplia gama de tipos de deterioro del medio ambiente en Environmental Costs and Priorities: A Study at Different Locations and Stages of Development, Grupo de Expertos en Desarrollo y Medio Ambiente, Ginebra, 4 al 12 de junio de 1971, p. 677.

11 Véase República de Chile: Informe para la Conferencia de Naciones Unidas sobre el Medio Ambiente Humano, op. cit., p. 9. 
el habitat animal, al punto de haberse extinguido en el país 19 especies de mamíferos.

Estos problemas derivan en gran parte del régimen poco equitativo de tenencia de la tierra, unido al crecimiento acelerado de la población y a una administración desastrosa de las explotaciones agrícolas. Sin embargo, incluso el empleo de técnicas excelentes y de modernos métodos de cultivo puede tener no deseados efectos secundarios imprevistos.

Las consecuencias desafortunadas que puede acarrear la expansión mal planificada del riego (salinización de los suelos o propagación de la esquistosomiasis), el uso indiscriminado de fertilizantes químicos (obstrucción de los cursos de agua) y la excesiva aplicación de pesticidas (con la consiguiente destrucción de especies predatorias que ayudan a conservar el equilibrio ecológico) son bien conocidas en el mundo, y América Latina no está libre de ellas. $Y$ por su parte, la mecanización de la agricultura puede destruir los ecosistemas forestales, como ha sucedido en el Mato Grosso brasileño. ${ }^{12}$

Dicho en otros términos, la utilización de la tierra encaminada a obtener resultados rápidos y de corto plazo, ya sea con fines de simple explotación, o para obtener metas de desarrollo aparentemente más desinteresadas, se ha traducido en el deterioro de la ecología natural de muchas zonas agrícolas y forestales.

Los bosques de América Latina se cuentan entre las principales víctimas de los métodos de "desarrollo" utilizados durante siglos. En Brasil, hay estados - Minas Gerais y São Paulo, por ejemplo- en que menos de $10 \%$ de la superficie está ahora cubierta de bosques, y gran parte de la zona desnuda está expuesta a la erosión. Además, se estima que todos los años se pierden 300000 toneladas de madera debido a los inadecuados métodos de tala. El hecho de que no se reemplace los árboles que se derriban, o que se pierdan por incendios o enfermedades, muestra que sólo se piensa en la explotación de corto plazo. Es probable que debido a ello Chile pierda anualmente 50000 hectáreas de bosques.

Los ejemplos citados son los que mejor ilustran el deterioro producido en el medio ambiente natural del continente. Sin embargo, hay otros, quizá menos palpables pero igualmente desafortunados: la extinción de $70 \%$ de la fauna del Brasil por la tala de grandes extensiones de bosques, y el peligro que se cierne sobre 44 especies; la amenaza a otras especies que significa la construcción de caminos en Colombia, al alterar la ecología natural de las zonas adyacentes y permitir el acceso a los cazadores del jaguar y el tapir; o la simple explotación excesiva de algunas especies de peces, como el atún aleta amarilla, el bonito peruano y la merluza, el camarón y la anchoveta del Caribe. La minería también ha contribuido al despojo y a la contaminación de los terrenos adyacentes, a la erosión ocasionada por las excavaciones mineras y a la contaminación de ríos y costas.

En el medio ambiente artificial - por lo general en los asentamientos

12 Véase Environmental Casts and Priorities, op. cit., p. 9 ss. 
humanos, pero sobre todo en las estructuras físicas de los grandes centros metropolitanos densamente poblados - también se han dejado sentir, a veces con fuerza, los efectos del crecimiento desequilibrado y de la presión demográfica.

La contaminación del aire, la tierra y el agua, particularmente en ciudades como Santiago de Chile, Lima, Buenos Aires, São Paulo y México, pero también en muchos otros centros en que se concentran la población, la industria, o ambas cosas, a veces es casi tan grave como la peor que experimentan las naciones industrializadas. Por ejemplo, en. Santiago de Chile el anhídrido sulfuroso y el polvo que contiene el aire de la ciudad en el invierno supera los niveles internacionalmente aceptables. La contaminación producida por los gases de escape de los vehículos automotores suele sobrepasar los límites permitidos, no obstante la reducida proporción de vehículos por habitante.13 Se estima que en 1969 cayeron sobre la ciudad 65 toneladas de polvo por kilómetro cuadrado. Otras ciudades también enfrentan estos problemas; el anhídrido sulfuroso y el polvo tanto en suspensión como depositado afectan de diversas maneras la mayoría de los grandes conglomerados urbanos del continente. La calefacción doméstica y la incineración privada de desperdicios causan parte de la contaminación del aire, pero mayor es la que ocasionan la industria y los vehículos automotores. En São Paulo, en la zona de Capuava se descargan diariamente 18 toneladas de compuestos de azufre, mientras que la población de São Caetano do Sul está expuesta a la contaminación por ácido sulfúrico y carburo de calcio provenientes de las refinerías de petróleo y las fundiciones de hierro. Centros pequeños como La Oroya, en Perú, que tiene 35000 habitantes, deben soportar las emanaciones de gases de azufre, plomo y arsénico provenientes de una planta metalúrgica. $Y$ en algunos valles rurales peruanos los cultivos de papas, los olivares y las frutas han sido destruidos por el anhídrido sulfuroso contenido en la atmósfera.

Sin embargo, los efectos más perjudiciales se han hecho sentir en las grandes ciudades, debido al tránsito de vehículos automotores y en especial de automóviles. Esos efectos se agravan cuando se combinan con condiciones climáticas especiales, como en la ciudad de México, Caracas y Santiago. En la ciudad de México, la contaminación atmosférica se debe en gran medida a los automóviles. En 1968 el $40 \%$ de los 1.6 millones de automóviles que hay en la nación se concentró en la capital y descargaron diariamente en la atmósfera del valle 4884 kilogramos de hidrocarburos y 24077 de partículas. Problemas similares se producen en las calles estrechas y hacinadas de casi todos los centros urbanos diseñados en tiempos coloniales para usos totalmente distintos. El centro de Lima, donde circulan 300000 vehículos, es uno de los ejemplos más severos de este problema.

Del mismo modo, el desarrollo desequilibrado del continente ha contribuido a la contaminación de los ríos y de los sistemas de agua. Las

13 Véase República de Chile: Informe para la Conferencia de las Naciones Unidas sobre el Medio Ambiente Humano, op. cit, p. 18. 
ciudades ofrecen los ejemplos más visibles de contaminación de cursos de agua de todos tamaños. El Río de la Plata de Buenos Aires, el Mapocho de Santiago, el Rimac de Lima, el Bogotá y la Bahía de Guanabara en Río, son receptáculos de aguas servidas y otros desperdicios.

Fuera de los grandes centros, los complejos industriales han causado contaminación en ciudades más pequeñas como Chimbote, en Perú, donde, antes del terremoto de 1970 , una planta siderúrgica y algunas fábricas de harina de pescado habían contaminado totalmente la bahía vecina. Además, en un continente donde sólo se somete a tratamiento alrededor de $10 \%$ de las aguas servidas, lo más probable es que cualquier asentamiento humano contribuya a la contaminación de las aguas.

Las descripciones precedentes sobre el deterioro del medio ambiente natural y la contaminación del ambiente artificial sugieren que hay relaciones recíprocas entre el medio ambiente (como elemento pasivo, receptor) y la población (como elemento activo), dentro de un marco sistemático. Este es un enfoque demasiado simplista de la situación. En efecto, dentro de la variable población hay sectores más activos y otros menos, según la posición social y política que ocupen dentro de la sociedad.

Sin entrar en mayores detalles, es evidente que todos contribuyen de manera más o menos igual a algunas formas de contaminación. No obstante, dentro de la amplia variedad de las formas más graves de destrucción y contaminación del medio ambiente, también es evidente que algunos grupos son más culpables que otros. De una parte, las causas de muchos de los problemas ocasionados por los minifundistas que trabajan tierras marginales se remontan mucho más atrás de la causa inmediata - el campesino-, pues proviene de un régimen de tenencia que reserva las mejores tierras a propietarios adinerados que no siempre las explotan con eficiencia. Así pues, el campesino tiene que optar entre tratar de cultivar las tierras marginales casi inexplotables, o contribuir a distintas formas de devastación ambiental sumándose a los movimientos migratorios para colonizar tierras vírgenes, o ganarse la vida en las zonas urbanas.

Con todo, hay que reconocer que el campesino, el poblador marginal, el trabajador sindicalizado e incluso gran parte de la clase media, no son responsables de la destrucción o contaminación en gran escala ocasionada por las actividades mineras, las industrias y los vehículos automotores.

En todo esto hay un elemento de injusticia social. En verdad, por lo general los grupos directa o indirectamente responsables de la contaminación son los que menos sufren sus efectos. Por ejemplo, gran parte de la contaminación industrial se debe a las fábricas que producen bienes duraderos para el consumo suntuario, pero son los grupos de menores ingresos los que trabajan y viven en las zonas industriales, los que respiran las emanaciones y usan el agua contaminada: los ricos y los que tienen influencia política viven lejos de tales distritos. Del mismo modo, los automóviles particulares, que causan gran parte del brumo 
urbano, generalmente ocasionan los problemas más graves en el centro de las ciudades y lejos' de los suburbios más acomodados. $\mathbf{Y}$ como efecto secundario, las minorías que utilizan automóviles y que son casi siempre las que tienen mayor influjo en la toma de decisiones, no se ven urgidas a mejorar los servicios de transporte público, que son por lo común sucios, ruidosos e ineficientes.

La situación antes descrita podría explicar en parte la falta de medidas adecuadas contra la contaminación atmosférica, del suelo y del agua, contra el hacinamiento y los ruidos causados por la industria y los automóviles particulares, todos ellos problemas originados por la opulencia y por un estilo de desarrollo que copia el del mundo industrializado.14

c) Los problemas ambientales $y$ sus consecuencias sociales. Uno de los planteamientos básicos de este análisis consiste en que hay interacción constante entre las distintas variables que configuran el proceso de desarrollo-subdesarrollo. Y esto sigue siendo aplicable al nexo población-medio ambiente. Hasta ahora se ha examinado una de las facetas de las relaciones: el efecto de la población (en la sociedad) sobre el medio ambiente. No obstante, si se expresa esta relación entre la población y el medio ambiente utilizando los símbolos $\mathrm{P}$ y E, podría decirse que el vínculo es más que sólo $\mathrm{P} \rightarrow \mathrm{E}$; resulta más realista expresarlo como $\mathrm{P} \rightarrow \mathrm{E} \rightarrow \mathrm{P}$ o bien $\mathrm{P} \rightleftarrows \mathrm{E}$, en que el factor población produce ciertos efectos en el medio ambiente natural y artificial, actuando- a través de la sociedad y aplicando sus instrumentos tecnológicos a los recursos disponibles para alcanzar modalidades de producción que satisfagan los estilos de consumo de distintos grupos sociales, determinados por factores culturales. Sin embargo, todo cambio que se introduzca en el medio ambiente natural o artificial actuaría a su vez sobre la población de manera que se producirá un efecto social que irá de E a P.

En las zonas rurales este efecto ha sacudido a la mayoría de los grupos. Las consecuencias de la presión demográfica, de la desigual distribución de la tierra, de la degradación del medio ambiente y de la "modernización" han sido amplias y variables. Pocos son los asentamientos rurales —e incluso los centros pequeños- que disponen de los servicios más rudimentarios para sus habitantes, mientras fuera de esos asentamientos, la elevada dispersión de gran parte del empleo

14 E. Novaes, E. Neira y J. Van Fleet, en Environmental Problems of Development, Banco Interamericano de Desarrollo, Washington, junio de 1971, pp. 12 a 13 (documento mimeografiado), se refieren a los problemas de transporte y observan que "parecen estar determinados inevitablemente por una modalidad de consumo que se debe más a la presencia de efectos de demostración que al verdadero poder adquisitivo de la población". Además, la propiedad privada de automóviles tiene efectos negativos en los sistemas de transporte público: "En estas circunstancias, el transporte urbano presenta hoy graves problemas de congestión y contribuye ampliamente a la contaminación del aire". Sin embargo, los autores no creen que haya muchas posibilidades de resolver las contradicciones que existen entre un crecimiento nacional que depende del desarrollo de la industria automotriz, y los problemas así creados por el medio ambiente urbano. 
rural en América Latina ${ }^{15}$ se traduce en condiciones de vida primitivas.

Escasean elementos tan esenciales como la vivienda adecuada, el agua potable, la electricidad, la educación y los servicios de salud. ${ }^{16}$ Así, por ejemplo, en 1970 sólo disponía de agua potable un $24 \%$ de la población rural de América Latina y un 3 o $4 \%$ de la de Bolivia, Brasil y Haití, y aunque cifras de esta índole tienden a ser algo arbitrarias, se estima que más de un $80 \%$ de las viviendas rurales de Guatemala, Honduras y Nicaragua son "deficientes".

Aparte del sufrimiento humano que sin duda causan, estas condiciones debilitan a la población rural y merman aún más su capacidad de producir lo suficiente para sí misma o para zonas urbanas en rápida expansión. El resultado más inmediato y evidente ha sido la emigración, particularmente de los elementos más jóvenes y dinámicos de la población, que en general dejan tras de sí a grupos residuales, de más edad, más conservadores' y menos instruidos, carentes a menudo de medios económicos adecuados y de servicios sociales aceptables, y, aunque la situación comienza a cambiar, desprovistos en general de suficiente conocimiento e influencia política para dar a conocer de manera eficaz sus necesidades y su descontento. ${ }^{17}$

La situación es cambiante, y son varios los autores que abogan por el fortalecimiento de las relaciones entre la ciudad y el campo para despertar a las zonas rurales.

Sin embargo, antes de intentar cualquier afirmación definitiva cabe plantearse ciertos interrogantes. En la esfera económica, por ejemplo, ¿hasta qué punto la penetración de nuevas ideas ha generado cambios en las técnicas de producción, mejoramiento del uso de la tierra y mayor productividad? $\mathrm{O}$, lo que es un problema social más complejo, ¿han alterado las relaciones entre el campesino y su patrón los valores nuevos creados por vínculos más estrechos entre la ciudad y el campo? ¿Las clases sociales menos privilegiadas tienen mayor o menor influencia política que en los días en que la periferia se encontraba más aislada? Si esa influencia es mayor, ¿de qué manera se expresa en el plano local y regional? ¿Se avanza hacia una mayor participación? ¿O simplemente se ha

15 En Panamá, por ejemplo, la población rural se encuentra dispersa o "...agrupada en pequeníísimos caseríos sin ningún plano propio instalados por lo general en áreas poco aptas para la agricultura, de topografía accidentada y alejados de las principales vías de comunicación". (Dra. L. Herrera, Atlas de geografía médica, Ministerio de Salud, República de Panamá, 1970.)

${ }_{16}$ "Si el $65 \%$ de la población total del país es la que vive en el medio rural ubicado en pequerias localidades que caracterizan a ésta como una población eminentemente dispersa, la misma que carece de los servicios básicos como son: de salud, educación, vivienda, agua potable, alcantarillado, transporte, etc... surge de por sí que las condiciones del medio ambiente son deficientes..." (Junta Nacional de Planificación, Breve consideración sobre la problemática del medio ambiente humano: caso ecuatoriano, Quito, Ecuador, sin fecha, p. 9.)

17 Véase Problemas de población y desarrollo en América Latina (sr/ecta/Conf.46/ L.1), documento presentado a la reunión del Grupo de Expertos sobre el Programa de Población de la cEpal (Santiago de Chile, 11 al 14 de diciembre de 1972). En pp. 33 ss. se analizan argumentos relativos a los efectos de las migraciones en las comunidades locales. 
cambiado una fuente de autoridad por otra, por ejemplo, del antiguo patrón a uno nuevo como el "hombre-nexo", que vincula el centro de decisión y el mercado urbano con el campo?

Es posible al menos sugerir algunas respuestas. El movimiento migratorio a las ciudades aún no ha resuelto la crisis del sector agropecuario que aflige a la mayoría de los países latinoamericanos. ${ }^{18}$ Pese a los grandes movimientos de personas hacia las zonas urbanas, la población rural sigue aumentando en América Latina a una tasa de aproximadamente $1.5 \%$ anual, tasa que se eleva a más de $2 \%$ en algunos de los países más pequeños y menos urbanizados. (Sin embargo, no debe olvidarse que esto encubre tanto la situación de algunas regiones inexploradas -que se están poblando y colonizando rápidamente gracias a la migración-, como la de zonas con asentamientos rurales más antiguos que se están estancando o perdiendo población al proporcionar mano de obra agrícola a zonas nuevas y pujantes.)

No obstante, con la llegada de los medios de información a las zonas más apartadas, y el constante ir y venir de migrantes entre zonas rurales y urbanas, la gran mayoría de los que viven en zonas periféricas inevitablemente confrontan nuevas ideas, valores y formas de vida.

Además, los efectos de estas influencias culturales se refuerzan con otros factores, entre ellos la aparición de nuevos bienes de consumo en las zonas rurales y los pueblos de la periferia que, como no pueden producirse alli, aumentan la dependencia del mercado nacional; la creciente influencia de los movimientos políticos nacionales originados principalmente en las ciudades y que se contraponen a las formas tradicionales de liderazgo local; la iniciación de políticas de reforma agraria que llevan al campo a expertos agrícolas, funcionarios públicos y políticos venidos de la ciudad, para capacitar, educar y tratar de incorporar las comunidades locales a la vida nacional; la apertura hacia comunidades periféricas antes apartadas, a través de caminos y servicios de transporte públicos que, por muy inadecuados o decrépitos que sean, no sólo muestran nuevas formas de vida o nuevos usos de la tierra (por ejemplo, para fines de esparcimiento), sino que permiten que la gente que antes vivía en comunidades se desplace y se comunique con más facilidad. ${ }^{10}$

De esta manera, la "modernización" del campo y de los pueblos pequeños introduce fuerzas nuevas y poderosas en zonas anteriormente tradicionales y casi estáticas; hace que las comunidades tomen conciencia de los distintos estilos de vida, y origina necesidades y expectativas nuevas. Como sucede en las zonas urbanas, estas tendencias conducen a una situación paradójica en que se pone más de manifiesto cada vez la contradicción entre los efectos de demostración culturales y lo que sus medios económicos permite a la mayoría de la gente. Hasta cierto

18 En un artículo publicado en Civilisations, wol. XV, núm. 4, 1965, p. 484, Denis Lambert sostiene que en America Latina el alejamiento de la tierra acarrea casi inevitablemente la disminución de la productividad agrícola.

19 Véase El cambio social y la política de desarrollo social en América Latina, Publicación de las Naciones Unidas, núm. de venta: S.70 III.G.3. 
punto, las migraciones -particularmente de los grupos más jóvenes, de más empuje y más calificados- pueden aminorar el problema, transfiriéndolo a los centros urbanos, pero el continuo crecimiento de la población rural, unido al problema permanente de encontrar empleo adecuado, hace que la situación siga siendo inestable.

Los efectos sociales de la devastación y el deterioro del medio ambiente son todavía más notables en las zonas urbanas, aunque sólo sea porque los problemas aparecen más concentrados y visibles en los barrios marginales que circundan los centros urbanos del continente y que albergan una proporción considerable de la población de las ciudades.

Estas condiciones van unidas a menudo a un incremento acelerado de la población nacional. Sin embargo, la situación de la Argentina, donde las bajas tasas de aumento de la población no han logrado librar a Buenos Aires de los problemas asociados a la distribución cada vez más desequilibrada de esa población, indica que éste es sólo uno de muchos factores. El tamaño mismo del Gran Buenos Aires (que posee más de un tercio de la población del país)

“... constituye una realidad económica y social cuyos costos son dif́ciles de mitigar. Por un lado, las distancias entre la vivienda y el empleo ocasionan un considerable desperdicio de tiempo en desplazamientos; por otro, la rapidez del proceso de urbanización producido entre 1947 y 1960 , y la ausencia de una acción sostenida en materia de construcción de vivienda, generaron un habitat rudimentario...

"Un estado de déficit crónico se ha vuelto característico. Gran parte de los habitantes metropolitanos se ven constreñidos a habituarse a interrupciones en la provisión de agua, al aislamiento por falta de líneas telefónicas, a desgastarse en interminables viajes diarios y recrearse en las riberas contaminadas.

"Finalmente, la desordenada apropiación de espacio urbano, y la imposibilidad de atender simultáneamente todas las necesidades, han acrecentado de tal modo las urgencias en el dominio de los equipamientos colectivos que la generalización de los "déficit" parecería constituir hoy otro rasgo característico de la vida metropolitana." 20

La concentración de la población y de las actividades económicas, sociales y de otra índole en las metropolis impone grandes exigencias, particularmente a los centros urbanos importantes. La tierra se usa en forma intensiva para construir en altura y concentrar apretadamente actividades comerciales, industriales y de administración pública (aunque por la especialización de las actividades y la inadecuada planificación urbana, gran parte del uso sólo es intensivo durante algunas horas del día). El suministro de agua para usos múltiples (y a menudo dispendiosos) también está sometido a severas presiones, y lo mismo sucede con otros recursos físicos, incluido el aire mismo de la ciudad. La gran demanda de todos ellos ha elevado los costo de utilización, ${ }^{21}$ ocasionan-

20 "Informe Nacional: República Argentina", op. cit., p. 5.

21 Véase oxa, Urbanización y el medio ambiente humano en América Latina (México, D. F., 1971, p. 4), donde, además, se cita la observación de Simon Kuznets de que se necesitan más recursos para satisfacer en la misma medida las necesidades de vi- 
do enormes problemas de decadencia y deterioro físicos en las grandes zonas urbanas.

No obstante, tras estos problemas de comodidad y agrado físicos se da una privación ambiental más profunda y compleja. Es probable que los efectos de la contaminación, el hacinamiento, el ruido y la falta de independencia afecten también a los habitantes de las ciudades en un sentido más amplio, al limitar el desarrollo pleno de sus potencialidades en el trabajo, y su capacidad para disfrutar de sus horas libres. Con el hacinamiento y el ruido muchos de ellos experimentarán ansiedades y tensiones nerviosas que los afectarán individualmente y en sus relaciones familiares y comunitarias. ${ }^{22}$

Con todo, al analizar las repercusiones sociales, económicas y culturales del tipo de desarrollo físico que tiene lugar en los centros hiperurbanizados de América Latina, no resulta fácil generalizar. Los estudios hechos sobre los grupos que se trasladan a las ciudades y se asientan en barrios de tugurios centrales o en las poblaciones marginales que circundan las zonas urbanas, indican que no se puede llegar a conclusiones ligeras ni desde el punto de vista social, ni desde una perspectiva política. No se conoce bien todavía la capacidad de los diversos grupos migrantes para adaptarse a las diferentes situaciones que plantea la vida en la ciudad, para participar activamente en la comunidad más amplia, para encontrar empleo o para crear nuevos lazos familiares y comunitarios.

Los grupos de clase media más afortunados encuentran empleo en el sector de los servicios, e incrementan las filas de las burocracias privada y estatal; realizan funciones que a menudo sólo son, en el mejor de los casos, marginalmente productivas y con frecuencia contraproducentes, porque lógicamente el objetivo principal de esas burocracias es crear oportunidades de trabajo y no resolver problemas en foma rápida y eficiente. La población marginal menos afortunada, que carece de la capacitación básica mínima para ingresar a las actividades del sector de los servicios en oficinas o tiendas, procura crear sus propias oportunidades en el sector terciario. ${ }^{23}$ Sus miembros se convierten en vendedores viajeros de cualquier bien de consumo o servicio que puedan ofrecer, en empleados domésticos de la clase media, o en trabajadores no calificados en la infraestructura de la ciudad y, sobre todo, en la industria de la construcción, sector que “... es muy sensible a los cambios en el ritmo del crecimiento económico y a las fluctuaciones del gasto público. Hacia él gravita la mano de obra urbana sin calificación que

vienda, alcantarillado, agua, transporte intraurbano, efc., que en las zonas menos. densamente pobladas. Esto sugiere que el análisis de umbral podría ayudar a proporcionar una mejor aproximación de los verdaderos costos y beneficios económicos del crecimiento metropolitano concentrado.

22 Véase Naciones Unidas, Departamento de Asuntos Economicos y Sociales, Human Settlements, Nueva York, vol. 1, núm. 3, julio de 1971, p. 12.

23 Para un análisis más detallado de este fenómeno, véase W.R. Armstrong y T.G. McGee, "Revolutionary change and the Third World city: A theory of urban involution", Civilisations, op. cit., PP. 353 a 378. 
no ha podido encontrar trabajo en otra actividad, y su fuerza de trabajo no es absorbida fácilmente por otras actividades económicas cuando baja el gasto en construcción". ${ }^{24}$ Y algunos se convierten en delincuentes menores. Como es de prever, la fuerza laboral sindicalizada del sector moderno se mantiene bastante estable en cuanto a volumen, y se abre poco a los grupos marginales.

Sin embargo, algunos autores sostienen que la ciudad ofrece a los migrantes mejores condiciones de vida en lo que se refiere a acceso al empleo y en especial a los servicios de salud y educación. Así pues, el deterioro del medio ambiente creado por el hombre tiene menos importancia que el nuevo horizonte social, económico y político que se les abre a ellos y a sus hijos en el ambiente urbano. ${ }^{25}$

Diferente es el panorama que surge de los estudios realizados en una serie de poblaciones marginales de Santiago de Chile, donde el autor encuentra, entre otras cosas, lo siguiente:

“...la reducción del campo de percepción social y la dualidad de la orientación perceptiva del mundo social, entre algunos de los problemas destacados. Lo primero se manifiesta en la manera vaga, inorgánica y difusa en que se percibe el mundo no inmediato y directamente referido a la vida cotidiana, mientras que ésta se percibe con nítida claridad, con elementos precisos, que permiten una definición clara de comportamiento. Lo segundo se manifiesta en que la vida diaria dentro del propio mundo de la marginalidad se percibe y se define con elementos realistas $y$, en cambio, se recurre a elementos de contenido mágico para definir el resto del universo social.

"De este modo se puede señalar de una manera provisoria que no solamente se encuentra entre los marginados la presencia de traumas en la formación de la personalidad síquica, fisuras que dan paso a inseguridad, a las desviaciones de tipos delictivo en algunos casos o predisposiciones a un cuadro psicótico, sino que la situación de marginalidad afecta un nivel más profundo de la sicología individual y de grupos." 26

Como es natural, ambos puntos de vista no se excluyen mutuamente; las tendencias son heterogéneas y los niveles de compromiso político, social y económico, así como los culturales, varían según las oportunidades que ofrezcan las distintas ciudades, la flexibilidad social de la sociedad, los antecedentes sociales y culturales de los migrantes, e incluso la generación a que pertenece el poblador marginal.

Podría aducirse que, al menos, la situación de los migrantes no es peor que la que tenían en las zonas rurales. Al incorporarse más a la corriente de la vida nacional representada por las ciudades se han creado graves tensiones en la vida familiar y comunitaria, que han agudizado

24 Henry Kirsch, "El empleo y el aprovechamiento de los recursos humanos en America Latina", Boletín Económico de América Latina, Publicación de las Naciones Unidas, núm. de venta S.73.II.G.3, p. 53.

25 Véase "Environmental Problems of Urban Development", op. cit., p. 7.

26 Carmen Pimentel Sevilla, Vidas Marginales, Editorial Universitaria, Cormorán, Santiago, 1973, p. 31. 
toda una gama de problemas sociales. ${ }^{27}$ No obstante, a cambio de estos costos sociales de la marginalidad, las personas que viven en el medio ambiente desfavorable de los barrios marginales pueden disfrutar de ciertos beneficios en virtud de su poder de facto para obtener de las autoridades la solución de problemas inmediatos: vivienda, agua, energía, etc.

Además, diversos autores han elogiado los elementos positivos de las poblaciones marginales. Según ellos, bajo la apariencia superficial de miseria ambiental, los barrios marginales dan la oportunidad de poner en práctica la ayuda propia entre grupos de personas que, en general, se han adaptado bien a las exigencias de la vida en la ciudad. Su deseo de bastarse a sí mismos, y de formar una entidad social estable dentro de la sociedad más amplia, se manifiesta comúnmente poco después de haber ocupado tierras para asentarse (habitualmente por medios ilegales). Construyen su propia vivienda a un costo muy inferior al que pueden lograr los planificadores, establecen muchos de los servicios necesarios, forman sus propias organizaciones locales, $y$, al parecer, se dedican a integrarse a la vida de la comunidad mayor.

Lo anterior es válido sin duda para algunas situaciones, pero, dada la dinámica evolución de la vida urbana latinoamericana, quedan todavía muchas preguntas sin responder. ¿Cuánto durará esta calma? La actual estabilidad podría romperse con la proxima generación, a la que se ha llevado a esperar más de la sociedad. Sus "necesidades manifiestas" comenzarán a un nivel más alto de expectativas y percepciones que las de la generación migrante más antigua.

En este punto podría plantearse también un interrogante más general relacionado con la adopción de políticas. Es indudable que los barrios marginales de América Latina constituyen una solución a falta de otra mejor, sobre todo para quienes tienen a su cargo las decisiones y para los planificadores que se enfrentan generalmente a una situación de hecho cuando se ocupan terrenos para un asentamiento de precaristas. Para los pobladores esto es mejor que nada, pues en tales asentamientos encuentran una suerte de respuesta que las autoridades no han podido dar: les. Además, esta solución conviene a la clase media, que continúa asî absorbiendo una proporción desmedida de las asignaciones públicas al sector de la vivienda. Sin embargo, se pasa por alto un problema de más envergadura: el hecho de que las políticas preventivas, a través del desarrollo regional eficaz, de la reforma agraria y de la centralización de la actividad económica, podrían abrir el camino a fin de evitar tales formas de crecimiento, y sus nocivas secuelas para el medio ambiente. Vistos en forma objetiva, los asentamientos de precaristas no previenen ni cutan; son por definición una respuesta espontánea al deterioro social.

27 Véanse ejemplos más detallados en diversos informes nacionales presentados a la Conferencia de las Naciones Unidas sobre el Medio Ambiente Humano realizada en Estocolmo, y sobre todo los siguientes: "Jamaica: National Report" (documento mimeografiado, sin fecha), p. 18; Breve consideración sobre la problemática del medio amr biente humano: caso ecuatoriano, op. cit., pp. 11, 17 y 18 , e Informe nacional dy Bolivia sobre 'El medio ambiente humano', op. cit, pp. 4 y 5. 
Sin desconocer las graves dificultades prácticas que impiden una planificación eficaz, se ha planteado aquí el tema de los barrios marginales para recordar a planificadores y políticos que el problema existe, no de manera aislada sino como parte de una vasta trama integral de causa y efecto.

\section{4) Políticas para un desarrollo integrado}

Para determinar si en América Latina es viable una estrategia de desarrollo que contenga objetivos ambientales, cabría ante todo analizar los efectos que podría tener la persistencia de las tendencias actuales -a lo más con interrupciones parciales y de corto plazo- en materia de políticas en los distintos sectores del sistema, frente a crisis individuales. $^{28}$

Aun sin una extrapolación detallada de cada aspecto de la trayectoria desarrollo/subdesarrollo de América Latina, parece lógico suponer que continuará la tendencia a la concentración de la población y de la actividad económica, y que, al menos en el próximo decenio o algo más, tal concentración se acentuará en virtud de tasas medianas o altas de aumento de la población. Lo más probable es que la migración sólo sirva en las zonas rurales para atenuar parcialmente la presión humana sobre la tierra, aunque cabe esperar cierto alivio de la apertura de nuevas zonas. Con todo, esto tendrá a menudo consecuencias perjudiciales para el medio ambiente.

Por otra parte, la importación indiscriminada de tecnología y su uso sin la debida consideración de sus efectos en el medio ambiente humano y natural, tendrán repercusiones cada vez más adversas de la índole descrita. Parece logico esperar que continúe la rápida destrucción y desperdicio de recursos naturales, y que las desigualdades en las estructuras sociopolíticas se traduzcan en crecientes diferencias entre los grupos ricos y pobres de la sociedad.

Es probable que ninguno de estos desequilibrios entre las variables se traduzca en una desintegración dramática o a corto plazo; el sistema vigente ha mostrado un grado considerable de flexibilidad para encarar las crisis. Sin embargo, se puede predecir que la degradación ininterrumpida del medio ambiente natural, unida a las contradicciones inherentes al medio artificial y social, harán cada vez más oneroso - tanto en términos económicos como sociales y políticos- mantener el esquema actual.

Muchos gobiernos se han percatado ya de las dificultades que acarrea pretender que los problemas sociales se resuelvan por sí solos, y han adoptado medidas institucionales para introducir cierto orden en el desarrollo mediante la formulación de planes nacionales. Pero, dejando de lado por el momento las discrepancias entre formulación y ejecución, hay pocos indicios de que tales planes hayan confrontado los pro-

28 Parte del esquema que sigue se basa en la estructura elaborada en A project of global energy planning por un grupo de expertos del Centro Europeo del Carnegie Endowment, en La Mainaz, Francia, el 4 y 5 de mayo de 1973. 
blemas de desarrollo - ni siquiera en su etapa de formulación- teniendo en cuenta que las variables son partes relacionadas de un sistema total.

Sin embargo, la elaboración de estrategias de desarrollo tiende a algo más que a evitar conflictos destructivos y a armonizar las distintas variables del proceso de desarrollo. Para ser coherente, la planificación debe establecer ciertas normas y metas cuya consecución exija cambios sociales y económicos. $\mathrm{Y}$ a su vez, tal postulación de principios y metas obliga a ponderar y seleccionar algunas opciones consecuentes con las metas adoptadas.

Para mencionar un solo ejemplo: el interés por mejorar el medio natural y social tal vez fuerce a adaptar la tecnología a fin de conservar los recursos, ofrecer más empleos y cambiar las modalidades de consumo de la sociedad. En vez de dedicar recursos de capital escasos a producir automb́viles para el sector privado, destinarlos a mejorar los servicios públicos de transporte y a proporcionar medios de transporte intermedios y más económicos - bicicletas, por ejemplo- que sirvan a la mayoría de la población. Políticas de esta naturaleza deben complementarse con formas de planificación urbana que, entre otras cosas, acerquen la gente a su trabajo y a los servicios sociales y culturales, y contribuyan así a crear un sentido de comunidad dentro de la entidad urbana mayor.

Con el factor ambiental como punto de partida en las regiones periféricas, quienes planifican y deciden podrían llegar a la conclusión de que es imprescindible introducir cambios importantes en las formas de vida y en las estructuras socioeconómicas si se desea lograr un desarrollo basado en un nivel más alto de autosuficiencia regional.

La adopción de esta norma llevaría a poner el acento en la conservación de los recursos mediante su uso múltiple y su reaprovechamiento; en la utilización planificada de los recursos locales (madera, piedra, arcilla, etc.) para la construcción de edificios, carreteras y otras obras de infraestructura, y en la creación de pequeñas empresas locales (agroindustrias 0 artesanías, etc.) que aplican tecnologías sencillas, de bajo costo, adaptadas a la capacidad y las necesidades locales (sin excluir el uso de tecnología más compleja si es necesaria para proyectos en gran escala). También se requerińa estimular el espíritu creador y la iniciativa latentes en la comunidad local, a través de servicios educativos y de extensión y de la ampliación a la base social de la participación en la toma de decisiones.

La aceptación de una estrategia de esta índole tal vez ayudaría a avanzar hacia formas armónicas de desarrollo que permitiesen conservar recursos escasos (por ejemplo, en el sector transportes, donde en el peor de los casos podría postergarse gran parte de la cuantiosa inversión en carreteras, ferrocarriles y terminales), y, a la vez, hacer uso más eficaz y equilibrado de los factores de desarrollo.

En síntesis, una etapa importante -0 , mejor dicho, esencial- del proceso de planificación, es la formulación de objetivos ideales basados 
en ciertas normas y principios que se consideran indispensables para alcanzar modalidades más equilibradas de desarrollo. Tal planificación normativa es necesaria para que las metas y principios de quienes adopten las decisiones sean claros, y para descubrir lo que haya de inadecuado y contradictorio en los estilos de desarrollo aplicados. Pero obviamente no es la condición decisiva para planificar en sociedades constreñidas por muchos obstáculos socioeconómicos, políticos o-en menor grado- físicos que deben tenerse en cuenta.

Para tratar de conciliar las diferencias entre las metas deseables y las limitaciones impuestas por la situación real, será preciso realizar estudios de factibilidad. En la mayoría de los países latinoamericanos son formidables las restricciones. Los obstáculos que oponen ciertos grupos influyentes, el espíritu conservador de las autoridades de gobierno, la pesada carga de las costumbres y de las actitudes tradicionales, la ineficiencia administrativa y la falta de recursos humanos y financieros, forman parte de las limitaciones sistemáticas que deben tener en cuenta quienes elaboran las políticas, en su intento de conciliar las metas normativas con las realidades prácticas de una situación determinada.

La experiencia indica que los planificadores latinoamericanos no han logrado encontrar una fórmula de transacción satisfactoria ni conciliar las distintas variables que podrían conducir a políticas de desarrollo más orgánicas. Los intentos realizados con miras a regular o modificar las tendencias existentes incluyen:

a) políticas destinadas a reducir el ritmo de crecimiento de la población, aunque más de palabra que de obra;

b) leyes encaminadas a evitar la contaminación y el consiguiente deterioro físico del medio ambiente urbano e industrial, ${ }^{29}$ pero sin considerar factores socioeconómicos que determinan en gran medida las condiciones ambientales;

c) políticas de desarrollo regional, copiadas en su enfoque técnico de las naciones ricas (cuyo éxito sólo ha sido parcial pese a su gran acervo de recursos humanos y financieros); con ellas se ha procurado disminuir el crecimiento de las grandes concentraciones urbanas, encauzando la actividad económica y las personas hacia otros polos de crecimiento creados fundamentalmente sobre la base de un cálculo de los costos y beneficios económicos para el sector privado;

d) programas de reforma agraria que, en muchas ocasiones, se han traducido en proyectos experimentales o programas de colonización, y no en una redistribución en gran escala destinada a combinar una mayor equidad social con la eficiencia económica. Son pocos los casos en que se ha logrado aplicar una reforma agraria que genere profundos cambios económicos, sociales y políticos en las zonas rurales;

e) políticas de reforma urbana, zonificación y vivienda cuyos efectos

29 Véase un breve informe de la labor realizada por un organismo de esta naturaleza creado en 1963, en virtud de un convenio suscrito por el Gobierno de Chile, la Organización Mundial de la Salud y el Programa de las Naciones Unidas para el Desarrollo en Instituto de Higiene del Trabajo y Estudio de la contaminación atmostérica, Santiago, Chile, oMs, Ginebra, 1970 (documento mimeografiado). 
han sido inadecuados frente a la magnitud de las exigencias derivadas del desarrollo regional desequilibrado que se observa en los países de América Latina.

Es difícil calcular hasta qué punto las políticas habitacionales se han quedado cortas frente a las necesidades de vivienda, ${ }^{30}$ pero basta mirar en torno para comprobar que la afluencia de migrantes hacia los centros urbanos deja muy mal parada a la mayoría de los programas de vivienda, $y$, a decir verdad, los de transporte urbano, zonificación y servicios sociales o de utilidad pública.

Las razones del poco éxito de la mayoría de los intentos de planificación en América Latina parecen bastante claras. Ante todo, en las intenciones generales de los gobiernos ha pesado poco la necesidad de elegir entre diferentes factores para idear estrategias de desarrollo integrado. Con demasiada frecuencia se ha entendido que el "desarrollo" consiste fundamentalmente en fomentar el crecimiento económico, aumentar la producción de bienes e incrementar el producto nacional bruto, más que en producir y distribuir bienes y servicios para satisfacer las necesidades sociales, culturales y ambientales de toda la población. Y por lo demás, cuando en el proceso de crecimiento se contraponen las metas de los particulares y de la comunidad, esta última suele ser la perjudicada.

Visto desde un ángulo levemente distinto, podría decirse que los fracasos se han debido a que los poderosos grupos de intereses socioeconómicos que controlan los mecanismos políticos y administrativos relegan a segundo término las metas no económicas. Las organizaciones a las que asesores y planificadores ofrecen sus sugerencias tienen pocas posibilidades de modificar esta situación, aunque tengan fe en los programas ideales que ofrecen los expertos.

Pero, aunque se puedan superar estos obstáculos y se llegue a la etapa de ejecución, las políticas suelen perder su valor cuando se ponen en práctica aisladamente, desvinculadas de problemas conexos. Los ejemplos citados antes indican que las políticas de esa índole se han concebido y aplicado como medidas aisladas para lograr ciertas metas, y no como partes integrales e interrelacionadas de una estrategia nacional más amplia.

$O$, a la inversa: cuando los problemas se analizan dentro de un marco más amplio, se observa que los obstáculos socioeconómicos existentes impiden adoptar medidas eficaces. Dos ejemplos de problemas ambientales que muchos países latinoamericanos soportan con diversas variantes, en condiciones extremas de urbanización moderna uno, y de estancamiento rural el otro, servirán para ilustrar tales obstáculos.

En el primer caso, las congestionadas zonas centrales de las grandes ciudades acusan una contaminación atmosférica de tal magnitud, que no puede pasarse por alto. Gradualmente, las autoridades realizan estudios, dictan leyes y establecen mecanismos reguladores para resolver el

80 Human Settlements, op. cit., p. 16. Véase además Situación de la vivienda en el mundo y estimaciones de las necesidades de vivienda, Publicación de las Naciones Unidas, núm. de venta: 65. IV.8, p. 32. 
problema. Sin embargo, sucede que antes se han establecido concentraciones industriales importantes en el sector de la zona urbana desde donde soplan los vientos dominantes. Las emanaciones que producen pueden reducirse hasta cierto punto, pero no eliminarse, y la reubicación de las industrias obligaría a incurrir en gastos prohibitivos, además de provocar resistencias en empresarios y trabajadores. El sistema de transporte público urbano es otro de los grandes causantes de la contaminación, y el problema que crea es aún más difícil de resolver. La mayoría de los vehículos están viejos y en mal estado. Las tarifas son muy bajas, y aumentarlas demasiado es difícil -o incluso peligroso desde el punto de vista político- por su gravitación en el presupuesto popular. Las empresas de autobuses producen utilidades sólo porque usan vehículos antiguos y gastan el mínimo en su conservación. Si se aplicaran disposiciones para retirar de circulación los vehículos que contaminan demasiado el medio ambiente, se paralizaría el sistema de transporte y las autoridades tendrían que hacer frente a protestas inmanejables. Así, las medidas y disposiciones para combatir la contaminación atmosférica a lo más lograría mantenerla dentro de límites más aceptables que aquellos a que llegaría sin ellas. Para aminorar en forma drástica la contaminación habría que introducir cambios profundos en las modalidades urbanas de crecimiento e incluso en la distribución del ingreso.

En el segundo caso, algunos grupos de labradores extremadamente pobres crían cabras en tierras marginales y fabrican carbón de leña con el fin de obtener algún ingreso en efectivo. El pastoreo de cabras y la fabricación de carbón de leña destruyen los pocos bosques que quedan en los cerros y ocasionan una funesta erosión. Los labradores lo saben, pero no pueden prescindir de este medio de vida complementario. La única forma de poner en vigor normas que prohíban el pastoreo y la fabricación de carbón es aplicar sistemas represivos, a costa de agravar la pobreza de esos grupos o de desplazar de la tierra a miles de familias cuyas condiciones de vida apenas bordean el nivel de subsistencia. Para resolver en forma aceptable y eficaz problemas al parecer tan simples como la deforestación y la destrucción de los suelos, las autoridades deben estar en condiciones de reasentar $u$ ofrecer otros medios de vida a las familias afectadas. Y ello exige a su vez políticas eficaces de reforma agraria, empleo y educación.

Esto no significa necesariamente que los organismos públicos dejen de estar conscientes de los factores causales. Sin embargo, por su incapacidad para hacer frente al vasto conjunto de problemas que es preciso abarcar para lograr una respuesta adecuada, se ven obligados a recurrir a paliativos, ya que las soluciones globales tropiezan inevitablemente con las rigideces y contradicciones del sistema. $\mathrm{Y}$ si a estas dificultades se suman la falta de datos estadísticos y de otra naturaleza y las presiones - siempre diferentes y en su mayoría exógenas - de una tecnología en evolución constante que tiende a estar en pugna con otras metas de desarrollo, es comprensible que los gobiernos vean pocas posibilidades de soluciones que vayan más allá del corto plazo. 
En realidad, las políticas de emergencia parecen haberse justificado hasta ahora, porque han logrado mantener a raya los problemas más apremiantes del subdesarrollo y crear condiciones de vida lo bastante flexibles como para que la mayor parte de la población se adapte en alguna forma a su situación. La tendencia natural y casi inevitable de los gobiernos es evitar las grandes soluciones de política que los podrían indisponer con poderosos grupos de interés, sin la compensación de conquistarles el apoyo inmediato de los sectores desposeídos de la sociedad. En todo caso, no es probable que haya cambios fundamentales a corto plazo, y son pocos los gobiernos que actúan en función de un plazo más largo del que dura su mandato.

Del conocimiento de los problemas derivados del propio sistema socioeconómico habrán de surgir las estrategias generales de desarrollo para convertirse a su vez en planes operativos eficaces. En América Latina se ha recorrido ya parte del camino y, a juzgar por la reacción en general favorable ante el concepto de desarrollo integral (o, dicho de otro modo: el "enfoque unificado") expuesto por la CEPAL, 31 parece haber al menos acuerdo formal en considerar la planificación con una perspectiva más amplia. Concretamente, algunos gobiernos han aceptado en principio -o han anticipado - las recomendaciones de la Conferencia de las Naciones Unidas sobre el Medio Ambiente Humano en el sentido de incluir integralmente los factores ambientales en la planificación global del desarrollo.

Aunque algo se ha avanzado, es probable que durante algún tiempo la reacción de los gobiernos sea cautelosa ante los argumentos en favor de un enfoque "unificado" o "integrado" del desarrollo.

Mientras tanto, pueden esbozarse algunos requisitos fundamentales para poner en práctica las estrategias de desarrollo integrado en los distintos países latinoamericanos, con el fin de ofrecer alguna apreciación, no sólo de la realidad que hay que conciliar con las metas normativas, sino también de los principales campos en los cuales cabría abogar por nuevos enfoques. Entre tales requisitos se hallan los siguientes:

a) la decisión de los gobiernos de aplicar tales políticas, para lo cual necesitan persuadir a los grupos sociales y económicos influyentes de que son valiosas y viables;

b) la eficacia operativa y la flexibilidad orgánica de los mecanismos administrativos del gobierno;

c) la capacidad financiera del gobierno y la mano de obra calificada de que dispone, y

d) la capacidad de los planificadores para llevar a cabo las estrategias nacionales de desarrollo, no sólo en función de las aspiraciones y los valores culturales de los distintos grupos sociales (que en sí puede entrañar la simple aceptación pasiva de lo que se ofrece), sino también con la participación activa - y a veces necesariamente agresiva- de los afectados por los planes.

31 Véase Evaluación de Quito. Primer bienio de la Estrategia Internacional de Des. arrollo, Santiago de Chile, abril de 1973, pp. 3 y 4. 
La participación popular es asunto especialmente complejo y depende en gran medida de la educación de todos los que intervienen en los cambios de política. Esto no significa, es de esperar, que se manejará a la gente para que acepte los programas del planificador, sino, por el contrario, que llevará a los expertos y la gente en general a elaborar conjuntamente los métodos para formular y ejecutar políticas. Para ello tendría que haber educación mutua a través del contacto de ambas partes, en un esfuerzo enderezado a cambiar las actitudes y aminorar en lo posible inevitables incomprensiones y recelos. ${ }^{82}$

Como es natural, tales requisitos entrañan unos cambios basados -al menos en parte- en soluciones de transacción para salvar los obstáculos políticos, culturales y sociales, y para abrir el camino a la elaboración de esquemas de desarrollo integrado.

El último requisito necesario en las economías de mercado latinoame. ricanas de carácter dependiente es la autonomía nacional. La ejecución de las estrategias integradas dependerá de la capacidad de las autoridades nacionales, regionales y locales para actuar frente a las presiones externas con la suficiente independencia. Y, a su vez, esto dependerá mucho de la medida en que se cumplen los demás requisitos.

\section{5) Conclusiones}

Uno de los aspectos que aquí se procura subrayar es que la población y el medio ambiente -pese a sus estrechas interrelaciones- no pueden tenerse en cuenta salvo en lo que toca a su situación dentro del campo más amplio del desarrollo societal. Estas relaciones tienen a su vez connotaciones adicionales para ambos elementos en el proceso de desarrollo.

En lo que toca a la población, la confrontación con las demás variables tal vez ayude a esclarecer algo que ha suscitado muchas polémicas: si la población es un elemento negativo o positivo en el logro de las metas societales. En la actualidad parece tener muchos adeptos el supuesto de que la gente causa molestias, agota los recursos y frena el progreso.

Este punto de vista no ayuda gran cosa a los países en que los seres humanos son el recurso potencial más valioso de que dispone la comunidad. Dentro del marco de una política a largo plazo encaminada a reducir el crecimiento de la población, parece más adecuado dar importancia a los atributos positivos de los individuos como seres que producen, deciden y contribuyen a la cultura y a la civilizacion, y no mirarlos como ratas de granero, voraces, destructivas y, por ende, prescindibles.

32 Solon Barraclough (véase "Rural Development Strategy...", op. cit., p. 31), refiriéndose especialmente a la situación del campo, menciona la necesidad de que haya "plena participación del campesino" en las políticas de desarrollo, y añade: "...toda estrategia de desamollo rural seguirá siendo inadecuada hasta que se tomen las duras decisiones políticas para avanzar directamente hacia metas de desarrollo, a pesar de los poderosos grupos de intereses que se oponen a compartir su poder y privilegios con los campesinos y demás grupos desposeídos". 
Esta última actitud es particularmente inapropiada en el mundo en desarrollo, donde el consumo por habitante de los recursos mundiales es sumamente bajo, si se compara con el de los países ricos.

Considerados en su conjunto, es evidente que los objetivos de desarrollo tendrán que contemplar un aflojamiento de las tasas de aumento de la población y el logro de una distribución espacial más equilibrada. Sin embargo, no todas las naciones del mundo pueden o deben avanzar al mismo ritmo. Si en América Latina disminuye la tasa de crecimiento y se producen cambios en la distribución de la población, será a consecuencia del desarrollo mismo, y no como parte de un conjunto de políticas basadas en un crecimiento económico nulo y un aumento demográfico nulo. Para reafirmar lo expresado antes cabría decir que será el aprovechamiento de todas las variables del desarrollo lo que permitirá crear las condiciones de vida más seguras para las masas rurales y urbanas de América Latina. $Y$ tales condiciones permitirán a su, vez cambiar las actitudes para que la sociedad conciba al niño como un ser humano, y no como una suerte de seguridad social: un asalariado adicional o un sostén para la vejez.

Del mismo modo, la relación población-medio ambiente debería analizarse dentro del marco más amplio de la sociedad en su conjunto. Equiparar de manera simplista la presión demográfica con la destrucción del medio ambiente es un criterio parcial y liviano que no tiene en cuenta las presiones sistemáticas que en América Latina llevan al mal uso de los recursos naturales en las zonas rurales, por poco pobladas que estén, y a la degradación del médio ambiente natural y artificial en los centros urbanos.

Los problemas de desequilibrio espacial y de tecnología inadecuada, así como las modalidades de producción y consumo, se analizaron antes, subrayando su papel en la relación población-medio ambiente-población. Por lo tanto, lo más útil ahora sería ubicar más claramente la relación en su marco global por medio de la siguiente pregunta: ¿Quiénes -o qué grupos de la sociedad- deterioran el medio ambiente y para quiénes? Esto incluye una serie de problemas conexos. ¿A quién culpar de la contaminación que ocasionan los automóviles particulares y de lo inadecuado de los servicios de transporte? ¿Quién obtiene mayores beneficios de los minerales que se extraen en los países latinoamericanos y quién se perjudica por la forma de extracción y de distribución de las utilidades? ¿Quién (o qué presiones de la comunidad) causa la continua corriente de migrantes desde las condiciones ambientales deficientes de la periferia a las condiciones a menudo igualmente deficientes del centro? Para responder tales preguntas se requiere un enfoque más amplio que el de la mayoría de los análisis realizados.

Para concluir, cabe hacer un comentario final sobre el papel que corresponde al propio medio ambiente. Como se destacó en varias oportunidades en la reunión de Founex, ${ }^{33}$ los problemas ambientales y el

s3 Véase El desarrollo y el medio ambiente, informe presentado por un grupo de expertos convocado por el Secretario General de la Conferencia de las Naciones Unidas sobre el Medio Ambiente Humano (Founex, Suiza, 4 al 12 de junio de 1971). 
crecimiento económico no deberían tratarse como alternativas mutuamente excluyentes; más bien, deberían ser elementos complementarios de los programas de desarrollo latinoamericano. El factor ambiental tiene la posibilidad de llamar la atención sobre las estructuras socioeconómicas y físicas de los países, y, en esta forma, de ampliar la base para establecer estrategias de desarrollo integradas.

Sin embargo, sólo ocurrirá esto si se tiene en cuenta el medio ambiente en las políticas de desarrollo cuyo objeto es fomentar el bienestar de la sociedad en su conjunto. Si llega a considerarse como algo ajeno a los problemas diarios a que hacen frente el legislador o el planificador, o simplemente como una cuestión de buen tono que puede llegar a disputar recursos escasos con otras exigencias al parecer más apremiantes, se pasará por alto, o para satisfacer el prestigio nacional -o también los requisitos de las concesiones de préstamos y créditos- se agregará apenas como decoración verbal a políticas ya adoptadas. 


\section{POBLACION Y DERECHOS HUMANOS EN AMERICA LATINA: ALGUNOS INTERROGANTES}

Topos los derechos humanos se refieren a la "población" - la raza humana-, pero a los fines del presente trabajo no sería útil enfrentar el tema en esos términos tan amplios. La atención se centra aquí en derechos relacionados con dos variables demográficas - fecundidad y distribución espacial- y en dos tipos de derechos: el derecho a recibir servicios y el derecho a la autodeterminación o autodefensa contra los dictados de la sociedad o el Estado. Mucho de lo que se diga sobre estos dos derechos se aplica también a aquellos que guardan relación con la tercera variable demográfica de importancia: la mortalidad, esto es, con la preservación de la vida. Sin embargo, el consenso acerca de esta última es más pronunciado, y tiene raíces más hondas, en valores humanos universalmente aceptados, que los derechos relativos a la fecundidad y a los movimientos espaciales de la población. Dada la brevedad de estas notas, parece preferible concentrarse en estas últimas dos variables.

Las siguientes características latinoamericanas son de particular importancia en el análisis:

a) Las garantías formales de los derechos humanos - preservadas en declaraciones internacionales y en las constituciones de los paises- han proliferado semiaisladas de la planificación del desarrollo y de la formu* lación de políticas, y también del incremento continuo y no planificado de leyes, reglamentos, mecanismos burocráticos y asignaciones de recure sos públicos que responden a necesidades de corto plazo y a presiones particularistas. En su mayoría, los planificadores del desarrollo han tratado los "derechos" como expresiones de buena intención que no obli* gan, aun cuando han hecho lo posible por prever en sus planes la exr pansión rápida de la educación, la salud y otros servicios sociales. Los políticos y los administradores, en su pugna por resolver problemas inme. diatos, sólo han prestado atención ocasional a los divergentes principios. generales que les proponen con insistencia los defensores de los derechos. humanos y los planificadores. Recientes manifestaciones de respaldo gubernamental al "desarrollo integral" y al "desarrollo humano" indican la intención de armonizar mejor los diferentes hilos de la formulación. de políticas, pero aún no se han explicado las consecuencias prácticas. y los medios para traducir en realidad esta intencion. ${ }^{1}$

b) La formulación y aplicación de políticas tendientes a perfeccionat. o salvaguardar los derechos humanos se efectúan en sociedades naciona.

1 Véanse América Latina y la Estrategia Internacional de Desarrollo: Primera evaluar. ción regional (E/CN.12/947/Rev.1), 19 de junio de 1973, capítulo 1, y la Evaluación de Quito, aprobada como resolución 320 (XV) en el decimoquinto período de sesio. nes de la crpar, en la cual se pasa revista a los avances logrados en el primer bienic, de aplicación de la RID. 
les estratificadas en las cuales el ingreso, el acceso al empleo y a los. servicios públicos, y la capacidad para participar en la toma de decisiones se encuentran distribuidos de manera muy dispareja. Además, los. sectores públicos carecen de los recursos financieros y administrativos necesarios para cumplir con su compromiso de promover el desarrollo y la justicia social. En consecuencia, los derechos que en principio son universales se respetan en proporción a la conciencia que de ellos tengan las diferentes clases o grupos de intereses en relación con sus propias situaciones, y en proporción a su capacidad para ejercer presión organizada con miras a ejercitarlos. Los argumentos basados en "derechos" se transforman en armas con las cuales los diferentes grupos refuerzan sus exigencias encaminadas a obtener una mayor porción de unos recursos públicos que no pueden estirarse hasta satisfacer todas las demandas. El Estado se enfrenta a un clamor incesante de grupos de intereses y localidades, que le exigen la "solución de sus problemas" como cosa "de derecho".2

c) Dentro de los patrones prevalecientes de estratificación social —con grandes porciones de la población que viven en la pobreza y que no participan, o solo participan "marginalmente", en el proceso político-, la formulación y aplicación de políticas adquiere rasgos "elitistas" que tienen particular significación en el caso de aquellas que inciden en el comportamiento reproductivo y en los movimientos migratorios. Las. minorías que participan en la toma de decisiones interpretan estos factores -y así lo manifiestan a las masas - de conformidad con sus propios puntos de vista sobre las prioridades del desarrollo nacional y el bienestar familiar, y en función de soluciones estandarizadas, que puedan aplicarse a gran número de personas para producir cambios que aparezcan en los indicadores estadísticos. Las interpretaciones subyacentes son muy diversas. Llevan a diferentes sectores de opinión a favorecer la fecundidad alta o baja, la urbanización rápida o la estabilización de la población rural en la tierra. Las grandes diferencias de situaciones reales entre los países latinoamericanos justifican en cierta medida puntos de vista divergentes, pero las diferencias de premisas ideológicas son tal vez un factor más importante. Cualesquiera que sean los objetivos que se adelanten en materia de población, las minorías capaces de expresarse están predispuestas a considerar a las masas como peones de una estrategia para el desarrollo, de una revolución o de la conservación deł orden existente. A los planificadores e ideólogos les cuesta mucho descender de la teorización global y de la elaboración de estrategias respecto al "papel de la población en el desarrollo", o al "papel de la población en el cambio revolucionario", a las necesidades y opciones

2 "Las autoridades públicas centrales, especialmente en sus actividades motivadas por consideraciones sociales, llegan a asemejarse a una niñera abrumada de obligaciones que trata de satisfacer todas las necesidades y regular todas las actividades de los niños a su cargo, demasiado agotada por la multiplicidad de sus tareas para juzgar cuál merece prioridad, cuál escapa a sus posibilidades y cuál no merece la pena realizarse." (Véase El cambio social y la política de desarrollo social en América Latina, op. cit.s p. 8.) 
reales con que chocan millones de individuos y familias, y que deberían ser el foco de la contribución de los "derechos humanos" a una política de población.

\section{1) Fecundidad y planificación de la familia}

En las numerosas declaraciones internacionales y nacionales de derechos sancionadas en los dos decenios últimos, se han expuesto con particular detalle los derechos a recibir servicios del Estado: derechos a la educación universal, servicios de salud, seguridad social, vivienda, nutrición. Sectores de opinión influyentes en el ámbito internacional han insistido últimamente en el derecho de là familia a decidir el número y espaciamiento de sus hijos, y en el deber que tiene el Estado de proporcionar servicios de planificación de la familia que permitan a ésta actuar de acuerdo con la información recibida. En los sectores de opinión dominantes en América Latina, el respaldo a este "derecho" -condicionado por suspicacias con respecto a las motivaciones de sus proponentes - ha sido bastante más renuente que en la mayor parte de las otras regiones del mundo, pero la mayoría de los gobiernos de la región ha aceptado ya la primera cláusula, si no la segunda.

La insistencia internacional cada vez mayor en el derecho a disponer de servicios de planificación de la familia tiene dos aspectos diferentes: a) el franco apoyo al derecho a utilizar un servicio que contribuye al bienestar y a la autodeterminación de la familia, y $b$ ) la expectativa de que la aceptación gubernamental del deber de proporcionar servicios de planificación de la familia a toda la población ayude a conseguir el objetivo más amplio de reducir las tasas de incremento de la población. ${ }^{3}$ Estar o no de acuerdo con esta expectativa no afecta la validez del derecho, pero tiene mucho que ver con la importancia relativa que se le atribuye.

Se ha sugerido que el derecho "universal" - públicamente respaldado- a disfrutar de los servicios, no se ejercita de manera universal ni equitativa en la mayoría de los países latinoamericanos, por falta de recursos públicos, por insuficiente capacidad administrativa para utilizarlos eficientemente, y por la relativa incapacidad de los estratos más necesitados de la población para dar expresión a demandas vigorosas y realistas. Cuando se reconoce un nuevo derecho que requiere recursos

3 La resolución sobre aspectos relacionados con los derechos humanos en la planificación de la familia, aprobada por la Conferencia Internacional de Derechos Humanos realizada en mayo de 1968 -así como varias otras declaraciones internacionales sobre cuestiones de población-, yuxtapone una condenación del crecimiento rápido de la población por considerar que obstaculiza la plena realización de los derechos humanos, y una reafirmación del derecho humano básico de las parejas a decidir libre y responsablemente el numero y espaciamiento de sus hijos y a recibir enseñanza e información al respecto. Hasta ahora, tales declaraciones no han planteado el problema de una posible contraposición entre objetivos relacionados con Jos derechos humanos si - como han aducido Kingsley Davis y varios otros demógrafos- la planificación de la familia basada en decisiones libres no resulta ser un medio eficaz para reducir el crecimiento de la población. 
públicos escasos, entra a competir por esos recursos, a cotejarse con objetivos de desarrollo más amplios y a luchar contra las presiones que distorsionan la distribución y el contenido y a las que están sujetos todos los servicios sociales y de infraestructura. ¿Qué prioridad se le dará frente a derechos establecidos con anterioridad y que aún no se cumplen plenamente? iSe le reclama con tanta insistencia como para que, desde el punto de vista político, sea conveniente ponerlo en vigor de inmediato $y$ en gran escala? ${ }_{2}$ Constituye el servicio en cuestion, en condiciones de elevada fecundidad, un requisito previo para la realización de otros derechos humanos? Desde el punto de vista de los objetivos y prioridades globales, ¿se justifica que el Estado no sólo proporcione el servicio a los grupos que lo piden activamente, sino que también haga campaña para extender la conciencia del problema, junto con el servicio, a grupos mayores pero ajenos a ellos o que se muestran apáticos? $\mathrm{Si}$ se elige esta última alternativa, ętiene el Estado capacidad administrativa para enfrentar toda la demanda potencial? Podría argumentarse que los recursos externos disponibles para la planificación de la familia eximen a este servicio de la necesidad de competir con otros servicios sociales para obtener recursos internos, pero es difícil que los gobiernos acepten tal dependencia implícita en tan delicada esfera de la política nacional.

La demanda social de servicios de planificación de la familia está sin duda aumentando, pero se halla todavía muy lejos de ser tan universal como la demanda de la educación o la salud. Por contar con servicios gratuitos de planificación de la familia las presiones de la población urbana seguramente se intensificarán en el próximo decenio, pero si los organismos públicos se limitan a responder a la demanda, sin anticiparla ni estimularla, pasará mucho tiempo sin que sea universal el acceso a estos servicios, y - como sucede con los demás servicios sociales- será la población rural la que los reciba con mayor atraso y más deficiencias. En tanto el lado de los "derechos humanos" no se vea reforzado por la convicción gubernamental de que la reducción de las tasas de crecimiento de la población es esencial para el desarrollo, y de que pueden ser un medio eficaz para lograrlo los programas de planificación de la familia, tales programas soblo pueden esperar una participación modesta en los recursos públicos. No existe todavía consenso decidido en los círculos gubernamentales ni en el público general sobre el papel del crecimiento de la población en el desarrollo, aunque la opinión generalizada parece inclinarse hacia menores tasas de incremento. Son tan grandes las diferencias en las situaciones nacionales que no es posible demostrar que el incremento de la población desempeña un mismo papel o exige un mismo tipo de acción pública en toda América Latina. Las razones más poderosas para que el Estado promueva activamente la información y los servicios para la planificación de la familia como uno de los derechos humanos, están ligadas por el momento a la política redistributiva. En situaciones nacionales típicas de modernización desequilibrada, las capas más acomodadas de la población tienen acceso a la planificación de la familia lo apruebe o no 
el Estado, en tanto que las mayorías de ingresos bajos -que son las que menos pueden mantener familias largas - gozan de poco o ningún acceso a ese servicio, o ni siquiera están conscientes de la posibilidad de regular la fecundidad, como sucede en la población rural. ${ }^{4}$ Sin embargo, el argumento tiene más fuerza en el papel que como factor determinante en la asignación de recursos públicos.

La formulación convencional del "derecho" que aquí se discute -el de la pareja o de la mujer a decidir con toda libertad el número de hijos que desea, y a actuar efectivamente según su decisión- entraña el derecho a rechazar la planificación de la familia o a usar el servicio para tener más hijos en lugar de menos, aun cuando el Estado esté decidido a reducir la tasa de incremento de la población, y aunque objetivamente sea obvio que tener más hijos será desastroso para el bienestar de la familia. (Al mismo tiempo, por supuesto, la formulación indicada entraña el derecho a utilizar anticonceptivos, aunque la política pública favorezca el crecimiento rápido de la población.) En este punto, la definición de "derechos" y "deberes" se complica. ¿Tiene derecho realmente la familia o el individuo a una reproducción ilimitada, si puede demostrarse que dañará los intereses de la sociedad y perjudicará las posibilidades de vida de todos los hijos de esa familia? Si no lo tiene, ¿qué puede hacer la sociedad al respecto? Excluida la compulsión por considerarla ilegítima o impracticable, ¿hasta qué punto se justifica que el Estado utilice incentivos, sanciones y tácticas de adoctrinamiento?

Estas cuestiones se han discutido poco en el medio latinoamericano, salvo bajo la forma de rechazos retóricos a toda interferencia en la libre -decisión. Hasta ahora no han tenido mucho significado práctico, dadas la falta de consenso en cuanto a los objetivos de la política de población y la debilidad del Estado para llevar a cabo cualquier política encaminada al cambio societal. El Estado interviene en la vida familiar de muchas maneras - las leyes de matrimonio y divorcio, la educación obligatoria, las políticas tributarias, la seguridad social, etc.- y ha convertido ciertos "derechos" en "obligaciones". Una vez logrado suficiente consenso acerca de los niveles deseables de fecundidad, sería absurdo esperar que la sociedad renunciara a todas las tácticas encaminadas a influir en las decisiones de las familias o las mujeres. El problema reside en que no es muy promisoria la gama de tácticas que son legítimas en cuanto a valores, acogida del público, capacidad de la administración pública y costos unitarios razonables. Sería así esencial efectuar campañas de promocion, pero el Estado, en la mayoría de los países latinoamericanos, tiene poca capacidad para movilizar a las masas tras determinados objetivos de desarrollo, y probablemente le abruman ciertas campaña tendientes a lograr otros objetivos más apremiantes.

4 Población y modernización en América Latina (E/CN.12/L.95), 30 de mayo de 1973, documento preparado por la CEPAL para el Simposio de las Naciones Unidas sobre Población y Desarrollo. Véase también "Tendencias de población y opciones para políticas de población en América Latina", Boletín económico de América Latina, vol. XVI, núm. 1, 1971. 
Las proposiciones de sancionar a las familias numerosas mediante impuestos, privación de servicios públicos, etc., son inaceptables, pues violarían derechos, y sería imposible aplicarlas en situaciones de pobreza generalizada en que muchas familias no alcanzan a pagar impuestos y no reciben casi servicios del Estado. Los incentivos financieros para las familias más pequeñas tendrían un costo prohibitivo, serían difíciles de administrar en escala adecuada y, probablemente, resultarían impracticables desde el punto de vista político.

Aunque el derecho a utilizar o rechazar los servicios de planificación de la familia no ha planteado hasta ahora un problema de consideración en las sociedades, por la falta de políticas coherentes y de capacidad para hacerlas obligatorias, el derecho está adquiriendo alguna importancia para las mujeres, debido a la extensión de la planificación de la familia en los servicios de salud materna. Estos servicios procuran informar a las mujeres de la conveniencia de utilizar anticonceptivos o de someterse a la esterilización precisamente en el momento en que darán mejor acogida a estas proposiciones: en el momento en que acaban de dar a luz. Si el personal de los servicios está convencido de la necesidad de limitar el número de hijos de las familias de ingresos bajos - - en general de reducir las tasas de crecimiento de la población-y si sus relaciones con las usuarias reflejan los habituales sentimientos de clase media de paternalismo y autoridad profesional hacia las clases inferiores y los "ignorantes", es probable que se tengan pocas contemplaciones con el derecho de la mujer a decidir libremente, una vez informada de las diversas posibilidades. Las polémicas que ha habido en algunos países de altos ingresos (y tambien en la India) sobre la esterilización como requisito para recibir ayuda pública o atención hospitalaria, denuncian la existencia de abusos que pueden hacerse más graves a medida que las esferas oficiales y profesionales se vayan convenciendo de la necesidad de regular la fecundidad. Tales abusos no pueden evitarse del todo mediante la protección legal de los derechos de la mujer en tanto no cambien profundamente las características actuales de la estratificación social, pues son sólo un aspecto más de un problema mucho mayor. Las relaciones entre las masas "marginalizadas" y las fuentes oficiales o privadas de ayuda y de servicios profesionales son una mezcla contradictoria de dependencia resignada, de busca de un "patrón" capaz de obtener beneficios de las autoridades, de exigencias respaldadas por lo que se ha dado en llamar "violencia representacional" (manifestaciones, tomas de edificios públicos, bloqueo de carreteras, etc.), y rechazo generalizado del tutelaje de un orden público en el cual las masas no tienen verdadera voz. Es de desear que las parejas y las mujeres que necesiten servicios de planificación de la familia participen en forma organizada en la planificación y prestación de tales servicios. Pero para lograr este desideratum habrá que efectuar grandes avances en la pugna más general por alcanzar la participación informa$\mathrm{da}$ de las masas en las decisiones que las afectan.

La lucha entre el derecho a recibir servicios, el derecho a la autode. 
terminación en su uso, y lo que el Estado entiende por auténticos intereses de la sociedad, toma una forma diferente frente al aborto. Los datos conocidos sobre la incidencia del aborto ilegal en América Latina revelan una demanda enorme de las mujeres urbanas de todos los estratos sociales. Esa demanda podrá evitarse difícilmente del todo con servicios de planificación de la familia. En efecto, las mujeres motivadas para utilizar anticonceptivos seguirían buscando soluciones ante fracasos o deslices. La demanda del aborto legalizado como un derecho - acicateada por movimientos femeninos de otras latitudes- casi no ha tocado aún América Latina, y seguramente encontraría aquí formidables resistencias de la sociedad. Los partidarios de la planificación de la familia, considerada como un derecho humano, parecen haber soslayado la cuestión por motivos tácticos. ${ }^{5}$

Fuera de América Latina, algunos cruzados que abogan por tasas de crecimiento de la población igual a cero, han hecho diversas propuestas relativas a la aplicación masiva de técnicas de control de la fecundidad que eliminarían toda libre decisión, por ejemplo, la diseminación de agentes esterilizantes a través de los alimentos o el agua. Afortunadamente, en el futuro inmediato los gobiernos latinoamericanos no tendrán el deseo ni la capacidad de aplicar estas técnicas para manipular la población. Sin embargo, si las mismas técnicas se hacen más fáciles de aplicar - y si en el futuro los gobiernos se convencen de la desesperada urgencia de reducir el ritmo de crecimiento de la población-, habrá que enfrentar problemas totalmente nuevos en materia de derechos y valores. Cabe preguntarse en ese caso si el derecho de la familia a decidir el número de hijos se consideraría un lujo que la sociedad no podría permitirse. Si la técnica se aplicara por igual a toda la población, ¿constituiría una interferencia en los derechos básicos, de distinta naturale$\mathrm{za}$, digamos, que la vacunación obligatoria o la colocación de flúor en el agua potable?

\section{2) Distribución espacial, migración, protección del medio ambiente $y$ explotación de recursos}

La relación entre los derechos humanos y el control de la fecundidad ha sido tema de mucha literatura polémica y exhortatoria. La relación entre los derechos humanos y los movimientos espaciales y los patrones de asentamiento de la población también ha sido extensamente debatida en algunos de sus aspectos - sobre todo el de las migraciones a través de fronteras nacionales-, pero se le ha prestado mucho menos atención en su calidad de vasta área de problemas cuyos contornos cam-

5 "Ningún representante gubernamental parece haber calificado el aborto voluntario como un "derecho humano" ... Dados estos puntos de vista, es poco probable que sea provechoso encarar este problema en las etapas iniciales del establecimiento del derecho a la planificación de la familia." (Véase Daniel G. Partan, Population in the UN System: Developing the Legal Capacity and Programs of UN Agencies, Law and Population Monograph, Series núm. 7, The Fletcher School of Law and Diplomacy, Medford, Massachusetts, s. f., p. 10.) 
bian con el incremento rápido de la población y con la concentración espacial. Dos aspectos del tema irán pasando a primer plano cada vez más -el derecho a recibir servicios y el derecho a defenderse de los dictados de la sociedad - a medida que las políticas de desarrollo, que hasta ahora han desestimado casi del todo la dimensión espacial, intenten incorporar objetivos relacionados con el asentamiento humano, la distribución geográfica de las actividades económicas, la protección de los recursos naturales y la preservación del equilibrio ecológico.

Se acepta en general que los actuales patrones y tendencias de la distribución espacial de la población y del uso de la tierra tienen muchas desventajas para el desarrollo y el bienestar humano. Con poblaciones relativamente pequeñas, la mayoría de los países latinoamericanos combinan diversos males: concentración excesiva en gigantescas aglomeraciones urbanas, agotamiento de los suelos y mano de obra superflua en las zonas agrícolas más antiguas, y destrucción de los suelos y bosques en zonas poco pobladas que actualmente se hallan en vías de ocuparse. Conforme aumenta la densidad de la población nacional y se eleva el consumo, se exacerban estos problemas. Se hace inevitable la compleja reglamentación del comportamiento y los movimientos de la población, para evitar que millones de actividades individuales o colectivas carentes de coordinación causen un daño irreparable a los intereses de largo plazo de la sociedad en su conjunto. El consenso sobre el papel de la distribución espacial de la población en el desarrollo ha sido insuficiente hasta ahora como marco de referencia de amplias políticas relativas a los patrones de distribución. Las políticas nacionales comúnmente tienden a réducir el ritmo de crecimiento de las ciudades más grandes, a desalentar la emigración desde localidades rurales y pueblos pequeños y a asentar planificadamente zonas despobladas hasta entonces. (Las medidas concretas para aplicar estas políticas han sido fragmentarias y, en general, se han visto contrarrestadas por otras que han estimulado una continuada concentración.) Las políticas más realistas no piden un viraje brusco de las tendencias, sino cambios en las proporciones: se espera que las ciudades más grandes sigan creciendo, pero en forma más lenta; que las zonas rurales no absorban todo su incremento natural, pero sí una proporción mayor del mismo; que las zonas de asentamiento no se vean invadidas desordenadamente, sino que se vayan poblando a medida que se puedan ir haciendo inversiones de infraestructura, llevando al mínimo la destrucción de recursos naturales. Se espera asimismo que la propensión a migrar responda a una combinación de incentivos y desincentivos moderados.

Sin embargo, si la población continúa creciendo a las tasas actuales, mientras pierden viabilidad las formas tradicionales de vida, y el predominio cada vez mayor de los mercados y patrones de consumo urbanos hacen más homogénea a la población en lo cultural, y a la vez le dan mayor movilidad, es posible que eso no suceda, aunque las medidas públicas sean más coherentes y estén mejor planificadas. ¿En qué medida se justifica entonces que el Estado intervenga en el derecho del 
individuo a vivir donde desee y como desee? ${ }_{2}$ En qué medida es capaz de hacerlo con eficacia y equidad? El Estado posee instrumentos legales que se pueden adaptar a este propósito. Su utilidad para controlar los movimientos de la población ha estado limitada hasta ahora, de un lado, por la poca importancia dada a los objetivos de distribución espacial por las fuerzas dominantes en las esferas gubernamentales, $y$, de otro, por la capacidad de los grupos afectados para defender sus intereses inmediatos, utilizando diversas tácticas de presión o evasión.

Las tácticas que se examinan a continuación son pertinentes, pero todas presentan deficiencias de factibilidad y legitimidad en las situaciones reales que prevalecen.

a) El Estado puede abstenerse deliberadamente de asignar recursos para acrecentar el suministro de vivienda, empleo y servicios sociales en los centros urbanos que considera sobrepoblados. Como en estas asignaciones las ciudades grandes siempre resultan más favorecidas que el resto de la población, la aparente denegación de "derechos" bien podría ser sólo un paso hacia un tratamiento más parejo de la población en su conjunto. Sin embargo, entre los habitantes de las grandes ciudades está más difundida la conciencia de los derechos ante el Estado, y hay mayor capacidad para ejercer presión organizada que en el resto de la población. Por ello, la viabilidad política de una solución de esta índole es discutible y su viabilidad económica dependería de una transformación simultánea de las estructuras de producción y distribución.

b) El Estado puede establecer sistemas de permisos de empleo o residencia para la población urbana, y transformar en delito el hecho de que los migrantes permanezcan sin ellos en las ciudades. Medidas de este tipo son muy conocidas en otros lugares del mundo, y los actuales sistemas de documentos de identificación ofrecen un marco administrativo fácilmente utilizable. Sin embargo, para controlar la migración hacia la ciudad mediante sistemas de permisos se requeriría una administración más eficiente e incorruptible que la que cabe esperar en la mayoría de las situaciones nacionales. En la práctica, su efecto en la tasa de crecimiento de las ciudades es probable que fuera pequeño, y lo que se lograría sería colocar a una parte de la población urbana -generalmente la más pobre y marginalizada- en una situación de ilegalidad que la expondría a discriminaciones ocupacionales y a exacciones de la policía. Incluso los sistemas actuales de documentos de identidad y registros de seguridad social, aplicados a grupos con poca educación o conciencia de sus derechos legales, se prestan para abusos.

c) El Estado, en representación de los intereses de la sociedad en su conjunto, puede prohibir la residencia en ciertas zonas o en ciertas condiciones subnormales, y erradicar la población afectada. Esta facultad legal se ha utilizado comúnmente para eliminar tugurios urbanos y para evacuar asentamientos rurales afectados por la construcción de presas. También se ha empleado en cierta medida para impedir aquellos usos de la tierra que se consideran excesivamente destructivos de suelos y bosques, como el cultivo de pendientes erosionables, el apacentamiento * 
de ganado cabrío o la quema de carbón vegetal. Además, suele intentarse el reasentamiento obligatorio de grupos rurales a los que -por hallarse demasiado dispersos- es difícil hacer llegar los servicios educativos y de salud y la acción policial, particularmente en el caso de tribus indígenas que habitan los bosques y de zonas en que las autoridades desean impedir el contacto entre campesinos y guerrilleros.

Las intervenciones de esta índole en los asentamientos humanos han sido hasta ahora limitadas en su alcance y fortuitas en sus objetivos, y han acumulado una deplorable historia de acción unilateral, promesas incumplidas e incapacidad burocrática para prever el efecto de "medidas progresistas" en las vidas humanas. Los agricultores desplazados por la construcción de presas, en el mejor de los casos, han enfrentado largas demoras antes de obtener las compensaciones prometidas o la concesión de tierras equivalentes; los habitantes erradicados de tugurios frecuentemente han tenido que batírselas solos o han sido hacinados en viviendas públicas sin acceso a sus fuentes de trabajo. A los campesinos marginales, cuyas cabras son su único capital y fuente de ingreso monetario, se les ha prohibido a veces tener ese ganado, sin ofrecerles otra forma compensatoria de ganarse la vida. En muchos casos, los grupos afectados por tales medidas han podido defenderse de un modo u otro, pero las tácticas defensivas naturalmente se centran en los intereses inmediatos, y, si tienen exito, perpetúan daños reales para la sociedad, y para ellos mismos.

d) El Estado puede encauzar grupos urbanos hacia zonas residenciales planificadas o hacia nuevos pueblos, y los grupos rurales hacia zonas de asentamiento agrícola. La radicación legalmente obligatoria de individuos y familias como instrumento de política para la redistribución espacial de la población es casi inconcebible en América Latina. Sin embargo, se ha aplicado a veces una semicompulsion, al trasladar familias desde sus viviendas anteriores sin dejarles otra alternativa real que aceptar espacio en algún proyecto habitacional o algún plan de asentamiento. Medidas de este tipo son inaceptables en términos de derechos humanos, y la experiencia muestra que son además ineficaces y de un costo financiero prohibitivo por familia reasentada. Los esquemas paternalistas de reasentamiento "planificado" en América Latina muestran un historial ininterrumpido de fracasos.

Pese a los inconvenientes y peligros de instrumentos de política como los enumerados, es probable que a medida que aumenten las responsa-bilidades del Estado en materia de desarrollo y que el incremento de la población intensifique los problemas existentes, se haga inevitable una considerable interferencia en las preferencias y decisiones libres de los individuos, familias y grupos locales. Desde el punto de vista del desarrollo, la justificación de esas medidas dependerá de su coherencia y armonía con el estilo de desarrollo perseguido, y de su capacidad para contribuir significativamente a que se logren los objetivos nacionales con costos soportables. Es evidentemente absurdo que el Estado interfiera en decisiones personales respecto a lugares de residencia y trabajo 
con medidas que se contraponen y destinan cuantiosos recursos a lograr objetivos secundarios o que eximen a los poderosos cuyas actividades causan los más graves perjuicios ambientales. Desde el punto de vista de los derechos humanos, la validez de tales medidas dependerá de la capacidad del Estado para aplicarlas con equidad y en auténtica consulta con los grupos afectados; para captar y comprender todas las repercusiones humanas de las medidas que se están considerando, y, sobre todo, para dar cumplimiento a su obligación de proporcionar a esos grupos oportunidades de trabajo y relación humana equivalentes o mejores que aquellas de las cuales se les está privando. Lo ideal sería que el propio proceso de cambio permitiese al grupo afectado acrecentar su capacidad para conocer y defender en forma organizada sus propios intereses, tanto de largo plazo como inmediatos, y relacionar estos intereses con una interpretación coherente de los intereses de la sociedad más amplia. Las observaciones formuladas respecto a la dificultad de lograr una auténtica participación popular en las decisiones de las sociedades, dadas las relaciones que prevalecen entre burocracias y profesionales, de un lado, y las masas de la población, de otro, es evidente que se aplican también a las medidas relativas a la distribución espacial, la protección del medio ambiente y el uso de recursos.

El análisis se ha centrado hasta aquí en problemas que surgen dentro de las sociedades nacionales de América Latina. Se sabe que el incremento de la población y la movilidad espacial, unidos a trastornos políticos y a un crecimiento económico mal distribuido, están generando en escala cada vez mayor diversos tipos de movimientos de población a través de fronteras nacionales, que plantean problemas de derechos humanos.

a) Cuando las oportunidades de empleo y los niveles de remuneración, o el acceso a la tierra de cultivo, difieren mucho a ambos lados de una frontera, los migrantes - salidos principalmente de la población rural subempleada - cruzan desde el país menos promisorio al que lo es más. Hasta hace poco tiempo, tales corrientes migratorias se producían en escala modesta y eran toleradas o bienvenidas por las autoridades de los países receptores, ya que proporcionaban mano de obra barata, en particular para el trabajo agrícola estacional. En esa etapa, los principales problemas de derechos humanos guardan relación con la explotación de los trabajadores migrantes, que generalmente tienen aún menos acceso a los servicios sociales, seguridad social, leyes de protección u organizaciones sindicales que los ciudadanos rurales de los países receptores. Con el aumento de la población nacional, la escala de tales migraciones ha aumentado y se ha debilitado la buena acogida. La migración de trabajadores no calificados a países foráneos a América Latina, que tuvo considerable magnitud en México y en algunos países del Caribe, se ha detenido prácticamente, o se la ha despojado de legalidad. En los países latinoamericanos más adelantados, la fuerza de trabajo nacional, que de por sí crece con rapidez y confronta condiciones de empleo insuficiente, se torna más renuente a aceptar la competencia de mano 
de obra barata proveniente del exterior. La concentración de extranjeros que, en calidad de trabajadores agrícolas y ocupantes de hecho, cultivan zonas fronterizas, despierta preocupación por la seguridad nacional. En algunas ciudades grandes, el crecimiento de barrios de tugurios, poblados principalmente por migrantes extranjeros, da origen a prejuicios que muchas veces adquieren matices raciales. Como grandes porciones de la población de los países de emigración son terriblemente pobres y poseen una capacidad declinante para sobrevivir, recurriendo a la agricultura de subsistencia y al trabajo estacional asalariado, y como las fronteras son extensas y casi imposibles de vigilar, los países receptores no pueden atajar la migración en la frontera. Dadas las condiciones prevalecientes en las zonas fronterizas, es muy probable que los intentos de descubrir y deportar a quienes logran deslizarse en ellas susciten arbitrariedades y crueldades, y creen resentimiento en el país de origen de los migrantes. Hasta ahora, este tipo de problemas ha ocasionado negociaciones prolongadas y unas pocas confrontaciones violentas entre naciones. Se precisa un reconocimiento regional más efectivo de los derechos de los migrantes ilegales como seres humanos; en tanto los estilos de desarrollo prevalecientes sigan generando mano de obra superflua, subempleada o dedicada a ocupaciones de baja productividad, el intento de encarar este problema desde el punto de vista de los derechos humanos no podrá ir mucho más allá de un simple tratamiento de síntomas.

b) La pluralidad de regímenes políticos en América Latina, los ocasionales cambios violentos de un tipo de régimen a otro, la aparición de estrategias de desarrollo que se contraponen a las expectativas de status, y las modalidades de propiedad y consumo de ciertas clases y grupos sociales, así como los movimientos que rechazan el orden existente en favor de la acción revolucionaria o terrorista, está generando, en escala sin precedentes, movimientos de refugiados, exiliados y migrantes voluntarios motivados por la inseguridad, por la privación de medios de ganarse la vida o por el rechazo de las consecuencias personales que tiene para ellos la estrategia de desarrollo nacional prevaleciente. En tanto que los migrantes mencionados en el punto a) provienen de los estratos más pobres de la población, los de esta segunda categoría, cualquiera que sea su color político, provienen principalmente de los estratos medios y altos, tienen una educación relativamente buena e incluyen una proporción importante de profesionales, estudiantes universitarios y empresarios potenciales. Los países latinoamericanos tienen normas claramente establecidas sobre los derechos y las obligaciones de los exiliados políticos, pero cuando las migraciones por motivos políticos a través de las fronteras nacionales adquieren grandes proporciones y se hacen más heterogéneas, tales normas resultan difíciles de aplicar y guardan escasa relación con algunos de los problemas reales. La primera categoría de migrantes plantea el problema básico del derecho a un mínimo pasar y a cierta dignidad humana. La segunda categoría ofrece una amplia gama de cuestiones más concretas con las cuales seguramente los países tendrán que lidiar aún por mucho tiempo: el derecho 
de los profesionales extranjeros a practicar su profesión, el derecho de los estudiantes a terminar su educación, el derecho de los extranjeros poseedores de capital a competir con empresas nacionales, el derecho de los exiliados a actuar de acuerdo con sus creencias políticas. Como están las cosas, los migrantes de clase media se hallan en mejor posición que los otros para hacerse oír, para enfrentarse con las regulaciones y para aprovechar los servicios.

\section{3) Anotación final}

El presente trabajo no ofrece "soluciones" a los problemas que plantea, y la abstención es deliberada. En tan breve estudio sobre una región de gran diversidad interna, sería ingenuo pretender dar recetas prácticas universales para tratar los síntomas de desajustes básicos en los procesos de crecimiento económico y cambio social, o proponer adiciones a las innumerables garantías de los derechos que figuran en leyes y constituciones. Las fuerzas dominantes en las diversas sociedades nacionales intentan tratar tanto los síntomas como los factores causales subyacentes, guiadas por concepciones muy divergentes sobre la naturaleza del desarrollo y de las prioridades para el bienestar humano, limitadas por combinaciones muy diversas de presiones y fuentes de respaldo político, y haciendo siempre frente a "un aluvión de asesoramiento generalizado..., tan voluminoso y heterogéneo que excede su capacidad de asimilar y elegir". "Se han delineado aquí algunos requisitos para adoptar decisiones que ponderen debidamente los derechos humanos dentro de políticas relativas a la fecundidad y a los movimientos espaciales de la población, y algunas de las medidas que se han propuesto o aplicado han servido para señalar la complejidad de los problemas y la imposibilidad de aplicar prescripciones simplificadas y universales. Las decisiones que surjan deberán tratar de conciliar diferentes valores y objetivos de desarrollo, todos legítimos en sí, que adoptan formas diferentes en cada sociedad nacional, y ninguno de los cuales puede lograrse plenamente en sociedades que se esfuerzan en hacer frente a los actuales procesos de crecimiento y de cambio.

6 Véase Informe sobre un criterio unificado para el análisis y la planificación del desarrollo, Informe preliminar del Secretario General, e/cN.5/477, octubre de 1973, p. 4. 


\section{Apéndice \\ INFORME DE LA REUNIÓN \\ LATINOAMERICANA PREPARATORIA \\ DE LA CONFERENCIA MUNDIAL DE POBLACIÓN}

(San José, Costa Rica, 15 al 19 de abril de 1974) 


\section{,}




\section{ORGANIZACION DE LA REUNIÓN}

\section{DURACTÓN DE LA REUNTÓN}

1. La Reunión Latinoamericana Preparatoria de la Conferencia Mundial de Población se llevó a cabo en San José de Costa Rica del 15 al 19 de abril de 1974.

\section{Aststencia}

2. Asistieron a la reunión representantes de 27 Estados miembros de la Comisión Económica para América Latina (cEPAL) y sus dos Estados miembros asociados, observadores de un Estado no miembro y representantes de organismos del sistema de las Naciones Unidas y de otras organizaciones intergubernamentales y no gubernamentales. (En el anexo I figura una lista completa de los participantes.)

\section{SESIONES DE APERTURA Y CLAUSURA}

3. En el acto inaugural, celebrado el día 15 de abril de 1974, hicieron uso de la palabra el Secretario General de la Conferencia Mundial de Población, señor Antonio Carrillo Flores; el Ministro de Salud de Costa Rica, señor José Luis Orlich; el Secretario de Gobernación y Presidente del Consejo Nacional de Población de México, señor Mario Moya Palencia, y el Presidente de la República de Costa Rica Excelentísimo señor Don José Figueres Ferrer. ${ }^{1}$ En la sesión de clausura, después de la exposición del Relator, pronunciaron discursos el Representante del Perú, Embajador José Alvarado Sánchez, y el Secretario Ejecutivo de la CEPal, señor Enrique V. Iglesias, quien glosó los resultados de los trabajos de la reunión.

\section{Elección de la Mesa}

4. En la primera sesión, celebrada el 15 de abril de 1974 , los participantes eligieron por aclamación la siguiente Mesa: Presidente: José Luis Molina (Costa Rica); Primer Vicepresidente: Benito P. Llambi (Argentina); Segundo Vicepresidente: C.G. Alleyne (Barbados); Relator: Luis Eduardo Rosas (Colombia). ${ }^{2}$

1 Los textos de los discursos del acto inaugural, junto con las exposiciones hechas en el debate general por los representantes de los Estados miembros y por funcionarios de los organismos de las Naciones Unidas y de la propia secretaría, figuran en el anexo III de este informe en su versión oficial mimeografiada. Dicho anexo (al igual que el IV) se han suprimido aquí por razones de espacio.

2 Por tenerse que ausentar de la reunion el señor Luis Eduardo Rosas, fue sustituido en la sesión de clausura por el señor Gonzalo Abad, Representante de Ecuador. 


\section{Programa de trabajo}

5. En la primera sesión los participantes aprobaron el siguiente programa de trabajo:

1. Discursos de inauguración

2. Elección de la Mesa

3. Aprobación del programa de trabajo

4. Tendencias demográficas recientes y perspectivas futuras

5. Relaciones entre el cambio demográfico y el desarrollo económico y social

6. Relaciones entre la población, los recursos y el medio ambiente

7. La población, la familia y el bienestar humano

8. Plan de Acción Mundial sobre Población

9. Otros asuntos

10. Consideración del informe de la reunión.

6. Por intermedio de la secretaría de la CEPAL, los participantes recibieron los documentos que prepararon los organismos auspiciadores de la reunión. Los títulos correspondientes aparecen en el anexo II de este informe.

\section{RESUMEN DE LOS DEBATES}

1) Situación $y$ perspectivas de los paises latinoamericanos en materia de población y principales enfoques sobre política demográfica

7. En amplio debate, con la intervención de las delegaciones presentes y de representantes de distintos organismos de las Naciones Unidas, así como de la propia secretaría, se hicieron extensas consideraciones sobre la situación demográfica de los países latinoamericanos, las perspectivas a mediano y a largo plazo, y los enfoques y factores que intervienen en la política de población.

8. Sin entrar en detalles que, por lo demás, quedan expuestos en la documentación presentada por la secretaría, ${ }^{3}$-así como en las intervenciones de los representantes, cuyo texto completo figura al final de este informe-, en los párrafos que siguen se procura destacar los resultados más importantes de las deliberaciones. Cabe subrayar que éstas son, por cierto, las primeras que hayan tenido lugar sobre este tema entre los gobiernos latinoamericanos y, en general, entre los Estados miembros de la Comisión. Por tal motivo, ofrecen especial interés para la Conferencia Mundial de Población de 1974.

9. Lo más significativo es la conciencia que en pocos años se ha creado acerca de los factores demográficos como elemento y parte integral

3 Véase anexo II.

4 Se recogen en el anexo III. (Se han suprimido aquí por razones de espacio.) 
del proceso de desarrollo socioeconómico. Aun teniendo en cuenta la diversidad de situaciones en materia de población, según las características de cada país - que están dadas por sus propios antecedentes históricos y culturales, su base de recursos naturales, su estilo de desarrollo, sus relaciones económicas con el exterior, su estructura social interna, su etapa de industrialización y urbanización, y por otras variables-, las exposiciones de los participantes no dejaron duda alguna de que los gobiernos y las comunidades nacionales prestan la mayor atención a la dinámica demográfica y a diversos procesos poblacionales dentro de un amplio contexto de consideraciones sobre el desarrollo económico y social.

10. Se hizo patente en las deliberaciones que constituye preocupación máxima de los países latinoamericanos mejorar las condiciones de la vida humana, superando deficiencias del pasado y abriendo, a traves del desarrollo integral, un horizonte de mayor bienestar y dignidad para el hombre. El compromiso es el desarrollo mismo, y hay que cumplirlo en forma acelerada y por diversas vías, de acuerdo con las diferentes condiciones nacionales. En el plano interno se precisa concebir el desarrollo como un proceso integral, que comporta cambios cualitativos y cuantitativos y conduce a condiciones justas de distribución del ingreso y a mayores oportunidades de empleo y mejoramiento social.

11. Para ello se requiere una adecuada cooperacion internacional que garantice relaciones económicas más justas y acceso a los mercados exteriores, apoyos científicos y tecnologicos, colaboración financiera y asistencia multilateral o bilateral en las múltiples tareas del desarrollo.

12. Así, los 316 millones de habitantes de la actual América Latina se enfrentan a un enorme desafío, mayor todavía que el prevaleciente en los últimos veinticinco años por cuanto las condiciones internacionales todavía no son favorables y en muchas áreas persisten desequilibrios internos.

13. Una de las características de la problemática reciente es el curso mismo de las variables demográficas fundamentales: el rejuvenecimiento de la población, la prevalencia en la mayoría de los países de muy elevadas tasas de incremento natural de la población - porque la fecundidad no descendió significativamente al reducirse rápidamente la mortalidad-, y la fuerte migración entre áreas rurales y urbanas.

14. Con las excepciones que se mencionan más adelante, América Latina en su conjunto se ha caracterizado en los decenios últimos por ser la región que registra la más elevada tasa de incremento demográfico, muy cercana al $3 \%$ anual. Esa tasa implica una duplicación de la población cada 23 años. La tasa bruta de mortalidad, relativamente baja, seguirá descendiendo durante los próximos decenios. La natalidad -cercana al 40 por mil- está aún condicionada en la mayoría de los países por múltiples factores que tienden a mantenerla alta. La proporción de población con edad inferior a los 15 años es de alrededor de $43 \%$, y -junto con la mayor de 65 años- da un elevado indice de dependencia. La tasa de crecimiento de la población urbana se acer- 
ca al $5 \%$ anual $\mathrm{y}$, sin embargo, la población asentada en áreas rurales aumenta todavía a razón de $1.7 \%$ anual, o sea a una tasa más alta que la población total en la gran mayoría de los países desarrollados.

15. Es verdad que ya se advierten indicios de una transición, aunque todavía lenta. $\mathrm{La}$ tasa global de incremento parece haber llegado a su máximo en los ańos últimos. Pero, por el efecto de la inercia demográfica, los descensos leves desde niveles muy altos de la fecundidad registrados recientemente en algunos países de importante dimensión poblacional, y los ocurridos con mayor intensidad en países de tamaño menor, tardarán en ejercer su influencia en la estructura por edades, en los contingentes de nuevo ingreso de la fuerza de trabajo y en las migraciones internas. Por lo mismo, durante bastante tiempo no se aliviará la presión que ya ha venido acusándose - y así se puso de manifiesto en el debate- sobre las tierras cultivables de algunos Estados, sobre el empleo y los servicios educativos y sociales y, en determinados casos, sobre el escaso territorio de ciertos países.

16. Frente a la problemática general, quedó también muy claro en las deliberaciones que existe considerable diferencia de condiciones demográficas entre los diversos países latinoamericanos. Un grupo pequeño de ellos registra reducidas tasas de incremento y una relación baja entre población y recursos actuales o potenciales. Se plantean allí necesidades apremiantes de incrementos demográficos para poner en explotación esos recursos y asentar población en vastos territorios.

17. En el otro extremo, varios países de pequeña dimensión física y, en algunos casos, de limitados o poco variados recursos naturales, acusan densidades muy elevadas y presiones demográficas reales, que agudizan los índices muy altos de fecundidad. Otro sector importante de países se encuentra en situación intermedia en lo que se refiere a territorio y recursos, pero la muy elevada tasa de incremento natural de su población constituye un obstáculo actual o potencial a su desarrollo, ya sea porque el solo incremento demográfico absorbe una parte sustancial de su capacidad de inversión $-y$, en consecuencia, no permite que se emplee plenamente la fuerza de trabajo-, o porque se producen fuertes desequilibrios intersectoriales, o entre áreas rurales y urbanas que hacen más difícil dentro de un plazo razonable la solución de los problemas planteados por un desarrollo económico y social integral. Finalmente, otros países con altas tasas de crecimiento de población, bien dotados de recursos y con extensos territorios no explotados, consideran el rápido crecimiento demográfico como un factor positivo en el mantenimiento del dinamismo de su desarrollo.

18. Se reiteró que en el simposio de las Naciones Unidas ${ }^{5}$ se había comprobado que son muy complejas las interrelaciones entre las variables demográficas y el cambio económico y social. Si bien se acepta ampliamente el papel central que desempeña el hombre como elemento creativo en los procesos de desarrollo, y la importancia de una pobla-

5 Véase Report of the Symposium on Population and Development, El Cairo, \& al 14 de junio de 1973. (No se cuenta con versión española de momento.) 
ción creciente en la formación de una economía integrada y de amplios mercados internos, no se han analizado en forma satisfactoria las consecuencias de las muy altas tasas de incremento poblacional prevalecientes en muchos países en desarrollo. Sin embargo, se perciben ya algunos de sus efectos, $y$, entre ellos, los mencionados en relación con América Latina.

19. En la reunión se reconoció que en los países latinoamericanos es todavía insuficiente el conocimiento de esas interrelaciones, y que será necesario profundizarlo mediante la recopilación de datos básicos y la investigación sistemática para obtener conclusiones cada vez más firmes. Sin embargo, ello no impide efectuar formulaciones tentativas - según el grado de urgencia de cada país- que ayuden a esbozar políticas de población.

20. Por otra parte, algunos aspectos del proceso de desarrollo afectan en forma más precisa las variables demográficas, como lo muestran la experiencia histórica de países de diversos sistemas económicos y sociales, y los procesos de cambio que conducen a un ingreso real más elevado, sin grandes desigualdades, con acentuado progreso de los programas educativos y de salud, con mayor participación de la mujer en el trabajo y elevación de su status general, y con incremento rápido de las comunicaciones, que generan nuevas actitudes hacia el espaciamiento de los hijos y el tamaño último de la familia.

21. Se señaló que en ciertos países latinoamericanos, o en determinadas zonas de algunos de ellos - particularmente en las áreas urbanas-, se advierten tendencias hacia el descenso de la fecundidad, con independencia de la implantación de programas de planificación familiar. Ello lleva a la observación de que parece ser requisito de una política poblacional de moderación de la natalidad lograr, en los procesos de desarrollo socioeconómicos, un conjunto de cambios que afectan a las motivaciones de la familia. Lo mismo debería decirse de políticas tendientes a aumentar la fecundidad.

22. Sólo algunos países latinoamericanos han declarado hasta ahora haber adoptado explícitamente medidas económicas y sociales destinadas a transformar, mediante condiciones propicias, el comportamiento reproductivo de la familia. Algunos de ellos persiguen cambios de estructura y procesos de desarrollo que probablemente tienen el efecto, presente o mediato, de afectar la fecundidad. $Y$, en uno o dos casos, se ha llegado incluso a establecer metas específicas. La mayoría de los gobiernos se limita a prestar apoyo a programas de planificacion familiar sin una adecuada interrelación con los planes de desarrollo económico y social, $y$, por su parte, algunos consideran la planificación familiar solamente como un servicio de salud materno-infantil.

23. Durante el debate se hizo evidente que los países latinoamericanos reconocen el derecho de la familia - consagrado ya en la Declaración de 1958 y en documentos posteriores de las Naciones Unidas- a decidir libremente el número y el espaciamiento de sus hijos. Sin embargo, la información y los servicios necesarios para hacer plenamente 
efectivo ese derecho no se han extendido mucho, sobre todo en los sectores rurales y los marginales urbanos.

24. En un buen número de países se han preparado programas nacionales de vasto alcance, de planificación familiar y paternidad responsable, enmarcados en una concepción global e integral del desarrollo socioeconómico. Estos países proyectan intensificar esos programas en los próximos años, como instrumentos tendientes a facilitar las tareas de su desarrollo y el mejoramiento de las condiciones de vida de la población en general. Se indicó al respecto que en algunos de ellos, de pequeña dimensión y en los que se ha agravado la presión demográfica, aquellos programas han evolucionado con arreglo a definiciones más precisas de la dinámica demográfica que se considera para esos países.

25. De lo anterior se concluyó que el tema de la política de población adquiere cada día mayor importancia en América Latina, pero que todavía no ha sido objeto de consideración suficiente. $Y$ es que esa política ofrece aspectos muy variados de la interrelación de fenómenos económicos, sociales, culturales y políticos, para los cuales no existe solución puramente técnica, ni se pueden admitir soluciones aisladas. De ahí el acento puesto durante las deliberaciones sobre la necesidad de que la política de población - como quiera que se la defina- guarde estrecha relación con los demás aspectos esenciales de la política de desarrollo. $\mathrm{Y}$ asimismo en que prevalezca el sentimiento de rechazo a soluciones parciales y a presiones externas, según las cuales, con la sola instauración de programas de planificación familiar se lograría una reducción de la fecundidad que, por sencillo curso de causa y efecto, elevaría el ingreso por habitante.

26. Se subrayó de modo especial que la política de población, como parte de los planes y programas de desarrollo económico y social, es cuestión eminentemente nacional, que cada país debe discutir, formular y decidir con arreglo a sus características culturales y a su situación y perspectivas básicas. Se puso así de manifiesto que en algunas áreas de América Latina, esa política debiera consistir en apresurar el crecimiento de la población -incluso con ayuda masiva de la inmigraciónpara lograr un aprovechamiento pleno del gran potencial de recursos.

27. En cambio, en otras áreas podría lograrse una gradual redistribución de la población mediante traslados internos en programas de asentamiento rural o urbano. Aun en aquellos casos en que se considera necesario obtener un descenso de la fecundidad en un plazo razonable, se prevén además aspectos de redistribución o relocalización, que son parte integral de una política de población.

28. Por otro lado, se indicó que en términos generales, no se concibe poder desarrollar políticas poblacionales que no vayan acompañadas de una intensificación -y en muchas ocasiones de una reestructuraciónde las políticas educativa, de salud, de vivienda y de saneamiento ambiental y social.

29. Como conclusión de tipo general, cabe afirmar que se hizo patente en la reunión un interés claramente definido de los países latino- 
americanos en considerar su perspectiva demográfica -inmediata o lejana- como elemento esencial de su problemática de desarrollo. Además, se estimó que tal elemento no es regional y aislado, sino que se enmarca en el ámbito mundial, y en particular en el de los demás países en desarrollo. En efecto, se reconoció ampliamente la interdependencia internacional característica de la época actual y que sin duda se acentuará en el futuro.

30. La perspectiva de una población latinoamericana que, según las proyecciones, pueda oscilar entre los 612 y 650 millones para fines del presente siglo no tiene por qué conducir a una visión. pesimista de la humanidad. Por el contrario, con arreglo a la prioridad que supone el mejoramiento de la condición del hombre, deberá significar -apoyada en las potencialidades educativas, científicas y tecnologicas - un desafío al que hay que dar positiva respuesta. Ello puede hacerse con una organización de la sociedad que rinda los frutos deseados, sobre todo para esas grandes mayorías marginadas hoy de los beneficios del progreso.

31. Los participantes coincidieron en que, sobre estas bases, los gobiernos latinoamericanos podrán concurrir a la próxima Conferencia Mundial de Población animados de un espíritu constructivo que - apoyado en la cooperación internacional- ayude a crear las orientaciones necesarias para que cada país esté en condiciones de alcanzar sus objetivos.

\section{2) Proyecto de Plan de Acción Mundial sobre Población (ST/ECLA/Conf.48/L.6)}

32. Al presentar este documento a consideración de las delegaciones, la Directora del celade observó que no siempre había sido posible concitar el interés del político en el significado del comportamiento demográfico peculiar a cada caso ni en sus efectos sobre la sociedad.

33. De la discusión en el ámbito latinoamericano del Proyecto de Plan de Acción Mundial sobre Población ${ }^{6}$ debe desprenderse si los países de la región creen que el Estado tiene una función que cumplir en la elaboración y ejecución de una política poblacional, y, si es así, qué variables han de recibir atención prioritaria, en qué forma el esfuerzo conjunto de los países o grupos de países puede contribuir a buscar soluciones en áreas críticas, y de qué manera la CEPAL, el CELADE y otros organismos del sistema de las Naciones Unidas prestarán colaboración a los países con el fin de que el Plan, concebido en el plano mundial, pueda hacerse operativo en América Latina.

34. Subray6 la dificultad de la tarea por la gran heterogeneidad de las sociedades latinoamericanas y por la falta de experiencia sobre la manera de insertar una política de población en las políticas globales de desarrollo. (Para la discusión de este problema el cerade había presentado algunos elementos en el documento Políticas de población y la familia: el caso latinoamericano [sT/ECLA/Conf.48/L.4].)

- Para evitar la larga mención "proyecto de Plan de Acción Mundial sobre Pobla. ción" se simplificará con la palabra "Plan", entendiéndose siempre que se trata del proyecto presentado en el documento. 
35. Señalo, además, que el Plan —como ya había manifestado en su exposición el Secretario General de la Conferencia Mundial de Población- ha recibido el aporte de la comunidad científica a través del Comité de Expertos especialmente creado a esos efectos, así como de los cuatro simposios preparatorios de la reunión de Bucarest. El Plan no supone compromiso internacional alguno en lo que se refiere a metas demográficas, sino que invita a aquellos países que consideran sus tasas excesivas o insuficientes, a estudiar el problema y a determinar sus propias acciones. Por último, no constituye una estrategia independiente, sino que es parte de la estrategia general de desarrollo en el contexto de los derechos humanos y de conformidad con los principios establecidos en los instrumentos internacionales pertinentes.

36. En relación con las recomendaciones del Plan respecto a la mortalidad, subray6 que en el documento sT/ECLA/Conf.48/L.5 se indica que hay "mucho camino sin recorrer en el descenso de la mortalidad en la región", y que - de haber prevalecido en el quinquenio actual las tasas de mortalidad por edades que Suecia registró en 1966- se habrían salvado anualmente en América Latina 1650000 vidas, de las cuales la mitad hubiera correspondido a menores de cinco años.

37. El Plan también reconoce la diversidad de políticas nacionales de población requeridas y procura reflejar las preocupaciones de los distintos países. Debe tenerse presente que en América Latina, si bien hay naciones -como México, por ejemplo- que han mantenido un invariable nivel alto de fecundidad, pese a sus elevadas tasas de urbanización y crecimiento económico, existen otras -como Costa Rica y Chile- que han experimentado pronunciados y sostenidos descensos que no predijeron las previsiones de hace algunos años.

38. Aunque la mayoría de los países no declara formalmente que sus programas de planificación familiar tienen objetivos demográficos, la demanda latente de la población femenina - sobre todo la urbanade información para reducir su fecundidad, convierte automáticamente esos programas en instrumentos potenciales de una política de población. En ellos la política gubernamental debe conjugarse con el pleno ejercicio del derecho a tener el número de hijos deseados.

39. En relación con la distribución de la población y la migración interna, la Directora del CELADE expresó que conviene tener en cuenta que en América Latina la población se distribuye en forma muy dispareja, tiende a concentrarse en grandes ciudades y a ocupar de manera dispersa el resto del territorio. Muchas ciudades duplican el número de sus habitantes cada diez años, pero la población rural continúa creciendo a tasas similares a las de la población total en los países desarrollados. Además, es posible que se esté produciendo - aunque a muy largo plazo - una declinación gradual del predominio de la metrópoli.

40. En cuanto a las migraciones internacionales, recordó que Ámérica Latina -región de inmigración en los años cincuenta- se convirtió en región de emigración en el decenio siguiente. En cifras de carácter precario, el exodo abarcó a cerca de 150000 personas anualmente entre 
1965 y 1970, fenómeno que los esquemas de integración económica existentes en América Latina deberán tomar en cuenta e incorporar en sus objetivos y en la política destinada a alcanzarlos.

41. Abocada la reunión al examen del Proyecto de Plan de Acción Mundial sobre Población, el Secretario General de la Conferencia Mundial de Población planteó algunos interrogantes básicos: ¿Se ha logrado elaborar un documento flexible y equilibrado, compatible con la enorme diversidad de regímenes políticos, grados de evolución socioeconómica, recursos naturales y problemas demográficos del mundo? ¿Respeta efectivamente el proyecto tanto la soberanía de los Estados como los derechos humanos fundamentales? ¿Puede la cooperación internacional en la ejecución de las políticas demográficas traducirse en una merma de la cooperación internacional para el desarrollo? ¿Es aceptable que la obtención de cooperación técnica y financiera internacional pueda depender de que el país solicitante aplique o no determinadas políticas de población?

42. Frente a tales preguntas, hubo consenso en estimar que el proyecto de Plan de Acción Mundial sometido a los participantes respeta la soberanía de los Estados y los derechos humanos de los individuos, que es equilibrado y coherente, y a la vez compatible con la diversidad de situaciones económicas, sociales y demográficas que se dan en el mundo en general y en América Latina en particular. Se consideró también que en los trabajos preparatorios del Plan se ha podido observar una creciente convergencia de los gobiernos en este campo, y asimismo se puso de relieve que el documento considerado establece sin lugar a dudas que la cooperación internacional en la ejecución de políticas de población no debe ni puede ir en desmedro de la asistencia económica para el desarrollo, sino ser adicional a ella (párrafo 73 del proyecto de Plan de Acción Mundial).

43. Sin embargo, dada la importancia del principio de respeto a la soberanía de los Estados en materia de población, se hizo notar que tal principio debería quedar reflejado explícitamente en el párrafo inicial del Plan. A tal efecto, una delegación, que obtuvo respaldo unánime, propuso que el Plan partiese de la afirmación de que es derecho soberano de cada pais formular sus políticas de población, conforme a sus propios objetivos y necesidades nacionales. Este principio fundamental debe regir cualquier entendimiento sobre acciones mundiales o regionales, sin mengua de la solidaridad universal, a fin de apoyar las tareas de elevar la calidad de la vida para todos los habitantes del planeta a través del progreso económico y social.

44. Un representante expresó que al ejercer ese derecho soberano los países deben tomar en cuenta los efectos de las políticas nacionales sobre las comunidades de naciones en el mundo de nuestros días, cada vez más interdependiente, así como la necesidad de promover los derechos humanos fundamentales reconocidos universalmente.

45. Una delegación estimó que, sin menoscabo de la soberanía nacional, existe la necesidad impostergable de encarar los problemas de po- 
blación a nivel regional con miras a una integración poblacional latinoamericana.

46. Otra delegación consideró indispensable definir más explícitamente el papel de los gobiernos nacionales en el proyecto de Plan de Acción Mundial, así como redactar de nuevo el capítulo correspondiente a los principios para dejar bien en claro que el respeto a la soberanía nacional es el principio básico del Plan. Señaló además que las enormes diferencias entre las diversas situaciones nacionales y las respectivas visiones de sus papeles y posiciones en la comunidad internacional impiden aplicar un plan de acción uniforme en toda la región, y menos aún en el mundo entero. Por ello es necesario recurrir a enfoques regionales y subregionales para aplicar planes de esa índole.

47. La misma delegación opinó que aislar los problemas demográficos sólo se justifica en términos analíticos, ya que forman parte orgánica de un complejo universo. Destacó la importancia de enfocarlos de manera integral, con acento suficiente en el desarrollo socioeconómico de todos los países, en especial en los campos en que más pueda hacerse por dignificar la vida humana, sin olvidar la estrecha interdependencia que existe entre los derechos humanos y la evolución y prosperidad de las comunidades nacionales. Toda acción que viola los derechos humanos obstaculiza la viabilidad a largo plazo de esas comunidades.

48. Otro representante expresó la necesidad de que el Plan establezca asimismo claramente que el objetivo básico de toda política de población -y por ende del Plan mismo- es mejorar la calidad de la vida humana completa, sin discriminación alguna.

49. De otra parte, se hizo notar que - de conformidad con la recomendación aprobada por la Comisión de Población de las Naciones Unidas en su tercer período extraordinario de sesiones- el Plan debería incluir: a) una declaración definida y clara de principios y objetivos basados en los ya establecidos en los documentos y en las deliberaciones y $b$ ) un programa de respaldo con recomendaciones y opciones concisas, explícitas y razonables, para la acción en el plano nacional e internacional, nítidamente expuestas para su consideración a nivel político, sobre la base del documento 292/Rev.l (primera versión del proyecto) y las observaciones y propuestas formuladas por la Comisión de Población durante el período de sesiones mencionado. Además las recomendacio nes deberían ser fáciles de entender por el público general.

50. Un representante estimó aconsejable elevar a la categoría de principios dentro del documento ciertos elementos ya considerados en él: a) el derecho de la pareja a determinar el número y espaciamiento de sus hijos y a tener acceso a la información y a los servicios que le permitan ejercerlo; $b$ ) el derecho a la atención materno-infantil como un objetivo en sí, y c) el mejoramiento de la condición de la mujer.

51. Una delegación propuso agregar al párrafo 18 b) del Plan la frase siguiente: "El mejoramiento de la situación de la mujer en la familia y en la sociedad en su conjunto contribuye a disminuir el tamaño de la familia; a su vez, ofrecer a la mujer la posibilidad de planificar su fecun- 
didad va a la par con sus derechos individuales y con una mejor condición social."

52. Otro representante - refiriéndose a los esfuerzos destinados a reducir la mortalidad y la morbilidad - señalo que la ayuda internacional es también necesaria en aquellos países que han logrado bajar en forma significativa las tasas correspondientes, para poder mantener o seguir reduciendo esos niveles.

53. Una delegación sugirió que en el texto del Plan se añada lo siguiente al párrafo 11: "Se llama particularmente la atención sobre el aporte de la planificación de la familia al mejoramiento de la salud materno-infantil, a través de un menor número de nacimientos y el mayor espaciamiento de los nacimientos durante los años más fecundos."

54. Con referencia a las formas de afectar los niveles de fecundidad mencionadas en el párrafo 14 del Plan, se consideró necesario aclarar en dicho texto la relación existente entre las medidas directas e indirectas que influyen en esos niveles.

55. Frente a la preocupación manifestada por algunas delegaciones en lo que toca a metas cuantitativas, se explicó que las que figuraban en el Plan eran las derivadas de las establecidas por aquellos países que las habían fijado.

56. También en relación con las metas cuantitativas, una delegación quiso dejar constancia, y contó para ello con amplio apoyo, de su preocupación por que la falta de fijación de tales metas se interpretara como que el país en cuestión no afronta un problema demográfico o no ha adoptado una política de población, y aún más por que se pudiera limitar el derecho de cada país a recibir, en igualdad de circunstancias, la asistencia internacional o regional que considere necesaria para sus programas nacionales en el campo de la población o el desarrollo, toda vez que se reconoce el derecho de cada Estado a formular y adoptar políticas de población y para fijarse metas cuantitativas respecto a alguna o todas las variables demográficas.

57. Otro representante estimó que en la sección del Plan relativa al crecimiento de la población hay que referirse en forma más concreta a la reducción de dicho crecimiento en los países más desarrollados, y propuso agregar el siguiente párrafo: "Se insta a los países más desarrollados a adoptar medidas que promuevan el continuo descenso de sus tasas de crecimiento de la población, con el objeto de lograr en 1985 - si no las han alcanzado todavía- tasas de reproducción de reemplazo, así como niveles de población casi estacionarios, lo antes posible después de esa fecha."

58. Varias delegaciones indicaron que era preciso considerar las tasas de crecimiento de la población en relación con las densidades demográficas de los países.

59. Ante las dudas planteadas por un representante en relación con la necesidad de "creciente coordinación", mencionada en el párrafo $77 \mathrm{del}$ Plan, el Secretario General de la Conferencia Mundial de Población hizo presente que los mecanismos para ejecutar el Plan no estaban in- 
cluidos en el programa de trabajo de la Conferencia de Bucarest, y que la decisión sobre este punto competía a los organismos regulares de las Naciones Unidas.

60. Como las medidas para regular el crecimiento demográfico sólo tienen efecto a plazo relativamente largo, se subrayó que es indispensable adoptar otras para evitar que el creciente tamaño de la población se convierta mientras tanto en un problema insoluble.

61. Algunos representantes estimaron que el término "planificación familiar" ha estado asociado en la práctica con objetivos de control de la natalidad y que, por lo tanto, en el Plan debe definirse en su verdadera acepción, para evitar interpretaciones erróneas del propio texto.

62. Varias delegaciones señalaron que, si bien la reducción de la natalidad es beneficiosa en ciertos casos, en otros puede aparejar una población envejecida y unas generaciones de reemplazo que sean insuficientes para sostener el desarrollo nacional.

63. Una delegación recomendó que en el Plan se tenga en cuenta que no existe "la familia" en abstracto, sino que cada grupo social tiene un tipo propio de familia que resulta de su evolución histórica y que condiciona su tamaño.

64. La reunión consideró con especial interés las migraciones internacionales dentro de América Latina. Una delegación hizo presente al respecto que no le parecía adecuado que el Plan se refiriera a las migraciones sólo como un problema, puesto que en muchos casos podía constituir incluso una solución. En vista de ello, propuso que se estudie la posibilidad de recurrir a la redistribución de la población en el plano regional como un medio optativo de enfrentar los problemas derivados del alto crecimiento demográfico de algunos países y en procura de una progresiva integración poblacional de América Latina.

65. La misma delegación señaló la necesidad de insistir en que los países de inmigración adopten las adecuadas medidas legales a fin de que los migrantes no sean sólo elementos generadores de riqueza para los países receptores, sino que también se integren a ellos social y económicamente.

66. De conformidad con lo señalado en el párrafo 41 del Plan, propuso asimismo que la CEPAL estudie la posibilidad de crear un instrumento intergubernamental encargado de promover la redistribución de la población entre los países de América Latina. Esta redistribución entrañaría no sólo el desplazamiento de migrantes, sino también el establecimiento de convenios laborales y de seguridad social y, en general, la protección de los derechos de los migrantes.

67. Algunas delegaciones concordaron con las propuestas precedentes sobre la integración cabal de los inmigrantes a las condiciones económicas y sociales prevalecientes en el país receptor. Además, recomendaron la concertación de convenios bilaterales y multilaterales para alcanzar tal fin.

68. Una delegación hizo notar que no debían considerarse sólo las migraciones rural-urbanas, sino también las intraurbanas, y que, en ma- 
teria de políticas de distribución de la población, debían tenerse en cuenta los desequilibrios respecto a edad, sexo y características socioeconomicas causados por la migración selectiva.

69. Los representantes de cinco países de un grupo subregional recomendaron introducir después del párrafo 33 del Plan el texto siguiente: "Las decisiones que hasta el presente se han tomado en el marco de los acuerdos regionales y en particular subregionales, constituyen pautas de acción que deben ser tomadas en cuenta por la comunidad internacional."

70. Otros representantes mostraron preocupación por la importante pérdida de fuerza de trabajo que significa en algunos casos la emigración espontánea, particularmente hacia países limítrofes. En este sentido, se destacó la conveniencia de estudiar medidas de desarrollo en los lugares de origen de esos migrantes con el fin de atenuar tales desplazamientos.

71. En cuanto a los estudios hechos hasta ahora sobre las relaciones entre la población y otras variables económicas y sociales, se observó que su insuficiencia dificulta la formulación de políticas de población debidamente fundamentadas. Aunque se estimó muy satisfactorio el programa de investigación previsto en el Plan, se sugirió que los planteamientos conceptuales se complementen con propuestas que lo hagan operativo.

72. Una delegación atribuyó gran importancia a los párrafos 45 y 66 del Plan referentes a la recopilación y análisis de datos, la investigación demográfica - incluido el estudio de las acciones entre las variables demográficas y socioeconómicas-, la capacitación, la educación y la información. Si bien muchos países han tenido que formular sus políticas de población con los datos y análisis disponibles, es indudable que debe profundizarse la investigación para conocer mejor las consecuencias de las tendencias actuales -o de cualquier cambio en ellasy para generar información adecuada sobre los procesos demográficos. También debe formarse cuanto antes el personal técnico requerido para los programas de población.

73. En los debates se puśo de manifiesto cierta procupación por las referencias del Plan (párrafo 59) a la capacitación de líderes. Una delegación señalo que esa capacitación era totalmente distinta de la de expertos y administradores. El líder selecciona los valores, mientras que el experto es sólo un economizador de recursos para alcanzarlos y está condicionado para aceptar determinados valores externos quizá no adaptables a su medio cultural. Esto podría ser una definición de subversión: que un líder se convierta en seguidor destruye el concepto mismo de liderazgo.

74. Un representante manifestó sus reservas al hecho de que en el párrafo 79 del proyecto del Plan se vincule su revisión bienal con el Informe de las Naciones Unidas sobre la Situación Mundial en materia de Población. Dicho informe podría analizarse en el mismo período de sesiones y ser, por lo tanto, un documento conexo, pero en todo caso, 
no sería aconsejable refundirlos porque con ello se perjudicarían ambos textos.

75. Finalmente, cabe señalar que, además de las observaciones y sugerencias que se hicieron en la discusión sobre el Proyecto de Plan de Acción Mundial, los participantes estuvieron acordes en que el Proyecto constituía una buena base para las deliberaciones de Bucarest, en las cuales los países latinoamericanos se proponen seguir aportando sus puntos de vista y sus observaciones a fin de afinar este instrumento operativo al que se asigna gran importancia como elemento fundamental dentro de las estrategias de desarrollo establecidas por la comunidad internacional para el presente decenio.

\section{OTROS ASUNTOS}

76. En la reunión participó el Ministro de Estado y Presidente de la Academia de Ciencias Sociales y Políticas de Rumania, que hizo una exposición sobre los problemas demográficos de su país y se mostró vivamente interesado en la situación de América Latina en este campo. Informó a las delegaciones asistentes de los preparativos que se están haciendo para la Conferencia Mundial sobre Población, que se celebrará este año en Bucarest, e invitó cordialmente a los representantes de los Estados miembros de la cePAl a que llevaran a ese foro los puntos de vista latinoamericanos.

77. En la última sesión de trabajo el representante de México propuso al Secretario Ejecutivo de la CEPAL que convocara en $1975-$ con la colaboración de la División de Población de las Naciones Unidas y el Centro Latinoamericano de Demografía (CErade) - una segunda reunión intergubernamental, a fin de evaluar los resultados de la Conferencia Mundial sobre Poblacion y las implicaciones que el Plan de Acción Mundial pueda tener en América Latina. Ofrecio la ciudad de México como sede de dicha reunión.

\section{CONCLUSIONES DE LA REUNION}

Del resumen de los debates que se ha hecho en las páginas precedentes y de las exposiciones de los representantes de los Estados miembros de la CEPAL y de los organismos internacionales se desprenden algunas conclusiones, que a veces han adoptado incluso la forma de recomendaciones o sugerencias. Parece necesario ordenarlas y examinarlas en esta cuarta parte del informe.

Conviene ante todo advertir que aquí se intenta identificar aquellos temas y problemas en que ha habido claras muestras de consenso en las deliberaciones de la reunión, así como los puntos de inicial coincidencia y de posible acuerdo entre los distintos países representados en ella. 
En apretada síntesis se ofrece en los párrafos que siguen lo que se estima han sido las principales conclusiones de los trabajos que hoy terminan.

1. Existe en América Latina cada vez mayor conciencia de los problemas de población y se les presta atención creciente dentro del marco amplio del desarrollo económico y social. Hay consenso en que para resolver los problemas de esta índole se requieren decisiones a nivel político, cualquiera que sea su sentido, contenido o alcance.

2. En este sentido, al reconocer el interés público en los asuntos de población, los gobiernos coinciden en la necesidad de destacar que todas las decisiones relativas a las metas y los medios de llevar a cabo políticas de población son, por su naturaleza, materias que competen al principio de la soberanía nacional. Hay amplio acuerdo en que los países deben fijar libremente sus políticas de población y en que éstas deben responder siempre a consideraciones de orden nacional.

3. De acuerdo con la Estrategia Internacional de Desarrollo y la Evaluación de Quito, se establece que la tarea primordial es el desarrollo integral sobre bases de mayor igualdad social, cambio estructural y participación y beneficio de las mayorías. Dicho desarrollo afectará a las variables demográficas $y$, en particular, podrá influir en el comportamiento reproductivo y en la formación de la familia.

4. Basándose en el respeto inrestricto a los derechos humanos, los gobiernos reiteran que el mejoramiento de la vida constituye el objetivo fundamental de toda acción en este campo. Se señala así la necesidad de ampliar con este objetivo la capacidad de decisión de los individuos, promoviendo su participación económica y social.

5. Las políticas de población no se cofisideran como alternativa a las de desarrollo económico y social, sino como uno de los instrumentos para lograrlo.

6. Los criterios que han de orientar la cooperación económica y financiera internacional no deberían verse afectados en manera alguna por las políticas de población que los Estados adopten en el ejercicio de sus derechos soberanos.

7. Durante el proceso de transición demográfica se requiere un esfuerzo extraordinario para llevar adelante el desarrollo económico y social con una población en constante aumento. La comunidad internacional y los países desarrollados deben cooperar con los países en desarrollo en la realización de este esfuerzo, a través de medidas de carácter económico, comercial y financiero que tiendan a una mayor justicia en las relaciones económicas internacionales. Es especialmente importante que se actúe sobre las variables económicas mediante una mayor cooperación internacional en aquellos países que, si bien registran un alto crecimiento demográfico, tienen también una baja densidad y en el futuro requerirán una mayor población para desarrollar integralmente sus recursos y ocupar en forma efectiva su territorio.

8. Se reconoce que, en conjunto, la tasa de incremento de la población latinoamericana es la mayor de cualquier región del mundo, y que 
la elevada natalidad, frente a una mortalidad en descenso, significa una fuerte proporción de población joven durante un período considerable. A su vez, esto significa que la tasa global de incremento no podrá disminuir en forma significativa antes de finales del presente siglo. Sin embargo, existe una diversidad de condiciones por países individualmente considerados: a) algunos de ellos acusan lento crecimiento y disponen de vastos territorios y recursos; $b$ ) otros países, tambien con territorio y recursos, tienen tasas elevadas de crecimiento; $c$ ) otros están en situación intermedia; $d$ ) otros más, por su escaso territorio o falta de recursos, experimentan síntomas de sobrepoblación actual o potencial.

9. La mayoría de los países, en reconocimiento de los derechos humanos y como contribución básica al mejoramiento de la salud, ofrecen información y servicios de planificación familiar.

10. Una gran mayoría de los países de América Latina rechaza el establecimiento de metas cuantitativas en los programas de población.

11. Se reconoce en general la apremiante necesidad de considerar políticas de redistribución geográfica interna de la población.

12. Se reconoce asimismo la existencia de problemas de migración internacional. Sin embargo, algunos países consideran la migración internacional como un instrumento de política poblacional que puede constituir una alternativa para la solución de problemas de desigual crecimiento demográfico.

13. Se establece la necesidad de promover políticas de educación integral, de salud, de empleo y otras de carácter social, como esencial elemento de una política de población.

14. Las políticas de población deben estar vinculadas con las estrategias de desarrollo $y$, en este sentido, ocuparse no sólo de la mortalidad y la natalidad, sino también de la distribución geográfica de la población, de su relación con los recursos naturales y el medio ambiente, y con las migraciones internacionales.

15. Las políticas de desarrollo tienen que prestar especial atención al desarrollo regional, a la incorporación de áreas nuevas y zonas deprimidas, a la creación de asentamientos humanos, a la utilización más racional de los recursos naturales, y adoptar medidas que, siendo compatibles con el acelerado ritmo de crecimiento económico requerido, eviten el deterioro del ambiente.

16. De acuerdo con las manifestaciones de los Gobiernos miembros en la reunión, la aplicación del Plan de Acción Mundial dentro de América Latina sería inseparable de las medidas destinadas a intensificar el desarrollo.

17. De una parte, existen todas aquellas cuestiones que se refieren directamente a la tasa de crecimiento demográfico y a las migraciones internas e internacionales, $y$, de otra, las implicaciones que tiene el considerar la variable población en el crecimiento económico y en el desarrollo social.

18. En cuanto a lo primero, las deliberaciones indican que algunos Gobiernos miembros propugnan la formulación de leyes especiales y 
favorecen la creación de instituciones que preparen las decisiones y ejecuten la acción del sector público.

19. En cuanto al segundo aspecto, no sólo se trata de incluir en forma explícita la variable población en los métodos de planificación y programación del desarrollo, sino más bien de prever las consecuencias que para los planes generales y las políticas específicas pueden derivarse de la estructura y del ritmo de crecimiento de la población.

20. Hay amplio consenso en torno a la idea de que los planes y estrategias nacionales de desarrollo deben considerar la situación y las tendencias de la población como un aspecto fundamental de la acción pública desde una triple perspectiva: a) en lo que toca a sus interrelaciones con el resto de los factores que influyen en el proceso de desarrollo; $b$ ) en el contexto de la política social de los gobiernos, y $c$ ) en función de los proyectos nacionales de desarrollo y tomando en cuenta aquellas consideraciones políticas y culturales que son más significativas en cada país.

21. Se considera tema del más alto interés la necesidad de eliminar las barreras que impiden la plena incorporación de la mujer a la vida social, económica y política. Sólo así podrá cumplir cabalmente su papel de ciudadana y de elemento básico y fundamental de la familia.

22. En lo que se refiere al mejoramiento del bienestar familiar, se toma en cuenta que la familia constituye el núcleo social sobre el que convergen los cambios que genera el desarrollo y que, a su vez, afecta de por vida la conducta futura de los individuos. Toda política de población debe tener presentes no sólo los efectos que producen sobre el núcleo familiar las variaciones en la mortalidad y la natalidad, sino también los problemas que afectan su constitución y modifican su estabilidad.

23. Como antes se ha dicho, frente a las diferentes situaciones socioeconómicas de los países, se han hecho en la reunión significativas propuestas que apuntan a la concertación de acuerdos bilaterales o multilaterales destinados a regular las migraciones entre los países de América Latina, facilitando la absorción de los migrantes sin desmedro del respeto a los derechos humanos.

24. En general, los representantes de los Gobiernos miembros apoyan los conceptos básicos contenidos en el Proyecto del Plan de Acción Mundial, destacándose su flexibilidad y respeto a la soberanía de los países.

25. Las deliberaciones permiten concluir que, sobre la base del respeto a la soberanía de los países - y reconociendo la variedad de situaciones nacionales y de orientaciones de las políticas de desarrollo-, existe fundamento amplio para la colaboración internacional dentro de América Latina:

26. Los planteamientos hechos por los gobiemos constituyen un desafío para la cooperación internacional, que exigirá un esfuerzo sin precedentes por parte de la CEPAL, el CELADE, y otros organismos intergubernamentales. Es indispensable no sólo sumar y organizar recursos 
humanos y materiales, sino encontrar estrategias que respondan de manera ágil y oportuna a las necesidades de los países. Hay que elaborar nuevas ideas $\mathrm{y}$ orientaciones, $\mathrm{y}$ abrir posibilidades que armonicen la imaginación y la audacia de pensamiento requeridas, con la búsqueda de derroteros prácticos para asistir a los gobiernos que así lo soliciten.

27. De las posiciones que los gobiernos han planteado respecto a los problemas y a las políticas en los países, y en consonancia con el Plan de Acción Mundial, se desprende que los organismos internacionales deben estar en condiciones de incrementar su acción en los campos de la investigación, asistencia técnica y actividades de orientación y evaluación.

28. Se considera que es en los propios países donde recae fundamentalmente la tarea de realizar la investigación necesaria, tanto demográfica como de las relaciones entre población y desarrollo, para la formulación de las políticas pertinentes. Sin embargo, en esta labor deben contar con el apoyo permanente de los organismos de las Naciones Unidas que operan en la región, organismos que pueden y deben concertar su acción para colaborar activamente con los países en materia dé investigación, capacitación y recolección de datos socioeconómicos y demográficos.

29. En la medida en que los gobiemos adopten estrategias y políticas de desarrollo que incluyan las variables demográficas se abre un amplio camino para la asistencia técnica internacional. Aun cuando el estado del conocimiento en este campo representa todavía una seria dificultad, es evidente la urgencia de realizar significativos esfuerzos para definir los parámetros y criterios de una política de población.

30. Las políticas de población formuladas por algunos gobiernos y las estrategias de desarrollo han previsto por regla general que, en el curso de los dos decenios próximos, continuará aumentando con rapidez el tamaño de la población. Frente a estas realidades será indispensable acelerar el ritmo de desarrollo y, paralelamente, buscar medios más eficaces para crear empleos y proporcionar aquellos servicios básicos que contribuyen a convertir a la población en factor de progreso. Responder en forma creativa al desafío de la transición demográfica, significa la adopción de nuevos criterios y concepciones que orienten el crecimiento urbano, la distribución geográfica de la población, el desarrollo rural y la transferencia y adopción de tecnologías.

31. Se requiere instrumentar políticas sociales y económicas que eviten de manera sistemática la marginación de sectores amplios de la población. Para ello es indispensable encontrar fórmulas realistas que hagan llegar la educación y los servicios de salud a la gran mayoría de la población, así como transformar las pautas de la vida rural, elevando la producción y el empleo. Es asimismo necesario elaborar medidas para programar un crecimiento de las ciudades que sea compatible con tasas muy elevadas de expansión urbana.

32. Las delegaciones han coincidido unánimemente en la conveniencia y utilidad de celebrar a principios de 1975 una nueva reunión re- 
gional para evaluar los resultados de la Conferencia Mundial sobre Población que tendrá lugar en Bucarest y sus implicaciones en América Latina. Será además provechoso examinar las experiencias y las conclusiones a que se llegue mediante los diversos enfoques que adopten al respecto los países. En este sentido, la reunión de San José ha acogido con especial beneplácito el ofrecimiento hecho por la delegación mexicana de que la ciudad de México sirva de sede para estas nuevas tareas conjuntas de los países latinoamericanos en el marco de la CEPAL y el CELADE y los demás organismos de las Naciones Unidas especializados en el campo de la población.

\section{Anexo I}

\section{LISTA DE ASISTENCIA}

\section{1) Estados miembros de la Comisión}

Argentina

Representante: Benito P. Llambi, Ministro del Interior

Miembros: Roberto J.V. Marcenaro

Lelio A. Mármora

Mario Aníbal Vernengo

Guillermo E. de Gamas

Barbados

Representante: Charles G. Alleyne

Bolivia

Representante: Jerjes Vaca Diez, Embajador

Miembros: Manuel Paz Soruco

Luis Llano Saavedra

Brasil

Representante: Miguel A. Ozorio de Almeida, Embajador Asesor

Miembro: Pedro Motta Pinto Coelho

\section{Canadá}

Representante: Bethany Armstrong E.

Miembro: André Lux

\section{Colombia}

Representante: Luis E. Rosas, Jefe del Departamento de Planeación Miembro: Rafael de Zubiria

Costa Rica

Representante: Gonzalo J. Facio, Ministro de Relaciones Exteriores 
Alterno: José Luis Molina, Embajador, Jefe de la Delegación Miembros: Óscar Alfaro

Oscar Arias

Bernal Jiménez

Víctor Hugo Morgan

Comisión Técnica Asesora:

Alvar Antillón

Wilda Quiñones

José Joaquún Chaverní

Elizabeth Odio

Guillermo Sandoval

Fernando Zumbado

V'ictor Brenes

Elena Quesada

Guillermo Macció

Ricardo Jiménez

Joaquín Alberto Fernández

Virginia Pérez Robles de Berrios

Claudio Soto Badilla

\section{Cuba}

Representante: Ernesto Meléndez Bachs, Vicepresidente de la Comisión de Coordinación Económica, Científica y Técnica

Miembros: Celestino Álvarez Lajonchere

Pablo A. González Díaz

Julián. López Díaz

Abelardo Moreno Fernández

Óscar Ramos Piñol

Héctor Sardiña Padilla

\section{Chile}

Representante: Alberto C. Spoerer, Ministro de Salud

Miembros: Āngel Guzmán Véliz, Subsecretario de Salud Francisco Cruz Pacheco

\section{Ecuador}

Representante: Gonzalo Abad

Miembro: Pedro Merlo

\section{El Salvador}

Representante: Coronel Juan Antonio Martínez Varela, Ministro del Interior

Miembros: Julio Ernesto Astacio, Ministro de Salud Pública y Asistencia Social

Ernesto Trigueros Alcaine, Embajador en Costa Rica René Ernesto Auerbach 
Roberto Chico Duarte

Román Mayorga Quirós

Héctor Francisco Oqueli Colindres

Estados Unidos

Representante: Ward P. Allen

Miembros: Carl J. Hemmer

Thomas F. McMahon

Jim B. Marshall

Francia

Representante: G. Froment

Guatemala

Representante: Jaime Barrios Peña, Embajador en Costa Rica

Miembros: Ramiro Bolaños Yela

Jorge Federico González Morales

\section{Honduras}

Representante: Rigoberto Alvarado, Subsecretario de Salud Pública

Jamaica

Representante: Carmen P. McFarlane

Miembro: George N. Roberts

México

Representante: Mario Moya Palencia, Secretario de Gobernación y Presidente del Consejo Nacional de Población

Miembros: Fernando Castro y Castro

Juan Gallardo Moreno

Luisa María Leal

José Manuel Septién

Víctor L. Urquidi

Carlos A. Bado López

María Elena Estrada de Castro

Marcela Ibániez de Moya

Carlos López Figueroa

Nicaragua

Representante: René Bustamante M., Director General de la Oficina

Nacional de Planificación de la Presidencia

Miembros: René Cajina S.

Enrique Lanzas Balladares

Enrique Zamora Castro

Paises Bajos

Representante: Siegfried Tecla

Miembro: Cornelis J. Vreidenburgh 


\section{Panamá}

Representante: Hildebrando Araica A.

Miembros: Ana Hernández de Pitti

Julio Amando Lavergne

Perú

Representante: José Alvarado Sánchez, Embajador en Costa Rica

Miembros: Otoniel Velascơ

Rosa Esther Silva y Silva

República Dominicana

Representante: Héctor Pereyra Ariza, Secretario de Salud Pública y Asistencia Social

Miembros: Luis González Fabra

Nelson Ramírez Madera

Santiago Gaslonde

Venezuela

Representante: Luis Homero Vivas R., Vice-Ministro de Salubridad y Asistencia Social

Miembros: José Miguel Avilán Rovira

Carmen Teresa Ayala

Josefina Cáceres Perera

Ana Brenda C. de Figueroa

José Balbino León

Haydée Martínez de Osorio

Belice

Representante: Carl L.B. Rogers, Ministro de Asuntos Interiores y Salud

Miembro: Henry Guy Yorke

Estados Asociados de las Indias Occidentales

Representante: Víctor Igor Cuffy, Ministro de Salud, San Vicente

Miembros: Erry B. John

Carlos A. Mulraine

2) Observadores de otros Estados miembros de las Naciones Unidas

Rumania

Representante: Mihnea Gheorghiu, Ministro de Estado y Presidente de la Academia de Ciencias Sociales y Políticas

Miembro: Vladimir Trebici 
3) Representantes de organismos de las Naciones Unidas

Organización Internacional del Trabajo (OIT) Ramiro Molina Cartes

Organización de las Naciones Unidas para la Agricultura y la Alimentación (FAO)

Antonio Merediz Montero

Organización de las Naciones Unidas para la Educación, la Ciencia y la Cultura (UNESCO)

Albert Sireau

Organización Mundial de la Salud (OMS)

Manuel M. Villa C. y Alfredo Arreaza Guzmán

Banco Internacional de Reconstrucción y Fomento (BIRF) M. Nydia Maraviglia

Fondo de las Naciones Unidas para la Infancia (UNICEF) Kenneth E. Grant

Programa de las Naciones Unidas para el Desarrollo (PNUD) Joseph Schützenberger, Representante Residente en Costa Rica

Fondo de las Naciones Unidas para Actividades en Materia de Población (UNFPA)

Suzanne Aurelius, José Donayre Valle, Héctor L. Goglio, Luis Olivos, Nafis Sacik y Joseph Schiitzenberger

4) Organismos intergubernamentales

Comité Intergubernamental para las Migraciones Europeas (CIME)

Silvio Cattani y Guillermo Mulet

5) Organizaciones no gubernamentales

Federación Internacional de Planificación de la Familia (IPPF)

Víctor Hugo Morgan y Lucio Burgos

6) Secretaría de la reunión

Comisión' Económica para América Latina (CEPAL)

Enrique V. Iglesias, Secretario Ejecutivo; Marshall Wolfe, César A. 
Peláez, Julio Valdés, Lil de Tiburcio y Luis Ratinoff, Asesor de la Secretaría

Secretaria General de la Conferencia Mundial de Población

Antonio Carrillo Flores, Secretario General, y Arthur McCormack

División de Población de las Naciones Unidas

León Tabah, Director de la División y Secretario General Adjunto de là Conferencia Mundial de Población, y Octavio Cabello

Centro Latinoamericano de Demografía (CELADE)

Carmen Miró, Directora, Guillermo A. Maccio, Ricardo Jordán, Gerardo González.

\section{ANExo II}

\section{LISTA DE DOCUMENTOS}

\section{Documentos de trabajo}

\section{Signatura}

ST/ECLA/Conf.48/L.1

ST/ECLA/Conf.48/L.2

ST/ECLA/Conf.48/L.3

ST/ECLA/Conf.48/L.4

ST/ECLA/Conf.48/L.5

\section{Título}

Temario provisional

Tendencias demográficas, desarrollo y distribución del ingreso en América Latina: Notas introductorias

Nota de la Secretaría. Informe del Secretario General sobre el Proyecto de Plan de Acción Mundial sobre Población. (E/cn.9/292/Rev.1)

Políticas de población y la familia: el caso latinoamericano (CELADE)

América Latina: Situación demográfica alrededor de 1973 y perspectivas para el año 2000 (CELADE)

ST/ecta/Conf.48/L.6 Proyecto de Plan de Acción Mundial sobre Población

ST/ECLA/Conf.48/L.7 Proyecto de informe de la Reunión Latinoamericana Preparatoria de la Conferencia Mundial de Población 
Documentos de referencia

Número 1

Población y desarrollo en América Latina, vol. I y II (E/CN.12/973)

Número 2

Conferencia Mundial de Población, 1974. Versiones preliminares de los documentos básicos para la conferencia y de los informes de los simposios. Informe del Simposio sobre la Población y los Derechos Humanos (Amsterdam 21 a 29 de enero de 1974). 
INDICES 



\section{INDICE DE CUADROS}

1 América Latina: Población por países, 1920-1970 . . . . 71

2 América Latina: Tasas de crecimiento demográfico por países, 1920-1970 . . . . . . . . . . .

3 América Latina: Crecimiento natural, natalidad y mortalidad, por países, 1960-1970 . . . . . . . . . . .

4 Brasil: Promedio de niños nacidos vivos de mujeres brasileñas

por edad y región, 1960 y 1970. colínicas públicas y pri-
5 Costa Rica: Casos nuevos y control en vadas de planificación familiar, 1966-1970 . • 1960-1965

6 América Latina: Esperanza de vida por país y sexo, 1960-1965 y $1965-1970$

7 América Latina: Proyecciones de la población por países, 19702000

8 América Latina: Resumen del crecimiento urbano y de la urbanización, 1950-1970

9 América Latina: Población total, urbana y rural, 1950, 1960 y 1970

10 América Latina: (Veinte países) número de ciudades y distribución de la población urbana según el tamaño de la ciudad, $1950-1970$.

11 Resumen de la urbanización y el crecimiento urbano en tres grupos de países latinoamericanos, 1960-1970 . . . .

12 Número de ciudades y distribución de la población urbana según el tamaño de las ciudades en tres grupos de países latinoamericanos, 1960-1970

13 América Latina y otras regiones del mundo: Indices globales de participación en la actividad económica, 1950-1970.

14 América Latina: Estimaciones y proyecciones de la relación de dependencia .

15 América Latina: Esperanza de vida al nacer y algunos indicadores de bienestar socioeconómico por países, 1965-1970.

16 Nicaragua: Muertes de hijos por cada mil nacidos vivos, por residencia urbana o rural y edad actual de la madre, 1971 .

17 Honduras: Mortalidad por residencia rural o urbana, 1971

18 Honduras: Mortalidad por niveles socioeconómicos, 1971 .

19 Nicaragua: Muertes de hijos por cada mil nacidos vivos, por nivel educativo y residencia urbana o rural de la madre, 1971

20 Indicadores de desarrollo por regiones del mundo alrededor de 1970 .

21 Políticas demográficas y servicios de planificación familiar en 20 países de la región . d · · d ·

22 Fechas de iniciación y consolidación de las actividades de pla- 
nificación familiar de las asociaciones privadas, y acuerdos de colaboración con las universidades y el sector público

23 Fechas de iniciación y de consolidación de las actividades de planificación familiar del sector público . . . . . .

24 Países clasificados según el número de mujeres en edad fecunda por cada clínica de planificación familiar, y porcentaje de mujeres en edad fecunda protegidas, a comienzos de 1969 .

25 Tasas de actividad femenina por ciudades y países (Porcentajes)

26 Tasas de actividad femenina por edades, por zonas urbanas y por países (Porcentajes)

27 Distribución de las mujeres económicamente activas según su ocupación (Porcentajes)

28 Actividad femenina por niveles de educación.

29 Distribución porcentual de mujeres económicamente activas e inactivas dentro y fuera del hogar.

30 Actividad económica de la mujer según su estado civil (Porcentajes)

31 Distribución porcentual y promedio de hijos nacidos vivos por mujer, según su actividad .

32 Promedio de hijos nacidos vivos por mujer y diferencia observada según su actividad

33 América Latina: Población económicamente activa, año 2000 (miles de personas).

34 Número de personas empadronadas en provincias distintas de aquellas en que nacieron, en algunos países latinoamericanos, 1940 a 1970

35 Colombia: Composición por edades de los migrantes recientes comparada con la de la población total, según sexo y lugar de destino (Porcentajes)

36 Colombia: Porcentaje de nativos, migtantes e inmigrantes, por edad y sexo, en cada cohorte de la población de Bogotá, de otras zonas urbanas y de las zonas rurales

37 Colombia: Relación de masculinidad de los migrantes recientes, por edad y lugar de destino.

38 Colombia: Comparación del estado civil de migrantes y residentes, por sexo, 1964 .

39 Colombia: Comparación de la proporción de personas no casadas en la población de migrantes y residentes, por sexo, lugar de destino y tipo de migración: Tasas normalizadas sobre la base de la distribución por edades de la población, 1964 .

40 Colombia: Alfabetismo de migrantes recientes y residentes, por sexo y lugar de destino, comparaciones expresadas en porcentajes y tasas normalizadas, 1964 a

41 Colombia: Comparación del nivel de instrucción de migrantes recientes y residentes, por edad, sexo y lugar de destino, 1964 (Porcentajes) .

42 Colombia: Comparación del nivel de instrucción de los mi- 
grantes residentes, por sexo y lugar de destino: tasas normalizadas de acuerdo con la composición por edades de la población, 1964

43 Colombia: Migrantes recientes y residentes económicamente activos, por edad, sexo y lugar de destino, 1964 .(Porcentajes)

44 Colombia: Rama de actividad económica de los migrantes recientes y residentes, por sexo y lugar de destino, 1964 (Porcentajes)

45 Colombia: Porcentaje de migrantes recientes y de residentes económicamente activos que trabajan en actividades manuales y no manuales, por sexo y lugar de destino, 1964 .

46 Colombia: Categoría de la ocupación de los migrantes y de los residentes económicamente activos, por sexo y lugar de destino, 1964 (Porcentajes)

47 Colombia: Comparacion del porcentaje de migrantes recientes y de residentes, de 10 años y más, que se dedican a actividades marginales, por sexo y lugar de destino, 1964 


\section{INDICE GENERAL}

Nota editorial . . . . . . . . . . . . . . . 7

Prólogo de Marshall Wolfe . . . . . . . . . . . . . . . 9

I. Tendencias demográficas y opciones para políticas de población

1. La situación actual y el futuro previsible . . . . . 16

a) Las tasas de crecimiento y sus determinantes . . . 16

b) Distribución geográfica, urbanización y migración interna . . . . . . . . 22

c) Esperanza de vida y distribución de la población por edad y sexo . . . . . . . . . . . . 26

d) Tipos de países . . . . . . . . . . . . . . . . 27

2. Relaciones entre el cambio demográfico, el cambio económico y social y la política pública . . . . . . 29

- a) La estratificación social y la familia . . . . . 29

b) Servicios sociales . . . . . . . . . . . . . 33

c) Empleo . . . . . . . . . . . . . 42

d) Ahorro . . . . . . . . . . . . . . 44

e) Uso y tenencia de la tierra . . . . . . . . 45

f) Recursos naturales y espacio . . . . . . . . 46

3. Políticas de población . . . . . . . . . . 49

a) Delimitación de la política de población . . . . 49

b) Concepciones e ideologías relativas al papel de la población en el desarrollo de América Latina . . . 51

c) Políticas y actitudes gubernamentales . . . . 55

d) Objetivos e instrumentos de una política de población 59

194.02 II. Las tendencias de la población en el decenio de 1960 . . 70

1. El crecimiento demográfico en el decenio de 1960 . . 70

2. Componentes del crecimiento demográfico . . . 75

a) Tendencias de la fecundidad . . . . . . . 75

b) Tendencias de la mortalidad . . . . . . . 81

c) La migración internacional . . . . . . . . . . . 84 
3. Perspectivas de crecimiento . . . . . . . . . 84

4. La urbanización y la distribución espacial . . . . 86

5. Repercusiones económicas de la estructura de la población 97

III. Factores sociales y económicos que afectan a las tendencias de la población.

A. Procesos que afectan la redistribución de la población.

1. Factores y tendencias de la urbanización

2. Factores inmediatos de la urbanización

B. Procesos sociales y económicos que influyen en los cambios de la fecundidad en América Latina

1. Marco orgánico

2. Influencias de la nupcialidad en la fecundidad .

a) Nupcialidad y fecundidad

b) Procesos socioeconómicos que afectan a la nupcialidad

3. Factores determinantes de la fecundidad marital

a) La salud biológica y las variables vinculadas al control deliberado de la fecundidad

b) Fecundidad marital no controlada ("natural") .

c) El control de la fecundidad marital

4. Procesos sociales que influyen en las condiciones necesarias para el control de la fecundidad marital .

a) Consideraciones metodológicas . . . . . . . 128

b) Procesos que influyen en la motivación . . 129

c) Procesos que influyen en la capacidad para controlar la fecundidad marital.

d) Procesos que influyen en el concepto de legitimidad del control de la fecundidad.

C. Factores socioeconómicos que influyen en los patrones de mortalidad

1. Diferencias de mortalidad por países

2. Urbanización y mortalidad .

3. La mortalidad y la estratificación social . . . . 143

D. Resumen y conclusiones . . . . . . . . . 145 
IV. Población y modernización

A. La población en las interpretaciones del desarrollo . . 150

1. La situación reciente . . . . . . . . . 150

2. Diagnóstico de la crisis y papel del crecimiento demográfico

a) Los pronósticos . . . . . . . . . . 151

b) La población y las perspectivas de cambio . . . 153

c) La población y el desarrollismo conservador . . 153

d) La población en la ética y en la práctica revolucionaria . . . . . . . . . 154

e) El crecimiento demográfico y los cambios de estructuras . . . . . . . . . . . . 154

3. Imágenes de la transición demográfica. . . . . 155

a) $\mathrm{La}$ autorregulación . . . . . . . . . 155

b) La fase crítica de indeterminación . . . . . 156

c) La trampa demográfica . . . . . . . . . 156

B. Estructura social y evolución demográfica . . . . . 156

1. Hipótesis sobre la transición demográfica . . . . 156

2. Urbanización y fecundidad . . . . . . . . 158

a) Las estructuras históricas. . . . . . . . 158

b) Las estructuras contemporáneas. . . . . . 159

3. Estructura social de la ciudad e incidencia de algunas variables.

a) Escolaridad de la madre . . . . . . . . . 162

b) Participación económica de la mujer . . . . 163

c) Estratificación social, movilidad y conducta reproductiva . . . . . . . . . . . . 164

d) Movilización de masas y natalidad . . . . . 165

C. La acción pública en el campo de población . . . . 166

1. Consideraciones sobre política de población . . . 166

2. El consenso social y la justificación de la intervención del Estado

3. Situación en materia de políticas de población . . 168

4. Los programas del sector público . . . . . . . 169

5. Origen de las actividades . . . . . . . . . 170

6. Situación actual de los programas . . . . . . . 172 
D. Conclusiones.

1. Niveles y aspectos conexos de la actividad económica femenina

2. La actividad económica de la mujer y la fecundidad . 186

3. Declinación de la fecundidad y evolución de la fuerza de trabajo.

VI. La migración interna en América Latina: volumen, características $y$ consecuencias

A. Volumen de la migración interna.

B. Adaptación de los migrantes y consecuencias de las migraciones.

1. Características sociales y demográficas . . . . . 198

a) Composición por edades de la población migrante 198

b) Composición por sexo de las corrientes migratorias

202

c) Estado civil

2. Características que determinan la adaptación económica de los migrantes

a) Alfabetismo y educación.

b) Participación de la fuerza laboral . . . . . 215

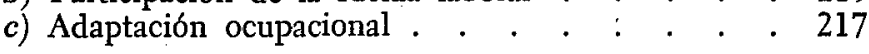

C. Resumen y conclusiones

VII. Población, medio ambiente y desarrollo: la experiencia latinoamericana

1. El desarrollo y sus componentes . . . . . . . . 234

2. El factor población. . . . . . . . . . . 236

a) Crecimiento y tamaño . . . . . . . . . . 236

b) La distribución de la población. . . . . . . . 238

c) La población y otras variables del desarrollo . . . 239

3. Población y medio ambiente . . . . . . . . 245

a) Relaciones recíprocas entre las variables . . . . 245 
b) Problemas ambientales . . . . . . . . . 245

c) Los problemas ambientales y sus consecuencias sociales 250

4. Políticas para un desarrollo integrado . . . . . . 257

5. Conclusiones. . . . . . . . . . . . . 263

VIII. Población y derechos humanos en América Latina: algunos interrogantes . . . . . . . . . . . . 266

1. Fecundidad y planificación de la familia . . . . 268

2. Distribución espacial, migración, protección del medio ambiente y explotación de recursos . . . . . . 272

3. Anotación final . . . . . . . . . . . 278

Apéndice: Informe de la Reunión Latinoamericana Preparatoria de la Conferencia Mundial de Población (San José, Costa Rica, abril de 1974)

I. Organización de la reunión . . . . . . . . . . . . 281

Duración de la reunión . . . . . . . . . . . 281

Asistencia . . . . . . . . . . . . . . . 281

Sesiones de apertura y clausura . . . . . . . . . . . 281

Elección de la Mesa. . . . . . . . . . . . 281

Programa de trabajo. . . . . . . . . . . . 282

II. Resumen de los debates . . . . . . . . . . . . 282

1. Situación y perspectivas de los países latinoamericanos en materia de población y principales enfoques sobre política demográfica. . . . . . . . . . . .

2. Proyecto de Plan de Acción Mundial sobre Población (ST/ECLA/Conf.48/L.6).

III. Otros asuntos.

IV. Conclusiones de la reunión . . . . . . . . . . . . 294

Anexo I. Lista de asistencia . . . . . . . . . . 299

Anexo II. Lista de documentos . . . . . . . . . . 304 